Julio Issao Kuwajima

Avaliação de Performance Computacional de Simplificações da Equação de Saint-Venant aplicadas na Operação da UHE Três Marias, MG.

São Carlos, SP - Brasil 

Julio Issao Kuwajima

\title{
Avaliação de Performance Computacional de Simplificações da Equação de Saint-Venant aplicadas na Operação da UHE Três Marias, MG.
}

\author{
Tese apresentada à Escola de Engenharia de São \\ Carlos, da Universidade de São Paulo, como \\ parte dos requisitos para obtenção do título de \\ Doutor em Ciências da Engenharia Ambiental
}

\author{
Universidade de São Paulo - USP \\ Escola de Engenharia de São Carlos - EESC \\ Programa de Pós-Graduação em Ciências da Engenharia Ambiental - PPG-SEA
}

Orientador: Prof. Assoc. Frederico Fábio Mauad

São Carlos, SP - Brasil 
AUTORIZO A REPRODUÇÃO TOTAL OU PARCIAL DESTE TRABALHO, POR QUALQUER MEIO CONVENCIONAL OU ELETRÔNICO, PARA FINS DE ESTUDO E PESQUISA, DESDE QUE CITADA A FONTE.

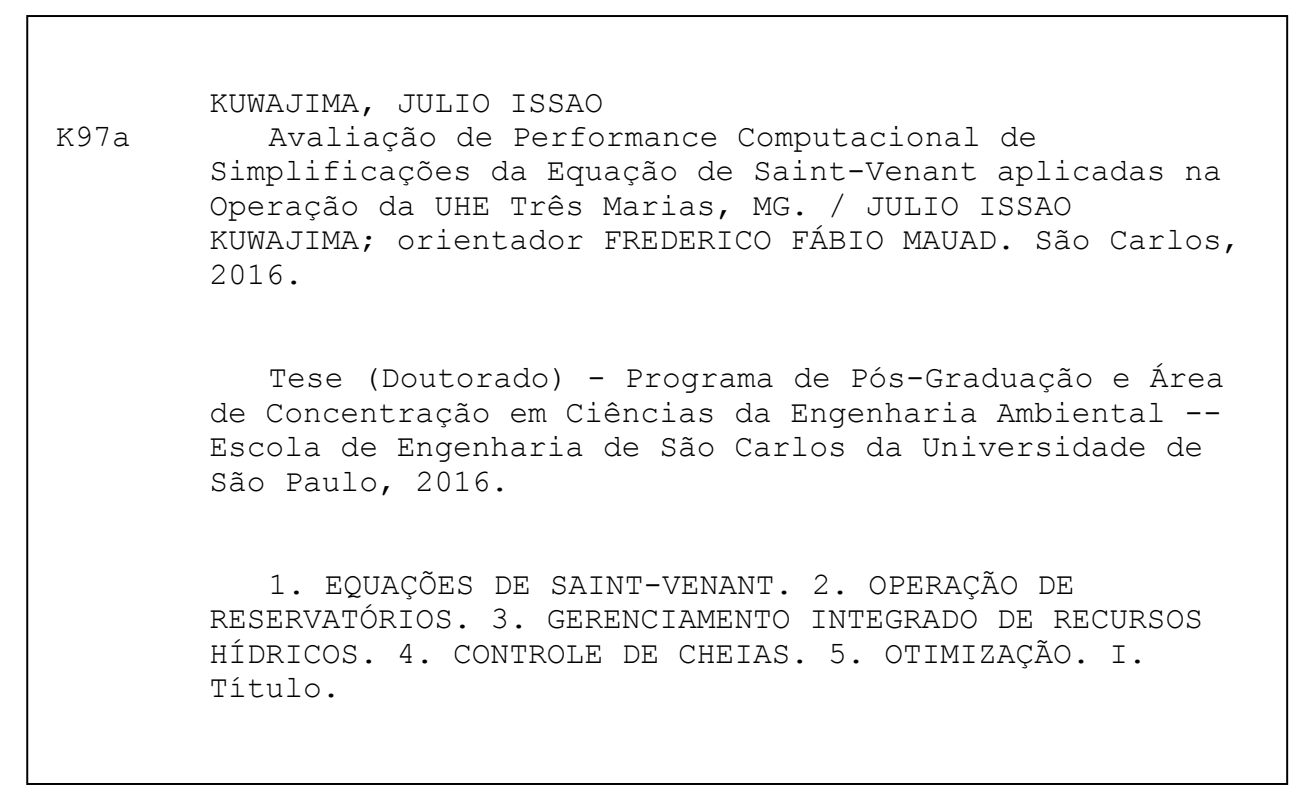




\section{FOLHA DE JULGAMENTO}

\section{Candidato: Engenheiro JULIO ISSAO KUWAJIMA.}

Título da tese: "Avaliação de performance computacional de simplificações da equação de Saint-Venant aplicadas na operação da UHE Três Marias, MG ".

Data da defesa: 09/12/2016.

\section{Comissão Julgadora:}

Prof. Associado Frederico Fábio Mauad

(Orientador)

(Escola de Engenharia de São Carlos/EESC)

Prof. Dr. Cristiano Poleto

(Universidade Federal do Rio Grande do Sul/UFRGS)

Prof. Dr. Tiago Zenker Gireli

(Universidade Estadual de Campinas/UNICAMP)

Prof. Dr. Alberto Luiz Francato

(Universidade Estadual de Campinas/UNICAMP)

Dr. Guilherme de Lima

(NHC Brasil Consultores)

\section{Resultado:}
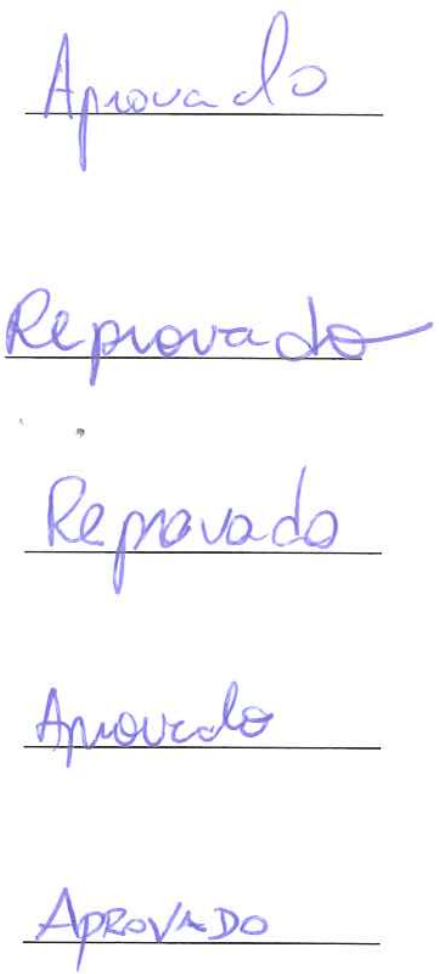

Coordenador do Programa de Pós-Graduação em Ciências da Engenharia Ambiental:

Prof. Associado Frederico Fabio Mauad

Presidente da Comissão de Pós-Graduação:

Prof. Associado Luis Fernando Costa Alberto 
Eu dedico este trabalho, fruto de muito esforço intelectual e emocional, à todas as pessoas interessadas nele.

Também uma dedicação especial aos meus pais que foram uma fonte inesgotável de apoio moral, emocional e financeiro durante este período de minha vida. 


\section{Agradecimentos}

Eu agradeço primeiramente ao meu orientador e meu amigo durante muitos anos, o Prof. Associado Frederico Fábio Mauad, por sempre acreditar no meu potencial e na minha pesquisa mesmo quando eu mesmo estava cheio de dúvidas.

Muitas pessoas foram importantes e contribuíram intelectualmente para este trabalho, eu começo os agradecimentos pelos meus colegas do Núcleo de Hidrometria, o Dr. Renato Billia de Miranda, Dr. Gustavo D’Almeida Scarpinella e Marcus Vinícius Estigoni, este último com um agradecimento especial por ter sempre sido um grande amigo durante toda minha carreira acadêmica.

Sou muito grato à orientação do Prof. Dr.-Ing André Niemann do Institut für Wasserbau und Wasserwirtschaft (WaWi) ${ }^{1}$ na Universität Duisburg-Essen, onde tive o prazer de trabalhar com excelentes colegas como Rodolfo Alvarado Monteiro, Timo Wortberg, Viktoria Berger, Julian Binias, Daniel Teschlade e Dr. Fernando Mainardi Fan. Não posso também deixar um agradecimento especial ao Dr.-Ing Dirk Schwanenberg da Deltares ${ }^{2}$ que teve um papel fundamental na supervisão e nos resultados desta pesquisa.

Devo também agradecimentos a todos os funcionários do Centro de Recursos Hídricos e Estudos Ambientais (CRHEA), do Programa de Pós-Graduação em Ciências da Engenharia Ambiental (PPG-SEA) ${ }^{3}$ e da Escola de Engenharia de São $\mathrm{Carlos}^{4}$, que durante muitos anos sempre estiveram disponíveis para nos ajudar.

E por último um agradecimento a CAPES por ter financiado minha pesquisa, possibilitando minha estágio doutoral em na Alemanha, ao pessoal da Deltares (Holanda) que me forneceu know-how e por último à CEMIG por ter fornecido os dados usados na minha pesquisa.

\footnotetext{
Institut für Wasserbau und Wasserwirtschaft $<$ https://www.uni-due.de/wasserbau/index.php $>$ Deltares <https://www.deltares.nl/> PPG-SEA<http://www1.eesc.usp.br/ppgsea/>

Escola de Engenharia de São Carlos<http://www.eesc.usp.br/portaleesc/>
} 

„We can only see a short distance ahead, but we can see plenty there that needs to be done. " Alan M. Turing (1912-1954) 



\section{Resumo}

KUWAJIMA,J.I. Avaliação de Performance Computacional de Simplificações da Equação de Saint-Venant aplicadas na Operação da UHE Três Marias, MG.. 2016. 335. Tese (Doutorado) - Escola de Engenharia de São Carlos - Universidade de São Paulo (EESC-USP) São Carlos, SP - Brasil, 2016.

O gerenciamento integrado de recursos hídricos envolve partes com usos conflitantes entre si. Portanto o gerenciamento eficiente dos reservatórios é importante para atender múltiplos objetivos operacionais: abastecimento hídrico, navegação, geração hidroelétrica, requisitos ambientais e controle de cheias. Recentemente desenvolvimentos na previsão numérica climática, dados de radares meteorológicos e aquisição de dados hidrológicos e meteorológicos on-line resultaram em um crescente interesse em processamento de importação de dados. Implementando controle preditivo com horizonte de previsão de curto prazo, é possível prever condições de estresse ou de pico de vazão, que auxilia os tomadores de decisão a agir antecipadamente, assim minimizando os impactos negativos destes eventos. Para eventos de cheia, os operadores podem verter previamente água do reservatório alocando volume de reservação adicional para mitigar os danos de inundação nas margens à jusante do corpo d'água. Neste cenário, para obter estimativas do escoamento a jusante referentes às mudanças de vertimento do reservatório, é necessário um modelo de escoamento robusto e rápido. Avaliou-se neste contexto cinco modelos diferentes quanto suas potencialidades de implementação em um modelo de controle preditivo para o reservatório de Três Marias, localizado na bacia do Alto São Francisco, Brasil. Estes modelos são: i) SOBEK que utiliza a equação hidrodinâmica de Saint-Venant; ii) SPRNT que utiliza a equação hidrodinâmica de Saint-Venant utilizando técnicas de aceleração para cálculo; iii-) MGB-IPH (Modelo Hidrológico de Grandes Bacias - Instituto de Pesquisas Hidráulicas), modelo chuva-vazão semi-distribuído que utiliza o método de Muskingum-Cunge para determinar o escoamento nos canais de interesse; iV) um modelo de onda difusiva; e v) um modelo simplificado de propagação de ondas em reservatório, equivalente à onda cinemática. Os dois últimos modelos estão implementados no pacote de ferramentas do RTC-Tools, a ferramenta de cálculo de controle em tempo real. Em geral os resultados entre os modelos simplificados do RTC-Tools e o modelo mais sofisticado SOBEK são comparáveis, no entanto os dois métodos com abordagem hidráulica, SOBEK e o modelo difusivo do RTC-Tools, apresentam difusão numérica por causa da baixa resolução espacial. No modelo de propagação de vazão por reservatórios simples a adoção de advecção pura através de um retardamento temporal mostrou-se uma correção eficiente para a difusão numérica excessiva apesar da baixa resolução espacial. Do ponto de vista de controle preditivo, esta abordagem possui melhor "custo-benefício" entre robustez, eficiência computacional e precisão.

Palavras-chave: Eq.de Saint-Venant. Modelos Hidrológicos. Otimização para controle de cheias. 



\section{Abstract}

KUWAJIMA,J.I. CPU Performance Evaluation of Saint-Venant Equations Simplifications applied to the Três Marias Dam Operation. 2016. 335. Tese (Doutorado) - Escola de Engenharia de São Carlos - Universidade de São Paulo (EESC-USP) São Carlos, SP - Brasil, 2016.

Integrated Water Resources Management involves parties with conflicting interests. Therefore an effective reservoir management is important to meet multiple operating objectives such as water supply, navigation, hydroelectricity generation, environmental obligations and flood protection. Recent upcomings in numerical weather forecast, radar data and online data acquisition resulted in an interest for data import processes. By implementing a predictive control approach over a short-term forecast horizon, it is possible to foresee stress conditions or peak flow events and support decision-makers to take actions before these events happen to minimize their negative impacts. In the case of flood events, this technique enables the operators to pre-release water from a reservoir for allocating additional storage before the flood event occurs in order to mitigate flood damage along downstream river reaches. In this scenario, a robust and fast routing model is required to obtain quick and reliable estimates of downstream flow conditions related to release changes of the reservoir. In this context, five different models are assessed concerning their implementation in a predictive control of the Três Marias reservoir located at the Upper River São Francisco in Brazil: i) a fully dynamic model using the software package SOBEK; ii)SPRNT a fully dynamic model using acceleration calculation techniques; iii) a semi-distributed rainfall-runoff model with Muskingum-Cunge routing for the flow reaches of interest, known as MGB-IPH (Modelo Hidrológico de Grandes Bacias - Instituto de Pesquisas Hidráulicas); iv) a diffusive wave model and v) Kinematic Wave equivalent simplified reservoir routing. The last two models are implemented in the RTC-Tool toolbox, a software for real-time control applications. In general, we find comparable results between the simplified models in RTC-Tools and the more sophisticated SOBEK model and a lower performance of the MGB model. However, both hydraulic modelling approaches, i.e. the SOBEK model as well as the diffusive wave model in RTC-Tools, suffer from too much numerical diffusion in case of course grids. In the reservoir routing approach, the introduction of pure advection by time lags offers an efficient solution for excessive numerical diffusion even on courser grids. From the predictive control point of view, this approach shows the best compromise in terms of robustness, computational efficiency and accuracy.

Keywords: Saint-Venant Equations. Hydraulic Routing. Optimization for Flood Control. 



\section{Lista de ilustrações}

Figura 1 - Matriz Elétrica Brasileira em 2015 . . . . . . . . . . . . . . . 35

Figura 2 - Comparação da Participação de Fontes de Energias Renováveis na Matriz Elétrica. . . . . . . . . . . . . . . . . . 58

Figura 3 - Evolução do Potencial Hidrelétrico Brasileiro (1970-2014). . . . . . . . . . 59

Figura 4 - Integração Eletroenergética Brasileira. . . . . . . . . . . . . . . . 61

Figura 5 - Horizontes de Previsão para o NEWWAVE, DECOMP e DESSEM . . . . . 64

Figura 6 - Esquema das Etapas do Processo de modelagem. . . . . . . . . . . . . 68

Figura 7 - Conceitualização do modelo SAC-SMA, ilustrando os armazenamentos de humidade do solo, componentes de escoamento superficial e trocas entre superfície do solo e atmosfera . . . . . . . . . . . . . . . .

Figura 8 - Exemplo de modelação integrada de bacia hidrográfica utilizando combinação de modelos compatíveis à OpenMI . . . . . . . . . . . . . . . . . . . . 82

Figura 9 - Representação conceitual do volume de armazenamento para o método de

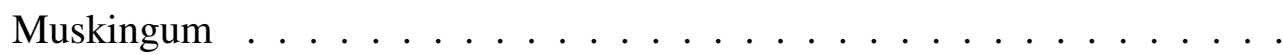

Figura 10 - Representação de discretizações em grade para Operadores de Diferença posterior, anterior e central (eixo horizontal representa espaço e o vertical o tempo . . . . . . . . . . . . . . . . . . 92

Figura 11 - Representação de um esquema de discretização Crank Nicholson . . . . . . 93

Figura 12 - Representação de uma seção Simplificada de um escoamento de canal aberto 95

Figura 13 - Variáveis de um Modelo de Controle Preditivo para a otimização do despacho hidrotérmico . . . . . . . . . . . . . . . . . . . . 110

Figura 14 - Princípio do Controle Preditivo aplicado ao despacho hidrotérmico . . . . . 111

Figura 15 - Impacto de um forçamento externo $f$, no estado do vetor do modelo de Lorenz (1963). (a) $f=0$, (b) $f=2$, (c) $f=3$ e (d) $f=4 \ldots \ldots$. . . . . . 119

Figura 16 - Diagrama em Árvore conforme RASO . . . . . . . . . . . . . . . . . 123

Figura 17 - Diagrama em Árvore para de Sistemas de produção hidroelétrica e comercialização de energia no verão. . . . . . . . . . . . . . . . . . . . . . . . . . . 124

Figura 18 - A configuração do modelo de controle preditivo que pode ser feito no RTC-

Tools utilizando otimizadores integrados. . . . . . . . . . . . . . . . 133

Figura 19 - Esquema do Modelo Hidráulico SOBEK. . . . . . . . . . . . . . . . . . . . 139

Figura 20 - Interface Gráfica de Resultados no Delft-FEWS. . . . . . . . . . . . . . . . 146

Figura 21 - Esquema da arquitetura do sistema de previsão Delft-FEWS . . . . . . . . . 147

Figura 22 - Comunicação entre os modelos e a inteface Delft-FEWS. . . . . . . . . . . 148

Figura 23 - Esquema da Arquitetura de Integracao dos Modelos no Delft-FEWS. . . . . 149

Figura 24 - Estrutura esquemática do sistema de previsão de cheias integrando bancos de dados e modelos dentro do Delft-FEWS . . . . . . . . . . . . . . . . 150 
Figura 25 - Exemplo de um Workflow (fluxo de trabalho) mostrando o processo de previsão para uma simulação hidrodinâmica de uma bacia hidrográfica. . . . . . 155

Figura 26 - Exemplo de um Workflow (fluxo de trabalho) mostrando os processos para a simulação. . . . . . . . . . . . . . . . . . . 156

Figura 27 - Local de Estudo UHE Três Marias, localizado no estado de Minas Gerais (MG).158 Figura 28 - Efeitos de Inundação na cidade de Pirapora para vazões de 4.000 e 7.000 m³/s. 160 Figura 29 - Situações de Operação de Três Marias. . . . . . . . . . . . . . . . . . . . . 162

Figura 30 - Esquematização geral da modelagem da bacia hidrográfica do estudo de caso 163

Figura 31 - Arquitetura do modelo para o SSD e Previsão Estocástica . . . . . . . . . . 165

Figura 32 - Localização das seções transversais para o Rio Abetés e Rio São Francisco. 166

Figura 33 - Visualização do MGB configurado no Delft-FEWS. . . . . . . . . . . . . 170

Figura 34 - Esquema da configuração da geometria para o SOBEK, com os transectos . 172

Figura 35 - Esquema da configuração da geometria para o SOBEK, com as contribuições laterais . . . . . . . . . . . . . . . . . . . 172

Figura 36 - Distribuição dos valores do coeficiente de Manning para a configuração SOBEK173 Figura 37 - Curva-Chave para Pirapora Ponte $(\mathrm{HxQ})$. . . . . . . . . . . . . . . . . . 175

Figura 38 - Esquema da configuração para onda difusa com resolução espacial grosseira 176

Figura 39 - Esquema da configuração para cascata de reservatórios . . . . . . . . . 176

Figura 40 - Comparação do modelo SPRNT com o SOBEK. . . . . . . . . . . . . . . . 190

Figura 41 - Modelo Totalmente dinâmico (SOBEK) e Modelos de Onda Difusiva (Diffusive Wave - DW). . . . . . . . . . . . . . . . . . . 191

Figura 42 - Comparação dos Modelos Conforme a Variação Espacial e Temporal. . . . . 192

Figura 43 - Comparação das simulações adotando intervalos de tempo de de 10, 30 e 60 min - Onda Difusiva com Baixa Resolução Espacial (Diffusive Wave -DW30km). . . . . . . . . . . . . . . . . . 192

Figura 44 - Comparação das simulações adotando intervalos de tempo de de 10, 30 e 60 min - Onda Difusiva com Alta Resolução Espacial (Diffusive Wave -DW10km).193

Figura 45 - Comparação das simulações adotando intervalos de tempo de de 10, 30 e 60 min - Cascata de Reservatórios (Reservoir Routing -RR). . . . . . . . . . . 193

Figura 46 - Comportamento dos modelos em eventos de pico de cheia. . . . . . . . . . 194

Figura 47 - Difusão Numérico dos modelos em eventos de variações de vazões. . . . . . 195

Figura 48 - NSE para os modelos de Onda Cinemática (RR) e Onda Diffusiva (DW). . . 195

Figura $49-R^{2}$ para os modelos de Onda Cinemática (RR) e Onda Diffusiva (DW). . . . 196

Figura 50 - RMSE para os modelos de Onda Cinemática (RR) e Onda Diffusiva (DW). . 197

Figura 51 - Bias para os modelos de Onda Cinemática (RR) e Onda Diffusiva (DW). . . 197

Figura 52 - Custo Relativo de Processamento refinamentos temporais dos modelos de Onda Difusa (DW-10km e DW-30km). . . . . . . . . . . . . . . . 198

Figura 53 - Custo Relativo de Processamento para refinamentos temporais do modelo de cascata de reservatórios $(\mathrm{RR})$. . . . . . . . . . . . . . . . . . . . . . 199 
Figura 54 - Resultados dos volumes do reservatório otimizados para o Cenário 1 . . . . 202

Figura 55 - Cenário 1: Comparação entre vazões defluentes simuladas e observadas do Reservatório. . . . . . . . . . . . . . . . . . . . 203

Figura 56 - Cenário 1: Comparação entre vazões simuladas e observadas no ponto de controle de Pirapora. . . . . . . . . . . . . . . . . . . . . . . . . . . . . . . 204

Figura 57 - Resultados dos volumes do reservatório otimizados para o Cenário 2 . . . 205

Figura 58 - Cenário 2: Comparação entre vazões defluentes simuladas e observadas do Reservatório. . . . . . . . . . . . . . . . . . . . 206

Figura 59 - Cenário 2: Comparação entre vazões simuladas e observadas no ponto de controle de Pirapora. . . . . . . . . . . . . . . . . . . . . . . 207

Figura 60 - Defluências do Reservatório para os Cenários de Simulação . . . . . . . . . 208

Figura 61 - Afluências em Pirapora para os Cenários de Simulação . . . . . . . . . . . 209

Figura 62 - Tempo de Processamento por numero de intevalos de tempo de simulação para os modelos de Onda Cinemática (RR) e Onda Difusiva (DW). . . . . . 215 



\section{Lista de tabelas}

Tabela 1 - Grandes Eventos de Inundação registrados na Europa, Ásia e América do Norte 39

Tabela 2 - Recursos e Reservas Energéticas Brasileiras em 2013 . . . . . . . . . . . . 58

Tabela 3 - Expansão hidrelétrica planejada (2015-2024). . . . . . . . . . . . . . . 60

Tabela 4 - Classificação de modelos hidráulicos segundo a sua dimensionalidade . . 87

Tabela 5 - Componentes da Equação de Conservação de Movimento. . . . . . . . . . . 98

Tabela 6 - Características das Simplificações das Equações de Saint-Venant. . . . . . . 99

Tabela 7 - Modelos Selecionados \& Equações Governantes. . . . . . . . . . . . . 131

Tabela 8 - Características da Usina Hidrelétrica de Três Marias. . . . . . . . . . . . 159

Tabela 9 - Características das Turbinas da UHE Três Marias. . . . . . . . . . . . . . 159

Tabela 10 - Resumo de Situação de Operação para o Reservatório de Três Marias. . . . 161

Tabela 11 - Delimitação problema:trechos dos rios Abaetés e São Francisco modelados. 166

Tabela 12 - Comprimentos das margens e canal principal do rio Abaetés . . . . . . . . 166

Tabela 13 - Comprimentos das margens e canal principal do rio São Francisco . . . . . 167

Tabela 14 - Parâmetros Fixos do MGB-IPH . . . . . . . . . . . . . . . . . 168

Tabela 15 - Parâmetros Calibráveis do MGB-IPH . . . . . . . . . . . . . . . . 169

Tabela 16 - Configuração dos cursos d’água no SOBEK . . . . . . . . . . . . . . 171

Tabela 17 - Configuração dos cursos d'água no SPRNT . . . . . . . . . . . . . . . 174

Tabela 18 - Seções transversais correspondentes aos nós do modelo difusivo com resolução grosseira $($ DW30km $) \ldots \ldots$. . . . . . . . . . . . . . . 177

Tabela 19 - Comprimento entre as seções para o modelo difusivo com resolução grosseira $(\mathrm{DW} 30 \mathrm{~km}) \ldots \ldots \ldots \ldots \ldots$. . . . . . . . . . . . . . . . . . . . . . .

Tabela 20 - Rugosidade das seções para o modelo difusivo com resolução grosseira $(\mathrm{DW} 30 \mathrm{~km}) \ldots \ldots \ldots \ldots \ldots$. . . . . . . . . . . . . . . . . . . . . . . . .

Tabela 21 - Seções transversais correspondentes aos nós do modelo difusivo com resolução refinada $(\mathrm{DW} 10 \mathrm{~km})$. . . . . . . . . . . . . . . . . . . . 179

Tabela 22 - Comprimento entre as seções para o modelo difusivo com resolução grosseira $(\mathrm{DW} 10 \mathrm{~km}) \ldots \ldots \ldots$. . . . . . . . . . . . . . . 179

Tabela 23 - Rugosidade das seções para o modelo difusivo com resolução grosseira $(\mathrm{DW} 10 \mathrm{~km}) \ldots \ldots \ldots \ldots$. . . . . . . . . . . . . 180

Tabela 24 - Delimitações dos Volumes de Controlo "Reservatórios"para a configuração de Cascata de Reservatórios . . . . . . . . . . . . . . . . . . 180

Tabela 25 - Defasagem Temporal em unidades de tempo para Vazões entre os "Reservatórios"para as intervalos de simulação de 60,30 e 10 minutos . . . . . . . . 180

Tabela 26 - Restrições Inflexíveis definidas no Otimizador . . . . . . . . . . . . . . . 181

Tabela 27 - Restrições Flexíveis definidas no Otimizador . . . . . . . . . . . . . . . . 181 
Tabela 28 - Indicadores de Performance Computacional e Estatísticos utilizados para avaliar os resultados. . . . . . . . . . . . . . . . . 183

Tabela 29 - Modelos e Períodos de Simulações dos Resultados. . . . . . . . . . . . . . 189

Tabela 30 - Cenários e Períodos de Otimizações. . . . . . . . . . . . . . . . . . . . 189

Tabela 31 - Gasto Computacional e Performance dos modelos totalmente dinâmicos sem implementação de contribuições laterais (SOBEK \& SPRNT). . . . . . . . 190

Tabela 32 - Redução do Custo relativo de processamento para os modelos de onda difusiva e de cascata de reservatórios . . . . . . . . . . . . . . 200

Tabela 33 - Descrição dos Cenários de Otimização . . . . . . . . . . . . . . . . . . 201

Tabela 34 - Estatísticas das Otimizações com Horizonte de Previsão de 1 ano: Nível de Água da Represa. . . . . . . . . . . . . . . . . . . . . . 210

Tabela 35 - Estatísticas das Otimizações com Horizonte de Previsão de 1 ano: Vazão de Saída da UHE Três Marias. . . . . . . . . . . . . . . . . . . . . . 210

Tabela 36 - Estatísticas das Otimizações com Horizonte de Previsão de 1 ano: Vazão no Ponto Pirapora. . . . . . . . . . . . . . . . . . . . . . . . 210

Tabela 37 - Critérios para caracterização da Situação de Operação no período de controle de cheias - PCC (Parte I) . . . . . . . . . . . . . . . . . . . 240

Tabela 38 - Critérios para caracterização da Situação de Operação no período de controle de cheias - PCC (Parte II) . . . . . . . . . . . . . . . . . . . . . . . 241

Tabela 39 - Características Geométricas da Seção 35200 do Rio Abaetés . . . . . . . . 246

Tabela 40 - Características Geométricas da Seção 34000 do Rio Abaetés ...... 247

Tabela 41 - Características Geométricas da Seção 30100 do Rio Abaetés . . . . . . . . 248

Tabela 42 - Características Geométricas da Seção 24200 do Rio Abaetés ...... . 249

Tabela 43 - Características Geométricas da Seção 20400 do Rio Abaetés . . . . . . . . 250

Tabela 44 - Características Geométricas da Seção 19300 do Rio Abaetés . . . . . . . . 251

Tabela 45 - Características Geométricas da Seção 16500 do Rio Abaetés . . . . . . . . 252

Tabela 46 - Características Geométricas da Seção 12400 do Rio Abaetés . . . . . . . . . 253

Tabela 47 - Características Geométricas da Seção RA0 do Rio Abaetés - Parte I . . . . . 254

Tabela 48 - Características Geométricas da Seção RA0 do Rio Abaetés - Parte II .. . . 255

Tabela 49 - Características Geométricas da Seção SF159600 do Rio São Francisco . 256

Tabela 50 - Características Geométricas da Seção SF156000 do Rio São Francisco . . 257

Tabela 51 - Características Geométricas da Seção SF153200 do Rio São Francisco 258

Tabela 52 - Características Geométricas da Seção SF148800 do Rio São Francisco . . 259

Tabela 53 - Características Geométricas da Seção SF144800 do Rio São Francisco . . 260

Tabela 54 - Características Geométricas da Seção SF142200 do Rio São Francisco . . . 261

Tabela 55 - Características Geométricas da Seção SF137600 do Rio São Francisco . . 262

Tabela 56 - Características Geométricas da Seção SF134000 do Rio São Francisco . . . 263

Tabela 57 - Características Geométricas da Seção SF130300 do Rio São Francisco . . 264

Tabela 58 - Características Geométricas da Seção SF127210 do Rio São Francisco - Parte I265 
Tabela 59 - Características Geométricas da Seção SF127210 do Rio São Francisco - Parte II266 Tabela 60 - Características Geométricas da Seção SF127190 do Rio São Francisco - Parte I267 Tabela 61 - Características Geométricas da Seção SF127190 do Rio São Francisco - Parte II268 Tabela 62 - Características Geométricas da Seção SF122100 do Rio São Francisco 269 Tabela 63 - Características Geométricas da Seção SF118800 do Rio São Francisco . . 270 Tabela 64 - Características Geométricas da Seção SF116400 do Rio São Francisco . . . 271 Tabela 65 - Características Geométricas da Seção SF111700 do Rio São Francisco . . . 272 Tabela 66 - Características Geométricas da Seção SF109400 do Rio São Francisco . . . 273 Tabela 67 - Características Geométricas da Seção SF102500 do Rio São Francisco . 274 Tabela 68 - Características Geométricas da Seção SF95600 do Rio São Francisco . . . . 275 Tabela 69 - Características Geométricas da Seção SF92600 do Rio São Francisco . 276 Tabela 70 - Características Geométricas da Seção SF86600 do Rio São Francisco . . . 277 Tabela 71 - Características Geométricas da Seção SF83200 do Rio São Francisco . . . . 278 Tabela 72 - Características Geométricas da Seção SF77200 do Rio São Francisco . . . . 279 Tabela 73 - Características Geométricas da Seção SF71100 do Rio São Francisco . . . . 280 Tabela 74 - Características Geométricas da Seção SF68200 do Rio São Francisco . . . . 281 Tabela 75 - Características Geométricas da Seção SF63800 do Rio São Francisco . . . . 282 Tabela 76 - Características Geométricas da Seção SF57000 do Rio São Francisco . . . 283 Tabela 77 - Características Geométricas da Seção SF53400 do Rio São Francisco . . . . 284 Tabela 78 - Características Geométricas da Seção SF44700 do Rio São Francisco . . . . 285 Tabela 79 - Características Geométricas da Seção SF38800 do Rio São Francisco - Parte I286 Tabela 80 - Características Geométricas da Seção SF38800 do Rio São Francisco - Parte II287 Tabela 81 - Características Geométricas da Seção SF35400 do Rio São Francisco - Parte I288 Tabela 82 - Características Geométricas da Seção SF35400 do Rio São Francisco - Parte II289 Tabela 83 - Características Geométricas da Seção SF32000 do Rio São Francisco - Parte I290 Tabela 84 - Características Geométricas da Seção SF32000 do Rio São Francisco - Parte II291 Tabela 85 - Características Geométricas da Seção SF30700 do Rio São Francisco . . . . 292 Tabela 86 - Características Geométricas da Seção SF29000 do Rio São Francisco - Parte I293 Tabela 87 - Características Geométricas da Seção SF29000 do Rio São Francisco - Parte II294 Tabela 88 - Parâmetros Fixos de Albedo para o MGB-IPH . . . . . . . . . . . . . . . 295 Tabela 89 - Parâmetros Fixos de Índice de Área Foliar (IAF) para o MGB-IPH ... . 296 Tabela 90 - Parâmetros Fixos de Altura do Dossel (Z) para o MGB-IPH . . . . . . . . . 296 Tabela 91 - Parâmetros Fixos de Resistência Superficial (RS) para o MGB-IPH . . . . . 297 Tabela 92 - Parâmetros Calibráveis para o MGB: CI, CS, CB e QB . . . . . . . . . . 297 Tabela 93 - Parâmetros Calibráveis Wm, b, Kbas, Kint, XL, CAP e Wc para as Bacia 1, 2,3 e $4 \ldots \ldots \ldots \ldots \ldots$

Tabela 94 - Parâmetros Calibráveis Wm, b, Kbas, Kint, XL, CAP e Wc para a Bacia 5, 6,

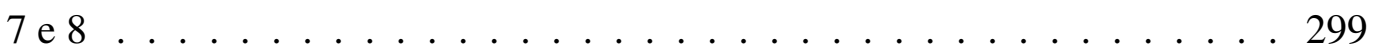


Tabela 95 - Parâmetros Calibráveis Wm, b, Kbas, Kint, XL, CAP e Wc para a Bacia 9,

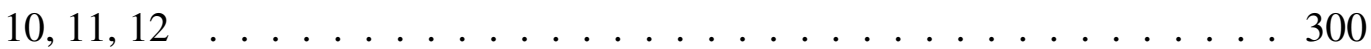

Tabela 96 - Parâmetros Calibráveis Wm, b, Kbas, Kint, XL, CAP e Wc para a Bacia 13301

Tabela 97 - Configuração Geométrica de nós para o SOBEK - Rio Abaetés . . . . . . . 303

Tabela 98 - Configuração Geométrica de nós para o SOBEK - Rio São Francisco 1 . . . 303

Tabela 99 - Configuração Geométrica de nós para o SOBEK - Rio São Francisco 2 . . 304

Tabela 100-SPRNT: Configuração completa do rio Abaetés . . . . . . . . . . . . . . 305

Tabela 101 -SPRNT: Configuração completa do rio São Francisco 1 . . . . . . . . . . 305

Tabela 102-SPRNT: Configuração completa do rio São Francisco 2 . . . . . . . . . . . 306

Tabela 103-SPRNT: Configuração reduzida do rio Abaetés . . . . . . . . . . . . 306

Tabela 104-SPRNT: Configuração completa do rio São Francisco 1 . . . . . . . . . . 306

Tabela 105-SPRNT: Configuração completa do rio São Francisco 2 . . . . . . . . . . . 307

Tabela 106 - Valores de Cota, Largura da Seção e Armazenamento para a Seção PBR040 -

Onda Difusiva Grosseira (DW30km) . . . . . . . . . . . . . . . 309

Tabela 107 - Valores de Cota, Largura da Seção e Armazenamento para a Seção TMarias -

Onda Difusiva Grosseira (DW30km) . . . . . . . . . . . . . . . 310

Tabela 108 - Valores de Cota, Largura da Seção e Armazenamento para a Seção N01 -

Onda Difusiva Grosseira (DW30km) . . . . . . . . . . . . . . . . 311

Tabela 109-Valores de Cota, Largura da Seção e Armazenamento para a Seção N02 -

Onda Difusiva Grosseira (DW30km) . . . . . . . . . . . . . . 312

Tabela 110 - Valores de Cota, Largura da Seção e Armazenamento para a Seção N03 -

Onda Difusiva Grosseira (DW30km) . . . . . . . . . . . . . . 313

Tabela 111 - Valores de Cota e Largura da Seção para a Seção Pirapora - Onda Difusiva

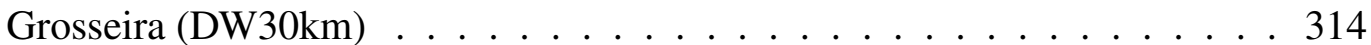

Tabela 112 - Valores de Cota, Largura da Seção e Armazenamento para a Seção PBR040 -

Onda Difusiva Refinada (DW10km) . . . . . . . . . . . . . . 315

Tabela 113 - Valores de Cota, Largura da Seção e Armazenamento para a Seção Três

Marias - Onda Difusiva Refinada (DW10km) . . . . . . . . . . . . 316

Tabela 114 - Valores de Cota, Largura da Seção e Armazenamento para a Seção N01a Onda Difusiva Refinada (DW10km) . . . . . . . . . . . . . . . 317

Tabela 115 - Valores de Cota, Largura da Seção e Armazenamento para a Seção N01b Onda Difusiva Refinada (DW10km) _ . . . . . . . . . . . . . 318

Tabela 116 - Valores de Cota, Largura da Seção e Armazenamento para a Seção N01 Onda Difusiva Refinada (DW10km) _ . . . . . . . . . . . . . . 319

Tabela 117 - Valores de Cota, Largura da Seção e Armazenamento para a Seção N02a Onda Difusiva Refinada (DW10km) _ . . . . . . . . . . . . . . 320

Tabela 118 - Valores de Cota, Largura da Seção e Armazenamento para a Seção N02b -

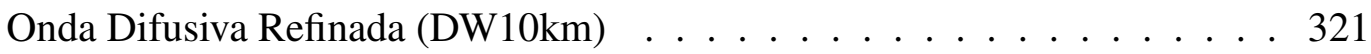


Tabela 119-Valores de Cota, Largura da Seção e Armazenamento para a Seção N02 Onda Difusiva Refinada (DW10km) . . . . . . . . . . . . . . . 322

Tabela 120 - Valores de Cota, Largura da Seção e Armazenamento para a Seção N03a Onda Difusiva Refinada (DW10km) . . . . . . . . . . . . . . . . 323

Tabela 121 - Valores de Cota, Largura da Seção e Armazenamento para a Seção N03b Onda Difusiva Refinada $(\mathrm{DW} 10 \mathrm{~km})$. . . . . . . . . . . . . . . 324

Tabela 122 - Valores de Cota, Largura da Seção e Armazenamento para a Seção N03 Onda Difusiva Refinada (DW10km) _ . . . . . . . . . . . . . 325

Tabela 123 - Valores de Cota, Largura da Seção e Armazenamento para a Seção N Pa Onda Difusiva Refinada (DW10km) . . . . . . . . . . . . . 326

Tabela 124 - Valores de Cota, Largura da Seção e Armazenamento para a Seção N Pb Onda Difusiva Refinada (DW10km) . . . . . . . . . . . . . . . . 327

Tabela 125 - Valores de Cota, Largura da Seção e Armazenamento para a Seção Piraporaponte - Onda Difusiva Refinada (DW10km) . . . . . . . . . . . . . . 328

Tabela 126 - Valores de Vazão, Largura da Seção e Armazenamento para o Rio Abaetés (PBR040) - Cascata de Reservatórios (RR) . . . . . . . . . . . . . . . . . . 329

Tabela 127-Valores de Vazão, Largura da Seção e Armazenamento para o Rio São Francisco (N01a) - Cascata de Reservatórios (RR) . . . . . . . . . . . 330

Tabela 128 - Valores de Vazão, Largura da Seção e Armazenamento para o Rio São Francisco (N02) - Cascata de Reservatórios (RR) . . . . . . . . . . . . . 331

Tabela 129-Valores de Vazão, Largura da Seção e Armazenamento para o Rio São Francisco (N03) - Cascata de Reservatórios (RR) . . . . . . . . . . . . 332

Tabela 130 - Valores de Vazão, Largura da Seção e Armazenamento para até Pirapora Cascata de Reservatórios (RR) . . . . . . . . . . . . . . . . . . 333

Tabela 131 - Desempenho estatístico e computacional dos modelos no Ponto Pirapora para os modelos hidrodinâmicos utilizados: SOBEK, MGB, R.R. e D.W. . . . . . 335 



\title{
Lista de abreviaturas e siglas
}

\author{
ADCIRC ADvanced CIRculation \\ ANA Agência Nacional de Águas \\ ANEEL Agência Nacional de Energia Elétrica \\ ASTER Advanced Spaceborne Thermal Emission and Reflection Radiometer \\ API Application Programming Interface \\ CEMIG Companhia Energética de Minas Gerais \\ CPTEC Centro de Previsão de Tempo e Estudos Climáticos \\ CPU Central Processing Unit \\ CVSF Comissão do Vale do São Francisco \\ Delft-FEWS Delft-Flood Early Warning System \\ DW Diffusive Wave \\ ECMWF European Centre for Medium-range Weather Forecast \\ EFFS European Flood Forecast System \\ EM Ensemble Médio \\ EPE Empresa de Pesquisas Energéticas \\ EPS European Prediction Centre \\ ESV Equações de Saint-Venant \\ FB Feedback Control \\ FF $\quad$ Feedfoward Control \\ FLOPs Floating-point Operations per Second \\ GCM General Circulation Model \\ GMT Greenwich Mean Time \\ HBV Hydrologiska Byråns Vattenbalansavdelining
}




\begin{tabular}{|c|c|}
\hline HEC-RAS & Hydrologic Engineering Center's River Analysis System \\
\hline HRU & Hydrology Responses Units ou Unidades de Resposta Hidrológicas \\
\hline IBM & International Business Machines \\
\hline IoT & Internet of Things \\
\hline IPOPT & Interior Point Optimizer \\
\hline $\mathrm{MC}$ & Muskingum-Cunge \\
\hline MGB & Modelos de Grandes Bacias \\
\hline MLT & Vazao Media de Longo Prazo \\
\hline MME & Ministério de Minas e Energias \\
\hline MPC & Model Predictive Control \\
\hline NEWAVE & $\begin{array}{l}\text { Modelo de Planejamento da Operação de Sistemas Hidrotérmicos Interliga- } \\
\text { dos de Longo e Médio Prazo }\end{array}$ \\
\hline NFFS & UK National Flood Forecasting System \\
\hline NLMC & Non-Linear Muskingum-Cunge \\
\hline NLMPC & Non-Linear Model Predictive Control \\
\hline NOAA & National Oceanic and Atmospheric Administration \\
\hline NSE & Nash-Sutcliffe Efficiency \\
\hline NWP & Numerical Weather Prediction \\
\hline NWS & National Weather Service \\
\hline OCDE & Organização para Cooperação e Desenvolvimento Econômico \\
\hline ONS & Operador Nacional do Sistema Elétrico \\
\hline PCC & Período de Controle de Cheias \\
\hline PID Controller & Proportional-Integral-Derivative Controller \\
\hline PNRH & Política Nacional dos Recursos Hídricos \\
\hline QPF & Quantitative Precipitation Forecasts \\
\hline RAM & Rapid Access Memory \\
\hline
\end{tabular}




\begin{tabular}{|c|c|}
\hline RIZA & Rijksinstituut voor Integraal Zoetwaterbeheer en Afvalwaterbehandeling \\
\hline RMSE & Root Main Square Error \\
\hline RMSP & Região Metropolitana de São Paulo \\
\hline $\mathrm{RR}$ & Reservoir Routing \\
\hline RTC-Tools & Real Time Control - Tools \\
\hline SABESP & Companhia de Saneamento do Estado de São Paulo \\
\hline SAC-SMA & Sacramento Soil Moisture Accounting Model \\
\hline SCS-CN & Soil Conservation Service - Curve Number \\
\hline SCS-UH & Soil Conservation Service - Unit Hydrograph \\
\hline SIN & Sistema Interligado Nacional \\
\hline SPRNT & Simulation Program for River Networks \\
\hline SSD & Sistemas de Suporte à Decisão \\
\hline SWFDP & Severe Weather Forecasting Demonstration Project \\
\hline $\mathrm{TCO}$ & Teoria do Controle Ótimo \\
\hline THORPEX & The Observing System Research and Precicability Experiment \\
\hline TIGGE & Interactive Grand Global Ensemble \\
\hline UHE & Usina Hidroelétrica \\
\hline USACE & US Army Corps of Engineers \\
\hline VLSI & Very Large System Integration \\
\hline WCD & World Comission of Dams \\
\hline WMO & World Meteorological Organization \\
\hline XML & eXtensive Markup Language \\
\hline
\end{tabular}





\section{Sumário}

O DESAFIO DO GERENCIAMENTO DE RECURSOS HÍDRICOS . 33

1.3 Operação de Barragens e Reservatórios para Gerenciamento de Recursos Hídricos.

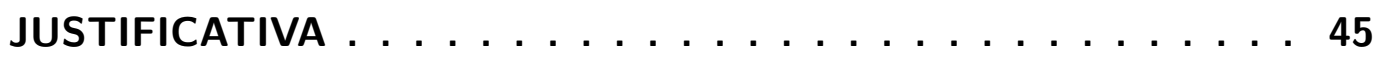

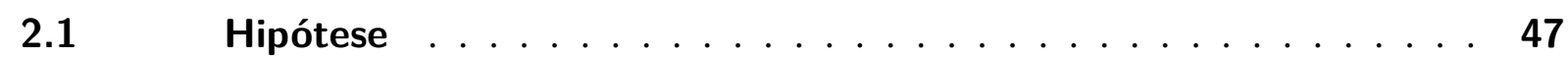

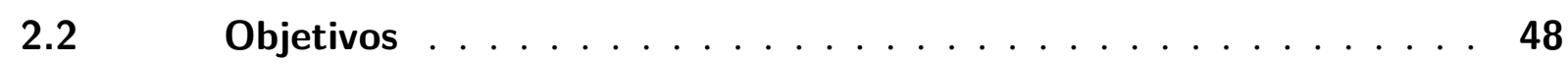

$2.2 .1 \quad$ Objetivos Especificos $\ldots \ldots \ldots \ldots$

REPRESAS, RESERVATÓRIOS E USINAS HIDRELÉTRICAS . . . 53

Setor Hidroenergético Brasileiro

3.4 Expansão Planejada do Setor Hidrelétrico . . . . . . . . . . . . 59

$3.5 \quad$ Agência Nacional de Energia Elétrica - ANEEL . . . . . . . . 60

$3.6 \quad$ Operador Nacional do Sistema Elétrico - ONS . . . . . . . . . 61

3.6.1 Sistema Interligado Nacional - SIN . . . . . . . . . . . . . . . 61

3.6.2 Políticas e Regras de Operação da ONS . . . . . . . . . . . . . 62

3.7 NEWAVE - Modelo de Planejamento da Operação de Sistemas Hidrotérmicos Interligados de Longo e Médio Prazo . . . . . . . 62

3.7.1 Diretrizes e Regras de Operação de Controle de Cheia . . . . . . . . . 65

4 MODELAGEM DE BACIA HIDROGRÁFICAS . . . . . . . . 67

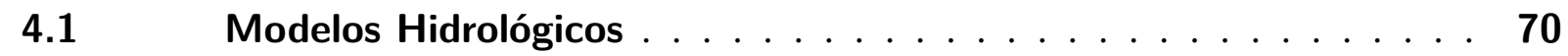

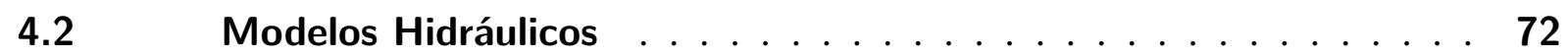

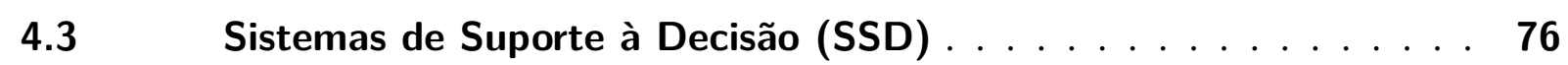

4.3.1 Sistemas de Previsão de Cheia e de Alerta . . . . . . . . . . . . . . . . 79 
ESCOAMENTO HIDRÁULICO EM CANAIS . . . . . . . . . . 89

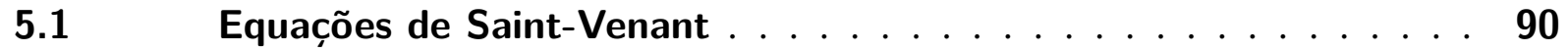

5.2 Comparação entre abordagem Implícita Explícita . . . . . . . . 93

5.3 Dedução das Equações 1D de Saint-Venant . . . . . . . . . . . 93

$5.4 \quad$ Simplificações das Equações de Saint-Venant $\ldots \ldots \ldots$. . . . . . 98

6 MODELO DE CONTROLE PREDITIVO - MPC . . . . . . . 101

6.1 Diferenças entre MPC sequencial e simultâneo . . . . . . . . 106

$6.1 .1 \quad$ MPC Simultâneo . . . . . . . . . . . . . . . . . . . . . . . 107

$6.1 .2 \quad$ MPC Sequencial . . . . . . . . . . . . . . . . . . 108

6.2 Aplicação na Operação de Reservatórios . . . . . . . . . . . 109

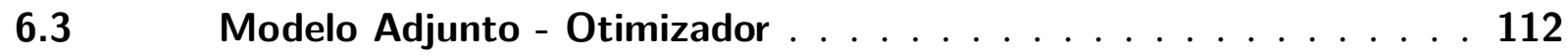

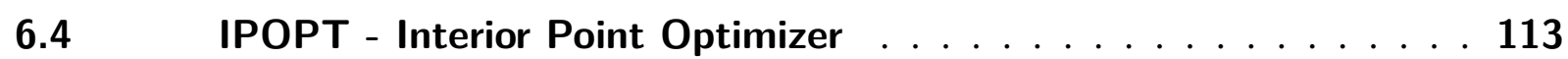

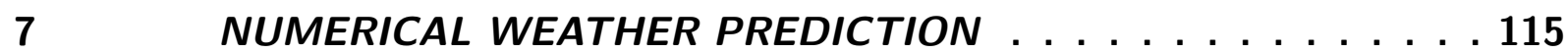

7.1 Previsão Estocástica x Previsão Determinísitica . . . . . . . . 115

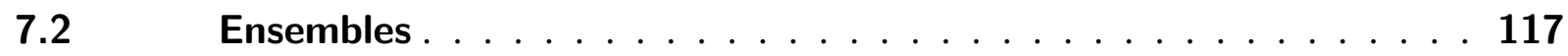

7.2 .1 Dispersão do Ensemble . . . . . . . . . . . . . . . . . . . . 121

7.2 .2 Diagrama de Previsões em Árvore . . . . . . . . . . . . . . . 122

7.2.3 Técnicas de Assimilação de Dados e Fontes de Incertezas . . . . . . . . . . 124

$\begin{array}{ll}\text { IV } & 129\end{array}$

8 MODELOS HIDRÁULICOS E HIDROLÓGICOS UTILIZADOS . . . 131

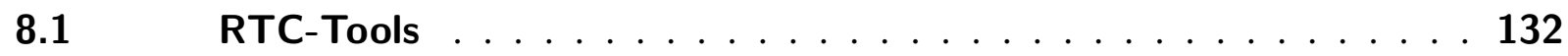

$8.2 \quad$ Cascata de Reservatórios - Reservoir Routing . . . . . . . . . . 134

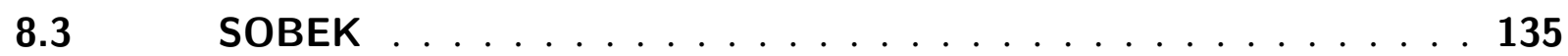

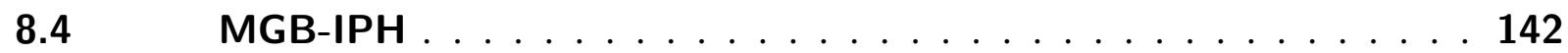

8.4 .1 Muskingum-Kunge . . . . . . . . . . . . . . . . . . . 143

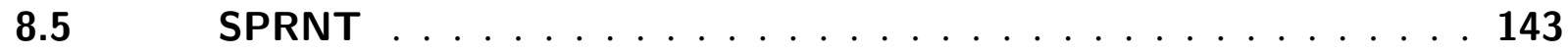

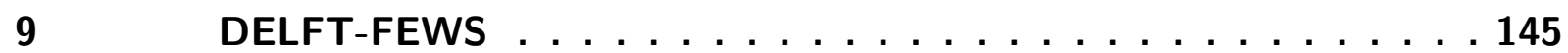

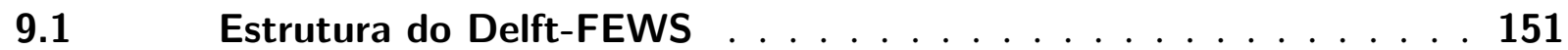

9.1.1 Importação, armazenamento, processamento e manipulação dos dados . . 152

9.1 .2 Integração de Modelos . . . . . . . . . . . . . . . . . . . . 154

10 ESTUDO DE CASO:BACIA HIDROGRÁFICA DO ALTO SÃO FRAN-

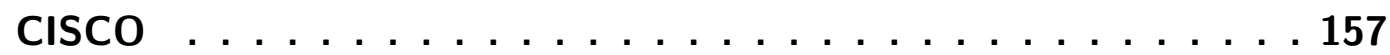

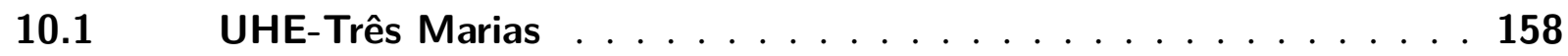

10.1.1 Caracterização da Situação de Operação de Três Marias . . . . . . . . . 160 
$10.2 \quad$ Modelo Conceitual do Problema . . . . . . . . . . . . . . . . 162

10.2.1 Integração de Modelos e Banco de Dados . . . . . . . . . . . . . . 164

10.3 Configuração e Calibração dos Modelos . . . . . . . . . . . . . . 165

10.3.1 Configuração do MGB . . . . . . . . . . . . . . . 168

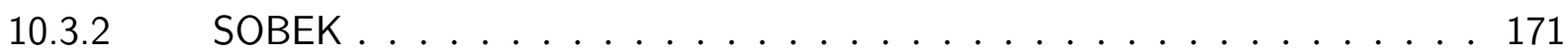

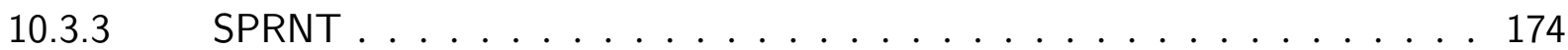

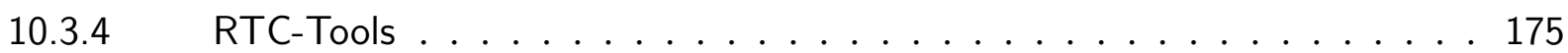

10.4 Configuração do IPOPT . . . . . . . . . . . . . . . 181

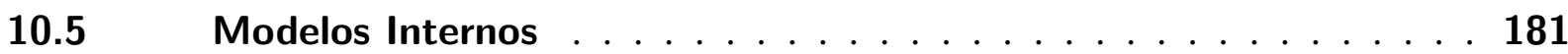

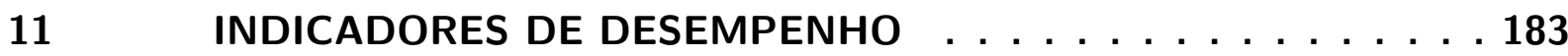

V RESULTADOS \& DISCUSSÃO

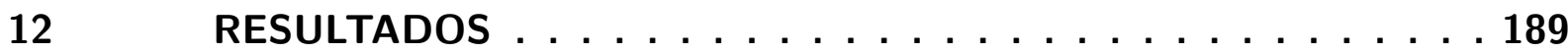

$12.1 \quad$ SOBEK $\times$ SPRNT . . . . . . . . . . . . . . 190

$12.2 \quad$ Impacto da Resolução Espacial . . . . . . . . . . . . . . . 191

$12.3 \quad$ Impacto da Resolução Temporal . . . . . . . . . . . . . . . . 191

12.4 SOBEK X MGB-IPH X RTC-Tools . . . . . . . . . . . . . . 194

$12.5 \quad$ Métricas de Desempenho . . . . . . . . . . . . 195

12.6 Avaliação de Performance Computacional dos Modelos . . . . . . 197

12.7 Resultados da Simulação do Otimizador . . . . . . . . . . . . . . 200

12.7.1 Cenário 1: Condição Normal . . . . . . . . . . . . . . . . 201

12.7.2 Cenário 2: Condição de Estiagem . . . . . . . . . . . . . . . . 202

12.8 Avaliação dos Resultados dos Cenário de Otimização . . . . . . . . 205

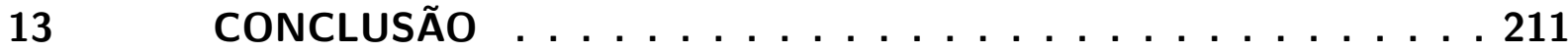

$13.1 \quad$ Trade-off entre Precisão e Desempenho Computacional . . . . . . . 214

$13.2 \quad$ Sugestões para futuras pesquisas . . . . . . . . . . . . . . 218

REFERÊNCIAS . . . . . . . . . . . . . . . 221

ANEXOS

ANEXO A - CARACTERIZAÇÃO DE SITUAÇÃO PARA OPERAÇÃO - ONS . . . . . . . . . . . . . . . . . 239 
APÊNDICE A - DADOS BATIMÉTRICOS DO RIO SÃO FRANCISCO E DO RIO ABAETÉS . . . . . . . . . 245

APÊNDICE B - PARÂMETROS CALIBRADOS PARA O MGB-IPH295

APÊNDICE C - GEOMETRIA DOS CANAIS DA CONFIGURAÇÃO DO SOBEK . . . . . . . . . 303

APÊNDICE D - GEOMETRIA DOS CANAIS DA CONFIGURA-

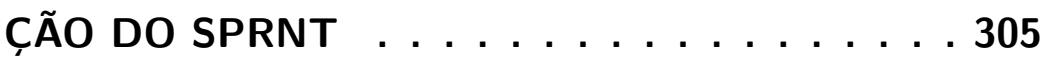

APÊNDICE E - RTC-TOOLS - GEOMETRIA PARA ONDA DIFUSIVA DE MALHA GROSSEIRA DO RTC-TOOLS309

APÊNDICE F - RTC-TOOLS - GEOMETRIA PARA ONDA DIFUSIVA MALHA REFINADA DO RTC-TOOLS . 315

APÊNDICE G - RTC-TOOLS - GEOMETRIA PARA CASACADA DE RESERVATÓRIOS DO RTC-TOOLS . . . . 329

APÊNDICE H-SUMÁRIO DOS RESULTADOS . . . . . 335 
Parte I

Introdução 



\section{O Desafio do Gerenciamento de Recursos Hídricos}

Neste capítulo introdutório pretende-se apresentar alguns conceitos básicos para o entendimento do problema a ser abordado nesta tese. Será debatida a importância dos recursos hídricos que é vital para o desenvolvimento humano, sendo esta relação pode ser traçada historicamente desde as primeiras sociedades organizadas até os dias de hoje.

Estes recursos trazem progresso, mas também podem infligir grandes prejuízos se houver falta de conhecimento sobre o comportamento deles e caso não existir um planejamento adequado para lidar com a variação deste recurso temporalmente, espacialmente, quantitativamente e qualitativamente. Ou seja, a disponibilidade da água depende da época do ano sendo mais abundante em épocas chuvosas e mais escassa em épocas de seca; da região, pois existem locais que sofrem de escassez e outros que possuem abundância; e de características quali-quantitativas, uma vez que o recurso pode existir no local e no momento, mas não na quantidade ou mesmo na qualidade desejada.

Os reservatórios e hidroelétricas podem, no entanto, servir como ferramentas para mitigar alguns dos impactos causados por esta variação da disponibilidade hídrica. Porém a operação de reservatórios para gerenciamento de recursos hídricos não é tarefa simples; o equacionamento deste problema envolve muitas variáveis e também diversos atores, o que torna a solução e otimização deste problema muito complexo,

Os recursos computacionais foram desenvolvidos e são muito eficientes em solucionar o equacionamento de sistemas complexos, portanto são usadas como uma ferramenta para solução deste problema extremamente complexo. Assim quando utilizadas em conjunto com o conhecimento prévio, experiência e bom senso dos tomadores de decisão e operadores do sistema, são peças vitais no gerenciamento integrado de recursos hídricos.

\subsection{Recursos Hídricos \& Desenvolvimento}

Historicamente o desenvolvimento humano sempre esteve relacionado com os recursos hídricos, ou seja, a disponibilidade hídrica, tanto quantitativamente quanto qualitativamente, determina o sucesso ou fracasso da população no local. Segundo Sivapalan, Savenije e Blöschl (2012), a água tem uma importância e impacto no crescimento, evolução e colapso final de muitas sociedades no passado. 
As grandes civilizações da antiguidade conseguiram estabeleceram numerosos povoados e cidades às margens de grandes rios; podendo citar entre eles o Tigre e o Eufrates na Mesopotâmia, Rio Nilo no Antigo Egito, Rio Indo na Índia e Rio Amarelo na China. Além do abastecimento de água para a população, estes rios desempenhavam funções importantes em suas sociedades como transporte, pesca irrigação e fertilização de campos férteis para colheitas. Em contrapartida raramente povoada humana floresceram em locais onde não havia tais recursos.

Assim sendo, o gerenciamento eficiente é de suma importância para garantir que não haja falta deste recurso. Em um estudo sobre a resiliência hídrica do Império Romano, Dermody et al. (2014) mostraram que eles possuíam uma intrincada e complicada rede de importação de água virtual(água necessária nos processos de produção de um bem, produto ou serviço), que permitia a prosperidade do império em resposta à urbanização e variabilidade climática de seus territórios, em outras palavras, embora não houvesse quantidade de água disponível na capital, os territórios administrados pelo império seriam capazes de abastecer os territórios deficitários de água.

Segundo Barker (1996), os romanos não foram a primeira civilização a utilizar-se de técnicas de gerenciamento hídrico, mas o grau de organização e sofisticação foi sem precedentes, o que permitiu um alto rendimento nas colheitas no império. Eles se utilizavam de diversas ferramentas para gerir o suprimento de água, eles dominavam tecnologias como barragens, aquedutos, canais, cisternas, rodas de água e qanats (Galerias de águas subterrâneas) (BARKER, 1996; WILSON, 1997).

O gerenciamento dos recursos hídricos era tão importante no Império Romano, que existiam impostos para a construção, operação e manutenção desta infraestrutura usada no gerenciamento hídrico, nas regiões do Egito, a extensão de terra irrigada era taxada e na Espanha, Sicília e Sardenha, havia impostos sobre a colheita (LLORIS, 2006; ERDKAMP, 2005). Em Lloris (2006), Butzer et al. (1985), Leeuw (1998) os autores afirmam que este complexo gerenciamento permitiu que a água superficial se tornasse um recurso confiável, sem a dependência sazonal e imprevisível de águas proveniente de precipitações.

Há uma importância e correlação entre a disponibilidade deste recursos e desenvolvimento, já que é virtualmente impossível desenvolver atividades humanas sem eles; Em um trabalho de Libânio, Chenicharo e Nascimento (2005), os autores compararam indicadores de disponibilidade hídrica e de saneamento com os indicadores de saúde e desenvolvimento social de municípios brasileiro, obtendo uma correlação entre eles, destacando a importância dos indicadores de saneamento básico como cobertura de serviços de água e esgoto e indicadores de disponibilidade hídrica e de sua qualidade.

É portanto vital que se utilize estes recursos de forma racional evitando que haja escassez 
ou mesmo degradação da qualidade de deles, o que reduzem as atividades que podem utiliza-los sem custos e processos de tratamento. Neste âmbito o gerenciamento de recursos hídricos se desenvolve ao passo que estes conflitos se tornam mais evidentes.

Em Biswas (2008) os autores relatam que o gerenciamento integrado dos recursos hídricos começou a ser desenvolvido durante o fim da década de 40 e ínicio dos anos 50, e que motivado pelos problemas ambientais teve um progresso intensificado durante os anos 80 e 90 . No entanto os autores ressaltam que ainda é necessário substanciosos progressos para que haja maior governança sobre estes recursos.

\section{Importância dos Recursos Hídricos no Brasil}

Atualmente no Brasil existe uma grande preocupação com o gerenciamento dos recursos hídricos visto que a geração elétrica do país é dependente de geração hidroelétrica, atualmente ela corresponde por $64,0 \%$ de toda energia elétrica produzida no país (Figura 1). Os valores desta porcentagem flutuam de ano a ano devido a sazonalidade pluviométrica, períodos recessão econômica e mudanças no perfil de consumo da população. Esta modalidade representava em 2011 por $67 \%$ ou $77.001 \mathrm{MW}$ da capacidade total instalada para geração elétrica no país de 115.162 MW.

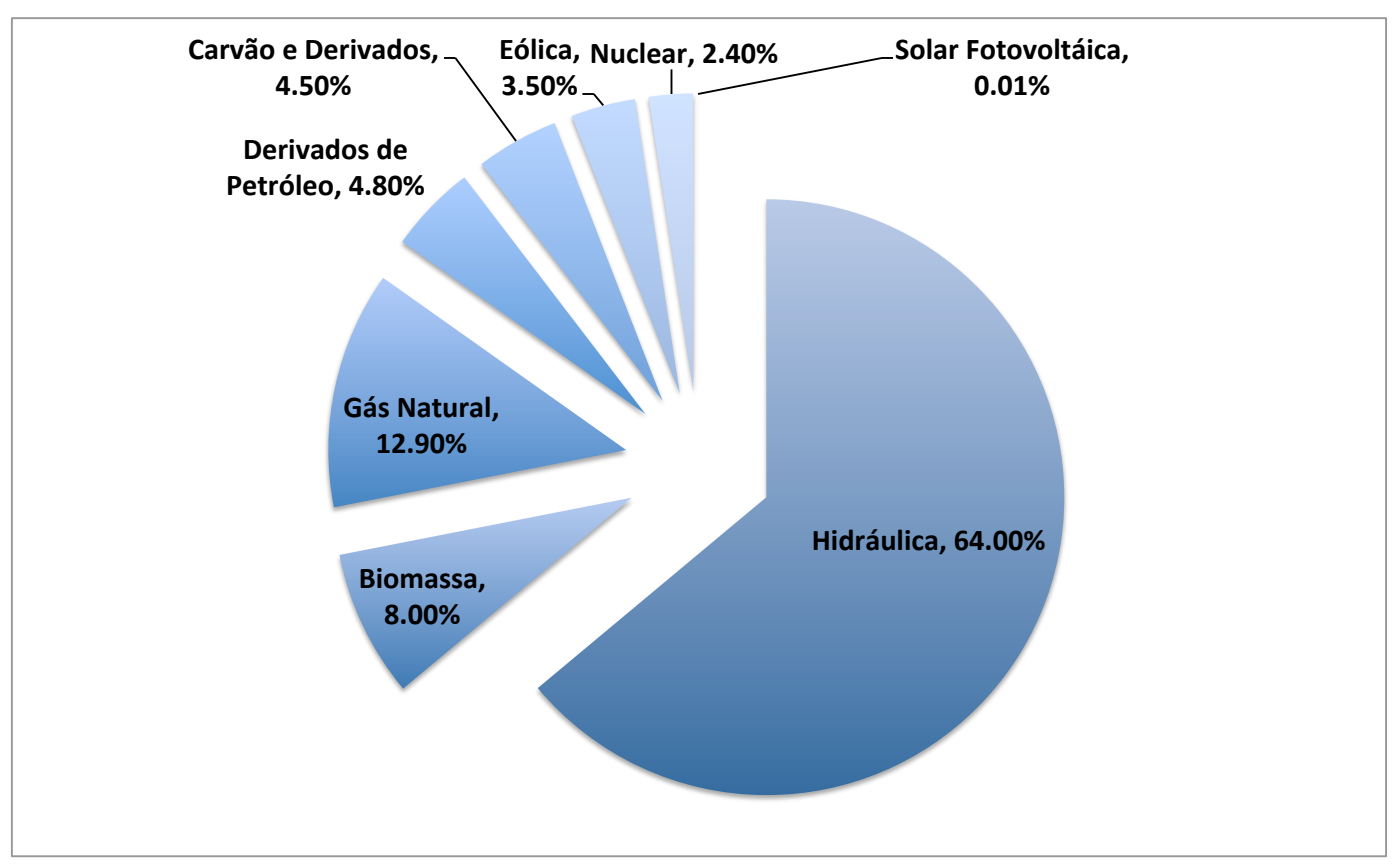

Adaptado de Empresa de Pesquisas Energéticas e Ministério de Minas e Energias (2016)

Figura 1 - Matriz Elétrica Brasileira em 2015.

Esta dependência de recursos hídricos para geração hidrelétrica torna o Brasil também vulnerável à eventuais crises de abastecimento elétrico em períodos de seca anormal, como 
os registrados entre 2001 e 2002, na chamada "crise do apagão", onde houve racionamento de energia e que motivou uma reestruturação do setor energético e a criação de uma agência nacional para o gerenciamento de recursos hídricos (ESTIGONI et al., 2011).

O desenvolvimento continua vinculado com a disponibilidade de água, visto que os recursos hídricos continuam a desempenhar papel essencial nas atividades humanas. Uma vez que os corpos de água ainda são utilizados para abastecimento hídrico, geração de energia, saneamento, transporte fluvial, pesca, irrigação, dessedentação animal, usos recreativos e paisagísticos.

\subsection{Impactos dos Eventos de Cheia e de Seca}

A conforme visto na seção 1.1 o desenvolvimento humano está intrinsecamente dependente e vulnerável à disponibilidade destes recursos, portanto a variabilidade temporal, espacial, quantitativa e qualitativa impacta diretamente o desenvolvimento dela. Eventos climáticos extremos, onde há escassez ou excesso deste recurso, podem resultar em impactos negativos podendo até resultar em danos e consequências irreversíveis tanto para o meio-ambiente quanto para a população.

\section{Eventos de Seca}

Os eventos de seca, geralmente são ocasionados por períodos longos de baixa pluviosidade que acarretam em estresse hídrico, ou seja, falta de água disponível. Além-claro de problemas para o abastecimento, a falta de água pode impactar economicamente e financeiramente, uma vez que as atividades agrícolas e pecuárias são completamente comprometidas, podendo em casos extremos causar fome e instabilidade sócio-política. Em países que dependem da energia hidroelétrica, isto pode também acarretar em desabastecimento elétrico.

Em Landon-Lane, Rockoff e H.Steckel (2009) é mostrado que os eventos de seca registrados no estado do Kansas, estão correlacionados com períodos de recessão econômica. O exemplo clássico é o chamado "The Dusty Bowl", que foi um evento de estiagem ocorrido nos EUA durante os anos 1930; foi mais crítico nos estados de Oklahoma, Texas e Novo México entre 1930 até 1936, este evento crítico é creditado como um dos deflagradores da Grande Depressão ou Crise de 29; causando prejuízos na agricultura avaliados em US\$ 153 Milhões em 1930 (corrigidos para US\$1,9 bilhões em 2007) além de declínio e deslocamento populacional.(HORNBECK, 2009; MURPHY, 1935).

No Brasil recentemente houve alguns eventos crítica os de seca documentados: 2005 na região amazônica, que passou pelo evento mais severo dos últimos 100 anos resultando em suspensão da navegação de trechos do rio Madeira e do Amazonas (MARENGO et al., 2008). Em 2012, eventos de grande magnitude foram registrados na região sul do país e entre 2011 
e a região nordeste foi afetada em 2013. Mais recentemente foi a vez da região Sudeste ser afetada por um evento deste tipo. Segundo Marengo et al. (2015) entre 2014 e 2015 um bloqueio atmosférico da Zona de Convergência do Atlântico Sul por 45 dias na época chuvosa resultou em um período de baixos índices pluviométricos. Este período de estiagem combinado com uma crescente demanda hídrica e um gerenciamento ineficiente dos recursos hídricos gerou a maior crise hídrica dos últimos 60 anos na Região Metropolitana de São Paulo (RMSP).

Esta seca causou casos de desabastecimento de água e racionamento durante o período mais crítico do evento, sendo que algumas regiões dependeram de caminhões-pipa para o abastecimento e a concessionária estatal SABESP (Companhia de Saneamento Básico do Estado de São Paulo), teve de reduzir a pressão da rede, reduziu a extração em um terço e ofereceu descontos para clientes que apresentassem redução de consumo. Outros impactos diretos deste evento foram aumento das tarifas de energia elétrica e aumento de preços de produtos MARENGO et al., op. cit..

\section{Eventos de Inundação}

Knight e Shamseldin (2005) categoriza as causas de cheias e enchentes em duas categorias:

1. Causas Naturais:

a) Precipitação ( chuva, granizo \& degelo);

b) Deslizamentos de terra (instabilidades de taludes, erosão, atividades sísmicas);

c) Tempestades (Zonas de baixa pressão elevando marés);

d) Elevação dos nível de água subterrânea;

e) Derretimento de geleiras ou colapso (devido à atividade vulcânica);

f) Mudança Climática ( alterações nos padrões de precipitação e dos níveis do mar);

2. Causadas por atividade antrópicas:

a) Rompimento de Barragens (catastrófico, galgamento, etc..);

b) Falha de Obras de Terraplanagem (Aterros de proteção contra enchentes de rio e costais);

c) Invasão das várzeas (Urbanização das planícies de inundação de rios, perda de volume de armazenamento dos rios);

d) Alteração do Uso e Ocupação do Terreno (Mudanças do tipo de culturas, compactação do solo, desflorestação, etc..); 
e) Controles de Planejamento Inadequados para a Área da Bacia hidrográfica (âmbitos Local e Nacional);

f) Capacidade de Drenagem Inadequada (Urbanizacao) e Assoreamento (Processos Naturais);

g) Integração Inadequada (ex: entre rio e sistemas de rede de esgoto/drenagem subterrânea);

h) Manutenção Inadequada ( Nos canais dos cursos de água urbanos e entupimento e bloqueio dos sistemas de canais de esgotos);

Muito embora as cheias tragam impactos positivos no meio-ambiente com fertilização das margens de inundação, recarga de lençóis freáticos além de terem um papel importante para os ecossistemas, estes eventos podem ameaçar a vida, saúde, manutenção e sustento do modo de vida e causar danos materiais. Segundo World Comission on Dams (2000) e (GREEN; PARKER; TUNSTALL, 2000) entre 1972 e 1996 aproximadamente 65 milhões de pessoas tiveram suas vidas afetadas por estes eventos.

Knight e Shamseldin (2005) um estudo dos eventos naturais catastróficos do mundo inteiro entre 1988 e 1997, indicam que as inundações representam um terço desses eventos, são responsáveis por metade das vítimas fatais e um terço do prejuízo financeiro. As inundações são também particularmente mais letais quando ocorrem em países com perfil populacional pobre e populoso. Na Tabela 1 lista alguns dos maiores eventos de cheia que ocorreram nos Países Baixos, China, EUA, Reino Unido, Bangladesh, Índia e Filipinas.

No âmbito nacional na última década houve eventos severos de enchente, os quais resultaram em perdas de vidas, evacuação de população e danos materiais. Em 2008, 77 municípios do vale do Itajaí na região sul do país foram atingidos por um evento que se estima ter afetado mais de 1,5 milhões de pessoas: 78.656 pessoas tiveram de ser evacuadas e 135 óbitos confirmados em decorrência destes eventos. Somente na cidade de Blumenau, os custos para reconstrução estavam estimados em 193,8 milhões de reais (AACI/FURB, 2009). Em 2011, outro evento desta magnitude atingiu a região serrana do estado de Rio de Janeiro, nos 15 municípios afetados foram contabilizados 910 óbitos, 662 pessoas desaparecidas e 36.083 pessoas evacuadas. O prejuízo do setor agrícola foi de 269 milhões de reais por causa dos danos causados pela enchente.

MARENGO et al., op. cit. As grandes precipitações no sul do Brasil, em 2015, já causaram prejuízos materiais da ordem de R $\$ 500$ milhões em 52 cidades do estado do Rio Grande do Sul. 
Tabela 1 - Grandes Eventos de Inundação registrados na Europa, Ásia e América do Norte

\begin{tabular}{ccc}
\hline \hline Ano & Local & Vítimas Fatais \\
\hline 1421 & Países Baixos & 100.000 \\
1530 & Países Baixos & 400.000 \\
1642 & China & 300.000 \\
1887 & Rio Amarelo, China & 900.000 \\
1900 & Galveston, Texas, EUA & 5.000 \\
1911 & Rio Yangtze, China & 100.000 \\
1931 & Rio Yangtze, China & 145.000 \\
1935 & Rio Yangtze, China & 142.000 \\
1938 & Rio Amarelo, China & 870.000 \\
1949 & Rio Yangtze, China & 5.700 \\
1953 & Países Baixos & 1.835 \\
1953 & Reino Unido & 356 \\
1954 & Rio Yangtze, China & 30.000 \\
1960 & Bangladesh & 10.000 \\
1963 & Vaiont, Itália & 1.800 \\
1979 & Morvi, Índia & 15.000 \\
1991 & Bangladesh & 139.000 \\
1991 & Filipinas & 6.000 \\
1991 & Rio Huai, China & 2.900 \\
1998 & Rio Yangtze, China & 1.320 \\
\hline \hline
\end{tabular}

Fonte: Adaptado de Knight e Shamseldin (2005)

\subsection{Operação de Barragens e Reservatórios para Gerenciamento de Recursos Hídricos}

Os reservatórios artificiais das barragens e represas podem ser usados como bacias de detenção utilizando-se de sua capacidade de armazenamento para reduzir os picos da propagação de ondas de cheia em regiões à jusante e com isso reduzir o perigo e risco destes eventos (GREEN; PARKER; TUNSTALL, 2000). Portanto estas estruturas que originalmente foram criados para atender as necessidades de atividades humanas como: irrigação, abastecimento de água, navegação, produção de peixes, recreação e produção hidrelétrica; surge como um importante ator na estratégia de mitigação de impactos ambientais ocasionados pelos eventos de cheia e secas. Para operar estas estruturas de maneira mais eficientemente possível, ações não estruturais podem contribuir significativamente. Estas ações incluem monitoramento hidrológico (pluviosidade, fluvial e nível de barragens), além disto, previsão hidrológica, sistemas de alerta rápidos e implementação offline e online de estratégias de operação.

Todo o gerenciamento de reservatórios é feito a partir destes dados de volume, que geralmente são expressos por uma curva que relaciona a cota da lâmina da água e sua respectiva 
área superficial com o volume respectivo a estes dados. Sendo assim, com uma simples leitura de régua, se verifica o volume do que o reservatório possui no exato momento. Fornecendo subsídio para se determinar vazões a serem utilizadas em seus diversos usos, a abertura de vertedores, etc.

As estratégias de gerenciamento de volume também tem um papel essencial, porque como já dito antes, além das funções de abastecimento de água, os reservatórios são usados para diversos outros usos como a geração de energia. Uma vez que o volume de água e a capacidade de reservação disponível são limitados e a quantidade de água para dividir entre todas as atividades conflitantes está suscetível ao regime de chuvas local e ao porte dos corpos hídricos que alimentam as barragens, estes conflitos de interesses acerca das prioridades e volumes disponíveis para os diferentes usos demandam que exista um gerenciamento que permita atender quando e se possível estes diversos interesses e necessidades para os recursos hídricos se torna imprescindível.

Duren e Beard (1972) já estava preocupado em desenvolver metodologias para conseguir operar reservatórios de forma a atender as diferentes demandas de água, citando que já haviam pesquisas neste tópico nos EUA desde 1966. De forma bem generalista podemos definir que é desejável que em uma operação eficiente de reservatórios para evitar conflitos.

O gerenciamento otimizado amplia um pouco mais a forma de operação engoblando não somente evitar conflitos, como guiar a operação para que não somente não haja falta de recurso como seja possível operar os reservatórios para que se utilize o máximo possível de volume de água. Para tanto deve-se armazenar o máximo de volume possível na época chuvosa, para criar reservas que serão deplecionadas na época seca. Isto é conveniente para o controle de cheias, já ao sair da época seca com volume de espera, é possível utiliza-lo para atenuar picos de cheias maiores.

HE et al. (2014) afirmam que atualmente grande parte destes processos de operação ainda dependem muito da experiência e julgamento do tomador de decisão em organizar a programação de vertimentos da barragem e que a solução do modelo de controle operacional de cheias de um reservatório por meio de métodos de otimização, levando em consideração a capacidade de reservação e vazões de entrada e de saída é geralmente complexo. Envolvendo um grande número de restrições como volume de espera disponível no reservatório, níveis dos rios à jusante, vazão de saída, e assim por diante.

Para resolver este tipo e dimensão de problema, devido sua complexidade, deve-se portanto utilizar técnicas computacionais e poder de processamento. Essas ferramentas computacionais fornecem recursos que somados com a experiência e conhecimento dos operadores servem de auxilio para utilização racional dos recursos. Nos últimos anos o poder de processamento, disponibilidade e custos de recursos computacionais evoluiu muito, sendo que atualmente, 
são largamente disponíveis e utilizados para resolução de problemas na hidrologia. 



\section{Parte II}

Hipótese \& Objetivos 



\section{Justificativa}

Conforme foi apresentado na seção 1.1, o desenvolvimento humano está intimamente relacionado com a disponibilidade de recursos hídricos, adicionado a isto na seção 1.2 , foi apresentado a sensibilidade e vulnerabilidade da população a eventos extremos tanto de secas quanto de inundações. A história nacional e internacional mostra que estes eventos podem causar impactos negativos, que impactam o desenvolvimento de diversas maneiras e graus, resultando em perdas materiais, financeiras e mesmo causar vítimas fatais.

A mitigação dos efeitos e magnitude de eventos climáticos extremos, é apresentada na seção 1.3; podendo ser feita tanto através de ações físicas, quanto de ações não-físicas. As ações físicas consistem de construção de estruturas hidráulicas como represas, reservatórios, diques e piscinões; já as ações não físicas consistem de atividades como monitoramento hidrológico e meteorológico e do gerenciamento dos recursos hídricos.

Garantir água suficiente para as atividades humanas evitando conflitos não é uma tarefa trivial, pois existem diversas demandas hídricas que podem ser conflitantes entre si, como por exemplo, navegação e geração hidrelétrica ou mesmo abastecimento humano e irrigação. Além disto, temos que as estruturas hidráulicas, como açudes, reservatórios, estações elevatórias e usinas hidrelétricas, devem ser operadas e controladas de forma atender diferentes requisitos e/ou limitações operacionais como: como níveis de operação (máximos e mínimos), vazões operacionais (máximas e mínimas), limitações na taxa de variação, custo operacional, despachos de energia além de atentar para controle da carga do sistema.

O processamento computacional de dados e processos complexos surge como um importante recurso para os tomadores de decisão, servindo como uma ferramenta complementar à experiência e julgamento do operador (LABADIE; SULLIVAN, 1986). A modelagem hidráulica de canais abertos é extremamente complexa e depende fortemente de muita capacidade de processamento de dados, existem uma vasta gama de modelos estudados e disponíveis na literatura, alguns tipos de simulações podem ser extremamente detalhadas e complexas (SCHUURMANS, 1997; SCHUURMANS; BOSGRA; BROUWER, 1995; FORTUNA, 2012; FRANZ; MELCHING, 1997; LIU; HODGES, 2014).

Portanto urge a necessidade de testar diferentes modelos, integrar metodologias e processos de modelagem hidráulicos/hidrológicos a fim de criar de um banco de modelos mais aptos para as condições locais e necessidades do usuário final, bem como avaliar as limitações e restrições de aplicabilidade, obtenção de parâmetros e regionalização dos modelos testados (NASR et al., 2004; NÉELZ; G.PENDER, 2013; NOAA, 2007; BECK et al., 2016; CRISPINO; GISONNI; 
IERVOLINO, 2014). Para sistemas de aviso rápido como os que são geralmente aplicados em problemas de controle de cheias e operação de vazão há necessidade de modelos hidráulicos rápidos, podendo avaliar mudanças súbitas de nível e vazão, bem como suas consequências à jusante do reservatório.

A aplicação de métodos de controle como o modelo de controle preditivo ou MPC (Model Predictive Control) para horizontes de previsão de curto prazo permite antever eventos meteorológicos críticos como estresse hídrico ou picos de vazão oferece uma pequena vantagem temporal, que permite aos tomadores de decisão agir antecipadamente, antevendo os impactos deste eventos e planejando ações mitigadoras que possibilitem a minimização dos impactos negativos. No caso de eventos de cheia, através destas técnicas, os operadores do conhecimento e analise do horizonte meteorológico futuro, podem esvaziar o reservatório previamente para alocar volume extra de reservação de forma permitir atenuação dos impactos de cheias a jusante.

Devido a imprevisibilidade meteorológica, para fins de operação de reservatórios otimizada é necessário que as simulações sejam constantemente revisadas e atualizadas, utilizando novos horizontes de previsão meteorológicas assim que estas forem criados e alimentando o sistema com novos estados e dados de entrada em tempo real. Assim novos cenários para operação ótima serão gerados e atualizados constantemente, conforme novos horizontes de previsão e novas condições futuras esperadas são fornecidas. Neste contexto é necessário um modelo de escoamento robusto e rápido, para obter estimativas do escoamento a jusante referente às mudanças de vertimento do reservatório.

O desenvolvimento de sistemas de previsão e alerta de enchentes é essencial tanto para o planejamento regional quanto para o nacional. Recentemente desenvolvimentos na previsão numérica climática, dados de radares meteorológicos e aquisição de dados hidrológicos e meteorológicos on-line resultaram em um crescente interesse em processamento de importação de dados.

No contexto do controle de cheias, a utilização de modelos hidrológicos em conjunto com o otimizador para apoiar a programação operacional, criando instruções que permitem que os operadores antevejam riscos de cheia e desta forma esvaziar o reservatório previamente para criar volume de espera antes que o evento de cheia aconteça. Isto evita que ocorram alguns problemas e violações de restrições operacionais que costumam ocorrer quando há falta de conhecimento dos horizontes futuros como esvaziar o reservatório muito rápido, criando impactos à jusante e liberação excessiva de volume para garantir que haja amortecimento dos efeitos dos picos de cheia.

Para a aplicação deste sistema de previsão e alerta de cheias, existem algumas premissas sendo estas que é necessário um modelo confiável, robusto e rápido para gerar estimativas 
confiáveis em tempo real e continuamente da vazão defluente da barragem, bem como dos efeitos decorrentes das mudanças causadas pelo vertimento dos volumes do reservatório no ponto de controle de cheia a jusante. Desta forma surgem os seguintes questionamentos:

a) Existem diversos modelos que são largamente utilizados na literatura nacional e internacional, mas, no entanto, seriam todos os modelos adequados para serem utilizados para Otimização de Operação de Reservatórios?

b) Qual seriam os impactos negativos ou positivos de perdas significativas de fidelidade dos resultados no caso de se realizar simplificações para diminuir o tempo e esforço de processamento de dados destes modelos?

\subsection{Hipótese}

No âmbito de otimizações da operação de reservatórios para controle de cheias com horizonte de previsão curta, a velocidade com que se consegue obter resultados pode ser tão crítica quanto à precisão dos dados. Além da complexidade existente no atendimento de múltiplas demandas e simulação hidráulico-hidrológica, alguns picos de cheia podem ocorrer rapidamente, portanto a eficiência em se gerar resultados implica em uma vantagem temporal para o operador adotar as medidas necessárias para conter os efeitos negativos da propagação da onda de cheia a jusante da barragem.

Existem duas formas de contornar o problema da velocidade das simulações, ou seja, da rapidez em gerar resultados; a primeira seria aumentar a capacidade computacional com utilização de supercomputadores, que implica em aumentos de custos e investimentos vultosos em infraestrutura; a segunda maneira seria de adotar simplificações nos modelos e configurações usados nas simulações, de maneira tal que não haja comprometimento significativo na precisão e o desempenho dos resultados.

Acredita-se o modelo mais complexo e completo nem sempre deverá ser necessariamente o modelo mais adequado para solucionar o complexo problema de controle de cheias em tempo real, e que simplificar as equações governantes poderá gerar ganhos significativos nos tempos necessários para realizar a simulação sem comprometer a precisão dos resultados gerados. Existem diversas versões equações de Saint-Venant disponíveis na literatura que podem ser utilizadas neste tipo de problema, além disto pode-se configurar estas diferentes versões com diferentes graus de detalhamento.

Por outro lado, ao utilizar diferentes modelos ou mesmo diferentes configurações separadamente pode ser uma tarefa dispendiosa, impraticável e muitas vezes ineficaz; há necessidade de criar diversos documentos de entrada de dados, realizar diversas conversões para diferentes os 
formatos das mesmas informações do banco de dados e comunicação entre estes modelos pode ser limitada caso não haja interoperabilidade ou aceitação de diversos formatos de arquivo.

Entende-se entanto que adotar uma plataforma que permita integração de diferentes modelos através de um gerenciamento eficiente dos bancos de dados, permite que se explore as potencialidades de diversos modelos criando um sistema de suporte à decisão (SSD) confeccionado e personalizado para as condições desejadas. Estas ferramentas também permitem empregar técnicas de aquisição de dados em tempo real, que são importantes em vista atualização e correção de dados visando geração de dados de forma contínua e rápida.

A presente pesquisa propõe abordar o pontos acima descritos através da criação da base de SSD desenvolvido para aplicações que envolvam operação e otimização de reservatórios para controle de cheias em tempo real. Para tanto foram testados diferentes modelos para verificar o desempenho computacional (velocidade de simulação) e estatístico (precisão das simulações) de seus resultados, os modelos foram integrados para permitir utilização de um banco de dados unificada e sempre que necessária utilização dos resultados como entrada de dados para melhorar as simulações, além de permitir fácil visualização e divulgação dos resultados. Por fim o modelo que apresentou melhores índices foi acoplado junto a um otimizador os quais foram testados fins do problema de controle de cheias com horizonte de previsão curta e em tempo real.

\subsection{Objetivos}

O trabalho tem como objetivo reportar novas informações sobre o desempenho computacional das simplificações das Equações de Saint-Venant (ESV) na operação de reservatórios para controle de cheias: Existem disponíveis na literatura científica muitos de modelos hidráulicos desenvolvidos e em desenvolvimento, no entanto existem poucos trabalhos que investigam a eficiência computacional deles em relação sua aplicabilidade em operação de reservatórios para controle de eventos extremos.

Na modelagem computacional de canais abertos utiliza-se geralmente a forma unidimensional das ESV, que requerem muita capacidade de processamento computacional para solução, no entanto ao negligenciar alguns termos da equação de momento, podemos simplifica-la e tornala mais fácil de ser solucionada; desta forma obtém-se: a equação hidrodinâmica ou totalmente dinâmica correspondente à versão completa; onda difusa e onda cinemática.

Entende-se que não necessariamente o modelo mais detalhado e sofisticado, é necessariamente mais adequado. Um modelo simplificado mais robusto e com menos custo computacional poderia mais indicado para um SSD online aplicado para funcionar também como um sistema de aviso prévio de cheias. 
Empregar plataformas de integração de modelos permite a que se utilize diferentes métodos e configurações, utilizando um banco de dados unificado, sem necessidade de criar diversos arquivos para entradas de dados e fácil visualização e comparação de resultados, outra vantagem deste tipo de plataforma é que permitem comunicação entre os modelos possibilitando utilizar os dados de saída quando pertinente para gerar melhorias dos resultados.

Portanto esta pesquisa tem como objetivo:

a) Analisar e comparar o desempenho das simplificações das ESV aplicadas na operação de reservatórios para controle de cheias;

b) Avaliar os impactos destas simplificações em termos de desempenho computacional dos modelos selecionados;

c) Selecionar dentre os modelos propostos, qual é mais adequado para ser utilizado em um Sistema de Suporte à Decisão (SSD) online aplicado para sistema de aviso prévio de cheias em tempo real;

d) Utilizar o modelo com maior potencial em um problema de otimização de volume de reservatórios;

e) Integrar dos modelos selecionados a fim de unificar o banco de dados, troca de dados (comunicação), extração de dados e visualização dos resultados obtidos, esta plataforma criada será a estrutura principal do SSD proposto;

\subsubsection{Objetivos Especificos}

Os objetivos específicos dos trabalho serão portanto avaliar 4 modelos diferentes quanto as suas potencialidades de implementação em um modelo de controle preditivo de cheia para a UHE Três Marias, localizada na bacia do Alto São Francisco, o ponto de controle de cheia definido é a cidade de Pirapora localizada a jusante da barragem:

I. SOBEK que utiliza a equação hidrodinâmica de Saint-Venant;

II. SPRNT que utiliza técnicas de aceleração computacional para solucionar a equação hidrodinâmica de Saint-Venant;

III. MGB-IPH, um modelo chuva-vazão semi-distribuído que utiliza o método de MuskingumCunge para determinar o escoamento nos canais de interesse;

IV. RTC-Tools usando três configurações distintas:

a) Onda Difusiva;

i. Resolução Espacial Grosseira; 


\section{ii. Resolução Espacial Refinada;}

b) Cascata de Reservatórios;

V. Avaliar a eficácia da técnica em otimizar o volume da UHE Três Marias;

VI. Avaliar a eficácia da técnica em controlar os efeitos de inundação na cidade de Pirapora;

A avaliação dos modelos deverá englobar a precisão, robustez e rapidez de processamento, avaliando também o impacto da resolução espacial e temporal nos resultados das simulações. E por último haverá integração do modelo mais apto em um otimizador para avaliar sua potencialidade para operação dos reservatórios. 


\section{Parte III}

\section{Revisão Bibliográfica}





\section{Represas, Reservatórios e Usinas Hidrelétri-}

\section{cas}

Neste capítulo serão descritos as partes e o funcionamento de Usinas Hidroelétricas (UHE), Reservatórios e Barragens os impactos geralmente associados a estas estruturas hidráulicas e como funciona a dinâmica destas estruturas hidráulicas, que podem ser usadas tanto para geração energética quanto para combater os impactos de eventos extremos, bem como os riscos envolvidos nesta operação.

\subsection{Usinas Hidroelétricas e Reservatórios}

A seguir segue uma explicação bem sucinta sobre os componentes e funcionamento de usinas de geração hidroelétricas ou usinas hidroelétricas (UHE). A geração de energia por usinas hidroelétricas podem ser feita através do aproveitamento da energia potencial hidráulica da região, este potencial geralmente está associado a uma queda d'água e um volume armazenado de água. Geralmente as UHE's apresentam as seguintes componentes: Barragem, Reservatório, Vertedor, Sistemas de Abdução, Casa de Força e Canal de Fuga.

A barragem é a estrutura civil que serve como barreira aos cursos de água com o objetivo de represar o volume de água que forma o reservatório, que é responsável por armazenar os volumes de água que serão utilizados como energia potencial para geração de energia ou para usos múltiplos.

O volume de água escoa do reservatório por dois caminhos:o primeiro deles o vertedor conduz a água diretamente para o curso de água a jusante e geralmente é utilizado para manter os níveis operacionais da barragem, o segundo os canais de abdução servem para conduzir a água até a casa de força, onde estão as turbinas e geradores, que são responsáveis por transformar a energia potencial hidráulica em energia cinética e finalmente em energia elétrica. E por ultimo o canal de fuga que conduz a agua da casa de maquinas ou casa de forca de volta para o rio.

De forma bem geral podemos classificar as UHEs conforme seu porte e conforme o tipo de reservação:

a) Porte da barragem, está relacionado ao tamanho do reservatório e sua capacidade de geração sendo comumente classificados como Usinas Hidrelétricas e Pequenas Centrais Elétricas (PCHs).

b) Tipo de Reservação: Existem dois tipos UHEs com reservação, as que possuem um 
reservatório capaz de estocar água para regularização de vazão e estocar energia potencial, que são geralmente implantados no início de um sistema de operação em cascatas; e as UHEs de operação a meio-fio, estas UHEs não possuem um reservatório capaz de armazenar grandes volumes de água e turbinam toda água que aflui em sua barragem.

As UHEs também estão relacionadas a alguns impactos e problemas, tipicamente estes problemas são a área deflorestada na implantação da UHE, alterações nos regimes fluviais, alterações nos ecossistemas. Outro problema típico de UHE e o assoreamento, devido a criação do reservatório cria-se um sistema lêntico que propicia processos de

\section{Assoreamento de Reservatórios}

Como consequência do assoreamento dos rios, podemos citar a redução do volume de água armazenado; o afogamento de locais de desovas, alimentação e abrigo de peixes; o aumento da turbidez da água, prejudicando os aproveitamentos hídricos e reduzindo as atividades de fotossíntese; alteração, destruição e degradação de ecossistemas aquáticos; a degradação da qualidade da água para consumo e consequente aumento dos custos de tratamento; a obstrução de canais de irrigação, navegação e trechos de cursos d'água; a formação de bancos de areia dificultando e alterando rotas de navegação; a dificuldade ou impedimento da entrada de água em estruturas hidráulicas de sistemas de captação

A deposição de sedimentos em reservatórios é um processo complexo que apresenta inúmeros fatores de influência, como o tamanho e a forma do reservatório; a razão entre a capacidade do reservatório e o tamanho da bacia; a razão entre a capacidade do reservatório e o deflúvio afluente; a topografia da bacia, uso da terra e cobertura vegetal; bem como a declividade e densidade da rede de canais; e características físicas e químicas do sedimento afluente

O problema no qual este projeto se foca, ocasionado pela deposição de sedimentos em reservatórios é a redução na produção de energia elétrica. Isto gera redução de receita com a produção energética, além de poder ocasionar problemas de manobras de operação nas estruturas hidráulicas da usina e gastos com dragagem de sedimentos nas proximidades da tomada d'água (AGÊNCIA NACIONAL DE ÁGUAS, 2009).

Neste contexto, de modo a evitar problemas futuros e minimizar os problemas já existentes, medidas corretivas e preventivas devem ser tomadas em conjunto.

Apesar de o problema de assoreamento do reservatório ser inevitável, pode-se minimizar parte desses problemas causados pela deposição de sedimentos nos reservatórios, tendo assim, um controle dos sedimentos afluentes ao reservatório por meio destas medidas, pois o assorea- 
mento causa grandes despesas ou até mesmo consequiências irreversíveis às obras hidráulicas (CARVALHO et al., 2000).

As medidas preventivas são mais econômicas, porém, apresentam resultados em longo prazo. Na década 1970, os estudos de impacto ambiental, e de sedimentação não eram obrigatórios no projeto e construção de usinas hidrelétricas como são hoje

A deposição destes sedimentos no fundo do rio geram alteração do relevo do fundo do reservatório, geralmente tendo como consequência a perda capacidade de armazenamento devido ao assoreamento. Desta maneira os sedimentos depositam no fundo da barragem, alterando esta capacidade de reservação. Em outras palavras, a condição original do levantamento topográfico prévio ao enchimento do reservatório é alterada, passando não mais condizer com a atualidade.

Quanto maior a idade do reservatório menor será a fidelidade do dado anterior ao enchimento com a condição real, devido a maior quantidade de sedimentos acumulados no reservatório e por isso uma menor capacidade de armazenamento de água, o que pode vir a gerar problemas de gestão.

O problema no qual este projeto se foca, ocasionado pela deposição de sedimentos em reservatórios é a redução na produção de energia elétrica. Isto gera redução de receita com a produção energética, além de poder ocasionar problemas de manobras de operação nas estruturas hidráulicas da usina e gastos com dragagem de sedimentos nas proximidades da tomada d'água (AGÊNCIA NACIONAL DE ÁGUAS, 2009).

Mais de 25\% da descarga global de sedimentos suspensos é considerada ser retida pelos reservatórios (VÖRÖSMARTY et al., 1997). Este acúmulo de sedimentos infligiu muitos danos desde o fim do século 20: Nos EUA, reservatórios passaram por reformas ou mesmo precisaram ser desativados e demolidos, nos rios Eufrates, Mekong, Syr Darya observa-se conflitos de uso da água reservada entre países à jusante e à montante, bem como sedimentação.

Um estudo do Banco Mundial (MAHMOOD, 1987) mostrou que a vida útil média dos reservatórios existentes em todos os países no Mundo decresceu de 100 para 22 anos, sendo avaliado em 6 bilhões de dólares anuais o custo para promover a remoção dos volumes que vão sendo assoreados. Foi demonstrado também que a perda média anual de volume dos reservatórios devido ao depósito de sedimentos era de 1\%, sendo variável de país para outro, bem como de região para outra.

Os custos para recuperação ou desativação das existentes infra-estruturas são provavelmente enormes (UNESCO, 2009). A reparação, o fortalecimento ou modificação de estruturas de antigas barragens, por exemplo, implicará em expressivos gastos. Em casos extremos, uma decisão reacionária seria a desativação de uma barragem, quando esta não mais desempenhar 
seu papel, como nos casos em que é velha e insegura, onde o nível do sedimentado está alto ou em locais onde o fluxo do rio precisa ser mantido para a pesca ou para outros ecossistemas. A recuperação e a desativação também devem ser escolhidos de acordo com os custos, se os custos de manutenção excederem seus benefícios financeiros e econômicos futuros. (WORLD COMISSION ON DAMS, 2000).

Apesar de o problema de assoreamento do reservatório ser inevitável, pode-se minimizar parte desses problemas causados pela deposição de sedimentos nos reservatórios, tendo assim, um controle dos sedimentos afluentes ao reservatório por meio destas medidas, pois o assoreamento causa grandes despesas ou até mesmo consequências irreversíveis às obras hidráulicas (CARVALHO et al., 2000).

Segundo mesmo autor, como consequência do assoreamento dos rios, ocorre redução do volume de água armazenado; o afogamento de locais de desovas, alimentação e abrigo de peixes; o aumento da turbidez da água, prejudicando os aproveitamentos hídricos e reduzindo as atividades de fotossíntese; alteração, destruição e degradação de ecossistemas aquáticos; a degradação da qualidade da água para consumo e consequente aumento dos custos de tratamento; a obstrução de canais de irrigação, navegação e trechos de cursos d'água; a formação de bancos de areia dificultando e alterando rotas de navegação; a dificuldade ou impedimento da entrada de água em estruturas hidráulicas de sistemas de captação.

\subsection{Usos Múltiplos}

Existem diversas atividades para os quais os recursos hídricos são utilizados, entre eles existem os usos consuntivos da água, que são definidos os usos em que há perda entre o captado e devolvido, ou seja que retiram a água de sua fonte natural diminuindo suas disponibilidades, espacial e temporalmente. Exs: dessedentação de animais, irrigação, abastecimento público, processamento industrial, etc.

Já os usos não-consuntivos não implicam em perda entre o captado, ou utilizado e o devolvido, ou seja referem-se aos usos que retornam à fonte de suprimento, praticamente a totalidade da água utilizada, podendo haver alterações no seu padrão temporal de qualidade. Exs: navegação, recreação, piscicultura, hidroeletricidade, etc.

Conforme prevê a Lei $\mathrm{n}^{\circ}$ 9.433, a gestão dos recursos hídricos deve sempre proporcionar o uso múltiplo das águas. Assim, todos os setores usuários da água têm igualdade de acesso aos recursos hídricos. A Política Nacional de Recursos Hídricos (PNRH) só traz uma exceção a esta regra, que vale para situações de escassez, em que os usos prioritários da água passam a ser o consumo humano e a dessedentação de animais. 
Como as demandas por água para os mais variados usos vêm aumentando, o número de conflitos de interesses envolvendo a água também cresceu. Por isso, a ANA age no sentido de mediar tais conflitos no Brasil que podem contrapor diversos setores, como: elétrico e hidroviário, saneamento e turismo, irrigação e elétrico, etc.

Para garantir os usos múltiplos da água, a Agência também trabalha para prevenir ou minimizar os efeitos de secas e inundações, por meio de sua Sala de Situação. Ela também trabalha planejando e promovendo ações para prevenir ou minimizar os efeitos de secas e inundações, em articulação com o órgão central do Sistema Nacional de Defesa Civil, por meio de sua Sala de Situação. O objetivo principal desta Sala é acompanhar as tendências hidrológicas em todo o território nacional, com a análise da evolução das chuvas, dos níveis e das vazões dos rios e reservatórios, da previsão do tempo e do clima, bem como a realização de simulações matemáticas que auxiliam na prevenção de eventos extremos.

Também visando a garantir o uso múltiplo dos recursos hídricos, a controlar as enchentes e a mitigar as secas, a ANA define as condições de operação de reservatórios por agentes públicos e privados, em consonância com os planos das respectivas bacias hidrográficas e em articulação com o Operador Nacional do Sistema Elétrico - ONS, em caso de reservatórios de aproveitamentos hidrelétricos.

A disponibilidade de quantidade e qualidade de recursos hídricos, não é só um requisito básico para o desenvolvimento humano como a própria sobrevivência depende deste bem.

\subsection{Setor Hidroenergético Brasileiro}

O Brasil é bastante progressista em relação ao setor energético, uma vez que há grande participação das fontes renováveis como energia solar, eólica e hidrelétrica em sua matriz elétrica (Figura 2). A porcentagem de fontes renováveis na matriz eleétrica nacional é quase 3,6 vezes maior comparada com a média mundial e quase 3,8 vezes maior do que a média dos países que compõe a OCDE ( Organização para Cooperação e desenvolvimento Econômico), que são em sua grande maioria países de alto desenvolvimento econômico e social. A participação destas modalidades, que são consideradas menos poluentes, representam quase $75 \%$ de toda eletrecidade produzida no país (EMPRESA DE PESQUISAS ENERGÉTICAS E MINISTÉRIO DE MINAS E ENERGIAS, 2016).

No entanto esta porcentagem alta se deve devido a enorme participação parte da energia produzida por fontes renováveis provém de energia hidrelétrica. Esta participação deverá diminuir nos próximos anos visto que quase toda a reserva nacional foi explorada sendo que grande parte do potencial hidroelétrico disponível no território nacional já foi explorado, existindo poucas bacias hidrográficas que ainda permitem a construção de grandes reservatórios. A Tabela 2, 


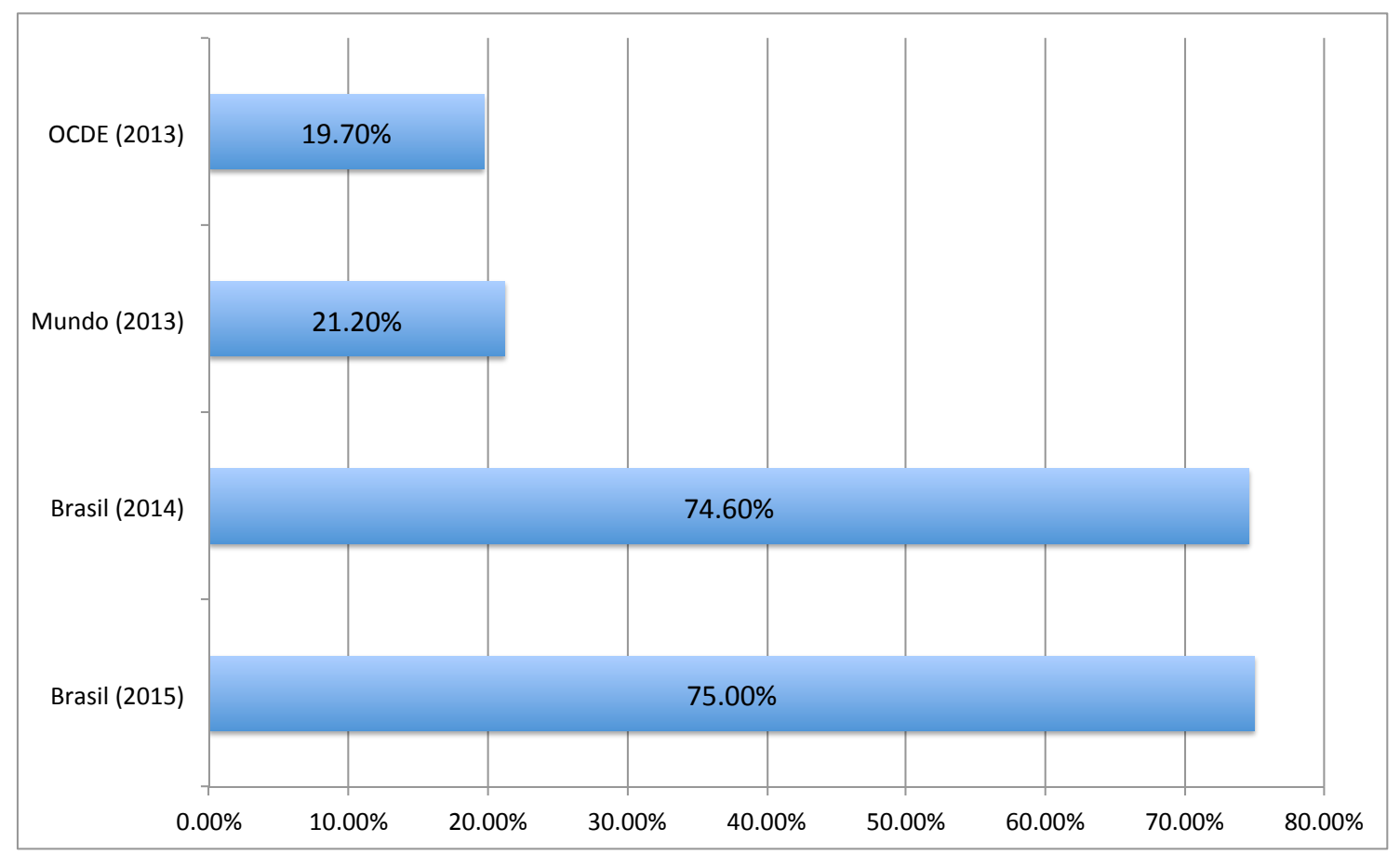

Adaptado de Empresa de Pesquisas Energéticas e Ministério de Minas e Energias (2016)

Figura 2 - Comparação da Participação de Fontes de Energias Renováveis na Matriz Elétrica.

mostra que cerca $80 \%$ todo o potencial hidrelétrico, $110 \mathrm{GW}$ dos $136 \mathrm{GW}$, já foi medido ou inventariado, restando $25,7 \mathrm{GW}$ para serem viabilizados.

Tabela 2 - Recursos e Reservas Energéticas Brasileiras em 2013.

\begin{tabular}{lccccc}
\hline & Unidade & $\begin{array}{c}\text { Medido/Indicado } \\
\text { /Inventariado }\end{array}$ & $\begin{array}{c}\text { Inferido } \\
\text { /Estimado }\end{array}$ & Total & $\begin{array}{c}\text { Equivalência Energética } \\
\mathbf{1 0}^{3} \text { tep }\end{array}$ \\
\hline PETRÓLEO & $10^{2} \mathrm{~m}^{3}$ & 2.572 .700 & 47.925 .600 & 50.498 .300 & 2.289 .703 \\
GÁS NATURAL & $10^{6} \mathrm{~m}^{3}$ & 471.148 & 388.689 & 859.837 & 467.850 \\
CARVÃO MINERAL $^{1}$ & $10^{6} \mathrm{t}$ & 25.742 & 6.535 & 32.277 & 7.027 .666 \\
HIDRÁULICA $^{2}$ & $\mathrm{GW}$ & 110,3 & 25,7 & 136,0 & 83.082 \\
ENERGIA NUCLEAR $^{3}$ & $\mathrm{t} \mathrm{U}_{3} \mathrm{O}_{8}$ & 177.500 & 131.870 & 309.370 & 1.254 .681 \\
\hline
\end{tabular}

Não inclui demais recursos energéticos renováveis.

${ }^{1}$ Considera recuperação de $70 \%$ e poder calorífico de $3.900 \mathrm{kcal} / \mathrm{kg}$.

${ }^{2}$ Valor anual para fator de capacidade de $55 \%$.

${ }^{3}$ Considera perdas de mineração e beneficiamento e não considera reciclagem de plutônio e urânio residual.

${ }^{4}$ Calculado sobre as reservas medidas/indicadas/inventariadas.

Fonte:Empresa de Pesquisas Energéticas e Ministério de Minas e Energias (2016)

De forma a complementar este conceito, a Figura 3 mostra a evolução do potencial hidroelétrico no pais, nesta figura observa-se que nos últimos 40 anos houve uma grande expansão no aproveitamento destes recursos na geração de energia elétrica, havendo um aumento de cerca de 50\% entre 1978 e 1996 . Porém este potencial energético já foi quase que totalmente explorado, não havendo um horizonte para grande aumento na exploração deste recurso para fins de geração elétrica. Portanto urge que haja maior governança e melhorias na gestão e operação 
dos reservatórios existentes.

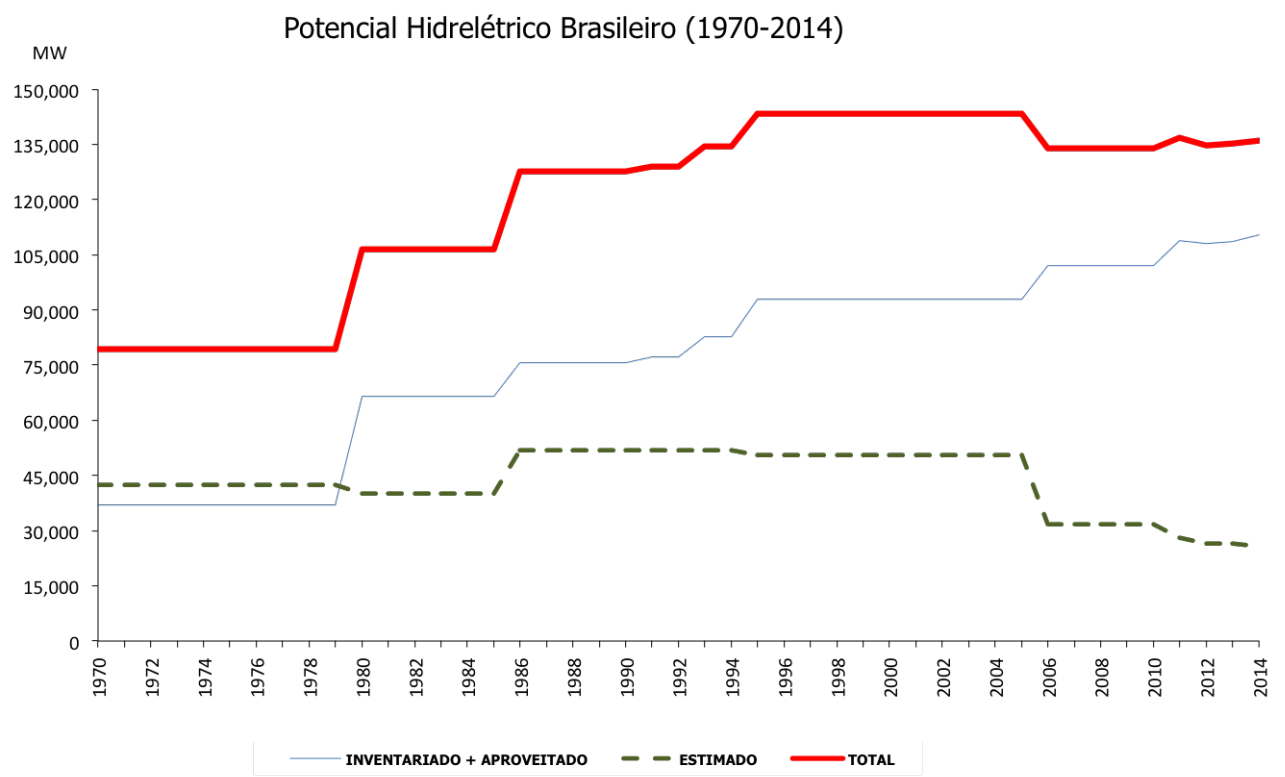

Fonte: (EMPRESA DE PESQUISAS ENERGÉTICAS E MINISTÉRIO DE MINAS E ENERGIAS, 2016)

Figura 3 - Evolução do Potencial Hidrelétrico Brasileiro (1970-2014).

\subsection{Expansão Planejada do Setor Hidrelétrico}

Embora não haja muito potencial hidroelétrico restante a ser explorado e inventariado, este setor ainda possuí papel significativo na expansão energética nacional. A expansão hidrelétrica planejada prevista até 2021 é de um acréscimo de 19 empreendimentos totalizando 19673 MW instalados para grandes centrais hidrelétricas, um aumento de 25,54\% (MME/EPE, 2015).

Segundo o mesmo relatório a taxa média de crescimento do consumo energético nacional é de 3,9\% ao ano, e o consumo nacional de energia elétrica para 2024 está estimado para atingir o valor de cerca de 692TWh. Portanto para suprir esta demanda crescente de está sendo planejada uma expansão do parque hidroelétrico brasileiro com a construção e implantação de novas hidrelétricas em todo o território brasileiro nos próximos anos.

Segundo a Tabela 3, deverão ser viabilizados até 202422 UHEs que somadas adicionarão aproximadamente $28,35 \mathrm{GW}$ de potência instalada na infraestrutura nacional. Observa-se que os empreendimentos planejados indicam uma tendência em construção de usinas de menor porte na porção sul do país e de usinas de grande porte nos estados da região norte principalmente no Pará.

Outra característica interessante desta expansão é que estão planejados mais de um empreendimento em um mesmo rio em um espaço temporal relativamente curto, por exemplo 
rio Teles Pires com 3 UHEs planejadas (UHE Teles Pires, UHE CoOlider e UHE São Manoel) e rios Piquiri e Tapajós com 2 Usinas planejadas para cada rio. O que reforça a necessidade de uma ação integrada e planejamento de operação.

Tabela 3 - Expansão hidrelétrica planejada (2015-2024).

\begin{tabular}{|c|c|c|c|c|}
\hline $\begin{array}{l}\text { Entrada em Operação } \\
\text { Ano }\end{array}$ & Projeto & Rio & Potência (MW) & UF \\
\hline \multirow[t]{2}{*}{2015} & UHE Teles Pires & Teles Pires & 1.820 & \multirow{2}{*}{ PA } \\
\hline & UHE Belo Monte & Xingu & 11.233 & \\
\hline \multirow{3}{*}{2016} & UHE Colider & Teles Pires & 300 & \multirow{2}{*}{ MT } \\
\hline & UHE Salto Apiacás & Apiacás & 45 & \\
\hline & UHE São Roque & Canoas & 135 & $\mathrm{SC}$ \\
\hline \multirow{2}{*}{2017} & UHE Cachoeira Caldeirão & Araguari & 219 & $\overline{\mathrm{AP}}$ \\
\hline & UHE Baixo Iguaçu & Iguaçu & 350 & PR \\
\hline \multirow{2}{*}{2018} & UHE São Manoel & \multirow{2}{*}{ Teles Pires } & 700 & $\mathrm{PA}$ \\
\hline & UHE Sinop & & 400 & MT \\
\hline 2019 & UHE Itaocara I & Paraíba do Sul & 150 & RJ \\
\hline \multirow{3}{*}{2021} & UHE São Luiz do Tapajós & Tapajós & 8.040 & PA \\
\hline & UHE Tabajara & Jiparaná & 350 & $\mathrm{RO}$ \\
\hline & UHE Apertados & \multirow{2}{*}{ Piquiri } & 139 & \multirow{7}{*}{ PR } \\
\hline \multirow{3}{*}{2022} & UHE Foz Piquiri & & 93 & \\
\hline & UHE Telêmaco Borba & Tibagi & 118 & \\
\hline & UHE Ercilândia & Piquiri & 87 & \\
\hline \multirow{3}{*}{2023} & UHE Comissário & Piquiri & 140 & \\
\hline & UHE Paranhos & Chopim & 67 & \\
\hline & UHE Jatobá & Tapajós & 2.338 & \\
\hline \multirow{3}{*}{2024} & UHE Castanheira & Arinos & 192 & MT \\
\hline & UHE Bem Querer & Branco & 708 & $\mathrm{RR}$ \\
\hline & UHE Itapiranga & Uruguai & 725 & SC/RS \\
\hline
\end{tabular}

FONTE: MME/EPE (2015)

\subsection{Agência Nacional de Energia Elétrica - ANEEL}

A Agência Nacional de Energia Elétrica (ANEEL) é uma autarquia vinculada ao Ministério de Minas e Energias criada em 1997 que tem como atribuição principal:

a) Regular a geração, produção, transmissão, distribuição e comercialização de energia elétrica;

b) Fiscalizar, diretamente ou mediante convênios com órgãos estaduais, as concessões, as permissões e os serviços de energia elétrica;

c) Implementar as políticas e diretrizes do governo federal relativas à exploração da energia elétrica e ao aproveitamento dos potenciais hidráulicos;

d) Estabelecer tarifas;

e) Promover as atividade de outorgas de concessão, permissão e autorização de empreendimentos e serviços de energia elétrica; 


\subsection{Operador Nacional do Sistema Elétrico - ONS}

O Operador Nacional do Sistema Elétrico (ONS) é o órgão responsável pela coordenação e controle da operação das instalações de geração e transmissão de energia elétrica no Sistema Interligado Nacional (SIN), sob a fiscalização e regulação da Agência Nacional de Energia Elétrica (ANEEL).

\subsubsection{Sistema Interligado Nacional - SIN}

O SIN ou Sistema Interligado Nacional é o sistema de interligação de geração elétrica do território brasileiro. O tamanho e características que permitem considerá-lo único em âmbito mundial, o sistema de produção e transmissão de energia elétrica do Brasil é um sistema hidrotérmico de grande porte, com forte predominância de usinas hidrelétricas e com múltiplos proprietários. O Sistema Interligado Nacional é formado pelas empresas das regiões Sul, Sudeste, Centro-Oeste, Nordeste e parte da região Norte. Apenas 1,7\% da energia requerida pelo país encontra-se fora do SIN, em pequenos sistemas isolados localizados principalmente na região amazônica.

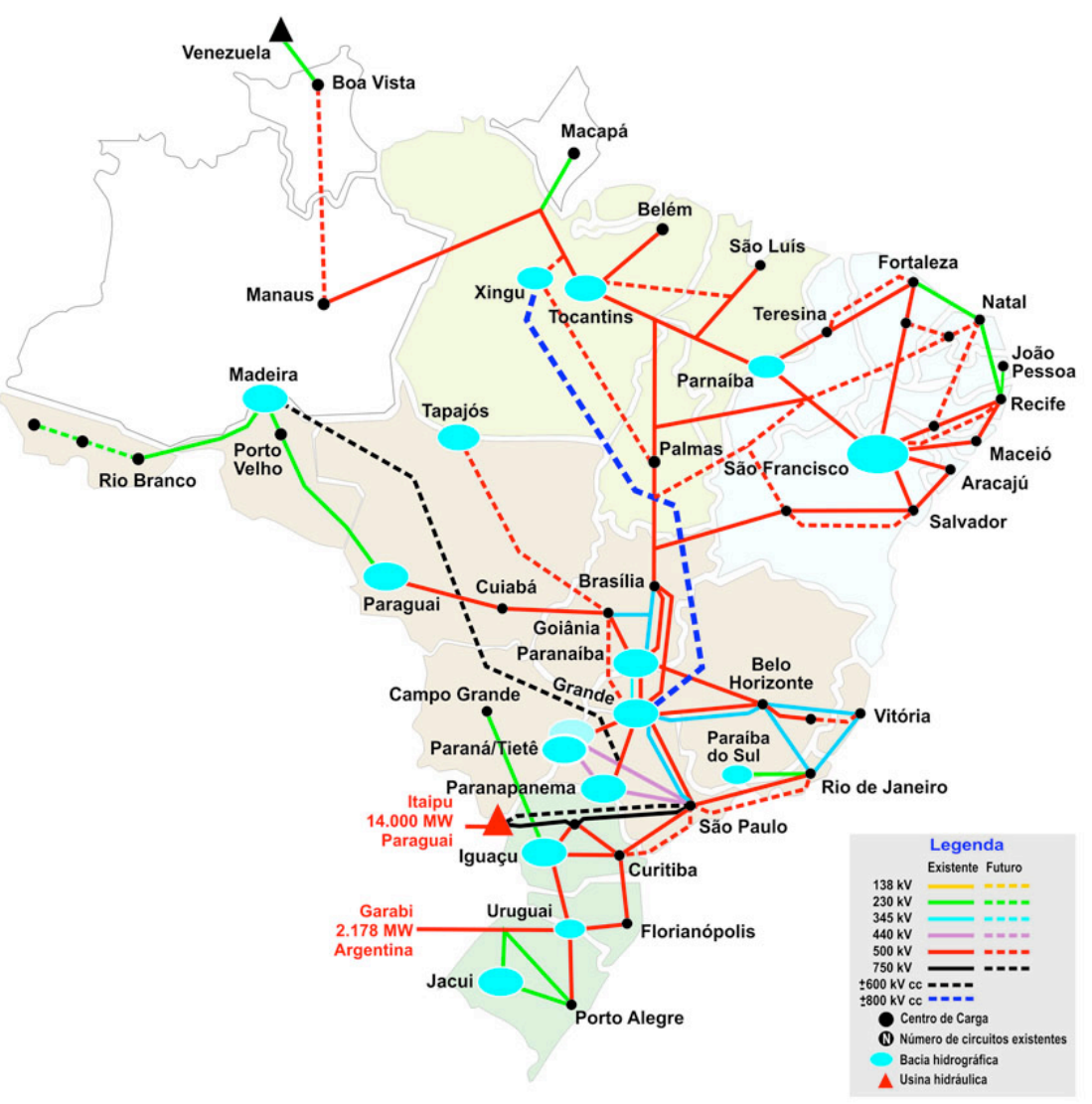

Fonte: (ONS, 2015)

Figura 4 - Integração Eletroenergética Brasileira. 


\subsubsection{Políticas e Regras de Operação da ONS}

ONS (2011b) define quatro categorias de condições de risco de operação de reservatórios, sendo que cada situação define diferentes riscos de inundação, riscos de violação de vazão de restrição (Vazão Máxima) e da disponibilidade de volume de espera conforme os valores permitidos pelas Regras Operacionais de Políticas de Controle de Inundação.

As quatro situações de operação são: Situação Normal, Situação de Atenção, Situação de Alerta e Situação de Emergência. Em uma condição de risco normal de inundação, não há risco de inundação, nem violação da descarga ou armazenagem; Estado de Atenção há risco de uma inundação ou o armazenamento está cheio, mas sem indicativo de máxima violação de descarga; Condição de Alerta é caracterizada por evento de risco de inundação, com pleno armazenamento e um indicativo de máxima violação de descarga; e condição de emergência significa que não há evento de risco de inundação com pleno armazenamento e máxima de descarga violação. Além do normal e atenção Condições, o operador tem pouca ou nenhuma liberdade operacional, apenas sob condições de alerta e de emergência, o operador pode decidir os valores-alvo para o vertedouro e para geração hidroelétrica.

Segundo ONS (2009b), a coordenação centralizada tem como objetivo otimizar o SIN globalmente e não otimizar cada unidade geradora de energia (incluindo das UHEs) individualmente . As regras de funcionamento para as políticas de controle de enchentes são baseados em cenários criados usando vazões históricas, séries hidrológicas sintéticas, resultando em um documento de orientação off-line que contém uma tabela que descreve diferentes restrições de operação em relação a diferentes condições de riscos de inundação (ONS, 2011b). No Apêndice A estão sumarizados estas caracterizações das situações de operação de reservatórios e critérios para caracerização da situação no período de controle de cheias (PCC).

Os despachos energéticos são feitos pela ANEEL e pelo ONS utilizando-se de recursos computacionais, existindo metas mensais e semanais, cuja programação é divulgada para os operadores com frequência. Este planejamento e controle é centralizado e feito de forma a otimizar e atender demandas e ofertas da infraestrutura do SIN como um todo.

\subsection{NEWAVE - Modelo de Planejamento da Operação de Sistemas Hidrotérmicos Interligados de Longo e Médio Prazo}

O planejamento dos despachos hidrelétricos é feito através de um gerenciamento e otimização centralizada pela ONS, que utiliza o modelo NEWAVE-DECOMP que a partir de previsões de vazão e de carga conseguem realizar uma otimização do uso deste recursos. $\mathrm{O}$ objetivo básico do planejamento da operação deste sistema é determinar, a cada mês, metas de geração para cada usina do sistema que atendam à demanda e minimizem o valor esperado 
do custo de operação ao longo do período de planejamento. Esse custo é composto pelo custo variável de combustível das usinas termelétricas e pelo custo atribuído às interrupções de fornecimento de energia, representado por uma função de penalização dos déficits de energia.

A decisão sobre quando utilizar os estoques de energia, representados pela água armazenada nos reservatórios, está intrinsecamente ligada à incerteza quanto às afluências futuras, devendo resultar de uma análise probabilística de seu comportamento. Além disso, a decisão operativa mais adequada dependerá das condições do sistema. Assim, é preciso determinar uma decisão operativa em função dos possíveis estados do sistema. Em sistemas com forte participação de hidrelétricas, dois tipos de informação compõem o estado do sistema: os níveis de armazenamento dos reservatórios e a tendência hidrológica futura do sistema, a qual pode ser representada pelas afluências aos reservatórios nos meses anteriores (CCCE-ONS, 2015).

Como a estratégia de operação deve ser calculada para todas as combinações de níveis de armazenamento e tendência hidrológica, o problema da operação ótima do sistema torna-se rapidamente intratável do ponto de vista computacional. No caso do sistema brasileiro, com mais de 100 reservatórios, torna-se necessário reduzir o número de variáveis de estado através da agregação dos diversos reservatórios de uma mesma região em um reservatório equivalente de energia, definindo, assim, um subsistema equivalente.

Sistemas com uma porcentagem substancial de geração hidrelétrica podem utilizar a energia armazenada "grátis" nos reservatórios do sistema para atender à demanda, substituindo a geração dispendiosa das unidades termelétricas. Entretanto, o volume de água afluente aos reservatórios é desconhecido, pois depende das chuvas que ocorrerão no futuro. Além disso, a disponibilidade de energia hidrelétrica é limitada pela capacidade de armazenamento nos reservatórios. Introduz-se, assim, uma relação entre a decisão de operação em um determinado estágio e as consequências futuras de tal decisão.

A existência de interligações entre submercados permite uma redução dos custos de operação, por meio do intercâmbio de energia, e um aumento da confiabilidade de fornecimento, através da repartição das reservas. Em sistemas hidrotérmicos, é necessário determinar o valor da geração hidrelétrica, dado pelo valor da geração térmica que se poderia substituir hoje ou no futuro.

Este valor é calculado como uma etapa do processo de determinação da política ótima. Com este conceito, pode-se representar uma hidrelétrica como uma "térmica", cujo custo marginal de operação é o valor da água.

Este valor não se mede de maneira isolada em cada usina, pois depende da operação conjunta do sistema. Para se obterem ganhos operativos máximos de um sistema hidrotérmico 
interligado, é necessário operar o sistema de maneira integrada, otimizando conjuntamente a operação de todos os subsistemas e submercados, com o objetivo de minimizar o custo total de operação e caracterizando este problema como de grande porte. No Brasil, e em diversos países, a solução do problema é obtida em etapas. Nestas etapas, são utilizados modelos com diferentes graus de detalhe para representação do sistema, abrangendo períodos de estudos com horizontes distintos, denominados de longo e médio prazo - modelo NEWAVE, curto prazo - modelo DECOMP (Modelo de Planejamento da Operação de Sistemas Hidrotérmicos Interligados de Curto Prazo) e programação da operação diária - modelo DESSEM (Modelo de Despacho Hidrotérmico de Curto Prazo)Figura 5 .

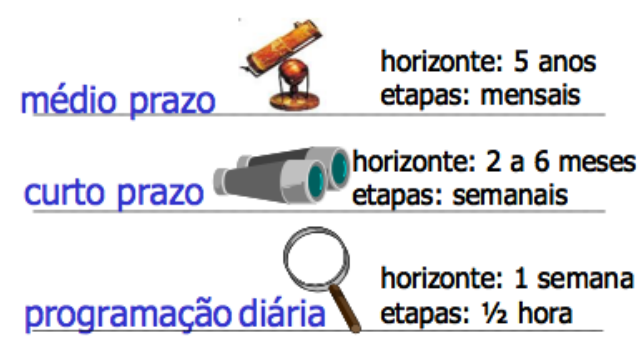

(a) Definição dos Horizontes de Previsão

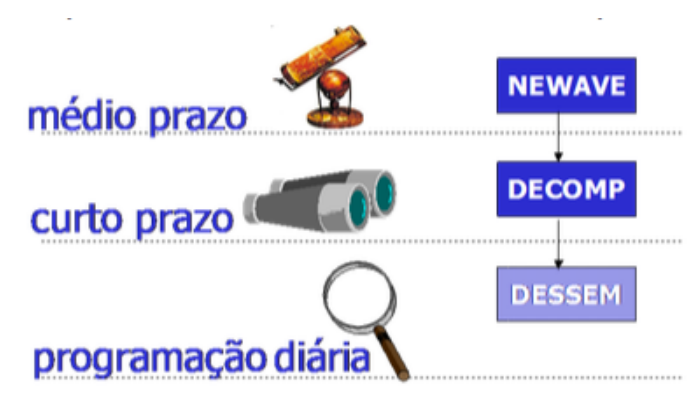

(b) NEWAVE, DECOMP e DESSEM

Fonte: CCCE-ONS (2015).

Figura 5 - Horizontes de Previsão para o NEWWAVE, DECOMP e DESSEM

O NEWAVE foi desenvolvido pelo CEPEL (Centro de Pesquisas de Energia Elétrica), no âmbito do Departamento de Otimização Energética e Meio Ambiente (DEA), para aplicação no planejamento da operação de sistemas hidrotérmicos interligados de longo e médio prazo, com representação agregada do parque hidrelétrico e cálculo da política de operação baseado em Programação Dinâmica Dual Estocástica (PDDE). É composto por quatro módulos computacionais:

\section{Módulo de cálculo dos sistemas equivalentes e energias afluentes}

Para cada subsistema, os reservatórios são agregados em um único reservatório equivalente de energia. A capacidade de armazenamento de cada reservatório equivalente é estimada pela energia produzida pelo esvaziamento completo dos reservatórios do subsistema, adotando-se a hipótese de operação em paralelo. Também agrega as vazões afluentes a cada subsistema em afluências energéticas equivalentes.

2. Módulo de cálculo do modelo estocástico de energias afluentes - modelo GEVAZP

Estima os parâmetros do modelo estocástico de energias afluentes aos subsistemas que é 
utilizado no módulo do cálculo da política de operação hidrotérmica. Este modelo estocástico também é empregado na geração de séries sintéticas de energias afluentes para análise de desempenho no módulo de simulação da operação.

\section{Módulo de cálculo da política de operação hidrotérmica}

Determina a política de operação mais econômica para os subsistemas equivalentes, com base no algoritmo de Programação Dinâmica Dual Estocástica (PDDE), considerando as incertezas nas afluências futuras, os patamares de demanda e a indisponibilidade dos equipamentos. Considera também a representação de restrições de despacho antecipado para usinas a GNL.

\section{Módulo de simulação da operação}

Simula a operação do sistema ao longo do período de planejamento, para distintos cenários de sequências hidrológicas, falhas dos componentes e variação da demanda, com base na política de operação obtida no módulo anterior. Calcula índices de desempenho, tais como a média dos custos de operação, o risco de déficit e os valores esperados de energia não suprida.

A versão executável do programa NEWAVE está disponível em ambiente de alto desempenho. Ele foi o primeiro programa da Cadeia de Modelos Energéticos do CEPEL a utilizar técnicas de processamento distribuído. Recentemente, o mecanismo de aversão a risco CVaR (Valor Condicionado a um dado Risco) foi internalizado no modelo, adicionando à função objetivo uma parcela referente ao custo dos cenários hidrológicos mais caros, com o objetivo de propiciar uma maior segurança no suprimento.

O Programa NEWAVE é utilizado nas seguintes atividades do Setor Elétrico Brasileiro:

a) Planejamento da Expansão.

b) Planejamento da Operação.

c) Comercialização - Cálculo do Preço de Liquidação de Diferenças(PLD).

d) Definição e Cálculo da Garantia Física e da Energia Assegurada de Empreendimentos de Geração.

e) Elaboração de Diretrizes para os Leilões de Energia.

\subsubsection{Diretrizes e Regras de Operação de Controle de Cheia}

Segundo ONS (2015), o planejamento da operação hidráulica para controle de cheias dos reservatórios do SIN é realizado em duas etapas: 
a) Estudos de prevenção de cheias, para determinar as necessidades de recursos físicos para o controle de cheias;

b) Estudos para definir diretrizes para as regras de operação de controle de cheias, onde são estabelecidas as medidas e ações (tanto administrativas quanto de engenharia) que deverão ser tomadas durante os eventos de cheia

Em sistemas de reservatórios para controle de cheias, as situações de operação de reservatórios devem ser caracterizadas no ponto de controle, e no reservatório situado imediatamente a montante da restrição (caso de restrição de jusante) ou imediatamente a jusante da restrição (caso de restrição de montante), de modo que os demais reservatórios desse sistema, mesmo que aloquem volume de espera, não acompanham essa caracterização de situação de operação. 


\section{Modelagem de Bacia Hidrográficas}

Os modelos matemáticos e métodos numéricos tem sido empregados nas mais diversas atividades para facilitar o entendimento de processos, para os recursos hídricos, estes modelos servem como discretizações e simplificações numéricas dos complexos processos que ocorrem na natureza, a fim de auxiliar pesquisadores e tomadores de decisão a terem uma melhor compreensão dos processos envolvidos, de maneira à auxiliar na gestão e tomada de decisões em relação a estes processos.

O processo de utilização de um modelo é conhecido como simulação. A simulação nada mais é do que a solução de um conjunto de expressões matemáticas estruturadas em sequência lógica, que transforma dados de entrada e parâmetros em resultados. Realizando várias simulações pode-se, testar, verificar, modificar e avaliar diferentes estratégias de utilização dos recursos hídricos e assim escolher a que for considerada a mais adequada.

A Figura 6 de Beven (2012), mostra a sequencia geralmente adotada para modelagem, a primeira etapa dos modelos perceptuais são definidos os processos que tem impacto no objeto ou área de estudo como por exemplo para um estudo de produção de sedimentos os principais processos envolvidos são a precipitação e condições dos solo; em seguida o modelo conceitual irá aprofundar sobre os processos definidos na etapa anterior, tomando o mesmo exemplo pode se optar por estudar a produção de sedimentos usando diferentes equações EUPS (Equação Universal de Perda de Solos), MEUPS (Modificação da Equação Universal de Perda de Solos) ou mesmo REUPS (Revisão da Equação Universal da Perda de Solos); a terceira etapa Modelo Procedural seria aquela em que as entradas de dados para as equações são feitas de forma permitir executar as simulações, a quarta etapa de calibração é a etapa de ajuste de parâmetros ou seja ajustar as incertezas dos dados de entrada a última seria a da validação, porém numa realidade bastante dinâmica, onde os locais estão sofrendo alterações de forma constante calibração pode perder validade rapidamente, sendo necessário recalibrar os modelos constantemente, o que torna a validação dos modelos uma tarefa de difícil aplicação.

Segundo Tucci (1998), as técnicas de modelagem são ferramentas essenciais para o planejamento e tomada de decisões dentro do complexo processo de condições naturais e para a interferência do homem. Estes modelos mostram ser úteis e versáteis uma vez que permitem avaliar as mais diversas questões relevantes aos recursos hídricos, bem como permitem geração de simulações e cenários. Através de cenários é possível entender a magnitude dos efeitos de eventos de estresse como escassez de água e como eles podem causar mudanças na bacia, rio ou reservatório influenciando tanto a disponibilidade quanto a qualidade da água, e desta forma 


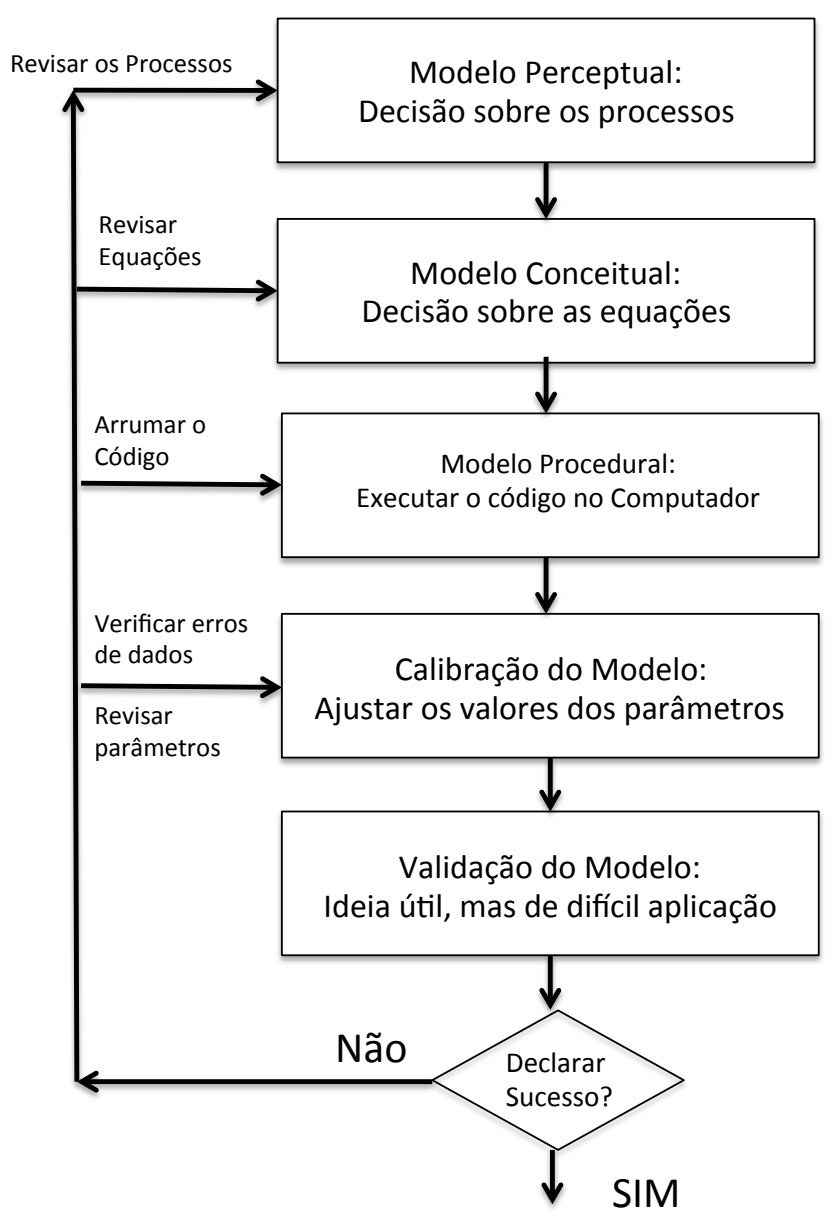

Figura 6 - Esquema das Etapas do Processo de modelagem.

Fonte: adaptado de Beven (2012)

é possível avaliar e planejar ações mitigadoras para promover a gestão otimizada dos recursos hídricos.

(RIGHETTO, 1998) comenta que a gestão de recursos hídricos compreende estudos, planejamento e ações para resolver as questões de escassez relativas aos recursos hídricos de uma determinada região. Dentre as várias atividades que merecem destaque na engenharia de sistemas hídricos pode-se citar a modelagem, simulação computacional e análise de cenários para tomada de decisão.

Para auxiliar as atividades de planejamento e gerenciamento de recursos hídricos de uma bacia hidrográfica modelos de planejamento são os mais adequados. Estes modelos são aqueles que simulam condições globais de um sistema maior, envolvendo uma região ou uma bacia hidrográfica e que buscam não somente a solução meramente hidráulica, hidrológica ou econômica, mas que engloba, também, fatores socioeconômicos e ambientais. Esse tipo de 
modelo utiliza vários tipos de modelos matemáticos e técnicas de análise para disciplinar as ações e investimentos (TUCCI, 1998).

Apesar dos modelos possuírem potencialidades e terem sidos desenvolvidos para fins diferentes e públicos diferentes, geralmente eles são projetados com o objetivo comum de proporcionar e facilitar a visão geral dos participantes do processo decisório dos processos que envolvem os sistemas hídricos, tais como; funcionamento deles, entendimento dos possíveis impactos econômicos, hidrológicos e ambientais de diferentes estratégias de desenvolvimento e gestão de uma determinada região. Assim devem possuir características para facilitar a entrada e armazenamento de dados para simulação e visualização dos resultados.

Uma das principais características que diferenciam esses modelos são as interfaces gráficas. Estas interfaces são desenvolvidas para dar ao usuário o controle da operação dos diferentes componentes e ferramentas dos modelos, como entrada de dados, simulações, otimizações, visualização dos resultados, análise de sensibilidade, análises estatísticas e outras.

Além das técnicas de simulação os modelos de planejamento também utilizam as técnicas de otimização. Portanto, esses modelos são capazes de simular um sistema e de identificar uma solução que maximiza ou minimiza uma determinada função objetivo. Segundo Righetto (1998) a gestão de recursos hídricos compreende estudos de planejamento e ações para resolver as questões de escassez relativas aos recursos hídricos de uma determinada região, sendo destacadas a modelagem, simulação computacional e análise de cenários para tomada de decisão.

Quanto a isso, a utilização de técnicas de simulação e otimização em conjunto tem sido realizada há muito tempo. Com o aumento significativo da capacidade de processamento de computadores pessoais dos últimos anos, o potencial do uso conjunto dessas técnicas aumentou expressivamente.

A esse respeito, as técnicas de simulação e de otimização são ferramentas importantes de suporte a decisão que serão cada vez mais utilizadas na prática da engenharia de recursos hídricos. Muitos problemas de otimização apresentavam-se complexos demais para serem resolvidos. No entanto, atualmente a capacidade de processamento dos microcomputadores está fazendo com que os problemas de dimensão se tornem cada vez menos relevante.

Existem diversos tipos de modelos hidrológicos descritos na literatura, sendo possível classifica-los em teóricos ou empíricos, sendo que um modelo teórico é baseado em princípios físicos, um modelo físico seria aquele cujo todos os processos que ele aborda são baseados em funções matemáticas e os modelos empíricos seriam aqueles em que os processos abordados pelos mesmos são representações dos dados observados. Atualmente a maioria dos modelos existentes tem sua componente física simplificada e incorporam componentes empíricas. Con- 
forme os resultados obtidos podem classificar estes modelos em estocásticos, quando uma ou mais variáveis são consideradas aleatórias podendo variar imprevisivelmente com o tempo ou determinísticos, quando as variáveis estão livres de uma variação aleatória (LOUKS; BEEK, 2005).

\subsection{Modelos Hidrológicos}

De acordo com Moradkhani e Sorooshian (2008), os modelos hidrológicos são representações simplificadas de processos que acontecem no mundo real, e portanto o melhor modelo é o que consegue obter resultados que melhor representem a realidade com o menor numero de parâmetros e complexidade. Este tipo de modelo é usado para estimar comportamentos e entendimento de diversos processos hidrológicos. (DEVI; GANASRI; DWARAKISH, 2015) cita que os principais entradas de dados para estes modelos são dados de precipitação e área de drenagem, juntamente com estes dados características da bacia hidrográfica como propriedades do solo, uso e ocupação do solo, topografia, e características de água subterrânea também são consideradas.

\section{HBV}

O modelo hidrológico Hydrologiska Byråns Vattenbalansavdelning ou HBV foi um dos primeiros modelos hidrológicos desenvolvidos, ele foi inicialmente desenvolvido para ser aplicado em bacias hidrográficas escandinavas (BERGSTRÖM; FORSMAN, 1973; BERGSTRÖM, 1995), mas provou-se aplicável também em regiões tropicais e subtropicais (ZHANG; LINDSTRÖM, 1997). Este modelo basicamente simula vazões a partir de dados de precipitação, temperatura e estimativas de evaporação potencial, e através de diferentes rotinas para representar derretimento e acúmulo de neve, capacidade de campo e evaporação, água subterrânea, geração de escoamento superficial e propagação por canais (HARLIN; KUNG, 1992).

\section{SAC-SMA}

O modelo conceitual chuva-vazão Sacramento Soil Moisture Accounting (SAC-SMA) (BURNASH; FERRAL; MCGUIRE, 1973; BURNASH, 1995), utiliza parametrização espacial aglomerada e é geralmente aplicado para bacias hidrográficas de 300 até $5.000 \mathrm{~km}^{2}$, as simulações deste modelo geralmente são feitas para escalas de tempo que variam a cada 6 horas, mas é possível simular utilizando qualquer escala temporal. (FINNERTY et al., 1997)

Este modelo representa a zona hidrologicamente ativa do solo em duas camadas: uma camada fina superior e outra mais profunda e espessa. Cada camada consiste de tensões, cujos componentes são deflagrados por processos mais lentos como evapotranspiração e difusão; e armazenamento de água livre, cujos componentes são ocasionados por processos mais rápidos 
de força gravitacional. Estas camadas interagem entre si para gerar estados de humidade de solo e um total de 5 componentes de escoamento, conforme pode ser visto na Figura 7 (ANDERSON; KOREN; REED, 2006).

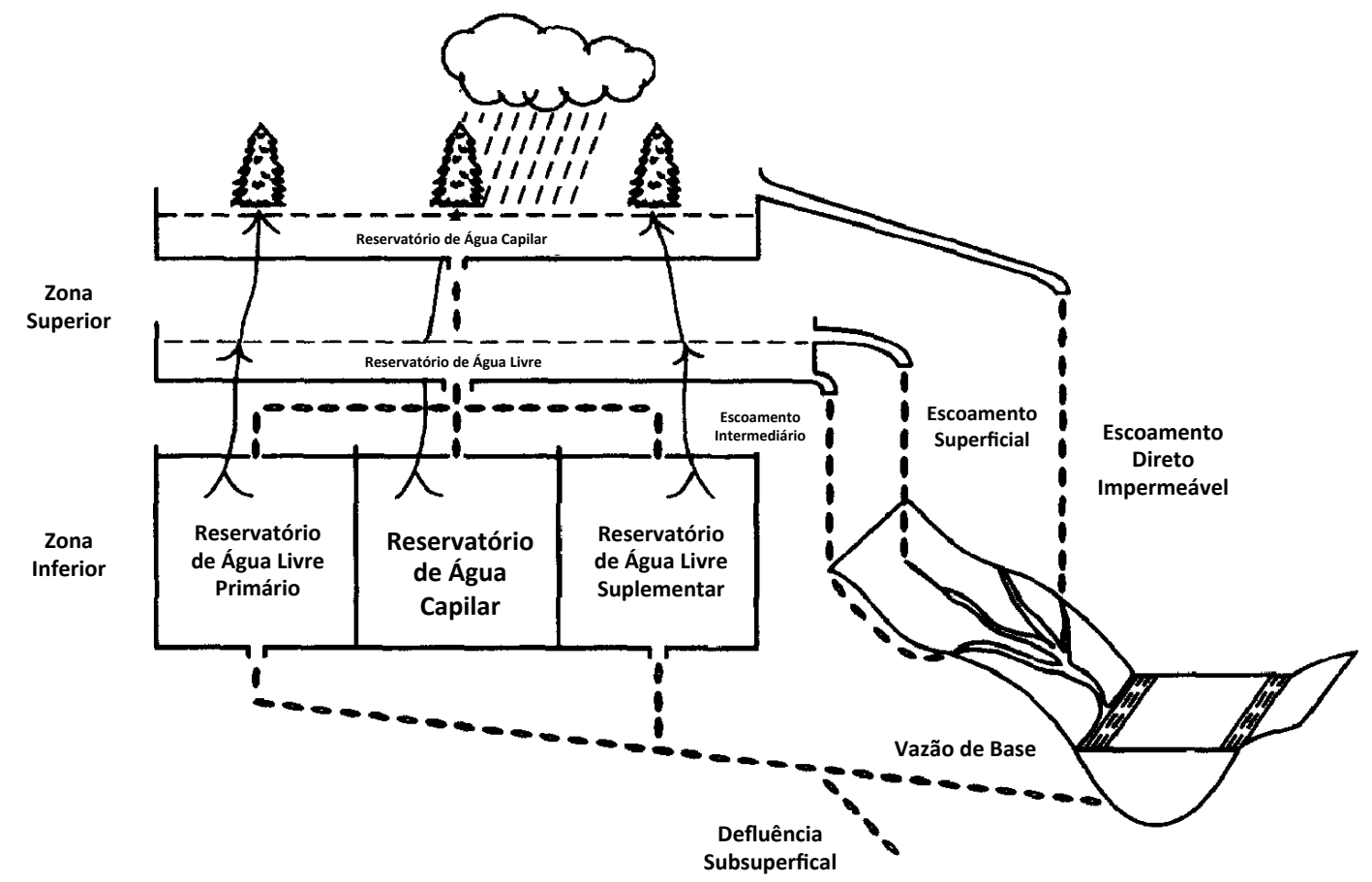

Figura 7 - Conceitualização do modelo SAC-SMA, ilustrando os armazenamentos de humidade do solo, componentes de escoamento superficial e trocas entre superfície do solo e atmosfera

Fonte: adaptado de Finnerty et al. (1997)

\section{HEC-HMS}

O Hydrologic Engineering Center's Hydrologic Modeling System (HEC-HMS) é um modelo chuva-vazão desenvolvido pelo USACE (US Army Corps of Engineers), que realiza simulações não contínuas baseadas em eventos. $\mathrm{O}$ usuário pode utilizar diferentes metodologias de hidrogramas unitários sintéticos como o modelo de Clark, o modelo de Snyder, SCS-UH (Soil Conservation Service - Unit Hydrograph) e modelo de onda cinemática (Kinematic Wave Model). O escoamento superficial pode ser calculado através do SCS-CN (Soil Conservation Service Curve Number), através de coeficiente de escoamento superficial ou através do excedente do volume de água que infiltra pela equação de Green-Ampt. 


\section{SWAT}

O Soil and Water Assessment Tool ou SWAT é a convergência e evolução de anos de experiências da USDA (United States Department of Agriculture), com outros modelos como o Basins e Simulator for Water Resources in Rural Basins (SWRB). Este modelo é um complexo modelo físic semi-distribuído projetado para realizar estimativas de água e produção de sedimentos em bacias pouco monitoradas com enfoque na agricultura.

\section{MGB-IPH}

O modelo foi empregado em diversas regiões do Brasil, bem como outros países da América Latina como Paraguai, Bolívia, Peru e Argentina (COLLISCHONN et al., 2007), sendo também aplicado na bacia do Rio Grande para predição de vazão a curto e longo prazo para planejamento operacional de sistemas de geração hidrelétrica, obtendo resultados satisfatórios a curto prazo com erros de $10 \%$ a $20 \%$ menores que o modelo estocástico atualmente empregado, porém sendo necessários melhorias nos "ensembles" de predição climatológica (TUCCI et al., 2008).

\subsection{Modelos Hidráulicos}

Os modelos hidráulicos geralmente são utilizados para entender o comportamento da propagação de ondas do escoamento em canais abertos para fins de controle de cheias, dimensionamento de estruturas hidráulicas e do impacto de ações mitigadoras nas características hidráulicas do trecho de rio.

Segundo Pender (2006) podemos dividir estes modelos segundo sua dimensionalidade ou a maneira como eles combinam diferentes abordagens de dimensionalidades, sendo elas modelos 1D, 1D+, 2D- e 2D; segundo Néelz e Pender (2009), modelos que utilizam três dimensões a partir das equações 3D Navier-Stokes podem ser usadas para calcular perfis 3D da velocidade de canais de rios e planícies de inundação, porém ainda existem desafios práticos a serem resolvidos para que haja aplicação em escala para processos decisórios envolvendo gerenciamento de risco de inundações.

Na Tabela 4 de Pender (2006), estão sumarizados as classificações de modelos hidráulicos segundo o método aplicado, aplicações, escala temporal de dados gerados.

\section{HEC-RAS}

Assim como o HEC-HMS, o HEC-RAS ou Hydrologic Engineering Center's - River Analysis System, foi desenvolvido pelo USACE, este software contém três componentes de análise hidráulica: computação de perfil de superfície de água com fluxo constante; simulação de 
fluxo inconstantes; e cálculos de limites móveis de transporte de sedimentos. Os três componentes se utilizam dos mesmos dados de representação geométrica e de mesmas rotinas de computação geométrica e hidráulica.

\section{SOBEK}

É um pacote de software com diversos módulos para diferentes aplicações de modelagem de sistemas hídricos, que foi desenvolvido conjuntamente por consultores particulares e de instituições públicas holandesas (DELTARES, 2014; NOAA, 2007). Os diferentes módulo permitem simular previsão de cheias, otimização de sistemas de drenagem, controle de sistemas de irrigação, dimensionamento de vazões críticas para sistemas de esgoto, controle de nível de água subterrânea, morfologia fluvial, intrusão marinha e qualidade de água superficial. Os módulos podem ser utilizados separadamente ou em conjunto. A transferência de dados entre eles é automática e para facilitar a interação física dos módulos existe a opção de executa-los tanto em sequência quanto em paralelo.

Asselman e Heynert (2003)realizaram um estudo das consequências das cheias na região da Holanda Central através da simulação hidráulica bidimensional. Foram estimados os níveis de água e velocidades geradas pelo rompimento de um dique próximo a Rotterdam e da proteção costeira próxima a Katwijk. Entre os resultados gerados pelo modelo estão os níveis e velocidades da água, assim como o tempo para ocorrência da inundação após o evento. As simulações indicaram que as consequências mais severas aconteceriam com o rompimento do dique, situação em que o nível de água varia entre 6 metros na região central e menos de 1 metro nas bordas da área inundada. As velocidades máximas encontradas foram em torno de $7 \mathrm{~m} / \mathrm{s}$ próximo à área rompida no dique, diminuindo para $0,1 \mathrm{~m} / \mathrm{s}$ nas bordas da área inundada. $\mathrm{A}$ inundação da área principal estudada aconteceu rapidamente, em torno de 5 horas, enquanto que nas regiões mais distantes o tempo decorrido para inundação foi de 5 dias.

Os métodos desenvolvidos e apresentados em ASSELMAN; HEYNERT, op. cit.para quantificar as consequências das cheias consideraram as perdas econômicas diretas e indiretas, danos para a agricultura e meio ambiente, colapso de construções e da infraestrutura, além de perdas humanas. Todos esses métodos necessitam de informações sobre a extensão das enchentes, níveis e velocidade da água. Para isso, sabendo-se da escassez dos dados de enchentes passadas nessa região, houve a necessidade de realização de simulações, para as quais, foi adotado o modelo hidráulico SOBEK, mais precisamente os módulos Overland Flow e Channel Flow. Os autores concluíram que em ambos os casos, a propagação da onda de cheia ocorre rapidamente em uma grande área próxima do local de rompimento, minimizando a possibilidade de alertas para a população.

As maiores vantagens da combinação de domínios 1d e 2D segundo Asselman e Heynert 
(2003) são:

- Os passos de tempo adotados num grid 2D podem ser significativamente maiores, já que não são necessários refinamentos no grid para a correta representação de estruturas hidráulicas e ravinas;

- Como resultado, as simulações despenderão menor quantidade de tempo para execução atingindo um nível comparável de acurácia nos resultados;

- Uma grande variedade de estruturas hidráulicas pode ser considerada;

- Robustez e acurácia.

Em um estudo realizado por Mashriqui, Halgren e Reed (2014), o módulo hidráulico unidimensional foi estendido até a região de marés do estuário do rio Potomac, Estados Unidos. Inicialmente, os autores utilizaram o modelo HEC-RAS (Hydrologic Engineering Center River Analisys System) e avaliaram os pontos positivos e as limitações da implementação em regime não permanente. Como uma das limitações identificadas, o modelo não representa de maneira adequada eventos gerados por forçantes de ventos devido à falta de um termo explícito de forçante de ventos. Por isso, para entender a significância dos ventos na hidráulica na zona de transição em Potomac, foram implementados os modelos SOBEK 1D (DELTARES, 2014) e ADCIRC 2D sigla para ADvanced CIRculation (WESTERINK et al., 1992) que incluem os termos de forçante explícita para os ventos.

Os resultados foram comparados com os gerados pelo HEC-RAS para o furacão Isabel. Para isso, foi utilizado o módulo SOBEK-Rural 1D-FLOW, e a implementação foi realizada através da importação do modelo HEC-RAS para o pacote do SOBEK. O modelo foi executado com diferentes cenários a fim de verificar sua influência no erro dos valores de níveis gerados pelo modelo 1D. Os resultados das simulações incluindo ventos mostraram que os picos observados puderam ser atingidos uma vez que o fator de redução de vento foi calibrado. Entretanto, os resultados do modelo não reduziram significativamente o erro de defasagem no tempo de ocorrência do pico no evento do furacão Isabel. Os autores também salientaram a necessidade de mais estudos de pesquisa para a orientação a aplicação operacional da dragagem pelo alto grau de incerteza gerado pela calibração do fator de redução do vento apenas para um evento. Dada a baixa demanda computacional requerida pelos modelos unidimensionais, se torna mais simples a realização da calibração de parâmetros de vento utilizando séries temporais de longo período.

Tarekegn et al. (2010) realizaram um estudo com os objetivos de analisar a representatividade dos resultados da modelagem hidrodinâmica 2D gerados como uso de um modelo digital do terreno ASTER (Advanced Spaceborne Thermal Emission and Reflection Radiometer)com 
15 metros de resolução, bem como, analisar a efetividade da modelagem hidrodinâmica 2D para simulação de eventos de cheia intensa em uma região de estudo complexa. A região estudada contempla a bacia do lago Tana, que alimenta o rio Nilo Azul, ao norte da Etiópia. Para tal, foi adotado o módulo 2D Flood Inundation do modelo SOBEK 1D2D. Com a modelagem foi possível estudar as características das enchentes geradas por vazões do rio Reb e o efeito de remanso induzido pelos elevados níveis de água no Lago Tana. Essa região é caracterizada pela escassez de dados disponíveis. Assim, foi necessário realizar um procedimento de GIS para a reconstrução do terreno do rio e da batimetria do canal utilizando imagens ASTER.

Os resultados de extensão das enchentes gerados pelo modelo e apresentados em Tarekegn et al. (2010), foram comparados com imagens do sensor MODIS (Resolution Imaging Spectroradiometer) e com observações históricas espacialmente distribuídas da extensão da planície de inundação. Os resultados gerados pelo modelo mostraram que a morfologia do terreno do rio afeta fortemente as características da vazão simulada. Os autores concluíram que o modelo digital de terreno ASTER com resolução de 15 m pode servir como entrada para a realização de modelagem hidrodinâmica detalhada em regiões com escassez de dados. Contudo é necessária a detalhada reconstrução da geometria do terreno do rio a da topografia da planície de alagamento baseada em observações de campo.

Twigt et al. (2009) realizou o acoplamento online dos softwares DEFLT3D, para a simulação tridimensional de águas costeiras, e do SOBEK para a simulação unidimensional da hidráulica de canais. A modelagem tridimensional simula a vazão com forçantes externas periódicas devido às marés e a distribuição de salinidade tanto para as estações secas quanto úmidas. Assim, os componentes 1D e 3D são acoplados online, o que implica que serão executados em paralelo. Comparando com o acoplamento off-line, em que os componentes são executados sequencialmente, o online permite o fluxo de informações em dois sentidos assim como do feedback e da interação entre os modelos.

Observou-se em Twigt et al. (2009), que a conservação de massa apresentou grande valor, tanto na hidrodinâmica quanto nas aplicações de qualidade de água, representando com acurácia o transporte de substâncias de montante para jusante no sistema. Uma desvantagem do acoplamento dos componentes 1D e 3D é a inviabilidade de resolver variações espaciais complexas de fluxo. Os autores aplicaram o acoplamento no delta do rio das Pérolas (rio Zhu Jiang), na província de Guangdong no sul da República Popular da China, determinado pela interação entre o rio e o mar do sul da China. Os modelos foram calibrados e validados, tendo sido encontrados valores de erro da raiz média quadrática (RMS) inferiores a 6\% para os níveis de água em todo o delta do rio das Pérolas. Os autores também verificaram que os modelos simularam tanto as descargas como os processos de transporte de salinidade com boa precisão.

Ji, Vriend e Hu (2003) realizou a aplicação e validação do modelo SOBEK 1-D a fim 
de estudar a redeposição de sedimentos num experimento protótipo de dragagem executado no estuário do rio Amarelo, na China, a fim de estudar o problema de assoreamento. Foi adotado, para solução do problema, um modelo numérico, modelo físico e análise de dados de campo, e os resultados gerados foram comparados. A análise dos resultados indicou que o modelo SOBEK apresenta forte adaptabilidade, podendo ser aplicado ao ambiente estuarino de maneira satisfatória.

\section{RTC-Tools}

O RTC-Tools ou Real-Time Control Tools, começou a ser desenvolvido em 2007 como resultado da experiência em projetos de sistemas de previsão e controle de cheias feitos em diversas regiões do mundo como Áustria, Alemanha e Paquistão e seu desenvolvimento continuou durante 2008 e 2010 com implementação de módulos hidráulicos, modelo adjunto para MPC e de controladores (SCHWANENBERG, 2013). A partir de 2012, tornou-se um software de código-aberto.

Dentre as aplicações do modelo podemos destacar Schwanenberg e Patzke (2008) com um estudo no rio Reno na região fronteiriça entre França, Alemanha e Suíça, onde foram testados as potencialidades do RTC-Tools como módulo de controle em tempo real dentro do SOBEK; Schwanenberg, Verhoeven e Boogaard (2010) em um estudo de aplicação de otimização de processos não-lineares;Schwanenberg et al. (2012) em um estudo de controle de níveis de um conjunto pôlderes na Holanda para economizar gasto energéticos; Schwanenberg et al. (2013) em um estudo de aplicação de controle de operação de reservatórios para curto-horizonte de previsão de tempo na UHE de queimados;Kuwajima et al. (2014) que compara diferentes configurações aplicadas para previsão de propagação de onda de cheias e Rodríguez (2013) onde ele compara controle real de operação com regras de operação fixas para reservatórios de múltiplos usos.

\subsection{Sistemas de Suporte à Decisão (SSD)}

Mais da metade da população do planeta vive em regiões costeiras, deltas e próximas às margens de rios. Estas regiões estão economicamente favorecidas por causa do solo rico e fértil e proximidade do mar ou hidrovias. Entretanto, o aumento do nível dos rios e do mar, alterações climáticas e a pressão crescente na infraestrutura dessas regiões têm levado ao crescente risco de alagamentos, deslizamentos e contaminação da água, especialmente nas regiões de menores altitudes e relevos mais planos. (KUMMU et al., 2011)

Assim, agências de gestão das águas e autoridades ao redor do mundo têm buscado utilizar sistemas automatizados e modelos a fim de realizar a gestão dos riscos de alagamento. Dessa forma, grande quantidade de dados, meteorológicos e hidráulicos tem sido combinada e processada para produzir subsídios para alerta de alagamentos e auxílio na tomada de decisões. 
Esta combinação e processamento têm culminado na criação de modernos sistemas de previsão de vazões e de alerta (KNIGHT; SHAMSELDIN, 2005). O sistema de operação de reservatórios se constitui em uma das aplicações deste tipo de sistema.

De maneira geral os Sistemas de Suporte à Decisão (SSD) são sistemas de informações com ferramentas avançadas para auxiliar no processo de tomada de decisões. As pesquisas sobre esses sistemas de informação têm recebido cada vez mais atenção devido ao crescente avanço da computação pessoal e da tecnologia da informação.

Segundo (KEEN; MORTON, 1978), o conceito de Sistemas de Suporte à Decisão teve início a partir das pesquisas realizadas no Instituto de Tecnologia de Carnegie sobre tomadas de decisões em organizações, entre o fim da década de 50 e início da década de 60, e os trabalhos sobre sistemas computacionais interativos desenvolvidos no Instituto de Tecnologia de Massachusetts, em 1960.

(PARKER; AL-UTAIBI, 1986) levantaram 350 artigos sobre SSD desde 1970. Os autores relatam que 77,3\% desses artigos foram publicados entre 1980 e 1983 e que o desenvolvimento desses sistemas era visto com muita crítica. Nesse trabalho os autores enfatizam algumas características que esses sistemas devem possuir, como por exemplo: o uso combinado de modelos e técnicas analíticas; facilidade de uso por parte de usuários não especializados; auxílio e aperfeiçoamento da análise humana sem tentar substituir a análise feita pelo usuário; entre outros.

Sobre a história da tecnologia dos SSDs, (RUSSELL et al., 2001) acreditam que essas ferramentas já estão disponíveis desde a criação dos computadores. No entanto, os SSDs permaneceram por muito tempo reservados para usos militares. Com o tempo esses sistemas começaram a ser utilizados por grandes empresas e só depois é que começaram a ser testados na área ambiental. Porém, os SSDs permaneceram por muito tempo sem destaque nessa área, uma vez que as estratégias políticas adotadas nos Estados Unidos não consideravam vital a integração dos modelos econômicos e ambientais. Os autores citam que os primeiros trabalhos a respeito do assunto foram realizados antes de 1972 e que um dos antecessores dos SSDs foi o modelo Delaware para estuários, que tinha como objetivo resolver conflitos de usos múltiplos da água.

A definição clássica apresentada por (SPRAGUE; CARLSON, 1982) é que um SSD é "um sistema computacional interativo que ajuda os tomadores de decisão a utilizar informações e modelos para resolver problemas complexos ainda não estruturados”. Um SSD integra os seguintes subsistemas:

I. base de modelos, 
II. banco de dados e

III. módulo de diálogo para a comunicação entre usuário e sistema.

(FINLAY, 1994) define SSD como um sistema baseado em computação que serve de auxílio no processo decisório. Já (TURBAN, 1995) define como um sistema computadorizado e interativo de informações, apresentando flexibilidade e adaptabilidade, já que é especialmente desenvolvido para auxiliar a solução de problemas não estruturados e assim aperfeiçoar a tomada de decisão. Esse sistema utiliza informações e dados através de uma interface fácil de usar e permite que o usuário tire suas próprias conclusões. Outras definições são apresentadas por (KEEN; MORTON, 1978) que definem SSD como ferramentas de auxílio baseadas em computadores para tomadores de decisão que estão envolvidos com problemas semiestruturados.

Sobre a classificação de SSD também não existe consenso na literatura. Cada autor tem sua própria classificação. Apesar de haver diferentes ideias quanto à definição, classificação e estrutura dos SSDs, os especialistas concordam que essas ferramentas são essenciais para o planejamento e gerenciamento de recursos hídricos. Esses sistemas permitem análises técnicas importantes e ajudam a definir políticas sustentáveis para cada região, levando em consideração não só fatores ambientais, mas também fatores sociais e econômicos. (LABADIE; SULLIVAN, 1986) consideram que estes sistemas constituem metodologia apropriada para o planejamento e gerenciamento de recursos hídricos.

Para (HÄTTENSCHWILER, 2001), um SSD pode ser classificado em passivo, ativo e cooperativo. Um SSD passivo é aquele que pode auxiliar o processo de tomada de decisão, mas não mostra soluções explícitas para os problemas. Já um SSD ativo apresenta soluções e sugestões para os problemas. Um SSD cooperativo é um sistema que permite ao tomador de decisão modificar, completar ou refinar as soluções apresentadas pelo sistema e depois utilizar o SSD para analisá-las novamente até que um consenso sobre as respostas seja obtido. Já (POWER, 2002) classifica os SSD como sendo: baseados na comunicação, baseados em dados, baseados em documentos, baseados no conhecimento e baseados em modelos. Um SSD dirigido a modelos enfatiza o acesso e a manipulação de modelos estatísticos, financeiros, de otimização e de simulação. Esse tipo de SSD utiliza de dados e parâmetros fornecidos pelo usuário para auxiliar o processo de tomada de decisão.

Ainda sobre a estrutura, os SSDs podem tanto ter uma estrutura personalizada para cada cliente quanto ser genéricos, o que significa que não é necessário reprogramar o SSD para que o mesmo seja utilizado por outros usuários. (DENZER, 2005) acredita que a segunda abordagem é mais efetiva em longo prazo apesar de ser muito mais complexa. Ele também concorda que em curto prazo é muito difícil construir um SSD integrado com várias metodologias de maneira 
genérica. E isso acontece, pois as ferramentas computacionais disponíveis atualmente não são satisfatórias para realizar esse trabalho.

\subsubsection{Sistemas de Previsão de Cheia e de Alerta}

O sistema de operação de um reservatório requer a tomada de uma série de decisões que determinam o processo de acumulação e vertimento ao longo do tempo (FABER; STEDINGER, 2001). A operação dos diversos reservatórios brasileiros apresenta ainda uma parcela extra de complexidade, pois muitos deles não estão limitados à geração de energia apenas. Atividades paralelas como controle de cheias, navegação, irrigação, saneamento e restrições quanto a níveis de jusante e montante figuram como balizadores dos processos decisórios envolvidos nas operações (FRANCO, 1993).Além disso, existem muitos casos de usinas hidrelétricas que operarem cascata, o que geralmente implica que a descarga de montante é uma porção significativa de sua afluência.

Dentre estes balizadores relacionados ao sistema de operação do reservatório, um dos mais importantes é o foco no controle de cheias, o que se torna um dificultador dentro deste processo, visto que, a hidrologia de enchentes está intimamente ligada às características de tempo, clima e fisiografia da região em questão (TARIQ; GIESEN, 2012).

O processo decisório na operação de reservatórios tem se tornado mais desafiador pela variabilidade natural das vazões dos rios, num mesmo ano e ao longo dos anos, bem como, pelas mudanças associadas ao aquecimento global. Além disto, tem aumentado a exigência do poder público e da própria sociedade para que os usos múltiplos sejam atendidos e contemplados dentro do plano gerenciamento dos recursos hídricos.

\section{Operação de Reservatório com Foco no Controle de Cheia}

Conforme visto no seção 3.3, a operação de hidroelétrica é geralmente baseada em políticas e regras operacionais definidas e decididas no planejamento estratégico. No Brasil este conjunto de ferramentas geralmente não contempla o controle operacional em tempo real.

A operação em tempo real de um reservatório é um processo de tomada de decisão e monitoramento contínuo, a fim de controlar o nível de água do reservatório e volume de água verte dele (vazões de saída).

A operação de reservatórios devem ser planejada e executada de forma atender os usos múltiplos de reservatórios, obedecendo todas as restrições de sua utilização da melhor maneira possível. Entre os usos mais comuns podemos citar a produção de energia, abastecimento de água à população, irrigação, pesca, lazer e transporte aquático. Dentre as Restrições citamos as condicionantes ambientais (vazões mínimas a jusante do reservatório), condicionantes de 
emergência (vazões máximas a jusante para evitar ou amenizar as inundações) e condicionantes físicas (valores mínimos e máximos de cotas e vazões em função das estruturas hidráulicas existentes).

Todas estas condicionantes (usos e restrições) podem ser expressas na Função objetivo. A Função Objetivo varia com cada caso conforme as prioridades a serem assumidas entre as diversas condicionantes do problema. Em geral a Função Objetivo é um somatório de diversos fatores ao longo do tempo de operação do reservatório. A otimização da operação do reservatório é a maximização ou minimização da Função Objetivo obedecendo às restrições ambientais e emergenciais. Estas restrições podem estar inseridas na Função Objetivo, entretanto geralmente são tratadas separadamente como Restrições às soluções da otimização da Função Objetivo. Estas restrições são representadas por inequações.

A solução da otimização da função objetivo passa pelo balanço hídrico do reservatório e pela simulação de sua operação ao longo de um tempo. Se envolver mais de um reservatório os cálculos são tratados com operações matriciais.

A otimização pode ser resolvida por diversas maneiras entre elas citamos:

- Otimização Estocástica Implícita (ISO);

- Otimização Estocástica explicita (ESO);

- Controle Ótimo;

- Métodos de programação heurística.

Dentre as metodologias não heurísticas (os 3 primeiros tipos na lista acima) citamos a programação linear, programação linear sequencial, programação quadrática sequencial (Lagrangeano projetado), método dos multiplicadores (Lagrangeano aumentado), método generalizado do gradiente reduzido, programação dinâmica. Muitos dos métodos acima são algoritmos estruturados com informações quantitativas e alguns associados a simulações com vazões sintéticas.

Já o Controle Ótimo é uma das técnicas subjacentes à Teoria de Controle, que pode ser definida como uma manipulação matemática de parâmetros que afetam o comportamento de um sistema de maneira a obter um resultado desejado. A Teoria de Controle se baseia no uso de controladores, dispositivos programados para controlar um sistema dinâmico com base em informações coletadas por sensores. Do ponto de vista mais abstrato, controladores são regras de decisão, que no caso do Controle Ótimo, procuram otimizar uma função de custo. 
Assim, a teoria do controle pode ser entendida como um caso específico de otimização: os trabalhos clássicos de Yeh (1985) e Labadie (2004) citam a Teoria de Controle como uma das ferramentas adotadas na otimização da operação de reservatórios. De fato, o controle na sua forma discreta apresenta similaridades com as técnicas de programação matemática não linear, em particular com o método do Lagrangeano Aumentado (LABADIE, 2004).

A Teoria do Controle oferece várias técnicas que podem ser utilizadas na operação ótima de reservatórios. No presente trabalho, apresentamos os Modelos de Controle Preditivo ou Model Predictive Control (MPCs).

Os métodos de programação heurísticos são baseados em experiências ou analogias diversas, aplicadas à informação quantitativa e qualitativa. Estes métodos procuram soluções aceitáveis ou satisfatórias, mas muitas vezes são capazes de alcançar soluções globais ideais para problemas onde os métodos tradicionais de algoritmos não conseguem convergir ou ficam presos em ótimos locais (LABADIE, 2004).

Dentre as metodologias heurísticas podem ser citadas os Algoritmos Genéticos, as Redes Neurais e a Lógica Difusa (Fuzzy). Os dois primeiros são algoritmos baseados na natureza. Os algoritmos genéticos se inspiram na seleção ocorrida de geração para geração e as redes neurais no funcionamento do cérebro humano com sua rede de neurônios capaz de aprender. Já a lógica difusa é o tratamento das incertezas através da inferência difusa no qual não existe apenas o valor verdadeiro ou falso, mas também valores intermediários. Com isso é possível não só tratar as incertezas como inferir conceitos qualitativos (vazão alta, média, baixa, etc.) e experiência de operadores.

\section{OpenMI - Open Modeling Interface}

Conforme explicado nas seções 4.2 e 4 existem diversos tipos de modelos que podem ser aplicados para as diferentes áreas da engenharia de recursos hídricos, sendo muito difícil um modelo capaz de integrar todas estas análises. Neste contexto surgem o OpenMI (Open Modelling Interface) e o Delft-FEWS, que são interfaces que permitem articular e vincular estes diferentes modelos. Na Figura 8 podemos observar um exemplo de integração de vários tipos de modelos como dados meteorológicos de estações (Met.Station), Modelos Chuva-Vazão (RR), Modelos Conceituais do Rio para montante e jusante (Conceptual River Model), um modelo distribuído 2D para aquífero (2D Ground Water Model) e Modelo Hidrodinâmico do Rio (Hydrodinamic River Model).

Gerenciar processos ambientais individualmente nem sempre resulta em decisões sensatas e devido à dificuldade e possivelmente inconveniência de conceber um modelo holístico, torna-se importante ser capaz de modelar processos individuais e de conseguir com que eles con- 


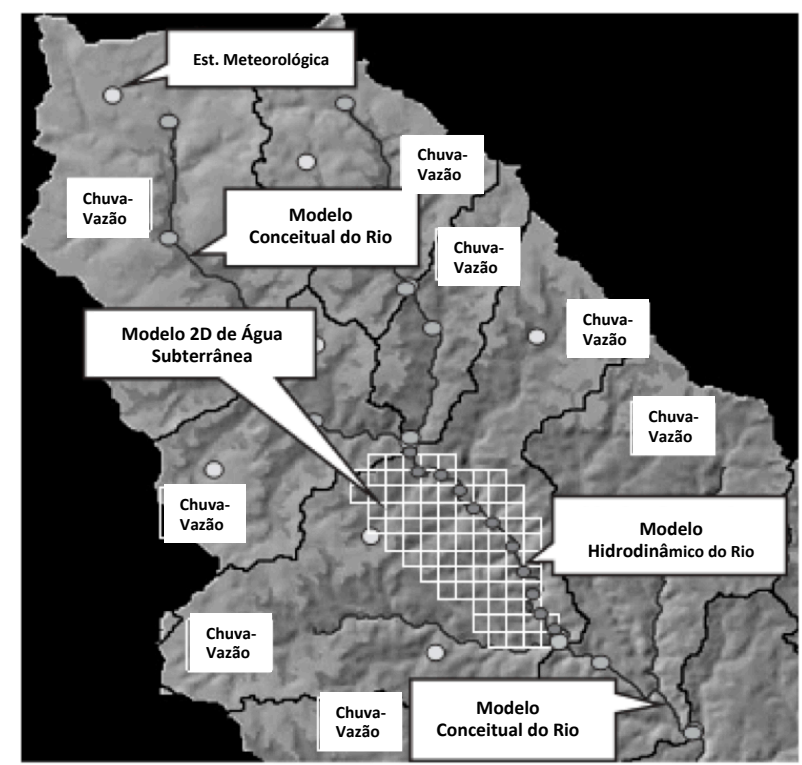

Figura 8 - Exemplo de modelação integrada de bacia hidrográfica utilizando combinação de modelos compatíveis à OpenMI

Fonte: adaptado de Gregersen, Gijsbers e Westen (2007)

sigam interagir entre si. Consequentemente, muitos dos modelos hidrológicos de SSD existentes se utilizam de modelos hidrológicos combinados como bloco base de construção (GREGERSEN; GIJSBERS; WESTEN, 2007).

Qualquer sistema pode ser adaptado para necessidades particulares, apresentando maior ou menor facilidade dependendo de sua arquitetura de software. Porém na maioria dos sistemas tal adaptação exige acesso ao código fonte. Na prática isto significa que tal sistema é desenvolvido por fornecedores de modelos utilizando apenas limitados pacotes de modelos, os quais tem seu código fonte aberto. Mesmo quando há grande disponibilidade de pacotes de modelos, o número de combinações disponíveis pode significar que a solução para o projeto em particular não esteja acessível como produto de prateleira, tornando inviável economicamente desenvolver o sistema para um único usuário ou projeto.

O padrão de OpenMI ou (Open Modeling Inteface) é por definição uma interface de componentes de software. Originalmente este padrão foi projetado para facilitar a simulação 
de processos relacionados ao Meio Ambiente que interagiam entre si, assim possibilitando que modelos independentes pudessem compartilhar seus bancos de dados, permitindo que fossem executados em paralelo, iterando a cada passo temporal.

Desde então o OpenMI foi expandido e aperfeiçoado para servir como uma solução genérica para este tipo de problema de compartilhamento de dados entre qualquer tipo de modelo, não se restringindo somente aos modelos ambientais, podendo inclusive servir para integrar componentes de software. Atualmente ele é usado para integrar e conectar qualquer combinação de modelos, compartilhar bases de dados e com ferramentas de análise e visualização embutidas.

A integração de aplicativos é uma tarefa complexa principalmente se o objetivo é proporcionar uma interface fácil de usar. Outro assunto é que cada aplicativo pode ter seu próprio banco de dados e que pode ser totalmente diferente dos demais. E isso pode resultar em um controle inadequado sobre os dados para o usuário.

Portanto, atualmente o melhor que pode ser feito é realizar a integração dos módulos de maneira personalizada para cada cliente. Infelizmente isso é o melhor que pode ser feito atualmente. No entanto, existem pesquisas em andamento que prometem soluções mais generalizadas como é o caso da iniciativa OpenMI (BLIND; GREGERSEN, 2005).

Normalmente a integração de diferentes módulos faz com que o usuário tenha que realizar trabalhos de importação e/ou exportação de dados. Isso resulta em uma enorme perda de tempo por parte do usuário, sendo que erros são frequentes nesses processos. Além disso, também resulta em uma grande quantidade de arquivos que podem ser facilmente confundidos pelo usuário. Esse tipo de tarefa pode ser aceitável quando se tratam de especialistas no assunto, no entanto não é aceitável para o usuário comum.

(BRAGA; BARBOSA; NAKAYAMA, 1998) também concordam que os SSDs são adequados para auxiliar as atividades de planejamento e gerenciamento de recursos hídricos. Segundo os autores, sistemas complexos e que possuam uma grande quantidade de informações não podem ser mais baseados e enfrentados apenas com a experiência e julgamento das equipes responsáveis. Nesse caso, tornam-se necessários sistemas sofisticados de armazenamento de dados e técnicas de análise desses dados. Os autores enfatizam que apesar da necessidade de técnicas avançadas de análise de dados no processo de tomada de decisão, não se pode esquecer a necessidade de interferência do homem em qualquer fase do processo.

A esse respeito os SSD são ferramentas importantes, pois não tornam a atividade decisória em um processo completamente automatizado e admitem a incorporação de julgamentos dos envolvidos na tomada de decisão. 


\section{Delft-FEWS}

Desde sua introdução em 2001/2003, a versão corrente da plataforma do Delft-FEWS foi implementada em mais de 40 centros operacionais (WERNER et al., 2013). A primeira implementação do Delft-FEWS se deu para a bacia do rio Nilo, sendo utilizado pelo Ministério de Irrigação e Recursos Hídricos no Sudão (GRIJSSEN et al., 1992). O mesmo sistema foi adaptado para a região do Punjab, localizado no Paquistão (WERNER; DIJK, 2005).

Os investimentos em pesquisa, desenvolvimento e em melhorias no sistema de previsão de cheias cresceu significativamente na Europa devido às recentes cheias em larga escala ocorridas. Uma das iniciativas tomadas foi o desenvolvimento do sistema europeu de previsão de cheias (European Flood Forecast System - EFFS) baseado na plataforma de previsão de cheias do DefltFEWS. A elaboração desse sistema foi realizada pelo consórcio de 19 institutos de pesquisa europeus, universidades e agências de estado, tendo a WL 1 Delft Hydraulics como instituição líder. Além disso, segundo Leedal et al. (2013), o mesmo sistema operacional tem sido utilizado pelo Sistema Nacional de Previsão de Cheias do Reino Unido UK National Flood Forecasting System - NFFS).

Verwey et al. (2006) apresentaram a potencial aplicabilidade do Delft-FEWS para a bacia do rio Mekong. O trabalho concluiu com a descrição de um número de vantagens específicas relativas ao uso do sistema como uma plataforma de previsão de cheias à bacia em questão. Os autores concluíram na análise que ao se adotar tal sistema, permite-se uma organização das previsões de cheia, ressaltando a vantagem da possibilidade de substituir módulos de softwares livres sem a necessidade de mudar toda a estrutura do sistema de previsão, como seria necessário no caso de uma abordagem centrada no modelo.

Em sistemas de previsão convencionais uma mudança relevante no módulo do software requereria significante reciclagem da organização no uso do sistema. Esse conceito tem sido reforçado em novas versões do Delft-FEWS, as quais já têm sido utilizadas em mais estudos de caso, tal como o sistema nacional de previsão de cheias para Inglaterra e País de Gales. Atualmente, Delft-FEWS tem sido utilizado em aplicações inéditas, como previsão de secas na Bacia do Rio Vermelho no Vietnã e previsão de intrusão marinha para a lagoa Songkhla na Tailândia.

Werner et al. (2013) discute os princípios nos quais o sistema Delft-FEWS tem sido desenvolvido, e apresenta um apanhado geral da arquitetura do sistema e dos princípios utilizados para o armazenamento e manipulação dos dados. Além disso, os autores discutem o papel dos estudos de previsão de vazões no contexto dos sistemas de alerta de enchente e apresentam algumas aplicações do sistema de previsão Delft-FEWS realizadas na Europa.

A primeira aplicação, na qual o Delft-FEWS atua como espinha dorsal foi na primeira 
versão do Sistema Nacional de Previsão de Enchentes do Reino Unido (WERNER et al., op. cit.). Historicamente, as previsões eram realizadas de maneira independente em cada uma das regiões correspondentes à Inglaterra, País de Gales e Escócia. A partir de 2005 tornou-se operacional nestas três regiões. Nos anos de 2006 e 2007 o sistema tornou-se operacional para as demais regiões do Reino Unido. Uma importante característica desta aplicação, o sistema foi inicialmente concebido a fim de integrar sistemas já operacionais nas regiões e assim, garantir a continuidade do serviço independentemente de mudanças no sistema através do qual as previsões eram realizadas. Outra aplicação para previsão de cheias também apresentada em (WERNER et al., op. cit.), que foi realizada pelo Departamento Ambiental Federal da Suíça.

Desde a aplicação deste sistema de previsão nacional foi notável o aumento do número de bacias e rios abrangidos pelos modelos já operacionais (WHITFIELD, 2005 apud WERNER et al., 2013) ${ }^{1}$. Além disso, o uso do Delft-FEWS como sistema integrador permitiu a uniformização dos dados utilizados nas diversas regiões abrangidas pelo estudo, e assim, facilitou a inserção de novos produtos ao sistema, como previsões numéricas do tempo do tipo (ensemble forecasting).

Tariq e Giesen (2012) investigaram o comportamento das maiores bacias e da gestão de enchentes a nível nacional no Paquistão. Considerando as três maiores bacias, a bacia do rio Indo tem como principal causa de enchentes as monções, enquanto que ondas do mediterrâneo e ciclones gerados no mar Arábico induzem as cheias na bacia de Kharan e na área costeira de Makran. Assim, desde a criação do país, o governo tem investido muitos recursos em operações de remediação e prevenção de enchentes. O sistema de alerta de cheias no país é de responsabilidade da Divisão de Prevenção de Cheias do Departamento Meteorológico do Paquistão, porém a Autoridade de Desenvolvimento de Água e Energia também contribuem para tal. O sistema de alerta de cheias foi iniciado em 1975, quando a telemetria em tempo real foi instalada em 16 estações fluviométricas e 24 estações pluviométricas. Um consórcio entre o Serviço Nacional de Engenharia do Paquistão e a Deltares realizou a implementação do Sistema de Alerta Antecipado de Enchentes (Flood Early Warning System - FEWS).

Weerts, Schellekens e Weiland (2010) mostra as possibilidades oferecidas pelas ferramentas do Delft-FEWS para a manipulação de dados geoespaciais, como valores obtidos por satélites e previsões de tempo e clima. Dois estudos de caso são apresentados pelos autores. No primeiro deles foi elaborado o sistema inédito de previsão de risco de queimadas utilizando dados de nível de água subterrânea. Classes de nível da água podem ser relacionadas à ocorrência de queimadas em turfas, assim, é possível estimar o risco de queimadas nesses ambientes através da aplicação de um modelo de águas subterrâneas que tem como entrada dados medidos ou previstos de precipitação.

1 WHITFIELD, D. The national flood forecasting system (nffs) of the uk environmental agency. In: International Conference on Innovation and Implementaion of Flood Forecasting Technology. Troms $\emptyset$, Norway: [s.n.], 2005. 
No segundo estudo de caso apresentado, foi realizada a validação da utilização de dados brutos oriundos de um modelo de circulação geral (General Circulation Model - GCM) para estudos hidrológicos. Já é bem conhecido que dados GCM, especialmente precipitação, apresentam grande desvio em relação aos valores observados. Nesse estudo, o Delft-FEWS foi configurado com o intuito de executar os modelos hidrológicos utilizando dados do modelo climático. Os resultados mostraram que os dados de precipitação GCM não podem ser utilizados sem uma prévia correção de erros.

Em Schwanenberg et al. (2013) é apresentado um projeto otimização de reservatório para curto horizonte de previsão de tempo em implantação para UHE de Queimados. O Delft-FEWS é usado como plataforma para integrar modelos chuva-vazão, modelos hidrológicos e modelos hidráulicos. 
Tabela 4 - Classificação de modelos hidráulicos segundo a sua dimensionalidade

\begin{tabular}{|c|c|c|c|c|}
\hline Método & Descrição & Tipos de Aplicações & $\begin{array}{l}\text { Escala tempo- } \\
\text { ral de Simula- } \\
\text { ção }\end{array}$ & Saídas de Dados \\
\hline 1D & $\begin{array}{l}\text { Solução das 1-D } \\
\text { ESV }\end{array}$ & $\begin{array}{l}\text { Modelagem em escala de } \\
\text { projeto na ordem de } 10 \mathrm{~s} \mathrm{a} \\
\text { 100s de km dependendo do } \\
\text { tamanho da bacia }\end{array}$ & Minutos & $\begin{array}{l}\text { Profundidade da água, veloci- } \\
\text { dade média da seção transver- } \\
\text { sal e descarga em cada seção } \\
\text { transversal. A extensão da inun- } \\
\text { dação de planícies de inunda- } \\
\text { ção se integrar a parte de 1D } \\
\text { Modelo, ou através da projeção } \\
\text { horizontal do nível da água }\end{array}$ \\
\hline $1 \mathrm{D}+$ & $\begin{array}{l}\text { 1D mais células de } \\
\text { armazenamento para } \\
\text { simulação de fluxo } \\
\text { na planície de inun- } \\
\text { dação }\end{array}$ & $\begin{array}{l}\text { A modelagem em escala de } \\
\text { projeto, que pode ser da or- } \\
\text { dem de } 10 \text { s a } 100 \text { s de km, } \\
\text { dependendo do tamanho } \\
\text { da bacia, também tem po- } \\
\text { tencial para aplicação em } \\
\text { larga escala se usada com } \\
\text { dados de seções transver- } \\
\text { sais esparsas }\end{array}$ & Minutos & $\begin{array}{l}\text { Mesmo que os modelos } 1 \mathrm{D} \text {, } \\
\text { além dos níveis de água e ex- } \\
\text { tensão de inundação em células } \\
\text { de armazenamento de volume } \\
\text { da planície de inundação }\end{array}$ \\
\hline 2D- & $\begin{array}{l}\text { 2D menos a lei de } \\
\text { conservação de quan- } \\
\text { tidade de movimento } \\
\text { para a planície de } \\
\text { inundação }\end{array}$ & $\begin{array}{l}\text { Modelação em larga escala } \\
\text { e aplicações onde os efeitos } \\
\text { inerciais não são importan- } \\
\text { tes }\end{array}$ & horas & $\begin{array}{l}\text { Extensão da inundação e níveis } \\
\text { de água }\end{array}$ \\
\hline $2 \mathrm{D}$ & $\begin{array}{l}\text { Solução para as equa- } \\
\text { ções bidimensional } \\
\text { de canais rasos }\end{array}$ & $\begin{array}{l}\text { Modelagem de escala de } \\
\text { projeto da ordem de } 10 \mathrm{~s} \\
\text { de km. Pode ter potencial } \\
\text { para uso em modelagem } \\
\text { em larga escala se aplicada } \\
\text { com grades muito grossei- } \\
\text { ras. }\end{array}$ & Dias & $\begin{array}{l}\text { Extensão da Inundação, Profun- } \\
\text { didade da água, Profundidade } \\
\text { média das velocidades }\end{array}$ \\
\hline $2 d+$ & $\begin{array}{l}\text { 2D mais a solução } \\
\text { para velocidades } \\
\text { verticais usando so- } \\
\text { mente continuidade }\end{array}$ & $\begin{array}{l}\text { Aplicações predominante- } \\
\text { mente costeiras onde os } \\
\text { perfis de velocidade 3D são } \\
\text { importantes. Também tem } \\
\text { sido aplicado para abordar } \\
\text { problemas de modelagem } \\
\text { de rios em projetos de pes- } \\
\text { quisa }\end{array}$ & Dias & $\begin{array}{l}\text { Extensão da Inundação, Profun- } \\
\text { didade da água e Velocidades } \\
\text { em } 3 \text { dimensões }\end{array}$ \\
\hline $3 \mathrm{D}$ & $\begin{array}{l}\text { Solução das equa- } \\
\text { ções tridimensionais } \\
\text { de Navier Stokes } \\
\text { com aproximação de } \\
\text { média de Reynolds }\end{array}$ & $\begin{array}{l}\text { Previsões locais dos cam- } \\
\text { pos tridimensionais de ve- } \\
\text { locidade em canais princi- } \\
\text { pais e planícies de inunda- } \\
\text { ção. }\end{array}$ & Dias & $\begin{array}{l}\text { Extensão da Inundação, Profun- } \\
\text { didade da água e Velocidades } \\
\text { em } 3 \text { dimensões }\end{array}$ \\
\hline
\end{tabular}

Fonte: Adaptado de Pender (2006). 



\section{Escoamento Hidráulico em Canais}

Os processos de escoamento em canais abertos descrevem propagações de ondas ao longo do tempo através de um percurso de um ponto inicial até o ponto final através do comportamento e transformação da distribuição da água neste sistema. Estas mudanças ao longo do tempo (temporal) e ao longo do percurso (espacial) podem ser também extrapoladas para descrever o comportamento das vazões de um rio e assim realizar simulações destes corpos d'água através do emprego de diferentes métodos, que geralmente podem ser categorizados em duas classes: Hidrológico ou hidráulico. O primeiro utiliza tipicamente uma aproximação simplificada para estimar os volumes de armazenamento de um trecho do rio para obter o balanço hidráulico (equação da continuidade), que pode ser definido como:

$$
Q=I-\frac{\partial S}{\partial t}
$$

Onde $Q$ representa a vazão de saída; I representa vazão de entrada; $S$ é capacidade de armazenamento, ou volume de armazenamento; e $t$ é o tempo.

Um exemplo clássico de um processo de escoamento hidrológico é o método de Muskingum (CHOW; MAIDMENT; MAYS, 1988). Neste método, o volume de armazenamento é aproximadamente a soma de um prisma formado pelo nível da lâmina superficial da água e a superfície do leito do rio e a cunha formada entre a lâmina superficial da do nível da água e linha de energia conforme Figura 9:

O volume armazenado no prisma é proporcional para a vazão de saída, enquanto a cunha pode ser calculada como um volume triangular determinado por um parâmetro de calibração:

$$
S_{1}=K . O
$$

$$
S_{2}=K . X .(I-O)
$$

Onde $S$ é o volume de armazenamento; $K$ é um coeficiente que reflete o armazenamento do prisma em relação ao comprimento; $X$ um coeficiente que reflete o formato triangular da cunha $X=0,5$. 


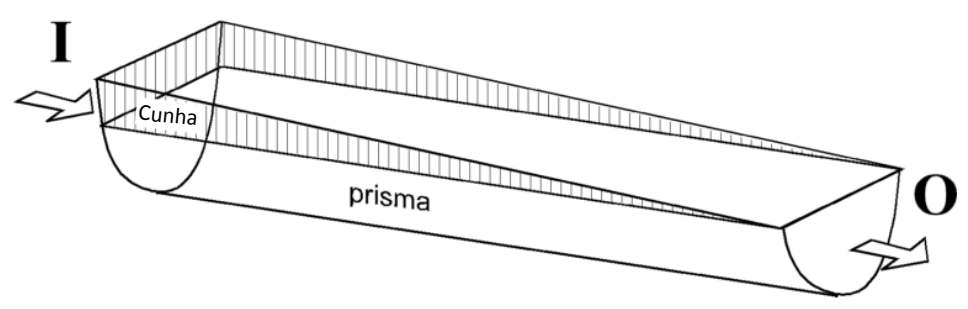

Figura 9 - Representação conceitual do volume de armazenamento para o método de Muskingum

Os valores de $K$ e $X$ devem então ser calibrados para cada caso específico de acordo com as características físicas. Porém é importante destacar que estes parâmetros podem mudar de acordo com o tempo e portanto sendo necessário valida-los.

Já os processos hidráulicos envolvem não somente o balanço hídrico e de massa, mas também a lei de conservação de massa para definir um sistema de equações que possa ser utilizado para estimar e quantificar as alterações que ocorrem em relação as vazões de entrada e saída de acordo com as propriedades físicas do trecho de rio. Estas propriedades estão relacionadas a geometria do trecho de rio como as seções transversais do rio, coeficientes de rugosidade, declividade do leito do rio e comprimento das seções do rio.

\subsection{Equações de Saint-Venant}

As equações unidimensionais para fluxo em canais abertos foram formuladas no século IX por dois matemáticos, de Saint-Venant e Bousinnesque. Elas são utilizadas para simular fluxos em canais abertos que consistem de um sistema de equações que descrevem processos físicos de conservação de quantidade de movimento (momento linear) e massa. (FRANZ; MELCHING, 1997).

Estas equação definem um sistema de equações que foi verticalmente integrados das equações de Navier-Stokes mais generalizada, assumindo que as condições de pressão hidroestáticas e relativamente pequena declividades. Para um sistema com condição unidimensional pode-se assumir mais uma simplificação que consiste em integrar a velocidade perpendicular ao 
canal. Este sistema resulta na seguintes expressões na forma conservativa (que considera o plano de referência fixo para um elemento infinitesimal):

$$
\begin{aligned}
& \frac{\partial A}{\partial t}+\frac{\partial Q}{\partial x}=0 \\
& \frac{\partial Q}{\partial t}+\frac{\partial}{\partial x}\left(\beta \frac{Q^{2}}{A}\right)+\frac{\partial}{\partial x}\left(\frac{P}{\rho}\right)=\left(S_{0}-S_{f}\right) g A
\end{aligned}
$$

A forma não-conservativa onde o plano de referência muda em relação ao fluxo, é expressa da sequinte forma:

$$
\begin{aligned}
& \frac{\partial y}{\partial t}+V \frac{\partial y}{\partial x}+y \frac{\partial V}{\partial x}=0 \\
& \frac{\partial V}{\partial t}+V \frac{\partial V}{\partial x}+g \frac{\partial y}{\partial x}=\left(S_{0}-S_{f}\right) g
\end{aligned}
$$

Onde $A$ representa a área molhada da seção tranversal; $Q$ é a vazão; $V$ é a velocidade de escoamento; $\beta$ o coeficiente de Bousineesq; $P$ é a pressão; $\rho$ a densidade; $S_{0}$ declividade do leito do rio; $S_{f}$ declividade da linha de energia; $g$ constante da gravidade; $y$ é a profundidade da lâmina da água; $x$ dimensão espacial e $t$ é o tempo.

A solução destes sistemas de equações resulta em informações do escoamento em termos de área e vazão para a forma conservativa e de nível de água e velocidade para a forma não-conservativa. É importante observar que os coeficientes de rugosidade são consideradas implicitamente na computação dos termos de fricção em cada caso. Isto é um parâmetro altamente sensível que necessita ser calibrado, em comparação aos fatores $K$ e $X$ do método Muskingum explicado anteriormente

\section{Representação Numérica}

O escoamento hidráulico pode ser analiticamente resolvido em alguns casos muito específicos somente quando alguns termos da equação da conservação de movimento podem ser desconsiderados(KAZEZY1LMAZ-ALHAN; MEDINA, 2007). Além disso para definições mais complexas das equações diferenciais requerem uso de métodos numéricos para aproximar a solução exata do sistema. Dentre estes métodos de diferenças finitas, onde as derivadas são aproximadas de acordo com o domínio discretizado através de uma expansão de Taylor. Assim desta forma a primeira derivada pode ser substituída por:

$$
\left(\frac{\partial y}{\partial x}\right)_{i, n}= \begin{cases}\frac{y_{i+1}^{k}-y_{i}^{k}}{\Delta x}+O(\Delta x) & \text { Operador de Diferença Anterior } \\ \frac{y_{i}^{k}-y_{1-i}^{k}}{\Delta x}+O(\Delta x) & \text { Operador de Diferença Posterior } \\ \frac{y_{i+1}^{k}-y_{i-1}^{k}}{\Delta x}+O(\Delta x)^{2} & \text { Operador de Diferença Central }\end{cases}
$$


Onde $i$ é o índice do ponto discreto onde a derivada está sendo calculada; $k$ é a escala temporal no qual a derivada está sendo calculada; $y, x$ são as variáveis dependentes e independentes da equação diferencial.

No sistema de equações 5.6, y e $x$ são usadas como variáveis dependentes e independentes e não restritas à altura da lâmina de água ou ao comprimento que normalmente estão associadas. Assim o mesmo pode ser aplicado para a derivada da vazão em relação ao espaço ao velocidade em relação ao tempo. Porém é importante destacar que estas expressões estão representadas em termos do atual espaço de tempo $k$, o qual induz a um de esquema explícito. A figura 10 representa as discretizações anteriores em uma grade na qual o eixo horizontal representa o espaço e o eixo vertical representa o tempo.
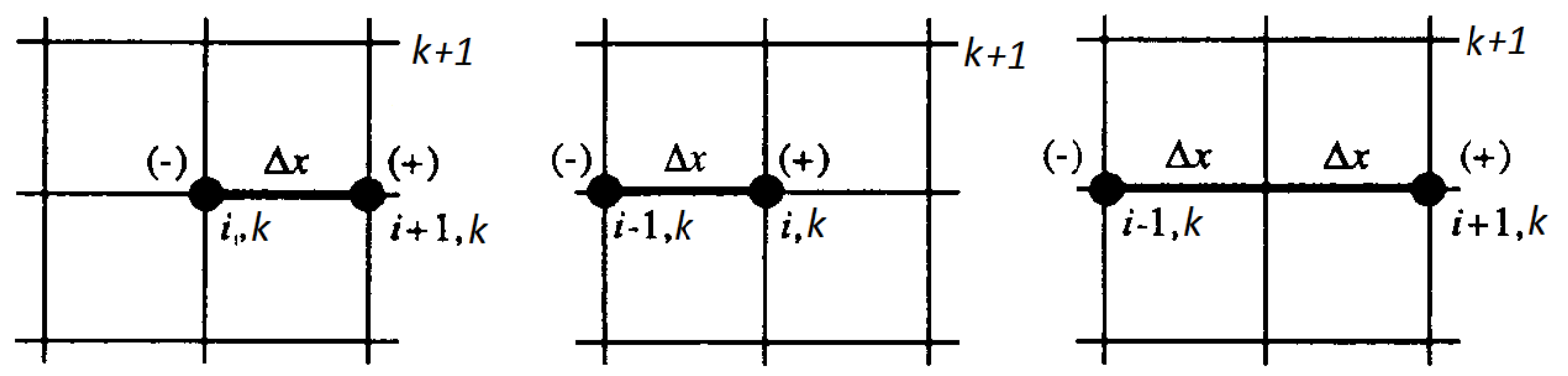

Figura 10 - Representação de discretizações em grade para Operadores de Diferença posterior, anterior e central (eixo horizontal representa espaço e o vertical o tempo)

Fonte: adaptado de Anderson (1995)

Para cada derivada espacial para o ponto $(i, k)$ são aproximadas a partir da informação do espaço de tempo $k$. Em um esquema implícito, a derivada são aproximadas considerando informação da espaço de tempo $k+1$. Assim desta forma para qualquer ponto existem pelo menos duas incógnitas, e portanto o sistema de equações deve ser definido e resolvido. $\mathrm{O}$ esquema $\theta$ por exemplo define um peso para ponderar a importância para derivadas no espaço de tempo $n$ e $k+1$ conforme a seguinte equação:

$$
\frac{\partial y}{\partial x}=(1-\theta) \frac{y_{i+1}^{k+1}-y_{i}^{k+1}}{\Delta x}+\frac{y_{i+1}^{k}-y_{i}^{k}}{\Delta x}
$$

Conforme descrito acima, há uma variável desconhecida adicional de $y$ na célula vizinha à $i+1$ para o espaço de tempo $k+1$, que deve ser resolvido a partir do sistema de equações. $\mathrm{O}$ esquema de Crank Nicholson, por exemplo, corresponde a um caso particular de $\theta=0,5$, que considera não apenas a aproximação da derivada no espaço de tempo $k$, mas também em $k+1$, como mostrado na figura a seguir (ANDERSON, 1995). 

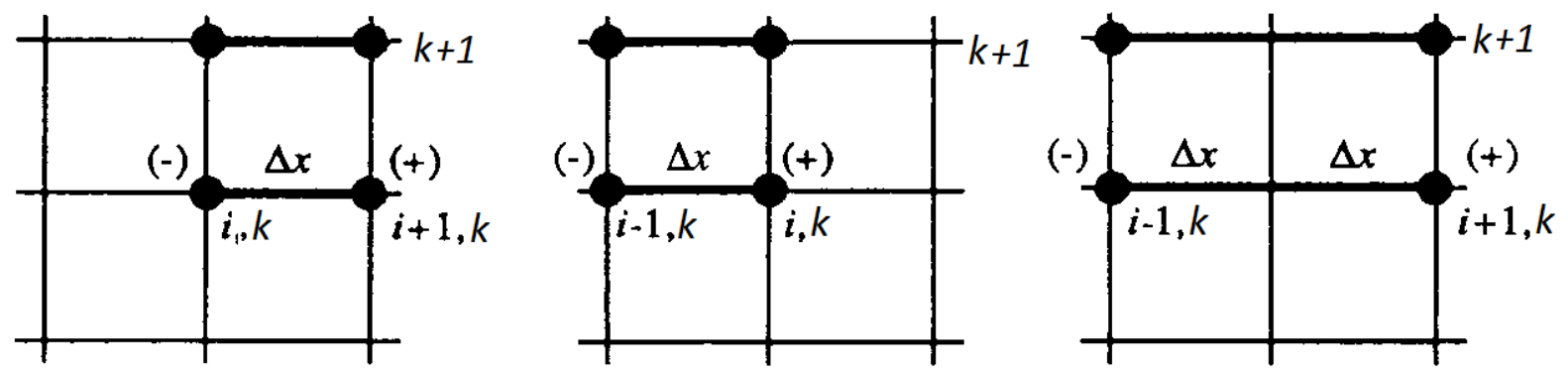

Figura 11 - Representação de um esquema de discretização Crank Nicholson

Fonte: adaptado de Anderson (1995)

\subsection{Comparação entre abordagem Implícita Explícita}

Segundo Anderson (1995) as vantagens de uma abordagem explícita seria a facilidade de configurar e formular o problema, mas a as desvantagens estaria que pra um conjunto dado de $\Delta x$, $\Delta t$, devem estar contidos dentre das restrições de estabilidade, sendo que em alguns casos deverá reduzir bastante o $\Delta t$ para manter esta estabilidade; resultando em tempos de processamento altos para realizar os cálculos para um intervalo de tempo $t$. Já para a abordagem implícita, as vantagens seriam que a estabilidade pode ser obtida para valores muito maiores de $\Delta t$, e desta forma utilizando menos espaços de tempo para realizar os cálculos para um intervalo $t$, o que implica diretamente em menos custo computacional. Porém este vantagem vem com algumas desvantagens: o problema é mais complicado de ser configurado e formulado; já que é necessário realizar grandes cálculos matriciais para cada espaço de tempo, o custo computacional relativo, ou seja tempo de cálculo por espaço de tempo é muito maior do que para a abordagem explícita; e já que grande $\Delta t$ pode ser considerado, o erro de truncamento e a utilização do método implícito para transientes exatos (variações temporais de uma variável independente) talvez não seja tão preciso quanto o método explícito. Porém para soluções dependentes do tempo no qual o espaço de estados é o resultado desejado, esta imprecisão relativa ao tempo não é relevante.

Em Fortuna (2012) a maior diferença entre métodos explícito de implícitos seria que em métodos explícitos utilizam equações independentes, permitindo solução direta, enquanto que os métodos que utilizam a discretização temporal implícita é necessário solução de um sistema de equação para cada unidade de tempo.

\subsection{Dedução das Equações 1D de Saint-Venant}

Os escoamento em rios e canais são descritos por equações diferenciais parciais nãolineares. As leis básicas da mecânica, as quais servem de base para os estudos relativos aos transientes hidráulicos em escoamentos livres, são a equação da continuidade(conservação de massa) e e a equação dinâmica( quantidade de movimento) (HENDERESON, 1966). O trata- 
mento matemático das ondas de translação também é feita através de equações deduzidas a partir das equações da continuidade e conservação da quantidade de movimento com características complexas. O escoamento livre de um canal pode ser considerado não-permanente ou variável, quando os valores das características do fluido como a profundidade da lâmina de água e outros parâmetros hidráulicos se alteram ou apresentam variação com o tempo. O escoamento nãopermanente é geralmente não-uniforme ou variado, sendo que a não uniformidade se caracteriza pelo não-paralelismo das linhas de corrente ao longo do escoamento (PORTO, 1999).

As relações obtidas são decorrentes da consideração de um conjunto de hipóteses simplificadoreas como: escoamento unidimensional, distribuição de pressão hidroestática, canal de baixa declividade, canal prismático(seção reta e declividade de fundo constantes em todas a extensão), fluido incompressível com vazão e perdad de carga no regime variável computada por uma equação de resistência do regime permanente e uniforme (PORTO, 1999).

Estas equações de fluxo não permanente em canais abertos formam os principais conceitos e hipóteses utilizadas na modelagem matemática de problemas de fluxo de fluidos. Considerando apenas as forças de fluxo mais importantes e dependendo da finalidade da modelagem omitindo aquelas forças que podem ser desprezadas. Desta forma, eles fornecem um modelo simples para fenômenos muito complexos.

Considerando uma seção de um canal aberta hipotética conforme a Figura 12, onde $Q_{i}$ é a vazão de entrada, $Q_{f}$ é a vazão de saída, $Z$ é a Elevação ou cota da superfície acima do Datum, $h$ é a profundidade da lâmina de água na secção, $\Delta x$ é o comprimento da seção e que $\Phi$ é o ângulo da declividade do canal.

Em sua forma unidimensional, assumindo densidade e temperatura constantes, podemos formular o escoamento em canais utilizando as Equação da Continuidade, que é baseada na lei de conservação de massa e a Equação de Conservação de Movimento, derivada da segunda lei de Newton (ALDRIGHETTI, 2007).

Assumindo que :

a) O Fluxo é unidmensional, ou seja a velocidade é uniforme através dos transectos e o nível de água, pode ser descrito por uma linha horizontal;

b) A curvatura das linhas de corrente é pequena e as acelerações verticais são insignificantes, de modo que a pressão se mantém hidroestática;

c) Os efeitos da fricção e turbulência podem ser representados através da lei de resistência análoga às usadas para fluxos permanentes;

d) a declividade média do leito do rio é desprezível, de modo que o cosseno do ângulo que ele forma com a linha horizontal pode ser substituído pela unidade; 


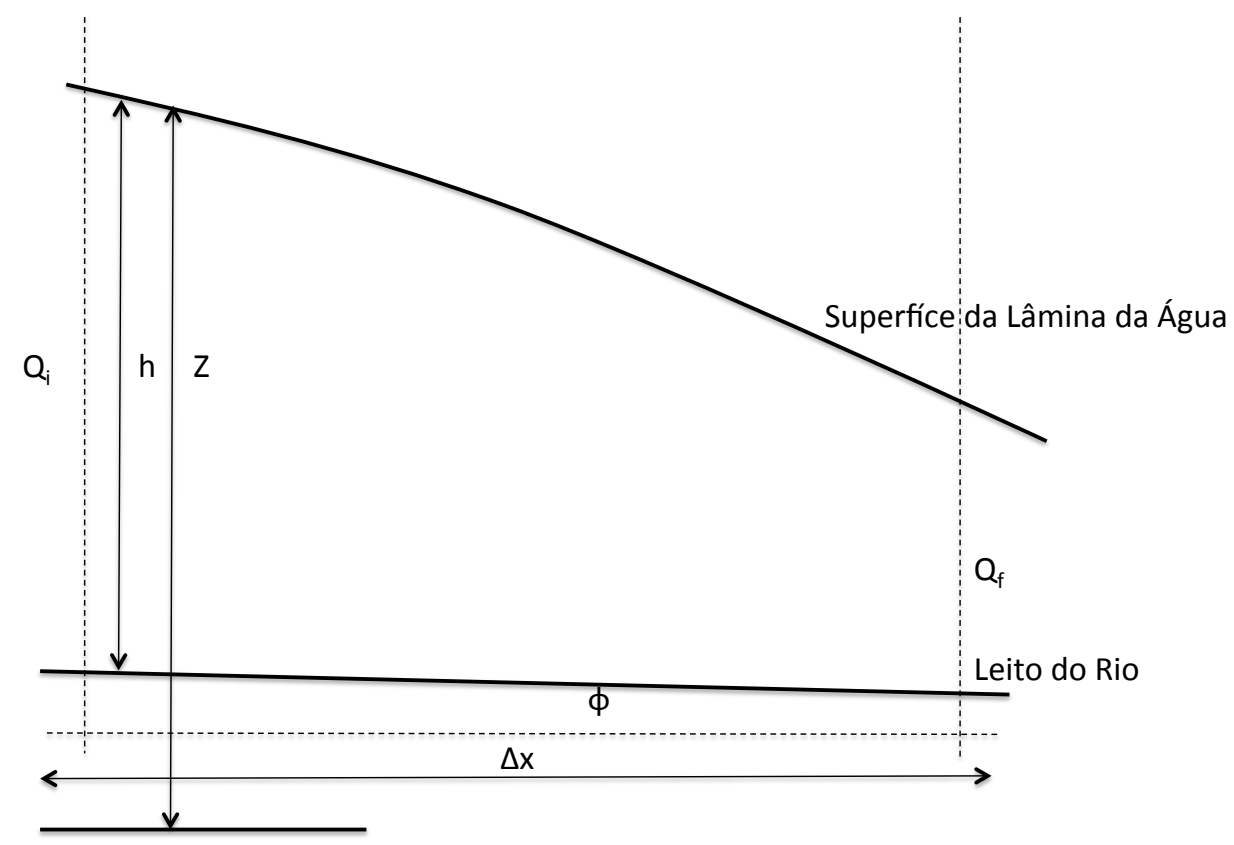

Figura 12 - Representação de uma seção Simplificada de um escoamento de canal aberto

Assumindo que não existem contribuições laterais então temos que:

$$
Q_{i}-Q_{f}=\frac{\partial Q}{\partial x} \Delta x
$$

Onde a derivada parcial define que a vazão não é constante ao longo de $\Delta x$ e ao longo do tempo $\Delta t$. Logo temos que o volume de água entre a seção inicial e seção final aumenta conforme:

$$
b \frac{\partial h}{\partial t} \Delta x
$$

Onde $b$ é a largura do topo da lâmina da água na seção e $v$ é a velocidade do escoamento perpendicular ao fluxo, temos que a área da seção molhada do rio é dada por:

$$
\begin{aligned}
& A=b h \\
& \frac{\partial A}{\partial t} \Delta x
\end{aligned}
$$


Então,

$$
\frac{\partial Q}{\partial x} \Delta x+b \frac{\partial h}{\partial t} \Delta x=0
$$

$\mathrm{e}$

$$
\frac{\partial Q}{\partial x}=\frac{\partial(A v)}{\partial x}
$$

Que resulta na equação da continuidade:

$$
v \frac{\partial A}{\partial x}+A \frac{\partial v}{\partial x}+b \frac{\partial h}{\partial t}=0
$$

Para deduzir a equação de conservação de momento, então aplicando a segunda lei de Newton para nossa representação de canal temos que, $F$ é força, $M$ é massa e $a$ é aceleração:

$$
\begin{aligned}
F= & M \cdot a \\
& \rho \Delta x \frac{\partial v}{\partial t} \\
& \rho \Delta x\left[v \frac{\partial v}{\partial x}+\frac{\partial v}{\partial t}\right]
\end{aligned}
$$

Considerando que $v$ varia tanto no espaçox quanto no tempo $t$ e que a aceleração é influenciada pela mudança na pressão estática $\frac{\partial H}{\partial x}$ e resistência causada pela fricção $\mu$ nas paredes do canal e pela força da gravidade $\rho g$ e a inclinação do leito do rio $\Phi$ :

$$
\frac{\partial H}{\partial x} \Delta x \cos \Phi-\mu \Delta x+\rho g A \sin \Phi
$$

E considerando ângulos para $\Phi$ pequenos, então temos que:

$$
\begin{aligned}
& \cos \Phi=1 ; \\
& \sin \Phi=\Phi=S_{f}
\end{aligned}
$$

Então:

$$
\frac{\partial H}{\partial x} \Delta x-\mu \Delta x+\rho g A \Delta x S_{f}
$$


Agora

$$
\frac{\partial H}{\partial x}=\rho g A \frac{\partial h}{\partial x}
$$

e

$$
\mu=\rho g A S_{0}
$$

Onde $S_{0}$ é a perda de energia por unidade de medida do comprimento do canal por unidade de massa do fluido. Então pode-se reescrever para:

$$
\rho A \Delta x\left(v \frac{\partial v}{\partial x}+\frac{\partial v}{\partial t}\right)=-\rho g A \frac{\partial h}{\partial x} \Delta x-\rho g A S_{0}+\rho g A \frac{\partial h}{\partial x} \Delta x-\rho g A S_{f}
$$

Reescrevendo novamente temos a equação de conservação de momento:

$$
g \frac{\partial h}{\partial x}+v \frac{\partial v}{\partial x}+\frac{\partial v}{\partial t}=g\left(S_{f}-S_{0}\right)
$$

O escoamento unidimensional pelas equações de Saint-Venant é portanto apresentado por duas equações: A Equação 5.23 representa as propriedades de conservação de massa e a Equação 5.24 representa a conservação de momento ou de momento linear.

Desta forma temos que:

$$
\begin{gathered}
\frac{\partial Y}{\partial t}+\frac{A \partial V}{B \partial x}+V \frac{\partial d}{\partial x}+\frac{V}{B}_{d=\text { constante }}=0 \\
\frac{\partial V}{\partial t}+V \frac{\partial V}{\partial x}+g \frac{\partial d}{\partial x}+g\left(S_{f}-S_{0}\right)=0
\end{gathered}
$$

Onde $A$ corresponde à área molhada ou fluxo da área transversal, $B$ é a largura da superfície livre, $d$ é a profundidade da água, o símbolo $Y$ representa a elevação da superfície livre ou a profundidade da água mais referência $(Y=d+Z 0)$, $T$ é o tempo, $x$ corresponde a distância ou espaço de coordenadas na direção do fluxo, $g$ é a constante gravitacional, $S 0$ é a inclinação do leito do rio ou a inclinação inferior e $S f$ é a inclinação da linha de energia ou de atrito. 
As forças de conservação de movimento representadas pela Equação 5.24, podem ser divididas em forças de aceleração local e convectiva, forças de pressão, forças gravitacionais e forças de atrito ou fricção. Na Tabela 5, estão descritos os termos da da equação que compõe a equação de conservação de momento.

$$
\underbrace{\frac{\partial V}{\partial t}}_{\text {I }}+\underbrace{V \frac{\partial V}{\partial x}}_{\text {II }}+\underbrace{g \frac{\partial d}{\partial x}}_{\text {III }}+\underbrace{g\left(S_{f}-S_{0}\right)}_{\text {IV }+\mathrm{V}}=0
$$

Tabela 5 - Componentes da Equação de Conservação de Movimento.

\begin{tabular}{ll}
\hline \hline Componente & Descrição \\
\hline I & Termo de Aceleração Local \\
II & Termo de Aceleração Convectiva \\
III & Termo de Força de Pressão \\
IV+V & Termo da Força de Gravidade + \\
& Termo da Força de Fricção \\
\hline \hline
\end{tabular}

\subsection{Simplificações das Equações de Saint-Venant}

Em alguns casos simples é possível solucionar analiticamente as ESV integrando equações diferenciais parciais; é possível também soluciona-las através de uma solução numérica por aproximação de diferenças finitas, o que geralmente requer muito processamento computacional. No entanto estas não são as únicas maneiras para solucionar estas equações, negligenciando os termos da equação Equação 5.26 obtém-se equações simplificadas, que são mais fáceis de serem solucionadas e que requerem menos esforço computacional.

Em algumas aplicações, as forças de aceleração (local e convectiva) e as forças de pressão podem ser desconsideradas, pois seus efeitos tem impactos desprezíveis ou não significativos nos processos hidráulicos que estão sendo computados. Na Tabela 6, estão apresentados as simplificações das ESV e as premissas adotadas para cada caso ao de negligenciar termos da equação de conservação de movimento.

$$
\overbrace{\frac{\partial V}{\partial t}+V \frac{\partial V}{\partial x}+\underbrace{g \frac{\partial d}{\partial x}+\underbrace{g\left(S_{f}-S_{0}\right)}_{\text {Onda Cinemática }}}_{\text {Onda Difusa }}}^{\text {Eq. Hidrodinâmica }}=0
$$

O modelo de onda cinemática desconsidera todos os termos da equação de conservação de movimento, excetuando as forças gravitacionais e de fricção, enquanto que os modelo de onda difusiva leva em conta também as forças de pressão. O modelo totalmente dinâmico adota 
Tabela 6 - Características das Simplificações das Equações de Saint-Venant.

\begin{tabular}{|c|c|c|c|}
\hline & $\begin{array}{l}\text { Onda Hidrodinâmica / } \\
\text { Totalmente Dinâmica }\end{array}$ & Onda Difusa & Onda Cinemática \\
\hline $\begin{array}{l}\text { Termos da Eq. de Conserva- } \\
\text { ção de Movimento }\end{array}$ & $\mathrm{I}+\mathrm{II}+\mathrm{III}+\mathrm{IV}+\mathrm{V}$ & $\mathrm{III}+\mathrm{IV}+\mathrm{V}$ & $\mathrm{IV}+\mathrm{V}$ \\
\hline $\begin{array}{l}\text { Inversão de Fluxo \& Efeitos } \\
\text { de Remanso }\end{array}$ & $\operatorname{Sim}$ & Sim & Não \\
\hline Atenuação da Ondas de Cheia & Sim & Sim & Não \\
\hline Aceleração de Fluxo & Sim & Não & Não \\
\hline
\end{tabular}

os temos de aceleração tanto local quanto convectiva no sistema de equações. Chow, Maidment e Mays (1988) explica que estes termos são importantes para pequenas declividades onde as forças de inércia são relevantes e subcríticos ocorrem a jusante.

Em suma, as expressões simplificadas podem representar com precisão problemas específicos, dependendo da importância e impactos de seus termos para determinadas aplicações (por exemplo, as forças de inércia em estuários, forças gravitacionais em regiões montanhosas, efeitos de remanso em planícies aluviais), com a vantagem de reduzir os custos computacionais (MONTERO et al., 2013):

a) A simplificação de onda dinâmica são usadas quando as forças inerciais e de pressão são importantes e os efeitos de remanso não podem ser desconsiderados (canais com declividade suave com controle à jusante);

b) O Modelo Inercial (BATES; HORRIT; FEWTRELL, 2010) negligencia o termo de aceleração e não pode ser utilizado em casos onde as forças de pressão tem papel importante juntamente com as forças gravitacionais e de atrito;

c) e finalmente na simplificação de onda cinética (LIGHTHILL; WHITMAN, 1955), que reduz a equação de conservação de movimento mantendo somente o termo de atrito ou fricção e forças gravitacionais, sendo aplicável quando as forças de atrito e gravidade compensam uma a outra (Declividade alta e sem efeitos de remanso); 



\section{Modelo de Controle Preditivo - MPC}

Em García, Prett e Morari (1989) um MPC (Model predictive control) é definido com um conjunto de controladores na qual há uso direto de um modelo explícito e identificável. Controladores baseados no conceito de MPC foram amplamente adotados na indústria (particularmente na indústria petroquímica), em especial devido à capacidade de designs baseados em MPCs em fornecer sistemas de controle de alto desempenho, capazes de operar sem supervisão por longos períodos de tempo. $\mathrm{O}$ autor também ressalta que ainda que MPCs não sejam inerentemente mais robustos que outros modelos clássicos, o ajuste da robustez de MPCs é mais fácil.

No entanto em Mayne et al. (2000) um MPC é caracterizado como aquele em que a decisão atual de controle é a solução de um problema de controle ótimo do tipo malha aberta (open loop) com horizonte finito. Este problema é resolvido a cada intervalo de amostragem do sistema, tal que o estado do sistema é a condição inicial de cada otimização. Esta otimização resulta numa política operativa ótima, da qual a decisão do primeiro período é adotada como a decisão operativa do sistema controlado. A principal vantagem de MPCs é sua capacidade de lidar com restrições rígidas sobre o controle e os estados do sistema.

O MPC é um caso específico da Teoria de Controle Ótimo (TCO). A Teoria do Controle é um estudo matemático para manipular os parâmetros que afetam o comportamento de um sistema a fim de alterar e controlar este sistema para obter o o comportamento e resultado desejado ou ótimo. Isto é, a TCO (e por extensão o MPC) estão associadas a problemas de otimização.

(YEH, 1985; LABADIE, 2004) tratam sobre operação ótima de reservatórios e citem a TCO como uma das técnicas usadas na otimização da operação de reservatórios. De fato, a TCO na sua forma discreta apresenta similaridades com as técnicas de programação matemática não linear, em particular com o método do Lagrangeano Aumentado, também denominado como Método dos Multiplicadores LABADIE, op. cit.. Assim, a adoção de MPCs, uma aplicação particular da TCO, para a operação de reservatórios é uma escolha natural.

A característica mais marcante de MPCs é sua capacidade em representar facilmente restrições rígidas durante o design e implementação do controlador (GARCÍA; PRETT; MORARI, 1989).Esta é a principal razão pela qual MPCs são tão amplamente utilizados na indústria.

Segundo Mayne et al. (2000), uma das características que distingue os MPCs de outros modelos de controle é sua natureza on-line, isto é, o modelo calcula uma decisão de controle a cada intervalo de amostragem do sistema. Isto contrasta com outros modelos de controle, que determinam todas as decisões para todos os estados do sistema, e por isso podem ser 
resolvidos off-line. Assim, a implementação de um MPC recai na modelagem de um problema de Programação Dinâmica, com a restrição de que o tempo computacional deve ser pequeno o suficiente para permitir o controle adequado do sistema.

(MAYNE et al., 2000) também enfatiza a importância que a estabilidade possui na modelagem de MPCs. Como um MPC se resume à resolução sequencial de múltiplos problemas de otimização malha aberta, deve-se prestar atenção à estabilidade das decisões, isto é, a decisão de controle retornada por um MPC deve minimizar as mudanças bruscas no estado do sistema. Os autores concluem que a teoria de estabilidade em MPCs está bem desenvolvida, ainda que maiores contribuições sejam bem vindas no caso de MPCs não lineares. Também são abordados os tópicos como robustez de MPCs (capacidade de absorver perturbações), retroalimentação e restrições suaves (que podem ser violadas eventualmente).

As técnicas mais comuns para controle de estruturas hidráulicas em sistemas de recursos hídricos, como as de barragens, são as regras de operação ou definição de regras de retroalimentação "off-line" através de programação dinâmica estocástica. Estas regras servem para definir abertura e lançamentos mínimos de forma garantir os níveis de água ou atenuar cheias e geralmente estão associados a controladores secundários para garantir um valor desejável no local como o caso dos controladores do tipo PID (Proportional-Integral-Derivative), também conhecidos como Controladores Proporcional Integral Derivativo, a um grande custo computacional. Estas técnicas funcionam bem em sistemas pequenos, mas conforme a complexidade de operação do sistema aumenta, este tipo de controle pode resultar em um controle sub-ótimo do sistema (SCHWANENBERG; BREUKELEN; HUMMEL, 2011).

Nestes casos onde o sistema é bastante complexo e observa-se alta interligação e interdependência entre os sistemas e/ou não é possível obter uma solução acessível através da programação dinâmica estocástica, aplica-se o MPC ou modelo de controle preditivo, que é um conceito de controle que utiliza modelos de processos para prever trajetórias futuras das variáveis controladas em um horizonte de previsão finito, de forma permitir um conjunto otimizado destas variáveis através de algoritmos de otimização. Uma parte integral deste conceito é a consideração explícita de restrições quanto aos dados de entrada, estados e dados de saída. Algumas considerações devem ser feitas sobre os mesmos SCHWANENBERG; BREUKELEN; HUMMEL, op. cit.

a) Os sitemas podem incluir componentes altamente não-lineares, em particular os relacionados às estruturas hidráulicas.

b) Se o controle de armazenamento for uma componente importante no MPC, o conflito entre os objetivos atuais e futuros podem exigir um modelo de previsão preciso sobre o horizonte de controle completo. 
c) Nem sempre existe um conjunto óbvio do sistema que permita linearização da dinâmica do sistema. $\mathrm{O}$ regime de vazão pode alterar em seus limites naturais.

A assimilação de dados é um fator fundamental para a implementação na prática destes controles, uma vez que contribui para a identificação do sistema off-line de redução de modelos internos de otimização de parâmetros e a assimilação de dados é utilizada na fase de operacional para atualização do modelo através da adaptação de parâmetros, estados ou resultados do modelo interno para melhoria da precisão do ciclo.

A MPC pode sofrer problemas computacionais, especialmente ao abordar problemas de gerenciamento de sistemas de grande escala para horizonte de controle de curto-prazo, que requer sequência de controle otimizada em um curto espaço de tempo. Nestes casos para melhorar a eficiência do MPC devem-se adotar sistemas de controle mais eficientes, mantendo controle centralizado e abordando as não linearidades e perturbações.

Uma série de métodos de controle podem ser utilizados para uma operação mais eficiente sistemas de reservatório; atender as descargas-alvo para otimizar a produção de energia e controlar o nível de água do reservatório, assim mitigar o impactos de inundações. Nesse sentido diferentes abordagens de algoritmos de controle podem ser aplicados: O feedback ( $F B$, também conhecido como circuito fechado) e Feedforward ( $F F$, também conhecido como open-loop).

Em uma aplicação em Noorderzijlvest no norte dos Países Baixos (SCHWANENBERG et al., 2012) utilizou-se MPC para otimizar um sistema de pôlderes, para controlar enchentes antecipando eventos de chuva através da previsão de vazão, além de reduzir custos de bombeamento utilizando prioritáriamente escoamento por gravidade e utilizado eletricidade somente a noite, quando as tarifas são mais baratas. Utilizando modelação adjunta (modelos hidrográficos), horizonte de previsão móvel para atualizar os estados dos modelos hidrológicos para previsão operacional de vazão e MPC, Schwanenberg et al. (2012) otimizou as descargas de um sistema de reservatório de grande escala com custo computacional bastante baixo.

Teoricamente, no $F B$ as variáveis são controladas e medidas diretamente, assim qualquer medida de controle e ações corretivas são alimentados de volta ao sistema, resultando em efeitos sobre os valores controlados para atender seus valores-alvo, enquanto que no $F F$ os efeitos são medidos ou previstos, a fim de determinar o controle e ações corretivas. Aplicando $F F$ permite redução dos efeitos de quaisquer perturbações nas variáveis, controladas, e aplicar o $F F$ é mais viável para reduzir as perturbações medidas nos valores-alvo. Na prática, uma vez que é difícil de medir todas as perturbações e prever o seu comportamento, o $F B$ pode ser mais eficaz do que o FF (SCHUURMANS, 1997).

De acordo com o Malaterre, Rogers e Schuurmans (1998) outras vantagens e desvanta- 
gens de cada técnica são: a limitação do FB nos casos em que as ações de controle apresentam atrasos de tempo e limitações do FF quando existem perturbações desconhecidas ou erros de estimativa e modelo. Portanto, ambas as técnicas podem ser aplicadas em conjunto; as grandes perturbações poderiam ser escaladas por FF e o efeito de distúrbios menores reduzidos por FB resultando em um sistema de controle muito preciso.

Outra maneira de resolver o problema de gestão de volumes reservatórios é de prever trajetórias futuras de estado em vez de operar com base em seu status atual e usar essas informações para computar uma estratégia de lançamento ideal em um horizonte de previsão de curto prazo. Esta técnica é referida como uma abordagem on-line e conhecida na engenharia de controle como MPC. Com ele é possível incorporar perturbações externas, tais como entradas de reservatório para o modelo de sistema e aplicar explicitamente restrições, por exemplo, para a elevação forebay (GARCÍA; PRETT; MORARI, 1989). A técnica recebe cada vez mais atenção para o gerenciamento de sistemas de água e tem sido aplicado por (OVERLOOP, 2006) (BLANCO et al., 2010), (KEARNEY; DOWER; CANTONI, 2011) (DELGODA; N.HALGAMUGE; MALANO, 2013), entre outros.

De acordo com o (MORARI; LEE, 1999), no MPC, estados do sistema futuros são calculados através de modelos internos. A diferença dos estados previstos e os seus pontos de ajuste para cada passo de tempo dentro de um período chamado horizonte de previsão são, então, incorporados em uma função objetiva. Esta função é usada como uma entrada, em conjunto com um conjunto de restrições, para definir um problema de otimização, cuja solução por um algoritmo de otimização representa o sistema de controle ótimo.

O MPC é especialmente útil para sistemas multi-usos e restrições problema desde múltiplas variáveis, por exemplo, níveis de água, descargas e produções hidroelétricas, pode ser facilmente acoplado na função objetivo usando fatores de ponderação que definem a importância de cada termo da otimização, enquanto que as restrições são dadas diretamente como entradas para o otimizador. Isso significa que se pode decidir como serão utilizadas estruturas hidráulicas tais como comportas, barragens e açudes, para diferentes fins, por exemplo, para produzir uma quantidade máxima de energia hidrelétrica, para manter um nível de água desejado no rio, ou para manter uma determinada vazão em um corpo d'água.

Então considerando um sistema de água arbitrário representado por:

$$
\begin{gathered}
x^{k}=f\left(x^{k-1}, x^{k}, u^{k}, d^{k}\right) \\
y^{k}=g\left(x^{k}, u^{k}, d^{k}\right)
\end{gathered}
$$


Onde $x, y, u, d$ são, respectivamente, o estado, variável dependente, controle de variáveis e vetor de perturbação e $k$ é a notação para o horizonte de tempo. As equações 6.1 e 6.2 são usados para prever trajetórias futuras do estado $x$ e variável dependente $y \mathrm{em}$ um horizonte de tempo finito representado por $k=1, \ldots, N$ instantes de tempo, para determinar o melhor conjunto de variáveis de controle $u$ usando um algoritmo de otimização. Assumindo que os futuros distúrbios que ocorrerão neste sistemas de água ao longo do horizonte de tempo são conhecidos, a formulação de MPC se torna:

$$
\min _{u, x^{*}} \sum_{k+1}^{N} J\left(x^{k}, y^{k}(x, u), u^{k}\right)+E\left(x^{N}, y^{N}(x, u), u^{N}\right)
$$

sujeito à

$$
\begin{gathered}
h\left(x^{*}(u), y^{k}(u), y^{k}(x, u), u^{N}\right) \leqslant 1, \ldots, N \\
x^{*, k}-f\left(x^{*, k-1}, x^{k}, u^{k}, d^{k}\right)=0
\end{gathered}
$$

onde $J()$ é uma função de custo associada a cada transição de estado, $E()$ é uma função custo adicional em relação às condições de estado final, e $h()$ são restrições duras sobre as variáveis de controle e estados, respectivamente. A notação $x^{*}$ refere-se a um subconjunto de variáveis de estado que se tornam variáveis de otimização independentes. Neste caso, o modelo de processo relacionado torna-se uma restrição de igualdade do problema de otimização em Equação 6.5 tal qual em uma otimização simultânea ou colocado configuração de otimização (XU; SCHWANENBERG, 2012).

O MPC define controle como um problema de otimização de uma função objetiva com um conjunto de restrições. Que podem ser restrições de desigualdade que limitam o intervalo de valores de controle, ou variáveis de estado ou também como restrições de igualdade que pode ser usadas para definir o modelo interno do sistema. No entanto, essas restrições de igualdade também podem ser implicitamente integradas na execução da função objetivo. Como explicado por (XU; SCHWANENBERG, 2012), os dois tipos de formulações MPC resultam da configuração específica: simultânea e sequencial. A primeira utiliza o modelo interno como uma restrição de igualdade da otimização enquanto o segundo se aplica simulação do modelo para cada iteração passo do otimizador na execução da função objetivo. Para sistemas de reservatório, que a abordagem sequencial é mais rápido do que o simultâneo uma vez que o número de variáveis no otimização é reduzido e a integração do modelo de processo é simples. 
Por motivos de desempenho, os otimizadores preferidos dentro do MPC geralmente recebem o gradiente da função objetivo em relação a cada variável de controle, o que reduz o tempo de computação tanto para aplicações simultâneas quanto para sequenciais.

Na abordagem simultânea, o cálculo do gradiente é simples , mas a abordagem sequencial requer diferenciação algorítmica do modelo de simulação através de procedimentos, tais como a diferenciação algorítmica ou, modelos adjuntos baseados na diferenciação algorítmica no modo reverso ou derivados por auxiliar formalismos como os multiplicadores de Lagrange (GRIENWANK; WALTHER, 2008).

\subsection{Diferenças entre MPC sequencial e simultâneo}

Para compreender a diferença entre um MPC sequencial de um simultâneo tomemos um exemplo onde consideramos um modelo simples de escoamento de reservatório como o modelo de processo interno. Sua esquematização explícita pode ser representada pela seguinte equação:

$$
h^{k}=h^{k-1}+\frac{\delta t}{A}\left(I^{k}-Q^{k}-f\left(h^{k-1}\right)\right)
$$

Onde $h$ é o nível de água; $\delta t$ a escala temporal; $A$ a área superficial; $I$ vazão de entrada; $Q$ vazão controlada de saída; $f()$ vertimento não controlado.

O vertimento é simulado como uma função de um vertedouro, conforme:

$$
f\left(h^{k-1}\right)=C \cdot B \cdot\left(h^{k-1}\right)^{1,5}
$$

Onde $C$ é o coeficiente do vertedouro e $B$ é a largura da estrutura hidráulica

Este processo é sujeito à seguinte restrição $0 \leqslant Q \leqslant Q_{\max }$ e a função objetivo a ser otimizada pode ser definida para cada espaço de tempo como:

$$
J=W_{k}\left(h^{k}-h_{s}\right)^{2}+W_{q}\left(Q^{k}-Q^{k-1}\right)^{2}
$$

Onde $h_{s}$ é o valor-alvo da altura da lâmina de água (profundidade), $W_{h}$ e $W_{q}$ Correspondem aos termos de ponderação atribuídos à profundidade e vazão.

De um modo mais geral, existe um número $n$ de termos de ponderação, e é conveniente que o resultado da incorporação deles em conjunto seja ao menos 1 ou que eles tenham um valor 
de referência que seja bem pensado para cada caso.

Assumindo que $h^{0}$ e $Q^{0}$ são dadas como condições iniciais, pode-se otimizar o sistema em dois espaços de tempo, e comparar os diferentes esquemas para MPC.

Um otimizador no qual o gradiente é introduzido pelo usuário é chamado de baseado no gradiente. $\mathrm{O}$ otimizador também pode calcular o gradiente da função objetivo e as próprias restrições por diferenciação numérica, embora esse processo seja mais demorado do que a primeira abordagem.

\subsubsection{MPC Simultâneo}

Em uma esquematização simultânea, o modelo interno é resolvido juntamente com a função objetivo pelo otimizador, assim como uma igualdade de restrição do problema de otimização. Portanto, tanto o nível como a liberação devem ser definidos como entradas no otimizador. As seguintes equações são dadas como entradas para o otimizador sob o esquema simultâneo. O modelo interno é geralmente dado por uma relação não linear entre a descarga e a profundidade da água, assim como no seguinte exemplo:

$$
\begin{aligned}
& J=\left[\left(h^{1}-h_{s}\right)^{2}+\left(Q^{1}-Q^{0}\right)^{2}\right]+\left[\left(h^{2}-h_{s}\right)^{2}+\left(Q^{2}-Q^{1}\right)^{2}\right] \\
& \left.\begin{array}{l}
C 1: 0=h^{1}-\left[h^{0}+\frac{\Delta t}{A}\left(I^{1}-Q^{1}-C \cdot B\left(h^{0}\right)^{1,5}\right]\right. \\
C 2: 0=h^{2}-\left[h^{1}+\frac{\Delta t}{A}\left(I^{2}-Q^{2}-C \cdot B\left(h^{1}\right)^{1,5}\right]\right.
\end{array}\right\} \\
& 0 \leq Q^{1} \leq Q_{\max } \\
& 0 \leq Q^{2} \leq Q_{\max }
\end{aligned}
$$

Então obtêm-se para este caso um total de 4 variáveis de controle a serem otimizadas, que será denominado vetor $U: h^{1}, h^{2}, Q^{1}, Q^{2}$. Caso se opte por um otimizador baseado em gradiente, a função objetivo e o gradiente de restrições das funções em relação a cada variável de controle precisam ser computado e dado como uma entrada adicional do otimizador. Portanto:

$$
\begin{gathered}
\frac{\partial J}{\partial U}=\left[2\left(h^{1}-h_{s}\right) 2\left(h^{2}-h_{s}\right) 2\left(Q^{1}-Q^{0}\right) 2\left(Q^{2}-Q^{1}\right)\right] \\
\frac{\partial C}{\partial U}=\left[\begin{array}{cccc}
1 & 0 & \frac{\Delta t}{A} & 0 \\
-1+\frac{\Delta t}{A} \cdot C \cdot B \cdot\left(1,5\left(h^{1}\right)^{0,5}\right) & 1 & 0 & \frac{\Delta t}{A}
\end{array}\right]
\end{gathered}
$$

Onde $C$ corresponde ao vetor de restrições definido no sistema anteriormente. Neste esquema as variáveis de controle são consideradas independentes para cada caso. 


\subsubsection{MPC Sequencial}

Em um MPC sequencial, a função objetiva incorpora o modelo interno. então as variáveis de controle são reduzidas para somente duas: $Q^{1}$ e $Q^{2}$. As entradas para o otimizador para este caso pode ser formulada da seguinte forma:

$$
\begin{aligned}
& J=\left[\left(\tilde{h}^{1}-h_{s}\right)^{2}+\left(Q^{1}-Q^{0}\right)^{2}\right]+\left[\left(\tilde{h^{2}}-h_{s}\right)^{2}+\left(Q^{2}-Q^{1}\right)^{2}\right] \\
& 0 \leq Q^{1} \leq Q_{\max } \\
& 0 \leq Q^{2} \leq Q_{\max }
\end{aligned}
$$

Desta forma pode-se definir o modelo dentro da função objetivo para calcular os valores correspondentes de $\tilde{h}^{1}$ e $\tilde{h}^{1}$. Então assim função objetivo é redefinida como:

$$
\begin{aligned}
& j=\left[\left(v-h_{s}\right)^{2}+\left(Q^{1}-Q^{0}\right)^{2}\right]+ \\
& \left((v)+\frac{\Delta t}{A}\left(I^{2}-Q^{2}-C \cdot B \cdot\left(v^{1,5}\right)-h_{s}\right)^{2}\right)^{2}+\left(Q^{2}-Q^{1}\right)^{2}
\end{aligned}
$$

onde :

$$
v=h^{0}+\frac{\Delta t}{A}\left(I^{1}-Q^{1}-C \cdot B \cdot\left(h^{0}\right)^{1,5}\right)
$$

Então como pode-se observar, através do MPC sequencial é possível reduz o número de variáveis a serem otimizadas e que esta técnica se concentra apenas nas variáveis de controle, não havendo desta forma a necessidade de realizar iterações sobre as variáveis de estado (profundidades de água neste exemplo). De forma similar ao MPC simultâneo, um esquema baseado em gradiente pode ser introduzido fornecendo o gradiente da função objetivo em relação às variáveis de controle. Tais equações são descritas abaixo:

$$
\begin{aligned}
& \frac{\partial J}{\partial Q^{1}}=2\left(h^{1}-h_{S}\right) \frac{\partial h^{1}}{\partial Q^{1}}+2\left(Q^{1}-Q^{0}\right)+2\left(h^{2}-h_{s}\right) \frac{\partial h^{2}}{\partial Q^{1}}+2\left(Q^{2}-Q^{1}\right) \\
& \frac{\partial J}{\partial Q^{2}}=2\left(h^{2}-h_{s}\right) \frac{\partial h^{2}}{\partial Q^{2}}+2\left(Q^{2}-Q^{1}\right)
\end{aligned}
$$

As derivadas da profundidade da água em relação às variáveis de controle se tornam então:

$$
\begin{aligned}
& \frac{\partial h^{1}}{\partial Q^{1}}=\frac{\Delta t}{A} \\
& \frac{\partial h^{2}}{\partial Q^{1}}=\frac{\partial h^{2}}{\partial h^{1}} \frac{\partial h^{1}}{\partial Q^{1}}=\left(1-\frac{\Delta t}{A} \cdot C \cdot B \cdot 1,5\left(h^{1}\right)^{0,5}\right) \frac{-\Delta t}{A} \\
& \frac{\partial h^{2}}{\partial Q^{2}}=0 \\
& \frac{\partial h^{2}}{\partial Q^{2}}=\frac{-\Delta t}{A}
\end{aligned}
$$




\subsection{Aplicação na Operação de Reservatórios}

O Sistema Interligado Nacional (SIN), devido à sua complexidade, foi objeto de múltiplos estudos com o intuito de otimizar sua operação. É natural que a aplicação de MPCs à operação de reservatórios tenha precedente no Brasil.

Marques, Cruz e Vinhal (2010) apresenta uma metodologia baseada em MPCs para a otimização do despacho hidrotérmico (hydrothermal scheduling). Esta se baseia nas informações de um previsor de vazões para definir a política operativa ótima do Sistema Interligado Nacional (SIN). Este tipo de problema geralmente é analisado através de programação estocástica, mas neste caso o Controle Preditivo permite considerar a incerteza através de previsões. Isto permite adotar uma modelagem similar à da otimização determinística, evitando as complexidades inerentes aos modelos de otimização estocástica (LABADIE, 2004).

Assim, em conformidade com as premissas dos MPCs, a política operativa é baseada num processo adaptativo de tomada de decisões, onde a cada intervalo de tempo as decisões são tomadas pelo algoritmo de otimização alimentado pelas previsões de afluências futuras. $\mathrm{O}$ procedimento de previsão/otimização é repetido a cada intervalo do horizonte de planejamento visando minimizar os desvios na trajetória ótima dos reservatórios provocados pelos erros entre os valores previstos e verificados.

Na Figura 13 apresenta as variáveis envolvidas no Controle Preditivo: $q_{t}, P_{t}, x_{t}$ e $y_{t}$ são definidas respectivamente como variável de controle (vazão turbinada), saída do sistema (geração hidrelétrica), variável de estado (armazenamento do reservatório) e entrada do sistema (vazão afluente); no intervalo de tempo $t$. O previsor de vazões fornece $\hat{q}_{t}$ é então avaliada por simulação, e se passa do intervalo de tempo $t$ para $t+1$.

O princípio do Controle Preditivo quando aplicado ao despacho hidrotérmico é ilustrado na Figura 14. No intervalo de tempo $t$ o previsor gera uma sequência de $T$ vazões afluentes previstas, e baseado nesta informação o otimizador calcula as ações de controle futuras para atender a demanda minimizando o custo da complementação termoelétrica. Somente a primeira decisão de controle $\left(q_{t}\right)$ é implementada até o próximo intervalo de tempo, quando todo o processo é repetido com base nas novas informações observadas. Este modo de operação minimiza os erros de operação em usinas hidrelétricas provocados pelos erros de previsão de vazões. Esta formulação foi expandida e explorada em Marques (2006) e Zambelli et al. (2011).

A aplicação de MPCs ao despacho hidrotérmico, um problema de planejamento de médio/longo prazo, é fundamentada no trabalho de Martinez e Soares (2002). Este trabalho contrasta a abordagem malha fechada (closed-loop) usualmente adotada na otimização do despacho com uma abordagem malha aberta (partial open-loop). 


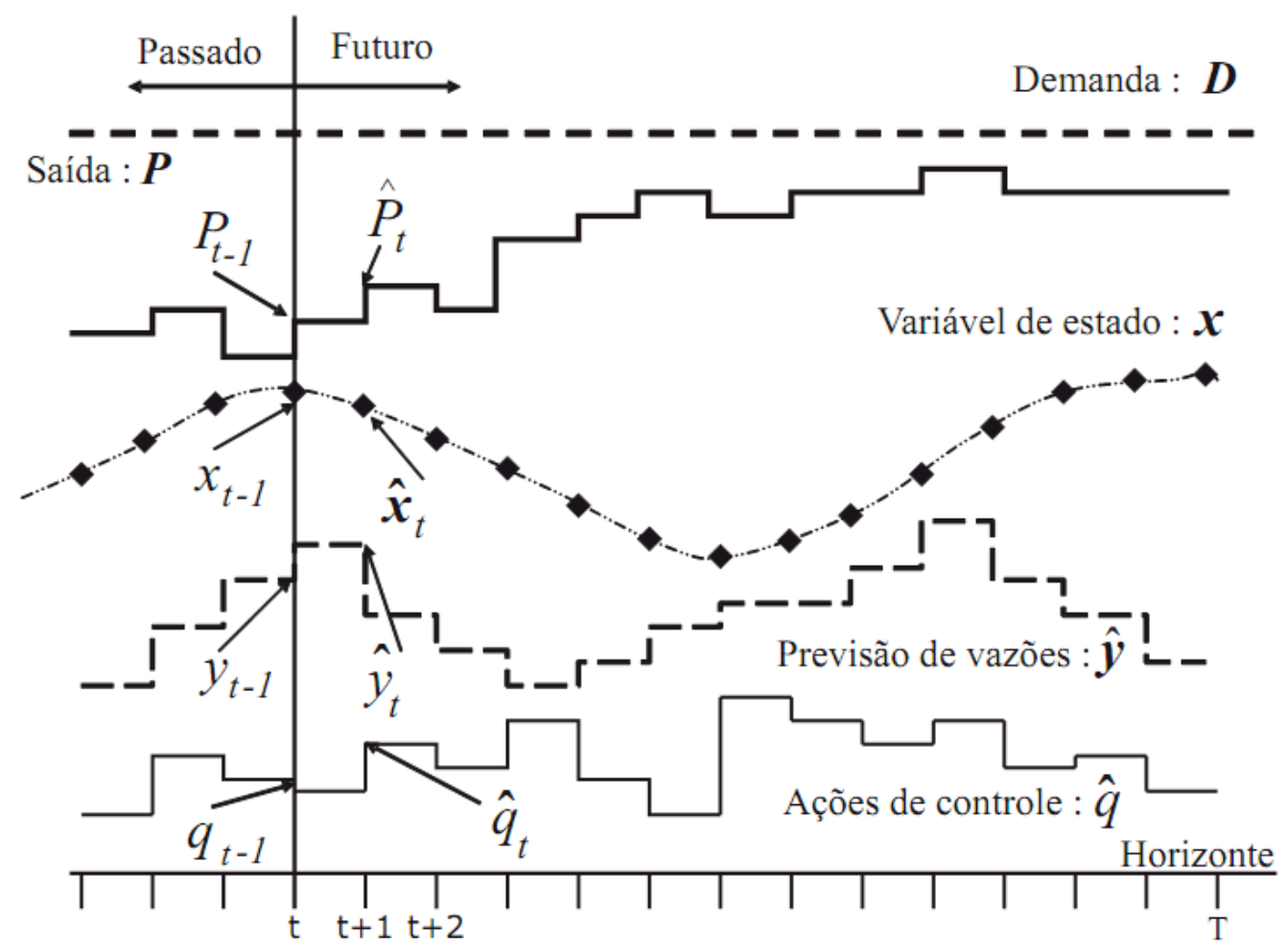

Fonte: Marques, Cruz e Vinhal (2010)

Figura 13 - Variáveis de um Modelo de Controle Preditivo para a otimização do despacho hidrotérmico

À primeira vista, uma abordagem malha fechada é mais robusta, pois esta fornece não apenas valores numéricos ótimos, mas sim uma função para determinar os valores ótimos com base no estado do sistema. No entanto, os autores enfatizam que a abordagem malha fechada é limitada pela "maldição da dimensionalidade", isto é, na explosão combinatória de estados a avaliar quando se faz uso de séries sintéticas (no caso do despacho hidrotérmico, séries de afluências hidrológicas). Algoritmos malha fechada são então forçados a adotar simplificações como a agregação em reservatórios equivalentes. Estas simplificações introduzem erros de modelagem que reduzem a qualidade dos resultados.

Os autores analisam como alternativa o uso de open-loop feedback control, onde a incerteza anteriormente modelada como séries temporais fica implícita por modelos de previsão. O Controle Preditivo é um exemplo de modelo que usa esta abordagem. O desafio é que a previsão de vazões em escalas maiores que o mês é bastante difícil para o Brasil. Ainda assim, os autores determinaram através de experimentos numéricos que uma abordagem malha aberta é mais eficiente em períodos de seca. O modelo malha fechada apresenta algumas vantagens quando são simuladas séries de afluência sintéticas.

No entanto, no presente projeto espera-se trabalhar com modelos de operação em condição de cheia, cujos horizontes de planejamento tendem a ser menores que os horizontes 


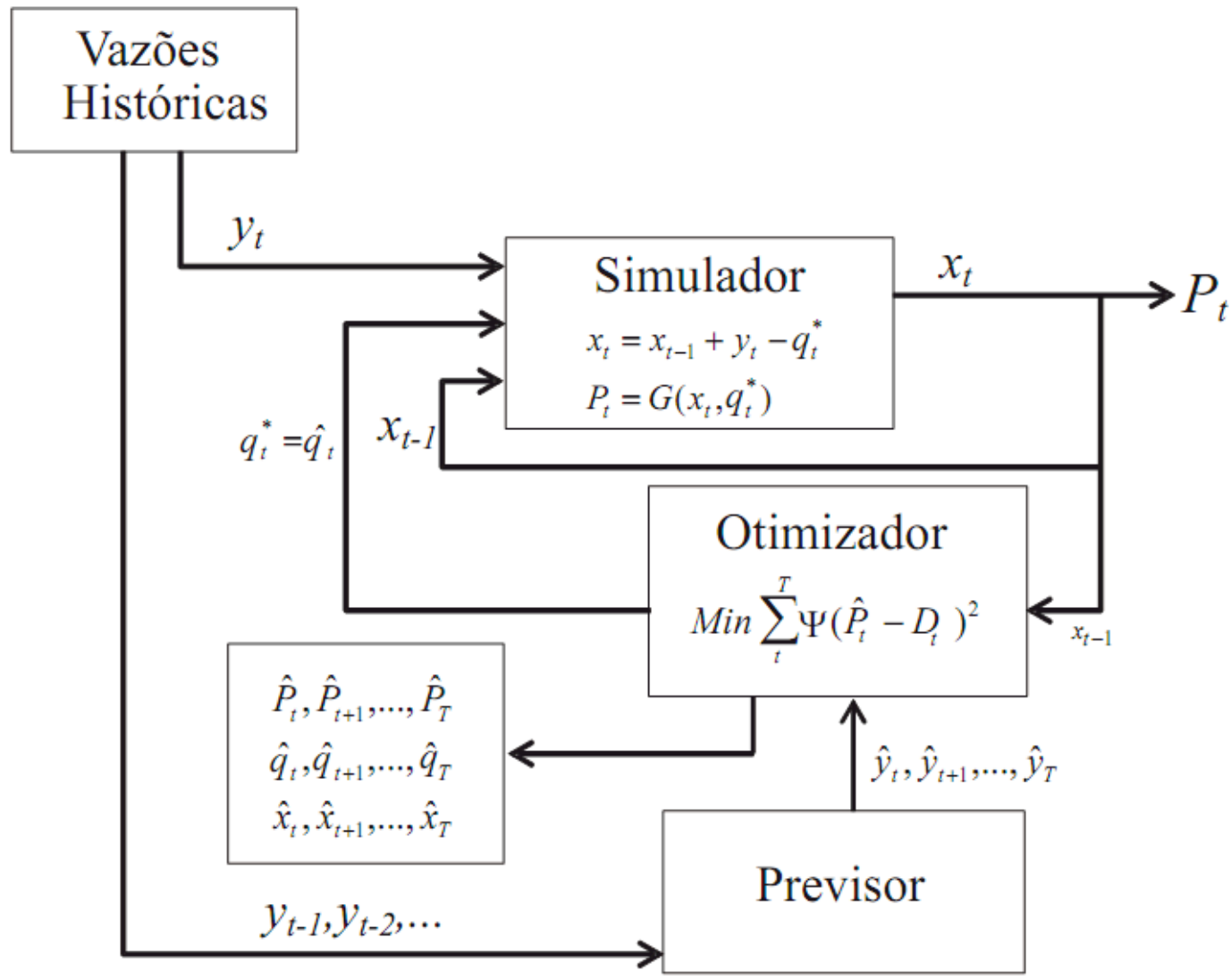

Fonte: (MARQUES; CRUZ; VINHAL, 2010)

Figura 14 - Princípio do Controle Preditivo aplicado ao despacho hidrotérmico

plurianuais do despacho hidrotérmico. Com um horizonte reduzido, é possível melhorar a qualidade da previsão de vazões, e neste caso uma abordagem malha aberta é claramente preferível. Assim, a adoção de MPCs na otimização da operação em condições de cheias é justificada.

Em um MPC os valores futuros para um sistema de espaço de estados são computados nos chamados modelos internos. A diferença entre a previsão dos estados e os valores alvo para cada espaço de tempo dentro do período chamado como horizonte de previsão são então incorporados em uma função objetivo. Esta função é usada como entrada de dados, em conjunto um grupo de restrições para o sistema, que definem o problema de otimização para qual a solução através de um algoritmo de otimização representa o controle ótimo do sistema.

O MPC é especialmente útil quando é necessário lidar com sistemas com múltiplas variáveis e problemas com restrições uma vez que vaiáveis múltiplas, como por exemplo níveis de água, vazões de saída e geração hidrelétrica podem ser facilmente integradas à função objetivo usando fatores de ponderação para definir a importância de cada termo na otimização, enquanto que as restrições podem ser integradas diretamente como entradas do otimizador. O que significa que é possível determinar como operar as estruturas hidráulicas, como as comportas hidráulicas, 
barragens e vertedouros, para diferentes fins como por exemplo, para produzir uma quantidade máxima de energia hidráulica, manter um nível de água desejado no rio ou manter uma dada descarga de um rio.

Diferentes tipos de modelos internos para MPC foram utilizados para aplicaçoes de recursos hídricos. O modelo Integrator Delay (ID)desenvolvido por Schuurmans et al. (1999), que também vou utilizado por Overloop (2006), Şahin e Morari (2009), Clemmens et al. (2012) se mostra vantajoso uma vez que possuí o recurso de considerar o retardamento temporal da propagação da onda.

Uma abordagem para um modelo hidráulico mais completo foi aplicada por outros autores como Glanzmann et al. (2005), que utilizou um modelo linearizado baseado nas ESV, desenvolvido por Chapuis (1998), que aplicou o MPC e um trecho de rio com hidrelétricas operando em cascada. Chiang, Wilems e Berlamont (2010) utilizou a versão totalmente dinâmica das ESV para calibrar e comparar os resultados obtidos por um modelo simplificado conceitual baseado em uma abordagem do tipo de reservatório, no qual foi utilizado para controle em tempo real de cheias para o rio Demer na Bélgica. A vantagem destes modelos é que eles são capazes de reproduzir o comportamento dinâmico do sistema. No entanto, estes modelos podem também implicar em um aumento significativo de esforço computacional para executar os processos iterativos do otimizador. Schwanenberg et al. (2012) é proposto utilizar um modelo de ondas difusivas para os sistemas de polderes na região de planície Holanda, que representa uma simplificação a simulação mantendo algumas das características dinâmicas e desta maneira obtendo uma resposta rápida necessária para um sistema controle em tempo real.

Os Modelos internos para MPC precisam ser precisos o suficiente para simular o processo de roteamento e refletir o comportamento dinâmico do sistema. No entanto, eles também devem ser mantidos tão simples quanto possível, a fim de evitar grande tempo computacional dentro das rotinas de otimização, preservando a robustez no processo de iteração. Os esforços para melhorar o desempenho incluem o uso de otimizadores baseados em gradiente, o que implicará em requisitos adicionais para a esquematização e implementação do modelo. $\mathrm{O}$ uso de um modelo adjunto para a computação do gradiente da função objetivo foi implementado por Schwanenberg, Verhoeven e Boogaard (2010) e aplicado no rio Reno, que se mostrou altamente eficiente na resolução de modelos não-lineares. Ding e Wang (2006) também usaram uma abordagem semelhante para obter os gradientes para módulos de otimização baseados em algoritmos de memória limitada semi-Newton.

\subsection{Modelo Adjunto - Otimizador}

Neste capitulo será explicado a ideia por trás do modelo adjunto do reservatório e como o otimizado selecionado para este trabalho resolve o problema de operação de reservatórios. 
Em um MPC simultâneo o modelo interno será declarado como uma igualdade de restrição definida pela Equação 6.5, já para um MPC Sequencial utiliza a simulação dos estados dentro da função objetivo conforme a as equações 6.1 e 6.2. Em Xu e Schwanenberg (2012) é demonstrada uma abordagem sequencial para sistemas reservatórios que se mostrou mais rápida que a simultânea, uma vez que o número de variáveis na otimização é reduzido e a integração do modelo de processos é feita diretamente.

Por motivos de desempenho, os otimizadores preferencialmente recebem o gradiente da função objetivo em relação a cada variável de controle dentro do MPC. Desta forma é possível reduzir o tempo de computação tanto para o o método simultâneo quanto para o sequencial. Enquanto que o cálculo do gradiente é feito diretamente na abordagem simultânea, na abordagem sequencial é necessário uma diferenciação algorítmica do modelo de simulação por procedimentos como a diferenciação algorítmica de modo posterior ou modelos adjuntos baseados na diferenciação algorítmica em modo reverso ou derivados através formalismos auxiliares como multiplicadores lagrangianos (GRIENWANK; WALTHER, 2008).

\subsection{IPOPT - Interior Point Optimizer}

IPOPT ou Interior Point Optmizer é um pacote de software open-source para otimização não linear de grande escala, sendo utilizado para problemas gerais de programação não-linear Wächter e Biegler (2006), Wächter (2009).

Um modelo simples pode fornecer uma precisão suficiente para a gestão de curto prazo. sendo apresentado pela seguinte forma:

$$
\begin{gathered}
\min _{x \in \mathbb{R}^{n}} f(x) \\
g_{L} \leq g(x) \leq g_{U} \\
x_{L} \leq x \leq x_{U}
\end{gathered}
$$

Onde $x \in \mathbb{R}^{n}$ são as variáveis de otimização com limites superiores e inferiores, respectivametne $x_{U}$ e $x_{L}$ e $f(x)$ é a função objetivo e $g$ são as constantes. Sendo que:

$$
x_{U} \in(\mathbb{R} \cup+\infty)^{n}
$$


$x_{L} \in(\mathbb{R} \cup-\infty)^{n}$

$f^{n}: \mathbb{R} \rightarrow \mathbb{R}$

$$
g^{n}: \mathbb{R} \rightarrow \mathbb{R}^{m}
$$




\section{Numerical Weather Prediction}

Em Shuman (1989) mostra que as técnicas de Numerical Weather Prediciton (NWP), vem sido aperfeiçoadas constantemente desde a década de 1960, e está diretamente vinculado com o desenvolvimento do poder de processamento e dos supercomputadores, muitos dos cálculos dos modelos conceituais iniciais, tomavam muito tempo para serem resolvidos mesmo com auxílio de supercomputadores. Somente recentemente este tipo de técnica se tornou mais acessível e confiável.

Um Ensemble Prediction System (EPS) pode ser definido como sendo um sistema de NWP, que permite estimar as incertezas em uma previsão climática, bem como a previsão climática mais provável. Ao invés de executar o NWP uma única vez (previsão determinística), o modelo é executado diversas vezes variando as condições iniciais ligeiramente. Em alguns casos os modelos físicos podem também ser ligeiramente modificados: No caso dos EPS multimodelos são empregados mais de um modelo no ensembles; e para o EPS multifísico utilizam-se diversas combinações de esquemas de parametrização física. Então o EPS é formado por diversas soluções sendo que cada solução individual NWP que o compõe é denomina membro do ensemble

Devido ao custo tanto financeiro quanto computacional para executar um NWP diversas vezes, o EPS geralmente é gerado com metade da resolução espacial ao NWP equivalente determinístico. O EPS geralmente inclue uma previsão controle, que utiliza a mesma resolução de um modelo ensemble mas sem quaisquer perturbações e alterações incorporadas à análise ou modelo (ECWMF, 2015).

A gama de soluções distintas fornecidas em uma previsão, permite avaliar a incerteza dela, e quão fidedigna é a previsão determinista. As incertezas podem variar bastante de um dia para outro por causa da situação sinótica; e a abordagem EPS permite realizar uma estimativa destas incertezas. O EPS é projetado para provar a função de distribuição de probabilidade de uma previsão climática, e muitas vezes é usado para produzir previsões de probabilidade, que serão usadas para avaliar a probabilidade de que os resultados irão ocorrer (WORLD METEOROLOGICAL ORGANIZATION, 2012).

\subsection{Previsão Estocástica x Previsão Determinísitica}

De acordo com Gneiting e Raftery (2005) ocorreu durante as últimas décadas uma mudança radical em relação a utilização e emprego de NWP (Numerical Weather Prediction). Até o início dos anos 90, as previsões para estados atmosféricos futuros eram geradas a partir de 
modelos de predição climática determinística, os quais cuidadosamente desenvolvidos para este fim em centros meteorológicos e utilizando sofisticados recursos computacionais (e até mesmo com supercomputadores).

Até então os pesquisadores da área entendiam que a previsão climática era uma tarefa intrinsecamente determinística, onde a melhor previsão climática era resultado do único e melhor conjunto dados iniciais. Muito embora previsões de tempo determinística ainda sejam largamente utilizadas, a previsão climática foi transformada com o advento de técnicas estocásticas.

Os modelos atmosféricos estocásticos apresentam vantagens em relação aos modelos determinísticos tradicionais, como por exemplo, o uso de previsões probabilísticas combinadas com a otimização estocástica multifásica é vantajosa em comparação com uma abordagem determinística para gerenciamento com horizonte de previsão de curto prazo para reservatórios porque as previsões probabilísticas muitas vezes mostram uma habilidade melhor e estão disponíveis para horizontes mais longos, o que permite detectar eventos críticos com maior antecedência e assim antecipar melhor os impactos e ações mitigadores através de decisões mais precoces; outra vantagem das previsões probabilísticas está na propagação das incertezas de previsão através do processo de tomada de decisões e sua visualização pelos stakeholders (SCHWANENBERG et al., 2015).

No entanto conforme as escalas temporais aumentam, como no caso das simulações de médio a longo prazo, estes modelos começam a apresentar deficiências e limitações, devido ao comportamento não-linear e caótico dos processos atmosféricos, então conforme a escala temporal avança observa-se um aumento dos erros nas condições iniciais (LORENZ, 1963; LORENZ, 1965).

Estas variações e erros podem resultar em previsões improváveis ou mesmo pouco factíveis, portanto uma forma de tratar os erros e variações gerados pelas condições iniciais e/ou mesmo por uma representação numérica inadequada utilizam-se as previsões por conjunto também conhecidas como ensembles.

Outro ponto importante que é discorrido em ECWMF (2015), é a importância na emissão de previsões de tempo confiáveis para qualquer serviço meteorológico durante condições meteorológicas normais, uma vez que estas constroem a confiança com o público; desta forma, ao criar confiança na capacidade do serviço de meteorologia em realizar previsões corretas em condições climáticas normais, cria-se naturalmente uma maior confiança mesmo nas previsões probabilísticas em casos de condições meteorológicas extremas. Porém há também necessidade de manter a consistência nas previsões durante o tempo, pois previsões precipitadas e instáveis tendem a minar a confiança pública, principalmente quando associadas a um evento extremo, já que uma previsão ruim para 5 dias só será identificada como tal, após os cinco dias, mas no caso 
de uma previsão precipitada será identificada imediatamente.

Muito embora haja uma certa necessidade de um NWP ser até certa medida "precipitado", não há necessidade nenhuma para transmitir essa informação "precipitada"ao público, baseado somente no resultado determinístico mais recente. A melhor maneira de evitar isto é através da informação sobre a incerteza da previsão, que pode ser melhor avaliado nas previsões estocásticas. As previsões estocásticas tem a vantagem de transmitir mais informações do que as previsões determinísticas simples, mas os meteorologistas podem ás vezes paradoxalmente ajudar os usuários finais das previsões ao não emitir previsões que contenham muita incertezas ECWMF, op. cit..

\subsection{Ensembles}

A geração elétrica das usinas termoelétricas é mais previsível, podendo ser programadas com maior facilidade, já que é possível aumentar ou diminuir a geração através do controle da alimentação do combustível dos geradores. Mas para usinas de fonte renováveis como o caso das hidroelétricas e geradores eólicos, não é possível realizar este controle da geração, uma vez que as fontes energéticas dos geradores estão sujeitas às incertezas decorrentes da variação temporal, espacial e climática das mesmas.

Em sistemas hidrodinâmicos o comportamento de fluxo pode apresentar padrões estacionários, ou mesmo com oscilações em períodos regulares, no entanto existem alguns padrões que apresentam uma variação irregular, que mesmo após observação de longos períodos não é possível identificar padrões de repetição. Estes casos podem ser determinados como não-periódicos.

Principalmente quando os padrões são periódicas ou não variam com o tempo, é possível obter soluções particulares de maneira analítica, porém geralmente as soluções para eventos nãoperiódicos não podem ser obtidas facilmente via procedimentos numéricos, para tanto sistemas finitos de equações determinísticas não-lineares ordinárias podem ser atribuídas para representar a dissipação do sistema. As soluções destas equações podem ser identificadas através de uma trajetória no espaço físico. Para estes sistemas com soluções delimitadas, é observado que as soluções não-periódicas são instáveis e sensíveis a pequenas mudanças nos estados iniciais do sistema (LORENZ, 1963).

Através do sistema de equações de convecção 7.1, proposto inicialmente por LORENZ, op. cit., é possível ilustrar como esses efeitos de baixa frequência influenciam a trajetória da 
função atmosférica considerando uma pequena modificação ao modelo.

$$
\left.\begin{array}{r}
\dot{x}=-\sigma x+\sigma y+f, \\
\dot{y}=-x z+r x-y-f, \\
\dot{z}=x y-b z,
\end{array}\right\}
$$

Onde

$$
\begin{array}{r}
\tau=\pi^{2} H^{-2}\left(1+a^{2}\right) k t \\
r=R_{e}^{-1} R_{a}, \\
R_{a}=g a H^{8} \Delta T v^{-1} k^{-1}, \\
R_{e}=\pi^{4} a^{-2}\left(1+a^{2}\right)^{3}, \\
b=4\left(1+a^{2}\right)^{-1}
\end{array}
$$

No sistema $7.1 \dot{x}, \dot{y}$ e $\dot{z}$ são derivadas em relação a uma escala de tempo $\tau$ adimensional (Equação 7.2), $H$ é a profundidade, $g$ é aceleração da gravidade, $a$ coeficiente de expansão térmica, $v$ viscosidade cinemática, $k$ condutividade térmica, $r$ é o número de Prandtl definido conforme 7.3 e $b$ conforme 7.4 .

Considerando que $f$ é considerado um forçamento atmosférico que está variando em uma escala de tempo longa, ou seja representa a evolução temporal de um evento atmosférico. Neste ao variar ligeiramente o valor de $f$ no sistema 7.1, mesmo para valores fixos de $x, y, z, r \mathrm{e}$ $b$ é esperado que haja uma grande variação nos estados finais ou resultados.

A Figura 15 mostra a escala temporal da componente $x$ para diferentes valores de $f$, averigua-se que o modelo é caótico e sensível aos valores iniciais, mas é claro que $f$ tem um efeito previsível na probabilidade do vetor encontrar-se em um dos regimes de Lorenz. Na prática o $f$ pode representar alguma variável do sistema atmosférico com variação lenta como o El Niño, a circulação termohalina ou efeitos dos gases estufa (PALMER et al., 2005).

A previsão climática por conjuntos ou por ensembles conforme dito anteriormente é uma previsão estocástica, eles consistem de múltiplos resultados (geralmente entre 5 e 100) de modelos NWPs. Cada resultado é gerado através variações em suas condições iniciais (LEITH, 1974; HOFFMAN; KALNAY, 1983) e/ou representação numérica da atmosférica diferentes 

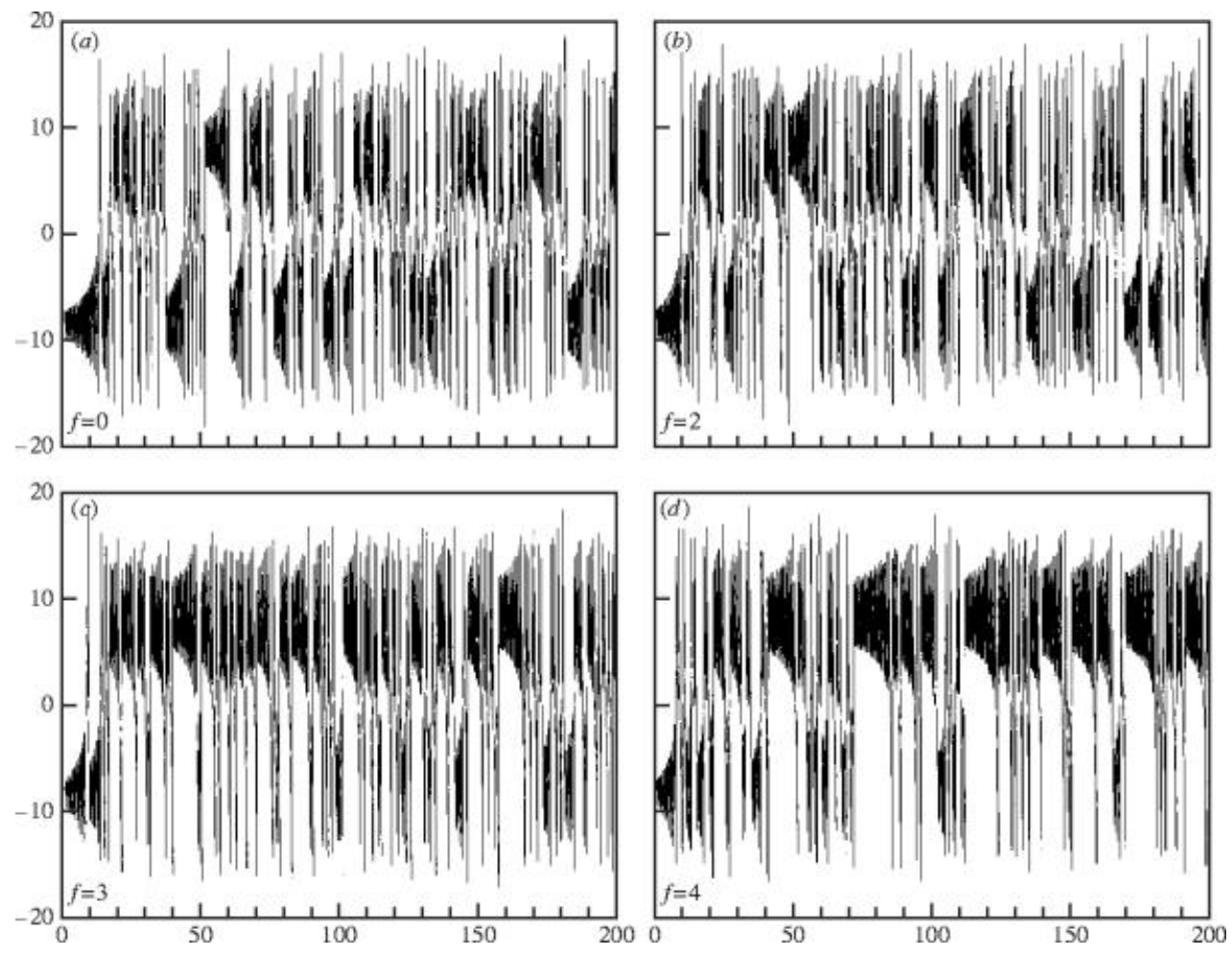

Fonte: Palmer et al. (2005)

Figura 15 - Impacto de um forçamento externo $f$, no estado do vetor do modelo de Lorenz (1963). (a) $f=0$, (b) $f=2$, (c) $f=3$ e (d) $f=4$.

entre si (STENSRUD; WEISS, 2002), ou ainda, previsões a partir de um conjunto de modelos distintos (ZHANG; KRISHNAMURTI, 1999; HOU; KALNAY; DROEGEMEIER, 2001).Desta forma é possível abordar as duas maiores fontes de incertezas nas previsões, que são justamente os dados de entrada, representações numéricas ou no modelo.

Esta técnica é bastante versátil sendo citadas na literatura internacional diferentes abordagens de aplicação. Os ensembles multimodelos, consiste de um conjunto de modelos com diferentes versões de parametrizações físicas (e/ou difusão), que se mostra superior quando comparado com modelos individuais. Conforme Krishnamurti et al. (2000) a capacidade desta técnica supera as dos modelos convencionais, uma vez que a trajetória da função da análise multi-modelo tende a apresentar valores mais próximos dos dados observado.

Outra forma de aplicação descrita por Taylor e Buizza (2003) descreve uma previsão para o intervalo de até 10 dias futuros para demanda elétrica utilizando 51 cenários para cada componente de demanda elétrica em comparação com a técnica padrão de um ponto para cada 
variável climática no modelo de demanda. Visto que a demanda é uma função não-linear de variáveis climáticas, o modelo convencional consiste em aproximar uma função não-linear de variáveis aleatórias por uma função não-linear dos mesmos valores previstos pelo modelo de simulação de incertezas de variáveis aleatórias. A técnica de 51 cenários é mais eficiente porque seria o equivalente a pegar os valores esperados de uma estimativa da função de densidade de probabilidade de demanda, esta técnica no entanto não contempla incertezas do modelo de demanda.

Para obter todo o potencial de uma previsão ensemble é necessário realizar pós-processamento estatístico dos resultados do modelo a fim de corrigir os vieses e representações insatisfatórias das incertezas da previsão. Junto com este pós-processamento estatísticos, estas previsões estocásticas fornecem previsões probabilísticas fluxo-dependentes através de distribuições probabilísticas para horizontes futuros.

A aptidão de um NWP em realizar previsões precisas é fluxo-dependente, ou seja, para melhorar a precisão de um ensemble deve-se Identificar as configurações de fluxo atmosféricos e quantificar a sensibilidade dos NWPs a estes eventos é relevante para a interpretação da previsão e desenvolvimento dos modelos.

As previsões probabilísticas permitem quantificar riscos relacionados ao clima, e para uma ampla gama de aplicações como geração elétrica, planejamento de rotas de aviões e navios, estudos financeiros de riscos climáticos; eles têm uma maior utilidade do que as previsões determinísticas (GNEITING; RAFTERY, 2005).

Os atuais desafios incluem representação das incertezas de previsão devido ao uso de modelos numéricos não otimizados. Estass incertezas podem ser abordadas através do emprego de ensembles multimodelos, no qual cada simulação é determinística; ou através de representações estocásticas de processos físicos parametrizados, conforme empregado no ensemble de médio prazo do ECMWF (European Centre for Medium-Range Weather Forecasts), desta forma introduzindo aleatoriedade nas simulações dos modelos.

É necessário também melhorias na comunicação, visualização e avaliação de previsões probabilísticas. Há também necessidade de reconciliar as diferentes interpretações da probabilidade, para evitar o risco aperfeiçoamento das metodologias de ensemble sem um objetivo claro. Por isso existe o paradigma de maximizar a nitidez das previsões probabilísticas através de restrições de calibração pode oferecer alguma orientação.A Calibração refere-se à consistência estatística entre as previsões probabilísticas e os dados observados; nitidez refere-se ao espalhamento ou grau de propagação das distribuições preditivas. O objetivo é aumentar a nitidez nas previsões, sem comprometer a validade das afirmações probabilísticas.(GNEITING; RAFTERY, 2005) 
Em Molteni et al. (1996), Buizza et al. (2005) as previsões quantitaticas de precipitação ou QPF (Quantitative Precipitation Forecasts) do EPS globlal do ECMWF são utilizadas como forçamento meteorológicos do modelo de previsão hidrológica. Os dados desta avaliação obtidos a partir dos portais THORPEX (The Observing System Research and Predictability Experiment) e TIGGE (Interactive Grand Global Ensemble) (BOUGEAULT et al., 2010). Em estudo de Fan et al. (2014) os ensembles do ECMWF mostraram melhor aptidão para a Bacia de Rio São Francisco em comparação com os NWP do NOAA e CPTEC .

As previsões EPS do ECMWF consistem de 50 membros de preciptação perturbada de 0,5 graus de resolução para todo o globo considerando incertezas iniciais através do uso de vetores singulares e modelos de incertezas devido a parametrizações físicas através de um esquema estocástico (BUIZZA et al., 2007). As informações são disponibilizadas duas vezes ao dia com um horizonte de previsão de 15 dias e escala temporal de 6 horas. Para aplicabilidade em modelo hidrológico, é necessário reduzir a escala espacial através de polígonos de Thiessen e desagrega-los para uma escala temporal horária. Como referência e comparação entre resultados determinísticos e probabilísticos, nós também consideramos a previsão probabilística do ECMWF, que também está disponível no portal TIGGE.

Os EPS globais do ECMWF são geralmente projetados e utilizados em previsões de médio-prazo (Horizonte de Previsão de 3-15 dias à frente). Eles utilizam NWP globais e são executados utilizando resoluções espaciais relativamente baixas com malhas variando entre $30 \mathrm{~km}$ e $70 \mathrm{~km}$. Apesar de serem concebidos com objetivo principal para previsões de médioprazo, devido ao fato que este produto está disponível para todas regiões do globo, em regiões onde não exista outro produto disponível,é possível aplica-lo para previsões de curto-prazo. Justamente por esta ser a situação de muitos países-membros da WMO (World Meteorological Organization), neste contexto, eles são usados extensivamente para gerar produtos de apoio em diversos projetos como o Severe Weather Forecasting Demonstration Project (SWFDP), (WORLD METEOROLOGICAL ORGANIZATION, 2012).

\subsubsection{Dispersão do Ensemble}

Justamente como foi explicado na seção 7.2, devido ao comportamento não-linear e caótico dos processos atmosféricos existem uma tendência de grandes desvios das trajetórias das previsões climáticas, conforme a escala do tempo avança mesmo quando as condições iniciais são ligeiramente entre si. Este comportamento de todos os membros do EPS de mudar de comportamento conforme o tempo avança é conhecida como a dispersão do ensemble.

Então a dispersão de um ensemble é definida como uma medida da diferença entre os membros e é representada pelo desvio padrão em relação ao ensemble médio (EM)(ECWMF, 2015; WORLD METEOROLOGICAL ORGANIZATION, 2012). Geralmente uma dispersão 
pequena indica uma alta precisão a priori da previsão enquanto que uma dispersão alta indica um baixa precisão a priori da previsão. A dispersão também fluxo-dependente e varia para os diversos parâmetros. Normalmente há uma tendência de aumentar conforme o horizonte de previsão, mas podem existir casos onde a dispersão está maior em horizontes menores em relação a horizontes maiores, isto pode ser explicado pelo fato que os primeiros dias apresentam uma grande influência de complexas relações e estruturas dos sistemas sinóticos, mas que no entanto serão seguidos por uma grande predominância de sistemas de alta pressão e de tempo bom.

A dispersão de um EM como medida da precisão a priori é aplicada somente para o erro da previsão do EM, não para mediana, controle ou HRES, mesmo no caso deles estarem dentro do horizonte de precisão do ensemble. A dispersão do ensemble, em relação a um membro específico do conjunto é por exemplo por volta de $41 \%$ maior do que a dispersão do EM. A dispersão em respeito ao controle e inicialmente a mesma do EM, mas vai gradualmente aumentando, até que alcança os mesmo $41 \%$ de qualquer membro(ECWMF, 2015).

\subsubsection{Diagrama de Previsões em Árvore}

Nas abordagens citadas acima, as incertezas são consideradas como sendo igual para todo o horizonte de previsão, assumindo implicitamente que nenhuma informação futura será atualizada, sendo que as incertezas mudam conforme as decisões são tomadas num estágio inicial ou final deste horizonte. Na prática novas informações serão disponibilizadas com o tempo, permitindo revelar qual ensemble terá mais probabilidade de ocorrer. Assim que a incerteza é resolvida, o controlador irá mudar a estratégia de controle, adaptando-a para o atual cenário.

O Diagrama de Cenários em Árvore possuí ramificações, apresentando no primeiro intervalo de tempo uma raiz que se ramificará após o primeiro vértice, nesta fase inicial todas as trajetórias futuras são possíveis. Conforme que as incertezas são definidas, ramificações são introduzidas. Em cada ponto de ramificação, o espaço amostral to ramo original se divide em ao menos dois novos subconjuntos.

Para previsões em tempo real, os diagramas de cenários em árvore mostram-se bastante adequados e apropriados, podendo ser empregadas em uma programação estocástica multiestágio, desta foram através do diagrama em árvore é possível observar quando as trajetórias das funções divergem entre si. Pode-se observar na que assim como nos ensembles, as trajetórias da função começam bastantes próximas no inicio do gráfico e posteriormente se divergindo conforme a escala de tempo avança.

Existem diferentes metodologias para gerar diagramas em árvore a partir de cenários completos de ensembles. Em Šutienè, Makackas e Pranevičius (2010), é demonstrado um método empírico de agrupamento de cenários; e em Raso et al. (2013), apresentada uma outra abordagem 
que considera somente as variáveis o controlador é capaz de observar ao longo do horizonte de previsão e os níveis de previsão. Já em Gröwe-Kuska, Heitsch e Römisch (2003) a construção dos cenários é feita utilizando uma estratégia de redução de cenários inversa, aplicada para cada passo de tempo do horizonte de previsão do ensemble.

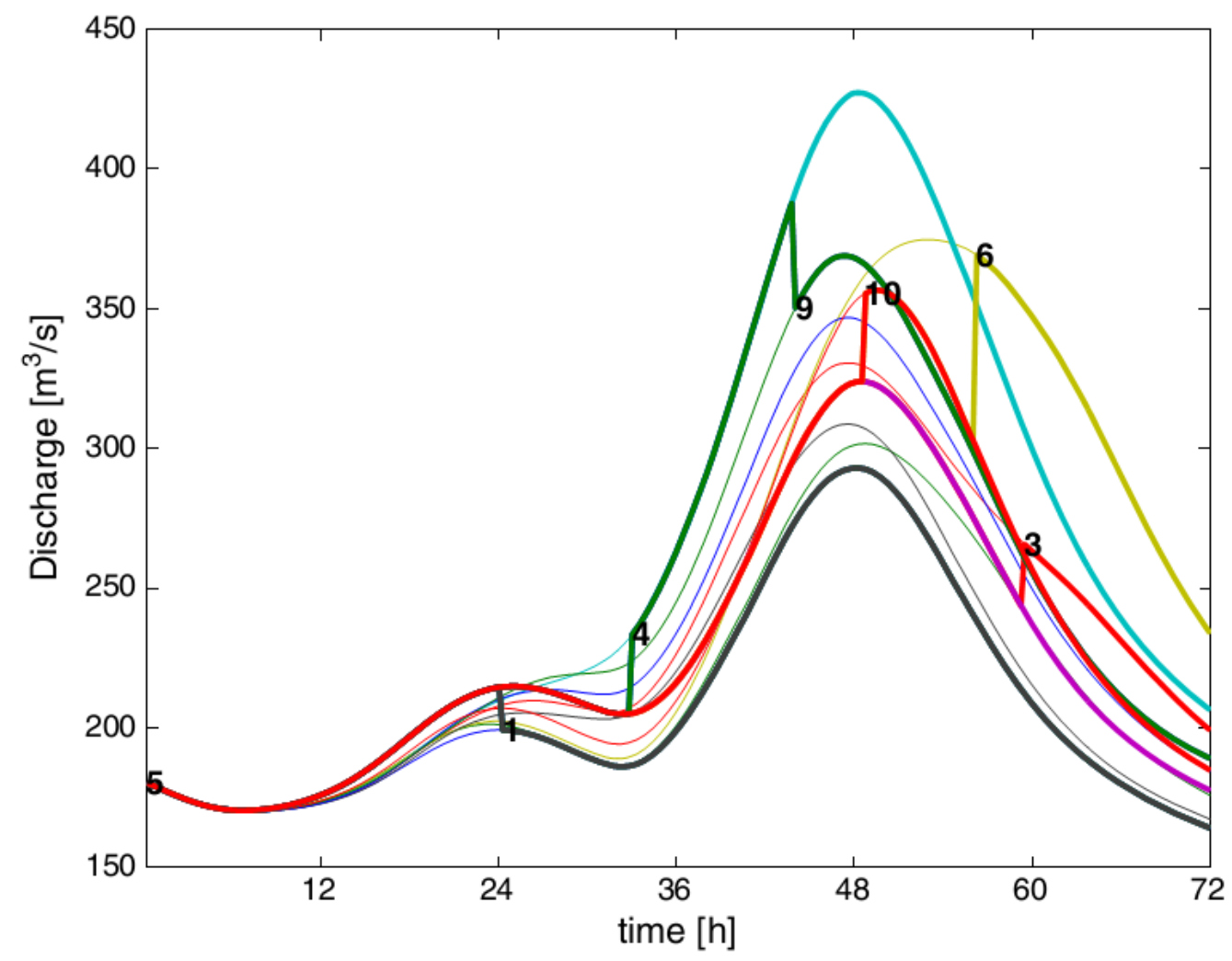

Fonte: Raso et al. (2013)

Figura 16 - Diagrama em Árvore conforme RASO.

O critério para encerrar a redução de cenários pode ser definido de diversas maneiras. Um diagrama de cenários em árvore com estrutura fixa pode ser criado por determinação de um número predefinido de reduções para qualquer intervalo de tempo no horizonte de previsão. Uma segunda abordagem é de utilizar uma estratégia de redução máxima para determinar uma distribuição de probabilidade reduzida do processo estocástico representado pela previsão de ensemble.

Os ensembles tem sido aplicados diretamente em programação estocástica, mas tendem a sobrestimar as incertezas, já que não consideram a solução esperada futura. A causa disto é a própria programação estocástica multiestágio, a árvore serve para incorporar dados dos ensembles na programação, especificando os momentos em que as incertezas são resolvidas.

Na Figura 17 (a grossura da linha representa a probabilidade e a cor a flexibilidade operacional); em Schwanenberg et al. (2015), os autores sugerem utilizar cenários em árvore 


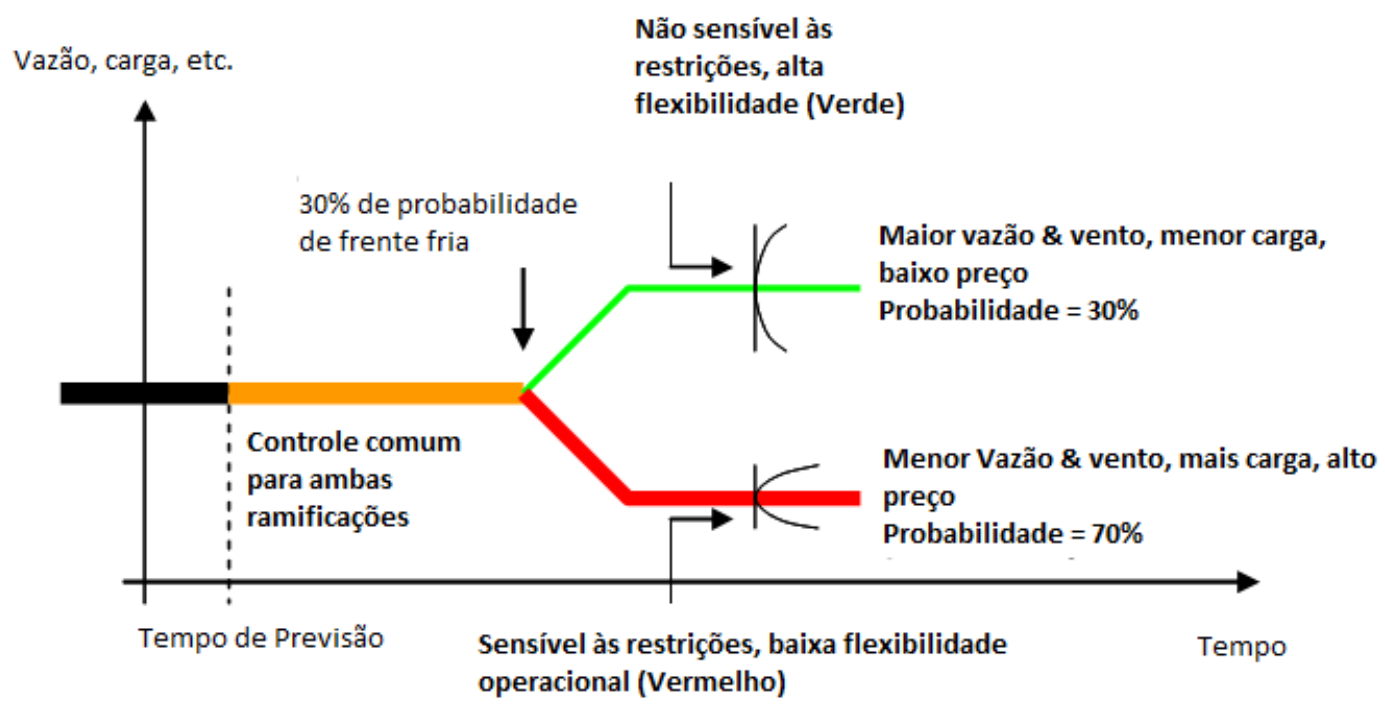

Fonte: Kuwajima et al. (2013)

Figura 17 - Diagrama em Árvore para de Sistemas de produção hidroelétrica e comercialização de energia no verão.

para uma melhor representação das incertezas de previsão para um ensemble em uma otimização estocástica multiestágio. através de um método que deriva o diagrama em árvore dos dados de precipitação para gerar um diagrama em árvore de vazões.

Desta forma é possível considerar a defasagem entre a precipitação observada e a previsão de vazão em bacia hidrográficas de grande escala, ou seja no momento em que a maior parte da incerteza meteorológica é definido. Além disto, nesta abordagem as médias do espaço amostra aplicado na geração do diagrama em árvore resultam por definição em um valor para o Erro Absoluto Médio idêntico entre o ensemble e a representação final do diagrama, já na abordagem de redução de diagramas de árvores padrão os ramos são excluídos do diagrama e as probabilidades são agregadas.

A extrapolação da otimização determinística para uma otimização com abordagem estocástica multiestágio resulta em várias vantagens conceituais. Uma vantagem importante é a opção de se tomar decisões baseadas no risco ao considerar as incertezas da previsão na otimização. Com isto provavelmente é possível obter-se decisões mais robustas. Além disto a amostragem das trajetórias controle facilita a integração de não-linearidades e das restrições.

\subsubsection{Técnicas de Assimilação de Dados e Fontes de Incertezas}

O desenvolvimento e aplicação de modelos para processos de chuva-vazão têm evoluído desde o começo da década de 1960 (VRUGT et al., 2006b); dentre estes modelos as classe comumente designada com o "Modelos Conceituais de Bacias Hidrográficas"representa aspectos 
perceptivos e conceituais do entendimento hidrológico do comportamento da bacia hidrográfica em escalas agegadas (KUCZERA, 1997). Os modelos conceituais utilizados na previsão de vazão operacional, costumam apresentar diversos parâmetros que especificam o comportamento de funções de transferência relativas às entradas e saídas de água através de caminhos que conectam os volumes conceituais de armazenamento de humidade para camadas do solo de diferentes profundidades. Assume-se que estes volumes de armazenamento conceituais sejam correspondentes com volumes de controle existentes no espaço físico "real, mesmo que os limites destes volumes de controle não possam ser explicitamente delineados.

Apesar do progresso no desenvolvimento e aplicação de procedimentos automatizados para calibração de modelos hidrológicos, estes métodos tendem a não tratar co rigor as fontes de incertezas (BEVEN; BINLEY, 1992; THIEMANN et al., 2001; VRUGT et al., 2005)). A maioria dos procedimentos tende a levar em conta explicitamente somente as incertezas de medição de vazão como em Sorooshian e Dracup (1980), Sorooshian, Duan e Gupta (1993) ou nas estimativas dos parâmetro com em Kuczera (1983a), Beven e Binley (1992), Gupta e Sorooshian (1998), Thiemann et al. (2001), Vrugt et al. (2003a), Vrugt et al. (2006a).

A maioria dos métodos utilizam processamento batch dos dados de pesquisa para buscar e determinar estimativas de parâmetros que minimizam a probabilidade de variância global estatística dos resíduos do modelo. Incertezas resultantes de erros associados ao sistema de dados de entrada medidos (precipitação e evapotranspiração potencial); resultantes de erros causados pela inicialização e propagação de variáveis de estado (capacidade de campo do solo); e mesmos dos erros estruturais do modelo decorrentes de uma representação inadequada dos processos físicos (incluindo a agregação de processos distribuídos espacialmente); não foram adequadamente tratadas de forma explícita (VRUGT et al., 2006b).

Durante as décadas passadas métodos para tratar os problemas acima destacados surgiram na literatura, com ênfase para soluções para o problema de se obter uma estimativa razoável para os limites das incertezas sobre as previsões numéricas do modelo. Dentre as estratégias para estimar parâmetros do modelo e incertezas da previsão de fluxo que podem fornecer previsões do valor mais provável de fluxo junto com estimativas dos intervalos de possíveis resultados podemos destacar os modelos bayesianos, pseudo-bayesianos, de teoria dos conjuntos, multi-critérios e de modelos recursivos. Estes métodos acima citados, geralmente sintetizam as incertezas dos modelos em termos de incertezas nas estimativas de parâmetros. (KUCZERA, 1983a; KUCZERA, 1983b; KEESMAN, 1990; STRATEN; KEESMAN, 1991; BEVEN; BINLEY, 1992; KLEPPER; SCHOLTEN; KAMER, 1991; FREER; BEVEN; AMBROISE, 1996; GUPTA; SOROOSHIAN, 1998; THIEMANN et al., 2001; YOUNG; BEVEN, 1994; VRUGT et al., 2003b; VRUGT et al., 2006a).

No começo da década de 1980, foram propostos métodos de filtragem por terem capa- 
cidade de manipular explícitamente as incertezas dos modelos hidrológicos. Ao contrário das técnicas mais tradicionais de calibração de modelos, estas técnicas de filtragem em espaço de estados podem contiuamente atualizar os estados dos modelos assim que novas medições se tornam disponíveis, e desta forma melhorando a previsão do modelo e precisão da previsão. Dentre as aplicações de algumas variações da técnica original do filtro de Kalman conforme (KALMAN, 1960) para previsão de fluxo em tempo real podem ser destacadas em (TODINI; A.SZÖLLÖSINAGY; WOOD, 1976 apud SCHILLING; MARTENS, 1986) ${ }^{1}$, (BRAS; RESTREPO-POSADA, 1980 apud VRUGT et al., 2006b) ${ }^{2}$, Kitanidis e Bras (1980a), Kitanidis e Bras (1980b), Bras e Rodriguez-Iturbe (1985), Wood e O’Connel (1985), Awwad e Valdés (1992), Awwad, Juan e Restrepo (1994), Young (2002).

Em Kitanidis e Bras (1980a), Kitanidis e Bras (1980b) são utilizados Filtros Kalman Estendidos ou Extended Kalman Filter (EKF) através de uma reformulaçao dos espaços de estados para o modelo Sacramento não-linear para investigar estimativas probabilísticas das variáveis de estado e para detectar erros gerados por erros de medição da precipitação atmosférica.

Já no caso da abordagem recursiva de filtros Kalman não teve utilidade operacional por não poder ser aplicada por questões práticas, uma delas pelo fato de que sua implementação exige que um modelo altamente não-linear seja transformado para uma fora de estados de espaço continuamente diferenciável, o que envolve muitas modificações e aproximações, além de que o comportamento de entrada e saída de dados do espaço de estados para o modelo reformulado pode divergir de maneira substancial do modelo original (GEORGAKAKOS; SPERSFLAGE, 1995 apud VRUGT et al., 2006b) ${ }^{3}$, (KITANIDIS; BRAS, 1980a; KITANIDIS; BRAS, 1980b; GEORGAKAKOS; RAJARAM; LI, 1988; REFSGAARD, 1997; SEO; KOREN; CAJINA, 2003).

É importante destacar também que em Evensen (1992), Miller, Ghil e Gauthiez (1994) mostram que os Filtros de Kalman Estendidos são extremamente instáveis no caso de haver muita não-linearidades no modelo. Seo, Koren e Cajina (2003) destaca também que as reformulações adequadas das equações derivadas dos modelos dependem consideravelmente de experiência e conhecimento do modelador. A principal restrição para sua aplicabilidade e uso prático dos métodos de filtragem de espaço de estados são os custos computacionais, que são significantes especialmente para os casos aplicados para problemas que envolvem modelos distribuídos espacialmente e vetores de espaço de estados de alta dimensão.

1 TODINI, E.; A.SZÖLLÖSI-NAGY; WOOD, E. F. Adaptive state/parameter estimation algorithms for real-time hydrologic forecasting: a case study. In: IIASA/WMO Workshop Recent Developments Real-Time Forecasting/Control Water Resource Sys. Laxenburg, Austria: [s.n.], 1976.

2 BRAS, R. L.; RESTREPO-POSADA, P. Real time automatic parameter calibration in conceptual runoff forecasting models. In: 3rd International Symposium on Stochastic Hydraulics. [S.1.: s.n.], 1980. p. 61-70.

3 GEORGAKAKOS, K. P.; SPERSFLAGE, J. A. Hydrological Forecast System-HFS: A user's manual. San Diego, CA, 1995. 
Recentemente também foram desenvolvidos esforços para modificar estes métodos para torna-los mais aplicáveis: Madsen e Skotner (2005) investigou a aproximação sub-ótima para filtro de Kalman de Cañizares et al. (2001) para atualização adaptiva do espaço de estados no modelo Mike-11, relatando redução dos custos computacionais tornando o método mais adequado que o método de filtro Kalman estendido ou mesmo o método do filtro de Kalman original para aplicações práticas.

Além das técnicas de Filtro de Kalman destacadas acima outras metodologias foram também exploradas recentemente: Seo, Koren e Cajina (2003) utilizou a aquisição variacional ou variational assimilation (VAR) como ferramenta para aquisição de dados estimativas climatológicas de evapotranspiração potencial e observações em tempo real de vazão e precipitações para melhorar as previsões de vazão do modelo Sacramento. Este método VAR, é aplicado largamente em modelos hidrometeorológcos e oceanográficas, não precisa de formulação e reformulações do estado de espaços, porém implica em implementar uma programação de um texto-código adjunto que pode ser difícil complicado de deduzir. A técnica de VAR é utilizada também em investigações e estudos hidrológicos, como no caso de Reichle, Entekhabi e McLaughlin (2001), que utiliza aquisição de dados através de sensoriamento remoto (espectro de ondas em um modelo de superfície terrestre) de para estimar distribuições espaciais da umidade de solo.

Recentemente, técnicas de previsão ensemble com aquisição de dados sequencial ou sequential data assimilation (SDA) tem sido cada vez mais empregadas em parte devido à capacidade desta técnica de tratar explicitamente diversas formas de incertezas em modelos hidrológicos operacionais. As técnicas relatadas inicialmente na literatura incluem a análise de identificação dinâmica para parametrização recursiva e detecção de variação temporal nos parâmetros do modelo (WAGENER et al., 2003); método de identificação de parâmetros baseados na localização das informações (VRUGT et al., 2002); e a abordagens para estimativas recursivas bayesianas (THIEMANN et al., 2001; BAYSAL, 2003; GUPTA et al., 2003).

Recentemente técnicas de Filtro Kalman para ensembles, denominadas Filtro Kalman de Ensembles ou Kalman Filter Ensemble (EnKF) tem mostrado poder e flexibilidade necessária para aquisição de dados através de modelos conceituais para bacias hidrográficas (EVENSEN, 1994). Vrugt et al. (2005) apresentou otimização simultânea e métodos de aquisição de dados ou Simultaneous Optimization and Data Assimilation (SODA), que utilizam EnKF para recursivamente atualizar os estados do modelo enquanto estimam valores invariantes aos tempo para parâmetros do modelo através da abordagem de otimização estocástica denominada Shuffled Complex Evolution Metropolis Stochastic-Ensemble Otimization (SCEM-UA) (VRUGT et al., 2003b).

Outras inovações que permitiram abordar o problema do custo computacional foram feitas através de uma nova função para a aquisição de dados por SODA, que é o tratamento explícito 
dos erros devido às incertezas de parametrização, incertezas de estado das variáveis, erros estruturais do modelo e erros na medição da vazão. Em Moradkhani et al. (2005), Moradkhani et al. (2005) são apresentados dois métodos de estimativa dupla de parâmetros de estado ou Different Dual State-Parameter Estimation (DSPE) baseados no método de filtragem EnKF e técnicas sequenciais de Monte-Carlos, que também é conhecidad como filtragem de partícula. Já em Gordon, Salmond e Smith (1993), Arulampalam et al. (2002), são implementadas a estimativa recursiva dependente temporalmente dos estados e parâmetros e estados dos modelos.

Tanto os métodos de EnKF quanto o método Sequencial de Monte-Carlo permitem rastreamento preciso dos instantes da função de segunda ordem de distribuição probabilística para modelos não-lineares, no entanto o método sequencial de Monte-Carlos permite também rastrear instantes de ordens superiores o que portanto implica em custos computacionais maiores. O EnKF permite melhor eficiência computacional através do emprego de regras lineares para atualização do espaço de estados, mas pode resultar em desempenho sub-ótimo quando há não-linearidades no modelo.

Vrugt et al. (2006b), sugerem que para Previsão Operacional de Eventos de Cheias são necessárias estimativas precisas das incertezas associadas às previsões de vazão geradas pelos modelos sejam fornecidas junto com os prováveis níveis de escoamento. Em uma implementação estocástica do modelo Chuva-Vazão Sacramento obtida de previsões determinísticas de vazão do NWS (National Weather Service) através de uma abordagem Simultânea de Otimização e Assimilação de Dados utilizando um filtro para ensembles, foi possível aplicar o modelo sem necessidade de grandes modificações e reconfigurações do modelo. Nesta aplicação no rio Leaf no Mississippi estima-se que houve uma melhora da ordem $30 \%$ a $50 \%$ do desempenho de previsão, mesmo com uma otimização sub-ótima do filtro de ensembles. 


\section{Parte IV}

Metodologia 



\section{Modelos Hidráulicos e Hidrológicos Utiliza-}

\section{dos}

Para implantação de um SSD online para operação de barragens e operação para controle de cheias foram avaliados diferentes modelos para eleger o mais apto neste caso específico; um modelo rápido, preciso e robusto para poder ser implementado em um MPC, o modelo será capaz de fornecer estimativas rápidas e confiáveis de condições de fluxo à jusante relacionadas com as descargas de um reservatório. Uma vez que não existe um modelo de universalmente superior para todas as aplicações, é necessário, portanto avaliar os prós e contras dos modelos disponíveis e aplicáveis para as condições de estudo.

Para esta aplicação, problemas de otimização reservatório de curto prazo de previsão, apontar o modelo mais adequado, é fundamental considerar algumas questões como se o modelo escolhido fornece informações hidráulicas suficientes para responder às perguntas do usuário; precisão do modelo; a precisão exigida da aplicação; a qualidade e a disponibilidade dos dados para alimentar os modelos; e custos computacional e de processamento.

Tabela 7 - Modelos Selecionados \& Equações Governantes.

\begin{tabular}{lll}
\hline \hline Nome do Modelo & Modelo Físico & Densidade de Nós de Cálculo \\
\hline SOBEK & ESV-Totalmente Hidrodinâmica & Deslocamento de Malha \\
SPRNT & ESV-Totalmente Hidrodinâmica & Transectos \\
MGB-IPH & Muskingum-Cunge Não-Linear & Não Aplicável \\
& RR com Integrador de Atraso & Não Aplicável \\
RTC-Tools & ESV-Onda Difusiva & $1 / 30 \mathrm{~km}$ \\
& & $1 / 10 \mathrm{~km}$ \\
\hline \hline
\end{tabular}

De forma geral,modelos que utilizam as simplifcações da ESV são atraentes para este tipo de aplicação devido à sua robustez e melhor desempenho da CPU; no entanto, as simplificações podem criar restrições de aplicabilidade, bem como comprometer a precisão dos resultados.

$\mathrm{Na}$ Tabela 7estão apresentados modelos selecionados, as equações governantes e a densidade de nós que de forma geral reflete o grau de simplificação espacial do modelo. Os modelos selecionados são: SOBEK, SPRNT, MGB-IPH e o RTC-Tools; sendo que este último pode utilizar diferentes modelos conceituais e portanto pode ser subdivido em 2 submodelos: Onda Difusiva (DW) e Cascata de Reservatórios (RR). Sendo que o submodelo DW apresenta 2 configurações espaciais diferentes.

Buscou-se escolher aqueles que se baseiam em diferentes modelos perceptuais e equações 
conceituais, assim cada um deles utiliza uma abordagem diferente para calcular a propagação do fluxo. Com isso pretende-se possibilitar avaliar a potencialidade deles em processamento simular corretamente os picos de cheias e bruscas alterações de niveis, típicas de operação de reservatórios, com o menor esforço computacional possível.

\subsection{RTC-Tools}

A ferramenta open source RTC-Tools (Real-Time Control Tool) é tool box modular para aplicações de controle em tempo real e SSD de estruturas hidráulicas. Estão incluídos dentro desta ferramenta estratégias de controle com gatilhos tanto em configuração feedback quanto feedfoward, regras operacionais e controladores além de um pacote avançado de configurações de MPC baseados na combinação de previsão e otimização. O pacote possui opções de configurações sendo possível utilizar diferentes configurações de métodos de estimativa de vazão: inercial, onda difusiva, onda cinemática e Cascata de Reservatórios; permitindo também dentro destas configurações utilizar diferentes esquematizações espaciais: central ou upwind. Outra característica que é possível definir são os esquemas de escalas temporal (implícitos ou explícitos), assim permitindo definir modelos físicos, conceituais, ou orientados aos dados para simular o escoamento superficial e escoamento de canais abertos (SCHWANENBERG; BECKER, 2014).

O RTC-Tools é resultado da integração de projetos específicos de módulos de simulação de reservatórios para sistemas de previsão de cheias na Áustria, Alemanha, Paquistão, Países Baixos e EUA. O modelo original de 2007 escrito em Java, também chamado de módulo de reservatório Delft-FEWS, tem como objetivo a simulação da transferência de volumes em reservatórios e sistemas de reservatórios com regras de operação e instrumentados. Em 2008 e 2009 foram adicionados controladores de previsão mais avançados, que incluíam um modelo de propagação cinemática de cheias, um modelo interno adicional para os controladores de previsão e um sistema subjacente para componentes de modelação selecionados, que resultaram em um aumento significativo da velocidade de processamento destes controladores. Em 2010, o conceito de gatilhos para acionamento dos controladores e regras de operação foram introduzidos, permitindo a simulação de esquemas de controle heurísticos mais sofisticados. Mais adiante o software foi reescrito em $\mathrm{C}++$ e aprimorado permitindo integração com pacotes SOBEK ou Delft-3D (SCHWANENBERG, 2009).

O RTC-Tools é um pacote de blocos de elementos para aplicações de controle em tempo real desenvolvido para ser um modelo para ser usado na operação de sistemas hidráulicos, portanto o principal intuito do RTC-Tools é de simular técnicas de controle em tempo real, e não de realizar simulações detalhadas para dimensionamento e projeto. Portanto as simulações deste modelo incluem por definição todos os estados de sistema, gatilhos, controladores, regras de operação e componentes de modelação. . 
Como este módulo foi desenvolvido para resolver problemas específicos de controle em tempo real, que podem ser integrados a sistemas maiores, o software fornece interfaces para os sistemas de previsão Delft-FEWS (interface PI-XML) e pacotes de modelação como o SOBEK e Deltf3D. A plataforma OpenMI habilita o usuário a combinar regras de operação e controladores definidos dentro RTC-Tools com componentes de modelação hidráulica mais detalhados, que estão disponíveis nos pacotes citados acima (SCHWANENBERG, 2009).

A Figura 18, mostra configurações possíveis dentro deste pacote, destacando a interoperacionalidade inata dele com modelos projetados para fins diferente como OpenDA para assimilação de dados, SOBEK e Delft3D para simulações mais detalhadas e Delft-FEWS para integração com outros modelos, interface gráfica para visualização de resultados, importação de dados e para configuração através de uma interface de programação.

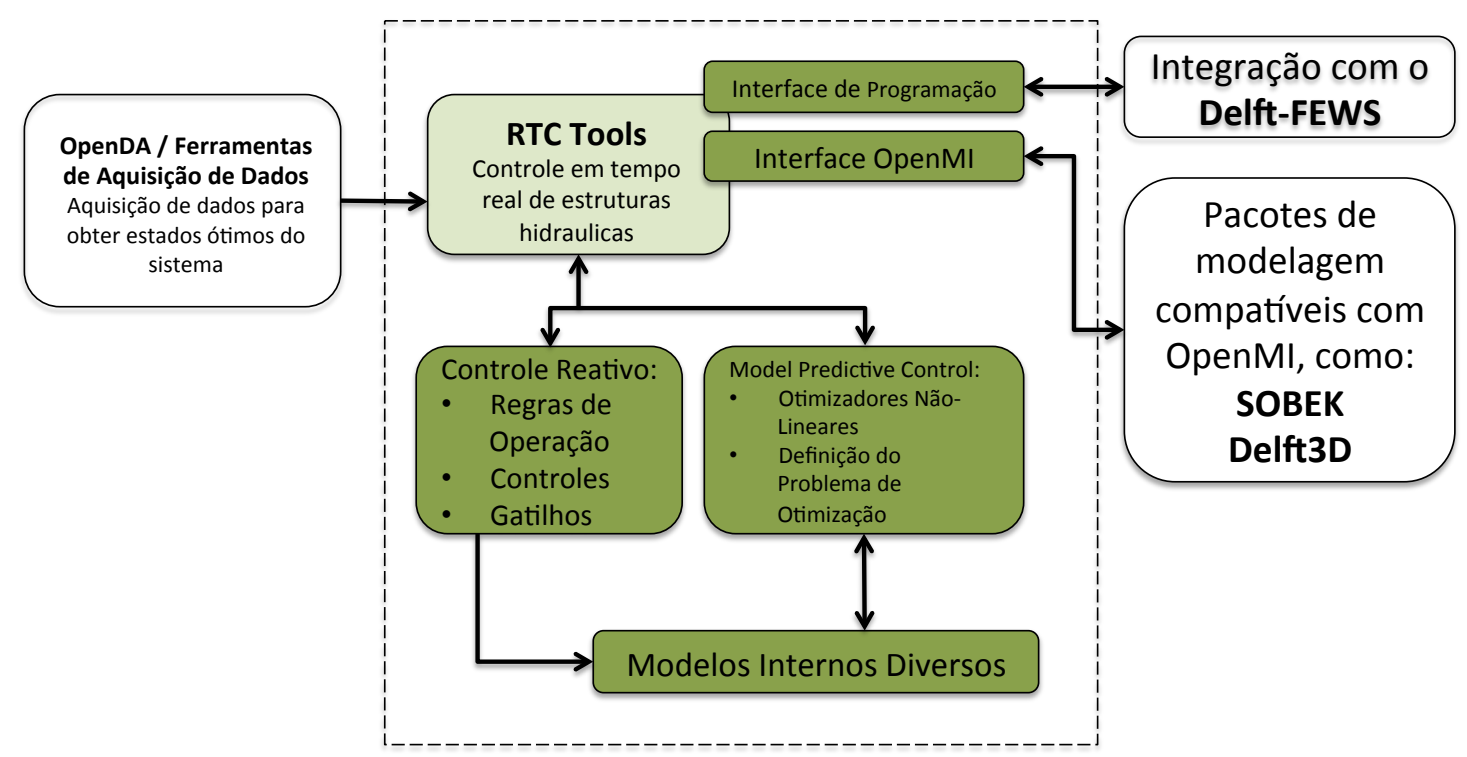

Adaptado de Schwanenberg (2009).

Figura 18 - A configuração do modelo de controle preditivo que pode ser feito no RTC-Tools utilizando otimizadores integrados.

Os componentes do RTC-Tools incluem interfaces importantes para aquisição de dados como OpenDA ou outras platformas para este fim, que permitem aplicar técnicas de assimilação e incorporação de dados para melhorar o estado do sistema dos componentes de modelagem, 
que podem ser utilizadas no contexto de previsão de controle preditivo.

Devido à necessidade de um modelo interno para controladores de modelos de previsão, esta ferramenta possui vários modelos simples de transferência, o que permite utilizar somente este modelo para sistemas de previsão. Além disto a interface OpenMI permite que o usuário utilize uma vasta gama de modelos hidráulicos complementares.

\subsection{Cascata de Reservatórios - Reservoir Routing}

Esta abordagem simplificada para calcular escoamento não-estacionário é baseado na conservação de massa, onde a diferença entre Vazão de entrada $I$ e Vazão de Saída $O$ é igual a da taxa de variação do armazenamento de um corpo d'água. Esta abordagem também é equivalente à simplificação da Onda Cinética da Equação de Saint-Venant. A Cascata de Reservatórios é dada por:

$$
I_{t}-Q_{t, h}=\frac{\partial s_{h}}{\partial_{t}}
$$

Onde $I$ corresponde a vazão de entrada no "reservatório", $Q$ é a vazão de descarga do reservatório e $s$ é a volume de armazenamento, $h$ é o nível d'água no reservatório, $t$ corresponde ao tempo. Utilizando escoamento em níveis, na qual o nível d'água para cada reservatório possui uma superfície horizontal, através do seu comprimento, é possível dividir a descarga dos "Reservatórios"em descarga controlada $Q_{c}$ e descarga não-controlada $Q_{u}$.

\section{Integrator Delay - Integrador de defasagem de tempo}

Schuurmans (1997) utiliza uma ferramenta para correção de defasagem chamada Integrator Delay, a qual será incorporada em na configuração adotada neste estudo. Entáo considerando o sistema abaixo:

$$
A \frac{\partial h(x, t)}{\partial h}=q\left(L_{u}, t\right)-q(L, t)
$$

Em fluxo transientes os picos de vazões são amortecidos de forma exponencial e muito rapidamente, não representando impactos no escoamento, e desta forma podem ser descartados (SCHUURMANS, 1997). Desta forma somente alterações na vazão à jusante poderiam ter efeitos no escoamento de canais abertos. O efeito a montante $q(0, t)$ na vazão a jusante é transiente e o 
modelo de defasagem de tempo é descrito por:

$$
q(x, t)=q(0, t-T(x))
$$

O tempo de defasagem $T(x)$ é dado pela Equação 8.3 de (SCHUURMANS; BOSGRA; BROUWER, 1995):

$$
\begin{aligned}
& T(x)=\frac{2 x}{(1+k) V_{0}} \\
& k=1+\frac{4 P_{0}}{3 B_{0}} \frac{\partial R_{h}}{\partial y}
\end{aligned}
$$

Onde $V_{0}$ é a velocidade média $(\mathrm{m} / \mathrm{s}) ; B$ é a largura superior $(\mathrm{m}) ; P$ é o perímetro molhado $(m) ; R_{h}$ é o raio hidráulico $(m)$; e $Y$ é a profundidade do escoamento $(m)$.

Schuurmans et al. (1999), recomenda em caso de não disponibilidade de dados dados geométricos, que podem ser difíceis de se obter, estimar os parâmetros através de ajuste da resposta do modelo às medições: utilizando as medidas das taxas de fluxo nas condições de contorno, a resposta do modelo pode ser ajustada para medir níveis de água através de ajuste de parâmetros.

No ID o rio é considerado como uma combinação linear de um reservatório e uma defluência defasada. No entanto, não são capazes de reproduzir o comportamento dinâmico não-linear da hidráulica fluvial e não podem reproduzir efeitos complexos como amortecimento de oscilações de onda, efeitos de remanso e presença inercial de ondas ao longo do sistema.

\subsection{SOBEK}

SOBEK é um sofisticado sistema de modelagem numérica dinâmica para canais abertos. O sistema foi desenvolvido pela antiga WLIDelft Hydraulics, que atualmente chama-se Deltares, em parceria com o RIZA (Rijksinstituut voor Integraal Zoetwaterbeheer en Afvalwaterbehandeling), que era o Instituto de Gestão de Águas Interiores e Tratamento de Águas Residuárias do governo Holandês (NOAA, 2007).

O nome SOBEK vem do deus-crocodilo do Antigo Egito que era associado ao rio Nilo. Os antigos egípicios acreditavam que os crocodilos podiam prever o futuro, já que botavam seus ovos exatamente acima do nível da proxima inundação do rio Nilo. O SOBEK é portanto compatível com o DELFT-FEWS (DELTARES, 2014). 
O modelo pode ser aplicado para modelagem hidrodinâmica de rios, estuários e redes de drenagens em estudos como simulação de gerenciamento de recursos hídricos, prevenção de cheias, dimensionamento e projeto de canais, sistemas de irrigação, qualidade da água, navegação e dragagem. O software está equipado com a linha de comando do usuário (user shell) capaz de resolver equações que descrevem o fluxo não-permanente, intrusão salina, transporte de sedimentos, morfologia e qualidade da água. O software pode ser aplicado

Ele utiliza um método numérico que permite obter soluções para simulações complexas. Este software utiliza as equações unidimensionais hidrodinâmicas de Saint-Venant através deslocamento de malhas utilizando diferenças finitas implícitas.

O programa possuí diversos módulos para aplicação à problemas relacionados de modelação hidrodinâmica e qualidade de água em rios. Seus módulos são: hidrologia, hidrodinâmica em canais, hidrodinâmica em rios, redes de águas pluviais e de esgoto, controle em tempo real, qualidade de água e previsão de enchentes. O programa permite representar os processos físicos e fenômenos em uma rede uni-dimensional (1D) e redes horizontais em duas dimensões (2D). O módulo de hidrologia do SOBEK possui uma biblioteca de modelos chuva-vazão incluindo o HBV, SAC-SMA (Sacramento) e o SCS-CN (Soil Conservation Service - Curve Number) (DELTARES, 2014).

Assim, o SOBEK consiste de um conjunto de módulos testados e validados, associados e integrados uns aos outros. Esses módulos representam fenômenos e processos físicos com precisão em sistemas unidimensionais e bidimensionais, são eles:

- Flow 1D Open Water;

- Flow 2D Overland;

- Rainfall Runoff Open Water;

- 1DMOR (incl. Transporte de Sedimentos);

- Water Quality 1D e 2D;

- Emission;

- Real Time Control.

O sistema de modelagem SOBEK apresenta três linhas: rural, urbana e fluvial. Todas utilizam a mesma interface sendo que as linhas rural e urbana estão totalmente integradas. As áreas de aplicação de cada uma delas e os correspondentes módulos integrantes são apresentados a seguir. SOBEK-Rural: 
- Irrigação, reabilitação, modernização, drenagem e proteção de cheias;

- Operação de reservatórios em tempo real e a longo termo;

- Controle em tempo real e automatização de sistemas de canais;

- Incorpora os módulos hidrodinâmico, hidrológico, de qualidade da água e de controle de cheia em tempo real.

SOBEK-Urban:

- Determinação de estruturas de drenagem urbanas, incluindo plantas de tratamento;

- Análise de frequência de transbordamento de esgotos;

- Projetos de bacias de detenção e controle em tempo real de sistemas de drenagem urbanos;

- Estudos ambientais de águas cinzas;

- Incorpora os módulos hidrodinâmico, hidrológico e de controle em tempo real.

\section{SOBEK-River:}

- Navegação;

- Proteção e análise de risco de cheias;

- Estudo de poluição da água;

- Estudos sedimentológicos e morfológicos;

- Incorpora os módulos hidrodinâmico, de qualidade da água e morfológico.

No presente estudo, serão aplicados os módulos hidrológico e hidrodinâmico do SOBEK para as bacias e usinas do Grupo 2. São eles os módulos Flow 1D Open Water, Flow 2D Overland e Rainfall Runoff Open Water descritos a seguir.

O módulo Flow 1D Open Water trabalha com equações de Saint Venant, incluindo fluxo transiente e perfis de remanso. Nele podem ser modeladas seções transversais abertas e fechadas, perfis assimétricos e na direção y-z. Com o programa também é possível definir diferentes subseções em uma seção transversal utilizando formulações alternativas para coeficientes em cada subseção. 
O módulo Flow 2D Overland consiste de um sistema de modelagem bidimensional baseado em equações de Navier-Stokes para fluxo de superfície livre integrado na vertical. Todas as equações são solucionadas através do método de diferenças finitas implícito, baseado num grid escalonado. No modelo, a maneira como os termos de momento convectivo são formulados permite a simulação de escoamentos sub e supercríticos e do comportamento de ressaltos hidráulicos. Para garantir maior robustez e acurácia aos resultados, não há necessidade de considerar a viscosidade artificial.

Em combinação com o sistema de modelagem 2D, o SOBEK consegue simular elementos unidimensionais como pequenos cursos d'água e estruturas hidráulicas. Saltos hidráulicos são simulados assim como canais com declividade moderada e escoamento subcrítico. Também é possível especificar qualquer tipo de estrutura hidráulica (bombas, barragens, comportas, galerias, eclusas e pontes de qualquer formato e tamanhos virtuais). Além disso, o modelo pode considerar sedimento depositado bloqueando parcialmente galerias e pontes. Várias opções de controle automático dessas estruturas estão disponíveis como padrão, incluindo controle de tempo e hidráulico. Os efeitos dos ventos sobre os níveis de água também podem ser modelados através da inserção de dados de velocidade e direção do vento como constantes ou séries temporais.

Nessa combinação 1D-2D, o fluxo superficial 2D, incluindo efeitos de terraplanagem ou diques naturais, é simulado através de equações 2D no módulo SOBEK - Overland Flow, enquanto que representações de cursos d'água menores, de grande declives, como barrancos, e de estruturas hidráulicas são simulados com o módulo de simulação unidimensional, SOBEK Channel Flow.

Assim, o SOBEK 1D2D foi desenvolvido a fim de combinar o modelo de fluxo em canais (1D, equações de Saint Venant) com o modelo bidimensional de resolução de equações para águas superficiais. O modelo resolve equações de águas rasas a fim de simular vazões de cheia de inundações através da conservação da massa e do momento. As equações da continuidade e do momento considerando as direções $x$ e $y$ são apresentadas:

$$
\begin{gathered}
\frac{\partial \xi}{\partial t}+\frac{\partial(u h)}{\partial x}+\frac{\partial(v h)}{\partial y}=0 \\
\frac{\partial u}{\partial t}+\frac{\partial u}{\partial x}+v \frac{\partial u}{\partial y}+g \frac{\partial \xi}{\partial x}+g \frac{u|V|}{C^{2} h}+a u|u|=0 \\
\frac{\partial v}{\partial t}+u \frac{\partial v}{\partial x}+v \frac{\partial v}{\partial y}+g \frac{\partial \xi}{\partial y}+g \frac{u|V|}{C^{2} h}+a v|v|=0
\end{gathered}
$$


Onde $\xi$ corresponde ao nível de água sobre o plano de referência (m); $u$ é a velocidade na direção $x\left(m s^{-1}\right)$; $C$ é o coeficiente de Chezy $\left(m^{1 / 2} S^{1 / 2}\right) ; V$ é a velocidade: $V=\sqrt{u^{2}+v^{2}}$ $\left(m s^{-1}\right) ; h$ é a profundidade total de água: $\xi+d(\mathrm{~m})$, com $d$ igual à profundidade abaixo do plano de referência $(\mathrm{m}) ; a$ é o coeficiente de atrito $\left(\mathrm{m}^{-1}\right)$.

Além das equações anteriores, são ainda utilizadas expressões para o cálculo das características de escoamento em estruturas como: pontes, passagens hidráulicas, sifões invertidos, orifícios, bombas, sifões e descarregadores. Nestas estruturas o escoamento depende dos níveis a montante e a jusante da estrutura, das suas dimensões e de um conjunto de parâmetros específicos de cada uma delas (PINHO; VIEIRA, 2006).

Dessa forma, ambos sistemas de modelagem produzem equações de diferenças finitas implícitas, e são acoplados através de uma formulação implícita para a articulação de equações de continuidade em locais onde compartilham pontos com mesmo nível de água (ASSELMAN; HEYNERT, 2003). A 19 mostra o esquema do modelo hidráulico para a configuração 1D2D

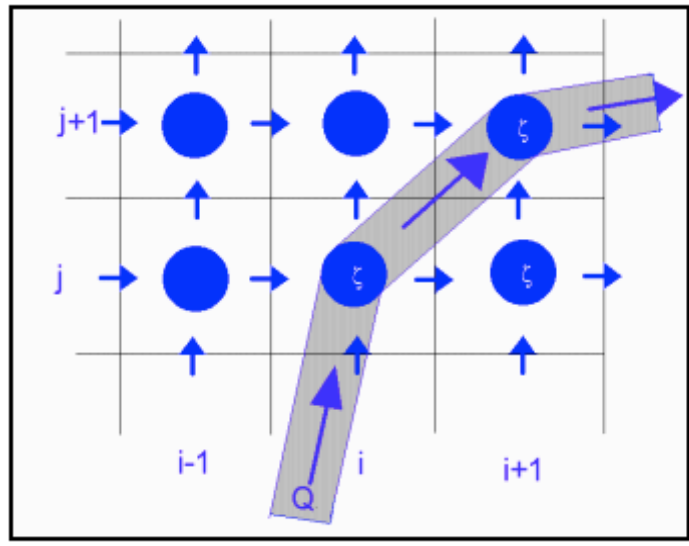

(a) Combinação do grid 1D/2D

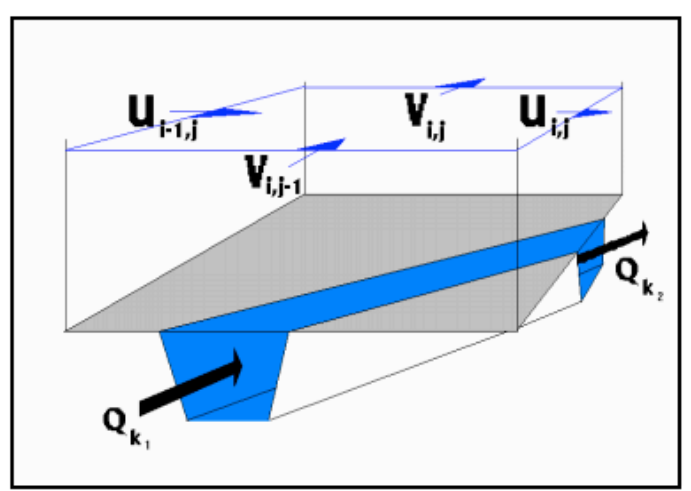

(b) Acoplamento da equação da continuidade para simulações 1D2D

Fonte: Asselman e Heynert (2003)

Figura 19 - Esquema do Modelo Hidráulico SOBEK.

Os módulos Overland Flow e Channel Flow do SOBEK são baseados nos mesmos princípios numéricos e ambos permitem cálculos extremamente estáveis e robustos. Isto é devido, primeiramente, às propriedades dos esquemas numéricos aplicados. Nesse mecanismo de simulação hidrodinâmica 1D/2D há um procedimento automático de alagamento e secamento $100 \%$ conservativo. A cada passo de cálculo uma verificação é realizada a fim de prevenir resultados fisicamente não realísticos, como níveis de água negativos. Se essa restrição não é satisfeita, o passo de tempo é então reduzido.

O procedimento acima também é aplicado no caso de alagamento e secamento de células no módulo Overland Flow. A cada passo de tempo apenas uma célula vizinha pode ser alagada 
ou seca, caso contrário, o passo de tempo será reduzido para satisfazer o critério. Além disso, a formulação implementada permite a supressão de direções aleatórias de vetores de velocidade em contornos irregulares. A verificação dos resultados pode ser realizada através da comparação com resultados de estudos experimentais, dados publicados e obtidos através de experimentos laboratoriais. A rigorosa conservação de volume é uma característica do modelo de particular interesse principalmente na simulação de transporte de poluentes.

O modelo oferece uma variedade de possíveis condições de contorno, como níveis de água ou descargas em função do tempo. As condições de contorno de descargas podem ser especificadas em um determinado número de células em função do transporte em cada célula individualmente. Nas fronteiras a jusante o usuário também pode especificar laços nas curvas chave, caso existentes. Condições iniciais podem ser dadas como fundo seco, profundidade de água ou nível de água. O modelo ajustará automaticamente o estado inicial correto de acordo com as condições de contorno inseridas. Uma função para início de simulação com condições de contorno e iniciais do modelo "pré-aquecido" também é disponível.

Ambos os módulos Overland Flow e Channel Flow permitem a consideração de efeitos meteorológicos, como vento, precipitação e evapotranspiração. Entretanto, no caso de simulação de um evento de cheia resultante do rompimento de um dique, esses processos podem ser negligenciados. Além disso, a variação espacial da rugosidade também é considerada nos dois módulos. A rugosidade hidráulica pode ser especificada por valores de Manning, Chézy ou White Colebrook. Cada célula do grid possui seu valor de rugosidade, que pode ser modificado através de importação por GIS ou através de um editor disponível na interface do usuário.

O módulo hidrológico do SOBEK (Rainfall Runoff Open Water) contém uma biblioteca de modelos chuva-vazão para pequenas e grandes bacias, como o HBV e o SCS. As áreas das bacias podem ser modeladas de maneira concentrada ou distribuída, sem restrições em relação ao número de bacias. O modelo permite calcular o escoamento instantâneo total, utilizando como dados de entrada a precipitação média na bacia e a evapotranspiração potencial. Nas simulações são considerados os diferentes usos de solo, altimetria e características de drenagem. O módulo utiliza eventos de precipitação e séries de dados meteorológicos para análise estatística. Há a possibilidade de utilizar diferentes padrões de precipitação ou dados históricos, além de considerar maior número de estações pluviométricas levando em consideração variações espaciais. Podem ser simulados tanto eventos de cheia quanto de seca. Este módulo pode ser aplicado em conjunto com o Flow 1D Open Channel e o RTC.

O módulo Rainfall Runoff Open Water é baseado no modelo de Sacramento. O modelo Sacramento divide o solo em duas camadas principais (PINHO; VIEIRA, 2006):

- A camada superior na qual ocorrem os processos rápidos junto à superfície do solo: 
evaporação, percolação, escoamento superficial e escoamento sub-superficial;

- A camada inferior em que ocorrem os processos lentos da região não saturada do solo: transpiração, recarga do aquífero e escoamento de base.

Em ambas as camadas são consideradas subzonas onde a água está sob o efeito da tensão superficial (capilaridade) ou está sob o efeito da pressão hidrostática (água livre). $\mathrm{O}$ mecanismo básico do modelo pode ser resumido do seguinte modo: a água é armazenada numa determinada porção da coluna do solo como água sob tensão superficial, até que a capacidade deste reservatório seja atingida. A partir daí, toda a água adicionada ao sistema será armazenada como água livre.

O volume de água sob tensão superficial só pode ser diminuído com a percolação da camada superior para a camada inferior, escoamento sub-superficial, escoamento de base e recarga do aquífero. A vazão instantânea total é composta por fluxos provenientes de processos que ocorrem nas sub-zonas de água livre das camadas superior e inferior:

- Escoamento direto: proveniente da chuva que cai sobre a fração impermeabilizada da bacia, apresentando uma resposta hidrológica à escala de horas;

- Escoamento superficial: proveniente da chuva quando a camada superior do solo estiver saturada, apresentando uma resposta hidrológica à escala de horas;

- Escoamento sub-superficial: função do grau de saturação parcial da subzona de água livre da camada superior, apresentando uma resposta hidrológica à escala de dias;

- Escoamento de base primário: proveniente da subzona de água livre primária da camada inferior, apresentando uma resposta hidrológica à escala de semanas ou meses;

- Escoamento de base suplementar: proveniente da subzona de água livre suplementar da camada inferior, apresentado uma resposta hidrológica à escala de dias a semanas.

Assim, o modelo é composto por uma série de reservatórios com capacidades prédeterminadas, interligados por processos que permitem a quantificação das condições de umidade do solo, as quais controlam a produção do escoamento fluvial. A medida que ocorrem eventos de precipitação estes reservatórios são preenchidos. O esvaziamento ocorre por percolação, evaporação ou drenagem lateral. Além disso, no modelo divide-se a área da bacia em regiões permeáveis e impermeáveis.

Pinho e Vieira (2006) definiram o seguinte fluxo de trabalho para a aplicação do SOBEK para a modelagem hidrológica, hidrodinâmica e de qualidade da água utilizada no desenvolvimento de um Sistema de Suporte à Decisão para a gestão da água no Empreendimento de 
Fins Múltiplos de Alqueva: preparação de mapa auxiliar à discretização espacial; criação de nós adequados à simulação das estruturas hidráulicas e fronteiras; estabelecimento das ligações internodais (por terem sido aplicados modelos unidimensionais, foram considerados nós em pontos em que existem estruturas hidráulicas, nas fronteiras e nos limites de trechos em que ocorrem variações de seção transversal); definição das seções transversais; e definição de vários conjuntos de dados relativos à simulação (duração, condições iniciais, parâmetros associados ao método numérico utilizado). No estudo, o sistema modelado compreendeu as bacias hidrográficas, os reservatórios, os canais e os principais cursos de água.

\subsection{MGB-IPH}

O MGB-IPH (Modelo de Grandes Bacias - do Instituto de Pesquisas Hidráulicas) é um modelo hidrológico utilizado para estimar o balanço hídrico, evapotranspiração e propagação de fluxo a partir de células e linhas de fluxo através da rede de drenagem gerando simulações em escala temporal diária ou sub-diária (horas). A bacia de drenagem é dividida em blocos quadrados formados por uma combinação de características quanto ao uso e ocupação, vegetação e solo e contendo três reservatórios (água superficial, água sub-superficial e subterrâneo).

Este modelo hidrológico distribuído desenvolvido para modelar para bacias de grande escala utiliza Muskingum-Cunge Não Linear (NLMC) como equação governante, que é apropriado para aplicações de grande escala(COLLISCHONN et al., 2007; PONTES; COLLISCHONN, 2012). Este modelo hidrológico estima as discargas atrvés do cálculo do escoamento superficial de acordo com o tipo de solo, usos e ocupação do solo dentro da bacia hidrográfica, os quais são novamente classificados utilizando Unidades de Resposta Hidrológica ou HRU (Hydrology Response Units e para a evapotranspiração o MGB utiliza equações de Penman-Monteith (KOUWEN et al., 1993). Para aplicações de previsaão em tempo real a escala temporal de simulação geralmente usada é a escala horária.

O modelo utiliza o modelo Xinanjiang para o balanço hídrico do solo, o método de Muskingum-Cunge para a propagação de fluxo e a equação de Pennman-Monteith para calcular a evapotranspiração (COLLISCHONN et al., 2007).

Este modelo apresenta uma grande potencialidade de ser aplicado em bacias hidrográficas de grande escala, com base de dados escassos, como é a maioria dos casos encontrados no América do Sul, bacias com grandes áreas e com poucas estações de monitoramento hidrológico distribuídas no território e com mapas disponíveis com relativa baixa resolução. O modelo foi empregado em diversas regiões do Brasil, bem como outros países da América Latina como Paraguai, Bolívia, Peru e Argentina, sendo também aplicado na bacia do Rio Grande para predição de vazão a curto e longo prazo para planejamento operacional de sistemas de geração hidrelétrica, obtendo resultados satisfatórios a curto prazo com erros de $10 \%$ a $20 \%$ menores que 
o modelo estocástico atualmente empregado, porém sendo necessários melhorias nos "ensembles" de predição climatológica.

\subsubsection{Muskingum-Kunge}

Chanson (2004) afirma que este método tem sido desenvolvido desde 1938, quando foi originalmente proposto por McCarthy e ampliado em 1969 com a adição de cálculo de contribuição lateral resultando no Método Não-Linear de Muskingum-Cunge (NLMC), em que a vazão é calculada em cada passo de tempo e, assim, os parâmetros $\kappa$ e $\varepsilon$, são atualizados e mudam ao longo do tempo e de acordo com a descarga.

$$
s=\kappa\left[\varepsilon I+Q_{\text {out }}(1-\varepsilon)\right]
$$

Os parâmetros $\kappa, \varepsilon, I, Q_{o u t}$, definem respectivamente coeficiente de armazenamento, fator de peso, a taxa de vazão afluente para o corpo d'água, taxa de vazão defluente do corpo d'água. A diferença infinita é formulado por:

$$
Q_{j+1}^{n+1}=C_{1} Q_{j}^{n}+C_{2} Q_{j}^{n+1}+C_{3} Q_{j+1}^{n}
$$

Onde $n$ é o tempo sobrescrito, $j$ é o espaço subscrito, $Q$ é vazão, e $t$ é o incremento de tempo de encaminhamento da célula de diferenças finitas.

\subsection{SPRNT}

SPRNT é acrônimo para (Simulation Program for River Networks), este modelo é uma ferramenta dinâmica de simulação de redes fluviais. Sendo capaz de solucionar redes complexas de canais de rios atarvés da forma totalmente dinâmica das ESV. Ao contrário de outros softwares de modelagem rio, SPRNT foi concebido como um "motor", não fornecendo uma interface de usuário. A idéia dos desenvolvedores deste modelo é de que o SPRNT seja utilizado como uma rotina interna de programas de simulação de redes fluviais como uma rotina de cálculo para simulações.

A configuração das redes de canais, termos forçantes e condições de contorno são todos especificados em um único arquivo-texto chamado "netlist". Os resultados da simulação também são salvos em um arquivo de texto com base em texto, e portanto deverá ser lido e plotados por qualquer software de visualização científica como MATLAB, Scilab,etc.. ou Integrado em Programas com Interface gráfica embutida como OpenFOAM, OpenMI, Delft-FEWS, etc.. o que poderá ser feito com relativa facilidade por modeladores e programadores. 
Liu e Hodges (2014), apresentam o modelo SPRNT, como sendo um modelo hidráulico capaz de resolver grandes redes complexas de rios com mais de $10^{3}$ elementos. $\mathrm{O}$ modelo conseguiu solucionar uma rede com $10^{5}$ elementos 330 vezes mais rápido que tempo real utilizando um computador pessoal. O modelo incorpora técnicas de aceleração para solucionar a equação de Saint-Venant.

O modelo incorpora conceitos originalmente utilizados para resolver integração de Sistemas Muito Grandes (VLSI -Very large System Integration), que são usados em problemas de projeto de microcomputadores. Neste modelo toda rede fluvial é simulada como uma única partição como uma matriz.

O SPRNT soluciona a forma não conservativa das ESV, realizando as seguintes operações:

I. Verificação topológica e da conectividade da rede de rio, bem como a especificação apropriada dos termos forçantes e condições de contorno;

II. Solução de escoamento estacionário do sistema de equações de Saint-Venant, para calcular as condições iniciais corretas;

III. Solução do escoamento não estacionário com vaiação do intervalo de tempo dos temos forçantes e condições de contorno.

Por ser estruturado para servir como motor para realizar os cálculos, ele também pode ser utlizado através de um conjunto de API (Application Programming Interface). Através da API, outro modelo pode ser utilizado para construir as redes fluviais, especificar os termos forçantes e condições de contorno, bem como executar soluções estáveis e instáveis. O SPRNT pode ser executado também no padrão go-stop-go-stop, e desta forma pode ser integrado a outros modelos, como um modelo hidrológico ou um modelo Chuva-Vazão (LIU, 2014). 


\section{Delft-FEWS}

O desenvolvimento de sistemas de alerta de previsão de enchentes é um elemento essencial tanto para o planejamento regional quanto para o nacional. Recentemente desenvolvimentos na previsão numérica climática, dados de radares meteorológicos e aquisição de dados hidrológicos e meteorológicos on-line resultaram em um crescente interesse em processamento de importação e dados de dados.

Delft-FEWS é uma plataforma de manipulação de dados aberto que foi inicialmente desenvolvido como um sistema para previsão e alerta de inundações. Essencialmente, é uma coleção sofisticada de módulos projetados para a construção de um sistema de previsão hidrológica personalizado para as necessidades específicas de uma organização individual. É um sistema moderno de alerta e previsão de inundações com integração de grandes conjuntos de dados, módulos especializados para processar os dados e interfaces abertas para permitir a fácil integração das capacidades de modelação existentes (Figura 20).

O software Delf-FEWS da Deltares representa um avanço em sistemas de previsão hidrológica e sistemas de alerta, introduzido em 2002/2003, ele permitir a criação e customização de modelos e sistemas através da integração de extensos conjuntos de dados e módulos especializados de processamento de dados e uma interface que permite a simulação em tempo real e a fácil integração dos modelos existentes permitindo adaptação dos modelos e sistemas conforme as necessidades de cada projeto específico. Esta abordagem modular garante maior flexibilidade de integração de novos modelos e algoritmos ao código-fonte, não sendo necessária extensa reprogramação para realizar modificações no mesmo (WERNER et al., 2013).

O sistema é "Open Shell” que permite ao usuário liberdade para gerenciar os dados e processos de previsão e de escolher o modelo hidrológico que melhor se adapte a suas necessidades. Este software incorpora uma extensa biblioteca de utilitários para gerenciamento de dados permitindo que uma vasta gama de modelos externos de previsão possam ser integrados ao sistema através de uma interface aberta.

Com uma natureza modular e altamente configurável é possível aplica-lo tanto em sistemas simples quanto em complexos e é adaptável para diversas aplicações incluindo previsão de enchentes, previsão de qualidade de água, gerenciamento de aquíferos, aplicações para controle em tempo real ou simplesmente como um banco de dados (DELTARES, 2012).

Para permitir o gereciamento de grandes quantidades de dados, o sistema fornece uma série de utilitários genéricos para permitir o suporte automatizado de tarefas como integração de 


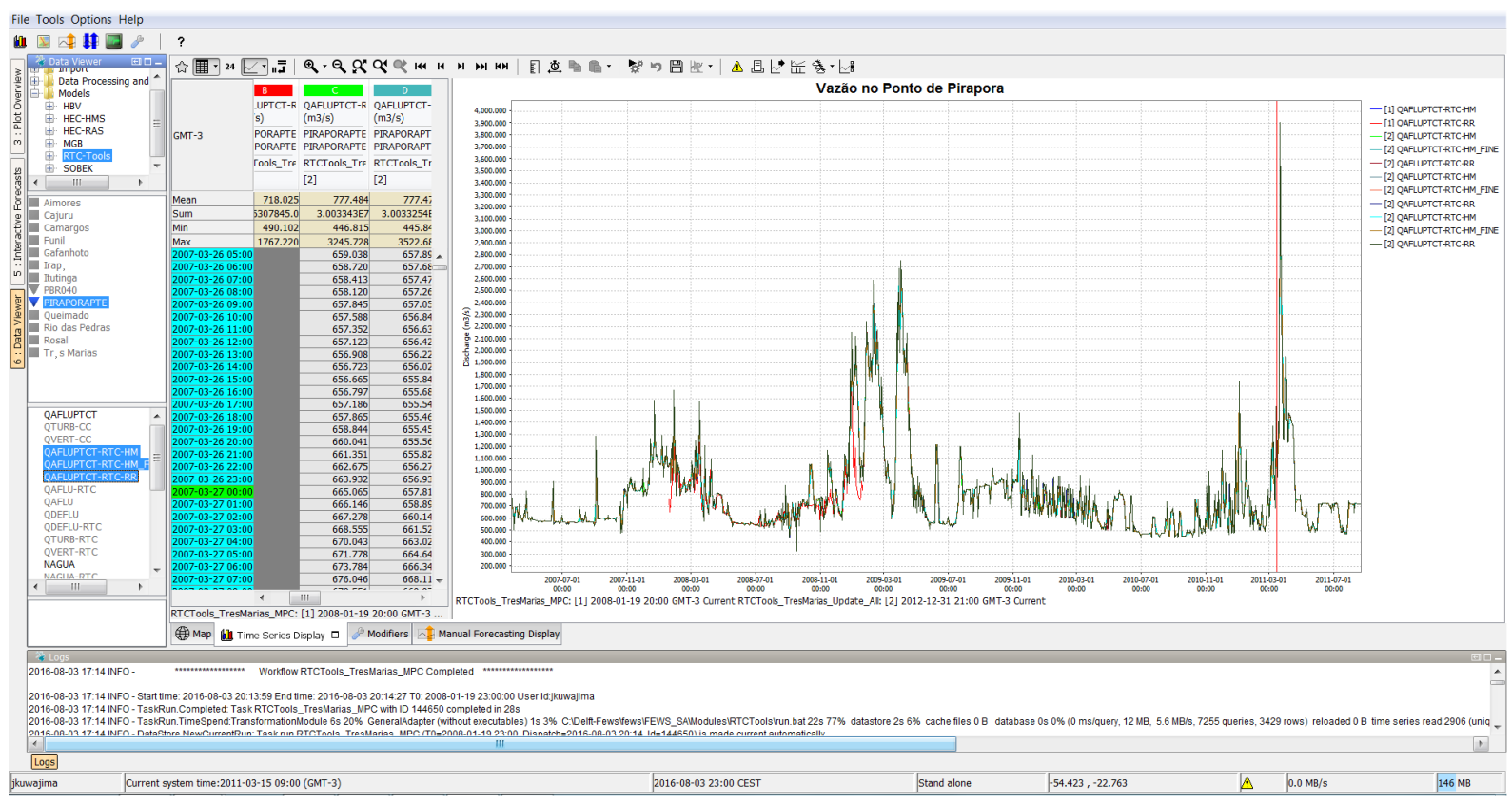

(a) Interface Gráfica de Usuário

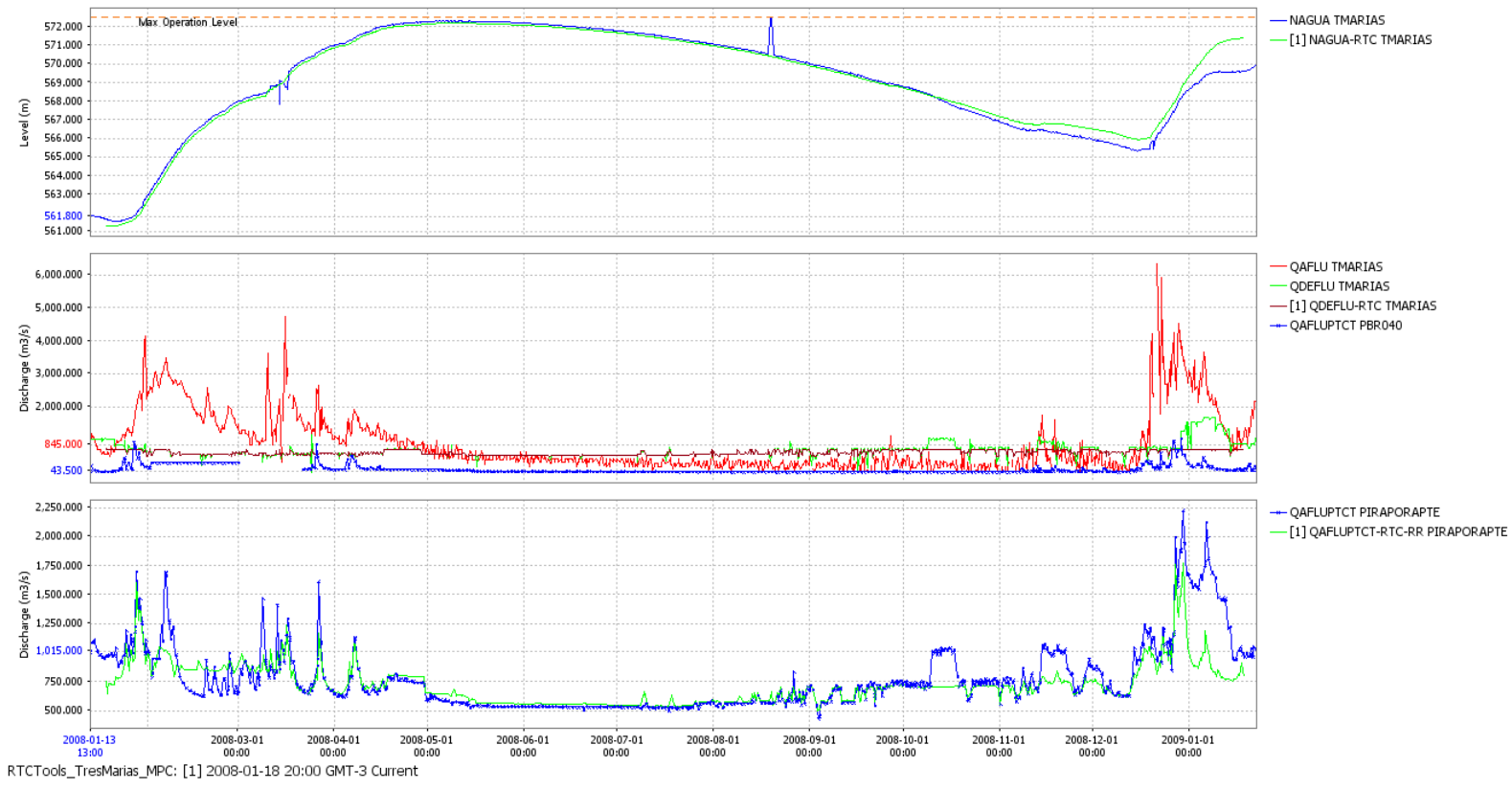

(b) Vizualização de Resultados

Figura 20 - Interface Gráfica de Resultados no Delft-FEWS. 
dados, validação e troca de informações. A verificação da consistência de dados externos é feita através da validação e opções de interpolação de dados por preenchimento de lacunas. Existem também ferramentas para correção de discrepâncias espaciais e temporais.

Na Figura 21 podemos visualizar os diferentes componentes do sistema. O centro de banco de dados forma o coração do sistema de previsão desta plataforma. Este núcleo serve para o gerenciamento de séries temporais de dados tanto para escalas de tempo equidistantes quanto não-equidistantes com representação em pontos, vetor, raster ou poligonal. Conforme demostrado na mesma figura todos os componentes comunicam entre si através desta central de base de dados através de comandos de armazenamento ou busca de dados sendo gerenciados por um módulo intermediário de acesso de dados, que permite ao sistema possuir uma independência em relação a implementação de banco de dados físcos. Atualmente o sistema utiliza o gerenciador de banco de dados Microsoft Access, Firebird para banco de dados locais e Oracle PostgreSQ1 ou servidor SQL como servidor para o banco de dados central em um sistema cliente-servidor (WEERTS; SCHELLEKENS; WEILAND, 2010).

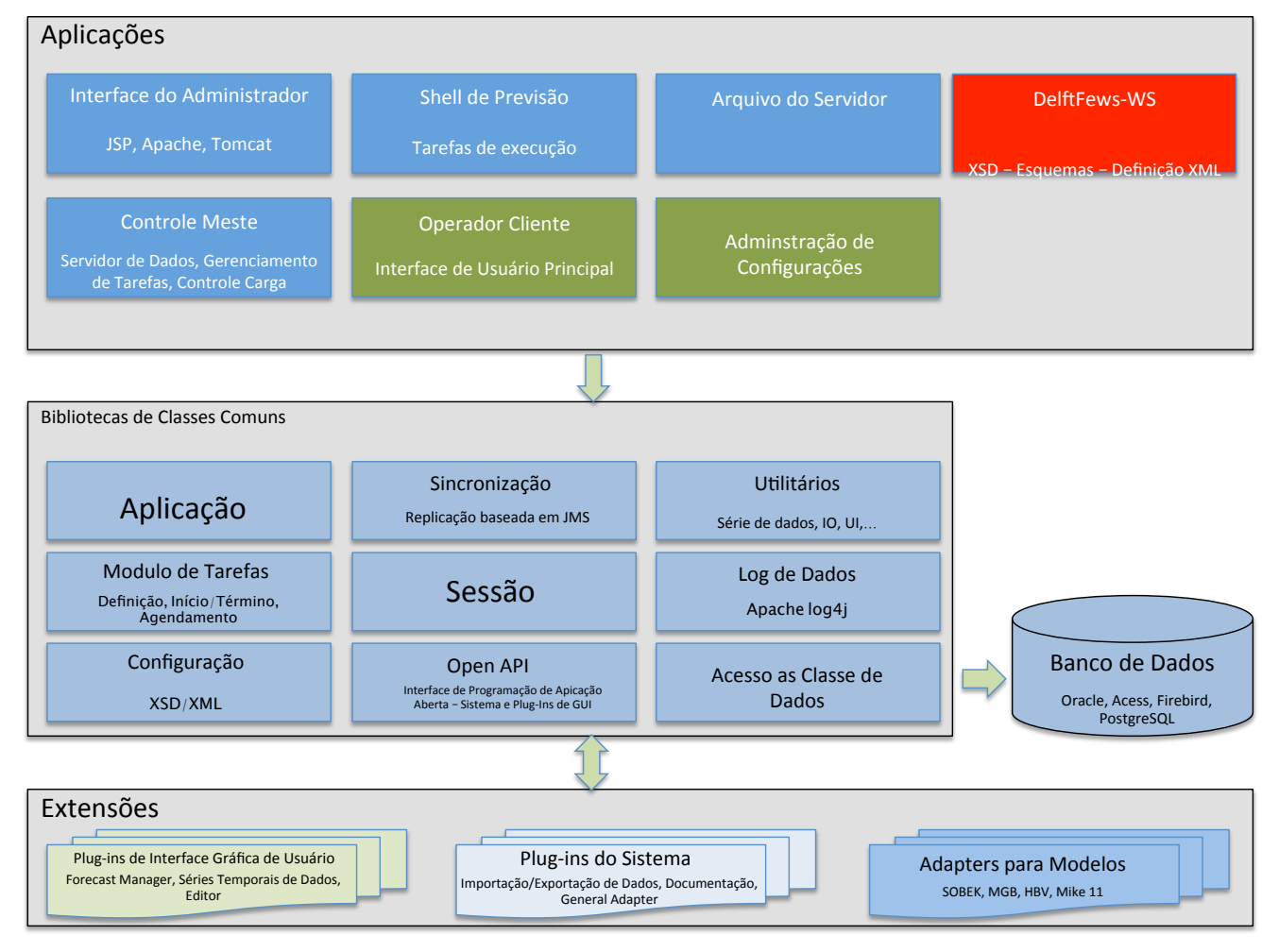

Figura 21 - Esquema da arquitetura do sistema de previsão Delft-FEWS.

Fonte: Adaptado de Weerts, Schellekens e Weiland (2010).

A comunicação entre o sistema de previsão e bancos de dados externos e feita através de módulos de importação e exportação, que incluem importação de previsões numéricas de clima NWP (Numerical Weather Predictions) e modelos meteorológicos de grande escala utilizando 
formatos padrões suportados pelas agências meteorológicas (GRIB, GRIB2 ou NetCDF-cf). Existe um módulo que permite os sumários e os resultados das previsões possam ser distribuídos via internet/intranet através de aquivos HTML/XML.

A plataforma apresenta uma vasta gama de modelos que podem ser incorporados a ela conforme o projeto específico; para facilitar a integração e comunicação entre eles uma interface define como esta troca de dados, escalas de tempo, estados e parâmetros será feita através de arquivos formatados XML. Para cada módulo incorporado ao sistema há necessidade de desenvolver um módulo de adaptação para implementar este padrão de comunicação via arquivos XML (Figura 22).

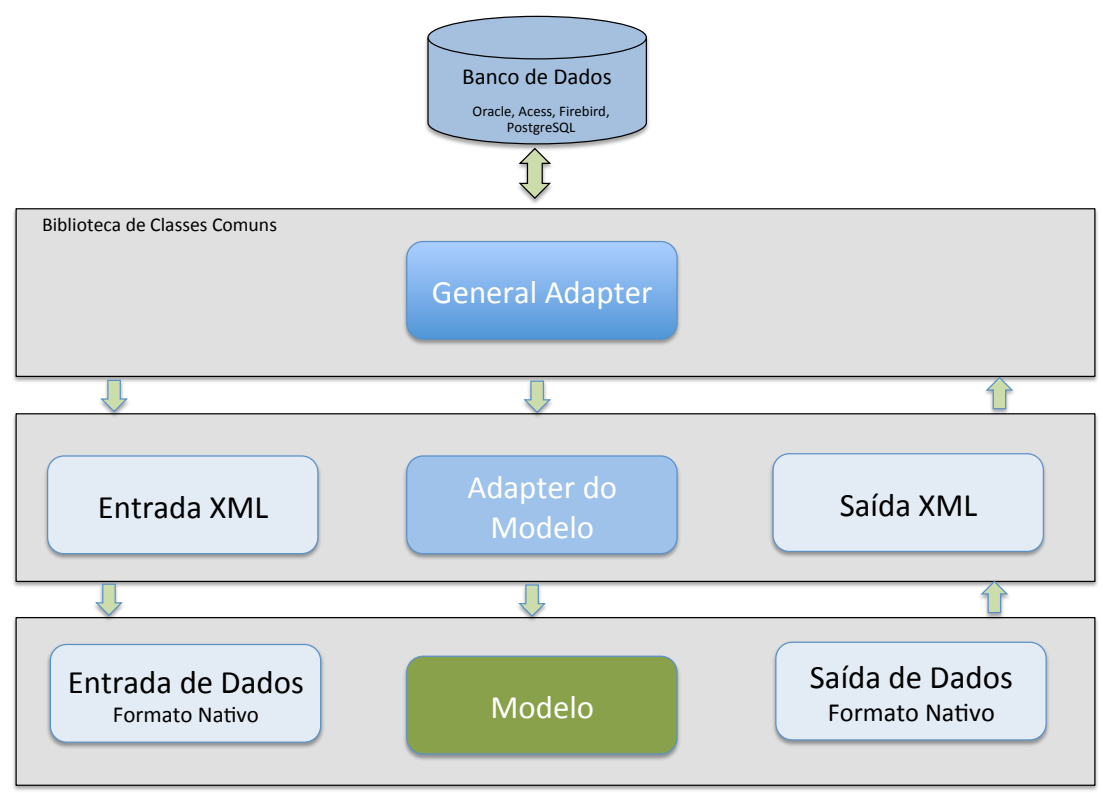

Figura 22 - Comunicação entre os modelos e a inteface Delft-FEWS.

Fonte: Adaptado de Weerts, Schellekens e Weiland (2010).

Atualmente o código fonte do Delft-FEWS ainda não se encontra totalmente aberto, embora muitos módulos de interface sejam "open source", o código fonte do núcleo do sistema não está disponível. Espera-se, que assim que o desenvolvimento e gerenciamento de processos que atendam os requistos operacionais para agências de previsão estiver completamente implementado, possa garantir a estabilidade do software e disponibilizar o código fonte (WERNER et al., 2013).

Atualmente existem aproximadamente 60 modelos compatíveis para esta plataforma entre eles modelos de Chuva-Vazão, Hidrodinâmicos, Propagação de cheias, Aquífero, Infiltração, Escoamento sub-superficial, de Simulação de reservatórios e de Operação em tempo real. Entre estes modelos destacam-se o RTC-Tools e o SOBEK. 
Na configuração de pesquisa utilizou-se o Delft-FEWS para integrar os bancos de dados de entradas dos modelos utilizados (SOBEK, MGB-IPH e RTC-Tools), e compartilhar dados de saída. Como o SOBEK e RTC-Tools são modelos exlclusivamente hidráulicos, as vazões incrementais e e laterais serão calculadas pelo MGB-IPH. O modelo hidrológico serve como espinha dorsal do SSD, fornecendo dados de entrada para os demais modelos. O esquema desta integração está representado na Figura 23.

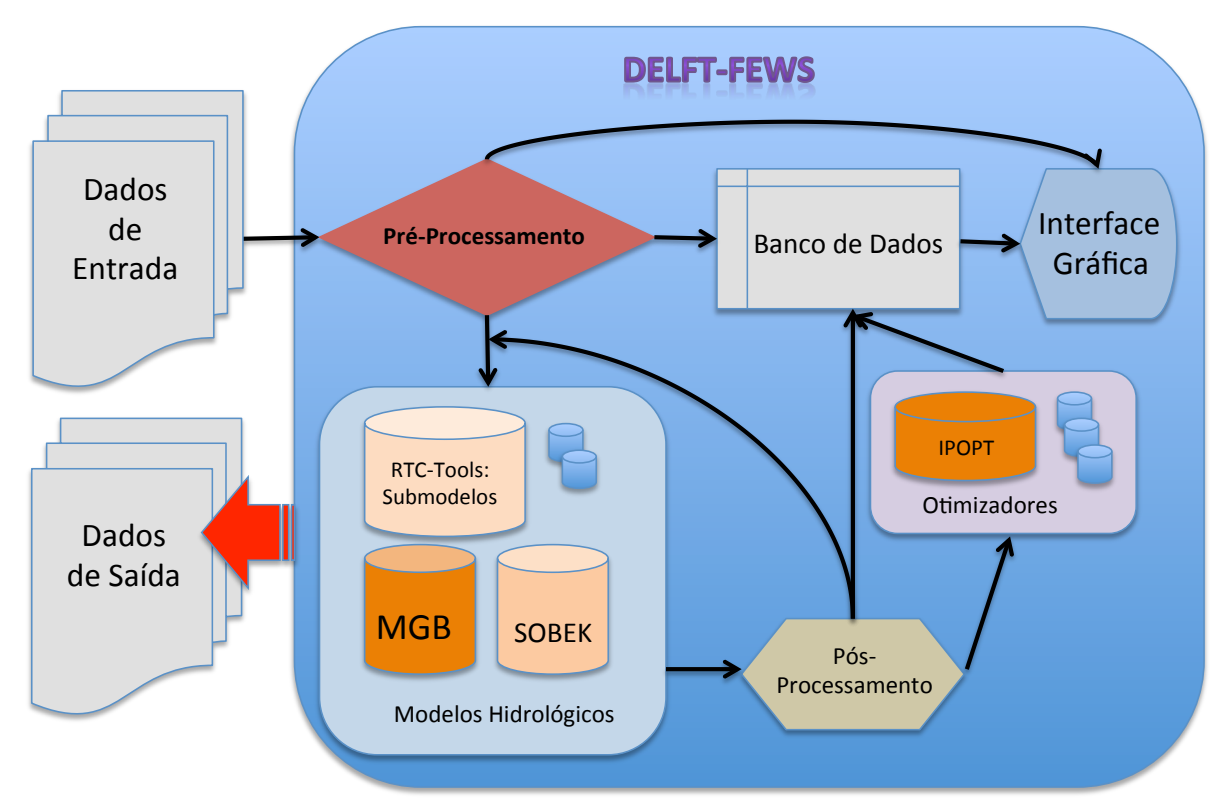

Figura 23 - Esquema da Arquitetura de Integracao dos Modelos no Delft-FEWS.

O Delft-FEWS é um sofisticado sistema composto por um conjunto de módulos que podem ser utilizados em cadeia a fim de construir um sistema operacional de gestão de recursos hídricos adaptável às necessidades individuais de cada agência (GIJSBERS, 2010). O sistema foi elaborado com o objetivo de possibilitar a manipulação e a conexão de uma grande variedade de dados hidrometeorológicos, tanto previstos como monitorados, assim como modelos hidrológicos e hidráulicos. Mais do que um suporte para tomada de decisões estratégicas, o Delft-FEWS forma uma classe especial de sistemas de suporte a decisões ambientais, tendo em vista que funciona em tempo real (MATTHIES; GIUPPONI; OSTENDORF, 2007). A aplicação do sistema se estende desde pequenas escalas, utilizando uma estação de trabalho em um computador de mesa, a grandes escalas, como num sistema de previsão de cheias nacional utilizando tecnologia cliente-servidor distribuída

Uma grande vantagem trazida pelo modelo é que o sistema provê uma plataforma através 
da qual sistemas operacionais de previsão podem ser construídos, o que gera flexibilidade na integração dos modelos e dados. Entretanto, cabe ressaltar que o Delft-FEWS não contém recursos de modelagem hidrológica em seu código base.

Refletindo sobre a interação entre sistemas de previsão e processos de alerta, de acordo com Haggett (1998), os elementos chave dos sistemas de previsão de vazões e alertas de enchente podem ser descritos em quatro passos:

- Detecção;

- Previsão;

- Disseminação e alerta;

- Resposta;

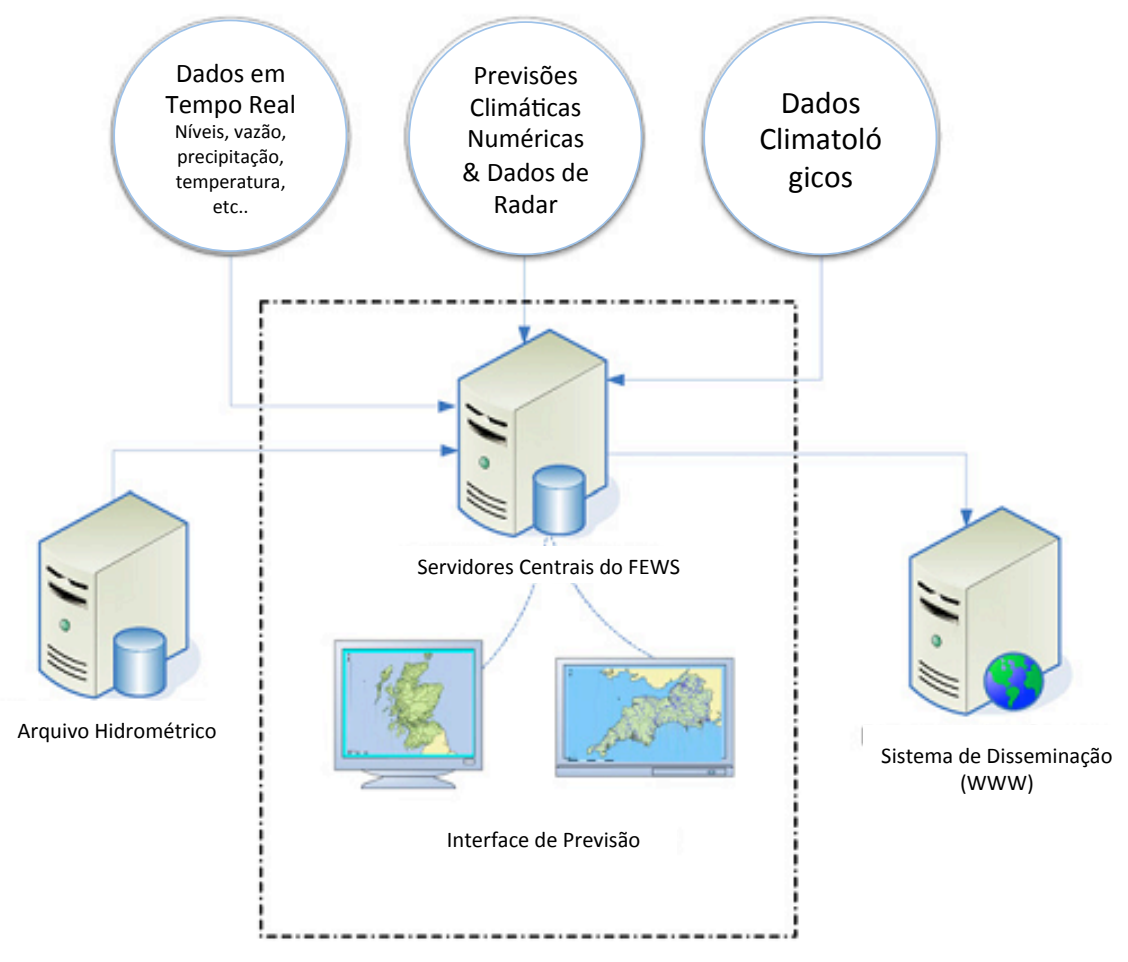

Figura 24 - Estrutura esquemática do sistema de previsão de cheias integrando bancos de dados e modelos dentro do Delft-FEWS.

Fonte: Adaptado de Werner et al. (2013). 
Assim, seguindo esses passos, o Delft-FEWS localiza-se no segundo, previsão. Dentro do passo de previsão, modelos hidrológicos e hidráulicos podem ser utilizados para realizar as predições, portanto, o sistema de previsão necessita funcionar como suporte para o funcionamento desses modelos em tempo real. Além disso, os sistemas de previsão necessitam suportar a entrada e atualização de dados, por meio dos quais os resultados dos modelos preditivos são atualizados a fim de reduzir as margens de erro (MADSEN et al., 2000 apud WERNER et al., 2013) ${ }^{1}$. A Figura 24 apresenta a estrutura esquemática de um sistema de previsão de cheias mostrando a posição do Delft-FEWS e a interação com os outros sistemas primários dentro do ambiente operacional.

\subsection{Estrutura do Delft-FEWS}

Sistemas operacionais de previsão de cheias têm sido desenvolvidos e aplicados em centros de previsão por muitos anos. Particularmente nos casos em que têm sido aplicados por longos períodos de tempo, nota-se uma centralização no uso específico de um modelo e de seus dados de entrada. Entretanto, há algumas desvantagens no uso de sistemas de suporte a decisões que contém uma estrutura fixa e definição rígida dos processos de entrada e saída face à possibilidade de futuras alterações, sejam elas em relação ao modelo ou aos dados a serem utilizados para realização das previsões.

Atendendo a essa demanda, o Delft-FEWS foi elaborado, segundo Rizzoli et al. (2008), abandonando o conceito de aplicações de modelagens monolíticas em favor da adoção da modelagem em componentes construídos em blocos bem definidos, o que garante flexibilidade. Assim, mais do que centrado em modelos, o Delft-FEWS tem como foco central os dados e o processamento dos mesmos. Dessa forma, com as mudanças necessárias nos sistemas operacionais de previsão, o design do Delft-FEWS segue o conceito descrito por Argent et al. (2009), no qual ele provê um software através do qual o sistema de previsão pode ser desenvolvido atendendo os requisitos específicos de um centro operacional de previsão.

Todos os componentes do sistema se comunicam através de uma base de dados central que requer que a aquisição e o armazenamento dos dados sejam realizados por um módulo de acesso. $\mathrm{O}$ foco dessa base de dados está na manipulação de séries temporais de dados, com passos de tempo que podem ser iguais ou não, em formato de ponto, vetor, raster ou polígono.

O uso de um módulo intermediário de acesso aos dados permite que o sistema seja independente de uma implementação física de uma base de dados. Em relação a este tópico foram realizadas algumas implementações recentes no sistema, tais como: inclusão de bases de dados do Microsoft Access e Firebird para a base de dados local, e Oracle PostgreSQL ou

1 MADSEN, H. et al. Data assimilation in rainfall runoff forecasting. In: 4th Hydroinformatics Conference. Cedar Rapids, Iowa: [s.n.], 2000. 
SQL Server para a base de dados central no sistema cliente servidor. Apesar de diversos módulos utilizados pelo modelo apresentarem-se abertos, o código base não possui acesso aberto. Alguns aprimoramentos recentes foram realizados no sistema, conforme segue (VERWEY et al., 2006):

- Maior abertura para o processamento dos dados de precipitação, incluindo modelagem climatológica, produtos gerados por radares e satélites;

- Maior abertura para a inclusão de uma variedade de sistemas de modelagem hidrológicos e hidráulicos calibrados. Dentre os modelos que já podem ser utilizados no acoplamento genérico, estão: Sacramento, NAM, LISFLOOD, HBV, SOBEK, Mike11, ISIS e HECRAS;

- Partes do sistema foram reprogramadas utilizando a tecnologia JavaTM a fim de facilitar a instalação em plataformas independentes para diferentes sistemas operacionais;

- Maior facilidade da configuração do sistema em satisfazer requerimentos específicos de cada configurador através da utilização de formatos de arquivos configurados em XML (eXtensive Markup Language);

- Maior desenvolvimento de ferramentas que permitem acesso a tabelas, indicadores de performance, ferramentas de calibração genérica do modelo, aplicativos de mapeamento de enchentes e simulação de cenários alternativos.

A linguagem de marcadores XML foi elaborada para descrever e estruturar dados. O XML é um padrão de armazenamento de dados em um formato de texto simples, o que significa que pode ser aberto em qualquer computador. Uma das características mais importantes da linguagem XML é que ela não apresenta número máximo de marcadores, podendo ser expandida.

\subsubsection{Importação, armazenamento, processamento e manipulação dos dados}

Em relação à importação e ao armazenamento de dados, na maioria dos sistemas operacionais, dados de diferentes fontes são utilizados, com diferentes formatos para armazenamento e publicação dos mesmos. Sendo assim, Delft-FEWS provê um módulo de importação de dados que foi concebido a fim possibilitar a manipulação de uma gama de dados em formatos diferentes, através de uma classificação em JAVA desenvolvida para formato de dados (DELTARES, 2012).

Muitos dos atuais conceitos de armazenamento e manipulação de dados no Delft-FEWS foram implementados na primeira versão do modelo, desenvolvida dentro do escopo de um projeto de pesquisa europeu (ROO et al., 2003). Os conceitos desses sistemas predecessores foram refinados e combinados com a presente versão do Delft-FEWS (segunda versão). A corrente versão do Delft-FEWS foi iniciada com o estabelecimento do Sistema Nacional de 
Previsão de Cheias da Inglaterra e País de Gales (National Flood Forecasting System in England $\&$ Wales). Esta segunda versão estabeleceu por completo a abertura para integração entre modelos e dados. Cabe ressaltar que o desenvolvimento do sistema tem sido muito dinâmico em vista de encontrar aplicação em um número crescente de sistemas operacionais de previsão. Assim, novos desenvolvimentos no sistema têm sido realizados de acordo com o aparecimento de necessidades de funcionalidades adicionais às novas aplicações.

Nesse contexto, a adoção de um mesmo formato de dados por parte de todas as agências fornecedoras proporciona redução do tempo dispendido para elaboração de novos códigos em JAVA. Uma vez analisados, os dados são armazenados na base de dados do Delft-FEWS. Esta base contém dados de configuração, incluindo informações de localização específica (coordenadas e outras propriedades), e séries dinâmicas de dados, que podem ser importadas de fontes externas. Dentro do Delft-FEWS as séries temporais são identificadas pela localização e tipo de dados, assim como um identificador da fonte dos dados.

Grande parte dos dados não está em escala temporal e espacial adequada para serem utilizados diretamente como entrada nos modelos preditivos. Como consequência, o processamento de dados constitui uma das etapas que requer maiores esforços e consome grande quantidade de tempo. Para a realização da manipulação dos dados, o sistema é equipado com uma extensa biblioteca de funções e processamento de dados, que incluem algumas funções hidrológicas específicas. As ferramentas de transformação de dados incluem métodos para agregação ou desagregação temporal, avaliação de equações simples e de funções hidrológicas simples assim como transformação de altura do nível de água em vazões através da curva-chave e cálculo de evapotranspiração (WERNER et al., 2013).

Os aplicativos do sistema incluem:

- Controle de qualidade dos dados de precipitação importados da base de dados hidrológicos em tempo real;

- Agregação dos dados em intervalos de 15 min à intervalos horários;

- Interpolação dos dados utilizando polígonos de Thiessen;

- Obtenção de taxa de precipitação através de imagens de radar;

- Obtenção de dados através do grid numérico;

- Correção da hidrograma gerado pelo modelo hidrológico através do algoritmo de correção de erro (ARMA);

- Dimensionamento da hidrógrafa para pequenos tributários não abrangidos pelo modelo, o que provê as condições de contorno de jusante para a o modelo hidrodinâmico. 
Grande parte das funções é aplicável a séries de dados em formato escalar ou matricial. Para operações espaciais complexas o sistema não possui recursos em seu código base, porém utiliza uma integração incorporada com a ferramenta de processamento espacial PCRaster.

Para o caso de necessidade de novas funções, novos algoritmos podem ser construídos e utilizados pelo sistema desde que o código em JAVA esteja incluído no aplicativo de interface de programação.

\subsubsection{Integração de Modelos}

Segundo Werner et al. (2013) o Delft-FEWS disponibiliza os dados de entrada e parâmetros, executa o modelo (hidrológico e/ou hidrodinâmico) e lê os resultados. Entretanto, devido a grande variedade de modelos que podem ser integrados, o sistema muitas vezes pode estar sujeito a erros ocasionados pela má interpretação dos dados e parâmetros. Para reduzir essa complexidade, o Delft-FEWS se utiliza de uma interface em XML através da qual toda comunicação entre os modelos é realizada.

Todos os modelos que têm sido integrados com o Delft-FEWS estão atualmente sendo executados em sistemas operacionais que seguem o conceito de interfaces XML independentes para modelos externos. O Delft-FEWS gera os dados de entrada como um conjunto de arquivos XML, um adaptador desenvolvido especialmente para o modelo em questão transforma os dados para um formato próprio para a realização da etapa de pré-processamento dos mesmos; o Delft-FEWS executa o modelo; e então o adaptador transforma novamente os dados no formato XML na etapa de pós-processamento. Subsequentemente os resultados são importados para a base de dados no formato XML. É o adaptador que permite que quaisquer modelos possam ser utilizados pelo Delft-FEWS (DELTARES, 2012).

O passo final no processo de previsão é a geração de produtos que podem ser divulgados num sistema de alerta. O Delft-FEWS pode gerar resultados na forma de gráficos, tabelas assim como resumos dos mesmos. Estes valores podem ser inseridos em base de mapas para permitir a visualização geográfica dos principais resultados. Os produtos gerados pelo sistema podem conter tanto previsões determinísticas quanto probabilísticas. Atualmente informações probabilísticas têm adquirido maior importância na disseminação dos resultados. No sistema, elas podem ser geradas em gráficos e tabelas, sumários estatísticos assim como probabilidade de excedência de valores estabelecidos.

Segundo Werner et al. (2013), nenhum dos módulos funcionais do Delft-FEWS tem acesso direto aos dados a não ser pela interface própria para tal, assim como não há comunicação direta entre os modelos. Cada passo realizado no processo de previsão é agrupado em um fluxo de trabalho, que simplesmente lista a sequência dos mesmos na ordem em que devem ser executados. 
Um exemplo de fluxo de trabalho pode ser visto na Figura 25.

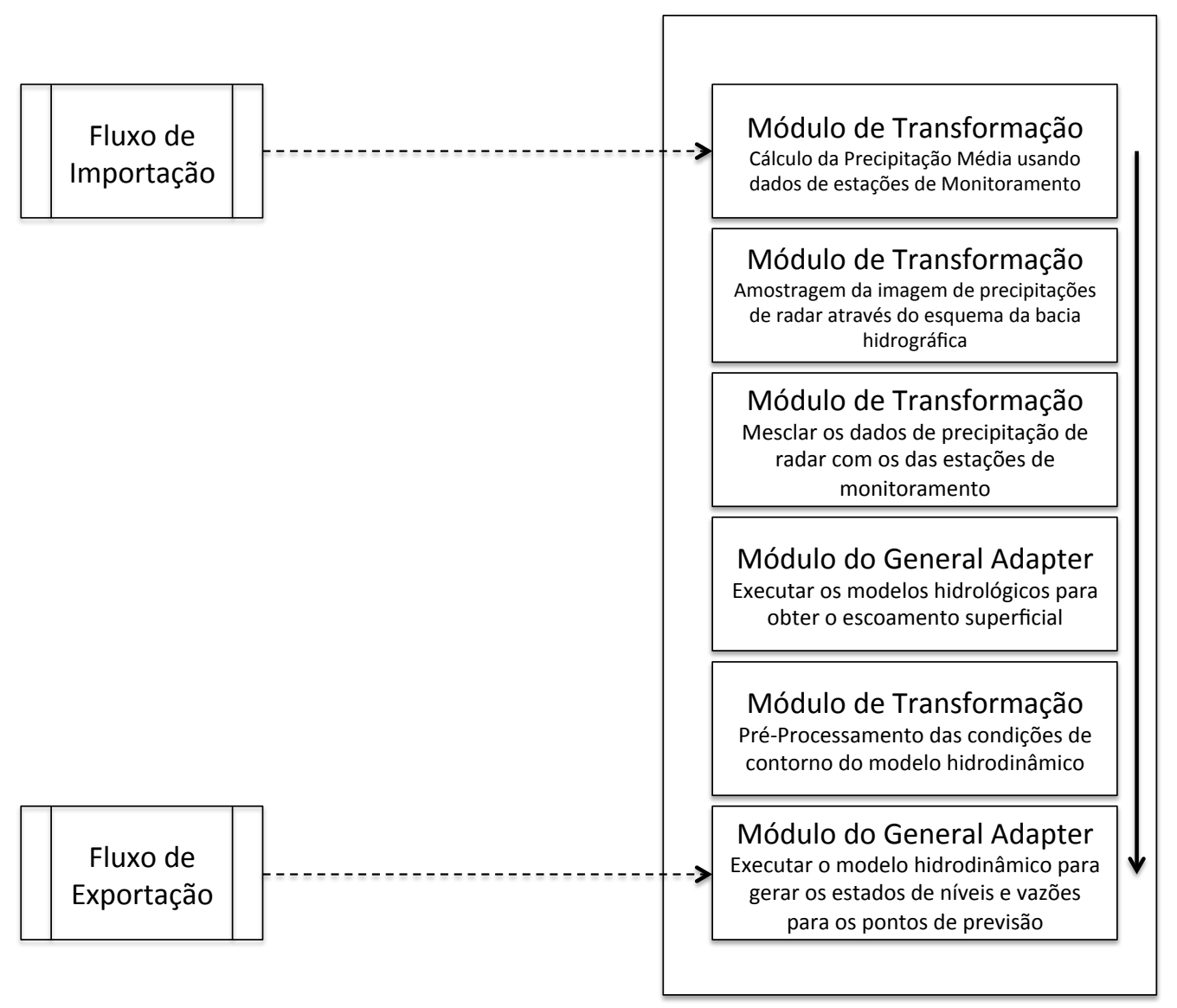

Figura 25 - Exemplo de um Workflow (fluxo de trabalho) mostrando o processo de previsão para uma simulação hidrodinâmica de uma bacia hidrográfica.

Fonte: Adaptado de Werner et al. (2013).

Conforme anteriormente citado, a configuração do Delft-FEWS é definida por um grupo de arquivos XML. Inicialmente, a configuração do sistema é composta por um conjunto de diretórios, cada um contendo diferentes partes da mesma. Depois, a configuração do modelo fica inteiramente contida no banco de dados local como um conjunto de tabelas, cada uma refletindo um dos subdiretórios da configuração inicial. Assim, quando iniciado, o Delft-FEWS procura pelas configurações contidas no diretório local, e quando não encontradas, ele procura dentro do banco de dados. No sistema em operação o conteúdo da base de dados será sincronizado entre todos os operadores e os servidores dos modelos de previsão, sendo assim, é esperado que seja igual em todas as partes do sistema (DELTARES, 2012).

Além da parte sincronizada da configuração, há ainda os arquivos de configuração de raiz, que são únicos para cada cliente operador e/ou para a linha de comando do servidor do sistema de previsão. 


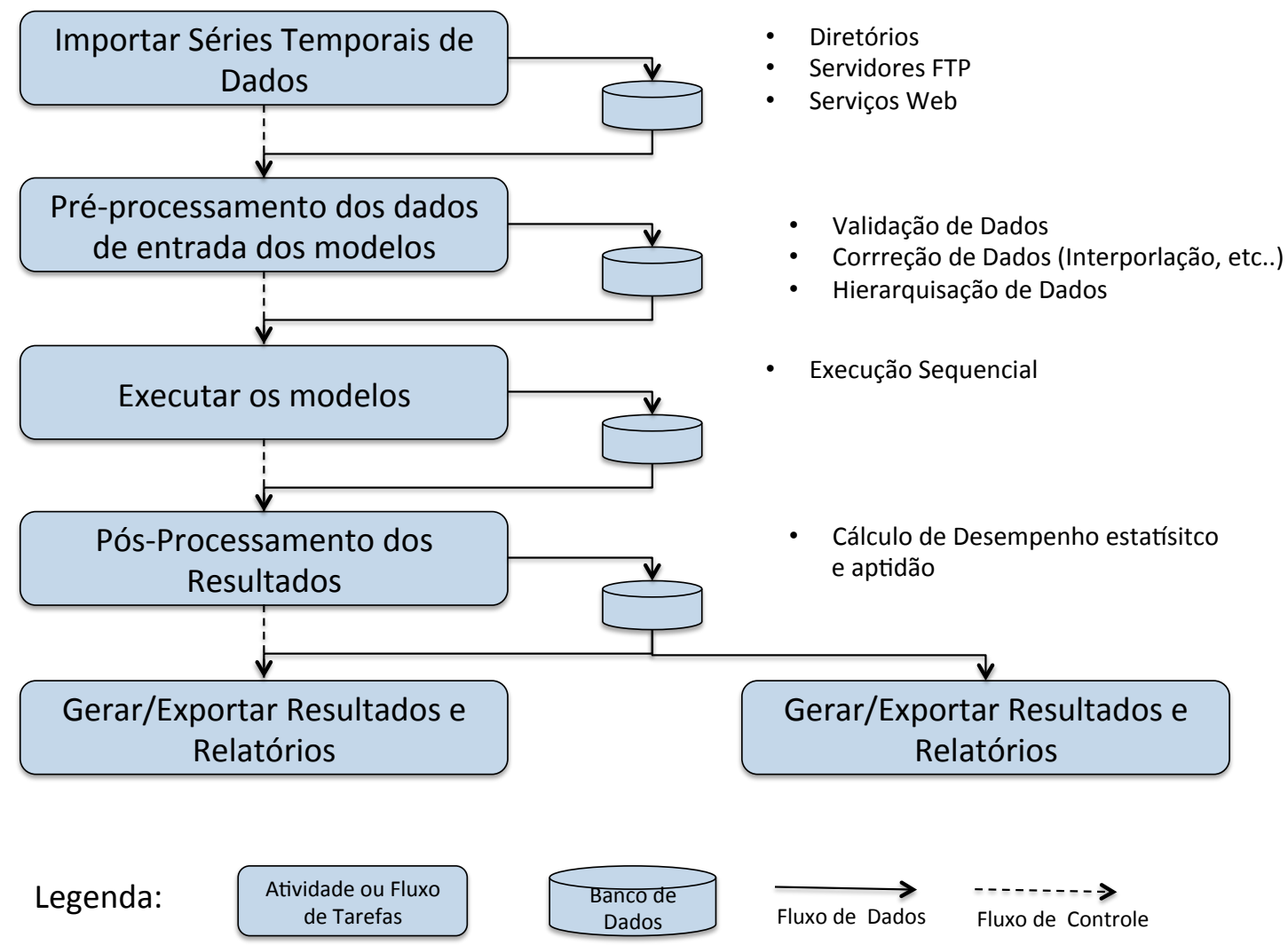

Figura 26 - Exemplo de um Workflow (fluxo de trabalho) mostrando os processos para a simulação.

Fonte: Adaptado de (GIJSBERS, 2010). 


\section{Estudo de Caso:Bacia Hidrográfica do Alto São Francisco}

Neste capítulo serão tratadas as peculiaridades da bacia hidrográfica usada para avaliar a performance computacional e as potencialidades dos modelos hidrológicos propostos para uso na operação de reservatórios. Serão também abordados as características hidrológicas da bacia, bem como as características e e restrições operativas da UHE-Três Marias.

A previsão de vazões afluentes e a operação do aproveitamento de Três Marias são relevantes no processo de operação dos demais reservatórios da bacia do rio São Francisco, localizados a jusante deste reservatório, uma vez que as afluências naturais a este aproveitamento representam cerca de $26 \%$ das afluências desse mesmo rio São Francisco e que, tais processos, interferem nas definições de estratégias energéticas para o Subsistema Nordeste (ONS, 2009a).

O reservatório de Três Marias localiza-se na região do Alto São Francisco, entre os

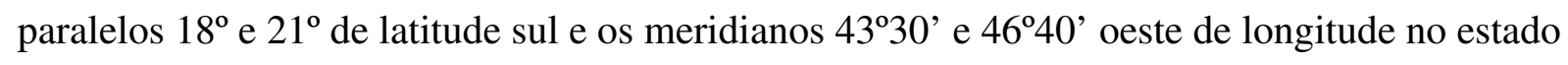
de Minas Gerais (Figura 01), em uma zona climática tropical. A área estende-se desde as cabeceiras, na Serra da Canastra, município de São Roque de Minas, até a cidade de Pirapora (MG), abrangendo as sub-bacias dos rios das Velhas, Pará e Indaiá, além das sub-bacias dos rios Abaeté e Jequitaí.

As unidades geomorfológicas existentes na bacia do Alto São Francisco são o Planalto Dissecado do Centro-Sul e Leste de Minas, a Depressão São Franciscana, o Planalto do São Francisco, o Quadrilátero Ferrífero e a Serra do Espinhaço. O Alto São Francisco apresenta topografia ligeiramente acidentada, com serras e terrenos ondulados e altitudes que variam de 1.600 a $600 \mathrm{~m}$. O divisor leste é formado pelas montanhas da Serra do Espinhaço, estreitas e alongadas na direção N-S, e com altitudes de 1.300 a $1.000 \mathrm{~m}$. Do lado oeste, destacam-se as Serras Gerais de Goiás, cujas cotas oscilam entre 1.200 e 800 m.

A Agência Nacional de Energia Elétrica - ANEEL divide a bacia do rio São Francisco em nove sub-bacias. A região estudada corresponde à sub-bacia 40. Esta sub-bacia representa a área de drenagem do reservatório de Três Marias e parte da área de drenagem do Alto São Francisco (sub-bacias 40 e 41) (ONS, 2009a).

Segundo a ANA/SPR, o Alto São Francisco possui 167 municípios, sendo 93\% da área urbanizada, com uma densidade demográfica de $62,9 \mathrm{hab} / \mathrm{km}^{2}$ e uma disponibilidade hídrica de $6.003 \mathrm{~m}^{3} / \mathrm{hab} / \mathrm{ano}$. 
O rio São Francisco é um dos mais importantes rios brasileiros e tem papel destacado principalmente na região sudeste e Nordeste. O "Velho Chico", como é chamado pelos moradores é essencial nesta parte do país, não só devido a sua importância estratégica, sendo ele o principal rio de um projeto de transferência de água entre bacias hidrográficas, que visa resolver a seca que afeta os estados do Nordeste: Ceará, Rio Grande do Norte, Paraíba e Pernambuco; mas também por causa de seu significado cultural, a área em torno dele está repleta de sítios arquitetônicos, arqueológicos e patrimoniais Santos (2003).

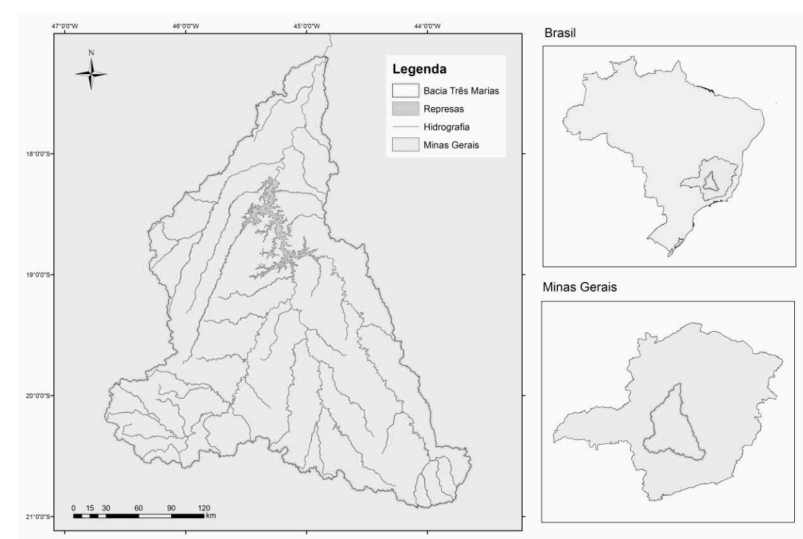

(a) Bacia Hidrográfica da UHE Três Marias

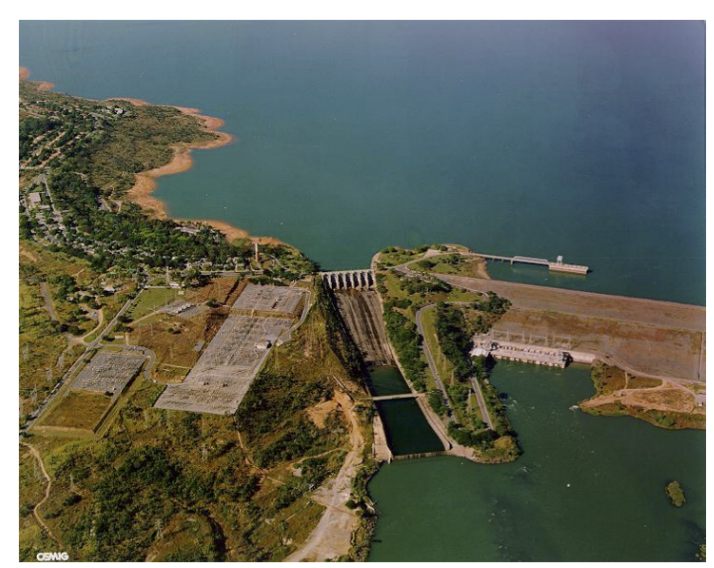

(b) Barragem da UHE Três Marias

Fonte: Adaptado de Schwanenberg et al. (2015) e Fan (2011).

Figura 27 - Local de Estudo UHE Três Marias, localizado no estado de Minas Gerais (MG).

O reservatório de Três Marias, também conhecido como UHE Bernardo Mascarenhas, é um dos 5 reservatórios construídos neste rio para fins de geração energética. O reservatório está localizado no Rio Região do Alto São Francisco, no centro do estado de Minas Gerais entre os municípios de São Gonçalo do Abaeté, Felixlândia, Morada Nova de Minas, Biquinhas, Paineiras, Pompéu, Abaeté e Três Marias Figura 27.

\subsection{UHE-Três Marias}

As obras de construção da represa tiveram início em maio de 1957, sendo concluída em janeiro de 1961, sob a responsabilidade da CVSF (Comissão do Vale do São Francisco). Sua construção teve como principais objetivos: regularização do curso das águas do rio São Francisco nas cheias periódicas, melhoria da navegabilidade, utilização do potencial hidrelétrico, e fomento da indústria e irrigação. No momento da sua inauguração, a UHE Três Marias era considerada a maior usina hidrelétrica brasileira.

As dimensões da represa são $2.700 \mathrm{~m}$ de largura e $75 \mathrm{~m}$ de altura. O reservatório tem uma área máxima de $1.010 \mathrm{~km}^{2}$ e mínima de $316 \mathrm{~km}^{2}$, correspondendo a volumes de $19.528 \mathrm{e}$ 
$4.250 \mathrm{hm}^{3}$, respectivamente. O nível máximo operativo é 572,50 m, e o nível mínimo operativo é $549,20 \mathrm{~m}$ e área de drenagem é de $50.732 \mathrm{~km}^{2}$ (Tabela 8).

Tabela 8 - Características da Usina Hidrelétrica de Três Marias.

\begin{tabular}{llllllll}
\hline \hline $\begin{array}{l}\text { Cota } \\
\text { doroa- } \\
\text { mento }\end{array}$ & $\begin{array}{l}\text { N.A. Ma- } \\
\text { ximorum } \\
(\mathrm{m})\end{array}$ & $\begin{array}{l}\text { N.A. Max } \\
\text { Normal }\end{array}$ & $\begin{array}{l}\text { N.A. Mín } \\
\text { Normal } \\
(\mathrm{m})\end{array}$ & $\begin{array}{l}\text { N.A. Mín } \\
\text { Ope- } \\
\text { rativo } \\
(\mathrm{m})\end{array}$ & $\begin{array}{l}\text { Potência } \\
\text { Instalada } \\
(\mathrm{MW})\end{array}$ & $\begin{array}{l}\text { Garantia } \\
\text { Física } \\
(\mathrm{MW}\end{array}$ & $\begin{array}{l}\text { Vazão } \\
\text { do Ver- } \\
\text { tedouro } \\
\left(\mathrm{m}^{3} / \mathrm{s}\right)\end{array}$ \\
\hline 576,23 & 573,40 & 572,50 & 549,20 & 549,20 & 396,00 & 239,00 & 8.700 \\
\hline
\end{tabular}

Fonte: Adaptado de Cavallari, Silva e Castro (2012)

Com seis geradores $66 \mathrm{MW}$ alimentado por turbinas Kaplan, a capacidade total instalada é de 396 MW (Tabela 9).

Tabela 9 - Características das Turbinas da UHE Três Marias.

\begin{tabular}{llll}
\hline \hline $\begin{array}{l}\text { Número de } \\
\text { Turbinas }\end{array}$ & $\begin{array}{l}\text { Tipo de } \\
\text { Turbina }\end{array}$ & $\begin{array}{l}\text { Potência } \\
(\mathrm{MW})\end{array}$ & $\begin{array}{l}\text { Vazão Máxima } \\
\left(\mathrm{m}^{3} / \mathrm{s}\right)\end{array}$ \\
\hline 6 & Kaplan & $6 \times 67,19$ & 900 \\
\hline \hline
\end{tabular}

Fonte: Adaptado de Cavallari, Silva e Castro (2012)

A barragem está atualmente administrada pela CEMIG (Companhia Energética de Minas Gerais) e a energia é entregue ao SIN (Sistema Interligado Nacional), a rede elétrica interligada brasileira, e sua operação é coordenada pelo ONS (Operador Nacional do Sistema Elétrico).

A defluência máxima da represa é de $9.600 \mathrm{~m}^{3} / \mathrm{s}$. A vazão histórica diária total da represa de Três Marias entre 1931 e 2011 variou entre 42 e $7.245 \mathrm{~m}^{3} / \mathrm{s}$ com uma vazão média de longo termo (MLT) e de $689 \mathrm{~m}^{3} / \mathrm{s}$. A previsão de descarga do reservatório é relevante para o processo operacional dos reservatórios a jusante subsequentes no rio São Francisco, uma vez que é responsável por cerca de $26 \%$ da vazão total do rio, e, portanto, afeta significativamente a estratégia energética da região Nordeste do país. (ONS, 2009b).

\section{Restrições de Operação da UHE Três Marias}

O reservatório tem restrições operacionais de descarga à jusante por causa de inundações causadas por vazões acima de $2.000 \mathrm{~m}^{3} / \mathrm{s}$, descargas desta ordem inundam ilhas habitadas por comunidades de subsistência localizadas à jusante da barragem. Outra restrição existente é em relação a vazões de descarga acima de $4.000 \mathrm{~m}^{3} / \mathrm{s}$, que causarão graves inundações na cidade de Pirapora, que está localizada cerca de 130 km da barragem Figura 28.

Caso as descargas da barragem e das bacias incrementais chegar à ordem de $8.000 \mathrm{~m} \mathrm{3} / \mathrm{s}$, os impactos de uma inundação causada por vazões desta magnitude podem ser notadas até em 
regiões no estado da Bahia; no médio e baixo São Francisco, que estão cerca de 700 km distantes da barragem. A gestão operacional da barragem é ainda limitada por restrições ambientais. A descarga só pode ser reduzida para valores inferiores a $460 \mathrm{~m}^{3} / \mathrm{s}$ após o monitoramento da ictiofauna, a fim de evitar o aprisionamento de peixes. A mesma regra é aplicada ao fechamento do vertedouro. Uma descarga mínima igual ou superior a $420 \mathrm{~m}^{3} / \mathrm{s}$ deve ser sempre assegurada para fins de vazões ambientais. A variação da vazão deve sempre ser feita lentamente, abaixando ou aumentando não mais do que $150 \mathrm{~m}^{3} / \mathrm{s}$ a cada 30 minutos (CAVALLARI; SILVA; CASTRO, 2012).

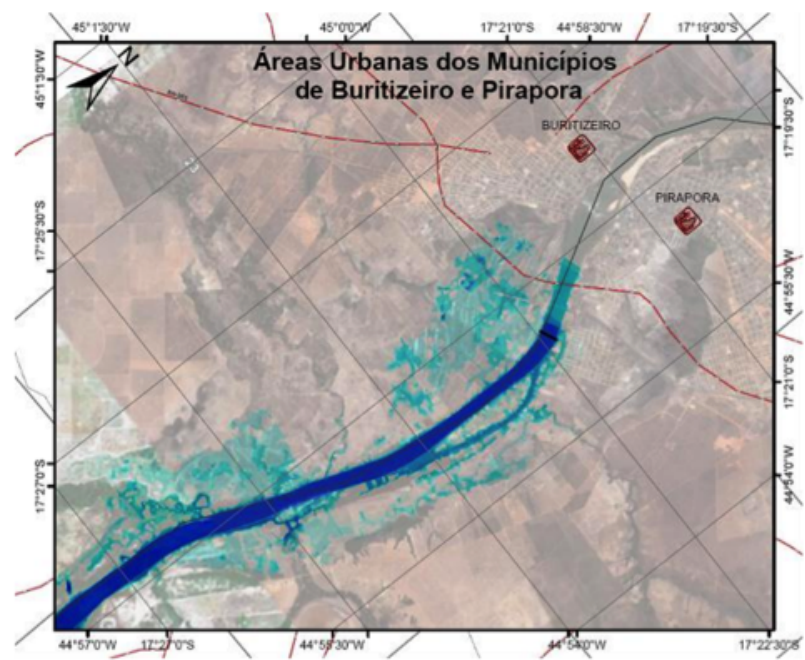

$4000 \mathrm{~m}^{3} / \mathrm{s}$

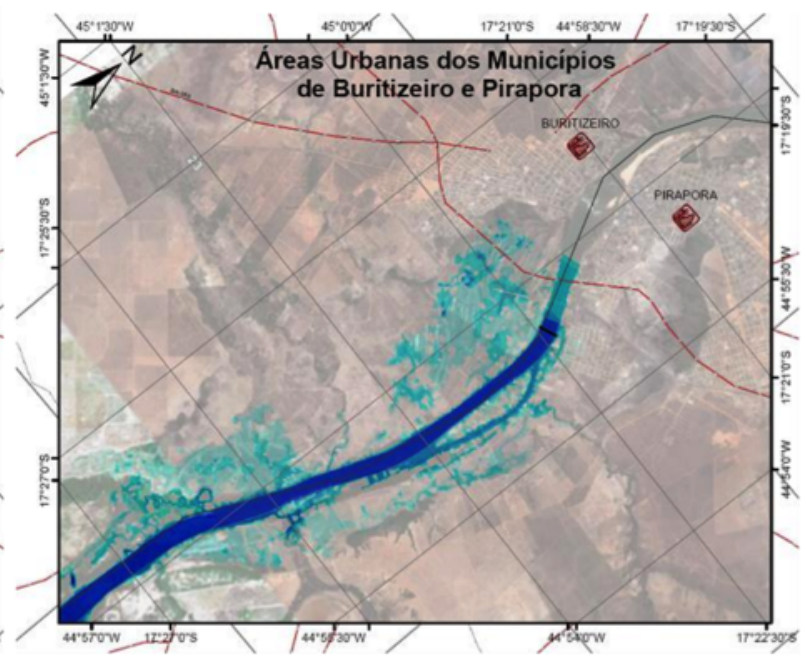

$7000 \mathrm{~m}^{3} / \mathrm{s}$

Fonte: Cavallari, Silva e Castro (2012)

Figura 28 - Efeitos de Inundação na cidade de Pirapora para vazões de 4.000 e 7.000 m³/s.

Conforme visto no seção 3.3, no Brasil a operação de hidrelétricas e o controle de enchentes é coordenado pelo ONS, que classifica as usinas de acordo com seu porte, conforme sua relevância hidráulica e energética, e seu papel na estabilidade da rede. A UHE de Três Marias está atualmente classificada como Tipo I, pois está conectada ao SIN e porque a operação dela causar impactos na operação hidráulica e de segurança da rede centralizadas do ONS. Para esta classificação de Barragens (Tipo I), o ONS é responsável pela programação dos despachos (valores-alvo) mensal, semanal, diários e em regime de tempo real(ONS, 2011a).

\subsubsection{Caracterização da Situação de Operação de Três Marias}

A previsão de vazões afluentes ao reservatório de Três Marias garante uma antecedência de até 3 dias no conhecimento do hidrograma afluente. $\mathrm{O}$ acompanhamento da evolução das vazões incrementais é de suma importância na tomada de decisões na operação de controle de cheias deste reservatório, pois a restrição de defluência em Três Marias é variável para que, ao 
se combinar com a vazão incremental no trecho Três Marias / Pirapora, não seja ultrapassada a vazão de 4.000 m³/s em Pirapora.

Tabela 10 - Resumo de Situação de Operação para o Reservatório de Três Marias.

\begin{tabular}{lllll}
\hline \hline Responsável & Situação & Afluência $\left(\mathrm{m}^{3} / \mathrm{s}\right)$ & Defluência $\left(\mathrm{m}^{3} / \mathrm{s}\right)$ & Volume (V) \\
\hline ONS & Normal & QAFL $<2500$ & QDEFL $\leqslant 2000$ & $\mathrm{~V} \leqslant \mathrm{VE}$ \\
ONS & Atenção & QAFL $<2500$ & QDEFL $\leqslant 2000$ e $\mathrm{INC}_{T M P R}$ & $\mathrm{~V}>\mathrm{VE}(1)$ \\
& & & $<1500$ & \\
ONS & Atenção & QAFL $\geqslant 2500$ & QDEFL $\leqslant 2000$ e $\mathrm{INC}_{T M P R}$ & $\mathrm{VE}<\mathrm{VE}<$ \\
& & & $<1500$ & $\mathrm{VEE}_{A T A L}$ \\
Agente & Alerta & QAFL $\geqslant 2500$ & $3500<$ QDEFL $+\mathrm{INC}_{T M P R}$ & $\mathrm{~V}>\mathrm{VE}$ \\
& & & $<4500$ ou V $\geqslant \mathrm{VE}_{A T A L}$ & \\
Agente & Emergência & QAFL $\geqslant 2500$ & $4000<$ QDEFL $+\mathrm{INC}_{T M P R}$ & $\mathrm{~V}>\mathrm{VE}$ \\
\hline \hline
\end{tabular}

Fonte: (ONS, 2015)

As diretrizes para regras de operação de controle de cheias do sistema independente de reservatórios da bacia do rio São Francisco, bem como do reservatório de Três Marias estão apresentadas em ONS (2015). No referido trabalho também apresenta-se a Tabela 10 , na qual estão apresentados os critérios de classificação da operação da UHE no período de controle de cheias, ou seja, caracteriza as situações Normal, Atenção, Alerta e Emergência com indicação do responsável pela operação.

A seguir são apresentadas as variáveis para o estabelecimento dos critérios de operação do reservatório de Três Marias, nas situações Normal, Atenção, Alerta e Emergência:

a) $\mathrm{QAFL}=$ Vazão afluente a Três Marias para 1 dia à frente;

b) QDEFL = Vazão defluente média de Três Marias, programada para 1 dia à frente;

c) $\mathrm{INC}_{T M P R}=$ Vazão incremental média diária no trecho Três Marias / Pirapora 1 dia à frente. No final de semana deverão ser feitas previsões para 3 dias à frente;

d) $\mathrm{VE}=\%$ de volume de espera definido no PAPC;

e) $\mathrm{VE}_{A T A L}=\%$ de volume de espera Atenção-Alerta, conforme RT-OR.BR.01 - Conceitos e Metodologias para a Operação Hidráulica dos Sistemas de Reservatórios;

f) $\mathrm{V}=\%$ de volume útil previsto para Três Marias 1 dia à frente.

Observação: Caso a confiabilidade das previsões de vazões seja aumentada, poderão ser fornecidas previsões de vazões para um horizonte maior.

A condicionante para definição da situação de Normal para Atenção pode ser uma vazão defluente média de Três Marias programada para 1 dia à frente inferior ou igual a $2.000 \mathrm{~m}^{3} / \mathrm{s}$, 
com vazões incrementais médias diárias previstas para um dia à frente inferior a $1.500 \mathrm{~m}^{3} / \mathrm{s}$ no trecho Três Marias - Pirapora.

Para Três Marias, tem-se $\mathrm{VE}_{A T A L}$ condicionando a definição da situação de Atenção para Alerta, podendo a situação de Alerta ficar caracterizada com vazões em Pirapora superiores a $3500 \mathrm{~m}^{3} / \mathrm{s}$ e inferiores a $4.000 \mathrm{~m}^{3} / \mathrm{s}$.

Os quadros abaixo apresentam os critérios de classificação da operação da UHE de Três Marias, no período de controle de cheias, ou seja, caracterizam as situações Normal, Atenção, Alerta e Emergência com indicação do responsável pela operação

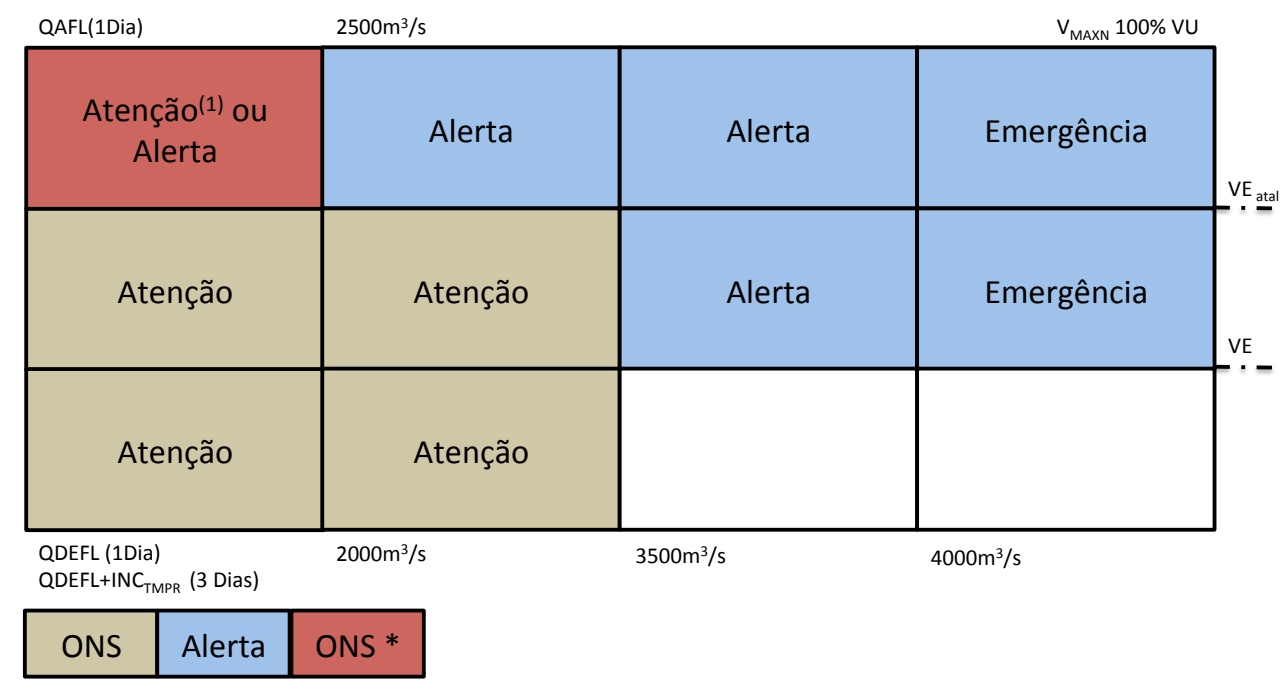

* Se a situação for de Atenção,, e AGENTE se a situação for de alerta

Fonte: ONS (2015)

Figura 29 - Situações de Operação de Três Marias.

\subsection{Modelo Conceitual do Problema}

Para o estudo de caso da UHE de Três Marias nós temos que o problema conceitual é controlar das vazões defluentes da UHE, que podem causar impactos de inundação a jusante em Pirapora. Desta forma para o estudo de caso podemos dividir o problema em três categorias:

a) Balanço hídrico na escala da bacia hidrográfica; 
b) Controle de volume de armazenamento, volume de espera e de vazão vertida pelo reservatório; e

c) Comportamento hidráulico a jusante da represa;

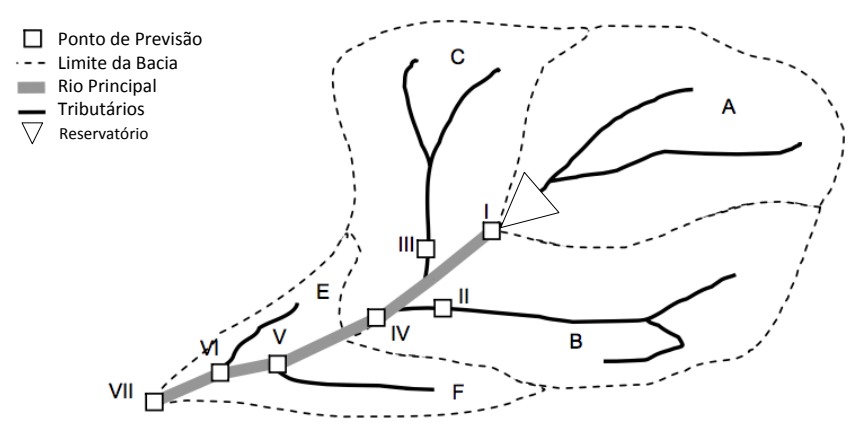

(a) Esquematização Conceitual da Bacia

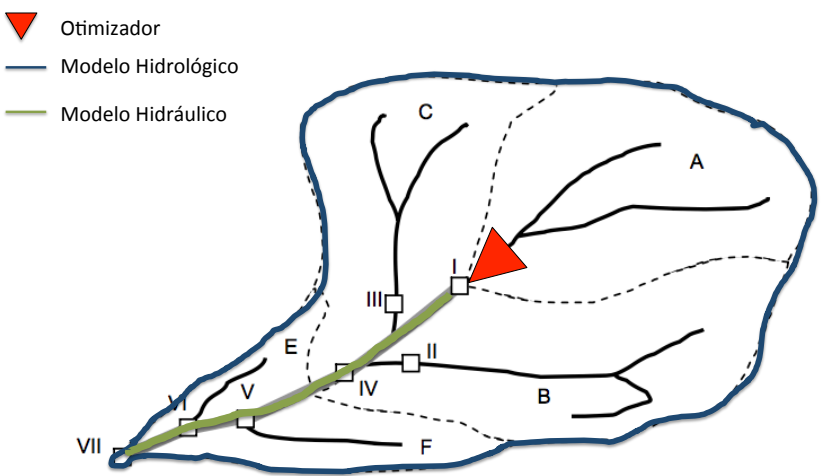

(b) Esquematização da Modelagem do Problema

Fonte: Adaptado de (WERNER; DIJK, 2005).

Figura 30 - Esquematização geral da modelagem da bacia hidrográfica do estudo de caso

Assim desta forma existem contribuições de escoamento superficial no rio principal, nos tributários e no Reservatório da Represa; além disto o reservatório da represa deve satisfazer diferentes usos, que para nosso estudo de caso, os usos serão simplificados para de geração elétrica e controle de cheias e finalmente exitem o comportamento da propagaçõa de ondas a jusante da barragem.

A Figura 30, mostra o modelo conceitual da baica a ser estuda, de maneira similar à Figura 8 dividiu-se os processos a fim de se empregar as ferramentas corretas para abordar o 
problema conceitual:

I. Modelo Hidrológico para os processos de escoamento superficial e balanço hídrico da Barragem;

II. Modelo Hidráulico para a seção do corpo d’água entre a barragem e o ponto de controle de inundação;

III. Otimizador para as os níveis e vazões afluentes ótimos do reservatório;

Naturalmente pode-se executar todas as etapas de modelação acima descritas separadamente e de maneira sequencial, ou seja, primeiro se modela a bacia hidrográfica para calcular as vazões de contribuição lateral, para em seguida importar os dados obtidos pelo modelo hidrológico ao modelo do reservatório e em seguida utilizar as saídas de ambos os modelos no modelo hidráulico para averiguar se haverá impactos no ponto de controle a jusante da barragem. Porém este processo pode ser lento e custoso, então optou-se por integrar as três etapas de modelagem para facilitar a comunicação e troca de resultados entre elas.

\subsubsection{Integração de Modelos e Banco de Dados}

A arquitetura de modelagem então para o estudo de caso seguirá a seguinte organização, serão integrados bancos de dados (ANA e CEMIG) contendo os dados de precipitações, vazões e níveis com diferentes tipos de modelos que serão empregados para modelar diferentes processos que ocorrem na bacia.

Os processos hidrológicos serão modelados utilizando o MGB-IPH, o modelo hidrológico servirá como espinha dorsal do programa, gerando dados de vazões incrementais que serão utilizadas pelos outros modelos a serem integrados. O MGB também consegue simular propagação de onda em canais abertos através de Muskigum-Cunge e portanto também pode ser utilizado para simular o comportamento e efeitos de inundação no ponto de controle em Pirapora.

Para estudar a propagação da onda de inundação no trecho do canal a jusante da barragem e o ponto de controle no exutório da modelagem. Serão utilizados uma séries de modelos dentre eles o SOBEK, MGB-IPH, RTC-Tools e SPRNT, o intuito de utilizar diversos modelos está em avaliar o modelo hidráulico mais robusto para a aplicação, o SPRNT por questões técnicas não é integrável aos outros e será avaliado separadamente.

E finalmente os volumes e descargas ótimas para o reservatório serão abordados utilizando um otimizador, no caso o IPOPT com o modelo hidráulico selecionado como sendo o 
mais robusto. $\mathrm{O}$ otimizador irá definir as potenciais vazões de descargas ótimas que mantém os níveis operacionais do reservatório, estas descargas entram como dados de entrada dos modelos hidráulicos que em seguida simularam os níveis no ponto de controle de inundação (Pirapora) e após esta conferência pode-se definir a vazão de descarga ótima e nivel operacional ótimo.

A Figura 31, mostra a arquitetura proposta para simulação para o estudo de caso. A simulação para o tempo de previsão $T_{0}$ segue a sequência Aquisição e Processamento de dados utilizando o MGB-IPH, em seguida os resultados gerados do MGB-IPH servirão também como entrada de dados para os modelos Hidráulicos (SOBEK e RTC-Tools). Já para o modo de previsão a sequência é um pouco diferente, novamente inicia-se com o MGB-IPH adquirindo e processando os dados da previsão numérica climática ou do Horizonte de previsão, cujos resultados serão incorporados ao Otimizador (MPC) e indiretamente aos modelos hidráulicos, porém para o caso de estudo só será utilizado o modelo mais apto na simulação de previsão e otimização.

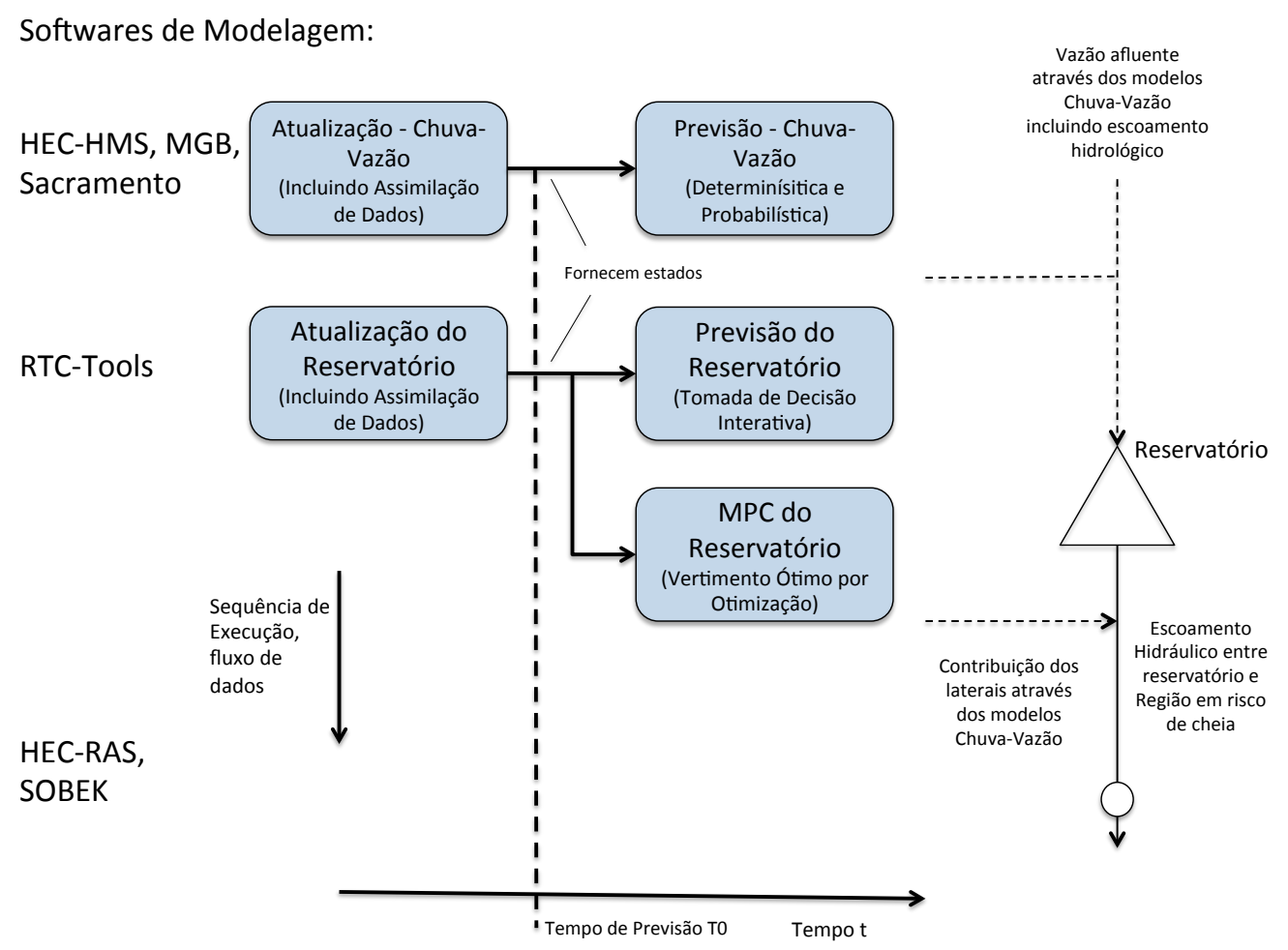

Figura 31 - Arquitetura do modelo para o SSD e Previsão Estocástica

Fonte: Baseado em Schwanenberg et al. (2013).

\subsection{Configuração e Calibração dos Modelos}

A geometria dos transectos dos canais foi obtida de dados fornecidos por um levantamento feito pela própria CEMIG, estes dados estão apresentados com mais detalhes no Apên- 
dice A. Neste Apêndice estão listados as geometrias das seções transversais dos cursos de rios utilizadas na modelação hidráulica deste trabalho. Foram modelados trechos dos rios Abaetés e São Francisco entre o UHE de Três Marias e a cidade de Pirapora.

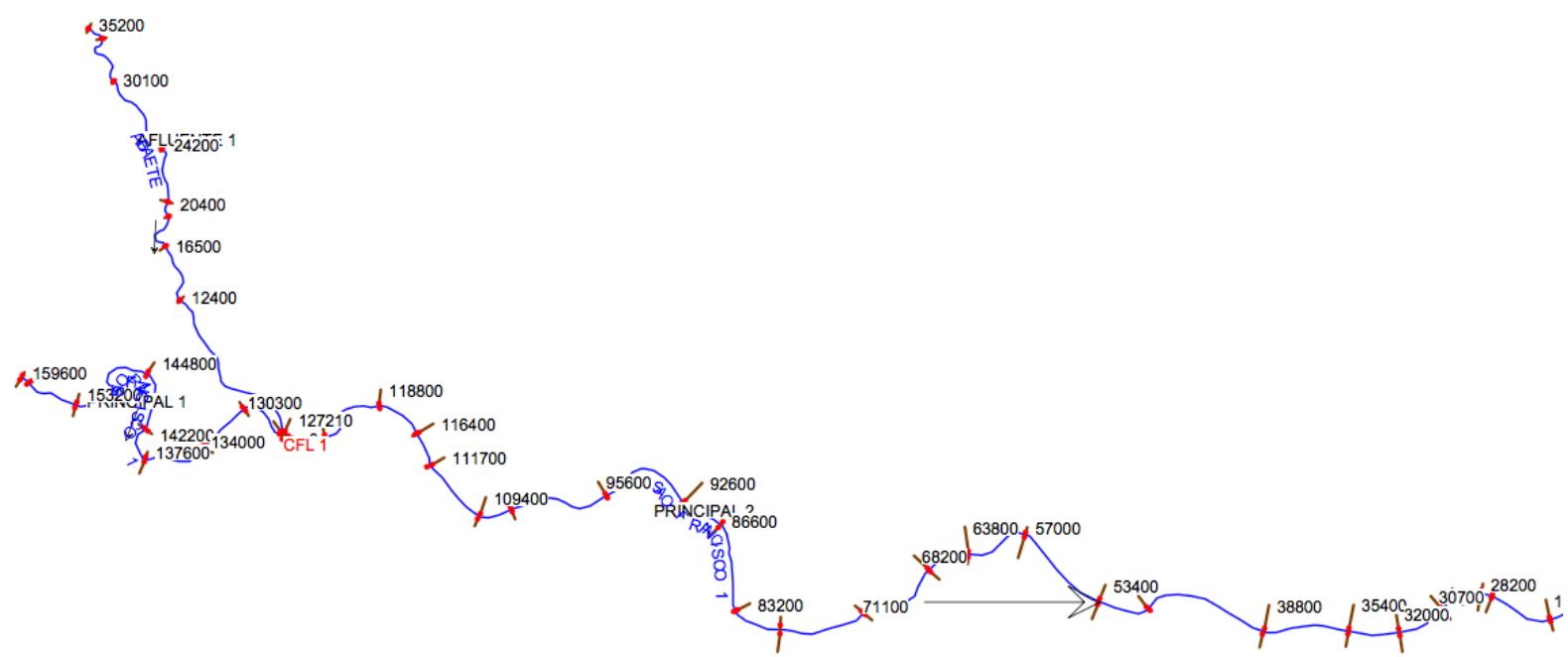

Figura 32 - Localização das seções transversais para o Rio Abetés e Rio São Francisco.

A Figura 32, mostra a disposição espacial destas seções. Foram levantados dados de dois rios: São Francisco e Abaetés. O ponto inicial do rio São Francisco está localizada a UHE Três Marias e no ponto inicial do rio Abetés está localizada a estação de medição da ANA PBR040. O ponto de confluência entre o a Abaeté e o São Francisco está na Seção 127200 e o ponto de controle de cheia para o problema proposto está na cidade de Pirapora a jusante da barragem, o ponto escolhido é a seção SF29000, onde está localizada a estação de monitoramento Piraporaponte.

Tabela 11 - Delimitação problema:trechos dos rios Abaetés e São Francisco modelados.

\begin{tabular}{ccc}
\hline \hline Nome Rio & Ponto de monitoramento de Entrada & Ponto de monitoramento de Saída \\
\hline rio Abaetés & Vazão no Ponto PBR040 & - \\
rio São Francisco & Defluência da UHE Três Marias & Vazão em PiraporaPonte \\
\hline \hline
\end{tabular}

Tabela 12 - Comprimentos das margens e canal principal do rio Abaetés

\begin{tabular}{cccc}
\hline \hline Nome do Transecto & Margem Esquerda & Canal Principal & Margem Direita \\
\hline RA35200 & 1189.6 & 1189.6 & 1189.6 \\
RA34000 & 3843.35 & 3858.52 & 3911.11 \\
RA30100 & 5912.85 & 5936.18 & 6017.09 \\
RA24200 & 3916.27 & 3741.22 & 3623.78 \\
RA20400 & 960.4 & 1082.55 & 1254.65 \\
RA19300 & 2849.04 & 2847.79 & 2842.77 \\
RA16500 & 4133.96 & 4105.91 & 4163.63 \\
RA12400 & 12330.43 & 12359.79 & 15151.78 \\
\hline \hline
\end{tabular}


A Tabela 11, mostra os rios que foram modelados bem como a delimitação do problema com seus pontos de entrada e saída dos quais foram utilizados dados de monitoramento para alimentar e calibrar o modelo.

Tabela 13 - Comprimentos das margens e canal principal do rio São Francisco

\begin{tabular}{cccc}
\hline \hline Nome do Transecto & Margem Esquerda & Canal Principal & Margem Direita \\
\hline SF159600 & 716.89 & 625.6 & 535.28 \\
SF156000 & 3634.71 & 3658.85 & 3918.75 \\
SF153200 & 2623.52 & 2755.75 & 3210.99 \\
SF148800 & 4683.94 & 4416.08 & 4329.27 \\
SF144800 & 4267.7 & 4031.3 & 3801.13 \\
SF142200 & 2384.24 & 2559.72 & 2793.18 \\
SF137600 & 4572.49 & 4640.05 & 4803.1 \\
SF134000 & 3532.26 & 3572.79 & 3594.37 \\
SF130300 & 3875.08 & 3655.49 & 3370.07 \\
SF127210 & - & - & - \\
SF127190 & 2861.47 & 3141.93 & 3290.83 \\
SF122100 & 5224.65 & 5091.66 & 5372.9 \\
SF118800 & 3500.42 & 3299.58 & 3232.88 \\
SF116400 & 2462.24 & 2362.04 & 2421.55 \\
SF111700 & 4647.58 & 4783.23 & 4948.76 \\
SF109400 & 2311.48 & 2293.68 & 2344.54 \\
SF102500 & 6934.43 & 6881.03 & 7033.62 \\
SF95600 & 7266.19 & 6854.29 & 6775.32 \\
SF92600 & 3162.65 & 3014.86 & 2880.03 \\
SF86600 & 5845.11 & 6008.01 & 6157.84 \\
SF83200 & 3409.68 & 3397.73 & 3400.99 \\
SF77200 & 5845.11 & 6008.01 & 6157.84 \\
SF71100 & 6020.11 & 6079.64 & 6200.95 \\
SF68200 & 3037.19 & 2959.5 & 2850.5 \\
SF63800 & 4825.64 & 4372.98 & 4434.43 \\
SF57000 & 7171.09 & 6829.41 & 6673.47 \\
SF53400 & 3381.97 & 3555.92 & 3640.73 \\
SF44700 & 8866.28 & 8731.16 & 8722 \\
SF38800 & 5761.03 & 5830.71 & 5964.14 \\
SF35400 & 3395.66 & 3445.99 & 3479.29 \\
SF32000 & 3261.99 & 3379.18 & 3517.51 \\
SF30700 & 1480.68 & 1344.91 & 1259.78 \\
SF29000 & 1675.84 & 1662.02 & 1760.78 \\
\hline \hline
\end{tabular}

As geometrias dos canais dos rios São Abaetés e do Rio São Francisco com os comprimentos das seções e respectivas geometrias transversais estão detalhadas no Apêndice A.

As tabelas 39 até 48 contém as características geométricas dos transectos do rio Abaetés coforme a Figura 32. Nas tabelas citadas $h$ corresponde à cota em metros e $z$ corresponde a largura da seção na cota correspondente em metros. 
A Tabela 12, mostra as distância entre os canais principais e margens esquerda e direita entre os transectos do rio Abaetés.

As tabelas 60 até 87 contém as características geométricas dos transectos do rio São Francisco conforme a Figura 32. Nas tabelas citadas $h$ corresponde à cota em metros e $z$ corresponde a largura da secção na cota correspondente em metros. A Tabela 13, contém as distância entre os canais principais e margens esquerda e direita entre os transectos do rio São Francisco.

\subsubsection{Configuração do MGB}

Na configuração o modelo atua como espinha dorsal dos modelos computando a vazão de entrada no reservatório de Três Marias e as vazões laterais a serem implementadas nos modelos hidráulicos.

Tabela 14 - Parâmetros Fixos do MGB-IPH

\begin{tabular}{ll}
\hline \hline Parâmetro Fixo & Descrição \\
\hline $\begin{array}{l}\text { Índice de Área Foliar } \\
\text { (IAF) }\end{array}$ & $\begin{array}{l}\text { O IAF expressa a relação entre a área das folhas de todas as plantas e da área } \\
\text { de uma parcela de solo. É um parâmetro adimensional }\left(\mathrm{m}^{2} . \mathrm{m}^{2}\right) \text { e que, em } \\
\text { geral, pode ser medido ou estimado a partir de informações na bibliografia. }\end{array}$ \\
$\begin{array}{l}\text { Albeldo } \\
\text { Resistência albedo é a parcela da radiação solar que é refletida ao atingir a superfície } \\
\text { cial (RS) }\end{array}$ & $\begin{array}{l}\text { do solo, considerando sua cobertura vegetal. } \\
\text { A resistência superficial representa a resistência ao fluxo de umidade do } \\
\text { solo, através das plantas, até a atmosfera. Esta resistência é diferente para os } \\
\text { diversos tipos de plantas e depende de variáveis ambientais como a umidade } \\
\text { do solo, a temperatura do ar e a radiação recebida pela planta. }\end{array}$ \\
Altura do Dossel (Z) & $\begin{array}{l}\text { Altura média da vegetação é utilizada no modelo hidrológico para esti- } \\
\text { mar a resistência aerodinâmica, que atua no controle da evapotranspiração. } \\
\text { Quanto maior a resistência aerodinâmica, menor é o fluxo de evapotranspi- } \\
\text { ração. A resistência aerodinâmica é considerada menor em florestas, onde a } \\
\text { altura média da vegetação é maior e intensifica a turbulência do vento. }\end{array}$ \\
\hline \hline
\end{tabular}

Fonte: Fan (2011)

Os dados de entrada do MGB podem ser divididos basicamente de 2 tipos: Dados rasterizados sobre a geografia da bacia que incluem informações sobre o relevo sendo estes dados o Modelo Digital de Elevação e dados sobre o uso e ocupação do solo e características dos solos da bacia a ser simulada; O segundo grupo de dados consiste de dados fluviométricos, pluviométricos e climatógicos da bacia a ser simulada (COLLISCHONN et al., 2010). Enquanto o primeiro grupo servirá para definir as condições hidráulicas da bacia como divisão de sub-bacias, Unidades de resposta Hidrológica e sentido de fluxos; segundo grupo servirá para determinar o balanço hídrico desta bacia.

Existe outro grupo de dados de entrada que são parâmetros fixos Tabela 14 e calibráveis 
Tabela 15: Os parâmetros fixos são valores podem ser medidos, ou que podem ser relacionados à vegetação, e não são alterados no processo de calibração do modelo; e os parâmetros calibrados são definidos como dados que são alterados durante a calibração do modelo, buscando um bom ajuste entre os dados de vazão observados e calculados e estão associados ao tipo de Unidade de Resposta Hidrológica e a sub-bacia.

Tabela 15 - Parâmetros Calibráveis do MGB-IPH

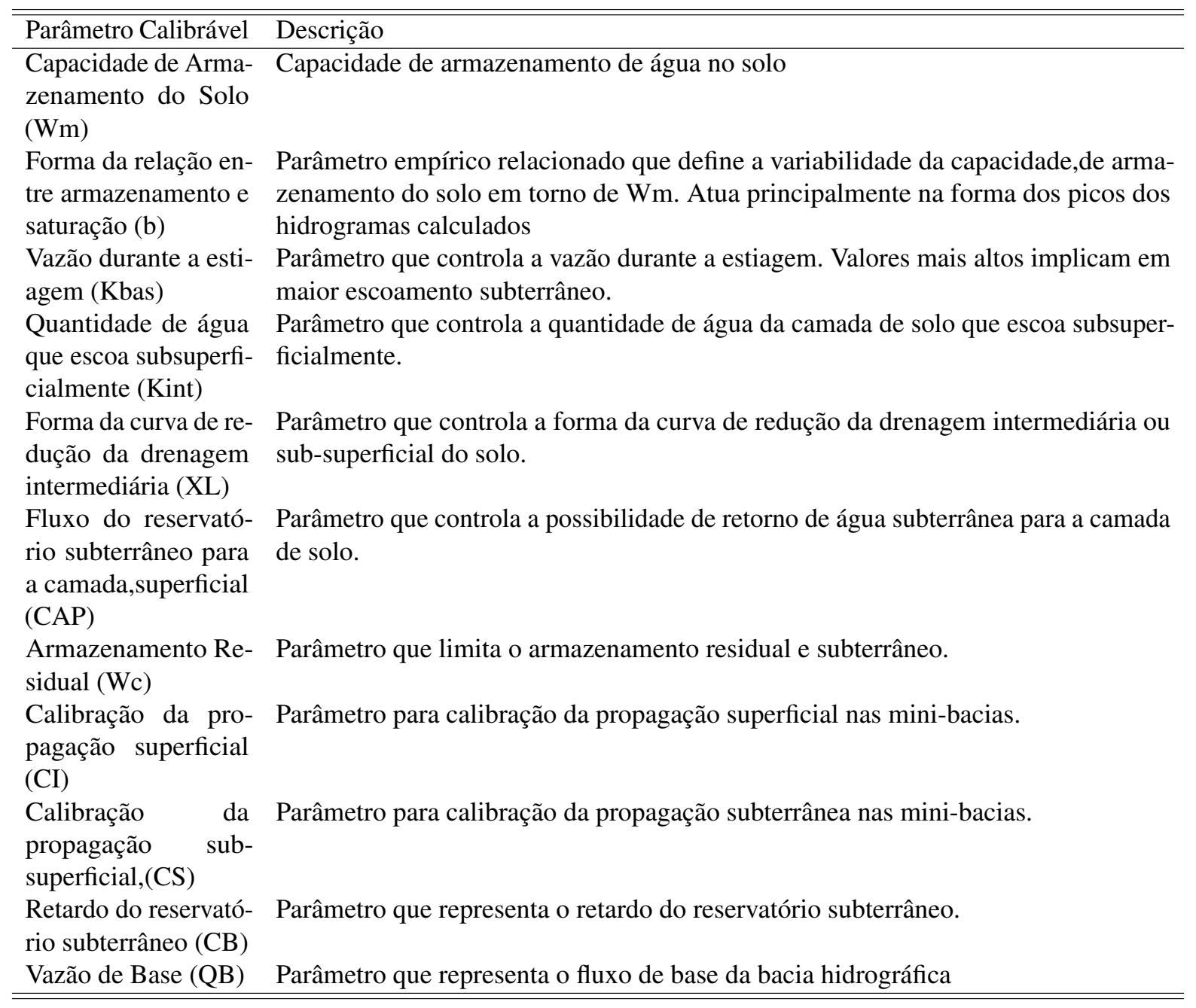

Fonte: Fan (2011)

\section{Calibração do MGB-IPH}

O MGB foi configurado exatamente conforme Fan (2011), sendo que o mapa de solos da bacia foi obtido através de dados da Universidade Federal de Viçosa (UFV), com dados do portal IDE-GeoMINAS e o mapa base para construção do Modelo Digital de Elevação do Terreno foi utilizado um mapa 1:1.000.000 obtido de Amaral (1993). O mapa de vegetação e classes de uso e ocupação do terreno foram obtidos de um mapa de resolução espacial de aproximadamente $1 \mathrm{~km}$ desenvolvido por Eva et al. (2002). 


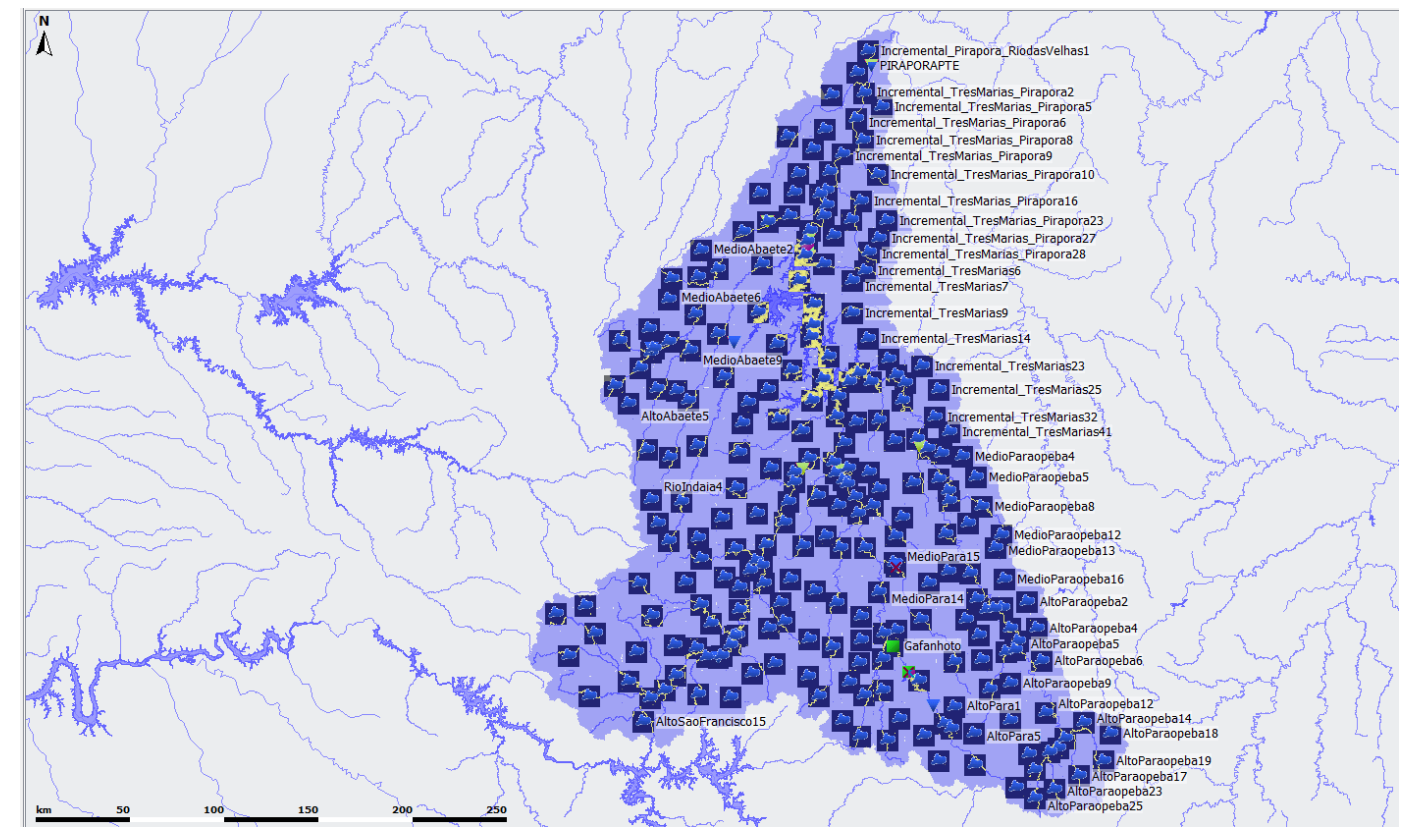

(a) Sub-Bacias configuradas no MGB

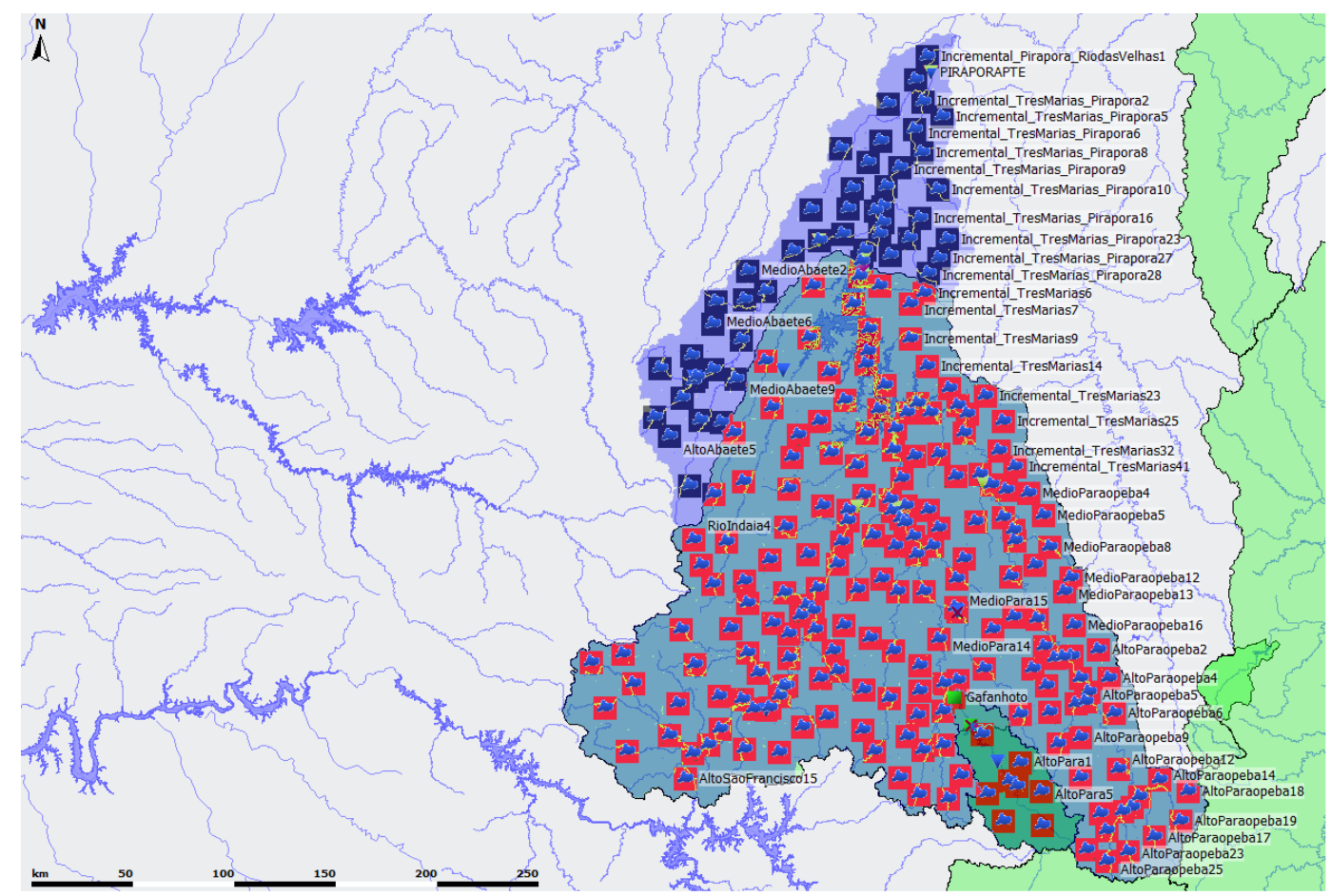

(b) Bacias do MGB-IPH

Figura 33 - Visualização do MGB configurado no Delft-FEWS.

Quanto aos parâmetros do modelo MGB, os dados acima resultaram no delineamento de 246 mini-bacias e 8 classes de Unidades de Resposta Hidrológica. Assim como em Fan (2011) a calibração foi feita automaticamente através de uma interface via MapWindow. Inicialmente foi definido que os parâmetros Wm, b, Kbas, Kint, CI, CS e CB de todas as Unidades de Resposta Hidrológicas (exceto água) deveriam ser calibrados considerando todos os postos fluviométricos selecionados. Em uma segunda calibração, apenas algumas sub-bacias foram calibradas, visando 
refinar os resultados obtidos para a região oeste da bacia. No Apêndice B, estão detalhados os valores dos parâmetros de calibração para o modelo MGB-IPH.

A figura 33, mostra a configuração descrita acima implementada dentro do DELT-FEWS. Nela é possível observar as sub-bacias simuladas com os dados de entrada de precipitação e vazão. $\mathrm{Na} 33 \mathrm{a}$ estão representadas espacialmente as 246 mini-bacias configuradas enquanto que na 33b, mostram em vermelho as sub-bacias a montante da barragem, que calculam a contribuição na represa de Três Marias e em azul as sub-bacias a jusante da barragem que calculam a contribuição para o ponto em Pirapora.

\subsubsection{SOBEK}

A versão utilizada do SOBEK neste trabalho foi a 2.12. O modelo foi configurado utilizando a geometria (seções transversais e distância entre elas) disponíveis em Apêndice A. Então de maneira análoga aos dados disponíveis, dividiu-se o corpo d’água em três: rio Abaetés, rio São Francisco 1 e rio São Francisco 2.

Tabela 16 - Configuração dos cursos d’água no SOBEK

\begin{tabular}{llll}
\hline \hline Nome do Curso do Rio & Comprimeto Total (m) & Condição de Entrada & Condição de Saída \\
\hline rio Abaetés & 35121.561 & Vazão no Ponto PBR040 & Seção 127200 \\
rio São Francisco 1 & 29915.628 & $\begin{array}{l}\text { Defluência da UHE Três } \\
\text { Marias }\end{array}$ & Seção 127200 \\
& & Seção 127200 & Vazão em PiraporaPonte \\
rio São Francisco 2 & 100259.662 & P
\end{tabular}

A configuração das condições de contorno e ligação entre os cursos d'água então é feita da seguinte forma: o rio Abetés possuí como condição forçante as vazões de entrada no ponto PBR040, o rio São Francisco 1 tem como condição forçante as vazões defluentes da UHE Trê Marias e a soma das vazões defluentes dos cursos d’água rio Abaetés e rio São Francisco 1 são somadas a um ponto de conexão (Seção 127200) que servirá de condição forçante de entrada de vazão para o rio São Francisco 2 e a condição de controle final no ponto PiraporaPonte são as vazões observadas (Tabela 16).

Na figura 34 é possível visualizar a configuração descrita acima com a localização dos transectos e das condições de contorno para o modelo hidráulico construído para esta configuração.

Para completar a confinguração, além da entrada de vazão nos pontos de condição de controle definidos acima, utilizou-se também aquisição de dados para melhorar os resultados do modelo; integrou-se nele as vazões incrementais fornecidas pelo MGB-IPH. Estas vazões foram adicionadas conforme sua correspondência local, na Figura 35, mostra a localização das contribuições das vazões incrementais para esta configuração. 


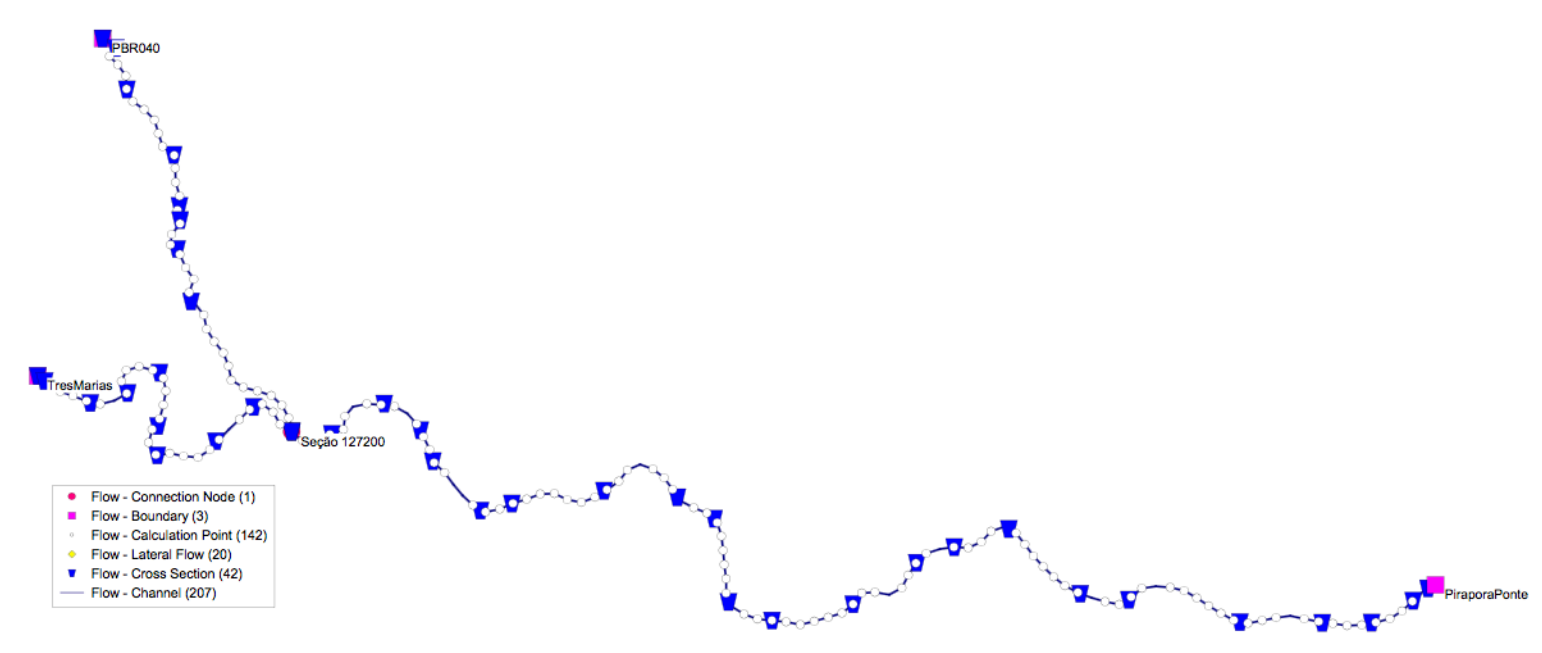

Figura 34 - Esquema da configuração da geometria para o SOBEK, com os transectos

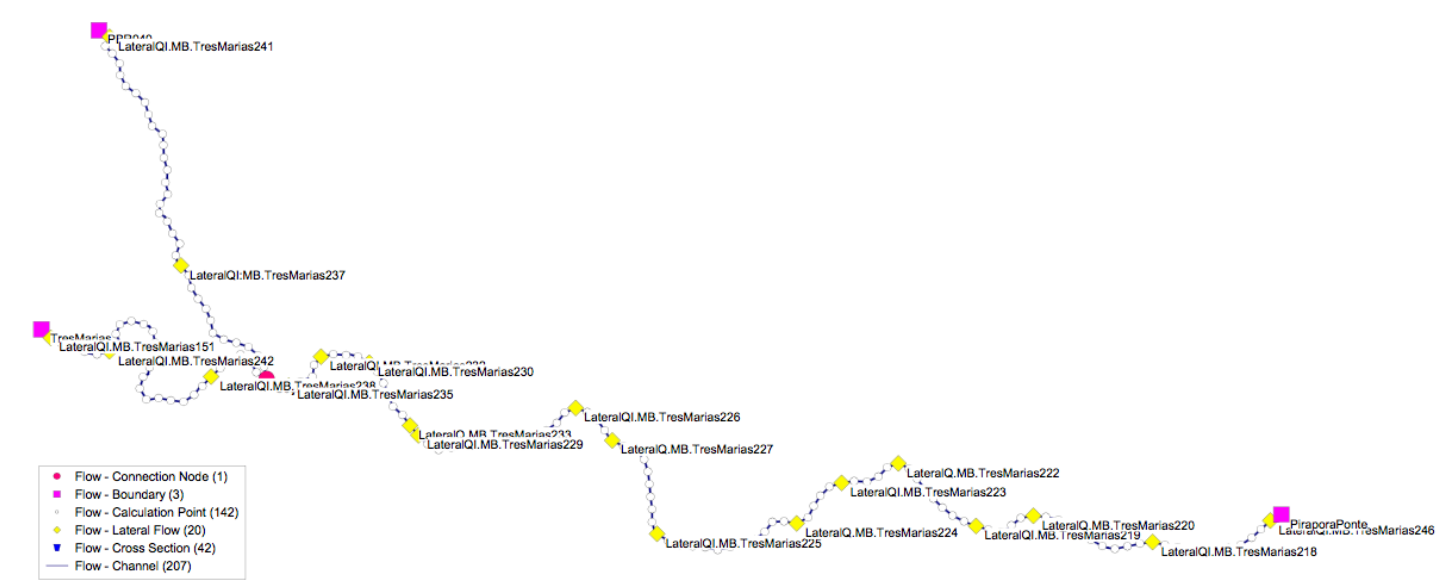

Figura 35 - Esquema da configuração da geometria para o SOBEK, com as contribuições laterais

Calibração do SOBEK

A calibração do modelo para esta configuração foi relativamente simples; sendo inicialmente feita uma calibração manual local dos cursos separadamente, e em seguida é feita uma refinada através de uma calibração global automatizada dos três cursos juntamente:

I. Calibração manual para os três cursos separadamente (rio Abetés, rio São Francisco 1 e rio São Francisco 2) utilizando:

a) Fluxo permanente com diferentes vazões críticas (máxima e mínima);

b) Fluxo não-permanente com séries de vazões históricas reais;

II. Calibração automatizada global para o trecho modelado inteiro 
Na primeira etapa, ajustou-se os valores de Manning nos quais os cursos rio abetés 1, rio São Francisco 2 e rio São Francisco 1 produziam o melhores resultados, o intuito era definir a faixa de valores nos quais o coeficiente de manning variava em cada transecto e testar se o valor médio era capaz de reproduzir bons resultados.

Na segunda calibração automatizada global tem como objetivo encontrar o conjunto ótimo de valores de manning para cada transecto. A calibração otimizada foi feita usando um script em phyton, que segue o seguinte workflow:

I. Importar as bibliotecas necessárias;

II. Importar o modelo e os dados medidos;

III. Comparar os resultados atuais com os medidos;

IV. Tomar a faixa de valores a ser usada na calibração do manning;

V. Rodar os modelos em sequência com os diferentes combinações de valores para o modelo;

VI. Calcular os valores de adequação de ajuste para cada caso e assim chegar no melhor configuração de calibração do modelo;

A figura 36, mostra o resultado d acalibração com a distribuição espacial dos valores de fricção (Coeficiente de Manning) ao longo do curso dos corpos d'água modelados. No Apêndice $\mathrm{C}$ estão listados os valores da geometria de canais para a configuração e os valores escolhidos para manning.

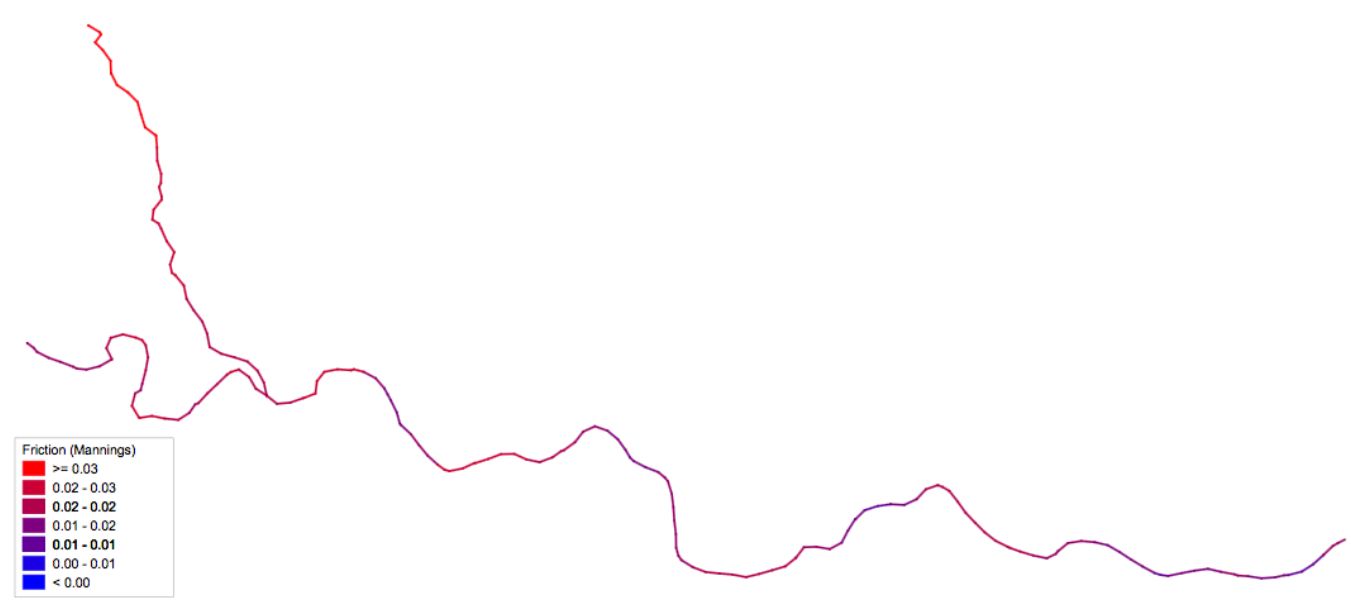

Figura 36 - Distribuição dos valores do coeficiente de Manning para a configuração SOBEK 


\subsubsection{SPRNT}

O SPRNT foi configurado de maneira análoga ao SOBEK, utilizou-se também a mesma geometria disponibilizada pela CEMIG. E assim como o no caso do SOBEK dividiu-se os corpos d’água em três cursos: rio Abetés, São Francisco 1 e São Francisco 2.

Também de maneira muito similar ao SOBEK, a confguração das condições de contorno e ligação entre os cursos d'água foi feita da seguinte forma: o rio Abetés possuí como condição forçante as vazões de entrada no ponto PBR040, o rio São Francisco 1 tem como condição forçante as vazões defluentes da UHE Trê Marias e a soma das vazões defluentes dos cursos d'água rio Abaetés e rio São Francisco 1 são somadas a um ponto de conexão (Seção 127200) que servirá de condição forçante de entrada de vazão para o rio São Francisco 2 e a condição de controle final no ponto PiraporaPonte é o nível do rio neste ponto em metros.

Tabela 17 - Configuração dos cursos d'água no SPRNT

\begin{tabular}{llll}
\hline \hline Nome do Curso do Rio & Comprimeto Total (m) & Condição de Entrada & Condição de Saída \\
\hline rio Abaetés & 35121.56 & Vazão no Ponto PBR040 & $\begin{array}{l}\text { Junção dos Rios Abaetés com } \\
\text { São Francisco }\end{array}$ \\
rio São Francisco 1 & 29915.63 & Defluência da UHE Três Marias & $\begin{array}{l}\text { Junção dos Rios Abaetés com } \\
\text { São Francisco }\end{array}$ \\
rio São Francisco 2 & 101327.47 & $\begin{array}{l}\text { Junção dos Rios Abaetés com } \\
\text { São Francisco }\end{array}$ & H PiraporaPonte (m) \\
\hline \hline
\end{tabular}

A Tabela 17 lista maiores detalhes da configuração listando os comprimentos totais dos rios, dados de entrada e condições de contorno em Pirapora Ponte.

Como o modelo é novo e está ainda em desenvolvimento, existiu uma dificuldade em achar configurações estáveis. Durante a fase de teste do modelo, duas configurações se mostraram mais estáveis:

a) Usando todas as seções transversais disponíveis, denominada versão completa;

b) Usando uma seção transversal em média a cada $10 \mathrm{~km}$. denominada versão reduzida;

\section{Calibração do SPRNT}

Para calibrar o modelo, foram utilizados as mesmos valores do coeficiente de manning usados na configuração do SOBEK, como o modelo utiliza condição de contorno diferente do SOBEK (nível em metros), foi necessário converter a vazão do ponto de monitoramento PiraporaPonte usando uma curva-chave calculada utilizando dados históricos de vazão e nível da régua de 2010 até 2012 (Figura 37).

É importante observar que os dados estão em valores relativos, então foi necessário aplicar uma correção de valores adicionando o datum do fundo do rio para obter os valores corretos de nível absolutos que são utilizados no modelo. 


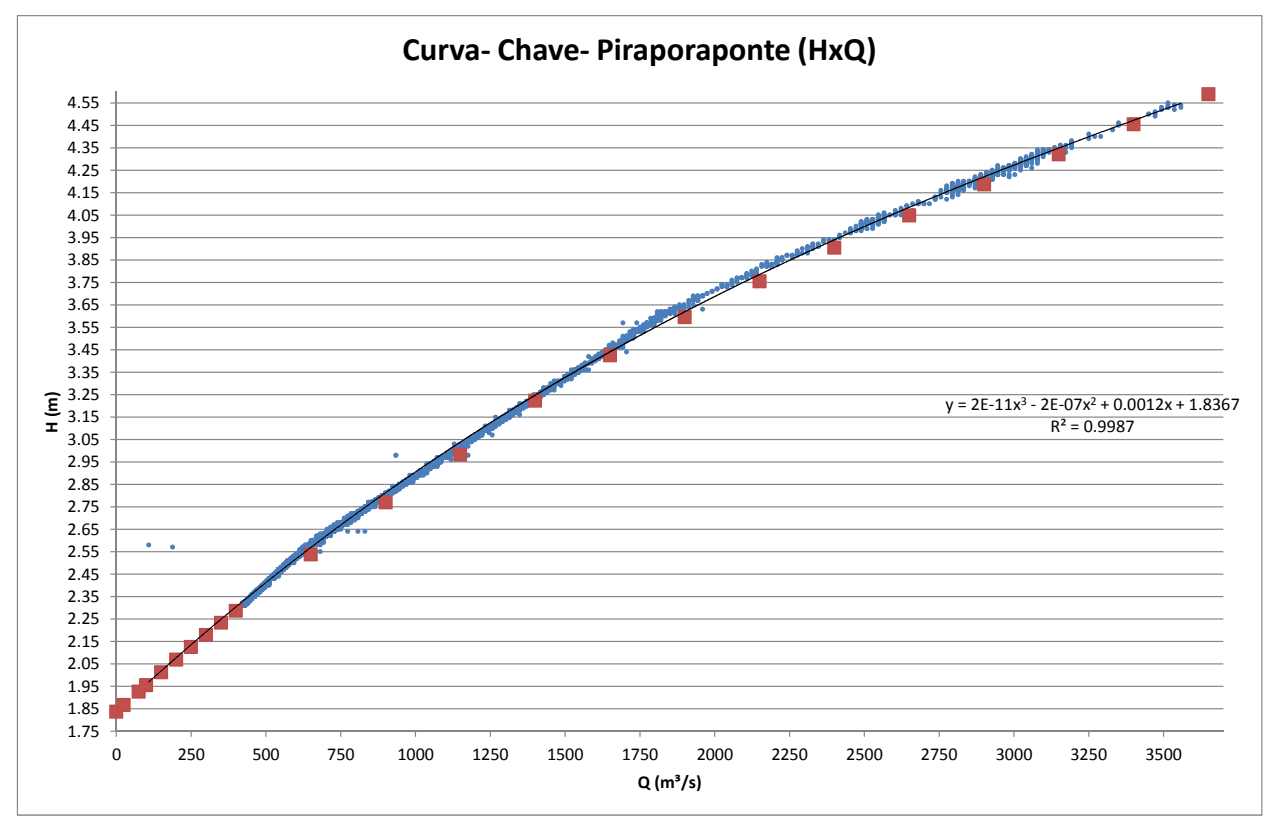

Figura 37 - Curva-Chave para Pirapora Ponte (HxQ)

A equação usada para conversão dos dados de vazão para dados do nível em metros foi:

$$
H_{\text {rel }}=2^{-11} Q^{3}-2^{-7} Q^{2}+1.2^{-3} Q+1.8367
$$

$$
H=H_{\text {rel }}+\text { Datum }
$$

Onde $H_{r e l}$ é a nível do rio relativo em metros e $H$ é o nível do rio absoluto em metros, $Q$ é vazão em $\mathrm{m}^{3} / \mathrm{s}$. O valor para o datum adotado foi de 481.38 metros.

\subsubsection{RTC-Tools}

A característica modular e personalizável do RTC-Tools permite diversas configurações, sendo possível utilizar diferentes equações governantes para solucionar problemas de canais superficiais abertos. Para o caso de estudo foram feitas três configurações diferentes: 1 usando Cascata de Reservaórios (RR) aplicando a correção de Integrator Delay (ID) de (SCHUURMANS, 1997) e 2 configurações utilizando onda cinemática (DW) sequencial implícita e upwind, 
porém com duas resoluções espaciais diferentes, a com a resolução espacial mais esparsa será denominada como de malha grosseira e a com maior resolução espacial será denominada de malha refinada.

Para o RTC-Tools ainda não há método de calibração automática, os valores utilizados foram calibrados manualmente baseados nos dados e relatórios de simulação gerados pelo SOBEK.

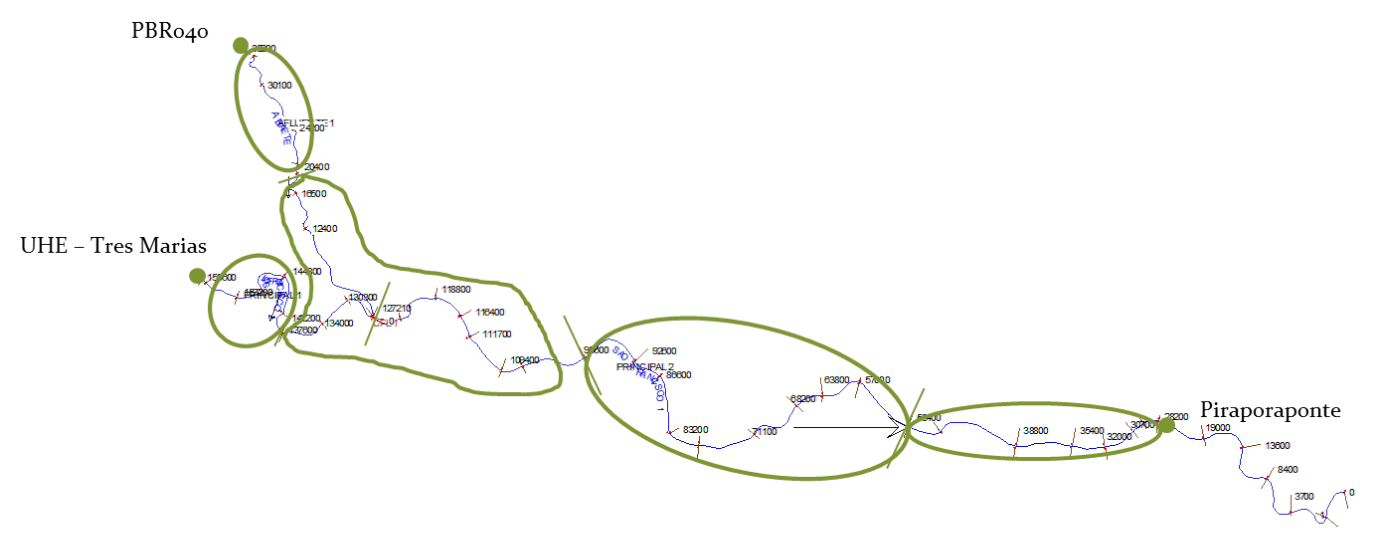

Figura 38 - Esquema da configuração para onda difusa com resolução espacial grosseira

\section{Onda Difusiva com Baixa Resolução Espacial - Diffusive Wave-Coarser (DW30km)}

Os valores de volume de armazenamento da seção do rio e comprimento foram obtidas dos resultados da simulação usando o modelo totalmente dinâmico SOBEK, as seções transversais foram utilizadas conforme os dados geométricos do Apêndice A. Foram configurados ao todo 6 seções transversais, que para esta configuração de Onda Difusiva estão aproximadamente

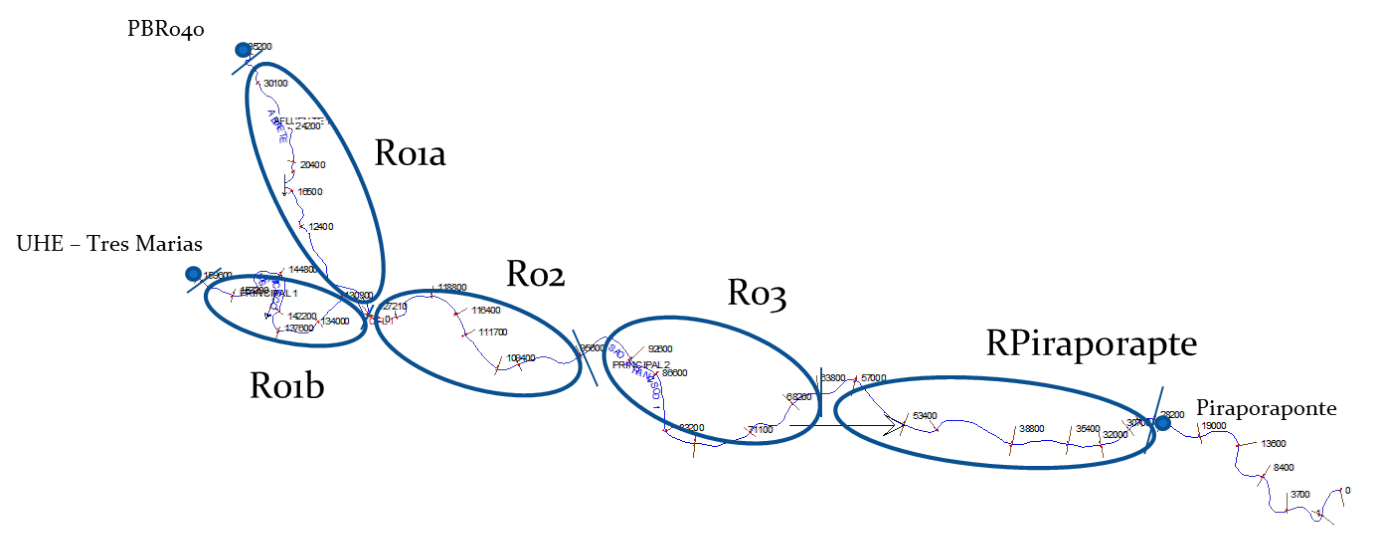

Figura 39 - Esquema da configuração para cascata de reservatórios 
a cada $30 \mathrm{~km}$ distantes entre si. NaTabela 18, mostra os nós configurados e suas geometrias correspondentes; as distâncias entre cada nó está descrito na tabela Tabela 19.

Tabela 18 - Seções transversais correspondentes aos nós do modelo difusivo com resolução grosseira (DW30km)

\begin{tabular}{llll}
\hline \hline Nome do Nó & Nome do Rio & Tipo de Nó & Nome da Seção Transversal \\
\hline PBR040 & Rio Abaetés & $\begin{array}{l}\text { Condição de Contorno } \\
\text { de Entrada (Vazão) }\end{array}$ & RA35200 \\
Tres Marias & Rio São Francisco 1 & $\begin{array}{l}\text { Condição de Contorno } \\
\text { de Entrada (Vazão) }\end{array}$ & SF159600 \\
N01 & Rio São Francisco 2 & Nó de Junção de Seções & SF127190 \\
N02 & Rio São Francisco 2 & Nõ de Cálculo & SF92600 \\
N03 & Rio São Francisco 2 & Nó de Cálculo & SF44700 \\
Piraporaponte & Rio São Francisco 2 & $\begin{array}{l}\text { Condico de Contorno } \\
\text { de Saída (Vazão) }\end{array}$ & SF29000 \\
\hline \hline
\end{tabular}

Tabela 19 - Comprimento entre as seções para o modelo difusivo com resolução grosseira (DW30km)

\begin{tabular}{ccc}
\hline \hline Nome da Seção & Nome do Rio & Comprimento (m) \\
\hline PBR040-N01 & Rio Abaetés & 35121.56 \\
Tres Marias-N01 & Rio São Francisco 1 & 29915.63 \\
N01-N02 & Rio São Francisco 2 & 34707.44 \\
N02-N03 & Rio São Francisco 2 & 31840.73 \\
N03-Piraporaponte & Rio São Francisco 2 & 34779.3 \\
\hline \hline
\end{tabular}

O único valor que foi Calibrado foi a rugosidade dos canais, como não há ainda uma calibração automatizada para o RTC-Tools, esta calibração foi feita manualmente tendo como referência os valores calibrados no SOBEK. Os valores adotados para a rugosidade estão apresentados na Tabela 20.

A única diferença no entanto é que a rugosidade no RTC-Tools é dada por Chézy:

$$
C=\frac{1}{n} R^{1 / 6}
$$

Onde $C$ é o coeficiente de Chézy em $m^{1 / 2} / s, R$ é o raio hidráulico em (m) e $n$ é o coeficiente de Manning.

Os valores dos comprimentos da seção molhada em relação a cota e armazenamento das seções consideradas para a configuração estão detalhadas no Apêndice E. 
Tabela 20 - Rugosidade das seções para o modelo difusivo com resolução grosseira (DW30km)

\begin{tabular}{ccc}
\hline \hline Nome da Seção & Cota $(\mathrm{m})$ & Chezy $\left(\mathrm{m}^{1 / 2} / \mathrm{s}\right)$ \\
\hline & 544.67 & 45 \\
PBR040-N01 & 545.3 & 45 \\
& 546.6 & 40 \\
& 549.17 & 40 \\
\hline & 509.57 & 45 \\
Tres Marias-N01 & 510.2 & 45 \\
& 511.5 & 40 \\
& 514.07 & 40 \\
\hline N01-N02 & 500.6 & 45 \\
& 501.23 & 45 \\
& 502.53 & 40 \\
& 505.1 & 40 \\
\hline N02-N03 & 490.64 & 45 \\
& 491.27 & 45 \\
& 492.27 & 40 \\
& 495.14 & 40 \\
\hline N03-Piraporaponte & 483.07 & 45 \\
& 483.7 & 45 \\
& 487.57 & 40 \\
\hline \hline
\end{tabular}

\section{Onda Difusiva com Alta Resolução Espacial - Diffusive Wave-Finer (DW10km)}

Assim como na configuração anterior para a configuração com a malha refinada, os valores de volume de armazenamento da seção do rio e comprimento foram obtidas dos resultados da simulação usando o modelo totalmente dinâmico SOBEK, as seções transversais foram utilizadas conforme os dados geométricos do Apêndice A. Foram configurados ao todo 14 seções transversais, que para esta configuração de Onda Difusiva estão aproximadamente a cada $10 \mathrm{~km}$ distantes entre si. NaTabela 18, mostra os nós configurados e suas geometrias correspondentes; as distâncias entre cada nó está descrito na tabela Tabela 22.

O único valor que foi Calibrado foi a rugosidade dos canais, como não há ainda uma calibração automatizada para o RTC-Tools, esta calibração foi feita manualmente tendo como referência os valores calibrados no SOBEK. Os valores adotados para a rugosidade estão apresentados na Tabela 23.

Os valores dos comprimentos da seção molhada em relação a cota e armazenamento das seções consideradas para a configuração estão detalhadas no Apêndice F. 
Tabela 21 - Seções transversais correspondentes aos nós do modelo difusivo com resolução refinada (DW10km)

\begin{tabular}{|c|c|c|c|}
\hline Nome do Nó & Nome do Rio & Tipo de Nó & Nome da Seção Transversal \\
\hline PBR040 & Rio Abaetés & $\begin{array}{l}\text { Condição de Contorno } \\
\text { de Entrada (Vazão) }\end{array}$ & RA35200 \\
\hline Tres Marias & Rio São Francisco 1 & $\begin{array}{l}\text { Condição de Contorno } \\
\text { de Entrada (Vazão) }\end{array}$ & SF159600 \\
\hline N01a & Rio São Francisco 1 & Nó de Cálculo & SF148800 \\
\hline N01b & Rio São Francisco 1 & Nó de Cálculo & SF153200 \\
\hline N01 & Rio São Francisco 2 & Nó de Junção de Seções & SF127190 \\
\hline N02a & Rio São Francisco 2 & Nó de Cálculo & SF116400 \\
\hline $\mathrm{N} 02 \mathrm{~b}$ & Rio São Francisco 2 & Nó de Cálculo & SF102500 \\
\hline N02 & Rio São Francisco 2 & Nó de Cálculo & SF92600 \\
\hline N03a & Rio São Francisco 2 & Nó de Cálculo & SF77200 \\
\hline N03b & Rio São Francisco 2 & Nó de Cálculo & SF68200 \\
\hline N03 & Rio São Francisco 2 & Nó de Cálculo & SF53400 \\
\hline $\mathrm{N} \mathrm{Pa}$ & Rio São Francisco 2 & Nó de Cálculo & SF38800 \\
\hline $\mathrm{N} \mathrm{Pb}$ & Rio São Francisco 2 & Nó de Cálculo & SF32000 \\
\hline Piraporaponte & Rio São Francisco 2 & $\begin{array}{l}\text { Condição de Contorno } \\
\text { de Saída (Vazão) }\end{array}$ & SF29000 \\
\hline
\end{tabular}

Tabela 22 - Comprimento entre as seções para o modelo difusivo com resolução grosseira (DW10km)

\begin{tabular}{ccc}
\hline \hline Nome da Seção & Nome do Rio & Comprimento $(\mathrm{m})$ \\
\hline PBR040-N01 & Rio Abaetés & 35121.56 \\
Tres Marias-N01a & Rio São Francisco 1 & 17040.2 \\
N01a-N01b & Rio São Francisco 1 & 11007.1 \\
N01b-N01 & Rio São Francisco 2 & 11868.33 \\
N01-N02a & Rio São Francisco 2 & 11533.17 \\
N02a-N02b & Rio São Francisco 2 & 9438.95 \\
N02b-N02 & Rio São Francisco 2 & 13735.32 \\
N02-N03a & Rio São Francisco 2 & 12420.6 \\
N03a-N03b & Rio São Francisco 2 & 12087.65 \\
N03b-N03 & Rio São Francisco 2 & 14161.89 \\
N03-N Pa & Rio São Francisco 2 & 12287.08 \\
N Pa- N Pb & Rio São Francisco 2 & 9276.7 \\
N Pb-Piraporapte & Rio São Francisco 2 & 6386.11 \\
\hline \hline
\end{tabular}

\section{Reservoir Routing}

Esta configuração é relativamente simples o trecho modelado foi divido em três volumes de controle, que são os chamados "reservatórios"sendo que cada volume apresenta duas tabelas sendo que uma relaciona cota $(\mathrm{m})$ com o volume de armazenamento $\left(\mathrm{m}^{3}\right)$ para a seção e outra que relaciona cota $(\mathrm{m})$ e a vazão para a seção em $\left(\mathrm{m}^{3} / \mathrm{s}\right)$. Os valores destas tabelas para as seções estão detalhadas no Apêndice G. 
Tabela 23 - Rugosidade das seções para o modelo difusivo com resolução grosseira (DW10km)

\begin{tabular}{|c|c|c|c|c|c|c|c|c|}
\hline Nome da Seção & Cota $(\mathrm{m})$ & Chezy $\left(m^{1 / 2} / s\right)$ & Nome da Seção & Cota $(\mathrm{m})$ & Chezy $\left(m^{1 / 2} / s\right)$ & Nome da Seção & Cota $(\mathrm{m})$ & Rugosidade \\
\hline \multirow{4}{*}{ PBR040-N01a } & 544.67 & 45 & - & - & - & - & - & - \\
\hline & 545.3 & 45 & - & - & - & - & - & - \\
\hline & 546.6 & 40 & - & - & - & - & - & - \\
\hline & 549.17 & 40 & - & - & - & - & - & - \\
\hline \multirow{4}{*}{ Tres Marias-N01a } & 509.57 & 45 & & 505.64 & 45 & \multirow{4}{*}{ N01b-N01 } & 502.99 & 45 \\
\hline & 511.18 & 45 & & 508.18 & 45 & & 503.5 & 45 \\
\hline & 511.37 & 40 & N01a-N01b & 510.56 & 40 & & 504.15 & 40 \\
\hline & 514.67 & 40 & & 512.52 & 40 & & 507.64 & 40 \\
\hline \multirow{4}{*}{ N01-N02a } & 500.6 & 45 & \multirow{4}{*}{ N02a-N02b } & 494.92 & 45 & \multirow{4}{*}{ N02b-N02 } & 493.32 & 45 \\
\hline & 502.18 & 45 & & 495.75 & 45 & & 494.52 & 45 \\
\hline & 504.8 & 40 & & 497.95 & 40 & & 495.9 & 40 \\
\hline & 505.42 & 40 & & 500.93 & 40 & & 498.81 & 40 \\
\hline \multirow{4}{*}{ N02-N03a } & 490.64 & 45 & \multirow{4}{*}{ N03a-N03b } & 487.65 & 45 & \multirow{4}{*}{ N03b-N03 } & 485.36 & 45 \\
\hline & 490.87 & 45 & & 489.06 & 45 & & 485.69 & 45 \\
\hline & 491.29 & 40 & & 490.19 & 40 & & 487.90 & 40 \\
\hline & 495.33 & 40 & & 492.95 & 40 & & 490.44 & 40 \\
\hline \multirow{4}{*}{ N03-N Pa } & 483.75 & 45 & \multirow{4}{*}{$\mathrm{N} \mathrm{Pa}-\mathrm{N} \mathrm{Pb}$} & 482.00 & 45 & \multirow{4}{*}{ N Pb-Piraporaponte } & 481.20 & 45 \\
\hline & 484.01 & 45 & & 483.05 & 45 & & 482.88 & 45 \\
\hline & 484.31 & 40 & & 483.80 & 40 & & 483.49 & 40 \\
\hline & 487.67 & 40 & & 486.26 & 40 & & 485.07 & 40 \\
\hline
\end{tabular}

Os valores de volume de armazenamento foram obtidos através dos resultados do SOBEK, as cotas das geometrias do rio conforme o Apêndice A, já as vazões foram obtidas para cada volume através dos dados obtidos do SOBEK que relacionam a área da seção molhada com a velocidade de escoamento.

Tabela 24 - Delimitações dos Volumes de Controlo "Reservatórios"para a configuração de Cascata de Reservatórios

\begin{tabular}{cccc}
\hline \hline Nome do Volume & Nome do Rio & Seção Incial & Seção Final (Seção de Controle) \\
\hline R01a & Rio Abaetés & RA35200 & RA0 \\
R01b & Rio São Francisco 1 & SF159600 & SF127210 \\
R02 & Rio São Francisco 2 & SF127190 & SF95600 \\
R03 & Rio São Francisco 2 & SF92600 & SF63800 \\
RPiraporapte & Rio São Francisco 2 & SF57000 & SF29000 \\
\hline \hline
\end{tabular}

Outro valor importante para esta configuração é o tempo de defasagem para da vazão entre os volumes do rio, estes volumes estão expressos em unidade de tempo de simulação e por isso mudam e devem ser recalculados conforme a resolução espacial de simulação muda.

Tabela 25 - Defasagem Temporal em unidades de tempo para Vazões entre os "Reservatórios"para as intervalos de simulação de 60, 30 e 10 minutos

\begin{tabular}{cccc}
\hline \hline \multirow{2}{*}{ Seção } & \multicolumn{3}{c}{ Defasgem (unidade de tempo) } \\
& 60 min & $30 \mathrm{~min}$ & $10 \mathrm{~min}$ \\
\hline R01a-R02 & 2.75 & 5.5 & 16.5 \\
R01b-R02 & 1.25 & 2.5 & 7.5 \\
R02-R03 & 3 & 6 & 18 \\
R03-RPiraporapte & 7 & 14 & 42 \\
\hline \hline
\end{tabular}




\subsection{Configuração do IPOPT}

Para o estudo de caso de UHE-Três Marias o problema de otimização é configurado usando a abordagem sequencial. Em seguida, um modelo adjunto é utilizado para fornecer o gradiente da função objetivo para um otimizador não-linear eficiente baseado em gradiente, neste caso no IPOPT (WÄCHTER; BIEGLER, 2006), e em seguida obtem-se as variáveis de controle sobre o horizonte de predição.

Para formular o problema então foi definido duas constantes a serem controladas, o nível do reservatório e a vazão defluente da barragem em dois pontos de controle: Vazão no ponto de controle em Pirapora e Vazão defluente da UHE-Três Marias.

Então como uma hard constraint, ou restrição inflexível, a qual nunca deve ser ultrapassada o valor do nível máximo normal do reservatório 572,50 metros e o mínimo normal 549,20 metros, a outra restrição inflexível foi a vazão mínima delfuente da UHE definida como 460 $\mathrm{m}^{3} / \mathrm{s}$. Os valores máximos de vazão de saída da UHE e vazões em Pirapora foram definida como uma soft constraint, ou restrição flexível, aquela que pode ser desobedecida, mas se o fizer deve haver uma penalidade, neste caso são os valores de ponderamento, então quanto maior o valor do ponderamento, mais grave é a infração da restrição.

Tabela 26 - Restrições Inflexíveis definidas no Otimizador

\begin{tabular}{ccc}
\hline \hline Variável & Valor Mínimo & Valor Máximo \\
\hline Nível de Operação da Barragem $(\mathrm{m})$ & 549,20 & 572,50 \\
Vazão defluente da Barragem $\left(\mathrm{m}^{3} / \mathrm{s}\right)$ & 460 & - \\
\hline \hline
\end{tabular}

Tabela 27 - Restrições Flexíveis definidas no Otimizador

\begin{tabular}{llll}
\hline \hline Variável & Valor de Referência & $\begin{array}{l}\text { Penalidade se for } \\
\text { Menor que o valor }\end{array}$ & $\begin{array}{l}\text { Penalidade se for } \\
\text { Maior que o valor }\end{array}$ \\
\hline \multirow{2}{*}{ Q defluente da UHE $\left(\mathrm{m}^{3} / \mathrm{s}\right)$} & 500 & 0.1 & - \\
\multirow{2}{*}{ Q em Pirapora $\left(\mathrm{m}^{3} / \mathrm{s}\right)$} & 800 & - & 0.001 \\
& 2.000 & - & 0.01 \\
& 3.000 & - & 1.0 \\
\hline \hline
\end{tabular}

\subsection{Modelos Internos}

Conforme visto no capítulo 6, para realizar as previsões dos estados futuros do sistema, um MPC precisa utilizar um modelo interno que será rodado iterativamente dentro da otimização para obter as variáveis de controle que minimizam a função objetivo. O modelo interno no RTCTools é baseado nos processos de escoamento descritos tanto pelos modelos de onda cinemática, pelo modelo de onda difusiva e pelo modelo de cascata de reservatórios. 
As equações governantes serão as ESVs; que descrevem o comportamento de nãoestacionário de corpos d’ água superficiais, estas que consistem de um grupo de equações usadas para solucionar os princípios físicos baseados nas propriedades de massa e conservação de movimento. O sistema original tridimensional de Navier-Stokes, podem ser reduzidos para um sistema unidimensional após descartados a velocidade em termos ortogonais à direção do fluxo Equação 5.5.

Para acelerar a solução ótima, é dado o gradiente da função objetivo para cada variável de controle do otimizador. O modelo adjunto melhora a computação de cada componente diferncial deste gradiente, uma vez que ele fornece um procedimento no qual as derivadas parciais da função objetivo serão computadas somente uma única vez para cada variável (GRIENWANK; WALTHER, 2008). Isto é feito através do cálculo reverso de diferenciação algorítmica dos derivativos da função objetiva. Os valores adjuntos correspondem ao total das derivadas da função objetiva para cada variável.

Considerando que os estados do sistema são definido por uma formulação explícita, então para cada intervalo de tempo $k$ os valores adjuntos podem ser obtidos através de:

$$
v_{k-1}^{-}=\frac{\partial J}{\partial v_{k-1}}+\overline{x_{k}} \cdot \frac{\partial x_{k}}{\partial v_{k-1}}
$$

onde $v$ representa qualquer variável do modelo interno $(x, u$, ou $d) ; J$ é a função objetiva 


\section{Indicadores de Desempenho}

Para avaliar as simulações selecionou-se dois tipos de indicadores: indicadores de desempenho de processamento e indicadores de desempenho estatísticos. O primeiro grupo de indicadores tem como objetivo avaliar o esforço computacional para as simulações através do tempo gasto para realiza-las e o custo computacional relativo destas simulações. Já o segundo grupo será utilizado para avaliar a confiabilidade dos resultados das simulações frente aos dados observados; ou seja avaliar a precisão dos resultados em simular os dados observados na Tabela 28 estão listados o grupos e os indicadores.

Tabela 28 - Indicadores de Performance Computacional e Estatísticos utilizados para avaliar os resultados.

\begin{tabular}{ccc}
\hline \hline Sigla Adotada & Unidade & Descrição \\
\hline CPU Time & \multicolumn{2}{c}{ Performance Computacional } \\
\hline CPU Time/Time Step & $\mathrm{ms}$ & Tempo total de processamento \\
\hline & & Performance Estatística \\
\hline Bias & $\mathrm{m}^{3} / \mathrm{s}$ & Verifica se as quantidades medidas são iguais \\
RMSE & $\mathrm{m}^{3} / \mathrm{s}$ & Magnitude do resíduo da amostra \\
$\mathrm{R}^{2}$ & - & Ajuste Geral das Curvas \\
NSE & - & Plotagem da Variância Residual pela Variância dos Dados \\
\hline \hline
\end{tabular}

O CPU Time ou tempo de processamento foi obtido dos arquivos de texto e relatórios gerados pelos modelos após a conclusão das simulações. Este tempo de processamento de dados para as simulações pode ser dividido em três partes: $O$ tempo de entrada/ saída para ler os arquivos texto, tempo usado para processar e simular os dados e novamente mais um tempo entra/saída para registrar os resultados em disco. É um dado absoluto medindo o tempo total de processamento da simulação.

O próximo indicador de performance utilizado foi de CPU Performance/Time Steps, que servirá para medir quanto poder de processamento relativo, ou seja quanto tempo de processamento é necessário para processar cada intervalo de tempo de simulação. É importante lembrar que as simulações que definem o tempo implicitamente, não podem ser avaliadas por este indicador.

$$
\text { CPUtime } / \text { TimeStep }=\frac{\Delta t}{N}
$$

Nesta equação $\Delta t$, corresponde ao tempo total necessário para completar a simulação e 
$N$ corresponde ao número de intervalos de tempo de simulação ou simplesmente o número de dados simulados.

Para analisar a precisão dos resultados de simulação foram selecionados quatro indicadores de performance: Tendência (Bias), Erro Médio Quadrádico (RMSE), Coeficiente de determinação $\left(R^{2}\right)$ e Eficiência de Nash-Sutcliffe (NSE):

A tendência ou (Bias) é uma função que estima a diferença entre os valores medidos e simulados. Um valor igual a zero é considerado sem viés. A tendência de uma equação é da pela Equação 11.2

$$
\text { Bias }=\frac{1}{N} \sum_{i}^{N}\left(\hat{x}_{i}-x_{i}\right)
$$

Onde $N$, corresponde ao número de pontos de dados, $\hat{x}$ são os valores calculados e $x$ corresponde aos valores observados ou ao valor de referência.

O Erro médio quadrádico (RMSE) ou Erro da Raiz Quadrada da Média ao Quadrado, mede a magnitude do erro em uma função periódica, ou seja que não é estável, indicando o a variância dos residuais, medindo o ruído da amostra. Um RMSE igual a zero indica um ajuste perfeito o RMSE é calculado por:

$$
R M S E=\sqrt{\frac{1}{N} \sum_{i}^{N}\left(\hat{x}_{i}-x_{i}\right)^{2}}
$$

Onde $N$, corresponde ao número de pontos de dados, $\hat{x}$ são os valores calculados e $x$ corresponde aos valores observados ou ao valor de referência.

A Correlação de Pearson ou Coeficiente de Correlação ou simplesmente $R^{2}$, serve assim como o RMSE para representar o grau de colinearidade entre o dados simulados com os observados, servindo para medir a proporção de ajuste da amostra. $\mathrm{O}$ valor do $R^{2}$ varia de 0 até 1 , sendo um $R^{2}$ igual a zero correspondente a nenhuma relação entre os dados existe e um valor próximo a 1, significa uma perfeita relação entre os dados. O coeficiente é calculado conforme:

$$
R^{2}=\left(\frac{\sum_{i}^{N}\left(\hat{x}_{i}-\hat{\bar{x}}_{i}\right)\left(\left(x_{i}-\hat{x}_{i}\right)\right)}{\sqrt{\sum_{i}^{N}\left(\hat{x}_{i}-\hat{\bar{x}}_{i}\right)} \sqrt{\sum_{i}^{N}\left(x_{i}-\bar{x}_{i}\right)}}\right)^{2}
$$

Onde, $N$, corresponde ao número de pontos de dados, $\hat{x}$ são os valores calculados, $\hat{\bar{x}}$ a 
media dos valores calculados, $x$ corresponde aos valores observados ou ao valor de referência e $\bar{x}$ a media dos valores observados.

O modelo de eficiência de Nash-Sutcliffe (NSE) é uma estatística normalizada utilizada para indicar o ajuste entre valores estimados com valores de referência, determinando a magnitude da variância residual, ou ruído comparado com a variância dos valores observados ou de referência. Ele indica o quão bem ajustado é a plotagem de dados observados contra os simulados. A faixa de valores para o NSE varia entre $-\infty$ e 1 . Um NSE igual a 1 indica que os valores simulados são exatamente iguais aos observados, valores entre 1 e zero são considerados aceitáveis e valores negativos indicam que a média do valor observado é uma estimativa melhor do que sua simulação. A fórmula para o NSE é dada por:

$$
N S E=1-\frac{\sum_{i}^{N}\left(\hat{x}_{i}-x_{i}\right)^{2}}{\sum_{i}^{N}\left(x_{i}-\bar{x}_{i}\right)^{2}}
$$

Onde, $N$, corresponde ao número de pontos de dados, $\hat{x}$ são os valores calculados, $x$ corresponde aos valores observados ou ao valor de referência e $\bar{x}$ a media dos valores observados. 

Parte V

Resultados \& Discussão 



\section{Resultados}

Na avaliação dos resultados e desempenho computacional dos modelos selecionados, foram realizadas diversas simulações de forma permitir avaliar como as diferentes versões das ESV e/ou diferentes configurações espaciais e temporais impactam o tempo de processamento das simulações e a precisão dos resultados.

Tabela 29 - Modelos e Períodos de Simulações dos Resultados.

\begin{tabular}{lcc}
\hline \hline Modelos Utilizados & Data de Início de Simulação & Data Final de Simulação \\
\hline SPRNT e SOBEK & $19 / 06 / 2006$ 21:00 & $22 / 09 / 2006$ 06:00 \\
$\Delta$ espacial - RTC-Tools & $15 / 01 / 200721: 00$ & $20 / 06 / 201100: 00$ \\
$\Delta$ temporal - RTC-Tools & & \\
SOBEK, MGB-IPH e RTC-Tools & & \\
\hline \hline
\end{tabular}

Na Tabela 29, estão listados os modelos e configurações e respectivos períodos utilizados nas simulações, ao todo foram feitas 3 análises; comparação do SOBEK em relação ao SPRNT; avaliação dos impactos da resolução espacial; avaliação da resolução temporal e por último comparação entre o SOBEK, MGB-IPH e RTC-Tools.

A primeira é uma comparação dos modelos totalmente dinâmicas (SOBEK e o SPRNT), nesta avaliação utilizou-se dados diários para o período de 19/06/2006 às 21:00 até 22/09/2006 às 06:00. A segunda e a terceira simulações foram feitas para avaliar como a resolução espacial e temporal impactam os resultados dos modelos e seu desempenho computacional e a última simulação envolveu os mais modelos e configurações que obtiveram melhor desempenho nas simulações anteriores (SOBEK, Cascata de Reservatórios Horário e Onda Difusiva com resolução espacial refinada também horário) em relação ao MGB-IPH. Para estas 3 simulações foi utilizado período entre 15/01/2007 21:00 até 20/06/2011 00:00.

Tabela 30 - Cenários e Períodos de Otimizações.

\begin{tabular}{lccc}
\hline \hline Modelos Utilizados & Cenário de Otimização & Data de Início & Horizonte de Otimização \\
\hline RTC-Tools acoplado no & Situação Normal & $19 / 01 / 2008$ 20:00 & \multirow{2}{*}{ ano } \\
Otimizador & Condição de Estiagem & $31 / 08 / 2008$ 00:00 & \\
\hline \hline
\end{tabular}

A seguir realizou-se simulações de problemas de otimização integrando o modelo mais apto, obtido da análise das simulações anteriores, ao otimizador IPOPT. Na Tabela 30 estão listados os períodos e horizontes de previsão que foram utilizados nos 2 cenários de otimização. Estes cenários tem como intuito demonstrar as capacidades do modelo em ser executado em conjunto com um otimizador para aplicações de SSD para operação de reservatórios e controle de cheias em tempo real. 


\subsection{SOBEK $\times$ SPRNT}

Conforme dito anteriormente foi feita uma comparação entre os dois modelos que utilizam a Equação Totalmente Dinâmica de Saint-Venant para simular a descarga em canais abertos. Nesta comparação, os modelos não foram integrados ao Delft-FEWS e portanto não receberam a correção de contribuição de descarga lateral.

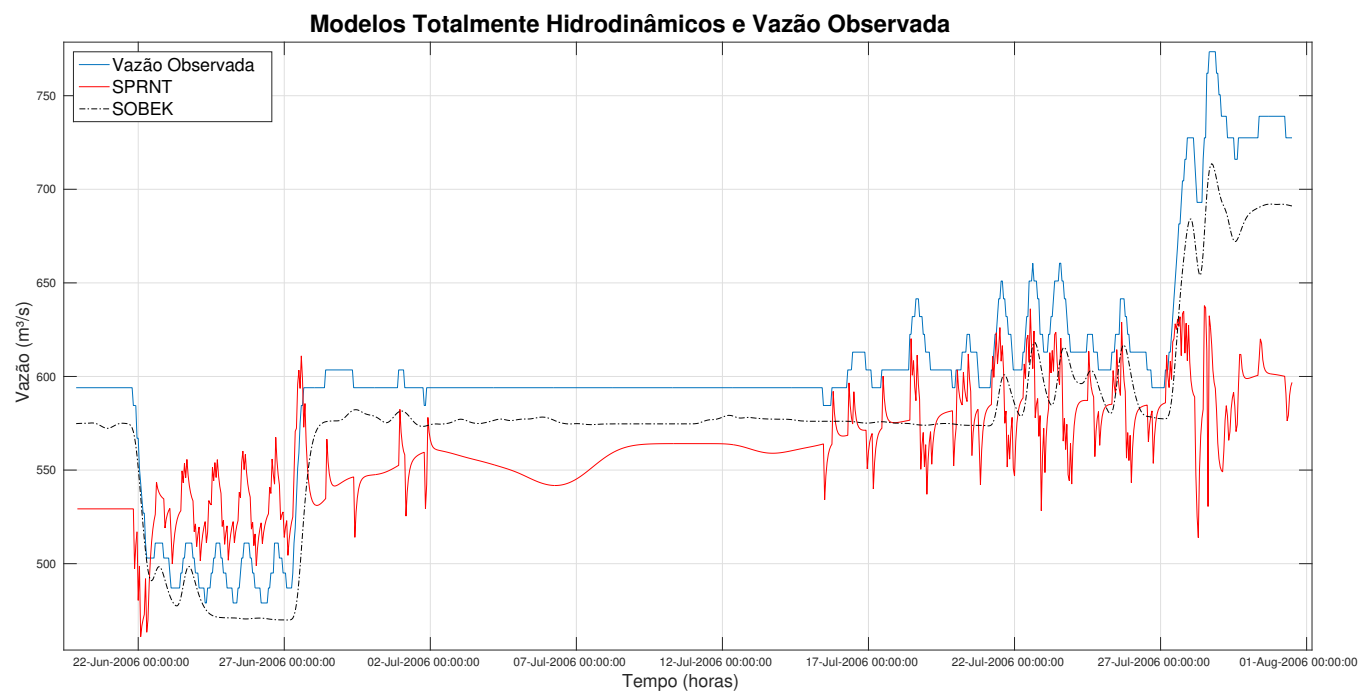

Figura 40 - Comparação do modelo SPRNT com o SOBEK.

Observando a Figura 40, os resultados do SOBEK, aqui são claramente superiores comparados com os resultados do SPNRT, ambos os modelos apresentam volume de água inferior ao observado, que pode ser explicado pela falta da contribuição lateral e o sinal gerado pelo SPRNT, muito embora responda as variações de vazão observadas, não consegue simular o formato ou a ordem de grandeza das simulações.

Tabela 31 - Gasto Computacional e Performance dos modelos totalmente dinâmicos sem implementação de contribuições laterais (SOBEK \& SPRNT).

\begin{tabular}{lccccc}
\hline \hline Modelo & Tempo de Processamento (s) & Bias & RMSE & NSE & R $^{2}$ \\
\hline SPRNT & 4,92 & $-23,25$ & 66,22 & 0,12 & 0,25 \\
SOBEK & 32,16 & $-21,24$ & 26,26 & 0.83 & 0,978 \\
\hline \hline
\end{tabular}

Na Tabela 31, a falta de contribuição lateral influencia o Bias de ambos os modelos deixando-o negativo levando em consideração que nestas métricas aqui utilizadas não estão com contribuição de vazão lateral por isso as estatísticas (BIAS) baixo nos dois modelos. Ambos os modelos apresentam um RMSE alto, já em relação ao encaixe das curvas mostram claramente que o SPRNT não conseguiu simular corretamente os resultados.

No entanto comparando os tempos de processamento dos dois modelos, o SPRNT que utiliza técnicas de aceleração de processamento foi muito superior ao SOBEK, sendo capaz de calcular a mesma série de dados XX vezes mais rápido. Porém este tempo real para obter os dados 
do SPRNT é maior pelo fato de que ele não está implementado no Delft-FEWS, dependendo de uso de softwares terceiros para importar, extrair e visualizar os dados gerados.

\subsection{Impacto da Resolução Espacial}

Na Figura 41, estão plotadas as duas curvas dos modelos de onda difusa, uma menos detalhada (DW-30km) e outra mais detalhada (DW-10km), podemos ver claramente que a resolução espacial mais refinada melhorou os gráficos, o timing da configuração mais detalhada esta mais correto, a outra menos detalhada apresenta um atraso no picos, além disto, os picos conseguem reproduzir mais corretamente os picos observados, no entanto ambas apresentam um amortecimento significativo dos sinais, principalmente nas seções onde existem variações curtas e rápidas decorrentes de um comportamento típico de operação de reservatórios, o sinal da onda difusa demora a responder este tipo de variação.

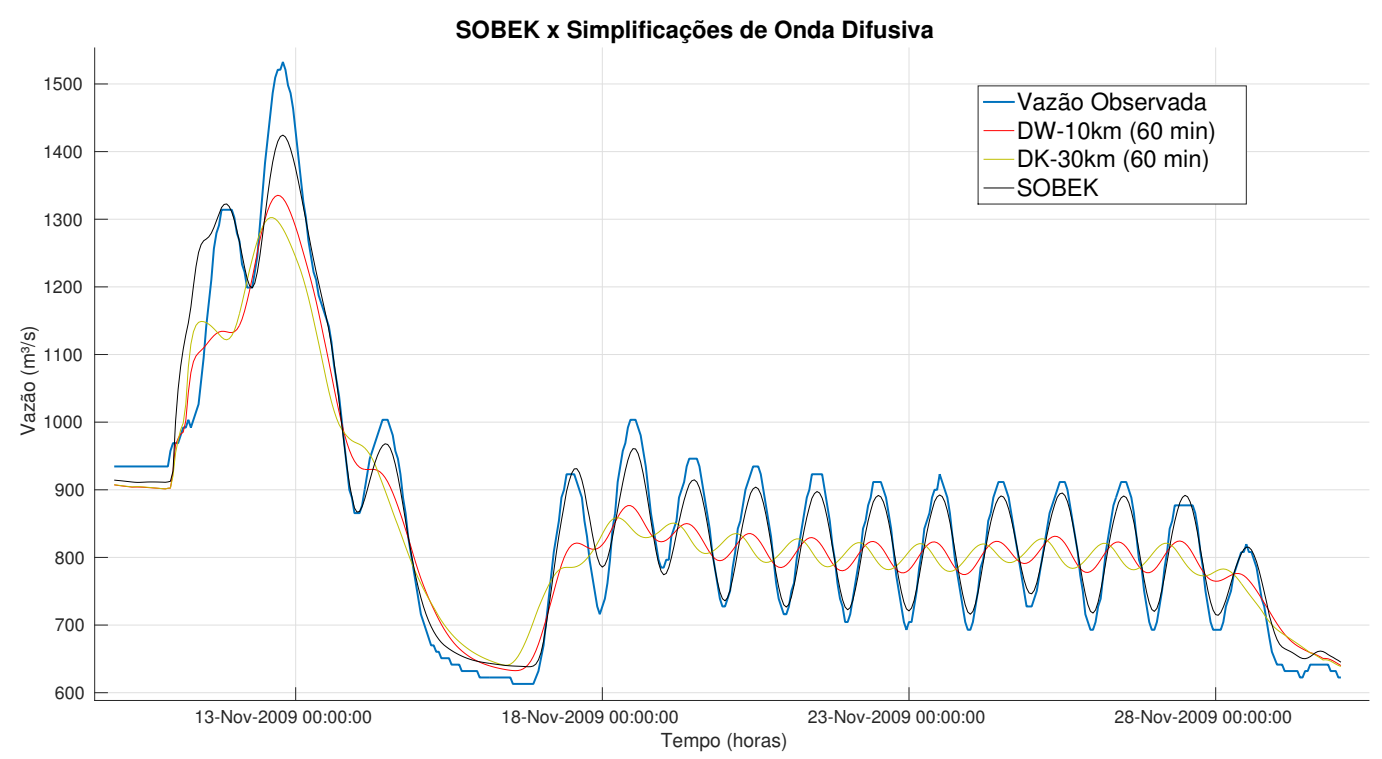

Figura 41 - Modelo Totalmente dinâmico (SOBEK) e Modelos de Onda Difusiva (Diffusive Wave - DW).

Observa-se também na Figura 41, que ao comparar o modelo totalmente hidrodinâmico, que tem a maior resolução espacial, com os que utilizam uma simplificação espacial e de equação governante, é possível notar que os modelos simplificados apresentam atenuações nos picos e uma menor resposta do sinal. Em termos de operação de reservatórios este comportamento é desvantajoso, pois o modelo pode não estimar corretamente a magnitude ou a rapidez de um evento de inundação, subestimando-o ou errando o tempo que ocorrerá.

\subsection{Impacto da Resolução Temporal}

O próximo passo foi de verificação se a variabilidade temporal poderia corrigir os comportamentos indesejados observados na seção anterior. Os modelos de Cascata de Reservatórios 
(RR), Onda Difusa com resolução espacial pouco detalhada (DW-30km) e Onda Difusa Detalhada (DW-10km). Novamente variou-se o intervalo temporal de simulações utilizando $(10,20$, 30, 40 e 60 minutos).

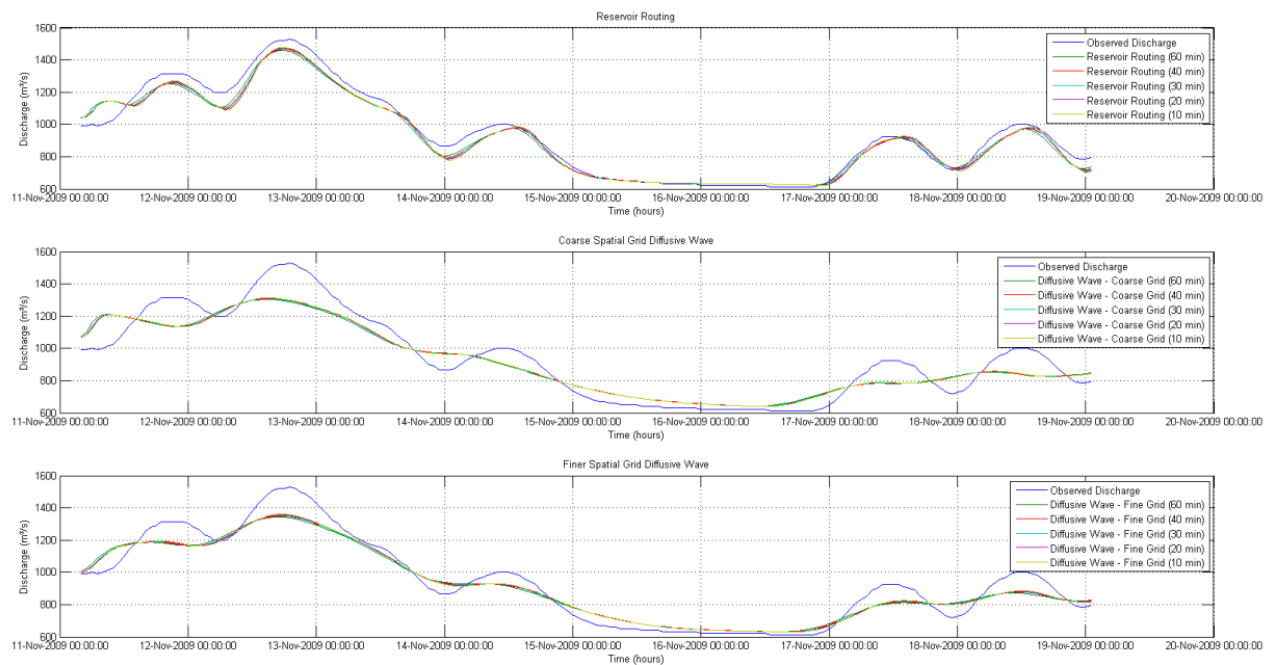

Figura 42 - Comparação dos Modelos Conforme a Variação Espacial e Temporal.

Na Figura 42, estão apresentados os sinais das configurações dos modelos acima descritos variando temporalmente. Podemos ver que houve uma latente melhora nos resultados, mas a evolução dos resultados conforme a escala temporal diminuía foi visualmente marginal, não conseguindo corrigir o amortecimento dos picos.

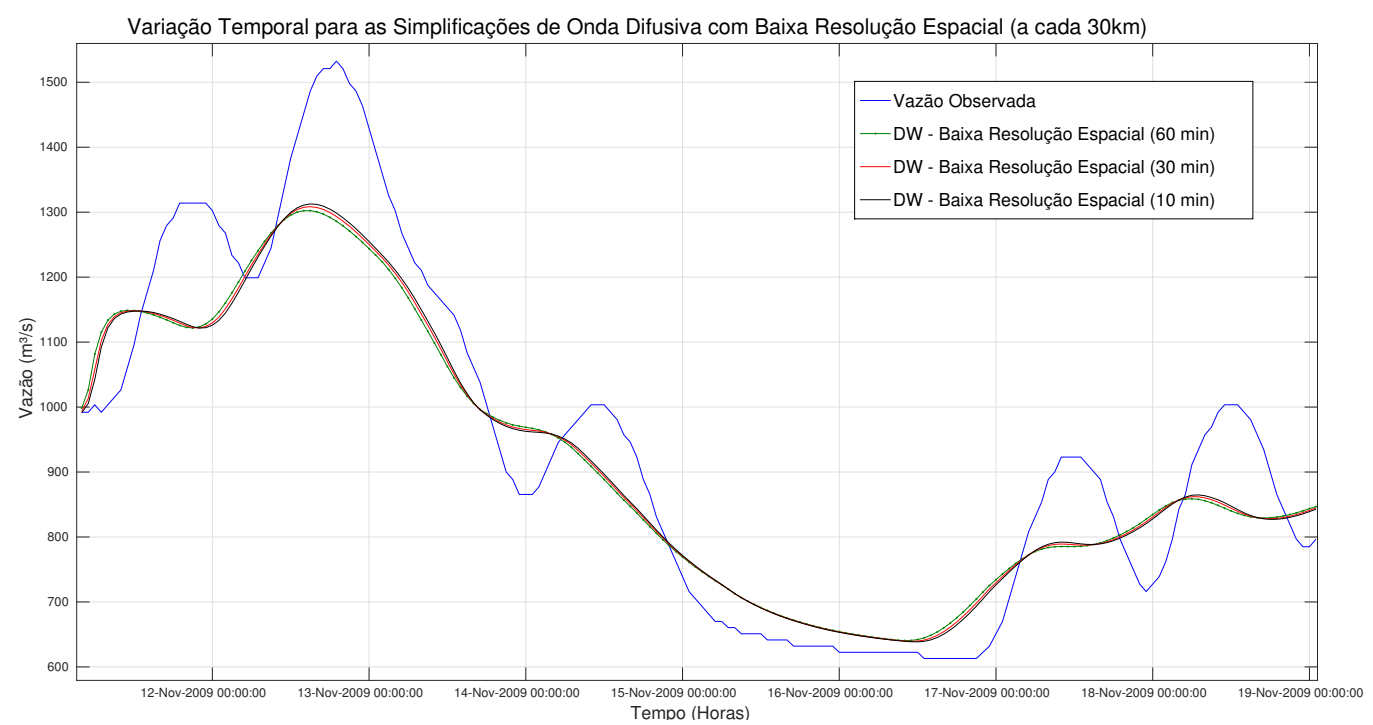

Figura 43 - Comparação das simulações adotando intervalos de tempo de de 10, 30 e 60 min Onda Difusiva com Baixa Resolução Espacial (Diffusive Wave -DW30km).

Analisando somente o comportamento do impacto da variabilidade temporal 10, 30 e 60 minutos no modelo de Onda Difusiva com baixa resolução espacial, o modelo menos detalhado na Figura 43, podemos ver que embora o aumento da resolução tenha melhorado os resultados, 
esta melhora no das curvas foi pequeno, havendo uma reprodução melhor dos picos e no tempo das curvas, mas há pouca diferença entre a simulação horária para a simulação a cada 10 minutos.

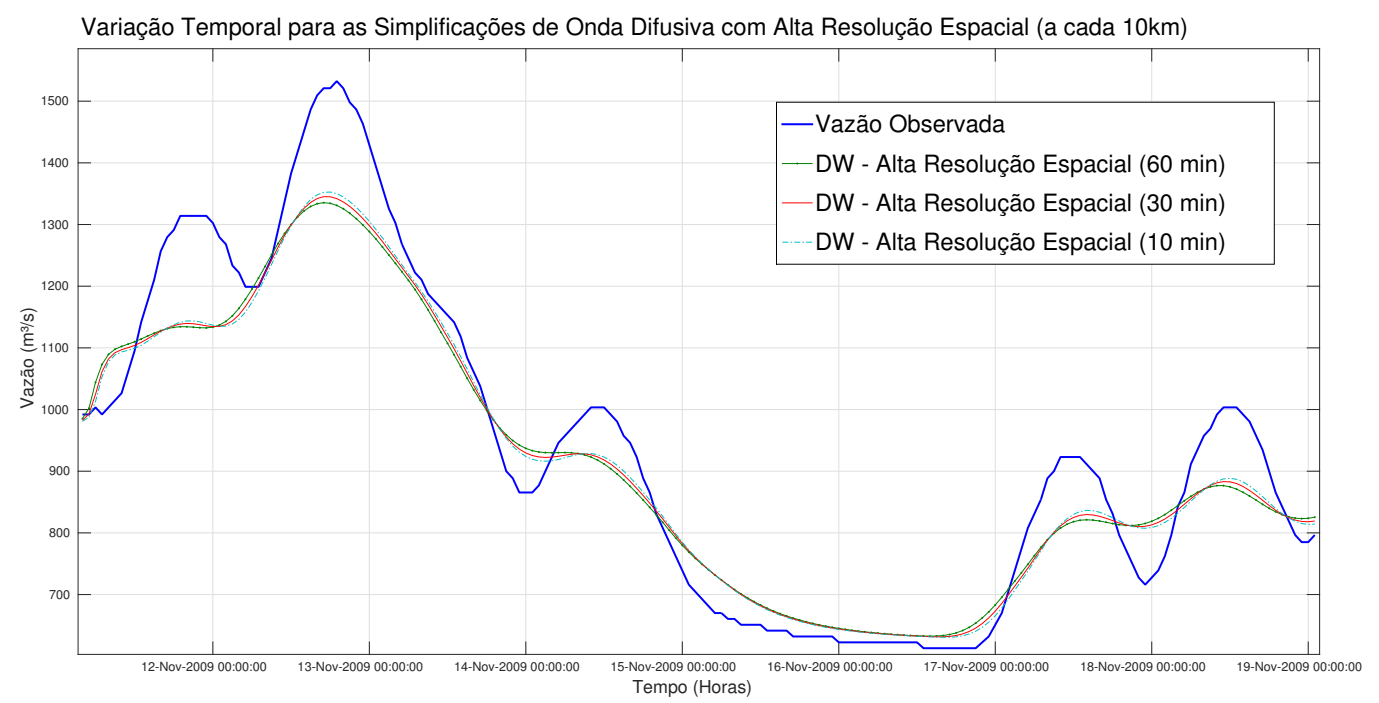

Figura 44 - Comparação das simulações adotando intervalos de tempo de de 10, 30 e 60 min Onda Difusiva com Alta Resolução Espacial (Diffusive Wave -DW10km).

$\mathrm{Na}$ Figura 44, temos os resultados da variação temporal (10, 30 e 60 minutos) para o modelo de Onda Difusiva mais detalhado com nós de cálculo a cada 10km. Embora haja uma melhora visual dos picos e no comportamento do sinal, assim como na figura anterior houve pouca diferença entre o modelo de 60 minutos para o modelo de 10 minutos.

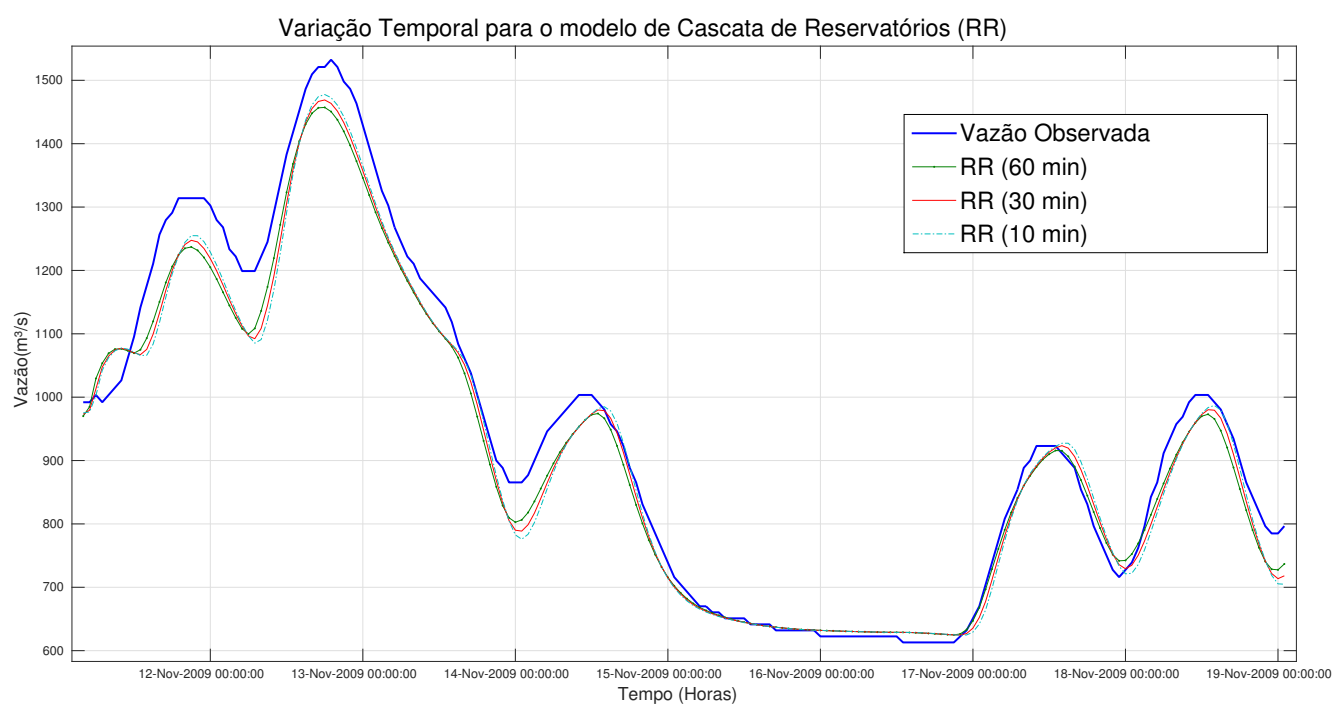

Figura 45 - Comparação das simulações adotando intervalos de tempo de de 10, 30 e 60 min Cascata de Reservatórios (Reservoir Routing -RR).

Por útimo analisando a Figura 45, para o modelo de Cascata de Reservatórios, podemos ver que o modelo tem um comportamento melhor que ambos os modelos de onda difusa (DW$10 \mathrm{~km}$ e DW-30km), conseguindo reproduzir os picos melhor assim como um ajuste e resposta 
melhores à mudanças bruscas do sinal observado. No entanto assim como os modelos anteriores, visualmente houve pouco impacto a variabilidade do intervalo temporal de simulações.

\subsection{SOBEK X MGB-IPH X RTC-Tools}

Nesta simulação foram analisados os modelos SOBEK, que utiliza a versão completa de ESV , o MGB-IPH que utiliza Muskingum-Kunge e o RTC-Tools, este utilizando três configurações diferentes, DW que utiliza a simplificação de Onda Difusa da Equação de Saint-Venant e RR (Reservoir Routing), ou Cascata de Reservatórios que utiliza uma equação equivalente à onda cinética da equação de Saint-Venant. Além disto foi feita a análise do impacto da variação espacial e temporal nos resultados para diferentes configurações do RTC-Tools.

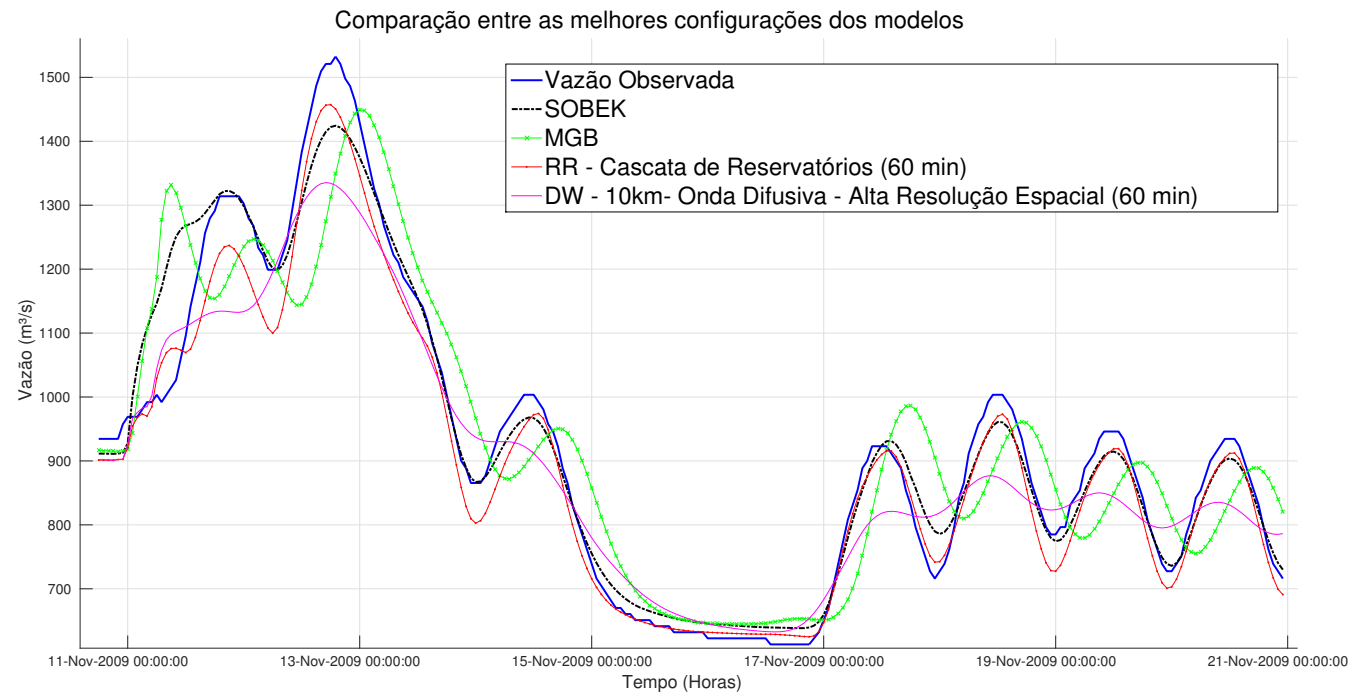

Figura 46 - Comportamento dos modelos em eventos de pico de cheia.

Como não é possível alterar a variação temporal ou espacial do MGB, sem comprometer os resultados obtidos, por isso estes dois não serão analisados quanto sua variabilidade temporal ou espacial. Já para o caso do modelo de Cascata de Reservatórios, também não é possível alterar a variabilidade espacial sem comprometer os resultados.

Portanto para a análise da variação temporal selecionou-se intervalos temporais das simulações de $10 \mathrm{~min}, 20 \mathrm{~min}, 30 \mathrm{~min}, 40 \mathrm{~min}$ e $60 \mathrm{~min}$. E para a análise da resolução espacial utilizaram-se duas resoluções espaciais para a onda difusa: uma mais esparsa com um nós de cálculo a cada 30 km (DW-30km) e outra mais concentrada com nós a cada 10 km (DW-10km).

A Figura 46, mostra o comportamento dos modelos quando há picos de vazão, que podem ser importantes no caso de operação de reservatórios visando controle de cheias. podemos ver que o MGB apresenta uma atraso nos resultados, que não é desejável para este tipo de aplicação, os modelos de Cascata de Reservatórios e SOBEK apresentaram um resultado similar e o de onda difusa apresentam considerável atenua cão dos picos. 


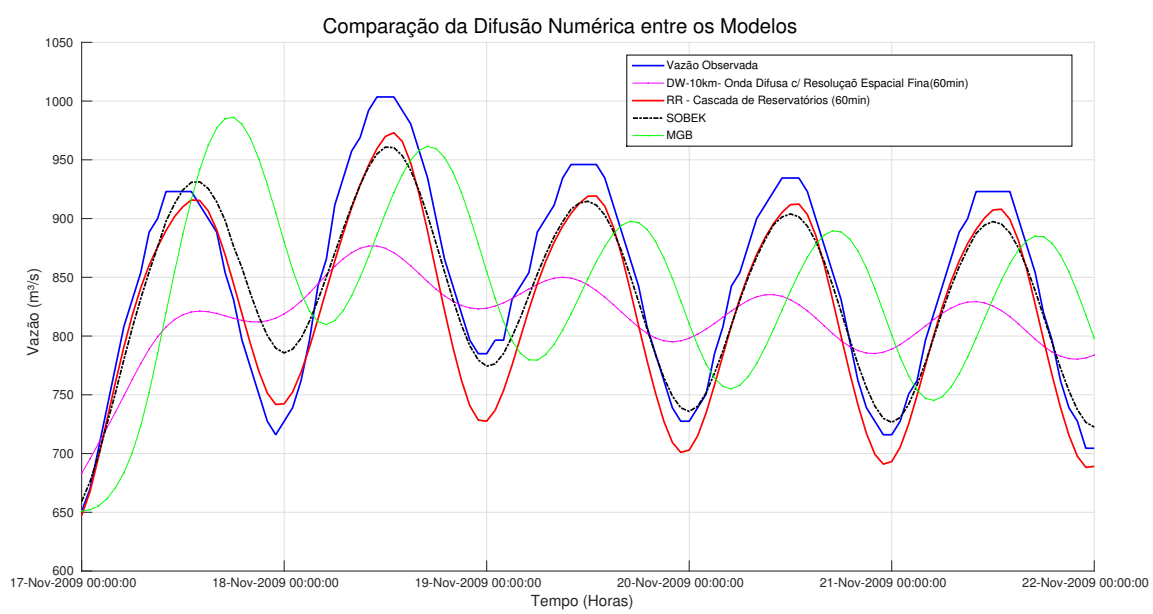

Figura 47 - Difusão Numérico dos modelos em eventos de variações de vazões.

Na Figura 47, podemos ver uma seção com um comportamento típico barragens, onde há num intervalo de tempo rápidas e seguidas mudanças de vazão, resultantes da operação. Podemos ver que o MGB está completamente fora de fase e que o modelo de onda difusa não consegue reproduzir o comportamento, reagindo muito lentamente a estas varições.

\subsection{Métricas de Desempenho}

\section{NSE}

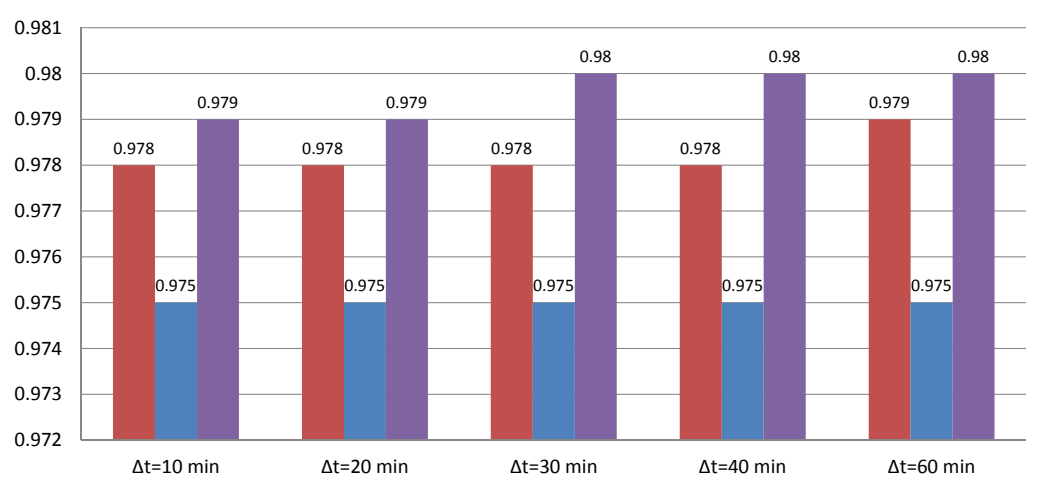

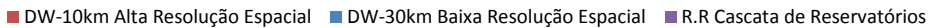

Figura 48 - NSE para os modelos de Onda Cinemática (RR) e Onda Diffusiva (DW).

A seguir serão apresentados os valores medidos das métricas estatísticas do Bias, NSE, RMSE e $\mathrm{R}^{2}$. De uma maneira geral não houve uma melhora significativa ao aumentar diminuir o intervalo temporal das simulações, os indicadores variaram pouco considerando que o número 
simulações feitas entre a simulação horária (60 minutos) e que gera resultados a cada 30 minutos dobra e para o intervalo de simulação menor de 10 minutos o numero de simulações sextiplica.

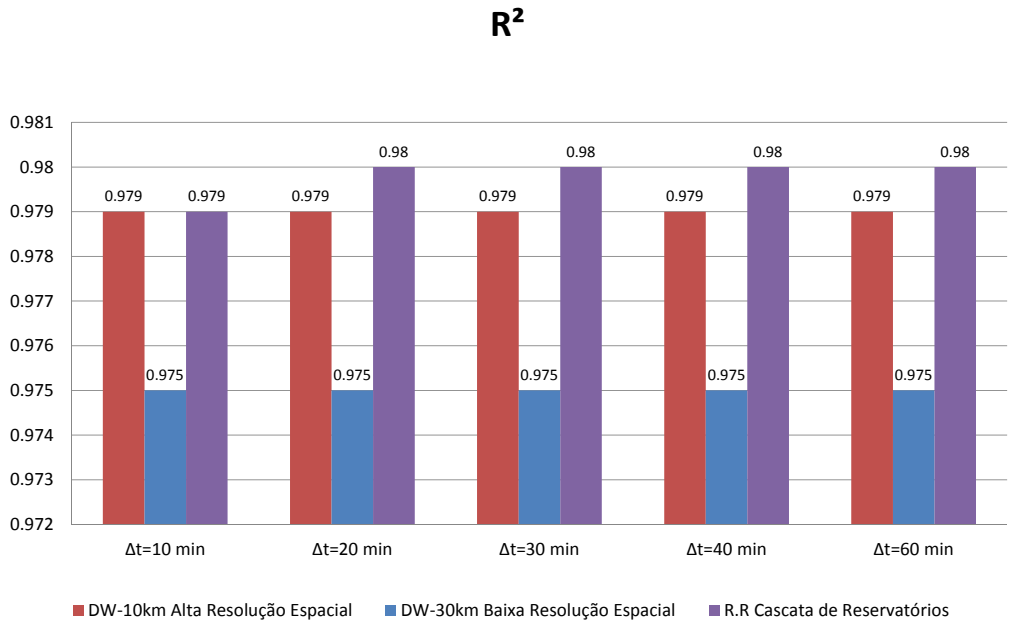

Figura $49-R^{2}$ para os modelos de Onda Cinemática (RR) e Onda Diffusiva (DW).

Os indicadores $\mathrm{R}^{2}$ e NSE permanecem estáveis e praticamente não foram afetados pelas alterações propostas. Nas figuras 49 e 48, podemos ver uma melhora muito discreta para 10 minutos, mas em compensação uma resolução espacial foi muito mais eficiente para melhoria dos dados, sendo observada nos modelos de Onda Difusa menos e mais detalhados.

No caso do RMSE, para os modelos de Onda Difusa houve uma tendência pequena de melhorar os valores conforme a escala temporal de simulação diminui e para o modelo de Cascata de Reservatórios a tendência não foi observada, os valore se mantiveram praticamente os mesmos. Novamente a variação espacial afeta mais os valores do que a variação temporal (Figura 50).

Na Figura 51 podemos ver que o Bias apresentou um comportamento bem evidente, conforme a resolução temporal aumenta, o valor também tende a aumentar para todos os modelos.O balanço de água piorou, visto que os modelos passaram a calcular um volume ligeiramente maior do que o observado. A resolução espacial também causou um impacto maior neste indicador do que a variação no intervalo temporal das simulações; conforme a resolução da malha de nós aumenta de 30km (DW-30km) para 10 km (DW-10km), o valor do Bias também aumenta. 


\section{$\operatorname{RMSE}\left(\mathrm{m}^{3} / \mathrm{s}\right)$}

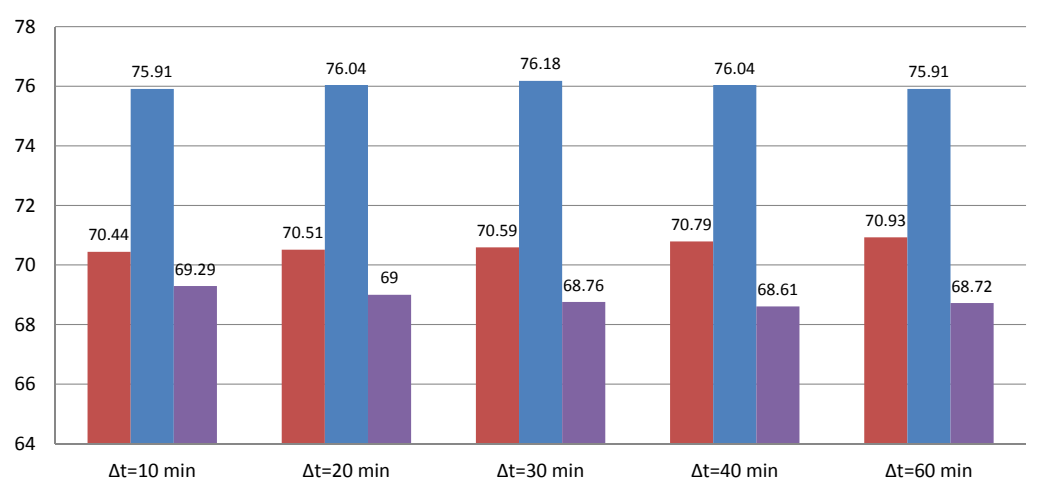

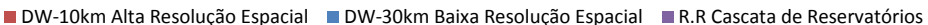

Figura 50 - RMSE para os modelos de Onda Cinemática (RR) e Onda Diffusiva (DW).

\section{$\operatorname{Bias}\left(\mathrm{m}^{3} / \mathrm{s}\right)$}

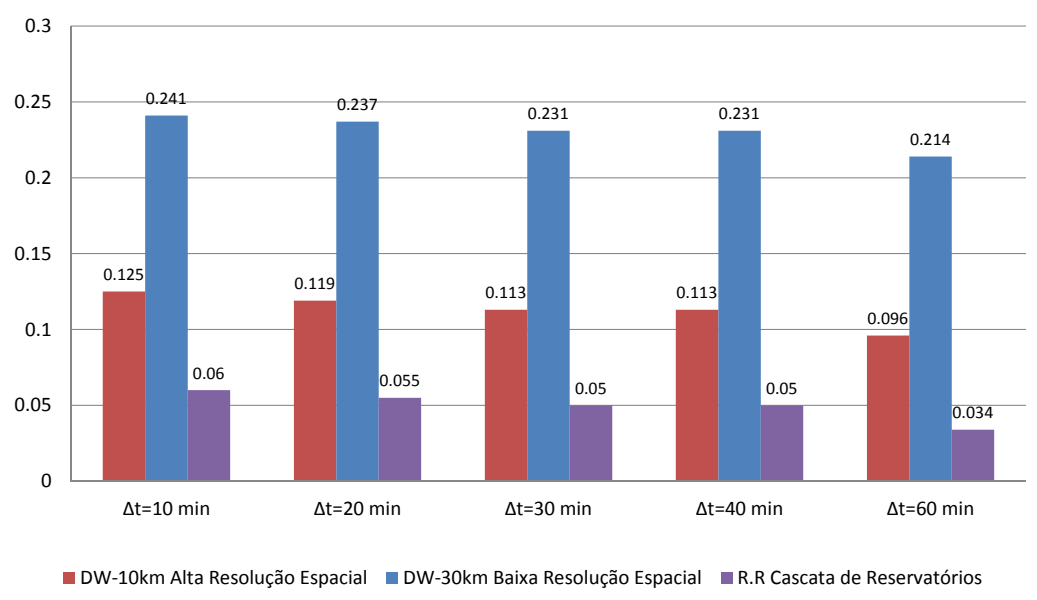

Figura 51 - Bias para os modelos de Onda Cinemática (RR) e Onda Diffusiva (DW).

\subsection{Avaliação de Performance Computacional dos Modelos}

Ao avaliar o desempenho computacional, conforme a resolução espacial do intervalo de tempo de simulação diminui (Time Step, o tempo de simulação CPU Time aumenta isso acontece porque o número de etapas para as simulações aumenta, a configuração de 30 minutos executa o dobro de simulações que a de 60 minutos e a de 10 minutos deve simular 6 vezes mais etapas do 
que a de 60 minutos e assim por diante. Desta forma para poder avaliar o custo computacional relativo destas simulações utilizou-se a Equação 11.1. Na Tabela 32, estão apresentados os resultados desta relação para os modelos analisados.

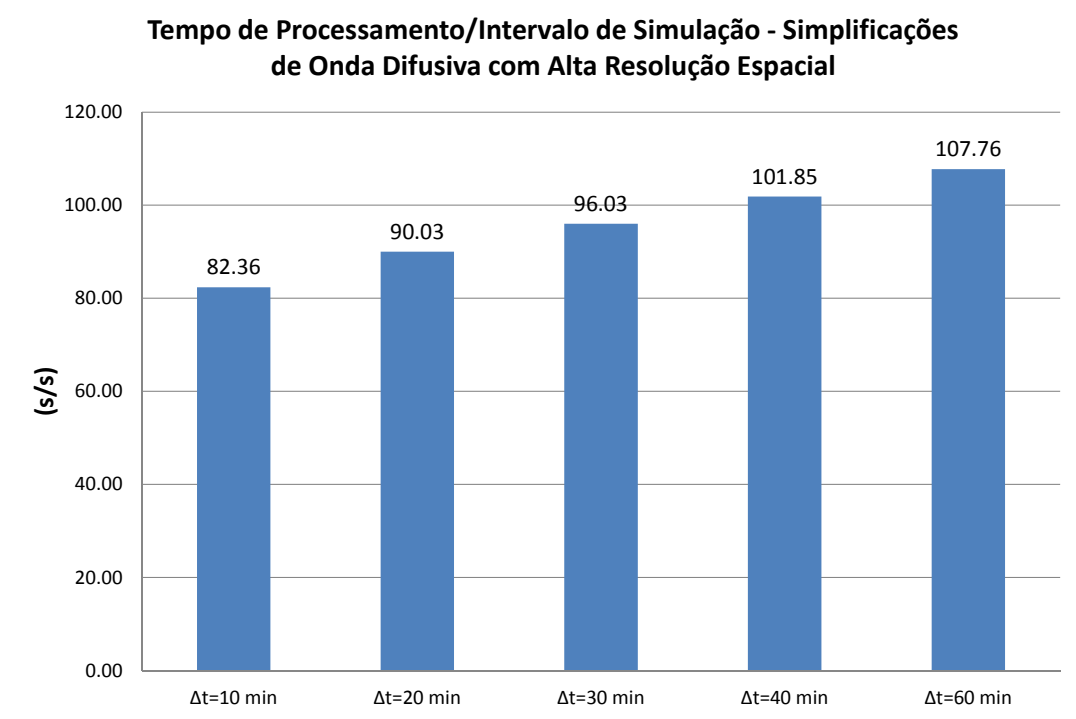

(a) DW $10 \mathrm{~km}$

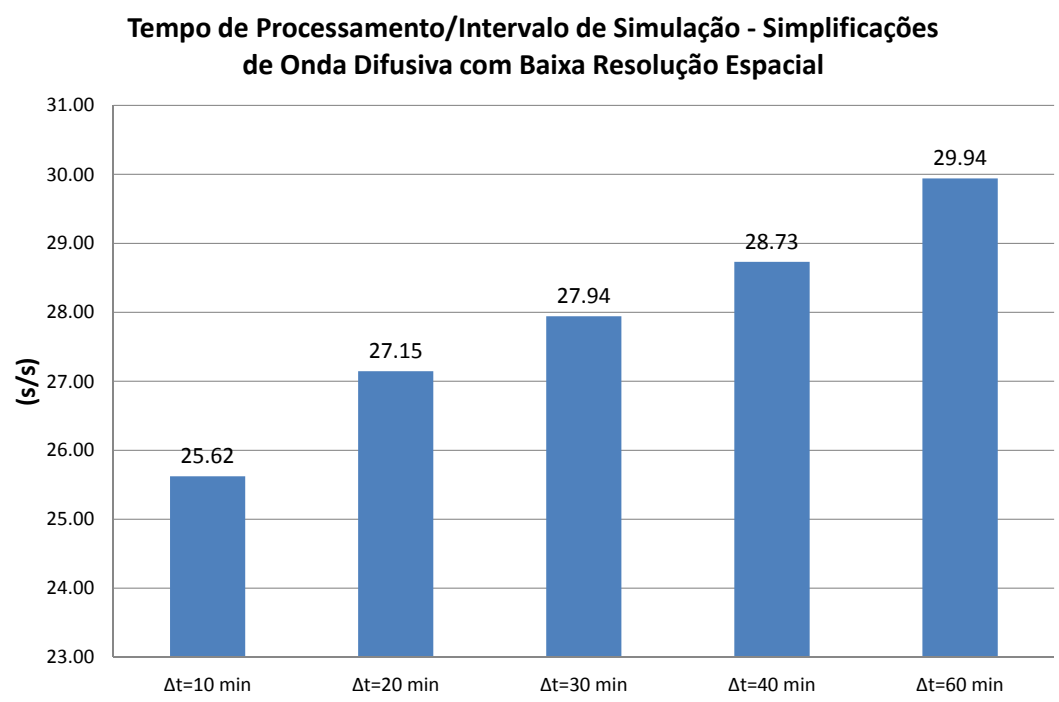

(b) DW $30 \mathrm{~km}$

Figura 52 - Custo Relativo de Processamento refinamentos temporais dos modelos de Onda Difusa (DW-10km e DW-30km).

O custo de processamento para os modelos de onda difusa diminuem conforme a escala 
temporal diminui, significando que para esta configuração é mais fácil processar intervalos de tempos menores do que intervalos de tempos maiores, já para o modelo RR a tendência foi inversa as escalas temporais menores aumentaram o custo de processamento, muito embora esta diferença seja quase desprezível.

Em relação ao custo de processamento para cada intervalo de simulação (Figura 52), foi observado que ao refinar a resolução temporal foi possível aumentar a eficiência de processamento, ou seja custo relativo para simular um intervalo de tempo de simulação; o aumento desta eficiência foi maior para o modelo com resolução espacial refinada (DW-10km)e ligeira no modelo de alta resolução espacial (DW-30km). Curiosamente esta relação não foi observada no modelo de cascata de reservatórios (RR) (Figura 53), ao contrário dos modelos de onda difusiva, o comportamento se manteve praticamente estável conforme a escala temporal era alterada, sendo que na escala temporal menor (10 min), foi observado uma pequena queda na eficiência.

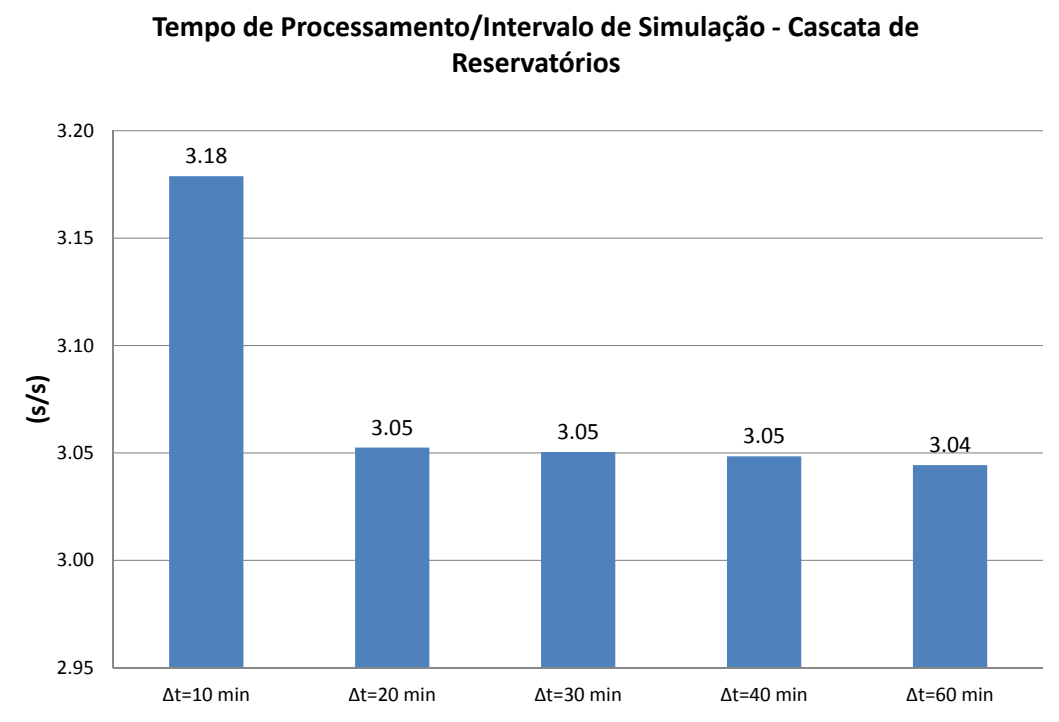

Figura 53 - Custo Relativo de Processamento para refinamentos temporais do modelo de cascata de reservatórios $(\mathrm{RR})$

Para os modelos de onda difusiva; embora haja aumento absoluto no tempo de processamento conforme a temporal aumenta, observa-se que um aumento de eficiência de processamento, ou seja redução do esforço computacional relativo, ou seja o tempo de processamento necessário para processar uma unidade do intervalo de simulação diminui. O modelo mais refinado usando a escala temporal de 10 minutos necessita de 25,62 segundo para simular 1 segundo do intervalo de simulação, já para uma escala maior 60 minutos seriam necessários 29,94. O mesmo é observado no modelo mais refinado o tempo para 60 minutos é 107,76 segundos para simular 1 segundo do intervalo de simulação reduzindo para 82,36 segundo na escala temporal de 10 minutos. 
Já para o modelo de Cascata de Reservatórios (RR) a tendência é inversa aos modelos de onda difusiva, a eficiência de simulação cai ligeiramente sendo 3,04 segundos para um intervalo de 60 minutos e para intervalo de 10 minutos este tempo seria 3,18 segundos.

Tabela 32 - Redução do Custo relativo de processamento para os modelos de onda difusiva e de cascata de reservatórios

\begin{tabular}{|c|c|c|c|}
\hline \multicolumn{4}{|c|}{ Onda Difusiva com alta resoulução espacial (DW-10 km) } \\
\hline \multirow[b]{2}{*}{$\Delta \mathrm{t}$} & \multirow[b]{2}{*}{ Tempo de Simulação/Intervalo de Simulação (s/s) } & \multicolumn{2}{|c|}{ Redução } \\
\hline & & $(\mathrm{s} / \mathrm{s})$ & $\%$ \\
\hline 60 & 107,76 & - & - \\
\hline 40 & 101,85 & 5,91 & $5,80 \%$ \\
\hline 30 & 96,03 & 5,82 & $6,06 \%$ \\
\hline 20 & 90,03 & 6 & $6,66 \%$ \\
\hline 10 & 82,36 & 7,67 & $9,31 \%$ \\
\hline Média & 95,61 & 6,35 & $6,96 \%$ \\
\hline \multicolumn{4}{|c|}{ Onda Difusiva com baixa resolução espacial (DW-30km) } \\
\hline & & \multicolumn{2}{|c|}{ Redução } \\
\hline$\Delta \mathrm{t}$ & Tempo de Simulação/Intervalo de Simulação (s/s) & $(\mathrm{s} / \mathrm{s})$ & $\%$ \\
\hline 60 & 29,94 & - & - \\
\hline 40 & 28,73 & 1,21 & $4,21 \%$ \\
\hline 30 & 27,94 & 0,79 & $2,83 \%$ \\
\hline 20 & 27,15 & 0,79 & $2,91 \%$ \\
\hline 10 & 25,62 & 1,53 & $5,97 \%$ \\
\hline Média & 27,88 & 1,08 & $3,98 \%$ \\
\hline \multicolumn{4}{|c|}{ Cascata de Reservatórios (RR) } \\
\hline & & \multicolumn{2}{|c|}{ Redução } \\
\hline$\Delta \mathrm{t}$ & Tempo de Simulação/Intervalo de Simulação (s/s) & $(\mathrm{s} / \mathrm{s})$ & $\%$ \\
\hline 60 & 3,04 & - & - \\
\hline 40 & 3,05 & $-0,01$ & $-0,33 \%$ \\
\hline 30 & 3,05 & 0 & $0,00 \%$ \\
\hline 20 & 3,05 & 0 & $0,00 \%$ \\
\hline 10 & 3,18 & $-0,13$ & $-4,09 \%$ \\
\hline Média & 3,07 & $-0,035$ & $-1,10 \%$ \\
\hline
\end{tabular}

\subsection{Resultados da Simulação do Otimizador}

O modelo hidráulico implementado para realizar as simulações foi o modelo de cascata de reservatórios do RTC-Tools. Os resultados das simulações do otimizador tem como intuito serem aplicadas em conjunto com algum sistema de previsão de chuvas. Os resultados gerados para vazão vertida e nível do reservatório em relação ao horizonte de previsão para estados possíveis futuros indicam a operação a ser feita para buscar aproveitar com o máximo de eficiência o volume de água a fim de permitir utilizar o máximo de volume no inverno e estocar o máximo de água no verão. 
Foram realizadas duas simulações com horizonte de previsão de 1 ano, ou seja, com conhecimento prévio das perturbações que irão ocorrer nos 8.760 intervalos de tempo do sistema. A primeira simulação (Período de 19/01/2008 às 20:00 até 19/01/2009 às 20:00) foi denominado como cenário normal; já na segunda simulação (horizonte de previsão de 31/08/2008 às 00:00 até 31/08/2009 às 00:00), foi denominado cenário de estiagem.

Tabela 33 - Descrição dos Cenários de Otimização

\begin{tabular}{lccc}
\hline \hline & Condição Simulada & Ínicio & Fim \\
\hline Cenário 1 & Normal & $19 / 01 / 2008$ às 20:00 & $19 / 01 / 2009$ às 20:00 \\
Cenário 2 & Estiagem & $31 / 08 / 2008$ às 00:00 & $31 / 08 / 2009$ às 00:00 \\
\hline
\end{tabular}

\subsubsection{Cenário 1: Condição Normal}

O primeiro cenário foi feito meramente com o intuito de demonstrar a eficácia do otimizador em condições normais, neste cenário os estados iniciais de volume serão idênticos aos observados. utilizou-se as mesmas condições iniciais do que as observadas.

Para avaliar os resultados do otimizador em relação ao controle de reservatório serão analisados os dados de nível do reservatório e sua vazão de saída, lembrando que existem restrições de operação conforme apresentado na Tabela 26 e 27. E para avaliar o desempenho do otimizador em relação ao controle de cheias será investigado os valores de vazão no ponto de monitoramento em Pirapora.

\section{Controle do Volume do Reservatório}

Os resultados para a operação otimizada do volume do reservatório estão apresentadas na Figura 54. Como podemos observar o sinal obtido foi bastante similar ao observado, o que indica que o sistema já operada consideravelmente otimizado; no entanto podemos observar que ao final do horizonte de previsão o volume simulado (em vermelho) fica ligeiramente maior do que o volume observado (em azul).

Outro resultado que é importante de ser observado é a vazão de defluência da barragem, existe uma condição de restrição ecológica, portanto deve-se evitar sempre que possível vazões menores do que $500 \mathrm{~m}^{3} / \mathrm{s}$.

$\mathrm{Na}$ figura 55a, é possível observar que os valores observados apresentam neste cenário vazões em alguns eventos muito menores do que a vazão mínima recomendável e que existem picos de vazão muito altos principalmente no final da série simulada, estes picos de vazão alta podem potencialmente causar inundações em Pirapora.

Por outro lado ao analisar e observar o sinal da figura 55b, rapidamente nota-se que a amplitude de vazão diminuiu consideravelmente ficando na faixa de 460 até $700 \mathrm{~m}^{3} / \mathrm{s}$. 


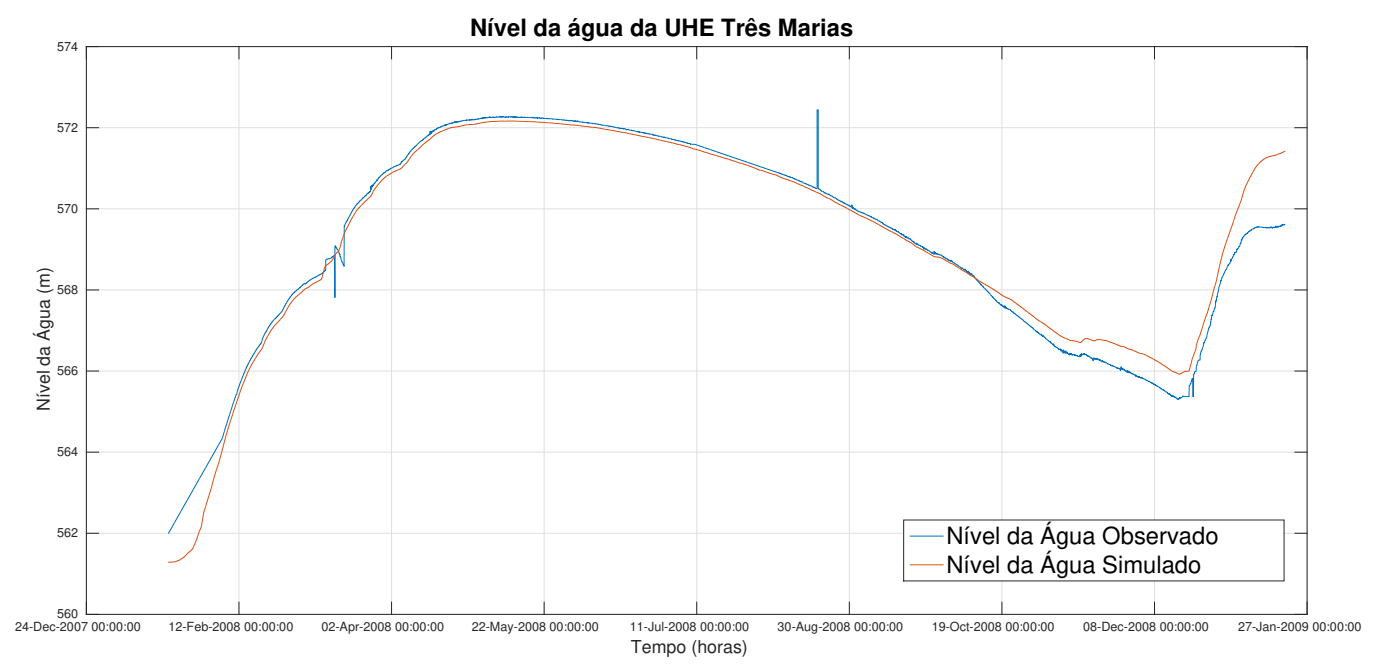

Figura 54 - Resultados dos volumes do reservatório otimizados para o Cenário 1

\section{Controle de Efeitos de Inundação}

Os resultados dos valores simulados para controle dos efeitos de inundação em Pirapora, estão apresentados na Figura 56. Na figura estão plotadas as curvas no ponto de controle de inundação observadas e simuladas.

Nas vazões observadas ( Figura 56a), no final da série podemos observar vazões beirando os $2.000 \mathrm{~m}^{3} / \mathrm{s}$, que não chegam a ser perigosos, mas entram na faixa definida por Cavallari, Silva e Castro (2012) como ínicio da fase de monitoramento de controle de cheia, uma vez podem representar potenciais riscos de inundação a ilhas utilizadas em culturas de subsistência. $\mathrm{Na}$ figura 56b, podemos observar que o otimizador consegue com sucesso atenuar estes picos, sendo que os valores máximos ficam em torno de $1.700 \mathrm{~m}^{3} / \mathrm{s}$.

\subsubsection{Cenário 2: Condição de Estiagem}

Ao contrário do primeiro cenário, neste segundo cenário o intuito é simular uma condição de estresse hídrico, a recuperação de um reservatório para um período de estiagem, desta forma portanto os estados iniciais de volume do reservatório serão menores que o observado. Pretendese neste cenário testar a capacidade do otimizador em conseguir recuperar volume de água e ao mesmo tempo atender as restrições operacionais.

Então de forma análoga ao cenário 1, os resultados do otimizador serão avaliados em relação ao controle de reservatório analisando os dados de nível do reservatório e sua vazão de saída, lembrando que existem restrições de operação conforme apresentado na Tabela 26 e 27. E para avaliar o desempenho do otimizador em relação ao controle de cheias será investigado os valores de vazão no ponto de monitoramento em Pirapora. 


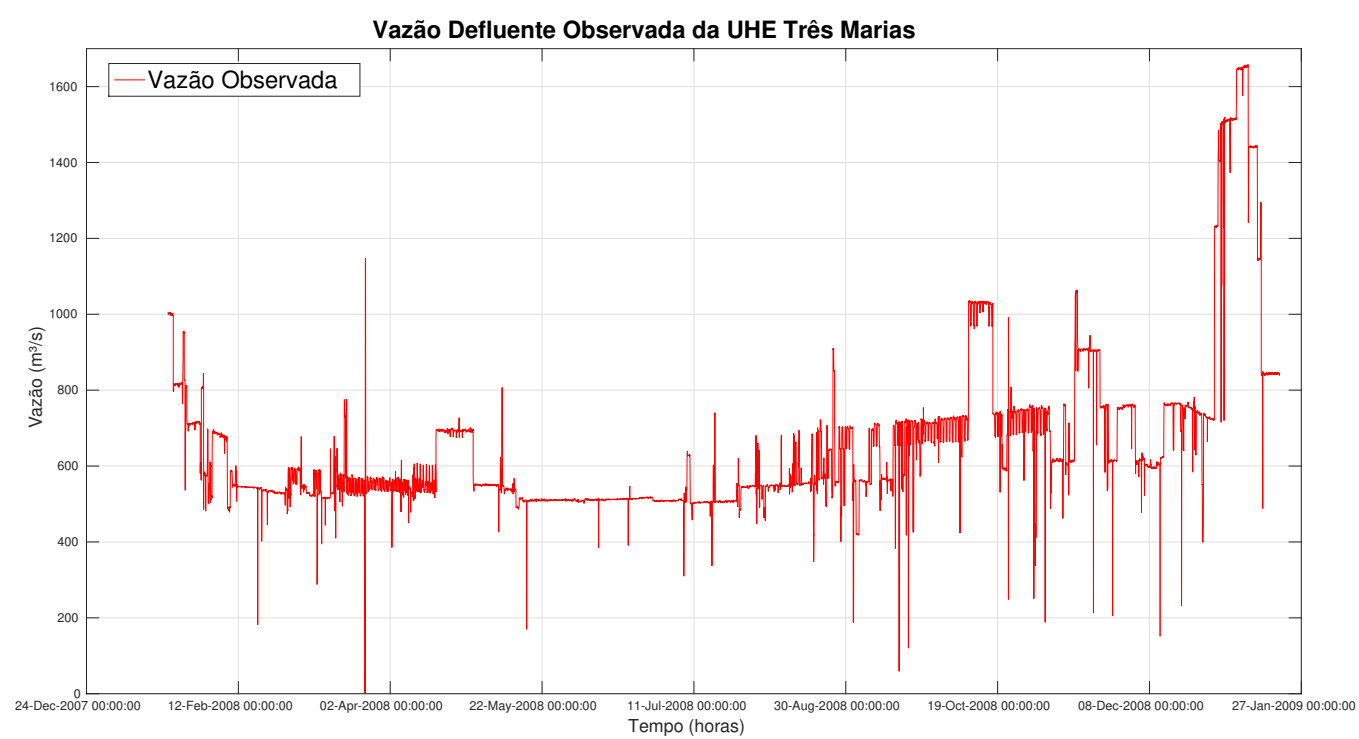

(a) Vazões Defluentes Observadas do Reservatório de Três Marias

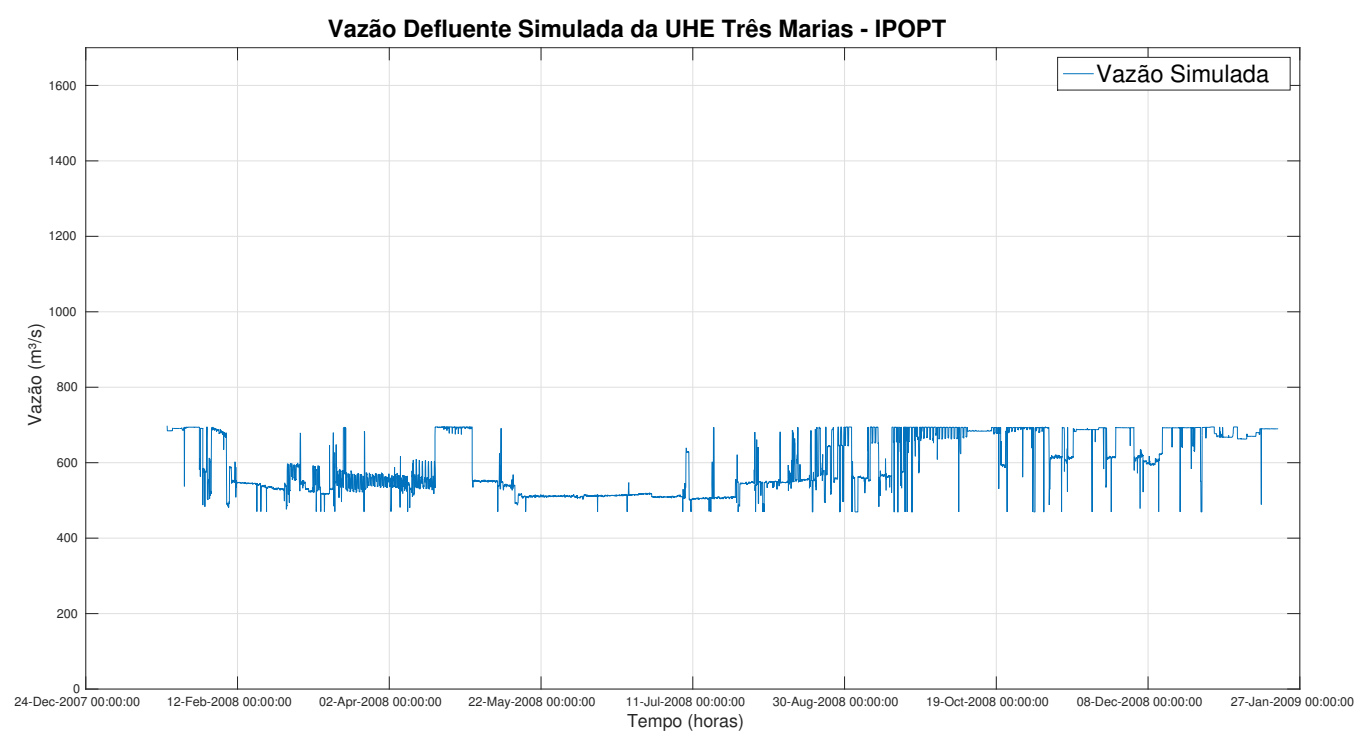

(b) Vazões Defluentes Simuladas do Reservatório de Três Marias

Figura 55 - Cenário 1: Comparação entre vazões defluentes simuladas e observadas do Reservatório.

\section{Controle do Volume do Reservatório}

Como explicado anteriormente a série do otimizador começa com um volume inferior ao observado, portanto seria como se o reservatório estivesse passado por um período de estiagem onde suas reservas estão baixas e será necessário utilizar o volume disponível racionalmente para tentar recupera-lo. Na Figura 57, podemos ver sinal em azul representando os dados observados e em vermelho os dados simulados, observa-se que a linha vermelha apesar de iniciar com menos volume que a azul consegue passar pelo inverno sem entrar em nível crítico e ao final do verão consegue recuperar o volume ficando praticamente que igualado ao observado. 


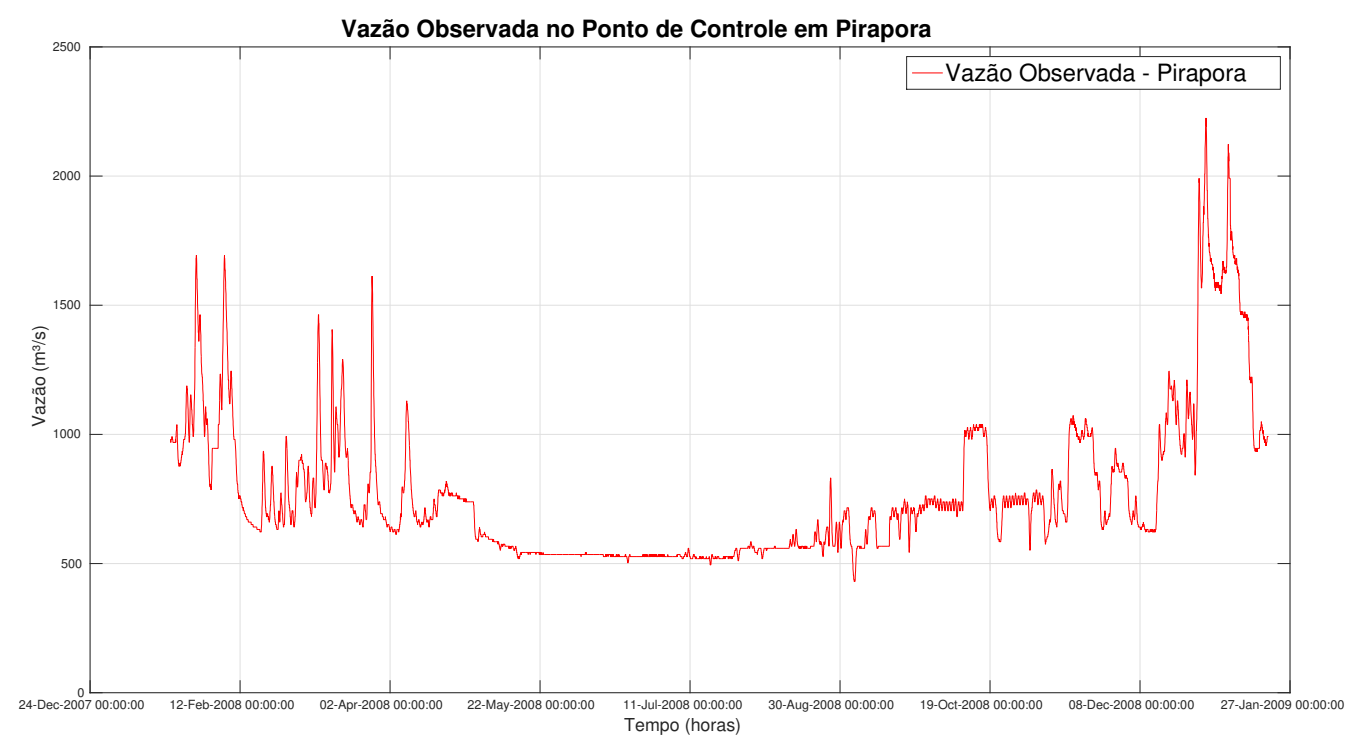

(a) Vazões Observadas em Pirapora

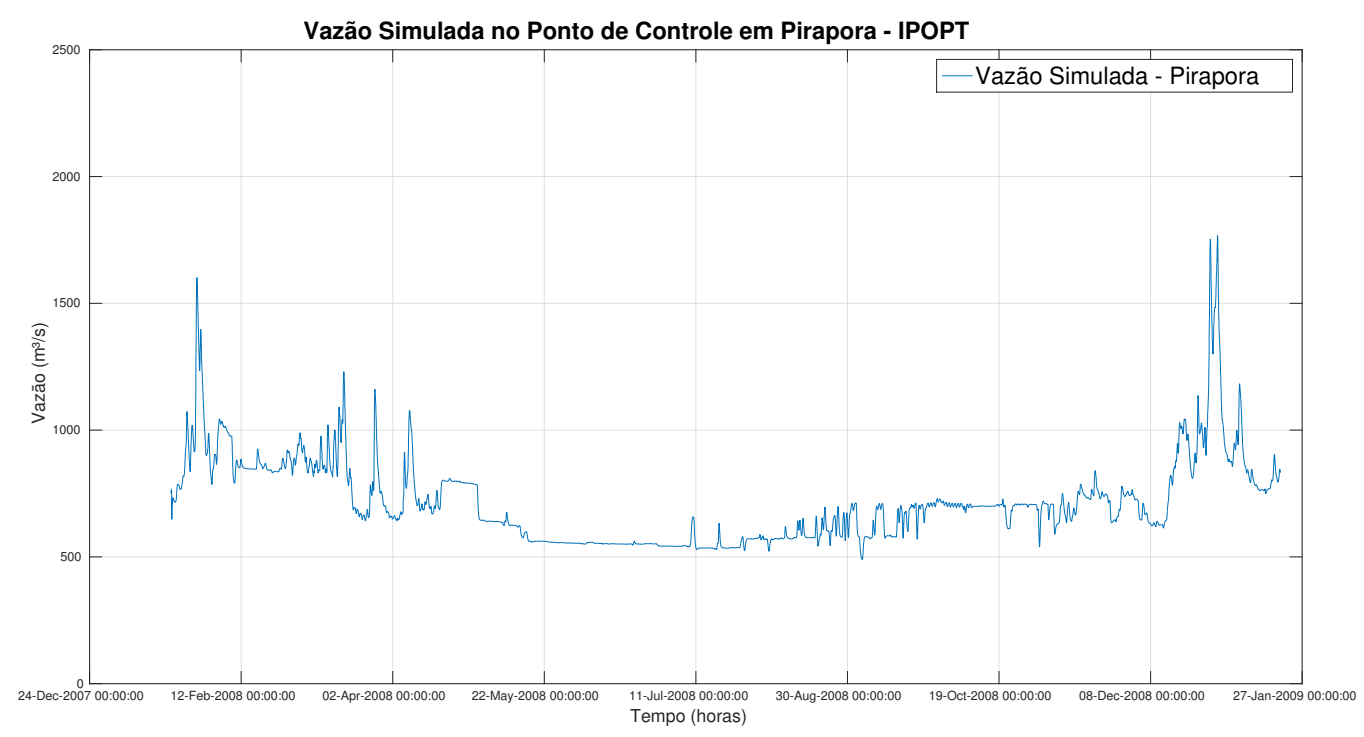

(b) Vazões Simuladas em Pirapora

Figura 56 - Cenário 1: Comparação entre vazões simuladas e observadas no ponto de controle de Pirapora.

É preciso lembrar que existem restrições operacionais na vazão de defluência da barragem, que devem ser respeitadas para uma operação ótima. A figura 58a, apresenta os valores observados para este cenário muito embora neste período de tempo não se observe descumprimento de restrição para vazões mínimas, no entanto podemos ver que existem picos grande de vazão que podem potencialmente causar inundações em Pirapora. O otimizador aproveita estes picos para recuperar o volume; a curva dos sinais observados (Figura 58b), comprova isto e assim como no cenário 1 as vazões de saída da UHE ficam restritas a uma faixa menor entre 490 e $690 \mathrm{~m}^{3} / \mathrm{s}$. 


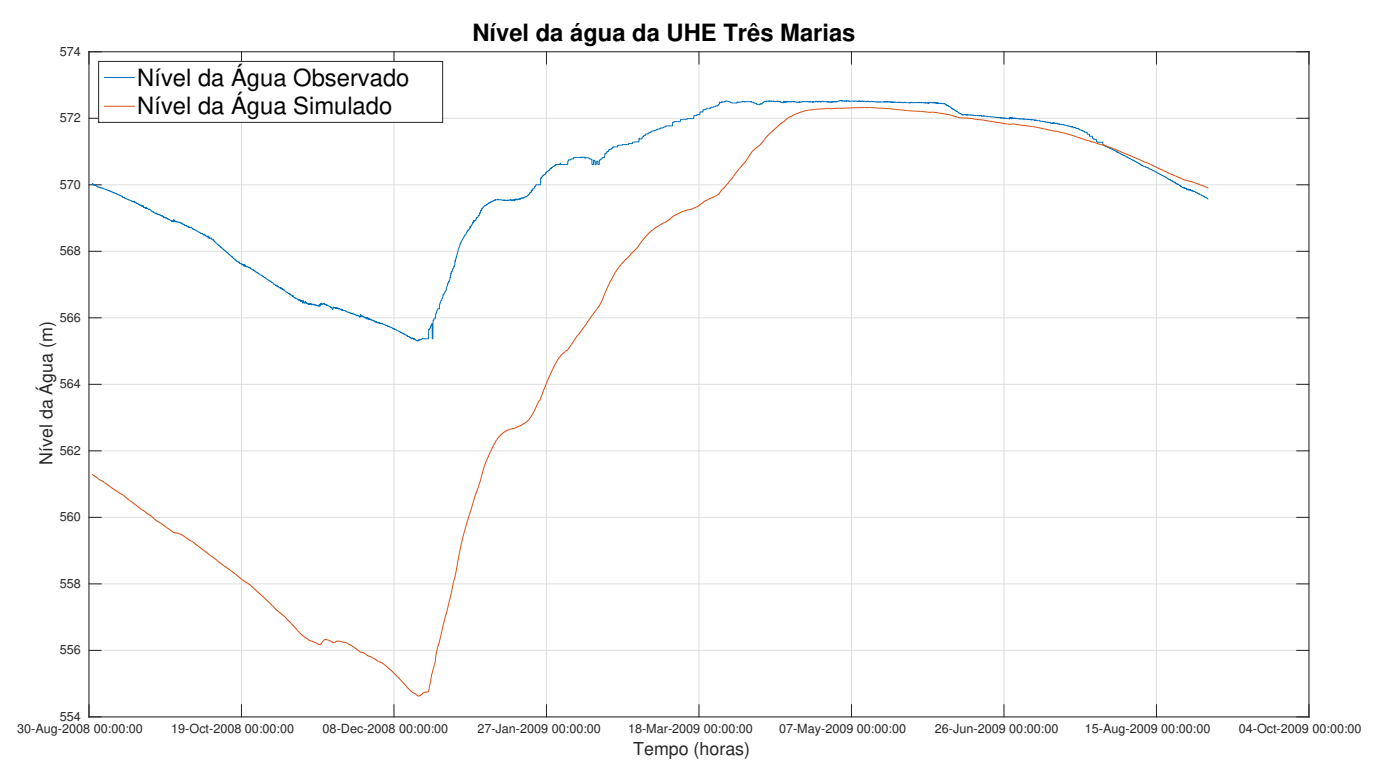

Figura 57 - Resultados dos volumes do reservatório otimizados para o Cenário 2

Controle de Efeitos de Inundação

Os resultados dos valores simulados no segundo cenário para controle dos efeitos de inundação em Pirapora, estão apresentados na Figura 59. Na figura estão plotadas as curvas no ponto de controle de inundação observadas e simuladas.

Nas vazões observadas, figura 59a, no final da série podemos observar dois picos de vazão superiores a $2.000 \mathrm{~m}^{3} / \mathrm{s}$, que conforme explicado anteriormente podem representar potenciais riscos de inundação a ilhas utilizadas em culturas de subsistência. Na figura 59b, podemos observar que o otimizador consegue com sucesso atenuar estes picos, sendo que os valores máximos ficam em torno de $1.700 \mathrm{~m}^{3} / \mathrm{s}$.

\subsection{Avaliação dos Resultados dos Cenário de Otimização}

Avaliando primeiramente os resultados na operação do volume, temos que na primeira simulação não há grande diferença na estratégia adotada pelos operadores do sistema (dados observados) e a do otimizador (dados simulados), com exceção de que ao final os dados do otimizador indicavam um nível de reservatório ligeiramente superior no final do período de simulação Figura 54. No segundo cenário, mesmo iniciando o verão com volume crítico, o otimizador acha uma solução na qual após um ano o volume reservado seria praticamente o mesmo do operador da Figura 57.

Outro dado interessante de ambas as simulações (Figura 60) conseguiram regularizaram a vazão de saída da barragem, atenuando os grandes picos de descarga e evitando as vazões de descarga mais baixas, um efeito colateral interessante de se adotar uma faixa menor de vertimento é que assim é possível evitar grandes variações nas vazões normalmente observadas decorrentes 


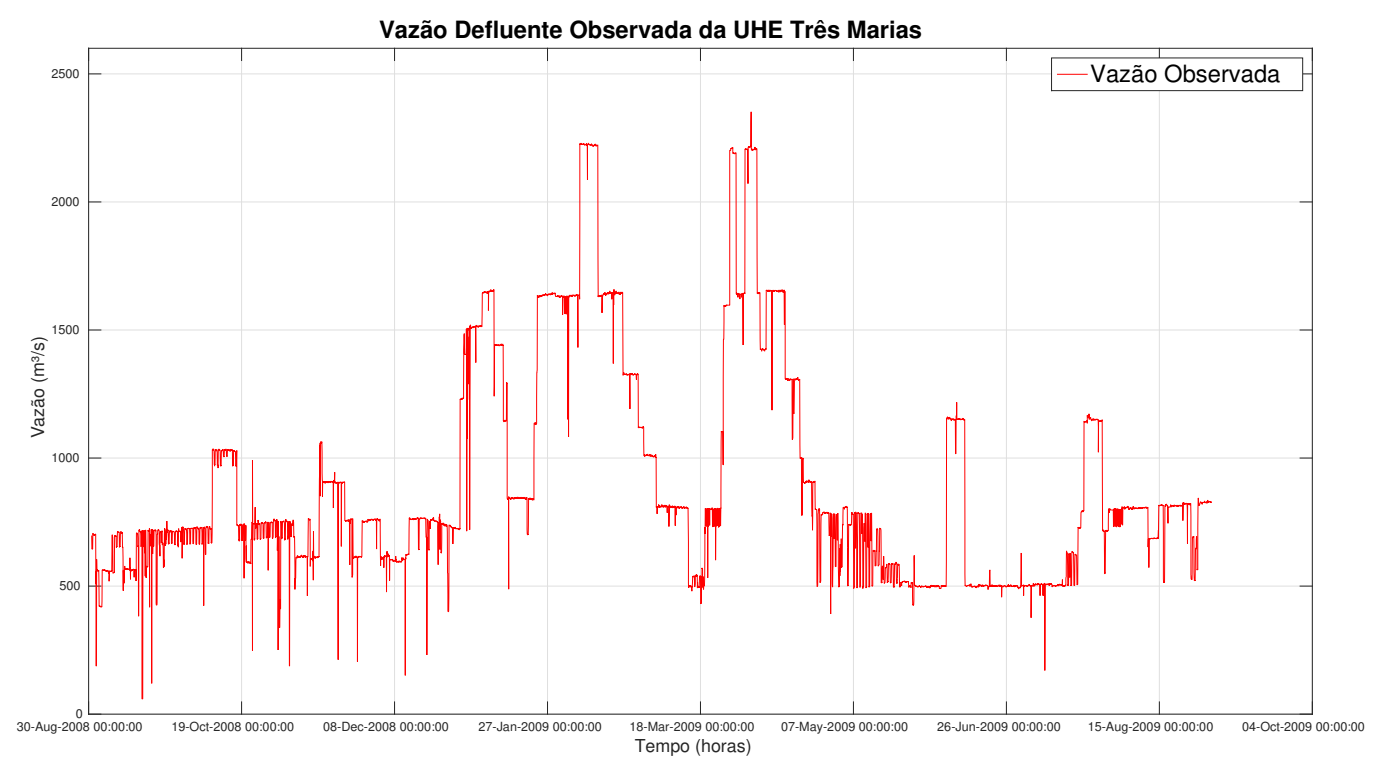

(a) Vazões Defluentes Observadas do Reservatório de Três Marias

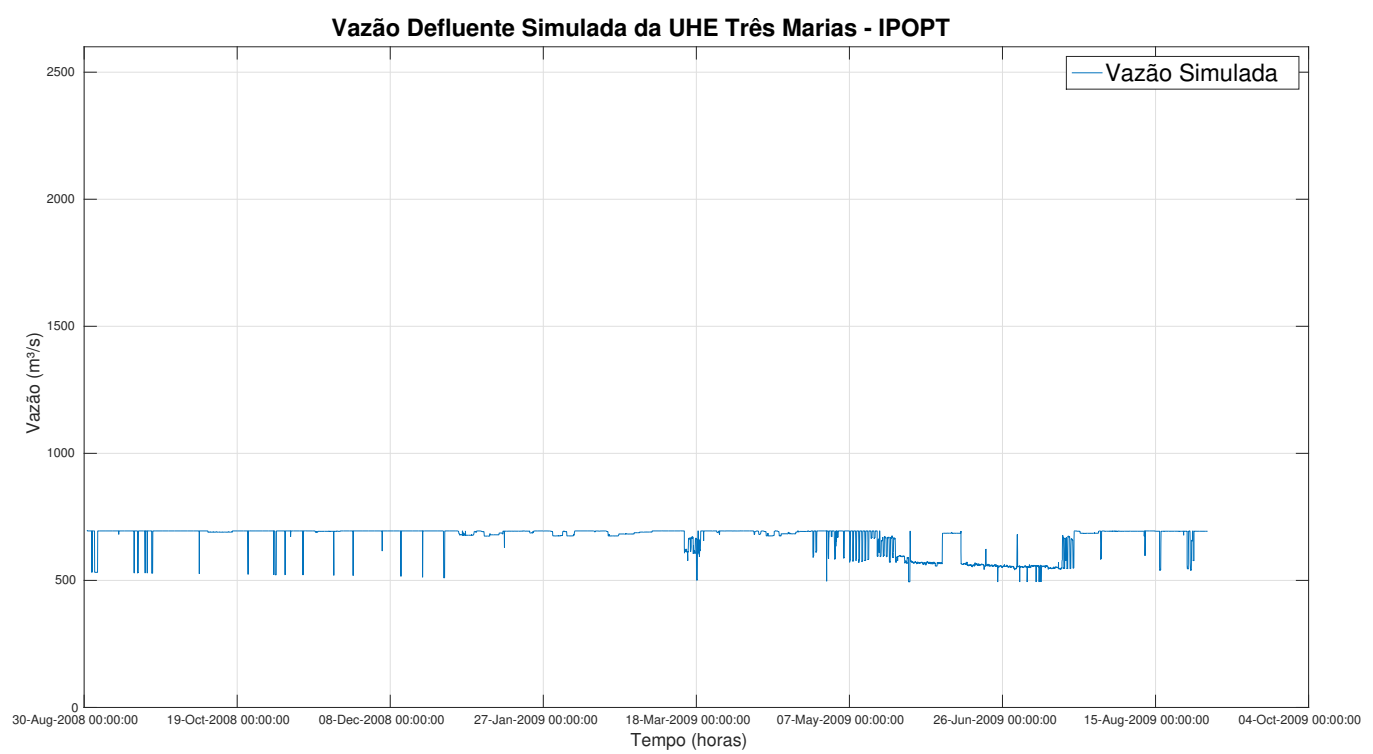

(b) Vazões Defluentes Simuladas do Reservatório de Três Marias

Figura 58 - Cenário 2: Comparação entre vazões defluentes simuladas e observadas do Reservatório.

da operação do reservatório, ao invés disso tanto na figura 60a, quanto na figura60b, pode-se observar que o sinal é mais constante.

Em relação o controle de inundação em Pirapora, em ambos os cenários nos resultados simulados foi possível atenuar os grandes picos de vazão e assim prevenindo os efeitos no ponto de controle em Pirapora (Figura 61), é importante destacar que os resultados conseguiram controlar as cheias bem não descumpriram nenhuma restrição de operação.

De forma a complementar as análises gráficas, elaborou-se algumas tabelas, que concentram os dados observados e simulados para ambos os cenários (com condições iniciais iguais às 


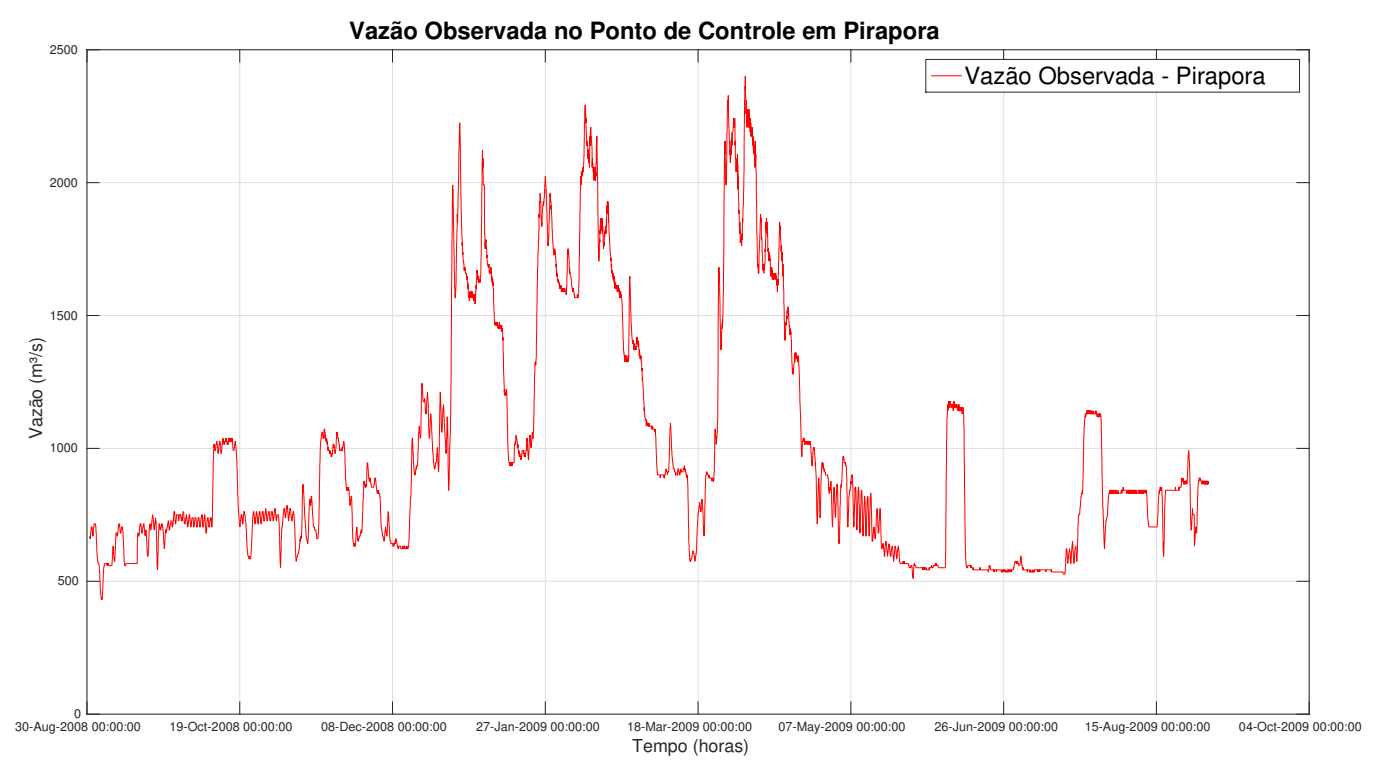

(a) Vazões Observadas em Pirapora

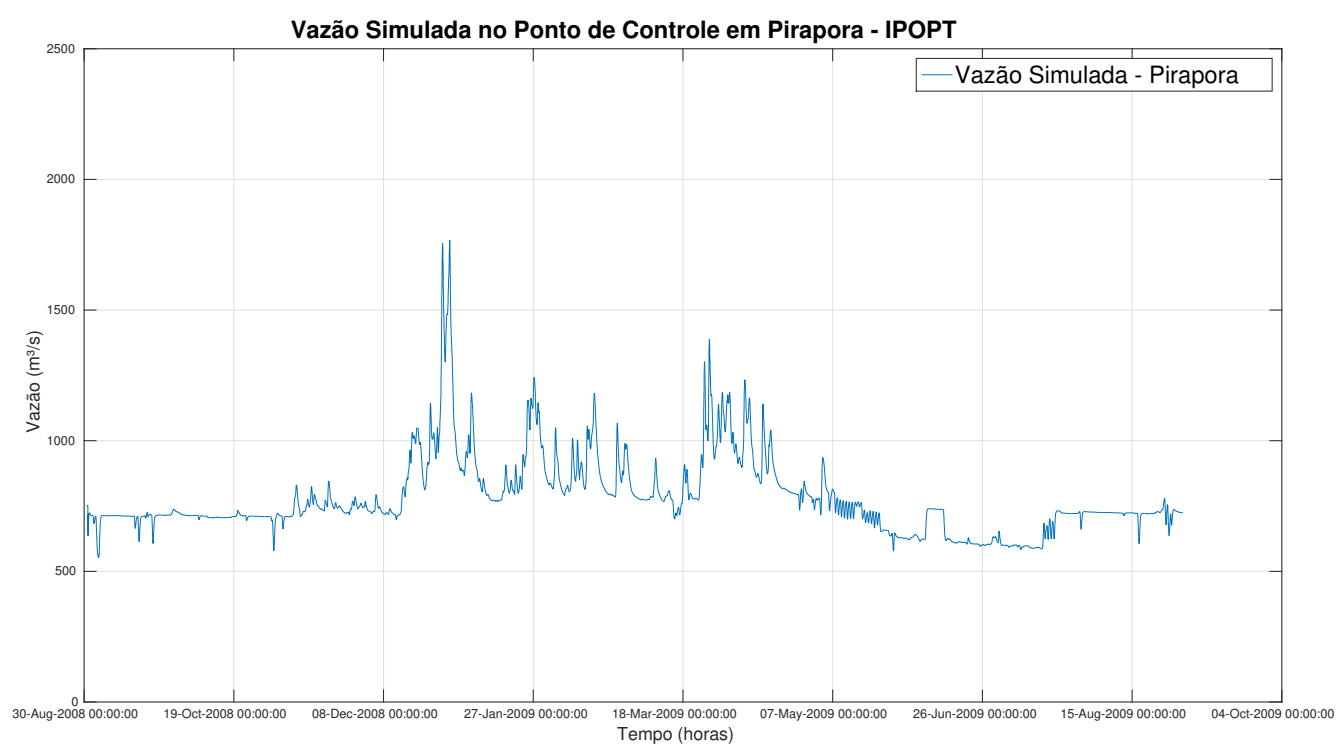

(b) Vazões Simuladas em Pirapora

Figura 59 - Cenário 2: Comparação entre vazões simuladas e observadas no ponto de controle de Pirapora.

observadas e com condições iniciais diferentes das observadas) dos Níveis da barragem durante as simulações Tabela 34, vazões de saída da UHE Três Marias durante as simulações Tabela 35 e vazões em Pirapora Tabela 36. Nas tabelas foram calculadas a média dos valores observados e simulados, a soma dos valores totais e valores máximos e mínimos. Os valores máximos e mínimos servem para identificar o quão perto os valores ficaram dos limites e restrições de operação, já a soma é uma boa estimativa do volume de água no período avaliado.

Na Tabela 34 analisando as métricas dos níveis de água das otimizações realizadas podemos observar que muito embora os dados observados e os dados obtidos da primeira otimização serem muito parecidos, podemos observar que o otimizador tende a arriscar mais 


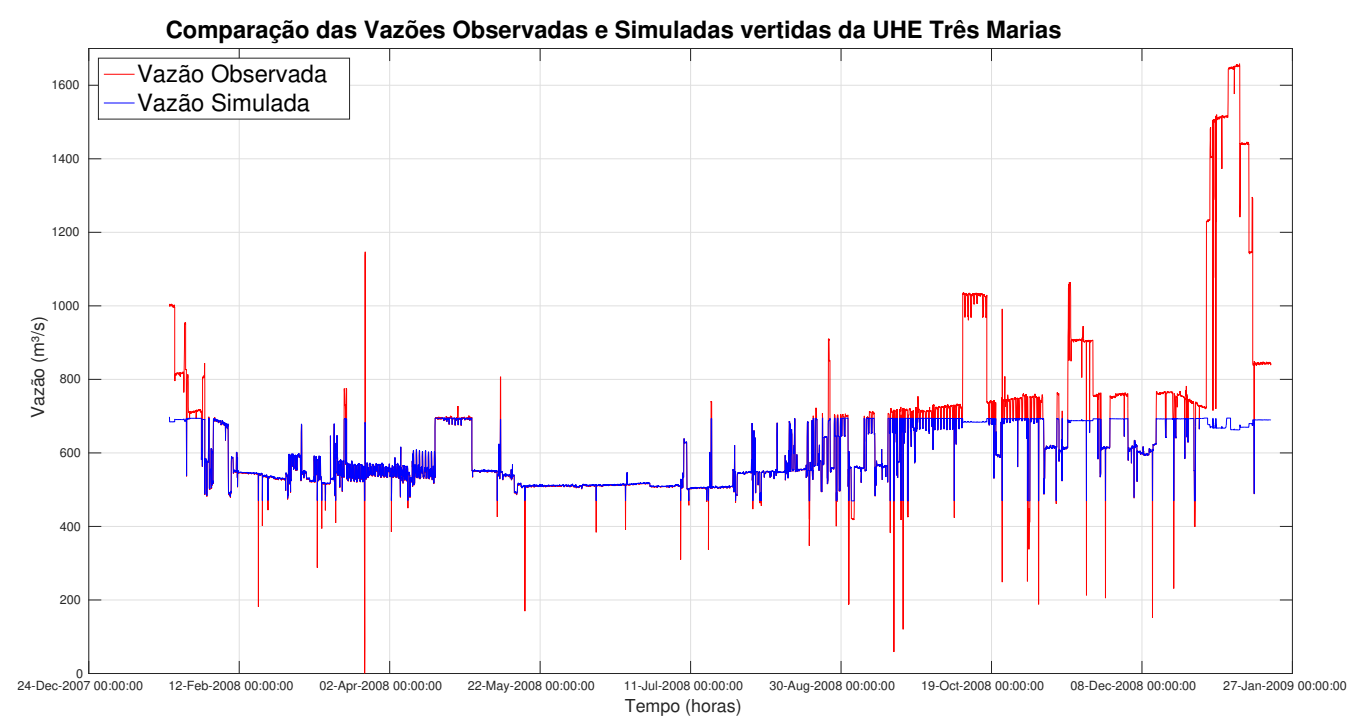

(a) Cenário 1: Vazões Defluentes do Reservatório de Três Marias

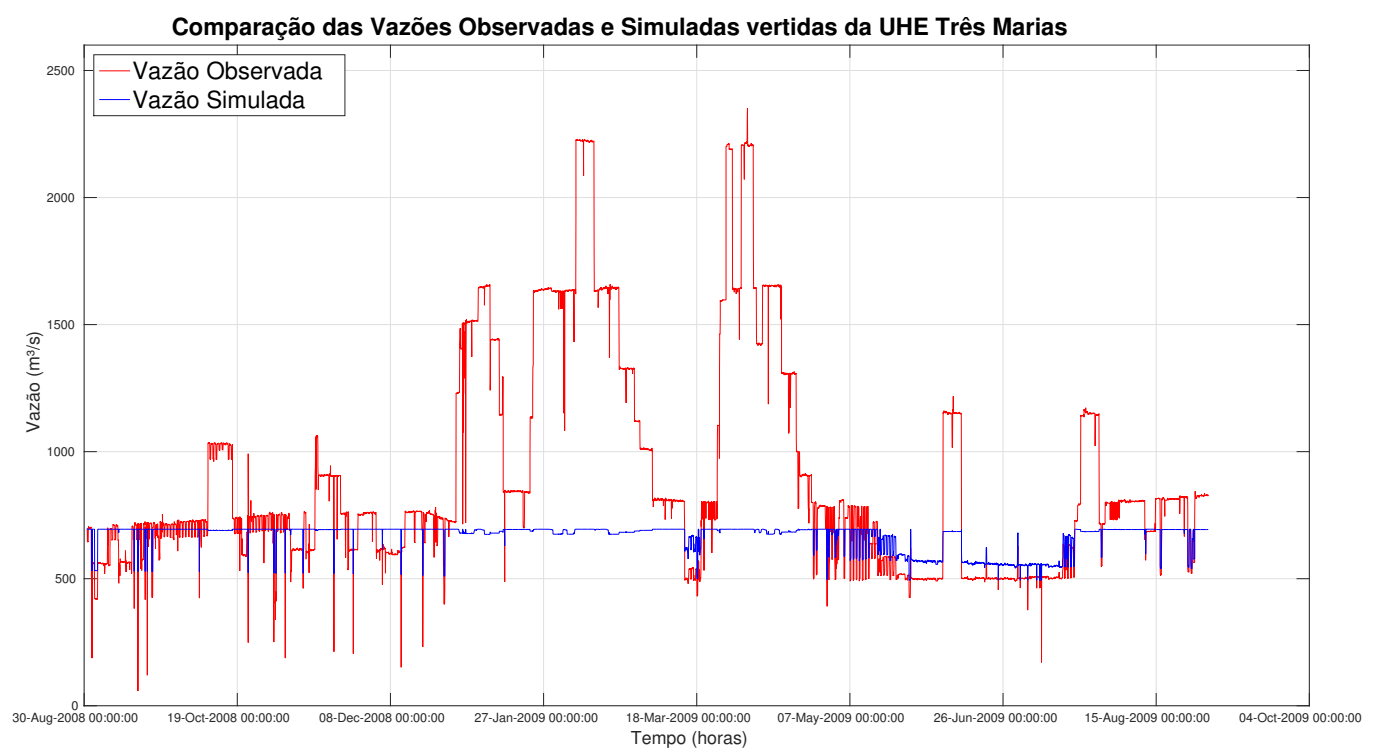

(b) Cenário 2: Vazões Defluentes do Reservatório de Três Marias

Figura 60 - Defluências do Reservatório para os Cenários de Simulação

em atingir níveis mais baixos, justamente pelo fato de ele considerar um horizonte de previsão para tomar as decisões e mais cauteloso com o nível máximo de operação, já que ele tenta evitar ao máximo passar deste nível por motivos de segurança. Já nos dados obtidos na segunda otimização que diferem bastante de comportamento, uma vez que o nível desta simulação começa propositadamente mais baixo.

As vazões de saída na barragem de Três Marias apresentadas na Tabela 35, também podem revelar bastante coisa sobre o comportamento do otimizador; tanto na primeira simulação, quanto na segunda os valores máximos são menores, mostrando que o otimizador está conseguindo atenuar o pico da propagação da onda de cheias, outro fator importante é que os valores mínimos dos dados do otimizador também são maiores do que os dados observados 


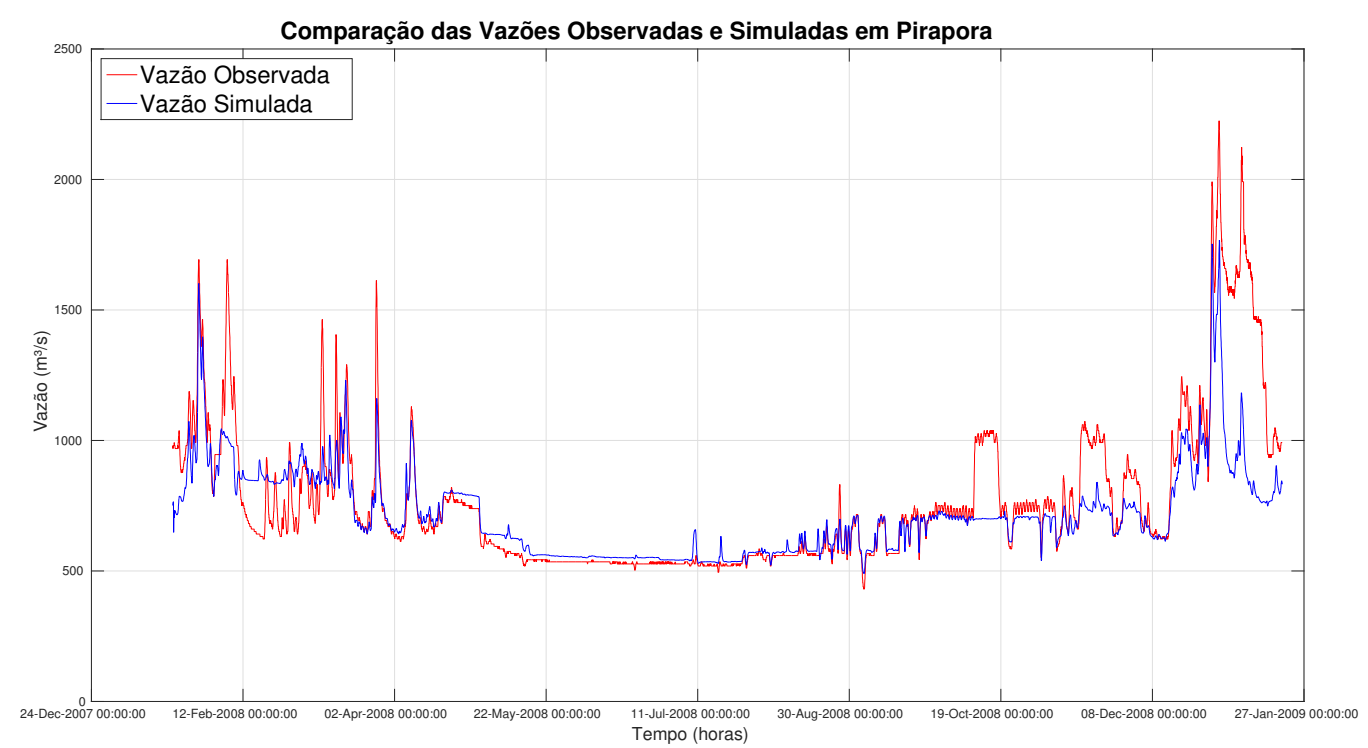

(a) Cenário 1: Vazões afluentes em Pirapora

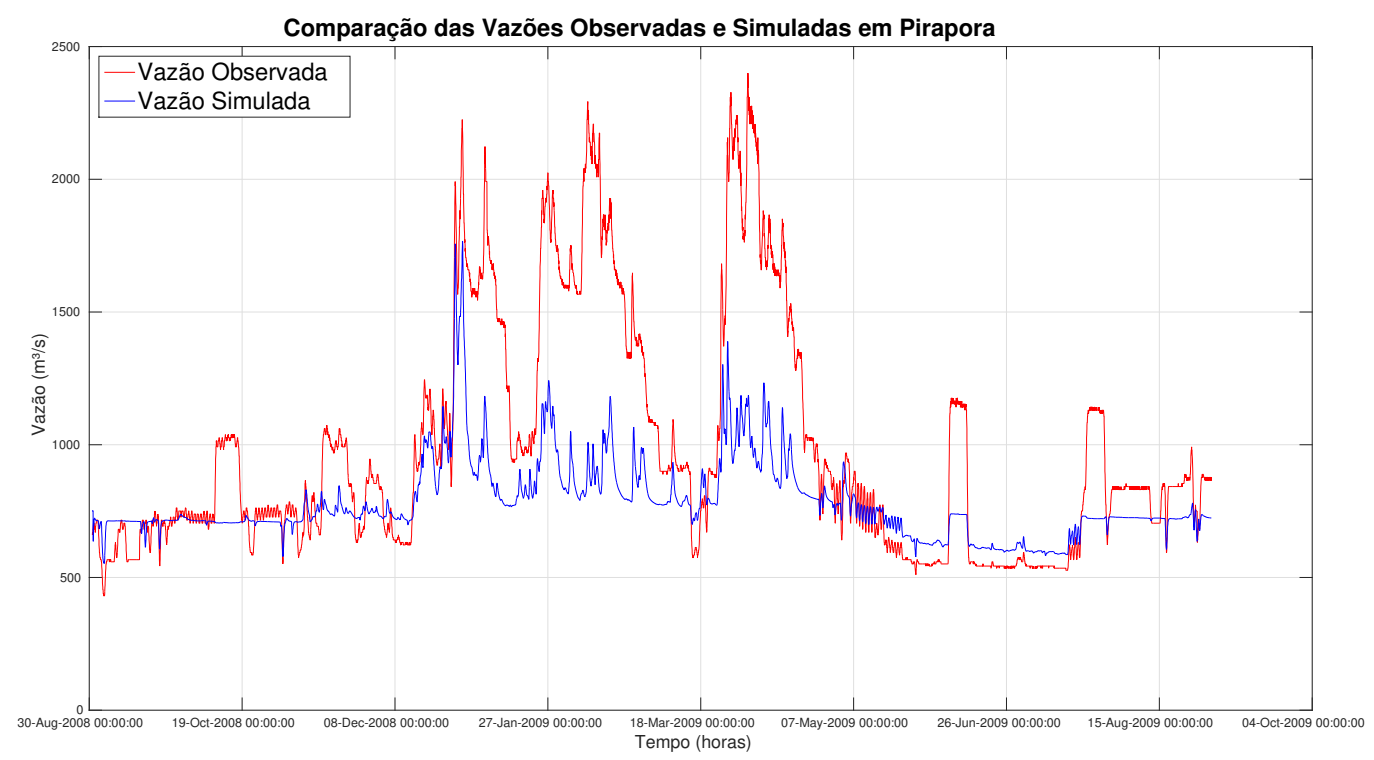

(b) Cenário 2: Vazões afluentes em Pirapora

Figura 61 - Afluências em Pirapora para os Cenários de Simulação

mostrando novamente que a modelagem está conseguindo regularizar as vazões do rio de forma mais otimizada. O último informação importante é o dado a soma da vazão vertida, o valor menor do que o observado mostra que as simulações estão conseguindo em geral reservar maior volume de água no reservatório.

A tabela com os dados de vazão no ponto da ponte de Pirapora, Tabela 36 nos mostram que tanto na primeira simulação, quanto na segunda os valores máximos são menores, o que significa otimizador está conseguindo atenuar o pico da propagação da onda de cheias mesmo no Ponto de Pirapora, outro fator importante é que os valores mínimos dos dados do otimizador também são maiores do que os dados observados mostrando novamente que a solução também está sendo eficiente no controle de cheias e regularização de vazões também em Pirapora que 
Tabela 34 - Estatísticas das Otimizações com Horizonte de Previsão de 1 ano: Nível de Água da Represa.

\begin{tabular}{lll|ll}
\hline \hline & \multicolumn{4}{c}{ Nivel da Represa (m) } \\
& \multicolumn{2}{c}{ Otimização 1} & \multicolumn{2}{c}{ Otimização 2} \\
& Observado & \multicolumn{1}{c}{ Simulado } & \multicolumn{1}{c}{ Observado } & Simulado \\
\hline Média & 568,952 & 569,214 & 570,134 & 565,615 \\
Soma & $4.582 .905,5$ & $4.981 .759,5$ & $4.937 .255,5$ & $4.937 .255,5$ \\
Mínimo & 561,510 & 561,286 & 565,300 & 554,623 \\
Máximo & 572,440 & 572,167 & 572,323 & 572,323 \\
\hline \hline
\end{tabular}

Tabela 35 - Estatísticas das Otimizações com Horizonte de Previsão de 1 ano: Vazão de Saída da UHE Três Marias.

\begin{tabular}{lll|ll}
\hline \hline & \multicolumn{3}{c}{ Vazão Defluente $\left(\mathbf{m}^{3} / \mathbf{s}\right)$} \\
& \multicolumn{2}{c}{ Otimização 1} & \multicolumn{2}{c}{ Otimização 2} \\
& Observado & \multicolumn{1}{c}{ Simulado } & \multicolumn{1}{c}{ Observado } & \multicolumn{1}{c}{ Simulado } \\
\hline Média & 654,306 & 597,632 & 987,908 & 781,613 \\
Soma & $5.725 .833,5$ & $5.2304 .472,0$ & $8.622 .458,0$ & $6.822 .700,0$ \\
Mínimo & 0,630 & 469,502 & 431,000 & 552,820 \\
Máximo & $1.658 .660,0$ & 694,737 & $2.400,000$ & $1.767,215$ \\
\hline \hline
\end{tabular}

Tabela 36 - Estatísticas das Otimizações com Horizonte de Previsão de 1 ano: Vazão no Ponto Pirapora.

\begin{tabular}{lll|ll}
\hline \hline & \multicolumn{4}{c}{ Vazão Afluente $\left(\mathbf{m}^{3} / \mathbf{s}\right)$} \\
& \multicolumn{2}{c}{ Otimização 1 } & \multicolumn{2}{c}{ Otimização 2 } \\
& Observado & \multicolumn{1}{c}{ Simulado } & \multicolumn{1}{c}{ Observado } & \multicolumn{1}{c}{ Simulado } \\
\hline Média & 768,156 & 717,696 & 990.477 & 782,526 \\
Soma & $6.722 .136,0$ & $6.281 .273,5$ & $8.517 .111,0$ & $6.729 .919,5$ \\
Mínimo & 431,000 & 490,102 & 431,000 & 552,820 \\
Máximo & $2.225,000$ & $1.767,220$ & $2.400,000$ & $1.767,215$ \\
\hline \hline
\end{tabular}

está à jusante da represa. 


\section{Conclusão}

Atualmente o cenário de expansão de energia elétrica através de geração hidroelétrica no Brasil está caminhando para uma estagnação. Há pouco potencial disponível nas grandes bacias hidroelétricas na porção austral do país enquanto que por motivos políticos e técnicos a construção de grandes empreendimentos nas bacias menos exploradas e com maior potencial como a bacia amazônica enfrentam impedimentos de ordem política e técnica.

Além disto a diminuição da demanda energética devido à diminuição do crescimento econômico do país contribuem para que não haja prioridade e necessidade em ampliara a oferta energética, ou seja construção de novas usinas.

Observa-se também uma tendência de maior integração dos centros geradores através do SIN e da ONS, tornando a operação e controle dos níveis dos reservatórios uma tarefa cada vez mais complexa.

Desta forma urge a necessidade de ferramentas eficientes que permitem aos operadores e tomadores de decisão operar de forma otimizada os reservatórios existentes, portanto a ferramenta proposta apresenta claras melhorias e contribuições operacionais, permitindo obtenção de soluções rápidas e confiáveis para situações críticas como controle de cheias ou mesmo períodos de estiagem.

Esta comparação dos modelos selecionados servirá para criar uma biblioteca de modelos com diferentes modelos de roteamento disponíveis para fazer uma seleção do mais apropriado dentro de um controlador preditivo para a previsão operacional e para o SSD da CEMIG.

No Apêndice H na Tabela 131, estão apresentados os resultados das análises de desempenho estatístico e computacional dos modelos analisados. Nesta tabela podemos ver que há uma tendência de aumento do tempo de processamento conforme a complexidade dos modelo conceitual e número de nós de cálculo aumenta. Isto pode ser explicado devido ao fato de que ao passo que se negligenciam termos da equação de conservação de quantidade de movimento, ou seja mais simplificações são adotadas, menos processamento é necessário para solucionar as ESV e também devido ao fato de que ao aumentarmos a resolução temporal aumenta-se o número de etapas de processamento.

Desta forma o SOBEK, que utiliza o modelo totalmente hidrodinâmico das ESV, foi o modelo que necessitou mais tempo para realizar a simulações; em seguida seguidos dos modelos de onda difusiva, que são uma simplificação do modelo totalmente dinâmico; os modelos mais 
simples que são baseados em alocação de volume (cascata de reservatórios e o MBG-IPH) foram portanto os modelos que necessitaram de menos processamento.

Em relação aos resultados, as duas configurações do modelo de onda difusa (baixa e alta resolução espacial) sofreram com efeitos de amortecimento dos picos. Estes efeitos podem ser notados na Figura 41, onde são comparados as duas configurações de onda difusa com o o SOBEK. Apesar de utilizarem uma equações governantes simplificadas em relação aos outros modelos, tanto o RTC-Tools com Cascata de Reservatórios quanto o MGB, não apresentaram difusão numérica; o outro modelo que também não apresentou este comportamento foi modelo totalmente hidrodinâmico (SOBEK) (Figura 47).

Embora não apresente a atenuação dos picos presente nos modelos de onda difusiva, no geral os resultados do MGB foram os piores dentre os modelos, justamente por causa da dessincronização e desfasagem entre os sinais simulados e observados e devido à exageros na estimativa da contribuição dos tributários no Rio São Francisco, que levando-se em consideração o aspecto operacional de reservatórios é prejudicial, pois pode colocar em risco todas as restrições operacionais, devido à esta defasagem entre os picos simulados e os observados, que pode resultar por exemplo em decisões precipitadas ou atrasadas.

Apesar da difusão já discutida acima os modelos de onda difusa, tanto o de resolução espacial mais detalhada, quanto o de resolução espacial menos detalhada, apresentaram bons índices de desempenho estatísticos. Porém observa-se uma incapacidade desta configuração em reproduzir a magnitude dos grandes picos de vazão, o que é uma característica indesejável pois para operação de reservatórios isto poderá significar que o modelo poderá subestimar picos da propagação de cheia, que pode significar em caso de um evento severo de inundação, riscos de violação das restrições operacionais do reservatório.

Em relação aos impactos resultantes do aumento da resolução espacial e temporal nos modelos de onda difusa; é importante ressaltar que apesar de haver pequena melhora nos resultados, os esforço computacional aumentou significativamente. Os refinamentos espaciais produziram maiores impactos nos resultados do que os refinamentos temporais. Porém estas melhorias não foram satisfatórias o suficiente para compensar o aumento de tempo de processamento resultante do aumento da complexidade resultante dos refinamentos nas resoluções espaciais e temporais.

Usando baixa resolução espacial, o modelo de onda difusa apresentou desempenho de processamento relativamente satisfatório, porém há excesso de difusão numérica em seus resultados e os refinamentos espaciais e temporais ao custo de esforço computacional, não foram capazes de melhorar substancialmente os resultados para corrigir a difusão.

O SOBEK, que é modelo mais complexo dentre os selecionados, em geral apresentou 
bons resultados com os indicadores, mas apesar disto, o alto custo computacional e ausência de um modelo adjunto, torna sua integração proibitiva para aplicação em um otimzador de controle de operação em tempo real.

O SPRNT se mostrou extremamente instável, não sendo possível configurar uma versão que pudesse simular períodos maiores do que 3 meses sem interrupção, assim sendo para avalialo com o SOBEK, foi escolhido o maior período no qual o SPRNT conseguiu ser executado. O modelo apesar de ser mais rápido para realizar as simulações que o seu similar (SOBEK), não aparenta conseguir reproduzir os picos de vazão no exutório (Pirapora), isto pode ser causado em parte porque não foi possível implementar nesta configuração as vazões laterais calculadas pelo MGB.

Ao incorporar as vazões laterais do MGB ao SPRNT, o mesmo se torna instável, resultando em interrupção das simulações por não ser capaz de convergir os resultados. Um dos motivos para esta instabilidade pode estar relacionado às condições de contorno do modelo de saída do modelo, que são níveis de água, para este estudo de caso elas foram obtidas indiretamente através de uma curva cota-vazão providenciada pela CEMIG (Figura 37).

Outra questão importante para a implementação do SPRNT como uma ferramenta para operação de barragens está na arquitetura de software, será necessário uma substancial mudança no código-fonte para facilitar o gerenciamento do banco de dados, visto que atualmente a configuração e a entrada de dados é feita através de um único arquivo texto. A saída de dados também é complicada, sendo necessário uso de softwares como SciLab ou Matlab para extração e visualização dos dados. Além disto o programa atualmente não compila em FORTRAN ou em plataforma Windows, sendo restrito para uso em distribuições Linux ou Mac OS através do uso de Mavericks.

O modelo de cascata de reservatórios (RR), que é o mais simplificado dentre os selecionados, obteve resultados similares aos do SOBEK com menos esforço computacional e ao contrário dos modelos de onda difusiva, apresentou resultados marginalmente piores com maiores resoluções temporais e não sofreu com difusão numérica dos mesmos. A defasagem temporal foi corrigida através da contribuição de Schuurmans, Bosgra e Brouwer (1995), que foi explicada na seção 8.2. Este modelo simples pode fornecer uma precisão suficiente para a gestão de curto prazo.

Em relação ao problema de otimização mesmo utilizando o modelo mais simplificado RR e considerando o problema do estudo de caso de maneira bastante simplificada, foi possível tanto controlar a operação mantendo os níveis e vazões operacionais quanto mitigar efeitos de inundação no ponto de controle. 
Um ponto positivo é que utilizou-se uma plataforma que representa o estado-da-arte na integração de banco de dados e modelos de diferentes naturezas, um dos modelos não foi integrado por questões técnicas, mas com uma biblioteca de modelos com diferente configurações e preparado para processos de aquisição de dados e para incorporação de diferentes soluções para NWPs.

\subsection{Trade-off entre Precisão e Desempenho Computacional}

Para a aplicação do estudo de caso deste trabalho, é de vital importância que o SSD proposto produza simulações confiáveis e rápida. Estas simulações hidráulicas no trecho entre a UHE Três Marias e o ponto de controle de inundação localizado cerca de $130 \mathrm{~km}$ a jusante da barragem no município de Pirapora, devem ser confiáveis para poderem ser usadas no controle de cheias e ao mesmo tempo rápidas uma vez que se propõe uma aplicação para controle em tempo real.

Considerando que estas soluções são obtidas através um problema de otimização e portanto que ocorram simulações iterativas, além do fato de que o SSD opera online, ou seja através de métodos de aquisição de dados em tempo real, novos inputs são introduzidos para atualizar os estados então urge configurar os modelo para que reproduzam resultados confiáveis e que ao mesmo tempo não exijam muito esforço computacional.

Portanto busca-se dentre os modelos testados aquele que apresente as duas características; precisão e rapidez. No entanto existe um ajuste entre maior precisão e maior esforço computacional. Conforme a complexidade do modelo ou da configuração mais processamento computacional é necessário para obter os resultados.

Considerando somente o esforço computacional e o tempo de processamento, conforme já apresentado no Apêndice $\mathrm{H}$, os resultados obtidos indicam que o modelo mais rápido foi indiscutivelmente a configuração do RTC-Tools usando Cascata de Reservatórios que precisou de 249 ms em sua resolução temporal horária para simular o período de 15/01/2007 até 20/06/2011; seguido do modelo MGB-IPH, que precisou de $345 \mathrm{~ms}$ para simular o mesmo período; em seguida as configurações de onda difusa do RTC-Tools que necessitaram de 2.449 e $8.814 \mathrm{~ms}$, respectivamente baixa e alta resolução espacial, para simular o período; o modelo SOBEK totalmente dinâmico foi o que apresentou o custo de CPU mais elevado, sendo necessários 51.090 ms para realizar a simulação do período.

Já analisando o desempenho dos modelos quanto a precisão dos seus resultados, através de indicadores de desempenho, observa-se que: no caso dos modelo que utilizam a simplificação da onda difusiva, o modelo com maior detalhamento espacial, o de resolução espacial refinada, apresentou indicadores um pouco melhores do que o que utiliza a baixa resolução espacial; e 
que o aumento da resolução temporal em ambas as resoluções espaciais resultaram apenas em melhoras marginais nos indicadores.

Observa-se então que existe um trade-off entre precisão e custo computacional, ou seja para obter maior precisão nos resultados é necessário maior esforço computacional o que significa que é necessário abdicar um pouco de precisão por conta das simplificações para gerar resultados mais rapidamente. Esta tendência é mais clara quando compara-se o desempenho computacional e indicadores entre os modelos de onda difusa; ao refinar a resolução espacial obtém-se melhores resultados a um maior esforço computacional que está representado pelo tempo em ms para realizar as simulações.

Essa troca entre custo computacional e precisão também é observada no custo relativo de processamento, ou seja quanto e o esforço computacional necessário para simular uma etapa temporal de simulação. Na Figura 62 mostra nitidamente que conforme os modelos se tornam mais simplificados a eficiência aumenta, ou seja o tempo necessário para simular uma etapa de simulação diminui. Curiosamente para os modelos de onda difusiva, há uma pequena tendência inversa para os refinamentos temporais, ao passo que a escala temporal é refinada menor o custo ou esforço.

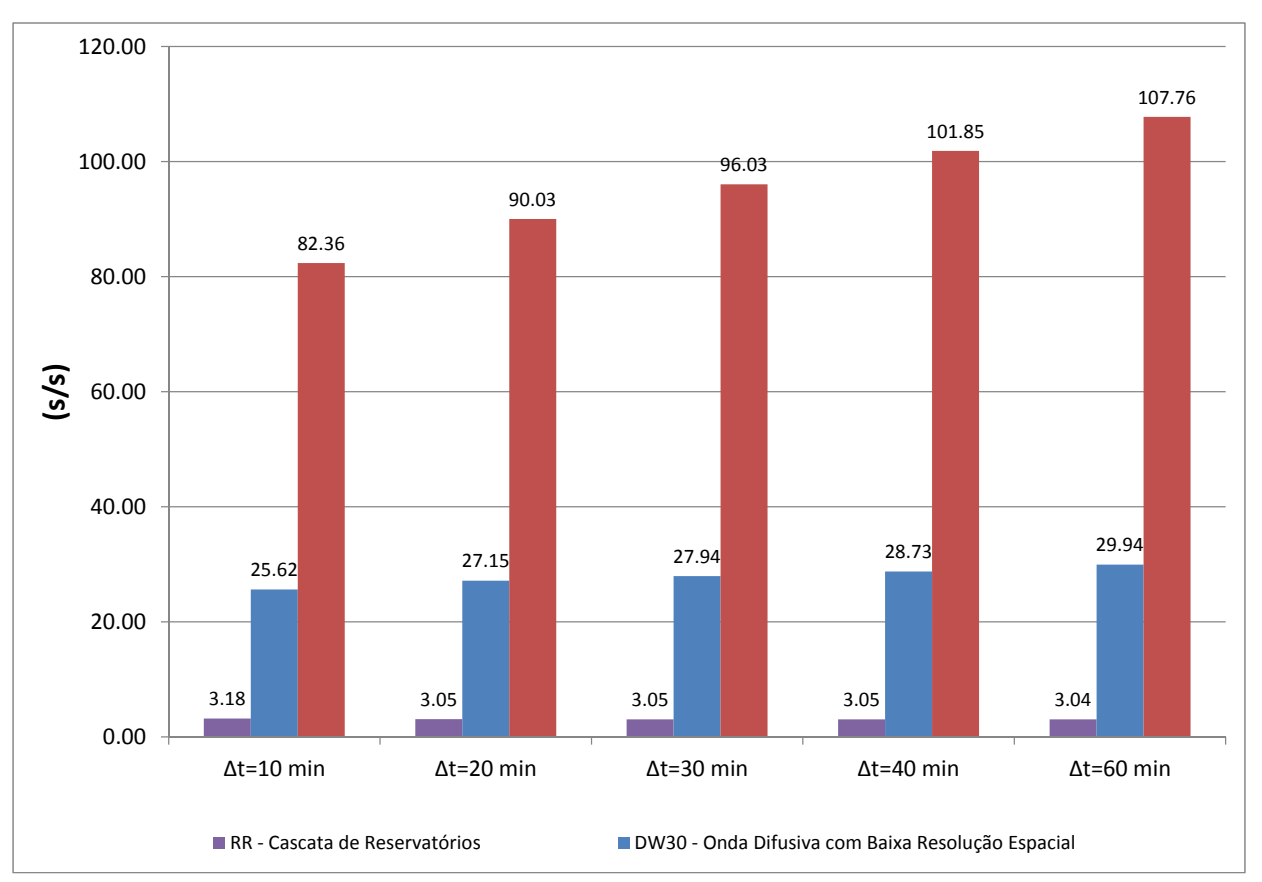

Figura 62 - Tempo de Processamento por numero de intevalos de tempo de simulação para os modelos de Onda Cinemática (RR) e Onda Difusiva (DW).

Sendo que a taxa em que este custo relativo diminui é maior para o modelo mais complexo 
e detalhado (DW-10km) do para a do modelo mais simplificado (DW-30km); diminuindo em média 6,96\% para o modelo de alta resolução espacial e em média de 3,98\% no modelo de baixa resolução espacial (Tabela 32). Já nos modelos de Cascata de Reservatórios observa-se uma tendência inversa a observada nos modelos de onda difusiva, nos modelos de alocação de volume, conforme a escala temporal é refinada, o custo relativo aumenta ligeiramente, em média de $1,10 \%$.

Deste modo ao adotar um modelo mais complexo em geral obtêm-se resultados mais precisos, mas é necessário maior capacidade de processamento, o que pode se tornar um problema quando este modelo está aplicado em um MPC. Apesar do SOBEK apresentar bons resultados, seu alto custo computacional desqualifica ele como melhor candidato para integração com o otimizador; de maneira inversa o modelo de onda difusiva com baixa resolução espacial apesar de apresentar desempenho de processamento relativamente bom, sofre de excesso de difusão numérica que pode gerar imprecisões ao simular picos e variações rápidas de vazão tornandoo inapropriado para ser usado como balizador das operações de reservatórios e controle de inundações.

Para o estudo de caso deste estudo, onde não há aparentemente efeitos de remanso, o modelo de Cascata de Reservatórios apresentou resultados semelhantes com o modelo mais complexo SOBEK, usando significativamente menos tempo de processamento computacional.

Esta abordagem de alocamento de volumes com introdução de advecção pura por deslocamentos temporais, do modelo Cascata de Reservatórios com integrador de atraso (RR), permite um ajuste fino do propagação do fluxo usando da integração dos deslocamentos temporais e reservatórios não-lineares permitem. Esta é uma solução eficiente para a difusão numérica excessiva, mesmo em casos de baixa resolução espacial. Do ponto de vista do controle preditivo, esta abordagem mostra o melhor compromisso em termos de robustez, eficiência e precisão dos resultados.

\section{Aplicabilidade para Operação de Reservatórios}

É importante destacar que os dados observados utilizados nas simulações são resultado dos despachos e vazões determinados pela otimização global feita pelo ONS através de seu modelo o NEWAVE, que otimiza as UHE globalmente, no âmbito do SIN, já que o objetivo é manter o suprimento de energia no país como um todos otimizado.

Na situação atual a aplicabilidade do sistema proposto está limitado às situações operacionais descritas no Apêndice A, nas quais o ONS, transfere a decisão de operação ao agente gerador; que são situações de emergência para controle e atenuação de cheias.

No entanto justamente esta falta de liberdade do operador de tomar algumas decisões 
localmente podem resultar eventualemente em operação sub-ótima dos reservatórios. Deve-se ressaltar também que os resultados aqui apresentados não são as soluções ótimas do sistema, mas sim soluções verossímeis e que é muito difícil conciliar as restrições operacionais, demandas de geração enérgicas com controle de cheias e otimização de volume existentes na realidade.

É de suma importância e utilidade para operação de reservatórios de reservação para gerenciamento de recursos hídricos integrados, atender os diversos usos da água evitando conflitos ou prejuízos financeiros, materiais e pessoais para os stakeholders, portanto neste âmbito esta ferramenta computacional atende as demandas dos operadores e tomadores de decisão, uma vez que permite mensurar melhor os riscos das ações a serem tomadas e suas consequências a jusante dando suporte aos operadores do sistemas, fornecendo informações críticas de forma precisa e rápida.

Através da análise dos gráficos e estatísticas resultantes de ambos os cenário de simulação, é notável a utilidade da ferramenta, visto que a técnica soluciona eficientemente os problemas de controle de cheias visto, já que as vazões de saída da barragem e à jusante da barragem no ponto de controle em Pirapora indicam claramente atenuação dos picos de vazão.

Na Tabela 32 apresentada na seção 12.5, os valores máximos, mínimos e médios, indicam que houve uma normalização da vazão afluente da barragem, a faixa de operação de vazão é menor se comparada com os valores anteriormente observados, indicando que as soluções evitaram ao máximo violar as condições de restrição do local, preferindo ao máximo operar numa faixa mais estreita de valores, que como consequência evitam grandes oscilações nas vazões de descarga, o que a torna mais constante e portanto normalizada.

Além disto, conforme pode ser observado nas Figura 54 e Figura 57, os gráficos mostram uma operação mais arrojada nas otimizações; devido ao conhecimento prévio das condições meteorológicas futuras, foi possível verter a água em situações críticas para alocar o volume de espera e ao final do período manter o mesmo volume no caso do primeiro cenário ou recuperar o volume de água no segundo cenário.

Então temos que foi possível através do uso do MPC, obter soluções para o controle dos reservatórios em que não só possibilitaram evitar violações das restrições operacionais e ambientais, como atenuar dos picos de vazão e otimizar tanto o volume dos reservatórios quanto os volumes vertidos da represa.

Deve-se salientar também que a total potencialidade da ferramenta proposta depende da aplicação ensembles confiáveis para geração dos horizontes de previsão futuros juntamente com técnicas de aquisição de dados em tempo real no MPC.

O grande grau de incertezas inerentes existentes na previsões meteorológicas disponíveis, 
principalmente nas que utilizam métodos determinísticos, implicam em resultados de otimização subotimizados ou não otimizados. Pois a qualidade das otimizações depende de horizontes de previsão futuro confiáveis, ou seja os cenários futuros de otimização são tão bons e confiáveis quanto os ensembles utilizados. Utilizando aquisição de dados em tempo real seria possível melhorar a qualidade das previsões e consequentemente dos resultados da otimização.

Por isso da importância do desenvolvimento de métodos, técnicas e ferramentas que permitam o gerenciamento integrado de cenários para diferentes contribuições de vazão e carga utilizando técnicas de otimização estocásticas e determinísticas, sistema de gestão conjunta para a produção de energia hidroelétrica e comercialização sobre diversas restrições: duras ou suaves, assim possibilitando visualização dos resultados para o suporte à decisão.

A utilização dos recursos de integração de modelos e banco de dados, facilitou a integração dos modelos, banco de dados e otimizador, permitindo importar e exportar dados, processar e transformar dados, simular, integrar modelos com o otimizador e retroalimentar resultados entre os modelos para fazer as iterações e avaliações necessárias para as situações propostas.

Estas novas tecnologias como OpenMI e OpenDA se destacam pois sem elas todos os processos relativos aos banco de dados como aquisição, armazenamento, correção, filtragem, importação e exportação não ocorreriam de forma rápida, eficaz e automatizada. Além disto o Delft-FEWS e OpenMI, permitiram integração rápida de modelos diferentes, permitindo comunicação entre eles, de forma que fosse possível unificar os dados de entrada e retroalimentar os modelos, ou seja utilizar os resultados de simulações como entrada de dados em outras simulações para melhorar Os resultados.

Isto permite flexibilidade ao modelador para criar soluções e configurações sob medida para diferentes problemas; a escolha de modelos e dados não é tão engessada permitindo criar configurações ou combinações de modelos para buscar soluções para o problema proposto.

Recentemente com o progresso no campo da computação sendo que os métodos de processamento evoluíram possibilitando utilizar técnicas e métodos de simulação mais complexos que não eram possíveis de utilização prática no passado. A nova onda computacional a quinta onda computacional será voltada na rápida disponibilidade e compartilhamento de dados via tecnologias como Cloud Computing e Internet das Coisas, o que implicará que num futuro próximo o armazenamento e manipulação de dados ser tornarão cada vez mais importantes.

\subsection{Sugestões para futuras pesquisas}

O modelo proposto aplicado para a otimização de operação de barragens para controle de cheias, permitem integrar de maneira eficiente modelos com um otimizador para serem 
executados de forma conjunta gerando de maneira rápida previsões de níveis e vazões de descarga para uma hidrelétrica baseados em predições futuras das condições meteorológicas. Contudo para garantir a precisão dos resultados conforme dito anteriormente há necessidade de melhorar os modelos de previsão meteorológica estocástica, refinando os modelos existentes para diferentes locais no território brasileiro.

Há também necessidade de melhorar a a precisão dos resultados de alguns modelos,como no caso do SPRNT, para tanto seria interessante conseguir através de uma bacia hidrográfica totalmente instrumentada testar técnicas de aquisição de dados em tempo real.

Como sugestão para aprofundar a discussão em futuras pesquisas, o autor elenca alguns tópicos que poderão representar avanços no conhecimento científico e técnico em relação ao gerenciamento de recurso hídricos focados na operação em tempo real de reservatórios:

a) Integração do SSD proposto com previsão meteorológica estocástica ( Ensembles). Investigar a aplicação deles e impactos deles na operação em tempo real dos reservatórios;

b) Aperfeiçoar os modelos e as restrições do otimizador para permitir também, avaliar se existem soluções otimizando não só o volume, mas também a geração elétrica;

c) Avaliar o impacto deste tipo de otimização de operação globalmente, ou seja se aplicando este tipo solução local seria possível obter melhorias para o atual sistema de otimização global do NEWAVE;

d) Avaliar se há benefícios em relação aos impactos ambientais relacionados às barragens e sistemas lênticos: Assoreamento, estratificação do reservatório, impactos à jusante, etc.

e) Avaliar como esta técnica funcionaria em represas em cascata, se haveria um ganho global otimizando-as desta forma;

f) Avaliar a aplicabilidade dos modelos desenvolvidos utilizando previsão de tempo estocástica para prever, programar e eventualmente executar flushing de sedimentos na época de chuva; 



\section{Referências}

AACI/FURB. Desastre de 2008 no Vale do Itajaí. àgua, gente e política. Blumenau: FURB, 2009. Citado na página 38.

AGÊNCIA NACIONAL DE ÁGUAS. MANUAL DE ESTUDOS DE DISPONIBILIDADE HÍDRICA PARA APROVEITAMENTOS HIDRELÉTRICOS - Manual do Usuário. [S.1.], 2009. Citado 2 vezes nas páginas 54 e 55 .

ALDRIGHETTI, E. Computational Hydraulic Techniques for the Saint-Venant Equations in arbitrarily shaped geometry. Tese (PhD Thesis) — Università Degli Studi di Trento, May 2007. Citado na página 94.

AMARAL, F. C. S. Aptidão Agrícola das Terras do Estado de Minas Gerais: Avaliação e Adequação. Dissertação (Dissertação( Mestrado em Solos e Nutrição de Plantas)) - ESALQUSP, Piracicaba, SP, 1993. Citado na página 169.

ANDERSON, J. D. Computacional Fluid Dynamics: The Basics with Applications. [S.1.]: MCGraw-Hill, 1995. Citado 2 vezes nas páginas 92 e 93.

ANDERSON, R. M.; KOREN, V. I.; REED, S. M. Using ssurgo data to improve sacramento model a priori parameter estimates. Journal of Hydrology, v. 320, n. 1-2, p. 103-116, March 2006. Citado na página 71.

ARGENT, R. M. et al. A new approach to water quality modelling and environmental decision support systems. Environmental Modelling \& Software, v. 24, n. 7, p. 809-818, July 2009. Citado na página 151.

ARULAMPALAM, M. S. et al. A tutorial on particle filters for online nonlinear/non-gaussian bayesian tracking. IEEE Transactions on Signal Processing, v. 50, n. 2, p. 174-188, February 2002. Citado na página 128.

ASSELMAN, N. E. M.; HEYNERT, K. Consequences of floods: $2 d$ hydraulic simulations for the case study area central holland. In: Delft-Cluster Publication. [S.1.: s.n.], 2003. p. 22p. Citado 3 vezes nas páginas 73, 74 e 139.

AWWAD, H. M.; JUAN; RESTREPO, P. J. Streamflow forecasting for han river basin, korea read more: http://ascelibrary.org/doi/abs/10.1061/(asce)0733-9496(1994)120Journal of Water Resources Planning and Management, v. 120, n. 5, p. 651-673, September 1994. Citado na página 126.

AWWAD, H. M.; VALDÉS, J. B. Adaptive parameter estimation for multisite hydrologic forecasting read more: http://ascelibrary.org/doi/abs/10.1061/(asce)0733-9429(1992)118Journal of Hydraulic Engineering, v. 118, n. 9, p. 1202-1221, September 1992. Citado na página 126.

BARKER, G. Farming the Desert: Synthesis. Paris, France: UNESCO Publishing, 1996. Citado na página 34.

BATES, P. D.; HORRIT, M. S.; FEWTRELL, T. J. A simple inertial formulation of the shallow water equations for efficient two-dimensional flood inundation modelling. Journal of Hydrology, v. 387, p. 33-45, 2010. Citado na página 99. 
BAYSAL, F. M. Improving efficiency and effectiveness of Bayesian recursive parameter estimation for hydrologic models. Tese (Doutorado) - University of Arizona, 2003. Citado na página 127.

BECK, H. E. et al. Global-scale regionalization of hydrologic model parameters. Water Resources Research, v. 52, n. 5, p. 3599-3622, May 2016. Citado 2 vezes nas páginas 45 e 46.

BERGSTRÖM, S. Computer models of watershed hydrology. In: . [S.1.]: Water Resources Publications, LLC, 1995. cap. The HBV Model. Citado na página 70.

BERGSTRÖM, S.; FORSMAN, A. Development of a conceptual deterministic rainfall-runoff model. Hydrology Research, v. 4, n. 3, p. 147-170, June 1973. Citado na página 70.

BEVEN, K. Rainfall-Runoff Modelling: The primer. 2nd edition. ed. [S.1.]: Willey-Blackwell, 2012. Citado 2 vezes nas páginas 67 e 68.

BEVEN, K.; BINLEY, A. The future of distributed models: Model calibration and uncertainty prediction. Hydrological Processes, v. 6, n. 3, p. 279-298, 1992. Citado na página 125.

BISWAS, A. K. Integrated water resources management: Is it working? Water Resources Development, v. 24, n. 1, p. 5-22, March 2008. Citado na página 35.

BLANCO, T. B. et al. Flood regulation using nonlinear model predictive control. Control Engineering Practice, v. 18, p. 1147-1157, 2010. Citado na página 104.

BLIND, M.; GREGERSEN, J. B. Towards an open modelling interface (openmi) the harmonit project. Advances in Geosciences, v. 4, p. 69-75, 2005. Citado na página 83.

BOUGEAULT, P. et al. The thorpex interactive grand global ensemble. Bulletin of the American Meteorological Society., v. 91, n. 8, p. 1059-1072, Agosto 2010. Citado na página 121.

BRAGA, B.; BARBOSA, P. S. F.; NAKAYAMA, P. T. Sistemas de suporte à decisão em recursos hídricos. RBRH - Revista Brasileira de Recursos Hídricos, v. 3, n. 3, p. 73-95, Jul/Set 1998. Citado na página 83.

BRAS, R. L.; RESTREPO-POSADA, P. Real time automatic parameter calibration in conceptual runoff forecasting models. In: 3rd International Symposium on Stochastic Hydraulics. [S.1.: s.n.], 1980. p. 61-70. Citado na página 126.

BRAS, R. L.; RODRIGUEZ-ITURBE, I. Random Functions and Hydrology. [S.1.]: AddisonWesley, 1985. Citado na página 126.

BUIZZA, R. et al. The new ecmwf vareps (variable resolution ensemble prediction system). Quarterly Journal of the Royal Meteorological Society, v. 133, n. 624, p. 681 - 695, 2007. Citado na página 121.

BUIZZA, R. et al. A comparison of the ecmwf, msc, and ncep global ensemble prediction systems. Monthly Weather Review, v. 133, p. 1076-1097, 2005. Citado na página 121.

BURNASH, R. J. C. Computer models of watershed hydrology. In: [S.1.]: Water Resources Publications, LLC, 1995. cap. The NWS river forecast system - cathement modeling. Citado na página 70. 
BURNASH, R. J. C.; FERRAL, R. L.; MCGUIRE, R. A. A Generalized Streamflow Simulation System: Conceptual Modeling for Digital Computers. [S.1.]: U.S. Department of Commerce, National Weather Service, and State of California, Department of Water Resources, 1973. Citado na página 70.

BUTZER, K. et al. Irrigation agrosystems in eastern spain: Roman or islamic origins? Annals of the Association of American Geographers, v. 75, p. 479-509, 1985. Citado na página 34.

CAÑIZARES, R. et al. Developments in operational shelf sea modelling in danish waters. Estuarine, Coastal and Shelf Science, v. 53, n. 4, p. 595-605, October 2001. Citado na página 127.

CARVALHO, N. de O. et al. Guia de avaliação de assoreamento de reservatórios. Brasília, DF: Agência Nacional de Energia Elétrica / Superintendência de Estudos e Informações Hidrológicas, 2000. Citado 2 vezes nas páginas 55 e 56.

CAVAllari, A.; SILVA, A. P. da; CASTRO, H. S. de. Manual de Procedimentos da Operação. [S.1.], 2012. Citado 3 vezes nas páginas 159, 160 e 202.

CCCE-ONS. Treinamento NEWAVE-DECOMP. [S.1.], 2015. Citado 2 vezes nas páginas 63 e 64.

CHANSON, H. The hydraulics of Open Channel Flow: An Introduction - Basic principles, sediment motion, hydraulic modelling, design of hydraulic structures. [S.1.]: Elsevier ButterworthHeinemann, 2004. Citado na página 143.

CHAPUIS, J. Modellierung und neues Konzept für die Regelung von Laufwasserkraftwerken. Tese (Diss. Techn. Wiss. Nr 12765) — ETH Zürich, 1998. Citado na página 112.

CHIANG, P. K.; WILEMS, P.; BERLAMONT, J. A conceptual river model to support real-time flood control (demer river, belgium). In: DITTRICH et al. (Ed.). River Flow 2010: Proceedings of the International Conference on Fluvial Hydraulics. Braunschweig, Germany: Bundesanstalt für Wasserbau, 2010. p. 1407-1414. Citado na página 112.

CHOW, V. T.; MAIDMENT, D. R.; MAYS, L. W. Applied Hydrology. [S.1.]: McGraw-Hill, 1988. Citado 2 vezes nas páginas 89 e 99.

CLEMMENS, A. J. et al. Estimating canal pool resonance with auto tune variation. Journal of Irrigation and Drainage Engineering, v. 138, n. 1, p. 9-15, January 2012. Citado na página 112.

COLLISCHONN, W. et al. The mgb-iph model for large-scale rainfall-runoff modelling. Hydrological Sciences - Journal des Sciences hydrologiques, p. 878-895, 2007. Citado 2 vezes nas páginas 72 e 142.

COLLISCHONN, W. et al. Modelo de Grande Bacias-IPH: Manual de Discretização de Bacias para Aplicação do modelo MGB-IPH. Versão 2.0. Porto Alegre, RS, 2010. Citado na página 168.

CRISPINO, G.; GISONNI, C.; IERVOLINO, M. Flood hazard assessment: comparison of 1d and 2d hydraulic models. International Journal of River Basin Management, v. 13, n. 2, p. 153-166, June 2014. Citado 2 vezes nas páginas 45 e 46. 
DELGODA, D. K.; N.HALGAMUGE, S. K. S. M.; MALANO, H. Multiple model predictive flood control in regulated river systems with uncertain inflows. Water Resources Management, v. 27, p. 765-790, 2013. Citado na página 104.

DELTARES. DELFT-FEWS Docuementation. 22. ed. http://publicwiki.deltares.nl/display/FEWSDOC/Home, 2012. Citado 4 vezes nas páginas 145, 152, 154 e 155.

DELTARES. SOBEK - Hydrodynamics, Rainfall, Runoff and Real TIme COntrol. [S.1.], 2014. Citado 4 vezes nas páginas 73, 74, 135 e 136.

DENZER, R. Generic integration of environmental decision support systems - state-of-the-art. Environmental Modelling and Software, v. 20, n. 10, p. 1217-1223, October 2005. Citado na página 78.

DERMODY, B. J. et al. A virtual water network of the roman world. Hydrology and Earth Sciences, v. 18, p. 5025-5040, November 2014. Citado na página 34.

DEVI, G. K.; GANASRI, B. P.; DWARAKISH, G. S. A review on hydrological models. Aquatic Procedia, v. 4, p. 1001-1007, 2015. Citado na página 70.

DING, Y.; WANG, S. Optimal control of open-channel flow using adjoint sensitivity analysis optimal control of open-channel flow using adjoint sensitivity analysis. Journal of Hydraulic Engineering, v. 132, n. 11, p. 1215-1228, November 2006. Citado na página 112.

DUREN, F. K.; BEARD, L. R. Optimizing Flood Control Allocation for a Multipurpose Reservoir. nstitute for Water Resources Hydrologic Engineering Center (HEC) 609 Second Street Davis, CA 95616-468, 1972. Citado na página 40.

ECWMF. User guide to ECMWF forecast products. Version 1.2. [S.1.], 2015. Citado 5 vezes nas páginas $115,116,117,121$ e 122.

EMPRESA DE PESQUISAS ENERGÉTICAS E MINISTÉRIO DE MINAS E ENERGIAS. Relatório Síntes do Balanço Energético Nacional - 2016 (Ano base 2015). [S.1.], 2016. Citado 4 vezes nas páginas $35,57,58$ e 59 .

ERDKAMP, P. The grain market in the Roman Empire: a social, po- litical and economic study. Cambridge, England: Cambridge University Press, 2005. Citado na página 34.

ESTIGONI, M. V. et al. Análise técnica da legislação e normas sobre estudos hidrossedimentológicos em empreendimentos hidrelétricos. In: XIV World Water Congress. [S.1.: s.n.], 2011. Citado na página 36.

EVA, H. D. et al. A Vegetation Map of South America. Luxembourg, 2002. Citado na página 169.

EVENSEN, G. Using the extended kalman filter with a multilayer quasi-geostrophic ocean model. Journal of Geophysical Research, v. 97, n. C11, p. 17905-19=7924, November 1992. Citado na página 126.

EVENSEN, G. Sequential data assimilation with a nonlinear quasi-geostrophic model using monte carlo methods to forecast error statistics. Journal of Geophysical Research, v. 99, n. C5, p. 10143-10162, May 1994. Citado na página 127. 
FABER, B. A.; STEDINGER, J. R. Reservoir optimization using sampling sdp with ensemble streamflow prediction (esp) forecasts. Journal of Hydrology, v. 249, n. 1-4, p. 113-133, August 2001. Citado na página 79.

FAN, F. M. Acoplamento entre Modelos Hidrológicos e Sistemas de Informação geográfica: Integração do Modelo MGB-IPH. Dissertação (Mestrado) - UFRGS-IPH, Porto Alegre, Dezembro 2011. Citado 4 vezes nas páginas 158, 168, 169 e 170.

FAN, F. M. et al. Ensemble streamflow predictions in the três marias basin, brazil. In: EGU GENERAL ASSEMBLY 2014. Geophysycal Research Abstracts. Vienna, Austria: Copernicus Publications, 2014. v. 16. Citado na página 121.

FINLAY, P. Introducing Decision Support Systems. 2nd edition. ed. [S.1.]: Blackwell Pub, 1994. Citado na página 78.

FINNERTY, B. D. et al. Space-time scale sensitivity of the sacramento model to radar-gage precipitation inputs. Journal of Hydrology, v. 203, n. 1-4, p. 21-38, December 1997. Citado 2 vezes nas páginas 70 e 71 .

FORTUNA, A. de O. Técnicas Computacionais para Dinâmica dos Fluidos. 2a . ed. São Paulo: EDUSP-Editora da Universidade de São Paulo, 2012. Citado 2 vezes nas páginas 45 e 93.

FRANCO, P. E. C. Planejamento da operação de curto prazo em sistemas hidrelétricos de potência por modelo de fluxo em redes. Tese (Doutorado) — UNICAMP, Campinas, SP, Outubro 1993. Citado na página 79.

FRANZ, D. D.; MELCHING, C. S. Full Equations (FEQ) model for the solution of the Full, Dynamic Equations of Motion for One-Dimensional Unsteady Flow in Open Channels and through Control Structures. Urbana, Illinois, 1997. Citado 2 vezes nas páginas 45 e 90.

FREER, J.; BEVEN, K.; AMBROISE, B. Bayesian estimation of uncertainty in runoff prediction and the value of data: An application of the glue approach. Water Resources Research, v. 32, n. 7 , p. 2161-2173, July 1996. Citado na página 125.

GARCÍA, C. E.; PRETT, D. M.; MORARI, M. Model predictive control: Theory and pratice - a survey. Automatica, v. 25, n. 3, p. 335-348, May 1989. Citado 2 vezes nas páginas 101 e 104.

GEORGAKAKOS, K. P.; RAJARAM, H.; LI, S. G. On Improved Operational Hydrologic Forecasting of Streamflows. Iowa Citty, 1988. Citado na página 126.

GEORGAKAKOS, K. P.; SPERSFLAGE, J. A. Hydrological Forecast System-HFS: A user's manual. San Diego, CA, 1995. Citado na página 126.

GIJSBERS, P. Opportunities and limitations of delftfews as a scientific workflow tool for environmental modeling. In: SWAYNE, D. A. et al. (Ed.). 2010 International Congress on Environmental Modelling and Software: Modelling for Environmental's Sake Fifth Biennial Meeting. Ottawa, Canada, 2010. Citado 2 vezes nas páginas 149 e 156.

GLANZMANN, G. et al. Supervisory water level control for cascaded river power plants. In: International Conference on Hydropower. Stavanger, Norway: [s.n.], 2005. Citado na página 112.

GNEITING, T.; RAFTERY, A. E. Waether forecasting with ensemble methods. Science, v. 310, p. 248-249, October 2005. Citado 2 vezes nas páginas 115 e 120. 
GORDON, N. J.; SALMOND, D. J.; SMITH, A. F. M. Novel approach to nonlinear/non-guasian bayesian state estimation. IEE Proceedings F - Radar and Signal Processing, v. 140, n. 2, p. 107-113, April 1993. Citado na página 128.

GREEN, C. H.; PARKER, D. J.; TUNSTALL, S. M. Assessment of Flood Control and Management Options. Cape Town, South Africa, 2000. Citado 2 vezes nas páginas 38 e 39.

GREGERSEN, J. B.; GIJSBERS, P. J. A.; WESTEN, S. J. P. Openmi: Open modelling interface. Journal of Hydroinformatics, v. 9, n. 3, p. 175-191, July 2007. Citado na página 82.

GRIENWANK, A.; WALTHER, A. Evaluating derivatives: principles and techniques of algorithmic differentiation. 2nd. ed. Philadelphia: SIAM-Society for Industrial and Applied Mathematics, 2008. Citado 3 vezes nas páginas 106, 113 e 182.

GRIJSSEN, J. et al. An information system for flood early warning. In: SAUL, A. (Ed.). 3rd international Conference on Floods \& Flood Management. Dordrecht: Springer Netherlands, 1992. p. 263-264. Citado na página 84.

GRÖWE-KUSKA, N.; HEITSCH, H.; RÖMISCH, W. Scenario reduction and scenario tree construction for power management problems. In: Power Tech Conference Proceedings, 2003 IEEE Bologna. [S.1.: s.n.], 2003. v. 3. Citado na página 123.

GUPTA, H. V.; SOROOSHIAN, S. Toward improved parameter inference in catchment models: 1. evaluating parameter uncertainty. Water Resources Research, v. 34, n. 4, p. 751-763, April 1998. Citado na página 125.

GUPTA, H. V. et al. Advances in automatic calibration of watershed models. In: . [S.1.]: American Geophysical Union, 2003. p. 113-124. Citado na página 127.

HAGGETT, C. An integrated approach to flood forecasting and warning in england and wales authors. Water and Environment, v. 12, n. 6, p. 425-432, Decembercember 1998. Citado na página 150.

HARLIN, J.; KUNG, C.-S. Parameter uncertainty and simulation of design floods in sweden. Journal of Hydrology, v. 137, n. 1-4, p. 209-230, August 1992. Citado na página 70.

HÄTTENSCHWILER, P. Absturz im freien fall - anlauf zu neuen höhenflügen: gutes entscheiden in wirtschaft, politik und gesellschaft. In: . [S.1.]: vdf Hochschulverlag AG an der ETh Zürich, 2001. cap. Neues anwenderfreundliches Konzept der Entscheidungsunterstützung. Citado na página 78 .

HE, Y. et al. Reservoir flood control operation based on chaotic particle swarm optimization algorithm. Applied Mathematical Modelling, v. 39, p. 4480-4492, March 2014. Citado na página 40.

HENDERESON, F. M. Open CHannel Flow. [S.1.]: McMilliam Publishing Company, 1966. Citado na página 93.

HOFFMAN, R. N.; KALNAY, E. Lagged average forecasting, an alternative to monte carlo forecasting. Tellus A, v. 35, n. 2, p. 100-118, 1983. Citado na página 118.

HORNBECK, R. The Enduring Impacts of the Amreican Dust Bowl: Short and Long-Run Adjustments to Environmental Catastrophe. [S.1.], 2009. Citado na página 36. 
HOU, D.; KALNAY, E.; DROEGEMEIER, K. K. Objective verification of the samex '98 ensemble forecasts. Monthly Weather Review, v. 129, n. 1, p. 73-91, January 2001. Citado na página 119.

JI, Z.; VRIEND, H. de; HU, C. Application of sobek model in the yellow river estuary. In: International Conference on Estuaries and Coasts. Hangzhou China: [s.n.], 2003. Citado na página 75.

KALMAN, R. E. A new approach to linear filtering and prediction problems. J. Basic eng, v. 82, n. 1, p. 35-45, March 1960. Citado na página 126.

KAZEZY1LMAZ-ALHAN, C.; MEDINA, M. A. Kinematic and diffusion waves: Analytical and numerical solutions to overland and channel flow kinematic and diffusion waves: Analytical and numerical solutions to overland and channel flow. Journal of Hydraulic Engineering, v. 133, n. 2, p. 217-228, February 2007. Citado na página 91.

KEARNEY, M.; DOWER, P. M.; CANTONI, M. Model predictive control for flood mitigation: A wivenhoe dam case study. In: 2011 Australian Control Conference. Melbourne, Australia: Engineers Australia, 2011. p. 290-296. Citado na página 104.

KEEN, P. G. W.; MORTON, M. S. S. Decision Support Systems: an organization perspective. Reading, MA: Addison-Wesley Pub Co, 1978. Citado 2 vezes nas páginas 77 e 78.

KEESMAN, K. Membership-set estimation using random scanning and principal component analysis. Mathematics and Computer in Simulation, v. 32, n. 5-6, p. 535-543, December 1990. Citado na página 125.

KITANIDIS, P. K.; BRAS, R. L. Real-time forecasting with a conceptual hydrologic model: 1 . analysis of uncertainty. Water Resources Research, v. 16, n. 6, p. 1025-1033, December 1980. Citado na página 126.

KITANIDIS, P. K.; BRAS, R. L. Real-time forecasting with a conceptual hydrologic model: 2. applications and results. Water Resources Research, v. 16, n. 6, p. 1034-1044, December 1980. Citado na página 126.

KLEPPER, O.; SCHOLTEN, H.; KAMER, J. P. G. D. van. Prediction uncertainty in an ecological model of the oosterschelde estuary. Journal of Forecasting, v. 10, n. 1-2, p. 191-209, January 1991. Citado na página 125.

KNIGHT, D. W.; SHAMSELDIN, A. Y. River Basin Modelling for Flood Risk Mitigation. [S.1.]: CRC Press, 2005. Citado 4 vezes nas páginas 37, 38, 39 e 77.

KOUWEN, N. et al. Grouped response units for distributed hydrologic modeling. Journal of Water Resources Planning and Management, p. 289-305, 1993. Citado na página 142.

KRISHNAMURTI, T. N. et al. Multimodel ensemble forecasts for weather and seasonal climate. Journal of Climate, v. 13, n. 23, p. 4196-4216, December 2000. Citado na página 119.

KUCZERA, G. Improved parameter inference in catchment models: 1. evaluating parameter uncertainty. Water Resources Research, v. 19, n. 5, p. 1151-1162, October 1983. Citado na página 125. 
KUCZERA, G. Improved parameter inference in catchment models: 2. combining different kinds of hydrologic data and testing their compatibility. Water Resources Research, v. 19, n. 5, p. 1163-1172, October 1983. Citado na página 125.

KUCZERA, G. Efficient subsspace probabilistic parameter optimization for catchment models. Water Resources Research, v. 33, n. 1, p. 177-185, January 1997. Citado na página 125.

KUMMU, M. et al. How close do we live to water? a global analysis of population distance to freshwater bodies. PLoS ONE, v. 6, n. 6, p. e20578-e20578, June 2011. Citado na página 76.

KUWAJIMA, J. I. et al. Oportunidades no desenvolvimento de ferramentas para modelação de otimização de operação de reservatórios para curto prazo. In: XX Simpósio Brasileiro de Recursos Hídricos. Bento Gonçalves - RS: ABRH, 2013. Citado na página 124.

KUWAJIMA, J. I. et al. Trade-off assessment of simplified routing models for short-term hydropower reservoir optimization. Geophysical Research Abstracts, v. 16, n. EGU2014, p. 15814-1, 2014. Citado na página 76.

LABADIE, J. W. Optimal operation of multireservoir systems: State-of-the-art review. Journal of Water Resources Planning and Management, v. 130, n. 2, p. 93-111, March 2004. Citado 3 vezes nas páginas 81, 101 e 109.

LABADIE, J. W.; SULLIVAN, C. H. Computerized decision support systems for water managers. Journal of Water Resources Planning and Management, v. 112, n. 3, p. 299-307, July 1986. Citado 2 vezes nas páginas 45 e 78.

LANDON-LANE, J.; ROCKOFF, H.; H.STECKEL, R. Droughts, Floods and Finantial Distress in the United States. [S.1.], 2009. Citado na página 36.

LEEDAL, D. et al. Application of data-based mechanistic modelling for flood forecasting at multiple locations in the eden catchment in the national flood forecasting system (england and wales). Hydrology and Earth System Sciences, v. 17, n. 1, p. 177-185, January 2013. Citado na página 84.

LEEUW, S. van der. he Archaeomedes project: understanding the natural and anthropogenic causes of land degradation and de-sertification in the Mediterranean basin: research results. Luxembourg: Office for Official Publications of the European Communities, 1998. Citado na página 34.

LEITH, C. E. Theoretical skill of monte carlo forecasts. Monthly Weather Review, v. 102, n. 6, p. 409-418, June 1974. Citado na página 118.

LIBÂNIO, P. A. C.; CHENICHARO, C. A. de L.; NASCIMENTO, N. de O. A dimensão da qualidade de água: avaliação da relação entre indicadores sociais, de disponibilidade hídrica, de saneamento e de saúde púublica. Engenharia Sanitária e Ambiental, v. 10, n. 3, p. 219-210, Setembro 2005. Citado na página 34.

LIGHTHILL, M. J.; WHITMAN, G. B. On kinematic waves i. flood movement in long rivers. Proceedings of the Royal Society of London. Series A, Mathematical and Physical Sciences, p. 281-316, 1955. Citado na página 99.

LIU, F. SPRNT User's Manual. 1.2.2. ed. [S.1.], 2014. Citado na página 144. 
LIU, F.; HODGES, B. R. Applying microprocessor analysis methods to river network modelling. Environmental Modelling and Software, v. 52, p. 234-252, February 2014. Citado 2 vezes nas páginas 45 e 144.

LLORIS, F. B. An irrigation decree from roman spain: The lex rivi hiberiensis. Journal of Roman Studies, v. 96, p. 147-196, 2006. Citado na página 34.

LORENZ, E. N. Deterministic nonperiodic flow. Journal of the Atmospheric Sciences, v. 20, n. 2, p. 130-141, March 1963. Citado 2 vezes nas páginas 116 e 117.

LORENZ, E. N. A study of the predictability of a 28-variable atmospheric model. Tellus, v. 17, n. 3, p. 321-333, August 1965. Citado na página 116.

LOUKS, D. P.; BEEK, E. van. Water Resources Systems Planning and Management: An Introduction to Methods, Models and Applications. 1. ed. [S.1.]: UNESCO Publishing, 2005. (ISBN 978-3-319-44232-7). Citado na página 70.

MADSEN, H. et al. Data assimilation in rainfall runoff forecasting. In: 4th Hydroinformatics Conference. Cedar Rapids, Iowa: [s.n.], 2000. Citado na página 151.

MADSEN, H.; SKOTNER, C. Adaptive state updating in real-time river flow forecasting-a combined filtering and error forecasting procedure. Journal of Hydrology, v. 308, n. 1-4, p. 302-312, July 2005. Citado na página 127.

MAHMOOD, K. Reservoir Sedimentation - Impact, Extent, and Mitigation. Washington, D.C., 1987. Citado na página 55.

MALATERRE, P.-O.; ROGERS, D. C.; SCHUURMANS, J. Classification of canal control algorithms. Journal of Irrigation and Drainage Engineering, v. 124, n. 1, p. 2-10, January/February 1998. Citado na página 103.

MARENGO, J. A. et al. A seca e a crise hídrica de 2014-2015 em são paulo. Revista USP, v. 106, p. 31-44, Julho/Agosto/Setembro 2015. Citado 2 vezes nas páginas 37 e 38.

MARENGO, J. A. et al. The drough of amazonia in 2005. Jounal of Climate, v. 21, p. 498-516, February 2008. Citado na página 36.

MARQUES, T. C. Uma politica operativa a usinas individualizadas para o planejamento da operação energetica do sistema interligado nacional. Tese (Doutorado) - FEEC-UNICAMP, Campinas, SP, 2006. Citado na página 109.

MARQUES, T. C.; CRUZ, G.; VINHAL, C. Uma nova política operativa a usinas individualizadas para o planejamento da operação energética. In: 2010 9th IEEE/IAS International Conference on Industry Applications (INDUSCON). [S.1.: s.n.], 2010. p. 1-7. Citado 3 vezes nas páginas 109, 110 e 111.

MARTINEZ, L.; SOARES, S. Comparison between closed-loop and partial open-loop feedback control policies in long term hydrothermal scheduling. IEEE Transactions on Power Systems, v. 17, n. 2, p. 330-336, May 2002. Citado na página 109.

MASHRIQUI, H. S.; HALGREN, J. S.; REED, S. M. 1d river hydraulic model for operational flood forecasting in the tidal potomac: Evaluation for freshwater, tidal, and wind-driven events. Journal of Hydraulic Engineering, v. 140, n. 5, May 2014. Citado na página 74. 
MATTHIES, M.; GIUPPONI, C.; OSTENDORF, B. Environmental decision support systems: Current issues, methods and tools. Environmental Modelling \& Software, v. 22, n. 2, p. 123-127, February 2007. Citado na página 149.

MAYNE, D. Q. et al. Constrained model predictive control: Stability and optimality. Automatica, v. 36, n. 6, p. 789-814, June 2000. Citado 2 vezes nas páginas 101 e 102.

MILLER, R. N.; GHIL, M.; GAUTHIEZ, F. Advanced data assimilation in strongly nonlinear dynamical systems. Journal of the Atmospheric Sciences, v. 51, n. 8, p. 1037-1056, April 1994. Citado na página 126.

MINISTÉRIO DE MINAS E ENERGIA EMPRESA DE PESQUISA ENERGÉTICA. Plano Decenal de Expansão de Energia 2024. Brasília, DF: MME/EPE, 2015. v. 2. Citado 2 vezes nas páginas 59 e 60.

MOLTENI, F. et al. The ecmwf ensemble prediction system: methodology and validation. Quarterly Journal of the Royal Meteorological Society, v. 122, p. 73-119, 1996. Citado na página 121.

MONTERO, R. A. et al. Simplified hydraulic modelling in model predictive control of flood mitigation measures along rivers. Journal of Applied Water Engineering and Research, v. 1, n. 1, p. 17-27, 2013. Citado na página 99.

MORADKHANI, H. et al. Uncertainty assessment of hydrologic model states and parameters: Sequential data assimilation using the particle filter. Water Resources Research, v. 41, n. 5, May 2005. Citado na página 128.

MORADKHANI, H.; SOROOSHIAN, S. General review of rainfall-runoff modeling: Model calibration, data assimilation, and uncertainty analysis. In: Hydrological Modelling and the Water Cycle: Coupling the Atmospheric and Hydrological Models. New York: Springer Berlin Heidelberg, 2008. p. 1-24. Citado na página 70.

MORADKHANI, H. et al. Dual state-parameter estimation of hydrological models using ensemble kalman filter. Advances in Water Resources, v. 28, n. 2, p. 135-147, February 2005. Citado na página 128 .

MORARI, M.; LEE, J. Model predictive control: past, present and futures. Computer and Chemical Engineering, p. 667-682, 1999. Citado na página 104.

MURPHY, P. G. The Drought of 1934. [S.1.], 1935. Citado na página 36.

NASR, A. et al. Physically-based, distributed, catchment modelling for estimating sediment and phosphorus loads to rivers and lakes: Issues of model complexity, spatial and temporal scales and data requirements. In: THE IRISH NATIONAL COMMITTEEES OF THE INTERNATIONAL HYDROLOGICAL PROGRAMME AND THE INTERNATIONAL COMMISSION ON IRRIGATION AND DRAINAGE. 5th National Hydrology Seminar 2004: The Water Framework Directive - Monitoring and Modelling Issues for River Basin Management. [S.1.], 2004. Citado 2 vezes nas páginas 45 e 46.

NÉELZ, S.; G.PENDER. Benchmarking the latest generation of 2D hydrailic modelling packages. Horison House, Deanery Road, Bristol, BS1 9AH, 2013. Citado 2 vezes nas páginas 45 e 46.

NÉELZ, S.; PENDER, G. Desktop review of 2D hydraulic modelling packages. Bristol, UK, 2009. Citado na página 72. 
NOAA. Evaluation of Different Hydraulic Models in Support of National Weather Service Operations. 1325 East-West highway, Silver Springs, Maryland 20910-3283, 2007. Citado 4 vezes nas páginas 45, 46, 73 e 135 .

ONS. Previsão de Vazão Diárias ao Reservatório de Três Marias usando a Técnica de redes Neurais - Revisão 01. [S.1.], 2009. Citado na página 157.

ONS. Submódulo 1.1 - O Operador Nacional do Sistema Elétrico e os Procedimentos de Rede:Visão geral Rev 1.0. [S.1.], 2009. Citado 2 vezes nas páginas 62 e 159.

ONS. Submódulo 26.2 - Critérios para classificação da modalidade de operação de usinas Rev.2.0. [S.1.], 2011. Citado na página 160.

ONS. Submódulo 9.4 - Estabelecimento das Regras para Operação de Controle de Cheias. [S.1.], 2011. Citado na página 62.

ONS. Diretrizes para as regras de Operação de Controle de Cheias - Bacia do Rio São Francisco (Ciclo 2015-206). Rio de Janeiro - RJ, Brasil, 2015. Citado 4 vezes nas páginas 61, 65, 161 e 162.

OVERLOOP, P. J. van. Model Predictive Control on Open Water Systems. Tese (PhD Dissertation) — Technische Universiteit Delft, Delft, The Netherlands, 2006. Citado 2 vezes nas páginas 104 e 112.

PALMER, T. N. et al. Probabilistic prediction of climate using multi-model ensembles: from basics to applications. Philosophical Transactions of The Royal Society B: Biological Sciences, v. 369, n. 1463, p. 1991-1998, October 2005. Citado 2 vezes nas páginas 118 e 119.

PARKER, B. J.; AL-UTAIBI, G. A. Decision support systems: The reality that seems hard to accept? Omega, v. 14, n. 2, p. 135-143, 1986. Citado na página 77.

PENDER, G. Briefing: Introducing the flood risk management research consortium. Proceedings of the Institution of Civil Engineers - Water Management, v. 159, n. 1, p. 3-8, March 2006. Citado 2 vezes nas páginas 72 e 87.

PINHO, J. L. S.; VIEIRA, P. M. Aspectos da aplicação do delft hydraulics 'sobek' no desenvolvimento de um sistema de gestão operacional da água em alqueva. In: ASSOCIAÇÃO PORTUGUESA DOS RECURSOS HÍDRICOS. $8^{\circ}$ Congresso da Água. [S.1.], 2006. Citado 3 vezes nas páginas 139, 140 e 141.

PONTES, P. R. M. P.; COLLISCHONN, W. Conservação de volume em modelos simplificados de propagação de vazão. RBRH - Revista Brasileira de Recursos hídricos, ABRH, v. 17, n. 4, p. 83-96, 2012. Citado na página 142.

PORTO, R. de M. Hidráulica Básica. 4a edição. ed. São Carlos-SP: EESC-USP, 1999. Citado na página 94.

POWER, D. J. Decision Support Systems: Concepts and Resources for Managers. 88 Post Road West, Westport: Quorum Books division Greenwood Publishing, 2002. Citado na página 78.

RASO, L. et al. Tree structure generation from ensemble forecasts for real time control. Hydrological Processes, v. 27, p. 75-82, 2013. Citado 2 vezes nas páginas 122 e 123. 
REFSGAARD, J. C. Validation and intercomparison of different updating procedures for realtime forecasting. Hydrology Research, v. 28, n. 2, p. 65-84, April 1997. Citado na página 126.

REICHLE, R. H.; ENTEKHABI, D.; MCLAUGHLIN, D. B. Downscaling of radio brightness measurements for soil moisture estimation: A four-dimensional variational data assimilation approach. Water Resources Research, v. 37, n. 9, p. 2353-2364, September 2001. Citado na página 127.

RIGHETTO, A. M. Hidrologia e Recursos Hídricos. São Carlos: EESC/USP, 1998. Citado 2 vezes nas páginas 68 e 69.

RIZZOLI, A. E. et al. Integrated modelling frameworks for environmental assessment and decision support. In: JAKEMAN A.A. VOINOV, A. R. A.; CHEN, S. (Ed.). Environmental Modelling, Software and Decision Support. [S.1.]: Elsevier, 2008, (Developments in Integrated Environmental Assesment, v. 3). cap. 7, p. 101-118. Citado na página 151.

RODRÍGUEZ, I. O. Operation of multi-purpose reservoirs: simulation study comparing fixed rules and real-time control. Dissertação (Master's Thesis) - RWTH Achen - Institute of Hydraulic Engineering and Water resource Managemente, Aachen Germany, 2013. Citado na página 76.

ROO, A. P. de et al. Development of a european flood forecasting system. International Journal of River Basin Management, v. 1, n. 1, p. 49-59, August 2003. Citado na página 152.

RUSSELL, C. S. et al. Investing in Water Quality: Measuring Benefits, Costs and Risks. Washington, D.C., 2001. Citado na página 77.

ŞAHIN, A.; MORARI, M. Intelligent infrastructures. In: . Dordrecht: Springer Netherlands, 2009. cap. Decentralized Model Predictive Control for a Cascade of River Power Plants, p. 463-485. Citado na página 112.

SANTOS, M. R. A. dos. Rio São Francisco: patrimônio cultural e natural. Belo Horizonte, MG: Assembléia Legislativa do Estado de Minas Gerais, 2003. Citado na página 158.

SCHILLING, W.; MARTENS, J. Recursive state and parameter estimation with applications in water resources. Applied Mathematical Modelling, v. 10, n. 6, p. 433-437, December 1986. Citado na página 126.

SCHUURMANS, J. Control of Water Levels in Open-Channels. Tese (PhD Thesis) - Technische Universiteit Delft, Delft, The Netherlands, 1997. Citado 4 vezes nas páginas 45, 103, 134 e 175.

SCHUURMANS, J.; BOSGRA, O.; BROUWER, R. Open-channel flow model approximation for controller design. Applied Mathematical Modelling, v. 19, p. 525-530, 1995. Citado 3 vezes nas páginas 45,135 e 213.

SCHUURMANS, J. et al. Modeling of irrigation and drainage canals for controller design. Journal of Irrigation and Drainage Engineering, p. 338-344, November/December 1999. Citado 2 vezes nas páginas 112 e 135 .

SCHWANENBERG, D. RTC-Tools Technical Reference \& Configuration Guide Version 0.9 Beta (April 2010). Delft, The Netherlands, 2009. Citado 2 vezes nas páginas 132 e 133. 
SCHWANENBERG, D. RTC-Tools for Modelling Real-Time Control. Delft, The Netherlands, 2013. Citado na página 76.

SCHWANENBERG, D.; BECKER, B. RTC-Tools Software Tools for Modelling Real-Time Control. Delft, The Netherlands, 2014. Citado na página 132.

SCHWANENBERG, D.; BREUKELEN, A. van; HUMMEL, S. Data assimilation for supporting optimum control in large-scale river networks. In: 2011 International Conference on Networking, Sensing and Control. Delft, The Netherlands: [s.n.], 2011. Citado na página 102.

SCHWANENBERG, D. et al. Short-term reservoir optimization for flood mitigation under meteorological and hydrological forecast uncertainty: Application to the três marias reservoir in brazil. Water Resources Management, v. 29, n. 5, p. 1635-1651, March 2015. Citado 3 vezes nas páginas 116, 123 e 158.

SCHWANENBERG, D. et al. Model predictive control of pumps and gates for draining dutch polder systems. In: 10th International Conference on Hydroinformatics Hamburg, Germany / Understanding Changing Climate and Environment and Finding Solutions. [S.1.]: TuTech Verlag TuTech Innovation GmbH, 2012. Citado 3 vezes nas páginas 76, 103 e 112.

SCHWANENBERG, D.; PATZKE, S. Machbarkeitsstudie Steuerreglement Oberrhein / Modellierung in SOBEK. [S.1.], 2008. Citado na página 76.

SCHWANENBERG, D. et al. Adjoint modeling framework for water resources models. In: 10th International Conference on Hydroinformatics Hamburg, Germany / Understanding Changing Climate and Environment and Finding Solutions. [S.1.]: TuTech Verlag TuTech Innovation GmbH, 2012. Citado na página 103.

SCHWANENBERG, D. et al. Short-term reservoir optimization for mitigation downstream flood risk. In: 8th International Conference of EWRA "Water Resources Management in an Interdisciplinary and Changing Context". Porto Portugal: [s.n.], 2013. Citado 3 vezes nas páginas 76, 86 e 165.

SCHWANENBERG, D.; VERHOEVEN, G. F.; BOOGAARD, H. van den. Nonlinear model predictive control of flood dentention basins in operational flood forecasting. In: 9th International Conference on Hydroinformatics - HIC 2010. Tianjin, China: [s.n.], 2010. Citado 2 vezes nas páginas 76 e 112.

SEO, D.-J.; KOREN, V.; CAJINA, N. Real-time variational assimilation of hydrologic and hydrometeorological data into operational hydrologic forecasting. Journal of Hydrometeorology, v. 4, n. 3, p. 627-641, June 2003. Citado 2 vezes nas páginas 126 e 127.

SHUMAN, F. G. History of numerical weather prediction at the national meteorological center. Weather and Forecasting, v. 4, p. 286-296, September 1989. Citado na página 115.

SIVAPALAN, M.; SAVENIJE, H. H. G.; BLÖSCHL, G. Socio-hydrology: A new science of people and water. Hydrological Processes, v. 26, p. 1270-1276, 2012. Citado na página 33.

SOROOSHIAN, S.; DRACUP, J. A. Stochastic parameter estimation procedures for hydrologie rainfall-runoff models: Correlated and heteroscedastic error cases. Water Resources Research, v. 6, n. 2, p. 430-442, April 1980. Citado na página 125. 
SOROOSHIAN, S.; DUAN, Q.; GUPTA, V. K. Calibration of rainfall-runoff models: Application of global optimization to the sacramento soil moisture accounting model. Water Resources Research, v. 29, n. 4, p. 1185-1194, April 1993. Citado na página 125.

SPRAGUE, R. H.; CARLSON, E. D. Building Effective Decision Support Systems. [S.1.]: Pearson Education Canada, 1982. Citado na página 77.

STENSRUD, D. J.; WEISS, S. J. Mesoscale model ensemble forecasts of the 3 may 1999 tornado outbreak. Weather and Forecasting, v. 17, n. 3, p. 526-543, June 2002. Citado na página 119.

STRATEN, G. T. van; KEESMAN, K. J. Uncertainty propagation and speculation in projective forecasts of environmental change: A lake-eutrophication example. Journal of Forecasting, v. 10, n. 1-2, p. 163-190, January 1991. Citado na página 125.

ŠUTIENĖ, K.; MAKACKAS, D.; PRANEVIČIUS, H. Multistage k-means clustering for scenario tree construction. Informatica, v. 21, n. 1, p. 123-138, January 2010. Citado na página 122.

TAREKEGN, T. H. et al. Assessment of an aster-generated dem for $2 \mathrm{~d}$ hydrodynamic flood modeling. International Journal of Applied Earth Observation and Geoinformation, v. 12, n. 6 , p. 457-465, December 2010. Citado 2 vezes nas páginas 74 e 75.

TARIQ, M. A. U. R.; GIESEN, N. van de. Floods and flood management in pakistan. Physics and Chemistry of the Earth, Parts $A / B / C$, v. 47-48, p. 11-20, 2012. Citado 2 vezes nas páginas 79 e 85.

TAYLOR, J. W.; BUIZZA, R. Using weather ensemble predictions in electricity demand forecasting. International Journal of Forecasting, v. 19, n. 1, p. 57-70, 2003. Citado na página 119.

THIEMANN, M. et al. Bayesian recursive parameter estimation for hydrologic models. Water Resources Research, v. 37, n. 10, p. 2521-2535, October 2001. Citado 2 vezes nas páginas 125 e 127.

TODINI, E.; A.SZÖLLÖSI-NAGY; WOOD, E. F. Adaptive state/parameter estimation algorithms for real-time hydrologic forecasting: a case study. In: IIASA/WMO Workshop Recent Developments Real-Time Forecasting/Control Water Resource Sys. Laxenburg, Austria: [s.n.], 1976. Citado na página 126.

TUCCI, C. E. M. Modelos Hidrológicos. Porto Alegre: UFRGS, 1998. Citado 2 vezes nas páginas 67 e 69.

TUCCI, C. E. M. et al. Short- and long-term flow forecasting in the rio grande watershed (brazil). Atmospheric Science Letters, v. 9, n. 2, p. 53-56, April/June 2008. Citado na página 72.

TURBAN, E. Decision Support and Expert Systems: Management Support Systems. 4th edition. ed. [S.1.]: Prentice Hall, 1995. Citado na página 78.

TWIGT, D. J. et al. Coupled 1d-3d hydrodynamic modelling with application to the pearl river delta. Ocean Dynamics, v. 59, n. 6, p. 1077, December 2009. Citado na página 75.

UNESCO. THE UNITED NATIONS WORLD WATER DEVELOPMENT REPORT. THE UNITED NATIONS WORLD WATER DEVELOPMENT REPORT 3: WATER IN A CHANGING WORLD. Paris: UNESCO Publishing and Earthscan, 2009. v. 3. Citado na página 55. 
VERWEY, A. et al. The potential of the delft-fews flood forecasting platform for application in the mekong basin. In: 4th Annual Mekong Flood Forum. Siem Reap, Cambodia: [s.n.], 2006. Citado 2 vezes nas páginas 84 e 152 .

VÖRÖSMARTY, C. J. et al. The potential impact of neo-castorization on sediment transport by the global network of rivers. In: WALLING, D.; PROBST, J.-L. (Ed.). Human Impact on Erosion and Sedimentation - Proceedings of the Fifth Scientific Assembly of th IAHS. Rabat, Morocco: IAHS Publication, 1997. Citado na página 55.

VRUGT, J. A. et al. Toward improved identifiability of hydrologic model parameters: The information content of experimental data authors toward improved identifiability of hydrologic model parameters: The information content of experimental data authors toward improved identifiability of hydrologic model parameters: The information content of experimental data. Water Resources Research, v. 38, n. 12, p. 48-1-48-13, December 2002. Citado na página 127.

VRUGT, J. A. et al. Improved treatment of uncertainty in hydrologic modeling: Combining the streghts of global optimization and data assimilation. Water Resources Research, v. 41, n. 1, January 2005. Citado 2 vezes nas páginas 125 e 127.

VRUGT, J. A. et al. Effective and efficient algorithm for multiobjective optimization of hydrologic models. Water Resources Research, v. 39, n. 8, August 2003. Citado na página 125.

VRUGT, J. A. et al. A shuffled complex evolution metropolis algorithm for optimization and uncertainty assessment of hydrologic model parameters. Water Resources Research, v. 39, n. 8, August 2003. Citado 2 vezes nas páginas 125 e 127.

VRUGT, J. A. et al. Application of stochastic parameter optimization to the sacramento soil moisture accounting model. Journal of Hydrology, v. 325, n. 1-4, p. 288-307, June 2006. Citado na página 125.

VRUGT, J. A. et al. Real-time data assimilation for operational ensemble streamflow forecasting. Journal of Hydrology, v. 7, n. 3, p. 548-565, June 2006. Citado 4 vezes nas páginas 124, 125 , 126 e 128.

WÄCHTER, A. Short tutorial: Getting started with ipopt in 90 minutes. In: Dagstuhl Seminar Proceedings 09061. [S.1.: s.n.], 2009. Citado na página 113.

WÄCHTER, A.; BIEGLER, L. T. On the implementation of a primal-dual interior point filter line search algorithm for large-scale nonlinear programming. Mathematical Programing, p. 25-27, 2006. Citado 2 vezes nas páginas 113 e 181.

WAGENER, T. et al. Towards reduced uncertainty in conceptual rainfall-runoff modelling: dynamic identifiability analysis. Hydrological Processes, v. 17, n. 2, p. 455-476, February 2003. Citado na página 127.

WEERTS, A. H.; SCHELLEKENS, J.; WEILAND, F. S. Real-time geospatial data handling and forecasting: Examples from delft-fews forecasting platform/system. IEEE Journal of Selected Topics in Applied Earth Observations and Remote Sensing, v. 3, n. 3, p. 386-394, September 2010. Citado 3 vezes nas páginas 85, 147 e 148.

WERNER, M.; DIJK, M. van. Developing flood forecasting systems: Examples from the uk, europe, and pakistan. In: International Conference on Innovation and Implementaion of Flood Forecasting Technology. Troms $\emptyset$, Norway: [s.n.], 2005. Citado 2 vezes nas páginas 84 e 163. 
WERNER, M. et al. The delft-fews flow forecasting system. Environmental Modelling \& Software, v. 40, p. 65-77, February 2013. Citado 9 vezes nas páginas 84, 85, 145, 148, 150, 151, 153,154 e 155.

WESTERINK, J. J. et al. Tide and storm surge predictions using finite element model. Journal of Hydraulic Engineering, v. 118, n. 19, p. 1373-1390, October 1992. Citado na página 74.

WHITFIELD, D. The national flood forecasting system (nffs) of the uk environmental agency. In: International Conference on Innovation and Implementaion of Flood Forecasting Technology. Tromsø, Norway: [s.n.], 2005. Citado na página 85.

WILSON, A. Water Management and Usage in Roman North Africa: A Social and Technological Study. [S.1.]: University of Oxford, 1997. Citado na página 34.

WOOD, E. F.; O'CONNEL, P. E. Hydrological forecasting. In: Sons, 1985. cap. Real-Time Forecasting. Citado na página 126. . [S.1.]: John Wiley and

WORLD COMISSION ON DAMS. Dams and Development: A New Framework for DecisionMaking. London, 2000. Citado 2 vezes nas páginas 38 e 56.

WORLD METEOROLOGICAL ORGANIZATION. Guidelines on Esemble Prediction Systems and Forecasting. Geneva, Switzerland, 2012. Citado 2 vezes nas páginas 115 e 121.

XU, M.; SCHWANENBERG, D. Comparison of sequential and simultaneous model predictive control of reservoir systems. In: 10th International Conference on Hydroinformatics Hamburg, Germany/Understanding Changing Climate and Environment and Finding Solutions. Hamburgo, Alemanha: TuTech Verlag TuTech Innovation $\mathrm{GmbH}, 2012$. Citado 2 vezes nas páginas 105 e 113.

YEH, W. W.-G. Reservoir management and operations models: A state-of-the-art review. Water Resources Research, v. 21, n. 12, p. 1797-1818, December 1985. Citado 2 vezes nas páginas 81 e 101.

YOUNG, P. C. Advances in real-time flood forecasting. Philosophical Transactions of The Royal Society A: Mathematical, Physical and Engineering Sciences, v. 360, n. 1796, p. 1433-1450, May 2002. Citado na página 126.

YOUNG, P. C.; BEVEN, K. J. Data-based mechanistic modelling and the rainfall-flow nonlinearity. Environmetrics, v. 5, n. 3, p. 335-363, September 1994. Citado na página 125.

ZAMBELLI, M. et al. Newave versus odin: comparison of stochastic and deterministic models for the long term hydropower scheduling of the interconnected brazilian system. Sba Controle \& Automação, v. 22, n. 6, p. 598-609, Nov/Dec 2011. Citado na página 109.

ZHANG, X.; LINDSTRÖM, G. Development of an automatic calibration scheme for the hbv hydrological model. Hydrological Processes, v. 11, n. 12, p. 1671-1682, October 1997. Citado na página 70 .

ZHANG, Z.; KRISHNAMURTI, T. N. A pertubation method for hurricane ensemble predictions. Monthly Weather Review, v. 127, n. 4, p. 447-469, April 1999. Citado na página 119. 
Anexos 



\section{ANEXO A - Caracterização de Situação para Operação - ONS}

\section{Notas}

a) Caracterização de Cheia: Previsão ou ocorrência de vazões naturais, nos pontos de controle, superiores às restrições de vazões máximas consideradas;

b) Ocupação de volumes de espera: Volumes vazios disponíveis iguais ou inferiores aos volumes de espera estabelecidos;

c) Indicativo de violação de restrições hidráulicas: Obtido com base nos estados de armazenamentos, de afluências aos reservatórios e de vazões incrementais entre os reservatórios e os pontos de controle, bem como de nível da água no ponto de controle.

d) Caracterização de seca: Período prolongado em que a ausência ou carência de chuvas, em uma região ou bacia hidrográfica, acarreta baixas afluências aos seus reservatórios.

e) $\mathrm{V}_{A T A L}: \%$ de volume de espera Atenção-Alerta. 
Tabela 37 - Critérios para caracterização da Situação de Operação no período de controle de cheias - PCC (Parte I).

\begin{tabular}{|c|c|c|}
\hline $\begin{array}{l}\text { Responsável pela co- } \\
\text { ordenação da opera- } \\
\text { ção do(s) reservató- } \\
\text { rio(s) }\end{array}$ & $\begin{array}{l}\text { Situação de } \\
\text { Operação }\end{array}$ & Caracterização da Situação \\
\hline \multirow[t]{2}{*}{ ONS } & Normal & $\begin{array}{l}\text { Não há indicativo de violação de quaisquer das res- } \\
\text { trições operativas hidráulicas máximas ou mínimas, } \\
\text { registradas pelo Agente junto ao ONS, ou informadas } \\
\text { em tempo real: } \\
\text {-Não há ocupação de volumes de espera; e } \\
\text {-Não há caracterização de cheias; e } \\
\text {-Não há situações de secas prolongadas, e as vazões } \\
\text { naturais no ponto de controle são iguais ou superiores } \\
\text { às restrições hidráulicas de vazões mínimas. }\end{array}$ \\
\hline & Alerta & $\begin{array}{l}\text { Não há indicativo de violação de quaisquer das res- } \\
\text { trições operativas hidráulicas máximas ou mínimas, } \\
\text { registradas pelo Agente junto ao ONS ou informadas } \\
\text { em tempo real; e } \\
\text { - Há ocupação de volumes de espera até o } \mathrm{V}_{A T A L} \text {; ou } \\
\text { - Há situações de secas prolongadas com vazões na- } \\
\text { turais no ponto de controle, inferiores às restrições } \\
\text { hidráulicas de vazões mínimas, ocasionando o depleci- } \\
\text { onamento do reservatório ou reservatório equivalente; } \\
\text { ou } \\
\text { - O nível d'água do reservatório é superior ao máximo } \\
\text { operativo normal ou inferior ao mínimo operativo nor- } \\
\text { mal, estabelecido para o reservatório; ou } \\
\text { Há indisponibilidade de equipamentos hidráulicos e } \\
\text { ou elétricos que afetam o controle operacional do(s) } \\
\text { reservatório(s), sem previsão de retorno à operação; } \\
\text { ou } \\
\text { - Há necessidade de procedimentos específicos para a } \\
\text { não violação de restrição não usual ou não cadastrada } \\
\text { anteriormente. }\end{array}$ \\
\hline
\end{tabular}


Tabela 38 - Critérios para caracterização da Situação de Operação no período de controle de cheias - PCC (Parte II).

\begin{tabular}{|c|c|c|}
\hline $\begin{array}{l}\text { Responsável pela co- } \\
\text { ordenação da opera- } \\
\text { ção do(s) reservató- } \\
\text { rio(s) }\end{array}$ & $\begin{array}{l}\text { Situação de } \\
\text { Operação }\end{array}$ & Caracterização da Situação \\
\hline Agente de Geração & Alerta & $\begin{array}{l}\text { Há indicativo de violação de quaisquer das restrições } \\
\text { operativas hidráulicas máximas ou mínimas, registra- } \\
\text { das pelo Agente junto ao ONS ou informadas em } \\
\text { tempo real; e } \\
\text { - Há caracterização de cheia e há ocupação de volumes } \\
\text { de espera acima do } V_{A T A L} \text {; ou } \\
\text { - Há situações de secas prolongadas com vazões na- } \\
\text { turais no ponto de controle, inferiores às restrições } \\
\text { hidráulicas de vazões mínimas, ocasionando o depleci- } \\
\text { onamento do reservatório ou reservatório equivalente; } \\
\text { ou } \\
\text { - O nível d'água do reservatório é superior ao máximo } \\
\text { operativo normal ou inferior ao mínimo operativo nor- } \\
\text { mal, estabelecido para o reservatório; ou \& \& - Há } \\
\text { indisponibilidade de equipamentos hidráulicos e ou } \\
\text { elétricos que afetam o controle operacional do(s) re- } \\
\text { servatório(s), sem previsão de retorno à operação; ou } \\
\text { - Há necessidade de procedimentos específicos para a } \\
\text { não violação de restrição não usual ou não cadastrada } \\
\text { anteriormente. }\end{array}$ \\
\hline Agente de Geração & Emergência & $\begin{array}{l}\text {-Há perda total de comunicação entre a usina e o centro } \\
\text { de operação de seu relacionamento; ou } \\
\text {-Há violação de quaisquer das restrições operativas } \\
\text { hidráulicas máximas ou mínimas, registradas pelo } \\
\text { Agente junto ao ONS ou informadas em tempo real; e } \\
\text { - Há situações de secas prolongadas com vazões na- } \\
\text { turais no ponto de controle, inferiores às restrições } \\
\text { hidráulicas de vazões mínimas, ocasionando o depleci- } \\
\text { onamento do reservatório ou reservatório equivalente; } \\
\text { ou } \\
\text { - O nível d'água do reservatório é superior ao máximo } \\
\text { operativo normal ou inferior ao mínimo operativo nor- } \\
\text { mal, estabelecido para o reservatório; ou } \\
\text { - Há indisponibilidade de equipamentos hidráulicos } \\
\text { e/ou elétricos que afetam o controle operacional do(s) } \\
\text { reservatório(s), sem previsão de retorno à operação; } \\
\text { ou } \\
\text { - Há fatos não hidráulicos ocorridos a montante ou a } \\
\text { jusante que comprometem a operação do reservatório. }\end{array}$ \\
\hline
\end{tabular}



Apêndices 

APÊNDICE A - Dados Batimétricos do Rio São Francisco e do Rio Abaetés 
Tabela 39 - Características Geométricas da Seção 35200 do Rio Abaetés

\begin{tabular}{ccc}
\hline \hline $\mathrm{N}^{\mathrm{o}}$ & $\mathrm{h}(\mathrm{m})$ & $\mathrm{z}(\mathrm{m})$ \\
\hline 1 & 337.5 & 548.36 \\
2 & 339.5 & 547.35 \\
3 & 341.5 & 547.35 \\
4 & 343.5 & 546.72 \\
5 & 345.5 & 545.35 \\
6 & 347.5 & 545.24 \\
7 & 349.5 & 545.24 \\
8 & 351.5 & 545.15 \\
9 & 353.5 & 544.57 \\
10 & 355.5 & 544.87 \\
11 & 357.5 & 544.79 \\
13 & 359.5 & 544.56 \\
14 & 361.5 & 544.31 \\
15 & 363.5 & 544.31 \\
16 & 365.5 & 544.19 \\
17 & 367.5 & 544.15 \\
18 & 369.5 & 543.95 \\
19 & 371.5 & 543.98 \\
20 & 373.5 & 544.02 \\
21 & 375.5 & 544.02 \\
22 & 377.5 & 544.1 \\
23 & 379.5 & 544.22 \\
24 & 381.5 & 544.3 \\
25 & 383.5 & 544.3 \\
26 & 385.5 & 544.31 \\
27 & 387.5 & 544.32 \\
28 & 389.5 & 544.32 \\
29 & 391.5 & 544.33 \\
30 & 393.5 & 544.34 \\
31 & 395.5 & 544.34 \\
32 & 397.5 & 544.36 \\
33 & 399.5 & 544.36 \\
34 & 401.5 & 544.36 \\
35 & 403.5 & 544.38 \\
36 & 405.5 & 544.38 \\
37 & 407.5 & 544.39 \\
38 & 409.5 & 544.49 \\
39 & 411.5 & 544.66 \\
40 & 413.5 & 546.79 \\
41 & 415.5 & 547.88 \\
42 & 420.11 & 551.56 \\
\hline \hline & & \\
\end{tabular}


Tabela 40 - Características Geométricas da Seção 34000 do Rio Abaetés

\begin{tabular}{ccc|ccc}
\hline \hline $\mathrm{n}^{\mathbf{o}}$ & $\mathrm{h}(\mathrm{m})$ & $\mathrm{z}(\mathrm{m})$ & $\mathrm{n}^{\mathbf{o}}$ & $\mathrm{h}(\mathrm{m})$ & $\mathrm{z}(\mathrm{m})$ \\
\hline 1 & 208.98 & 547.62 & 33 & 275.32 & 543.55 \\
2 & 214.66 & 545.4 & 34 & 275.32 & 543.55 \\
3 & 215.32 & 545.35 & 35 & 277.32 & 543.59 \\
4 & 217.32 & 544.11 & 36 & 279.32 & 543.71 \\
5 & 219.32 & 543.82 & 37 & 281.32 & 543.82 \\
6 & 221.32 & 543.32 & 38 & 283.32 & 543.99 \\
7 & 223.32 & 543.28 & 39 & 285.32 & 544.11 \\
8 & 225.32 & 543.36 & 40 & 287.32 & 544.21 \\
9 & 227.32 & 543.42 & 41 & 289.32 & 544.32 \\
10 & 229.32 & 543.6 & 42 & 291.32 & 544.4 \\
11 & 231.32 & 543.88 & 43 & 293.32 & 544.41 \\
12 & 233.32 & 543.91 & 44 & 295.32 & 544.79 \\
13 & 235.32 & 544.03 & 45 & 297.32 & 544.89 \\
14 & 237.32 & 544.1 & 46 & 299.32 & 545 \\
15 & 239.32 & 544.13 & 47 & 301.32 & 544.99 \\
16 & 241.32 & 544.17 & 48 & 303.32 & 544.99 \\
17 & 243.32 & 543.91 & 49 & 305.32 & 544.99 \\
18 & 245.32 & 543.76 & 50 & 307.32 & 544.89 \\
19 & 247.32 & 543.66 & 51 & 309.32 & 544.72 \\
20 & 249.32 & 543.21 & 52 & 311.32 & 544.6 \\
21 & 251.32 & 543.31 & 53 & 313.32 & 544.69 \\
22 & 253.32 & 543.31 & 54 & 315.32 & 544.71 \\
23 & 255.32 & 543.32 & 55 & 317.32 & 544.74 \\
24 & 257.32 & 543.61 & 56 & 319.32 & 544.71 \\
25 & 259.32 & 543.52 & 57 & 321.32 & 544.71 \\
26 & 261.32 & 543.4 & 58 & 323.32 & 544.64 \\
27 & 263.32 & 543.34 & 59 & 325.32 & 544.82 \\
28 & 265.32 & 543.32 & 60 & 327.32 & 544.92 \\
29 & 267.32 & 543.3 & 61 & 329.32 & 545.4 \\
30 & 269.32 & 543.29 & 62 & 331.32 & 545.4 \\
31 & 271.32 & 543.26 & 63 & 336.92 & 547.62 \\
32 & 273.32 & 543.31 & - & - & - \\
\hline \hline & & & & &
\end{tabular}


Tabela 41 - Características Geométricas da Seção 30100 do Rio Abaetés

\begin{tabular}{ccc|ccc}
\hline \hline $\mathrm{n}^{\mathbf{o}}$ & $\mathrm{h}(\mathrm{m})$ & $\mathrm{z}(\mathrm{m})$ & $\mathrm{n}^{\mathbf{o}}$ & $\mathrm{h}(\mathrm{m})$ & $\mathrm{z}(\mathrm{m})$ \\
\hline 1 & 132.43 & 537.53 & 28 & 184 & 535.31 \\
2 & 133 & 537.4 & 29 & 186 & 535.3 \\
3 & 134 & 537.18 & 30 & 188 & 534.81 \\
4 & 136 & 536.72 & 31 & 190 & 534.29 \\
5 & 138 & 536.27 & 32 & 192 & 533.77 \\
6 & 140 & 535.99 & 33 & 194 & 533.5 \\
7 & 142 & 535.9 & 34 & 196 & 533.51 \\
8 & 144 & 535.81 & 35 & 198 & 533.51 \\
9 & 146 & 535.73 & 36 & 200 & 533.51 \\
10 & 148 & 535.64 & 37 & 202 & 533.51 \\
11 & 150 & 535.56 & 38 & 204 & 533.51 \\
12 & 152 & 535.51 & 39 & 206 & 533.51 \\
13 & 154 & 535.52 & 40 & 208 & 533.5 \\
14 & 156 & 535.53 & 41 & 210 & 533.5 \\
15 & 158 & 535.54 & 42 & 212 & 533.5 \\
16 & 160 & 535.55 & 43 & 214 & 533.55 \\
17 & 162 & 535.55 & 44 & 216 & 533.6 \\
18 & 164 & 535.54 & 45 & 218 & 533.66 \\
19 & 166 & 535.53 & 46 & 220 & 533.79 \\
20 & 168 & 535.49 & 47 & 222 & 534.04 \\
21 & 170 & 535.44 & 48 & 224 & 534.3 \\
22 & 172 & 535.4 & 49 & 226 & 534.55 \\
23 & 174 & 535.37 & 50 & 228 & 534.8 \\
24 & 176 & 535.34 & 51 & 230 & 533.26 \\
25 & 178 & 535.31 & 52 & 232 & 536.4 \\
26 & 180 & 535.31 & 53 & 234 & 537.54 \\
27 & 182 & 535.31 & - & - & - \\
\hline \hline
\end{tabular}


Tabela 42 - Características Geométricas da Seção 24200 do Rio Abaetés

\begin{tabular}{ccc|ccc}
\hline \hline $\mathrm{n}^{\mathrm{o}}$ & $\mathrm{h}(\mathrm{m})$ & $\mathrm{z}(\mathrm{m})$ & $\mathrm{n}^{\mathrm{o}}$ & $\mathrm{h}(\mathrm{m})$ & $\mathrm{z}(\mathrm{m})$ \\
\hline 1 & 353.2 & 523.54 & 30 & 410 & 522.43 \\
2 & 354 & 523.35 & 31 & 412 & 522.25 \\
3 & 356 & 522.96 & 32 & 414 & 522.2 \\
4 & 358 & 522.58 & 33 & 416 & 522.15 \\
5 & 360 & 522.52 & 34 & 418 & 522.02 \\
6 & 362 & 522.62 & 35 & 420 & 521.93 \\
7 & 364 & 522.72 & 36 & 422 & 521.88 \\
8 & 366 & 522.75 & 37 & 424 & 521.83 \\
9 & 368 & 522.75 & 38 & 426 & 521.77 \\
10 & 370 & 522.84 & 39 & 428 & 521.63 \\
11 & 372 & 522.95 & 40 & 430 & 521.43 \\
12 & 374 & 522.87 & 41 & 432 & 521.24 \\
13 & 376 & 522.82 & 42 & 434 & 521.06 \\
14 & 378 & 522.79 & 43 & 436 & 521.04 \\
15 & 380 & 522.76 & 44 & 438 & 521.01 \\
16 & 382 & 522.73 & 45 & 440 & 520.99 \\
17 & 384 & 522.7 & 46 & 442 & 520.93 \\
18 & 386 & 522.68 & 47 & 444 & 520.71 \\
19 & 388 & 522.68 & 48 & 446 & 520.49 \\
20 & 390 & 522.73 & 49 & 448 & 520.14 \\
21 & 392 & 522.8 & 50 & 450 & 520.06 \\
22 & 394 & 522.8 & 51 & 452 & 520.28 \\
23 & 396 & 522.72 & 52 & 454 & 520.51 \\
24 & 398 & 522.69 & 53 & 456 & 520.77 \\
25 & 400 & 522.71 & 54 & 458 & 521.67 \\
26 & 402 & 522.64 & 55 & 460 & 522.56 \\
27 & 404 & 522.61 & 56 & 462 & 523.54 \\
28 & 406 & 522.58 & 57 & 465.23 & 525.12 \\
29 & 408 & 522.53 & - & - & - \\
\hline \hline
\end{tabular}


Tabela 43 - Características Geométricas da Seção 20400 do Rio Abaetés

\begin{tabular}{ccc|ccc}
\hline \hline $\mathrm{n}^{\mathrm{o}}$ & $\mathrm{h}(\mathrm{m})$ & $\mathrm{z}(\mathrm{m})$ & $\mathrm{n}^{\mathrm{o}}$ & $\mathrm{h}(\mathrm{m})$ & $\mathrm{z}(\mathrm{m})$ \\
\hline 1 & 256.74 & 521.72 & 32 & 316.71 & 520.04 \\
2 & 257.71 & 521.21 & 33 & 318.71 & 520.06 \\
3 & 258.71 & 520.57 & 34 & 320.71 & 520.09 \\
4 & 260.71 & 519.9 & 35 & 322.71 & 520.12 \\
5 & 262.71 & 519.41 & 36 & 324.71 & 520.15 \\
6 & 264.71 & 518.99 & 37 & 326.71 & 520.19 \\
7 & 266.71 & 519.02 & 38 & 328.71 & 520.24 \\
8 & 268.71 & 519.04 & 39 & 330.71 & 520.28 \\
9 & 270.71 & 519.07 & 40 & 332.71 & 520.32 \\
10 & 272.71 & 519.18 & 41 & 334.71 & 520.43 \\
11 & 274.71 & 519.34 & 42 & 336.71 & 520.57 \\
12 & 276.71 & 519.5 & 43 & 338.71 & 520.76 \\
13 & 278.71 & 519.66 & 44 & 340.71 & 521.01 \\
14 & 280.71 & 519.78 & 45 & 342.71 & 520.71 \\
15 & 282.71 & 519.9 & 46 & 344.71 & 520.48 \\
16 & 284.71 & 519.94 & 47 & 346.71 & 520.69 \\
17 & 286.71 & 519.88 & 48 & 348.71 & 520.25 \\
18 & 288.71 & 519.82 & 49 & 350.71 & 520.52 \\
19 & 290.71 & 519.76 & 50 & 352.71 & 520.8 \\
20 & 292.71 & 519.7 & 51 & 354.71 & 521.08 \\
21 & 294.71 & 519.75 & 52 & 356.71 & 521.1 \\
22 & 296.71 & 519.81 & 53 & 358.71 & 521.07 \\
23 & 298.71 & 519.86 & 54 & 360.71 & 521.04 \\
24 & 300.71 & 519.93 & 55 & 362.71 & 521.04 \\
25 & 302.71 & 519.94 & 56 & 364.71 & 521.12 \\
26 & 304.71 & 519.94 & 57 & 366.71 & 521.05 \\
27 & 306.71 & 519.94 & 58 & 368.71 & 520.97 \\
28 & 308.71 & 519.95 & 59 & 370.71 & 521.18 \\
29 & 310.71 & 519.97 & 60 & 372.71 & 521.46 \\
30 & 312.71 & 519.99 & 61 & 374.71 & 521.72 \\
31 & 314.71 & 520.02 & - & - & - \\
\hline \hline & & & & & \\
\hline
\end{tabular}


Tabela 44 - Características Geométricas da Seção 19300 do Rio Abaetés

\begin{tabular}{ccc|ccc}
\hline \hline $\mathrm{n}^{\mathrm{o}}$ & $\mathrm{h}(\mathrm{m})$ & $\mathrm{z}(\mathrm{m})$ & $\mathrm{n}^{\mathrm{o}}$ & $\mathrm{h}(\mathrm{m})$ & $\mathrm{z}(\mathrm{m})$ \\
\hline 1 & 81.39 & 517.98 & 27 & 131.79 & 516.03 \\
2 & 82.79 & 517.85 & 28 & 133.79 & 516.27 \\
3 & 83.79 & 517.61 & 29 & 135.79 & 516.5 \\
4 & 85.79 & 517.12 & 30 & 137.79 & 516.58 \\
5 & 87.79 & 516.63 & 31 & 139.79 & 516.67 \\
6 & 89.79 & 516.14 & 32 & 141.79 & 516.71 \\
7 & 91.79 & 515.87 & 33 & 143.79 & 516.72 \\
8 & 93.79 & 516.53 & 34 & 145.79 & 516.72 \\
9 & 95.79 & 516.23 & 35 & 147.79 & 516.71 \\
10 & 97.79 & 515.93 & 36 & 149.79 & 516.7 \\
11 & 99.79 & 515.63 & 37 & 151.79 & 516.68 \\
12 & 101.79 & 515.57 & 38 & 153.79 & 516.81 \\
13 & 103.79 & 515.19 & 39 & 155.79 & 517.01 \\
14 & 105.79 & 515.02 & 40 & 157.79 & 517.18 \\
15 & 107.79 & 514.86 & 41 & 159.79 & 516.91 \\
16 & 109.79 & 514.71 & 42 & 161.79 & 516.63 \\
17 & 111.79 & 514.77 & 43 & 163.79 & 516.36 \\
18 & 113.79 & 514.84 & 44 & 165.79 & 516.23 \\
19 & 115.79 & 514.87 & 45 & 167.79 & 516.31 \\
20 & 117.79 & 514.84 & 46 & 169.79 & 516.4 \\
21 & 119.79 & 514.91 & 47 & 171.79 & 516.56 \\
22 & 121.79 & 515.16 & 48 & 173.79 & 516.71 \\
23 & 123.79 & 515.4 & 49 & 175.79 & 517.13 \\
24 & 125.79 & 515.63 & 50 & 177.79 & 517.55 \\
25 & 127.79 & 515.75 & 51 & 179.79 & 517.98 \\
26 & 129.79 & 515.86 & - & - & - \\
\hline \hline & & & & &
\end{tabular}


Tabela 45 - Características Geométricas da Seção 16500 do Rio Abaetés

\begin{tabular}{ccc|ccc}
\hline \hline $\mathrm{n}^{\mathrm{o}}$ & $\mathrm{h}(\mathrm{m})$ & $\mathrm{z}(\mathrm{m})$ & $\mathrm{n}^{\mathrm{o}}$ & $\mathrm{h}(\mathrm{m})$ & $\mathrm{z}(\mathrm{m})$ \\
\hline 1 & 130.71 & 515.21 & 25 & 178.13 & 511.06 \\
2 & 132.13 & 514.67 & 26 & 180.13 & 511.3 \\
3 & 134.13 & 514.24 & 27 & 182.13 & 511.63 \\
4 & 136.13 & 513.82 & 28 & 184.13 & 512.06 \\
5 & 138.13 & 513.38 & 29 & 186.13 & 512.5 \\
6 & 140.13 & 512.87 & 30 & 188.13 & 512.84 \\
7 & 142.13 & 512.51 & 31 & 190.13 & 513.14 \\
8 & 144.13 & 512.45 & 32 & 192.13 & 513.33 \\
9 & 146.13 & 512.4 & 33 & 194.13 & 513.28 \\
10 & 148.13 & 512.35 & 34 & 196.13 & 513.23 \\
11 & 150.13 & 512.3 & 35 & 198.13 & 513.18 \\
12 & 152.13 & 512.24 & 36 & 200.13 & 513.13 \\
13 & 154.13 & 512.19 & 37 & 202.13 & 513.34 \\
14 & 156.13 & 512.14 & 38 & 204.13 & 513.59 \\
15 & 158.13 & 511.88 & 39 & 206.13 & 513.78 \\
16 & 160.13 & 511.57 & 40 & 208.13 & 513.67 \\
17 & 162.13 & 511.26 & 41 & 210.13 & 513.56 \\
18 & 164.13 & 510.94 & 42 & 212.13 & 513.55 \\
19 & 166.13 & 510.63 & 43 & 214.13 & 513.54 \\
20 & 168.13 & 510.51 & 44 & 216.13 & 513.56 \\
21 & 170.13 & 510.59 & 45 & 218.13 & 513.6 \\
22 & 172.13 & 510.67 & 46 & 220.13 & 513.63 \\
23 & 174.13 & 510.75 & 47 & 222.13 & 514.22 \\
24 & 176.13 & 510.83 & 48 & 224.13 & 515.21 \\
\hline \hline
\end{tabular}


Tabela 46 - Características Geométricas da Seção 12400 do Rio Abaetés

\begin{tabular}{ccc|ccc}
\hline \hline $\mathrm{n}^{\mathrm{o}}$ & $\mathrm{h}(\mathrm{m})$ & $\mathrm{z}(\mathrm{m})$ & $\mathrm{n}^{\mathrm{o}}$ & $\mathrm{h}(\mathrm{m})$ & $\mathrm{z}(\mathrm{m})$ \\
\hline 1 & 294.85 & 511.31 & 31 & 353.65 & 509.64 \\
2 & 295.65 & 511.19 & 32 & 355.65 & 509.7 \\
3 & 297.65 & 510.83 & 33 & 357.65 & 509.7 \\
4 & 299.65 & 510.48 & 34 & 359.65 & 509.58 \\
5 & 301.65 & 510.12 & 35 & 361.65 & 509.47 \\
6 & 303.65 & 509.76 & 36 & 363.65 & 509.36 \\
7 & 305.65 & 509.66 & 37 & 365.65 & 509.25 \\
8 & 307.65 & 509.69 & 38 & 367.65 & 509.35 \\
9 & 309.65 & 509.71 & 39 & 369.65 & 509.43 \\
10 & 311.65 & 509.74 & 40 & 371.65 & 509.46 \\
11 & 313.65 & 509.74 & 41 & 373.65 & 509.49 \\
12 & 315.65 & 509.74 & 42 & 375.65 & 509.47 \\
13 & 317.65 & 509.74 & 43 & 377.65 & 509.44 \\
14 & 319.65 & 509.74 & 44 & 379.65 & 509.43 \\
15 & 321.65 & 509.72 & 45 & 381.65 & 509.44 \\
16 & 323.65 & 509.66 & 46 & 383.65 & 509.42 \\
17 & 325.65 & 509.61 & 47 & 385.65 & 509.34 \\
18 & 327.65 & 509.55 & 48 & 387.65 & 509.36 \\
19 & 329.65 & 509.53 & 49 & 389.65 & 509.43 \\
20 & 331.65 & 509.54 & 50 & 391.65 & 509.51 \\
21 & 333.65 & 509.54 & 51 & 393.65 & 509.45 \\
22 & 335.65 & 509.54 & 52 & 395.65 & 509.36 \\
23 & 337.65 & 509.54 & 53 & 397.65 & 509.28 \\
24 & 339.65 & 509.53 & 54 & 399.65 & 509.3 \\
25 & 341.65 & 509.5 & 55 & 401.65 & 509.45 \\
26 & 343.65 & 509.48 & 56 & 403.65 & 509.6 \\
27 & 345.65 & 509.46 & 57 & 405.65 & 509.78 \\
28 & 347.65 & 509.44 & 58 & 407.65 & 510.05 \\
29 & 349.65 & 509.5 & 59 & 409.65 & 510.68 \\
30 & 351.65 & 509.57 & 60 & 411.65 & 511.31 \\
\hline \hline & & & & &
\end{tabular}


Tabela 47 - Características Geométricas da Seção RA0 do Rio Abaetés - Parte I

\begin{tabular}{lll|lll|lll|lll}
\hline \hline 1 & 0 & 521.73 & 28 & 983 & 504.24 & 55 & 1126 & 502.19 & 82 & 1180 & 501.66 \\
2 & 83 & 520.54 & 29 & 995 & 504.33 & 56 & 1128 & 502.24 & 83 & 1182 & 501.6 \\
3 & 195 & 520.11 & 30 & 1005 & 504.38 & 57 & 1130 & 502.29 & 84 & 1184 & 501.61 \\
4 & 299 & 519.83 & 31 & 1020 & 504.34 & 58 & 1132 & 502.35 & 85 & 1186 & 501.62 \\
5 & 337 & 518.95 & 32 & 1035 & 504 & 59 & 1134 & 502.22 & 86 & 1188 & 501.63 \\
6 & 355 & 518.92 & 33 & 1058 & 504.14 & 60 & 1136 & 502.08 & 87 & 1190 & 501.58 \\
7 & 400 & 517.28 & 34 & 1066 & 503.78 & 61 & 1138 & 501.87 & 88 & 1192 & 501.5 \\
8 & 445 & 514.88 & 35 & 1073 & 503.9 & 62 & 1140 & 501.68 & 89 & 1194 & 501.43 \\
9 & 487 & 512.53 & 36 & 1079 & 503.74 & 63 & 1142 & 501.71 & 90 & 1196 & 501.36 \\
10 & 547 & 510.74 & 37 & 1084 & 503.81 & 64 & 1144 & 501.74 & 91 & 1198 & 501.28 \\
11 & 558 & 510.85 & 38 & 1086 & 504.14 & 65 & 1146 & 501.67 & 92 & 1200 & 501.19 \\
12 & 607 & 510.75 & 39 & 1092 & 506.71 & 66 & 1148 & 501.63 & 93 & 1202 & 501.06 \\
13 & 658 & 510.86 & 40 & 1095 & 507.94 & 67 & 1150 & 501.66 & 94 & 1204 & 500.88 \\
14 & 708 & 511.59 & 41 & 1098 & 507.88 & 68 & 1152 & 501.68 & 95 & 1206 & 500.81 \\
15 & 759 & 511.79 & 42 & 1102 & 505.36 & 69 & 1154 & 501.71 & 96 & 1208 & 500.75 \\
16 & 810 & 511.44 & 43 & 1103 & 504.22 & 70 & 1156 & 501.75 & 97 & 1210 & 500.69 \\
17 & 860 & 511.77 & 44 & 1103.66 & 504.24 & 71 & 1158 & 501.79 & 98 & 1212 & 500.64 \\
18 & 910 & 504.24 & 45 & 1106 & 504.22 & 72 & 1160 & 501.81 & 99 & 1214 & 500.65 \\
19 & 915 & 502.29 & 46 & 1108 & 504.19 & 73 & 1162 & 501.81 & 100 & 1216 & 500.67 \\
20 & 921 & 502.02 & 47 & 1110 & 503.79 & 74 & 1164 & 501.8 & 101 & 1218 & 500.68 \\
21 & 927 & 502.13 & 48 & 1112 & 503.28 & 75 & 1166 & 501.76 & 102 & 1220 & 500.69 \\
22 & 934 & 502.07 & 49 & 1114 & 502.8 & 76 & 1168 & 501.72 & 103 & 1222 & 500.7 \\
23 & 944 & 501.76 & 50 & 1116 & 502.31 & 77 & 1170 & 501.71 & 104 & 1224 & 500.72 \\
24 & 953 & 501.9 & 51 & 1118 & 501.83 & 78 & 1172 & 501.75 & 105 & 1226 & 500.73 \\
25 & 964 & 502.39 & 52 & 1120 & 501.97 & 79 & 1174 & 501.78 & 106 & 1228 & 500.74 \\
26 & 971 & 502.45 & 53 & 1122 & 502.1 & 80 & 1176 & 501.81 & 107 & 1230 & 500.76 \\
27 & 978 & 504.24 & 54 & 1124 & 502.17 & 81 & 1178 & 501.74 & 108 & 1232 & 500.73 \\
\hline \hline & & & & & & & & & & & \\
& & & & & & & & & &
\end{tabular}


Tabela 48 - Características Geométricas da Seção RA0 do Rio Abaetés - Parte II

\begin{tabular}{lll|lll|lll|lll}
\hline \hline 109 & 1234 & 500.61 & 135 & 1286 & 501.68 & 161 & 1338 & 503.02 & 187 & 1390 & 503.43 \\
110 & 1236 & 500.5 & 136 & 1288 & 501.73 & 162 & 1340 & 502.98 & 188 & 1392 & 503.4 \\
111 & 1238 & 500.39 & 137 & 1290 & 501.78 & 163 & 1342 & 502.95 & 189 & 1394 & 503.38 \\
112 & 1240 & 500.28 & 138 & 1292 & 501.83 & 164 & 1344 & 502.96 & 190 & 1396 & 503.35 \\
113 & 1242 & 500.17 & 139 & 1294 & 501.99 & 165 & 1346 & 503.03 & 191 & 1398 & 503.34 \\
114 & 1244 & 500.06 & 140 & 1296 & 502.2 & 166 & 1348 & 503.1 & 192 & 1400 & 503.41 \\
115 & 1246 & 499.95 & 141 & 1298 & 502.4 & 167 & 1350 & 503.17 & 193 & 1402 & 503.47 \\
116 & 1248 & 499.85 & 142 & 1300 & 502.59 & 168 & 1352 & 503.22 & 194 & 1404 & 503.54 \\
117 & 1250 & 499.86 & 143 & 1302 & 502.71 & 169 & 1354 & 503.26 & 195 & 1406 & 503.44 \\
118 & 1252 & 499.87 & 144 & 1304 & 502.44 & 170 & 1356 & 503.3 & 196 & 1408 & 503.35 \\
119 & 1254 & 499.88 & 145 & 1306 & 502.64 & 171 & 1358 & 503.34 & 197 & 1410 & 503.25 \\
120 & 1256 & 499.89 & 146 & 1308 & 502.93 & 172 & 1360 & 503.35 & 198 & 1412 & 503.17 \\
121 & 1258 & 499.91 & 147 & 1310 & 503 & 173 & 1362 & 503.35 & 199 & 1414 & 503.53 \\
122 & 1260 & 499.92 & 148 & 1312 & 502.7 & 174 & 1364 & 503.34 & 200 & 1416 & 503.89 \\
123 & 1262 & 499.93 & 149 & 1314 & 502.39 & 175 & 1366 & 503.34 & 201 & 1418 & 504.22 \\
124 & 1264 & 500.03 & 150 & 1316 & 502.45 & 176 & 1368 & 503.35 & 202 & 1425.35 & 505.5 \\
125 & 1266 & 500.23 & 151 & 1318 & 502.52 & 177 & 1370 & 503.36 & 203 & 1436.79 & 506.55 \\
126 & 1268 & 500.42 & 152 & 1320 & 502.58 & 178 & 1372 & 503.38 & 204 & 1445.52 & 507.71 \\
127 & 1270 & 500.61 & 153 & 1322 & 502.64 & 179 & 1374 & 503.39 & 205 & 1452.59 & 510.11 \\
128 & 1272 & 500.61 & 154 & 1324 & 502.71 & 180 & 1376 & 503.37 & 206 & 1458.47 & 512.59 \\
129 & 1274 & 500.61 & 155 & 1326 & 502.8 & 181 & 1378 & 503.32 & 207 & 1461.49 & 514.62 \\
130 & 1276 & 500.71 & 156 & 1328 & 502.89 & 182 & 1380 & 503.26 & 208 & 1469.13 & 516.5 \\
131 & 1278 & 500.97 & 157 & 1330 & 502.98 & 183 & 1382 & 503.2 & 209 & 1476.32 & 518.11 \\
132 & 1280 & 501.21 & 158 & 1332 & 503.07 & 184 & 1384 & 503.23 & 210 & 1485.27 & 519.96 \\
133 & 1282 & 501.45 & 159 & 1334 & 503.09 & 185 & 1386 & 503.29 & 211 & 1494.31 & 521.77 \\
134 & 1284 & 501.62 & 160 & 1336 & 503.05 & 186 & 1388 & 503.36 & - & - & - \\
\hline \hline & & & & & & & & & & & \\
\hline
\end{tabular}


Tabela 49 - Características Geométricas da Seção SF159600 do Rio São Francisco

\begin{tabular}{|c|c|c|c|c|c|c|c|c|c|c|c|}
\hline$n^{\circ}$ & $\mathrm{h}(\mathrm{m})$ & $\mathrm{z}(\mathrm{m})$ & $\mathrm{n}^{\mathrm{o}}$ & $\mathrm{h}(\mathrm{m})$ & $\mathrm{z}(\mathrm{m})$ & $\mathrm{n}^{\mathrm{o}}$ & $\mathrm{h}(\mathrm{m})$ & $\mathrm{z}(\mathrm{m})$ & $\mathrm{n}^{\mathrm{o}}$ & $\mathrm{h}(\mathrm{m})$ & $\mathrm{z}(\mathrm{m})$ \\
\hline 1 & 0 & 531.29 & 42 & 310.54 & 509.34 & 83 & 392.54 & 509.42 & 124 & 474.54 & 510.81 \\
\hline 2 & 21.15 & 530.73 & 43 & 312.54 & 509.34 & 84 & 394.54 & 509.42 & 125 & 476.54 & 510.87 \\
\hline 3 & 35.35 & 530.11 & 44 & 314.54 & 509.33 & 85 & 396.54 & 509.41 & 126 & 478.54 & 510.93 \\
\hline 4 & 49.04 & 529.29 & 45 & 316.54 & 509.33 & 86 & 398.54 & 509.4 & 127 & 480.54 & 511 \\
\hline 5 & 61.13 & 528.69 & 46 & 318.54 & 509.33 & 87 & 400.54 & 509.38 & 128 & 482.54 & 511.06 \\
\hline 6 & 90.57 & 527.32 & 47 & 320.54 & 509.33 & 88 & 402.54 & 509.32 & 129 & 484.54 & 511.12 \\
\hline 7 & 105.49 & 526.5 & 48 & 322.54 & 509.33 & 89 & 404.54 & 509.27 & 130 & 486.54 & 511.19 \\
\hline 8 & 118.36 & 525.54 & 49 & 324.54 & 509.33 & 90 & 406.54 & 509.22 & 131 & 488.54 & 511.25 \\
\hline 9 & 134.01 & 524.53 & 50 & 326.54 & 509.33 & 91 & 408.54 & 509.07 & 132 & 490.54 & 511.31 \\
\hline 10 & 146.07 & 523.51 & 51 & 328.54 & 509.33 & 92 & 410.54 & 509.2 & 133 & 492.54 & 511.31 \\
\hline 11 & 164.31 & 521.55 & 52 & 330.54 & 509.33 & 93 & 412.54 & 509.33 & 134 & 494.54 & 511.31 \\
\hline 12 & 190.03 & 519.56 & 53 & 332.54 & 509.33 & 94 & 414.54 & 509.59 & 135 & 496.54 & 511.3 \\
\hline 13 & 208.87 & 519.16 & 54 & 334.54 & 509.34 & 95 & 41 & 50 & 136 & .54 & .29 \\
\hline 14 & 244.21 & 519.02 & 55 & 336.54 & 509.34 & 96 & 418.54 & 509.89 & 137 & 500.54 & 511.28 \\
\hline 15 & 254.11 & 516.02 & 56 & 338.54 & 509.34 & 97 & 420.54 & 509.89 & 138 & 502.54 & 511.28 \\
\hline 16 & 259.6 & 513.8 & 57 & 340.54 & 509.34 & 98 & 422.54 & 510.97 & 139 & 504.54 & 511.48 \\
\hline 17 & 260.54 & 512.5 & 58 & 342.54 & 509.34 & 99 & 424.54 & 510.06 & 140 & 506.54 & 511.62 \\
\hline 18 & 262.54 & 511.8 & 59 & 344.54 & 509.34 & 100 & 426.54 & 510.14 & 141 & 508.54 & 511.76 \\
\hline 19 & 264.54 & 511.62 & 60 & 346.54 & 509.34 & 101 & 428.54 & 510.23 & 142 & 510.54 & 511.9 \\
\hline 20 & 266.54 & 511.45 & 61 & 348.54 & 509.34 & 102 & 430.54 & 510.31 & 143 & 512.54 & 512.04 \\
\hline 21 & 268.54 & 511.37 & 62 & 350.54 & 509.34 & 103 & 432.54 & 510.35 & 144 & 514.54 & 512.18 \\
\hline 22 & 270.54 & 511.27 & 63 & 352.54 & 509.34 & 104 & 434.54 & 510.38 & 145 & 516.54 & 512.32 \\
\hline 23 & 272.54 & 511.27 & 64 & 354.54 & 509.34 & 105 & 436.54 & 510.41 & 146 & 518.54 & 513.52 \\
\hline 24 & 274.54 & 511.27 & 65 & 356.54 & 509.34 & 106 & 438.54 & 510.45 & 147 & 520.54 & 512.66 \\
\hline 25 & 276.54 & 511.26 & 66 & 358.54 & 509.33 & 107 & 440.54 & 510.48 & 148 & 522.54 & 512.74 \\
\hline 26 & 278.54 & 511.26 & 67 & 360.54 & 509.32 & 108 & 442.54 & 510.51 & 149 & 524.54 & 512.88 \\
\hline 27 & 280.54 & 511.26 & 68 & 362.54 & 509.31 & 109 & 444.54 & 510.54 & 150 & 526.54 & 513.02 \\
\hline 28 & 282.54 & 511.26 & 69 & 364.54 & 509.3 & 110 & 446.54 & 510.56 & 151 & 528.54 & 513.41 \\
\hline 29 & 284.54 & 511.02 & 70 & 366.54 & 509.29 & 111 & 448.54 & 510.61 & 152 & 530.54 & 513.32 \\
\hline 30 & 286.54 & 510.78 & 71 & 368.54 & 509.27 & 112 & 450.54 & 510.71 & 153 & 532.54 & 513.41 \\
\hline 31 & 288.54 & 510.55 & 72 & 370.54 & 509.26 & 113 & 452.54 & 510.8 & 154 & 534.54 & 513.5 \\
\hline 32 & 290.54 & 510.31 & 73 & 372.54 & 509.26 & 114 & 454.54 & 510.9 & 155 & 536.54 & 513.59 \\
\hline 33 & 292.54 & 510.07 & 74 & 374.54 & 509.31 & 115 & 456.54 & 511 & 156 & 538.54 & 513.68 \\
\hline 34 & 294.54 & 509.84 & 75 & 376.54 & 509.35 & 116 & 458.54 & 511.09 & 157 & 540.54 & 513.8 \\
\hline 35 & 296.54 & 509.6 & 76 & 378.54 & 509.4 & 117 & 460.54 & 511.19 & 158 & 592.32 & 518.17 \\
\hline 36 & 298.54 & 509.36 & 77 & 380.54 & 509.44 & 118 & 462.54 & 511.06 & 159 & 639.5 & 520.03 \\
\hline 37 & 300.54 & 509.36 & 78 & 382.54 & 509.49 & 119 & 464.54 & 511.06 & 160 & 697.77 & 520.05 \\
\hline 38 & 302.54 & 509.35 & 79 & 384.54 & 509.48 & 120 & 466.54 & 511.01 & 161 & 757.14 & 519.54 \\
\hline 39 & 304.54 & 509.35 & 80 & 386.54 & 509.47 & 121 & 468.54 & 510.96 & 162 & 878.64 & 521.28 \\
\hline 40 & 306.54 & 509.34 & 81 & 388.54 & 509.46 & 122 & 470.54 & 510.91 & 163 & 1006.55 & 530.48 \\
\hline 41 & 308.54 & 509.34 & 82 & 390.54 & 509.43 & 123 & 472.54 & 510.86 & 164 & 1135.67 & 535.67 \\
\hline
\end{tabular}


Tabela 50 - Características Geométricas da Seção SF156000 do Rio São Francisco

\begin{tabular}{|c|c|c|c|c|c|c|c|c|c|c|c|}
\hline$\overline{n^{\circ}}$ & $\mathrm{h}(\mathrm{m})$ & $\mathrm{z}(\mathrm{m})$ & $\overline{\mathrm{n}^{\mathrm{o}}}$ & $\mathrm{h}(\mathrm{m})$ & $\mathrm{z}(\mathrm{m})$ & $\overline{\mathrm{n}^{\circ}}$ & $\mathrm{h}(\mathrm{m})$ & $\overline{\mathrm{z}(\mathrm{m})}$ & $\overline{\mathrm{n}^{\mathrm{o}}}$ & $\mathrm{h}(\mathrm{m})$ & $\mathrm{z}(\mathrm{m})$ \\
\hline 1 & 0 & 524.48 & 44 & 621.33 & 509.59 & 87 & 707.33 & 512.08 & 130 & 793.33 & 511.61 \\
\hline 2 & 11.34 & 524.46 & 45 & 623.33 & 509.59 & 88 & 709.33 & 512.08 & 131 & 795.33 & 511.6 \\
\hline 3 & 26.63 & 524.37 & 46 & 625.33 & 509.59 & 89 & 711.33 & 512.08 & 132 & 797.33 & 511.75 \\
\hline 4 & 41.69 & 524.51 & 47 & 627.33 & 509.59 & 90 & 713.33 & 512.08 & 133 & 799.33 & 512.9 \\
\hline 5 & 100.17 & 524.54 & 48 & 629.33 & 509.6 & 91 & 715.33 & 512.07 & 134 & 801.33 & 512.04 \\
\hline 6 & 115.03 & 524.68 & 49 & 631.33 & 509.71 & 92 & 717.33 & 512.07 & 135 & 803.33 & 512.18 \\
\hline 7 & 144.76 & 524.82 & 50 & 633.33 & 509.89 & 93 & 719.33 & 512.07 & 136 & 805.33 & 512.32 \\
\hline 8 & 190.56 & 525.02 & 51 & 635.33 & 510.04 & 94 & 721.33 & 512.07 & 137 & 807.33 & 512.31 \\
\hline 9 & 243.44 & 525.27 & 52 & 637.33 & 510.19 & 95 & 723.33 & 512.06 & 138 & 809.33 & 512.41 \\
\hline 10 & 272.88 & 525.21 & 53 & 639.33 & 510.34 & 96 & 725.33 & 512.04 & 139 & 811.33 & 512.43 \\
\hline 11 & 306.1 & 525.09 & 54 & 641.33 & 510.49 & 97 & 727.33 & 512.02 & 140 & 813.33 & 512.49 \\
\hline 12 & 350.75 & 524.84 & 55 & 643.33 & 510.64 & 98 & 729.33 & 512 & 141 & 815.33 & 512.57 \\
\hline 13 & 391.81 & 524.13 & 56 & 645.33 & 510.79 & 99 & 731.33 & 511.98 & 142 & 817.33 & 512.58 \\
\hline 14 & 434.9 & 522.58 & 57 & 647.33 & 510.72 & 100 & 733.33 & 511.96 & 143 & 819.33 & 512.58 \\
\hline 15 & 478.69 & 519.71 & 58 & 649.33 & 510.65 & 101 & 735.33 & 511.94 & 144 & 821.33 & 512.58 \\
\hline 16 & 554.5 & 516.5 & 59 & 651.33 & 510.58 & 102 & 737.33 & 511.92 & 145 & 823.33 & 512.58 \\
\hline 17 & 567.91 & 513.74 & 60 & 653.33 & 510.51 & 103 & 739.33 & 511.9 & 146 & 825.33 & 512.58 \\
\hline 18 & 569.33 & 513.1 & 61 & 655.33 & 510.44 & 104 & 741.33 & 511.81 & 147 & 827.33 & 512.59 \\
\hline 19 & 571.33 & 511.6 & 62 & 657.33 & 510.37 & 105 & 743.33 & 511.72 & 148 & 829.33 & 512.59 \\
\hline 20 & 573.33 & 511.5 & 63 & 659.33 & 510.3 & 106 & 745.33 & 511.64 & 149 & 831.33 & 512.59 \\
\hline 21 & 575.33 & 511.4 & 64 & 661.33 & 510.3 & 107 & 747.33 & 511.55 & 150 & 833.33 & 512.59 \\
\hline 22 & 577.33 & 511.3 & 65 & 663.33 & 510.34 & 108 & 749.33 & 511.47 & 151 & 835.33 & 512.59 \\
\hline 23 & 579.33 & 510.2 & 66 & 665.33 & 510.39 & 109 & 751.33 & 511.38 & 152 & 837.33 & 512.58 \\
\hline 24 & 581.33 & 510.1 & 67 & 667.33 & 510.44 & 110 & 753.33 & 511.3 & 153 & 839.33 & 512.57 \\
\hline 25 & 583.33 & 511 & 68 & 669.33 & 510.48 & 111 & 755.33 & 511.21 & 154 & 841.33 & 512.57 \\
\hline 26 & 585.33 & 510.9 & 69 & 671.33 & 510.53 & 112 & 757.33 & 511.13 & 155 & 843.33 & 512.57 \\
\hline 27 & 587.33 & 510.7 & 70 & 673.33 & 510.57 & 113 & 759.33 & 511.04 & 156 & 845.33 & 512.57 \\
\hline 28 & 589.33 & 510.48 & 71 & 675.33 & 510.66 & 114 & 761.33 & 510.96 & 157 & 847.33 & 512.57 \\
\hline 29 & 591.33 & 510.26 & 72 & 677.33 & 510.75 & 115 & 763.33 & 510.87 & 158 & 849.33 & 512.57 \\
\hline 30 & 593.33 & 510.04 & 73 & 679.33 & 510.84 & 116 & 765.33 & 510.88 & 159 & 851.33 & 512.57 \\
\hline 31 & 595.33 & 509.82 & 74 & 681.33 & 510.92 & 117 & 767.33 & 510.92 & 160 & 853.33 & 512.56 \\
\hline 32 & 597.33 & 509.6 & 75 & 683.33 & 511.01 & 118 & 769.33 & 510.96 & 161 & 855.33 & 512.54 \\
\hline 33 & 599.33 & 509.6 & 76 & 685.33 & 511.1 & 119 & 771.33 & 511 & 162 & 857.33 & 512.67 \\
\hline 34 & 601.33 & 509.6 & 77 & 687.33 & 511.19 & 120 & 773.33 & 511.05 & 163 & 859.33 & 513.15 \\
\hline 35 & 603.33 & 509.6 & 78 & 689.33 & 511.28 & 121 & 775.33 & 511.09 & 164 & 861.33 & 513.74 \\
\hline 36 & 605.33 & 509.6 & 79 & 691.33 & 511.36 & 122 & 777.33 & 511.13 & 165 & 871.11 & 514.93 \\
\hline 37 & 607.33 & 509.6 & 80 & 693.33 & 511.48 & 123 & 779.33 & 511.18 & 166 & 886.47 & 516.88 \\
\hline 38 & 609.33 & 509.6 & 81 & 695.33 & 511.6 & 124 & 781.33 & 511.23 & 167 & 903.29 & 516.51 \\
\hline 39 & 611.33 & 509.59 & 82 & 697.33 & 511.72 & 125 & 783.33 & 511.28 & 168 & 934.92 & 518.41 \\
\hline 40 & 613.33 & 509.59 & 83 & 699.33 & 511.84 & 126 & 785.33 & 511.33 & 169 & 957.01 & 520.37 \\
\hline 41 & 615.33 & 509.59 & 84 & 701.33 & 511.96 & 127 & 787.33 & 511.41 & 170 & 965.23 & 524.1 \\
\hline 42 & 617.33 & 509.59 & 85 & 703.33 & 512.08 & 128 & 789.33 & 511.47 & 171 & 974.28 & 527.35 \\
\hline 43 & 619.33 & 509.59 & 86 & 705.33 & 512.08 & 129 & 791.33 & 511.54 & - & - & - \\
\hline
\end{tabular}


Tabela 51 - Características Geométricas da Seção SF153200 do Rio São Francisco

\begin{tabular}{|c|c|c|c|c|c|c|c|c|c|c|c|}
\hline$\overline{n^{\circ}}$ & $\overline{\mathrm{h}(\mathrm{m})}$ & $\overline{z z(m)}$ & $\overline{n^{\circ}}$ & $\overline{\mathrm{h}(\mathrm{m})}$ & $\bar{z}(\mathrm{z}(\mathrm{m})$ & $\overline{\mathrm{n}^{\circ}}$ & $\overline{\mathrm{h}(\mathrm{m})}$ & $\bar{z}(\mathrm{~m})$ & $\overline{\mathrm{n}^{\circ}}$ & $\overline{\mathrm{h}(\mathrm{m})}$ & $\overline{z z(m)}$ \\
\hline 1 & 0 & 525.62 & 48 & 674.34 & 508.83 & 95 & 768.34 & 511.88 & 142 & 862.34 & 509.39 \\
\hline 2 & 51.01 & 524.47 & 49 & 676.34 & 508.8 & 96 & 770.34 & 510.9 & 143 & 864.34 & 509.39 \\
\hline 3 & 105.33 & 524.63 & 50 & 678.34 & 508.77 & 97 & 772.34 & 510.77 & 144 & 866.34 & 509.39 \\
\hline 4 & 152.65 & 524.19 & 51 & 680.34 & 508.74 & 98 & 774.34 & 510.63 & 145 & 868.34 & 509.4 \\
\hline 5 & 189.73 & 523.51 & 52 & 682.34 & 508.69 & 99 & 776.34 & 510.5 & 146 & 870.34 & 509.43 \\
\hline 6 & 244.98 & 521.85 & 53 & 684.34 & 508.73 & 100 & 778.34 & 510.3 & 147 & 872.34 & 509.46 \\
\hline 7 & 272.23 & 521.07 & 54 & 686.34 & 508.77 & 101 & 780.34 & 510.36 & 148 & 874.34 & 509.49 \\
\hline 8 & 290.47 & 520.58 & 55 & 688.34 & 508.81 & 102 & 782.34 & 510.36 & 149 & 876.34 & 509.52 \\
\hline 9 & 312.78 & 520.07 & 56 & 690.34 & 508.85 & 103 & 784.34 & 510.36 & 150 & 878.34 & 509.53 \\
\hline 10 & 333.17 & 519.66 & 57 & 692.34 & 508.89 & 104 & 786.34 & 510.36 & 151 & 880.34 & 509.49 \\
\hline 11 & 356.86 & 519.33 & 58 & 694.34 & 508.91 & 105 & 788.34 & 509.92 & 152 & 882.34 & 509.45 \\
\hline 12 & 379.97 & 518.93 & 59 & 696.34 & 508.93 & 106 & 790.34 & 509.56 & 153 & 884.34 & 509.41 \\
\hline 13 & 429.6 & 518.18 & 60 & 698.34 & 508.89 & 107 & 792.34 & 510.01 & 154 & 886.34 & 509.31 \\
\hline 14 & 466.5 & 516.28 & 61 & 700.34 & 508.84 & 108 & 794.34 & 509.92 & 155 & 34 & 509.2 \\
\hline 15 & 487.66 & 515.69 & 62 & 702.34 & 508.8 & 109 & 796.34 & 509.83 & 156 & 890.34 & 509.1 \\
\hline 16 & 511.86 & 515.4 & 63 & 704.34 & 508.76 & 110 & 798.34 & 509.74 & 157 & 892.34 & 508.99 \\
\hline 17 & 552.82 & 516.78 & 64 & 706.34 & 508.72 & 111 & 800.34 & 510.37 & 158 & 894.34 & 508.89 \\
\hline 18 & 583.61 & 516.5 & 65 & 708.34 & 508.67 & 112 & 802.34 & 510.23 & 159 & 896.34 & 508.91 \\
\hline 19 & 613.77 & 514.12 & 66 & 710.34 & 508.68 & 113 & 804.34 & 510.08 & 160 & 898.34 & 508.92 \\
\hline 20 & 618.78 & 512.46 & 67 & 712.34 & 508.69 & 114 & 806.34 & 510.02 & 161 & 900.34 & 508.9 \\
\hline 21 & 620.34 & 512.42 & 68 & 714.34 & 508.7 & 115 & 808.34 & 509.94 & 162 & 902.34 & 508.85 \\
\hline 22 & 622.34 & 510.4 & 69 & 716.34 & 508.71 & 116 & 810.34 & 509.81 & 163 & 904.34 & 508.88 \\
\hline 23 & 624.34 & 510.38 & 70 & 718.34 & 508.72 & 117 & 812.34 & 509.69 & 164 & 34 & 508.89 \\
\hline 24 & 626.34 & 510.24 & 71 & 720.34 & 508.73 & 118 & 814.34 & 509.57 & 165 & 908.34 & 508.9 \\
\hline 25 & 628.34 & 510.15 & 72 & 722.34 & 508.76 & 119 & 816.34 & 509.45 & 166 & 910.34 & 509 \\
\hline 26 & 630.34 & 510.09 & 73 & 724.34 & 508.79 & 120 & 818.34 & 509.33 & 167 & 912.34 & 509.1 \\
\hline 27 & 632.34 & 510.04 & 74 & 726.34 & 508.83 & 121 & 820.34 & 509.2 & 168 & 914.34 & 509.19 \\
\hline 28 & 634.34 & 509.99 & 75 & 728.34 & 508.85 & 122 & 822.34 & 509.2 & 169 & 916.34 & 509.29 \\
\hline 29 & 636.34 & 509.94 & 76 & 730.34 & 508.96 & 123 & 824.34 & 509.2 & 170 & 918.34 & 509.38 \\
\hline 30 & 638.34 & 509.89 & 77 & 732.34 & 509.18 & 124 & 826.34 & 509.19 & 171 & 920.34 & 509.37 \\
\hline 31 & 640.34 & 509.88 & 78 & 734.34 & 509.28 & 125 & 828.34 & 509.19 & 172 & 922.34 & 509.37 \\
\hline 32 & 642.34 & 509.71 & 79 & 736.34 & 509.39 & 126 & 830.34 & 509.19 & 173 & 924.34 & 509.37 \\
\hline 33 & 644.34 & 509.53 & 80 & 738.34 & 509.39 & 127 & 832.34 & 509.32 & 174 & 926.34 & 509.37 \\
\hline 34 & 646.34 & 509.45 & 81 & 740.34 & 509.38 & 128 & 834.34 & 509.44 & 175 & 928.34 & 509.37 \\
\hline 35 & 648.34 & 509.36 & 82 & 742.34 & 509.37 & 129 & 836.34 & 509.44 & 176 & 930.34 & 510.42 \\
\hline 36 & 650.34 & 509.36 & 83 & 744.34 & 509.38 & 130 & 838.34 & 509.43 & 177 & 932.34 & 511.47 \\
\hline 37 & 652.34 & 509.25 & 84 & 746.34 & 509.62 & 131 & 840.34 & 509.43 & 178 & 934.34 & 512.46 \\
\hline 38 & 654.34 & 509.14 & 85 & 748.34 & 509.87 & 132 & 842.34 & 509.42 & 179 & 938.06 & 513.62 \\
\hline 39 & 656.34 & 509.04 & 86 & 750.34 & 510.11 & 133 & 844.34 & 509.42 & 180 & 958.3 & 516.48 \\
\hline 40 & 658.34 & 508.93 & 87 & 752.34 & 510.12 & 134 & 846.34 & 509.41 & 181 & 985.57 & 516.04 \\
\hline 41 & 660.34 & 508.91 & 88 & 754.34 & 510.27 & 135 & 848.34 & 509.42 & 182 & 1133.03 & 516.43 \\
\hline 42 & 662.34 & 508.9 & 89 & 756.34 & 510.42 & 136 & 850.34 & 509.41 & 183 & 1287.41 & 518.33 \\
\hline 43 & 664.34 & 508.89 & 90 & 758.34 & 510.58 & 137 & 852.34 & 509.4 & 184 & 1365.52 & 520.86 \\
\hline 44 & 666.34 & 508.88 & 91 & 760.34 & 510.58 & 138 & 854.34 & 509.39 & 185 & 1535.76 & 529.25 \\
\hline 45 & 668.34 & 508.87 & 92 & 762.34 & 510.9 & 139 & 856.34 & 509.38 & - & - & - \\
\hline 46 & 670.34 & 508.87 & 93 & 764.34 & 511.23 & 140 & 858.34 & 509.38 & - & - & - \\
\hline 47 & 672.34 & 508.85 & 94 & 766.34 & 511.56 & 141 & 860.34 & 509.39 & - & - & - \\
\hline
\end{tabular}


Tabela 52 - Características Geométricas da Seção SF148800 do Rio São Francisco

\begin{tabular}{|c|c|c|c|c|c|c|c|c|c|c|c|}
\hline $\mathrm{n}^{\mathrm{o}}$ & $\mathrm{h}(\mathrm{m})$ & $\mathrm{z}(\mathrm{m})$ & $\mathrm{n}^{\mathrm{o}}$ & $\mathrm{h}(\mathrm{m})$ & $\mathrm{z}(\mathrm{m})$ & $\overline{\mathrm{n}^{\mathrm{o}}}$ & $\mathrm{h}(\mathrm{m})$ & $\mathrm{z}(\mathrm{m})$ & $\overline{\mathrm{n}^{\mathrm{o}}}$ & $\mathrm{h}(\mathrm{m})$ & $\mathrm{z}(\mathrm{m})$ \\
\hline 1 & 0 & 527.51 & 45 & 478.84 & 505.21 & 89 & 566.84 & 510.31 & 133 & 654.84 & 508.75 \\
\hline 2 & 18.35 & 526.15 & 46 & 480.84 & 505.32 & 90 & 568.84 & 510.46 & 134 & 656.84 & 508.71 \\
\hline 3 & 57.72 & 524.09 & 47 & 482.84 & 505.43 & 91 & 570.84 & 510.62 & 135 & 658.84 & 508.76 \\
\hline 4 & 94.58 & 521.76 & 48 & 484.84 & 505.54 & 92 & 572.84 & 510.78 & 136 & 660.84 & 508.81 \\
\hline 5 & 134.34 & 519.52 & 49 & 486.84 & 505.85 & 93 & 574.84 & 510.75 & 137 & 662.84 & 508.97 \\
\hline 6 & 158.62 & 518.53 & 50 & 488.84 & 505.9 & 94 & 576.84 & 510.67 & 138 & 664.84 & 509.18 \\
\hline 7 & 188.92 & 517.24 & 51 & 490.84 & 506.15 & 95 & 578.84 & 510.57 & 139 & 666.84 & 509.39 \\
\hline 8 & 210.21 & 516.42 & 52 & 492.84 & 506.41 & 96 & 580.84 & 510.47 & 140 & 668.84 & 509.39 \\
\hline 9 & 235.51 & 515.4 & 53 & 494.84 & 506.66 & 97 & 582.84 & 510.36 & 141 & 670.84 & 508.84 \\
\hline 10 & 258.26 & 515.03 & 54 & 496.84 & 507.13 & 98 & 584.84 & 510.29 & 142 & 672.84 & 508.2 \\
\hline 11 & 264.29 & 514.95 & 55 & 498.84 & 507.34 & 99 & 586.84 & 510.21 & 143 & 674.84 & 509.46 \\
\hline 12 & 269.01 & 514.95 & 56 & 500.84 & 507.55 & 100 & 588.84 & 510.14 & 144 & 676.84 & 510.07 \\
\hline 13 & 280.58 & 515.07 & 57 & 502.84 & 507.77 & 101 & 590.84 & 510.06 & 145 & 678.84 & 510.05 \\
\hline 14 & 299.58 & 514.95 & 58 & 504.84 & 507.98 & 102 & 592.84 & 510.16 & 146 & 68 & 509.94 \\
\hline 15 & 325.15 & 514.94 & 59 & 506.84 & 508.19 & 103 & 594.84 & 510.26 & 147 & 682.84 & 509.81 \\
\hline 16 & 349.61 & 515.19 & 60 & 508.84 & 508.41 & 104 & 596.84 & 510.46 & 148 & 684.84 & 509.68 \\
\hline 17 & 414.64 & 514.69 & 61 & 510.84 & 508.32 & 105 & 598.84 & 510.65 & 149 & 68 & 509.7 \\
\hline 18 & 425.88 & 512.02 & 62 & 512.84 & 508.28 & 106 & 600.84 & 510.49 & 150 & 68 & 509.79 \\
\hline 19 & 426.84 & 512.07 & 63 & 514.84 & 508.15 & 107 & 602.84 & 510.34 & 151 & 690.84 & 509.91 \\
\hline 20 & 428.84 & 511.27 & 64 & 516.84 & 507.03 & 108 & 604.84 & 510.18 & 152 & 692.84 & 509.93 \\
\hline 21 & 430.84 & 510.45 & 65 & 518.84 & 507.9 & 109 & 606.84 & 510.02 & 153 & 69 & 509.95 \\
\hline 22 & 432.84 & 509.5 & 66 & 520.84 & 507.78 & 110 & 608.84 & 509.86 & 154 & 696.84 & 509.99 \\
\hline 23 & 434.84 & 509.17 & 67 & 522.84 & 507.65 & 111 & 610.84 & 509.7 & 155 & 69 & 510.03 \\
\hline 24 & 436.84 & 508.66 & 68 & 524.84 & 507.56 & 112 & 612.84 & 509.5 & 156 & 700.84 & 510.07 \\
\hline 25 & 438.84 & 508.15 & 69 & 526.84 & 507.41 & 113 & 614.84 & 509.29 & 157 & 702.84 & 510.05 \\
\hline 26 & 440.84 & 507.23 & 70 & 528.84 & 507.17 & 114 & 616.84 & 508.09 & 158 & 704.84 & 510 \\
\hline 27 & 442.84 & 506.82 & 71 & 530.84 & 506.93 & 115 & 618.84 & 508.89 & 159 & 706.84 & 509.93 \\
\hline 28 & 444.84 & 506.4 & 72 & 532.84 & 506.69 & 116 & 620.84 & 508.68 & 160 & 708.84 & 509.87 \\
\hline 29 & 446.84 & 505.99 & 73 & 534.84 & 506.88 & 117 & 622.84 & 508.47 & 161 & 710.84 & 509.85 \\
\hline 30 & 448.84 & 505.58 & 74 & 536.84 & 507.06 & 118 & 624.84 & 508.46 & 162 & 712.84 & 510.29 \\
\hline 31 & 450.84 & 505.17 & 75 & 538.84 & 507.24 & 119 & 626.84 & 508.44 & 163 & 714.84 & 510.71 \\
\hline 32 & 452.84 & 505.17 & 76 & 540.84 & 507.42 & 120 & 628.84 & 508.41 & 164 & 716.84 & 511.14 \\
\hline 33 & 454.84 & 505.17 & 77 & 542.84 & 507.6 & 121 & 630.84 & 508.39 & 165 & 718.84 & 511.56 \\
\hline 34 & 456.84 & 505.16 & 78 & 544.84 & 507.99 & 122 & 632.84 & 508.36 & 166 & 720.84 & 512.02 \\
\hline 35 & 458.84 & 505.16 & 79 & 546.84 & 508.97 & 123 & 634.84 & 508.34 & 167 & 723.27 & 512.48 \\
\hline 36 & 460.84 & 505.16 & 80 & 548.84 & 508.3 & 124 & 636.84 & 508.32 & 168 & 734.32 & 514.28 \\
\hline 37 & 462.84 & 505.11 & 81 & 550.84 & 508.46 & 125 & 638.84 & 508.29 & 169 & 772.3 & 516.11 \\
\hline 38 & 464.84 & 505.07 & 82 & 552.84 & 508.76 & 126 & 640.84 & 508.3 & 170 & 831.6 & 516.19 \\
\hline 39 & 466.84 & 505.02 & 83 & 554.84 & 509.07 & 127 & 642.84 & 508.33 & 171 & 866.12 & 515.9 \\
\hline 40 & 468.84 & 504.98 & 84 & 556.84 & 509.38 & 128 & 644.84 & 508.37 & 172 & 1041.6 & 513.76 \\
\hline 41 & 470.84 & 504.93 & 85 & 558.84 & 509.76 & 129 & 646.84 & 508.4 & 173 & 1546.26 & 528.62 \\
\hline 42 & 472.84 & 504.82 & 86 & 560.84 & 509.84 & 130 & 648.84 & 508.45 & . & - & - \\
\hline 43 & 474.84 & 504.99 & 87 & 562.84 & 510 & 131 & 650.84 & 508.55 & - & - & - \\
\hline 44 & 476.84 & 505.1 & 88 & 564.84 & 510.15 & 132 & 652.84 & 508.66 & - & - & - \\
\hline
\end{tabular}


Tabela 53 - Características Geométricas da Seção SF144800 do Rio São Francisco

\begin{tabular}{|c|c|c|c|c|c|c|c|c|}
\hline$\overline{\mathrm{n}^{\circ}}$ & $\bar{~} \mathrm{~h}(\mathrm{~m})$ & $\overline{\mathrm{z}(\mathrm{m})}$ & $\overline{\mathrm{n}^{\mathrm{o}}}$ & $\overline{\mathrm{h}(\mathrm{m})}$ & $\overline{\mathrm{z}(\mathrm{m})}$ & $\overline{n^{\circ}}$ & $\overline{\mathrm{h}(\mathrm{m})}$ & $\overline{z z(m)}$ \\
\hline 1 & 0 & 524.25 & 45 & 843.65 & 504.69 & 89 & 931.65 & 505.1 \\
\hline 2 & 89.07 & 520.02 & 46 & 845.65 & 504.6 & 90 & 933.65 & 505.13 \\
\hline 3 & 97.67 & 519.43 & 47 & 847.65 & 504.51 & 91 & 935.65 & 505.16 \\
\hline 4 & 209.75 & 514.9 & 48 & 849.65 & 504.65 & 92 & 937.65 & 505.19 \\
\hline 5 & 298.71 & 513.98 & 49 & 851.65 & 504.8 & 93 & 939.65 & 505.22 \\
\hline 6 & 418.14 & 513.69 & 50 & 853.65 & 504.94 & 94 & 941.65 & 505.25 \\
\hline 7 & 482.55 & 513.64 & 51 & 855.65 & 505.08 & 95 & 943.65 & 505.28 \\
\hline 8 & 513.38 & 511.92 & 52 & 857.65 & 504.75 & 96 & 945.65 & 505.31 \\
\hline 9 & 554.34 & 512.55 & 53 & 859.65 & 504.43 & 97 & 947.65 & 505.34 \\
\hline 10 & 591.74 & 512.59 & 54 & 861.65 & 504.1 & 98 & 949.65 & 505.29 \\
\hline 11 & 655.58 & 513.56 & 55 & 863.65 & 504.22 & 99 & 951.65 & 505.23 \\
\hline 12 & 710.26 & 513.26 & 56 & 865.65 & 504.33 & 100 & 953.65 & 505.17 \\
\hline 13 & 768.37 & 510.51 & 57 & 867.65 & 504.44 & 101 & 955.65 & 505.12 \\
\hline 14 & 782.79 & 508.13 & 58 & 869.65 & 504.56 & 102 & 957.65 & 505.06 \\
\hline 15 & 783.65 & 507.84 & 59 & 871.65 & 504.67 & 103 & 959.65 & 505.22 \\
\hline 16 & 785.65 & 507.55 & 60 & 873.65 & 504.78 & 104 & 961.65 & 505.38 \\
\hline 17 & 787.65 & 507.38 & 61 & 875.65 & 504.89 & 105 & 963.65 & 505.54 \\
\hline 18 & 789.65 & 507.22 & 62 & 877.65 & 504.99 & 106 & 965.65 & 505.7 \\
\hline 19 & 791.65 & 507.06 & 63 & 879.65 & 505.1 & 107 & 967.65 & 505.86 \\
\hline 20 & 793.65 & 506.89 & 64 & 881.65 & 505 & 108 & 969.65 & 506.03 \\
\hline 21 & 795.65 & 506.72 & 65 & 883.65 & 504.91 & 109 & 971.65 & 505.95 \\
\hline 22 & 797.65 & 506.5 & 66 & 885.65 & 504.81 & 110 & 973.65 & 505.87 \\
\hline 23 & 799.65 & 506.56 & 67 & 887.65 & 504.71 & 111 & 975.65 & 505.79 \\
\hline 24 & 801.65 & 506.48 & 68 & 889.65 & 504.62 & 112 & 977.65 & 505.71 \\
\hline 25 & 803.65 & 506.41 & 69 & 891.65 & 504.52 & 113 & 979.65 & 505.64 \\
\hline 26 & 805.65 & 506.34 & 70 & 893.65 & 504.42 & 114 & 981.65 & 505.56 \\
\hline 27 & 807.65 & 505.62 & 71 & 895.65 & 504.45 & 115 & 983.65 & 505.88 \\
\hline 28 & 809.65 & 506 & 72 & 897.65 & 504.75 & 116 & 985.65 & 506.2 \\
\hline 29 & 811.65 & 505.04 & 73 & 899.65 & 504.5 & 117 & 987.65 & 506.52 \\
\hline 30 & 813.65 & 505.07 & 74 & 901.65 & 504.53 & 118 & 989.65 & 506.84 \\
\hline 31 & 815.65 & 505.09 & 75 & 903.65 & 504.56 & 119 & 991.65 & 507.16 \\
\hline 32 & 817.65 & 505.11 & 76 & 905.65 & 504.56 & 120 & 993.65 & 507.48 \\
\hline 33 & 819.65 & 505.06 & 77 & 907.65 & 504.59 & 121 & 995.65 & 507.8 \\
\hline 34 & 821.65 & 505.01 & 78 & 909.65 & 504.66 & 122 & 997.65 & 507.8 \\
\hline 35 & 823.65 & 505.02 & 79 & 911.65 & 504.74 & 123 & 999.65 & 508.13 \\
\hline 36 & 825.65 & 505.04 & 80 & 913.65 & 504.81 & 124 & 1005.63 & 509.4 \\
\hline 37 & 827.65 & 505.06 & 81 & 915.65 & 504.89 & 125 & 1031.28 & 513.19 \\
\hline 38 & 829.65 & 505.09 & 82 & 917.65 & 504.91 & 126 & 1077.17 & 516.79 \\
\hline 39 & 831.65 & 505.12 & 83 & 919.65 & 504.94 & 127 & 1122.65 & 518.53 \\
\hline 40 & 833.65 & 505.14 & 84 & 921.65 & 504.96 & 128 & 1149.04 & 516.96 \\
\hline 41 & 835.65 & 505.15 & 85 & 923.65 & 504.99 & 129 & 1167.24 & 517.35 \\
\hline 42 & 837.65 & 505.02 & 86 & 925.65 & 505.01 & 130 & 1188.53 & 522.96 \\
\hline 43 & 839.65 & 504.9 & 87 & 927.65 & 505.04 & - & - & - \\
\hline 44 & 841.65 & 504.78 & 88 & 929.65 & 505.07 & - & - & - \\
\hline
\end{tabular}


Tabela 54 - Características Geométricas da Seção SF142200 do Rio São Francisco

\begin{tabular}{|c|c|c|c|c|c|c|c|c|c|c|c|}
\hline $\mathrm{n}^{\mathrm{o}}$ & $\mathrm{h}(\mathrm{m})$ & $\mathrm{z}(\mathrm{m})$ & $\mathrm{n}^{\mathrm{o}}$ & $\mathrm{h}(\mathrm{m})$ & $\mathrm{z}(\mathrm{m})$ & $\mathrm{n}^{\mathrm{o}}$ & $\mathrm{h}(\mathrm{m})$ & $\mathrm{z}(\mathrm{m})$ & $\mathrm{n}^{\mathrm{o}}$ & $\mathrm{h}(\mathrm{m})$ & $\mathrm{z}(\mathrm{m})$ \\
\hline 1 & 0 & 520.51 & 41 & 417.91 & 502.83 & 81 & 497.91 & 504.9 & 121 & 577.91 & 504.84 \\
\hline 2 & 79.47 & 516 & 42 & 419.91 & 502.91 & 82 & 499.91 & 504.76 & 122 & 579.91 & 504.89 \\
\hline 3 & 116.21 & 514.7 & 43 & 421.91 & 502.88 & 83 & 501.91 & 504.76 & 123 & 581.91 & 504.94 \\
\hline 4 & 158.82 & 513.57 & 44 & 423.91 & 502.84 & 84 & 503.91 & 504.75 & 124 & 583.91 & 504.9 \\
\hline 5 & 207.18 & 512.11 & 45 & 425.91 & 502.8 & 85 & 505.91 & 504.75 & 125 & 585.91 & 504.85 \\
\hline 6 & 234.84 & 511.9 & 46 & 427.91 & 502.81 & 86 & 507.91 & 504.94 & 126 & 587.91 & 504.8 \\
\hline 7 & 266.77 & 511.97 & 47 & 429.91 & 502.99 & 87 & 509.91 & 505.13 & 127 & 589.91 & 504.76 \\
\hline 8 & 294.98 & 512.21 & 48 & 431.91 & 503.17 & 88 & 511.91 & 504.98 & 128 & 591.91 & 504.71 \\
\hline 9 & 320.16 & 514.7 & 49 & 433.91 & 503.25 & 89 & 513.91 & 504.84 & 129 & 593.91 & 504.67 \\
\hline 10 & 349.55 & 509.96 & 50 & 435.91 & 503.35 & 90 & 515.91 & 504.9 & 130 & 595.91 & 504.63 \\
\hline 11 & 358.2 & 507.09 & 51 & 437.91 & 503.28 & 91 & 91 & .97 & 131 & 597.91 & 504.66 \\
\hline 12 & 359.91 & 506.66 & 52 & 439.91 & 503.21 & 92 & 519.91 & 505.04 & 132 & 599.91 & 504.7 \\
\hline 13 & 361.91 & 506.25 & 53 & 441.91 & 503.14 & 93 & 521.91 & 504.03 & 133 & 601.91 & 504.73 \\
\hline 14 & 363.91 & 505.84 & 54 & 443.91 & 503.1 & 94 & 523.91 & 504.03 & 134 & 603.91 & 504.77 \\
\hline 15 & 365.91 & 505.01 & 55 & 445.91 & 503.07 & 95 & 525.91 & 505.03 & 135 & 605.91 & 504.81 \\
\hline 16 & 367.91 & 504.85 & 56 & 447.91 & 503.03 & 96 & 527.91 & 505.3 & 136 & 607.91 & 504.85 \\
\hline 17 & 369.91 & 504.87 & 57 & 449.91 & 503.03 & 97 & 529.91 & 508.39 & 137 & 609.91 & 504.91 \\
\hline 18 & 371.91 & 504.52 & 58 & 451.91 & 503.04 & 98 & 531.91 & 505.57 & 138 & 611.91 & 504.97 \\
\hline 19 & 373.91 & 504.46 & 59 & 453.91 & 503.05 & 99 & 533.91 & 505.56 & 139 & 613.91 & 505.02 \\
\hline 20 & 375.91 & 504.39 & 60 & 455.91 & 502.9 & 100 & 535.91 & 55 & 140 & 615.91 & 505 \\
\hline 21 & 377.91 & 504.32 & 61 & 457.91 & 502.75 & 101 & 537.91 & 505.55 & 141 & 617.91 & 504.97 \\
\hline 22 & 379.91 & 504.39 & 62 & 459.91 & 502.65 & 102 & 539.91 & 505.44 & 142 & 619.91 & 504.95 \\
\hline 23 & 381.91 & 504.46 & 63 & 461.91 & 502.56 & 103 & 541.91 & 505.33 & 143 & 621.91 & 504.8 \\
\hline 24 & 383.91 & 504.53 & 64 & 463.91 & 502.55 & 104 & 543.91 & 505.29 & 144 & 623.91 & 504.73 \\
\hline 25 & 385.91 & 504.02 & 65 & 465.91 & 502.54 & 105 & 545.91 & 505.25 & 145 & 625.91 & 504.7 \\
\hline 26 & 387.91 & 503.5 & 66 & 467.91 & 502.53 & 106 & 547.91 & 505.38 & 146 & 627.91 & 504.68 \\
\hline 27 & 389.91 & 504.41 & 67 & 469.91 & 502.7 & 107 & 549.91 & 505.51 & 147 & 629.91 & 504.65 \\
\hline 28 & 391.91 & 504.31 & 68 & 471.91 & 502.87 & 108 & 551.91 & 505.38 & 148 & 631.91 & 504.63 \\
\hline 29 & 393.91 & 503.22 & 69 & 473.91 & 503.04 & 109 & 553.91 & 505.25 & 149 & 633.91 & 505.46 \\
\hline 30 & 395.91 & 503.15 & 70 & 475.91 & 503.04 & 110 & 555.91 & 505.13 & 150 & 635.91 & 506.28 \\
\hline 31 & 397.91 & 503.09 & 71 & 477.91 & 503.04 & 111 & 557.91 & 505.1 & 151 & 637.91 & 507.09 \\
\hline 32 & 399.91 & 503.09 & 72 & 479.91 & 503.16 & 112 & 559.91 & 505.02 & 152 & 641.57 & 508.7 \\
\hline 33 & 401.91 & 503.05 & 73 & 481.91 & 503.28 & 113 & 561.91 & 505.06 & 153 & 645.98 & 509.96 \\
\hline 34 & 403.91 & 503 & 74 & 483.91 & 503.41 & 114 & 563.91 & 505.1 & 154 & 665.62 & 513.51 \\
\hline 35 & 405.91 & 503.01 & 75 & 485.91 & 503.53 & 115 & 565.91 & 505.15 & 155 & 728.59 & 513.21 \\
\hline 36 & 407.91 & 502.91 & 76 & 487.91 & 504.12 & 116 & 567.91 & 505.1 & 156 & 862.95 & 512.44 \\
\hline 37 & 409.91 & 502.91 & 77 & 489.91 & 505.25 & 117 & 569.91 & 505.07 & 157 & 978.33 & 516.49 \\
\hline 38 & 411.91 & 502.81 & 78 & 491.91 & 505.31 & 118 & 571.91 & 505.05 & 158 & 1098.03 & 525.5 \\
\hline 39 & 413.91 & 502.78 & 79 & 493.91 & 505.17 & 119 & 573.91 & 506.92 & - & - & - \\
\hline 40 & 415.91 & 502.75 & 80 & 495.91 & 505.04 & 120 & 575.91 & 504.79 & - & - & - \\
\hline
\end{tabular}


Tabela 55 - Características Geométricas da Seção SF137600 do Rio São Francisco

\begin{tabular}{|c|c|c|c|c|c|c|c|c|c|c|c|}
\hline$\overline{\overline{n^{\circ}}}$ & $\mathrm{h}(\mathrm{m})$ & $\mathrm{z}(\mathrm{m})$ & $\overline{n^{\circ}}$ & $\mathrm{h}(\mathrm{m})$ & $\mathrm{z}(\mathrm{m})$ & 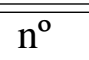 & $\mathrm{h}(\mathrm{m})$ & $\mathrm{z}(\mathrm{m})$ & $\overline{\mathrm{n}^{\circ}}$ & $\mathrm{h}(\mathrm{m})$ & $\mathrm{z}(\mathrm{m})$ \\
\hline 1 & 0 & 523.33 & 46 & 464.34 & 502.68 & 91 & 554.34 & 503.97 & 136 & 644.34 & 503.25 \\
\hline 2 & 37.98 & 520.67 & 47 & 466.34 & 502.7 & 92 & 556.34 & 504.05 & 137 & 646.34 & 503.36 \\
\hline 3 & 79.22 & 518.94 & 48 & 468.34 & 502.73 & 93 & 558.34 & 504.13 & 138 & 648.34 & 503.38 \\
\hline 4 & 94.55 & 518.32 & 49 & 470.34 & 502.75 & 94 & 560.34 & 504.15 & 139 & 650.34 & 503.41 \\
\hline 5 & 111.56 & 517.54 & 50 & 472.34 & 502.78 & 95 & 562.34 & 504.16 & 140 & 652.34 & 503.43 \\
\hline 6 & 128.54 & 516.77 & 51 & 474.34 & 502.8 & 96 & 564.34 & 504.17 & 141 & 654.34 & 503.46 \\
\hline 7 & 159.82 & 515.79 & 52 & 476.34 & 502.82 & 97 & 566.34 & 504.12 & 142 & 656.34 & 503.6 \\
\hline 8 & 179.26 & 514.53 & 53 & 478.34 & 502.85 & 98 & 568.34 & 504.07 & 143 & 658.34 & 503.74 \\
\hline 9 & 204.31 & 512.71 & 54 & 480.34 & 502.6 & 99 & 570.34 & 504.02 & 144 & 660.34 & 503.88 \\
\hline 10 & 279.81 & 512.64 & 55 & 482.34 & 502.36 & 100 & 572.34 & 502 & 145 & 662.34 & 504.02 \\
\hline 11 & 315.72 & 512.99 & 56 & 484.34 & 502.12 & 101 & 574.34 & 503.97 & 146 & 664.34 & 504.16 \\
\hline 12 & 354.49 & 513.59 & 57 & 486.34 & 502.53 & 102 & 576.34 & 503.77 & 147 & 666.34 & 505.02 \\
\hline 13 & 392.44 & 508.97 & 58 & 488.34 & 502.94 & 103 & 578.34 & 503.56 & 148 & 668.34 & 505.88 \\
\hline 14 & 401.02 & 506.76 & 59 & 490.34 & 503.35 & 104 & 580.34 & 503.36 & 149 & 670.34 & 506.76 \\
\hline 15 & 402.34 & 506.01 & 60 & 492.34 & 503.28 & 105 & 582.34 & 503.15 & 150 & 679.91 & 508.25 \\
\hline 16 & 404.34 & 505.25 & 61 & 494.34 & 503.22 & 106 & 584.34 & 503.17 & 151 & 31 & 513.9 \\
\hline 17 & 406.34 & 504.49 & 62 & 496.34 & 503.16 & 107 & 586.34 & 503.19 & 152 & 720.35 & 513 \\
\hline 18 & 408.34 & 503.9 & 63 & 498.34 & 502.91 & 108 & 588.34 & 503.29 & 153 & 77 & 511.32 \\
\hline 19 & 410.34 & 503.3 & 64 & 500.34 & 502.85 & 109 & 590.34 & 503.38 & 154 & 825.55 & 511.2 \\
\hline 20 & 412.34 & 503.4 & 65 & 502.34 & 502.75 & 110 & 592.34 & 503.48 & 155 & 870.43 & 510.8 \\
\hline 21 & 414.34 & 503.35 & 66 & 504.34 & 502.66 & 111 & 594.34 & 503.71 & 156 & 907.45 & 510.59 \\
\hline 22 & 416.34 & 503.29 & 67 & 506.34 & 502.29 & 112 & 596.34 & 503.47 & 157 & 920.45 & 510.53 \\
\hline 23 & 418.34 & 503.29 & 68 & 508.34 & 502.52 & 113 & 598.34 & 503.41 & 158 & 970.61 & 510.33 \\
\hline 24 & 420.34 & 503.24 & 69 & 510.34 & 502.46 & 114 & 600.34 & 503.36 & 159 & 970.96 & 510.44 \\
\hline 25 & 422.34 & 503.19 & 70 & 512.34 & 502.88 & 115 & 602.34 & 503.38 & 160 & 1070.73 & 510.71 \\
\hline 26 & 424.34 & 503.19 & 71 & 514.34 & 502.78 & 116 & 604.34 & 503.4 & 161 & 1096.42 & 512.17 \\
\hline 27 & 426.34 & 503.19 & 72 & 516.34 & 502.64 & 117 & 606.34 & 503.43 & 162 & 1170.45 & 512.1 \\
\hline 28 & 428.34 & 503.15 & 73 & 518.34 & 502.62 & 118 & 608.34 & 503.45 & 163 & 1170.96 & 512.09 \\
\hline 29 & 430.34 & 503.11 & 74 & 520.34 & 502.59 & 119 & 610.34 & 503.44 & 164 & 1185.98 & 511.89 \\
\hline 30 & 432.34 & 503.07 & 75 & 522.34 & 502.56 & 120 & 612.34 & 503.43 & 165 & 1200.76 & 510.93 \\
\hline 31 & 434.34 & 503.03 & 76 & 524.34 & 502.65 & 121 & 614.34 & 503.42 & 166 & 1251.67 & 509.75 \\
\hline 32 & 436.34 & 502.98 & 77 & 526.34 & 502.74 & 122 & 616.34 & 503.4 & 167 & 1270.83 & 508.87 \\
\hline 33 & 438.34 & 502.96 & 78 & 528.34 & 502.83 & 123 & 618.34 & 503.38 & 168 & 1318.34 & 506.74 \\
\hline 34 & 440.34 & 502.93 & 79 & 530.34 & 502.92 & 124 & 620.34 & 503.36 & 169 & 1323.59 & 505.74 \\
\hline 35 & 442.34 & 502.9 & 80 & 532.34 & 503.01 & 125 & 622.34 & 503.4 & 170 & 1328.61 & 505.12 \\
\hline 36 & 444.34 & 502.8 & 81 & 534.34 & 503.1 & 126 & 624.34 & 503.43 & 171 & 1333.65 & 505.13 \\
\hline 37 & 446.34 & 502.88 & 82 & 536.34 & 503.2 & 127 & 626.34 & 503.39 & 172 & 1338.8 & 505.45 \\
\hline 38 & 448.34 & 502.86 & 83 & 538.34 & 503.26 & 128 & 628.34 & 503.34 & 173 & 1339.34 & 506.74 \\
\hline 39 & 450.34 & 502.85 & 84 & 540.34 & 503.33 & 129 & 630.34 & 503.3 & 174 & 1370.34 & 511.13 \\
\hline 40 & 452.34 & 502.83 & 85 & 542.34 & 503.4 & 130 & 632.34 & 503.25 & 175 & 1420.75 & 511.67 \\
\hline 41 & 454.34 & 502.82 & 86 & 544.34 & 503.46 & 131 & 634.34 & 503.22 & 176 & 1470.56 & 511.94 \\
\hline 42 & 456.34 & 502.8 & 87 & 546.34 & 503.64 & 132 & 636.34 & 503.2 & 177 & 1520.59 & 512.21 \\
\hline 43 & 458.34 & 502.77 & 88 & 548.34 & 503.81 & 133 & 638.34 & 503.17 & 178 & 1553.5 & 520 \\
\hline 44 & 460.34 & 502.74 & 89 & 550.34 & 503.99 & 134 & 640.34 & 503.15 & - & . & - \\
\hline 45 & 462.34 & 502.71 & 90 & 552.34 & 503.98 & 135 & 642.34 & 503.2 & - & - & - \\
\hline
\end{tabular}


Tabela 56 - Características Geométricas da Seção SF134000 do Rio São Francisco

\begin{tabular}{|c|c|c|c|c|c|c|c|c|c|c|c|}
\hline $\mathrm{n}^{\mathrm{o}}$ & $\mathrm{h}(\mathrm{m})$ & $\mathrm{z}(\mathrm{m})$ & $\mathrm{n}^{\mathrm{o}}$ & $\mathrm{h}(\mathrm{m})$ & $\mathrm{z}(\mathrm{m})$ & $\mathrm{n}^{\mathrm{o}}$ & $\mathrm{h}(\mathrm{m})$ & $\mathrm{z}(\mathrm{m})$ & $\mathrm{n}^{\circ}$ & $\mathrm{h}(\mathrm{m})$ & $\mathrm{z}(\mathrm{m})$ \\
\hline 1 & 0 & 520.55 & 36 & 203.67 & 500.17 & 71 & 273.67 & 500.03 & 106 & 343.67 & 501.87 \\
\hline 2 & 26.13 & 519.38 & 37 & 205.67 & 500.1 & 72 & 275.67 & 500.02 & 107 & 345.67 & 501.91 \\
\hline 3 & 35.39 & 518.51 & 38 & 207.67 & 500.02 & 73 & 277.67 & 500.02 & 108 & 347.67 & 501.95 \\
\hline 4 & 56.05 & 514.86 & 39 & 209.67 & 500.02 & 74 & 279.67 & 500.22 & 109 & 349.67 & 502 \\
\hline 5 & 75.17 & 511.56 & 40 & 211.67 & 499.94 & 75 & 281.67 & 501.42 & 110 & 351.67 & 502.04 \\
\hline 6 & 94.33 & 511.65 & 41 & 213.67 & 499.86 & 76 & 283.67 & 500.62 & 111 & 353.67 & 502 \\
\hline 7 & 122.45 & 512.54 & 42 & 215.67 & 499.85 & 77 & 285.67 & 500.81 & 112 & 355.67 & 501.95 \\
\hline 8 & 144.99 & 507.38 & 43 & 217.67 & 499.85 & 78 & 287.67 & 501.01 & 113 & 357.67 & 501.9 \\
\hline 9 & 151.15 & 505.37 & 44 & 219.67 & 499.85 & 79 & 289.67 & 501.02 & 114 & 359.67 & 501.86 \\
\hline 10 & 151.67 & 505.35 & 45 & 221.67 & 499.84 & 80 & 291.67 & 501.02 & 115 & 361.67 & 501.81 \\
\hline 11 & 153.67 & 504.68 & 46 & 223.67 & 499.84 & 81 & 293.67 & 501.02 & 116 & 363.67 & 501.88 \\
\hline 12 & 155.67 & 504.01 & 47 & 225.67 & 499.83 & 82 & 295.67 & 501.02 & 117 & 365.67 & 501.95 \\
\hline 13 & 157.67 & 503.34 & 48 & 227.67 & 499.94 & 83 & 297.67 & 501.03 & 118 & 367.67 & 502.02 \\
\hline 14 & 159.67 & 502.67 & 49 & 229.67 & 500.04 & 84 & 299.67 & 501.03 & 119 & 369.67 & 502.09 \\
\hline 15 & 161.67 & 501.99 & 50 & 231.67 & 500.14 & 85 & 301.67 & 501.03 & 120 & 371.67 & 502.16 \\
\hline 16 & 163.67 & 501.95 & 51 & 233.67 & 500.24 & 86 & 303.67 & 501.03 & 121 & 373.67 & 502.16 \\
\hline 17 & 165.67 & 501.91 & 52 & 235.67 & 500.34 & 87 & 305.67 & 501.07 & 122 & 375.67 & 505.15 \\
\hline 18 & 167.67 & 501.87 & 53 & 237.67 & 500.44 & 88 & 307.67 & 501.09 & 123 & 377.67 & 502.14 \\
\hline 19 & 169.67 & 501.83 & 54 & 239.67 & 500.41 & 89 & 309.67 & 501.11 & 124 & 379.67 & 502.14 \\
\hline 20 & 171.67 & 501.68 & 55 & 241.67 & 500.38 & 90 & 311.67 & 501.12 & 125 & 381.67 & 502.2 \\
\hline 21 & 173.67 & 501.53 & 56 & 243.67 & 500.34 & 91 & 313.67 & 501.17 & 126 & 383.67 & 502.27 \\
\hline 22 & 175.67 & 501.38 & 57 & 245.67 & 500.31 & 92 & 315.67 & 501.21 & 127 & 385.67 & 502.34 \\
\hline 23 & 177.67 & 501.23 & 58 & 247.67 & 500.32 & 93 & 317.67 & 501.25 & 128 & 387.67 & 502.5 \\
\hline 24 & 179.67 & 501.08 & 59 & 249.67 & 500.33 & 94 & 319.67 & 501.29 & 129 & 389.67 & 502.66 \\
\hline 25 & 181.67 & 500.97 & 60 & 251.67 & 500.33 & 95 & 321.67 & 501.32 & 130 & 391.67 & 502.83 \\
\hline 26 & 183.67 & 500.86 & 61 & 253.67 & 500.34 & 96 & 323.67 & 501.36 & 131 & 393.67 & 503.68 \\
\hline 27 & 185.67 & 500.75 & 62 & 255.67 & 500.34 & 97 & 325.67 & 501.42 & 132 & 395.67 & 504.53 \\
\hline 28 & 187.67 & 500.75 & 63 & 257.67 & 500.28 & 98 & 327.67 & 501.47 & 133 & 397.67 & 505.37 \\
\hline 29 & 189.67 & 500.64 & 64 & 259.67 & 500.22 & 99 & 329.67 & 501.52 & 134 & 438.2 & 511.76 \\
\hline 30 & 191.67 & 500.54 & 65 & 261.67 & 500.16 & 100 & 331.67 & 501.57 & 135 & 495.02 & 510.95 \\
\hline 31 & 193.67 & 500.48 & 66 & 263.67 & 500.1 & 101 & 333.67 & 501.63 & 136 & 568.37 & 509.68 \\
\hline 32 & 195.67 & 500.42 & 67 & 265.67 & 500.04 & 102 & 335.67 & 501.68 & 137 & 699.29 & 510.88 \\
\hline 33 & 197.67 & 500.36 & 68 & 267.67 & 500.04 & 103 & 337.67 & 501.73 & 138 & 800.01 & 510.34 \\
\hline 34 & 199.67 & 500.31 & 69 & 269.67 & 500.03 & 104 & 339.67 & 501.78 & 139 & 909.31 & 512.87 \\
\hline 35 & 201.67 & 500.25 & 70 & 271.67 & 500.03 & 105 & 341.67 & 501.82 & 140 & 1010.32 & 517.92 \\
\hline
\end{tabular}


Tabela 57 - Características Geométricas da Seção SF130300 do Rio São Francisco

\begin{tabular}{|c|c|c|c|c|c|c|c|c|c|c|c|}
\hline $\mathrm{n}^{\mathrm{o}}$ & $\overline{\mathrm{h}(\mathrm{m})}$ & $\mathrm{z}(\mathrm{m})$ & $\mathrm{n}^{\mathrm{o}}$ & $\mathrm{h}(\mathrm{m})$ & $\mathrm{z}(\mathrm{m})$ & $\mathrm{n}^{\mathrm{o}}$ & $\mathrm{h}(\mathrm{m})$ & $\bar{z}(\mathrm{~m})$ & $\mathrm{n}^{\mathrm{o}}$ & $\mathrm{h}(\mathrm{m})$ & $\mathrm{z}(\mathrm{m})$ \\
\hline 1 & 0 & 519.99 & 39 & 496.71 & 501.55 & 77 & 572.71 & 502.5 & 115 & 648.71 & 502.82 \\
\hline 2 & 64.09 & 515.04 & 40 & 498.71 & 501.77 & 78 & 574.71 & 502.53 & 116 & 650.71 & 502.8 \\
\hline 3 & 129.94 & 511.21 & 41 & 500.71 & 501.99 & 79 & 576.71 & 502.56 & 117 & 652.71 & 502.82 \\
\hline 4 & 180.31 & 509.65 & 42 & 502.71 & 501.91 & 80 & 578.71 & 502.61 & 118 & 654.71 & 502.84 \\
\hline 5 & 243.69 & 509.06 & 43 & 504.71 & 501.84 & 81 & 580.71 & 502.67 & 119 & 656.71 & 502.86 \\
\hline 6 & 301.33 & 509.62 & 44 & 506.71 & 501.76 & 82 & 582.71 & 502.72 & 120 & 658.71 & 502.78 \\
\hline 7 & 367.37 & 509.88 & 45 & 508.71 & 501.69 & 83 & 584.71 & 502.77 & 121 & 660.71 & 502.7 \\
\hline 8 & 408.3 & 510.54 & 46 & 510.71 & 501.73 & 84 & 586.71 & 502.77 & 122 & 662.71 & 502.62 \\
\hline 9 & 429.19 & 507.92 & 47 & 512.71 & 501.77 & 85 & 588.71 & 502.77 & 123 & 664.71 & 502.55 \\
\hline 10 & 439.84 & 504.88 & 48 & 514.71 & 501.81 & 86 & 590.71 & 502.77 & 124 & 666.71 & 502.55 \\
\hline 11 & 440.71 & 504.56 & 49 & 516.71 & 501.88 & 87 & 592.71 & 502.84 & 125 & 668.71 & 502.55 \\
\hline 12 & 442.71 & 504.21 & 50 & 518.71 & 501.94 & 88 & 594.71 & 502.91 & 126 & 670.71 & 502.55 \\
\hline 13 & 444.71 & 503.51 & 51 & 520.71 & 502.01 & 89 & 596.71 & 502.99 & 127 & 672.71 & 502.56 \\
\hline 14 & 446.71 & 503.16 & 52 & 522.71 & 502.07 & 90 & 598.71 & 503.06 & 128 & 674.71 & 502.6 \\
\hline 15 & 448.71 & 502.81 & 53 & 524.71 & 502.13 & 91 & 600.71 & 503.04 & 129 & 676.71 & 502.63 \\
\hline 16 & 450.71 & 502.63 & 54 & 526.71 & 502.18 & 92 & 602.71 & 503.03 & 130 & .71 & 502.67 \\
\hline 17 & 452.71 & 502.46 & 55 & 528.71 & 502.23 & 93 & 604.71 & 503.01 & 131 & 680.71 & 502.71 \\
\hline 18 & 454.71 & 502.12 & 56 & 530.71 & 502.28 & 94 & 606.71 & 502.99 & 132 & 71 & 502.91 \\
\hline 19 & 456.71 & 501.81 & 57 & 532.71 & 502.28 & 95 & 608.71 & 502.95 & 133 & 684.71 & 503.11 \\
\hline 20 & 458.71 & 501.5 & 58 & 534.71 & 502.28 & 96 & 610.71 & 502.92 & 134 & 686.71 & 503.31 \\
\hline 21 & 460.71 & 501.27 & 59 & 536.71 & 502.28 & 97 & 612.71 & 502.88 & 135 & 688.71 & 502.3 \\
\hline 22 & 462.71 & 501.03 & 60 & 538.71 & 502.29 & 98 & 614.71 & 502.85 & 136 & 690.71 & 503.29 \\
\hline 23 & 464.71 & 500.8 & 61 & 540.71 & 502.28 & 99 & 616.71 & 502.87 & 137 & 692.71 & 503.29 \\
\hline 24 & 466.71 & 500.63 & 62 & 542.71 & 502.27 & 100 & 618.71 & 502.9 & 138 & 694.71 & 503.29 \\
\hline 25 & 468.71 & 500.45 & 63 & 544.71 & 502.27 & 101 & 620.71 & 502.92 & 139 & 696.71 & 503.28 \\
\hline 26 & 470.71 & 500.28 & 64 & 546.71 & 502.26 & 102 & 622.71 & 502.94 & 140 & 698.71 & 503.67 \\
\hline 27 & 472.71 & 500.29 & 65 & 548.71 & 502.29 & 103 & 624.71 & 503.01 & 141 & 700.71 & 504.06 \\
\hline 28 & 474.71 & 500.29 & 66 & 550.71 & 502.33 & 104 & 626.71 & 503.08 & 142 & 702.71 & 504.45 \\
\hline 29 & 476.71 & 500.29 & 67 & 552.71 & 502.36 & 105 & 628.71 & 503.27 & 143 & 704.71 & 504.88 \\
\hline 30 & 478.71 & 500.31 & 68 & 554.71 & 502.41 & 106 & 630.71 & 503.22 & 144 & 715.65 & 507.02 \\
\hline 31 & 480.71 & 500.36 & 69 & 556.71 & 502.46 & 107 & 632.71 & 503.17 & 145 & 721.23 & 508.53 \\
\hline 32 & 482.71 & 500.4 & 70 & 558.71 & 502.52 & 108 & 634.71 & 503.12 & 146 & 726.86 & 510.57 \\
\hline 33 & 484.71 & 500.46 & 71 & 560.71 & 502.57 & 109 & 636.71 & 503.07 & 147 & 764.98 & 510.79 \\
\hline 34 & 486.71 & 500.38 & 72 & 562.71 & 502.54 & 110 & 638.71 & 503 & 148 & 820.34 & 510.15 \\
\hline 35 & 488.71 & 500.31 & 73 & 564.71 & 502.51 & 111 & 640.71 & 502.94 & 149 & 970.23 & 510.03 \\
\hline 36 & 490.71 & 500.65 & 74 & 566.71 & 502.48 & 112 & 642.71 & 502.87 & 150 & 1110.15 & 521 \\
\hline 37 & 492.71 & 500.99 & 75 & 568.71 & 502.45 & 113 & 644.71 & 502.85 & . & 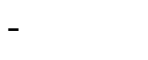 & . \\
\hline 38 & 494.71 & 501.33 & 76 & 570.71 & 502.47 & 114 & 646.71 & 502.84 & - & - & - \\
\hline
\end{tabular}


Tabela 58 - Características Geométricas da Seção SF127210 do Rio São Francisco - Parte I

\begin{tabular}{ccc|ccc|ccc}
\hline \hline $\mathrm{n}^{\mathbf{o}}$ & $\mathrm{h}(\mathrm{m})$ & $\mathrm{z}(\mathrm{m})$ & $\mathrm{n}^{\mathbf{o}}$ & $\mathrm{h}(\mathrm{m})$ & $\mathrm{z}(\mathrm{m})$ & $\mathrm{n}^{\mathbf{o}}$ & $\mathrm{h}(\mathrm{m})$ & $\mathrm{z}(\mathrm{m})$ \\
\hline 1 & 0 & 521.73 & 37 & 1084 & 503.81 & 73 & 1162 & 501.81 \\
2 & 83 & 520.54 & 38 & 1086 & 504.14 & 74 & 1164 & 501.8 \\
3 & 195 & 520.11 & 39 & 1092 & 506.71 & 75 & 1166 & 501.76 \\
4 & 299 & 519.83 & 40 & 1095 & 507.94 & 76 & 1168 & 501.72 \\
5 & 337 & 518.95 & 41 & 1098 & 507.88 & 77 & 1170 & 501.71 \\
6 & 355 & 518.92 & 42 & 1102 & 505.36 & 78 & 1172 & 501.75 \\
7 & 400 & 517.28 & 43 & 1103 & 504.22 & 79 & 1174 & 501.78 \\
8 & 445 & 514.88 & 44 & 1103.66 & 504.24 & 80 & 1176 & 501.81 \\
9 & 487 & 512.53 & 45 & 1106 & 504.22 & 81 & 1178 & 501.74 \\
10 & 547 & 510.74 & 46 & 1108 & 504.19 & 82 & 1180 & 501.66 \\
11 & 558 & 510.85 & 47 & 1110 & 503.79 & 83 & 1182 & 501.6 \\
12 & 607 & 510.75 & 48 & 1112 & 503.28 & 84 & 1184 & 501.61 \\
13 & 658 & 510.86 & 49 & 1114 & 502.8 & 85 & 1186 & 501.62 \\
14 & 708 & 511.59 & 50 & 1116 & 502.31 & 86 & 1188 & 501.63 \\
15 & 759 & 511.79 & 51 & 1118 & 501.83 & 87 & 1190 & 501.58 \\
16 & 810 & 511.44 & 52 & 1120 & 501.97 & 88 & 1192 & 501.5 \\
17 & 860 & 511.77 & 53 & 1122 & 502.1 & 89 & 1194 & 501.43 \\
18 & 910 & 504.24 & 54 & 1124 & 502.17 & 90 & 1196 & 501.36 \\
19 & 915 & 502.29 & 55 & 1126 & 502.19 & 91 & 1198 & 501.28 \\
20 & 921 & 502.02 & 56 & 1128 & 502.24 & 92 & 1200 & 501.19 \\
21 & 927 & 502.13 & 57 & 1130 & 502.29 & 93 & 1202 & 501.06 \\
22 & 934 & 502.07 & 58 & 1132 & 502.35 & 94 & 1204 & 500.88 \\
23 & 944 & 501.76 & 59 & 1134 & 502.22 & 95 & 1206 & 500.81 \\
24 & 953 & 501.9 & 60 & 1136 & 502.08 & 96 & 1208 & 500.75 \\
25 & 964 & 502.39 & 61 & 1138 & 501.87 & 97 & 1210 & 500.69 \\
26 & 971 & 502.45 & 62 & 1140 & 501.68 & 98 & 1212 & 500.64 \\
27 & 978 & 504.24 & 63 & 1142 & 501.71 & 99 & 1214 & 500.65 \\
28 & 983 & 504.24 & 64 & 1144 & 501.74 & 100 & 1216 & 500.67 \\
29 & 995 & 504.33 & 65 & 1146 & 501.67 & 101 & 1218 & 500.68 \\
30 & 1005 & 504.38 & 66 & 1148 & 501.63 & 102 & 1220 & 500.69 \\
31 & 1020 & 504.34 & 67 & 1150 & 501.66 & 103 & 1222 & 500.7 \\
32 & 1035 & 504 & 68 & 1152 & 501.68 & 104 & 1224 & 500.72 \\
33 & 1058 & 504.14 & 69 & 1154 & 501.71 & 105 & 1226 & 500.73 \\
34 & 1066 & 503.78 & 70 & 1156 & 501.75 & 106 & 1228 & 500.74 \\
35 & 1073 & 503.9 & 71 & 1158 & 501.79 & 107 & 1230 & 500.76 \\
36 & 1079 & 503.74 & 72 & 1160 & 501.81 & 108 & 1232 & 500.73 \\
\hline \hline & & & & & & & &
\end{tabular}


Tabela 59 - Características Geométricas da Seção SF127210 do Rio São Francisco - Parte II

\begin{tabular}{ccc|ccc|ccc}
\hline \hline $\mathrm{n}^{\mathrm{o}}$ & $\mathrm{h}(\mathrm{m})$ & $\mathrm{z}(\mathrm{m})$ & $\mathrm{n}^{\mathrm{o}}$ & $\mathrm{h}(\mathrm{m})$ & $\mathrm{z}(\mathrm{m})$ & $\mathrm{n}^{\mathrm{o}}$ & $\mathrm{h}(\mathrm{m})$ & $\mathrm{z}(\mathrm{m})$ \\
\hline 109 & 1234 & 500.61 & 144 & 1304 & 502.44 & 179 & 1374 & 503.39 \\
110 & 1236 & 500.5 & 145 & 1306 & 502.64 & 180 & 1376 & 503.37 \\
111 & 1238 & 500.39 & 146 & 1308 & 502.93 & 181 & 1378 & 503.32 \\
112 & 1240 & 500.28 & 147 & 1310 & 503 & 182 & 1380 & 503.26 \\
113 & 1242 & 500.17 & 148 & 1312 & 502.7 & 183 & 1382 & 503.2 \\
114 & 1244 & 500.06 & 149 & 1314 & 502.39 & 184 & 1384 & 503.23 \\
115 & 1246 & 499.95 & 150 & 1316 & 502.45 & 185 & 1386 & 503.29 \\
116 & 1248 & 499.85 & 151 & 1318 & 502.52 & 186 & 1388 & 503.36 \\
117 & 1250 & 499.86 & 152 & 1320 & 502.58 & 187 & 1390 & 503.43 \\
118 & 1252 & 499.87 & 153 & 1322 & 502.64 & 188 & 1392 & 503.4 \\
119 & 1254 & 499.88 & 154 & 1324 & 502.71 & 189 & 1394 & 503.38 \\
120 & 1256 & 499.89 & 155 & 1326 & 502.8 & 190 & 1396 & 503.35 \\
121 & 1258 & 499.91 & 156 & 1328 & 502.89 & 191 & 1398 & 503.34 \\
122 & 1260 & 499.92 & 157 & 1330 & 502.98 & 192 & 1400 & 503.41 \\
123 & 1262 & 499.93 & 158 & 1332 & 503.07 & 193 & 1402 & 503.47 \\
124 & 1264 & 500.03 & 159 & 1334 & 503.09 & 194 & 1404 & 503.54 \\
125 & 1266 & 500.23 & 160 & 1336 & 503.05 & 195 & 1406 & 503.44 \\
126 & 1268 & 500.42 & 161 & 1338 & 503.02 & 196 & 1408 & 503.35 \\
127 & 1270 & 500.61 & 162 & 1340 & 502.98 & 197 & 1410 & 503.25 \\
128 & 1272 & 500.61 & 163 & 1342 & 502.95 & 198 & 1412 & 503.17 \\
129 & 1274 & 500.61 & 164 & 1344 & 502.96 & 199 & 1414 & 503.53 \\
130 & 1276 & 500.71 & 165 & 1346 & 503.03 & 200 & 1416 & 503.89 \\
131 & 1278 & 500.97 & 166 & 1348 & 503.1 & 201 & 1418 & 504.22 \\
132 & 1280 & 501.21 & 167 & 1350 & 503.17 & 202 & 1425.35 & 505.5 \\
133 & 1282 & 501.45 & 168 & 1352 & 503.22 & 203 & 1436.79 & 506.55 \\
134 & 1284 & 501.62 & 169 & 1354 & 503.26 & 204 & 1445.52 & 507.71 \\
135 & 1286 & 501.68 & 170 & 1356 & 503.3 & 205 & 1452.59 & 510.11 \\
136 & 1288 & 501.73 & 171 & 1358 & 503.34 & 206 & 1458.47 & 512.59 \\
137 & 1290 & 501.78 & 172 & 1360 & 503.35 & 207 & 1461.49 & 514.62 \\
138 & 1292 & 501.83 & 173 & 1362 & 503.35 & 208 & 1469.13 & 516.5 \\
139 & 1294 & 501.99 & 174 & 1364 & 503.34 & 209 & 1476.32 & 518.11 \\
140 & 1296 & 502.2 & 175 & 1366 & 503.34 & 210 & 1485.27 & 519.96 \\
141 & 1298 & 502.4 & 176 & 1368 & 503.35 & 211 & 1494.31 & 521.77 \\
142 & 1300 & 502.59 & 177 & 1370 & 503.36 & - & - & - \\
143 & 1302 & 502.71 & 178 & 1372 & 503.38 & - & - & - \\
\hline \hline & & & & & & & & \\
113
\end{tabular}


Tabela 60 - Características Geométricas da Seção SF127190 do Rio São Francisco - Parte I

\begin{tabular}{ccc|ccc|ccc}
\hline \hline $\mathrm{n}^{\mathbf{o}}$ & $\mathrm{h}(\mathrm{m})$ & $\mathrm{z}(\mathrm{m})$ & $\mathrm{n}^{\mathbf{o}}$ & $\mathrm{h}(\mathrm{m})$ & $\mathrm{z}(\mathrm{m})$ & $\mathrm{n}^{\mathbf{o}}$ & $\mathrm{h}(\mathrm{m})$ & $\mathrm{z}(\mathrm{m})$ \\
\hline 1 & 0 & 521.73 & 37 & 1084 & 503.81 & 73 & 1162 & 501.81 \\
2 & 83 & 520.54 & 38 & 1086 & 504.14 & 74 & 1164 & 501.8 \\
3 & 195 & 520.11 & 39 & 1092 & 506.71 & 75 & 1166 & 501.76 \\
4 & 299 & 519.83 & 40 & 1095 & 507.94 & 76 & 1168 & 501.72 \\
5 & 337 & 518.95 & 41 & 1098 & 507.88 & 77 & 1170 & 501.71 \\
6 & 355 & 518.92 & 42 & 1102 & 505.36 & 78 & 1172 & 501.75 \\
7 & 400 & 517.28 & 43 & 1103 & 504.22 & 79 & 1174 & 501.78 \\
8 & 445 & 514.88 & 44 & 1103.66 & 504.24 & 80 & 1176 & 501.81 \\
9 & 487 & 512.53 & 45 & 1106 & 504.22 & 81 & 1178 & 501.74 \\
10 & 547 & 510.74 & 46 & 1108 & 504.19 & 82 & 1180 & 501.66 \\
11 & 558 & 510.85 & 47 & 1110 & 503.79 & 83 & 1182 & 501.6 \\
12 & 607 & 510.75 & 48 & 1112 & 503.28 & 84 & 1184 & 501.61 \\
13 & 658 & 510.86 & 49 & 1114 & 502.8 & 85 & 1186 & 501.62 \\
14 & 708 & 511.59 & 50 & 1116 & 502.31 & 86 & 1188 & 501.63 \\
15 & 759 & 511.79 & 51 & 1118 & 501.83 & 87 & 1190 & 501.58 \\
16 & 810 & 511.44 & 52 & 1120 & 501.97 & 88 & 1192 & 501.5 \\
17 & 860 & 511.77 & 53 & 1122 & 502.1 & 89 & 1194 & 501.43 \\
18 & 910 & 504.24 & 54 & 1124 & 502.17 & 90 & 1196 & 501.36 \\
19 & 915 & 502.29 & 55 & 1126 & 502.19 & 91 & 1198 & 501.28 \\
20 & 921 & 502.02 & 56 & 1128 & 502.24 & 92 & 1200 & 501.19 \\
21 & 927 & 502.13 & 57 & 1130 & 502.29 & 93 & 1202 & 501.06 \\
22 & 934 & 502.07 & 58 & 1132 & 502.35 & 94 & 1204 & 500.88 \\
23 & 944 & 501.76 & 59 & 1134 & 502.22 & 95 & 1206 & 500.81 \\
24 & 953 & 501.9 & 60 & 1136 & 502.08 & 96 & 1208 & 500.75 \\
25 & 964 & 502.39 & 61 & 1138 & 501.87 & 97 & 1210 & 500.69 \\
26 & 971 & 502.45 & 62 & 1140 & 501.68 & 98 & 1212 & 500.64 \\
27 & 978 & 504.24 & 63 & 1142 & 501.71 & 99 & 1214 & 500.65 \\
28 & 983 & 504.24 & 64 & 1144 & 501.74 & 100 & 1216 & 500.67 \\
29 & 995 & 504.33 & 65 & 1146 & 501.67 & 101 & 1218 & 500.68 \\
30 & 1005 & 504.38 & 66 & 1148 & 501.63 & 102 & 1220 & 500.69 \\
31 & 1020 & 504.34 & 67 & 1150 & 501.66 & 103 & 1222 & 500.7 \\
32 & 1035 & 504 & 68 & 1152 & 501.68 & 104 & 1224 & 500.72 \\
33 & 1058 & 504.14 & 69 & 1154 & 501.71 & 105 & 1226 & 500.73 \\
34 & 1066 & 503.78 & 70 & 1156 & 501.75 & 106 & 1228 & 500.74 \\
35 & 1073 & 503.9 & 71 & 1158 & 501.79 & 107 & 1230 & 500.76 \\
36 & 1079 & 503.74 & 72 & 1160 & 501.81 & 108 & 1232 & 500.73 \\
\hline \hline & & & & & & & &
\end{tabular}


Tabela 61 - Características Geométricas da Seção SF127190 do Rio São Francisco - Parte II

\begin{tabular}{ccc|ccc|ccc}
\hline \hline $\mathrm{n}^{\mathrm{o}}$ & $\mathrm{h}(\mathrm{m})$ & $\mathrm{z}(\mathrm{m})$ & $\mathrm{n}^{\mathrm{o}}$ & $\mathrm{h}(\mathrm{m})$ & $\mathrm{z}(\mathrm{m})$ & $\mathrm{n}^{\mathrm{o}}$ & $\mathrm{h}(\mathrm{m})$ & $\mathrm{z}(\mathrm{m})$ \\
\hline 109 & 1234 & 500.61 & 144 & 1304 & 502.44 & 179 & 1374 & 503.39 \\
110 & 1236 & 500.5 & 145 & 1306 & 502.64 & 180 & 1376 & 503.37 \\
111 & 1238 & 500.39 & 146 & 1308 & 502.93 & 181 & 1378 & 503.32 \\
112 & 1240 & 500.28 & 147 & 1310 & 503 & 182 & 1380 & 503.26 \\
113 & 1242 & 500.17 & 148 & 1312 & 502.7 & 183 & 1382 & 503.2 \\
114 & 1244 & 500.06 & 149 & 1314 & 502.39 & 184 & 1384 & 503.23 \\
115 & 1246 & 499.95 & 150 & 1316 & 502.45 & 185 & 1386 & 503.29 \\
116 & 1248 & 499.85 & 151 & 1318 & 502.52 & 186 & 1388 & 503.36 \\
117 & 1250 & 499.86 & 152 & 1320 & 502.58 & 187 & 1390 & 503.43 \\
118 & 1252 & 499.87 & 153 & 1322 & 502.64 & 188 & 1392 & 503.4 \\
119 & 1254 & 499.88 & 154 & 1324 & 502.71 & 189 & 1394 & 503.38 \\
120 & 1256 & 499.89 & 155 & 1326 & 502.8 & 190 & 1396 & 503.35 \\
121 & 1258 & 499.91 & 156 & 1328 & 502.89 & 191 & 1398 & 503.34 \\
122 & 1260 & 499.92 & 157 & 1330 & 502.98 & 192 & 1400 & 503.41 \\
123 & 1262 & 499.93 & 158 & 1332 & 503.07 & 193 & 1402 & 503.47 \\
124 & 1264 & 500.03 & 159 & 1334 & 503.09 & 194 & 1404 & 503.54 \\
125 & 1266 & 500.23 & 160 & 1336 & 503.05 & 195 & 1406 & 503.44 \\
126 & 1268 & 500.42 & 161 & 1338 & 503.02 & 196 & 1408 & 503.35 \\
127 & 1270 & 500.61 & 162 & 1340 & 502.98 & 197 & 1410 & 503.25 \\
128 & 1272 & 500.61 & 163 & 1342 & 502.95 & 198 & 1412 & 503.17 \\
129 & 1274 & 500.61 & 164 & 1344 & 502.96 & 199 & 1414 & 503.53 \\
130 & 1276 & 500.71 & 165 & 1346 & 503.03 & 200 & 1416 & 503.89 \\
131 & 1278 & 500.97 & 166 & 1348 & 503.1 & 201 & 1418 & 504.22 \\
132 & 1280 & 501.21 & 167 & 1350 & 503.17 & 202 & 1425.35 & 505.5 \\
133 & 1282 & 501.45 & 168 & 1352 & 503.22 & 203 & 1436.79 & 506.55 \\
134 & 1284 & 501.62 & 169 & 1354 & 503.26 & 204 & 1445.52 & 507.71 \\
135 & 1286 & 501.68 & 170 & 1356 & 503.3 & 205 & 1452.59 & 510.11 \\
136 & 1288 & 501.73 & 171 & 1358 & 503.34 & 206 & 1458.47 & 512.59 \\
137 & 1290 & 501.78 & 172 & 1360 & 503.35 & 207 & 1461.49 & 514.62 \\
138 & 1292 & 501.83 & 173 & 1362 & 503.35 & 208 & 1469.13 & 516.5 \\
139 & 1294 & 501.99 & 174 & 1364 & 503.34 & 209 & 1476.32 & 518.11 \\
140 & 1296 & 502.2 & 175 & 1366 & 503.34 & 210 & 1485.27 & 519.96 \\
141 & 1298 & 502.4 & 176 & 1368 & 503.35 & 211 & 1494.31 & 521.77 \\
142 & 1300 & 502.59 & 177 & 1370 & 503.36 & - & - & - \\
143 & 1302 & 502.71 & 178 & 1372 & 503.38 & - & - & - \\
\hline \hline & & & & & & & & \\
113
\end{tabular}


Tabela 62 - Características Geométricas da Seção SF122100 do Rio São Francisco

\begin{tabular}{|c|c|c|c|c|c|c|c|c|c|c|c|}
\hline$\overline{n^{\circ}}$ & $\overline{\mathrm{h}(\mathrm{m})}$ & $\overline{\mathrm{z}(\mathrm{m})}$ & $\overline{n^{\circ}}$ & $\overline{\mathrm{h}(\mathrm{m})}$ & $\overline{\mathrm{z}(\mathrm{m})}$ & $\overline{n^{\circ}}$ & $\overline{\mathrm{h}(\mathrm{m})}$ & $\overline{z z(m)}$ & $\overline{\mathrm{n}^{\circ}}$ & $\overline{\mathrm{h}(\mathrm{m})}$ & $\overline{z z(m)}$ \\
\hline 1 & 0 & 523.83 & 43 & 619 & 501.21 & 85 & 703 & 499.24 & 127 & 787 & 498.71 \\
\hline 2 & 3 & 523.23 & 44 & 621 & 501.22 & 86 & 705 & 499.18 & 128 & 789 & 498.9 \\
\hline 3 & 8 & 523.73 & 45 & 623 & 501.24 & 87 & 707 & 499.12 & 129 & 791 & 499.05 \\
\hline 4 & 69 & 521.15 & 46 & 625 & 501.26 & 88 & 709 & 499.06 & 130 & 793 & 499.19 \\
\hline 5 & 109 & 519.02 & 47 & 627 & 501.29 & 89 & 711 & 499 & 131 & 795 & 499.33 \\
\hline 6 & 160 & 515.94 & 48 & 629 & 501.31 & 90 & 713 & 498.94 & 132 & 797 & 499.47 \\
\hline 7 & 210 & 512.43 & 49 & 631 & 501.34 & 91 & 715 & 498.88 & 133 & 799 & 499.61 \\
\hline 8 & 261 & 509.27 & 50 & 633 & 501.36 & 92 & 717 & 498.82 & 134 & 801 & 499.63 \\
\hline 9 & 311 & 508.31 & 51 & 635 & 501.38 & 93 & 719 & 498.76 & 135 & 803 & 499.65 \\
\hline 10 & 362 & 508.72 & 52 & 637 & 501.4 & 94 & 721 & 498.7 & 136 & 805 & 499.67 \\
\hline 11 & 412 & 508.26 & 53 & 639 & 501.42 & 95 & 723 & 498.64 & 137 & 807 & 499.68 \\
\hline 12 & 462 & 510.74 & 54 & 641 & 501.44 & 96 & 725 & 498.58 & 138 & 809 & 499.7 \\
\hline 13 & 512 & 511.15 & 55 & 643 & 501.38 & 97 & 727 & 498.53 & 139 & 811 & 499.72 \\
\hline 14 & 561.28 & 503.6 & 56 & 645 & 501.3 & 98 & 729 & 498.51 & 140 & 813 & 499.83 \\
\hline 15 & 562 & 503.59 & 57 & 647 & 501.23 & 99 & 731 & 498.48 & 141 & 815 & 499.98 \\
\hline 16 & 565 & 502.09 & 58 & 649 & 501.16 & 100 & 733 & 498.46 & 142 & 817 & 500.14 \\
\hline 17 & 567 & 501.51 & 59 & 651 & 501.11 & 101 & 735 & 498.44 & 143 & 819 & 500.3 \\
\hline 18 & 569 & 501.3 & 60 & 653 & 501.08 & 102 & 737 & 498.42 & 144 & 821 & 500.52 \\
\hline 19 & 571 & 501.25 & 61 & 655 & 501.04 & 103 & 739 & 498.33 & 145 & 823 & 500.89 \\
\hline 20 & 573 & 501.3 & 62 & 657 & 501.01 & 104 & 741 & 498.23 & 146 & 825 & 501.27 \\
\hline 21 & 575 & 501.35 & 63 & 659 & 500.98 & 105 & 743 & 498.12 & 147 & 827 & 501.65 \\
\hline 22 & 577 & 501.4 & 64 & 661 & 500.92 & 106 & 745 & 498.02 & 148 & 829 & 502.14 \\
\hline 23 & 579 & 501.33 & 65 & 663 & 500.82 & 107 & 747 & 497.92 & 149 & 831 & 502.9 \\
\hline 24 & 581 & 501.13 & 66 & 665 & 500.72 & 108 & 749 & 497.94 & 150 & 833 & 503.59 \\
\hline 25 & 583 & 500.94 & 67 & 667 & 500.61 & 109 & 751 & 497.97 & 151 & 838.67 & 506.17 \\
\hline 26 & 585 & 500.98 & 68 & 669 & 500.51 & 110 & 753 & 498 & 152 & 843.38 & 507.86 \\
\hline 27 & 587 & 501.01 & 69 & 671 & 500.41 & 111 & 755 & 498.03 & 153 & 852.59 & 509.27 \\
\hline 28 & 589 & 501.05 & 70 & 673 & 500.32 & 112 & 757 & 498.07 & 154 & 863.05 & 509.27 \\
\hline 29 & 591 & 501.07 & 71 & 675 & 500.24 & 113 & 759 & 498.1 & 155 & 876.92 & 509.88 \\
\hline 30 & 593 & 501.07 & 72 & 677 & 500.15 & 114 & 761 & 498.15 & 156 & 888.18 & 510.31 \\
\hline 31 & 595 & 501.06 & 73 & 679 & 500.07 & 115 & 763 & 498.21 & 157 & 896.31 & 510.69 \\
\hline 32 & 597 & 501.05 & 74 & 681 & 499.98 & 116 & 765 & 498.27 & 158 & 905.98 & 511.15 \\
\hline 33 & 599 & 501.04 & 75 & 683 & 499.91 & 117 & 767 & 498.34 & 159 & 917.85 & 512.06 \\
\hline 34 & 601 & 501.07 & 76 & 685 & 499.84 & 118 & 769 & 498.4 & 160 & 933.87 & 513.11 \\
\hline 35 & 603 & 501.1 & 77 & 687 & 499.77 & 119 & 771 & 498.33 & 161 & 940.93 & 513.61 \\
\hline 36 & 605 & 501.14 & 78 & 689 & 499.7 & 120 & 773 & 498.23 & 162 & 947.34 & 514.1 \\
\hline 37 & 607 & 501.14 & 79 & 691 & 499.63 & 121 & 775 & 498.14 & 163 & 956.11 & 514.85 \\
\hline 38 & 609 & 501.14 & 80 & 693 & 499.56 & 122 & 777 & 498.05 & 164 & 977.9 & 516.99 \\
\hline 39 & 611 & 501.14 & 81 & 695 & 499.5 & 123 & 779 & 497.96 & 165 & 983 & 517.66 \\
\hline 40 & 613 & 501.16 & 82 & 697 & 499.43 & 124 & 781 & 498.13 & 166 & 998 & 519.13 \\
\hline 41 & 615 & 501.17 & 83 & 699 & 499.37 & 125 & 783 & 498.32 & - & - & - \\
\hline 42 & 617 & 501.19 & 84 & 701 & 499.31 & 126 & 785 & 498.52 & - & - & - \\
\hline
\end{tabular}


Tabela 63 - Características Geométricas da Seção SF118800 do Rio São Francisco

\begin{tabular}{|c|c|c|c|c|c|c|c|c|}
\hline$\overline{n^{\circ}}$ & $\overline{\mathrm{h}(\mathrm{m})}$ & $\overline{\mathrm{z}(\mathrm{m})}$ & $\overline{\mathrm{n}^{\mathrm{o}}}$ & $\overline{\mathrm{h}(\mathrm{m})}$ & $\bar{z} \mathrm{z}(\mathrm{m})$ & $\overline{\mathrm{n}^{\mathrm{o}}}$ & $\overline{\mathrm{h}(\mathrm{m})}$ & $\overline{z \mathrm{z}(\mathrm{m})}$ \\
\hline 1 & 0 & 515.76 & 45 & 1091 & 496.88 & 89 & 1179 & 497.36 \\
\hline 2 & 19 & 514.69 & 46 & 1093 & 496.88 & 90 & 1181 & 497.23 \\
\hline 3 & 66 & 512.93 & 47 & 1095 & 496.84 & 91 & 1183 & 497.11 \\
\hline 4 & 119 & 510.92 & 48 & 1097 & 496.78 & 92 & 1185 & 496.99 \\
\hline 5 & 169 & 508.04 & 49 & 1099 & 496.73 & 93 & 1187 & 496.87 \\
\hline 6 & 219 & 507.06 & 50 & 1101 & 496.68 & 94 & 1189 & 496.75 \\
\hline 7 & 279 & 506.79 & 51 & 1103 & 496.68 & 95 & 1191 & 496.62 \\
\hline 8 & 319 & 507.06 & 52 & 1105 & 496.68 & 96 & 1193 & 496.5 \\
\hline 9 & 379 & 506.75 & 53 & 1107 & 496.68 & 97 & 1195 & 496.38 \\
\hline 10 & 441 & 506.57 & 54 & 1109 & 496.67 & 98 & 1197 & 496.22 \\
\hline 11 & 503 & 506.81 & 55 & 1111 & 496.63 & 99 & 1199 & 496.06 \\
\hline 12 & 558 & 505.81 & 56 & 1113 & 496.6 & 100 & 1201 & 495.91 \\
\hline 13 & 603 & 505.12 & 57 & 1115 & 496.41 & 101 & 1203 & 495.89 \\
\hline 14 & 658 & 507.14 & 58 & 1117 & 496.19 & 102 & 1205 & 495.89 \\
\hline 15 & 703 & 507.29 & 59 & 1119 & 496.14 & 103 & 1207 & 495.88 \\
\hline 16 & 758 & 506.52 & 60 & 1121 & 496.37 & 104 & 1209 & 495.88 \\
\hline 17 & 818 & 507.09 & 61 & 1123 & 496.88 & 105 & 1211 & 495.87 \\
\hline 18 & 868 & 506.43 & 62 & 1125 & 496.8 & 106 & 1213 & 495.86 \\
\hline 19 & 923 & 508.25 & 63 & 1127 & 496.73 & 107 & 1215 & 496.18 \\
\hline 20 & 983 & 506.02 & 64 & 1129 & 496.42 & 108 & 1217 & 496.49 \\
\hline 21 & 1043 & 501.38 & 65 & 1131 & 497.04 & 109 & 1219 & 496.75 \\
\hline 22 & 1045 & 501.12 & 66 & 1133 & 497.71 & 110 & 1221 & 497.02 \\
\hline 23 & 1047 & 500.92 & 67 & 1135 & 497.56 & 111 & 1223 & 497.29 \\
\hline 24 & 1049 & 499.77 & 68 & 1137 & 497.12 & 112 & 1225 & 497.55 \\
\hline 25 & 1051 & 498.04 & 69 & 1139 & 496.68 & 113 & 1227 & 497.82 \\
\hline 26 & 1053 & 497.68 & 70 & 1141 & 496.46 & 114 & 1229 & 498.07 \\
\hline 27 & 1055 & 497.47 & 71 & 1143 & 496.69 & 115 & 1231 & 498.31 \\
\hline 28 & 1057 & 497.33 & 72 & 1145 & 496.91 & 116 & 1233 & 498.55 \\
\hline 29 & 1059 & 497.31 & 73 & 1147 & 496.91 & 117 & 1235 & 498.8 \\
\hline 30 & 1061 & 497.38 & 74 & 1149 & 496.91 & 118 & 1237 & 499.22 \\
\hline 31 & 1063 & 497.44 & 75 & 1151 & 496.91 & 119 & 1239 & 499.69 \\
\hline 32 & 1065 & 497.32 & 76 & 1153 & 496.9 & 120 & 1241 & 500.23 \\
\hline 33 & 1067 & 496.93 & 77 & 1155 & 497 & 121 & 1243 & 500.81 \\
\hline 34 & 1069 & 497.75 & 78 & 1157 & 497.13 & 122 & 1245 & 501.38 \\
\hline 35 & 1071 & 497.56 & 79 & 1159 & 497.27 & 123 & 1252.71 & 505.22 \\
\hline 36 & 1073 & 497.3 & 80 & 1161 & 497.4 & 124 & 1258.12 & 506.65 \\
\hline 37 & 1075 & 497.05 & 81 & 1163 & 497.53 & 125 & 1275.21 & 508.89 \\
\hline 38 & 1077 & 496.84 & 82 & 1165 & 497.66 & 126 & 1290.56 & 511.05 \\
\hline 39 & 1079 & 496.74 & 83 & 1167 & 497.79 & 127 & 1322.12 & 512.91 \\
\hline 40 & 1081 & 496.65 & 84 & 1169 & 497.92 & 128 & 1340.37 & 514.42 \\
\hline 41 & 1083 & 496.62 & 85 & 1171 & 497.84 & 129 & 1355.11 & 515.81 \\
\hline 42 & 1085 & 496.73 & 86 & 1173 & 497.72 & 130 & 1370.21 & 517.11 \\
\hline 43 & 1087 & 496.84 & 87 & 1175 & 497.6 & 131 & 1378 & 517.63 \\
\hline 44 & 1089 & 496.88 & 88 & 1177 & 497.48 & - & - & - \\
\hline
\end{tabular}


Tabela 64 - Características Geométricas da Seção SF116400 do Rio São Francisco

\begin{tabular}{|c|c|c|c|c|c|c|c|c|}
\hline $\mathrm{n}^{\mathrm{o}}$ & $\mathrm{h}(\mathrm{m})$ & $\mathrm{z}(\mathrm{m})$ & $\mathrm{n}^{\circ}$ & $\mathrm{h}(\mathrm{m})$ & $\mathrm{z}(\mathrm{m})$ & 11 & $\mathrm{~h}(\mathrm{~m})$ & $\mathrm{z}(\mathrm{m})$ \\
\hline 1 & 0 & 120 & 47 & & & 02 & & $\tau$ \\
\hline 2 & 5 & & & & & & & \\
\hline 3 & & & & & & & & \\
\hline 4 & 0 & & & & & & & \\
\hline 5 & 248.09 & & & 政 & & 97 & & \\
\hline 6 & 31 & & & 96 & 41 & & & \\
\hline 7 & & & & & & 99 & & \\
\hline 0 & 4 & & & 0 & & & & \\
\hline 9 & & & & & & & & \\
\hline 10 & 5.59 & & 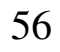 & 30.96 & & & & 496.69 \\
\hline 1 & 4 & & & & & & & \\
\hline 12 & 644.77 & & & & & & & 497.02 \\
\hline 1. & 1.26 & & & & & & & נונותד \\
\hline 14 & 1 & & & & & & & \\
\hline 15 & & & & & & & & 497.02 \\
\hline 10 & & & & & & & & \\
\hline 17 & $\mathrm{r} J$ & & 6 & 6 & & & & 35 \\
\hline 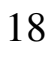 & & & & & & & & \\
\hline 19 & & & & & & & & \\
\hline 20 & & & & & & & & \\
\hline 21 & & & & & & & & \\
\hline 2 & & & & & & & & \\
\hline 23 & & & & & & & & \\
\hline 2 & & & & & & & & \\
\hline & & & & & & & & \\
\hline 20 & & & & & & & & \\
\hline & & & & & & & & \\
\hline 2 & & & & & & & & \\
\hline 2 & & & & & & & & \\
\hline 30 & & & & & & & & \\
\hline 3 & & & & & & & & \\
\hline 32 & & & & & & & & \\
\hline 33 & & & & & & & & \\
\hline 3 & & & & & & & & \\
\hline 35 & & & & & & & & \\
\hline 36 & & & & & & & & 497.65 \\
\hline 37 & & & & & & & & \\
\hline 38 & & & & & & & & 499.98 \\
\hline 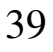 & & & & & & & & \\
\hline 40 & & & & & & & & \\
\hline 4 & & & & & & & & .13 \\
\hline 42 & & & & & & & & 507.08 \\
\hline 43 & & & & & & 13 & & 508.38 \\
\hline . & & & & & & & & \\
\hline 45 & & & 9 & & & 137 & 1630.6 & 516.01 \\
\hline 46 & 0.96 & & 92 & 13 & & & & 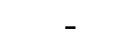 \\
\hline
\end{tabular}


Tabela 65 - Características Geométricas da Seção SF111700 do Rio São Francisco

\begin{tabular}{|c|c|c|c|c|c|c|c|c|c|c|c|}
\hline$\overline{\mathrm{n}^{\circ}}$ & $\overline{\mathrm{h}(\mathrm{m})}$ & $\overline{z z(m)}$ & $\overline{n^{\circ}}$ & $\overline{\mathrm{h}(\mathrm{m})}$ & $\mathrm{z}(\mathrm{m})$ & $\overline{n^{\circ}}$ & $\mathrm{h}(\mathrm{m})$ & $\mathrm{z}(\mathrm{m})$ & $\overline{\bar{n}} \mathrm{n}^{\circ}$ & $\bar{~} \overline{h(m)}$ & $\mathrm{z}(\mathrm{m})$ \\
\hline 1 & 0 & 513.61 & 47 & 998.22 & 495.36 & 93 & 1090.22 & 496.68 & 139 & 1182.22 & 496.27 \\
\hline 2 & 25.06 & 513.18 & 48 & 1000.22 & 495.36 & 94 & 1092.22 & 496.65 & 140 & 1184.22 & 496.15 \\
\hline 3 & 51.27 & 512.66 & 49 & 1002.22 & 495.36 & 95 & 1094.22 & 496.62 & 141 & 1186.22 & 496.03 \\
\hline 4 & 63.04 & 512.55 & 50 & 1004.22 & 495.37 & 96 & 1096.22 & 496.59 & 142 & 1188.22 & 495.93 \\
\hline 5 & 74.83 & 512.3 & 51 & 1006.22 & 495.26 & 97 & 1098.22 & 496.56 & 143 & 1190.22 & 495.95 \\
\hline 6 & 86.24 & 512.19 & 52 & 1008.22 & 495.15 & 98 & 1100.22 & 496.55 & 144 & 1192.22 & 495.97 \\
\hline 7 & 115.6 & 511.65 & 53 & 1010.22 & 495.04 & 99 & 1102.22 & 496.55 & 145 & 1194.22 & 496.99 \\
\hline 8 & 145.81 & 511.24 & 54 & 1012.22 & 494.93 & 100 & 1104.22 & 496.55 & 146 & 1196.22 & 496.01 \\
\hline 9 & 175.5 & 510.99 & 55 & 1014.22 & 494.83 & 101 & 1106.22 & 496.55 & 147 & 11 & 496.03 \\
\hline 10 & 201.7 & 510.61 & 56 & 1016.22 & 494.93 & 102 & 1108.22 & 496.54 & 148 & 1200.22 & 496.05 \\
\hline 11 & 225.55 & 510.33 & 57 & 1018.22 & 495.02 & 103 & 1110.22 & 496.54 & 149 & 1202.22 & 496.07 \\
\hline 12 & 238.59 & 510.18 & 58 & 1020.22 & 495.11 & 104 & 1112.22 & 496.58 & 150 & 1204.22 & 496.09 \\
\hline 13 & 266.22 & 509.62 & 59 & 1022.22 & 495.21 & 105 & 1114.22 & 496.42 & 151 & 1206.22 & 496.11 \\
\hline 14 & 304.68 & 509.35 & 60 & 1024.22 & 495.3 & 106 & 1116.22 & 496.66 & 152 & 121 & 496.13 \\
\hline 15 & 342.97 & 509.19 & 61 & 1026.22 & 495.4 & 107 & 1118.22 & 496.7 & 153 & 1210.22 & 496.22 \\
\hline 16 & 356.82 & 509.08 & 62 & 1028.22 & 495.49 & 108 & 112 & 496.73 & 154 & & 496.3 \\
\hline 17 & 370.89 & 508.62 & 63 & 1030.22 & 495.56 & 109 & 1122.22 & 496.77 & 155 & 1214.22 & 496.39 \\
\hline 18 & 410.73 & 508.18 & 64 & 1032.22 & 495.63 & 110 & 112 & 49 & 156 & 12 & 496.47 \\
\hline 19 & 436.72 & 508.18 & 65 & 1034.22 & 495.7 & 111 & 1126.22 & 496.85 & 157 & 121 & 496.56 \\
\hline 20 & 448.47 & 507.92 & 66 & 1036.22 & 495.77 & 112 & 1128.22 & 496.87 & 158 & 122 & 496.64 \\
\hline 21 & 460.57 & 507.43 & 67 & 1038.22 & 495.84 & 113 & 1130.22 & 496.89 & 159 & 122 & 496.76 \\
\hline 22 & 493.73 & 507.09 & 68 & 1040.22 & 495.91 & 114 & 1132.22 & 496.91 & 160 & 1224.22 & 496.87 \\
\hline 23 & 521.37 & 506.53 & 69 & 1042.22 & 496.13 & 115 & 113 & 496.93 & 161 & 12 & 496.99 \\
\hline 24 & 563.49 & 506.05 & 70 & 1044.22 & 496.36 & 116 & 1136.22 & 496.95 & 162 & 1228.22 & 497.1 \\
\hline 25 & 605.12 & 504.32 & 71 & 1046.22 & 496.58 & 117 & 113 & 496.97 & 163 & 12 & 497.12 \\
\hline 26 & 642.38 & 503.93 & 72 & 1048.22 & 496.81 & 118 & 1140.22 & 497.98 & 164 & 1232.22 & 497.22 \\
\hline 27 & 666.56 & 503.55 & 73 & 1050.22 & 497.04 & 119 & 1142.22 & 497 & 165 & 123 & 497.32 \\
\hline 28 & 698.46 & 503.4 & 74 & 1052.22 & 496.97 & 120 & 1144.22 & 497.03 & 166 & 1236.22 & 497.41 \\
\hline 29 & 725.83 & 503.9 & 75 & 1054.22 & 496.7 & 121 & 1146.22 & 497.03 & 167 & 1238.22 & 497.51 \\
\hline 30 & 770.52 & 504.24 & 76 & 1056.22 & 496.84 & 122 & 1148.22 & 497.04 & 168 & 1240.22 & 497.61 \\
\hline 31 & 796.88 & 505.01 & 77 & 1058.22 & 496.77 & 123 & 1150.22 & 497.05 & 169 & 124 & 497.6 \\
\hline 32 & 827.2 & 505.33 & 78 & 1060.22 & 496.71 & 124 & 1152.22 & 497.05 & 170 & 1244.22 & 497.59 \\
\hline 33 & 859.23 & 506.81 & 79 & 1062.22 & 496.64 & 125 & 1154.22 & 497.06 & 171 & 1246.22 & 497.57 \\
\hline 34 & 886.28 & 506.85 & 80 & 1064.22 & 496.58 & 126 & 1156.22 & 497.07 & 172 & 1248.22 & 497.72 \\
\hline 35 & 914.98 & 506.89 & 81 & 1066.22 & 496.54 & 127 & 1158.22 & 497.75 & 173 & 1250.22 & 497.87 \\
\hline 36 & 964.01 & 501.39 & 82 & 1068.22 & 496.5 & 128 & 1160.22 & 497.08 & 174 & 1252.22 & 498.02 \\
\hline 37 & 978.38 & 498.15 & 83 & 1070.22 & 496.46 & 129 & 1162.22 & 497.09 & 175 & 1254.22 & 498.15 \\
\hline 38 & 980.22 & 497.67 & 84 & 1072.22 & 496.42 & 130 & 1164.22 & 497.1 & 176 & 1262.22 & 500.95 \\
\hline 39 & 982.22 & 497.21 & 85 & 1074.22 & 496.38 & 131 & 1166.22 & 497.1 & 177 & 1281.17 & 504.18 \\
\hline 40 & 984.22 & 496.74 & 86 & 1076.22 & 496.34 & 132 & 1168.22 & 497.11 & 178 & 1306.62 & 507.54 \\
\hline 41 & 986.22 & 496.28 & 87 & 1078.22 & 496.45 & 133 & 1170.22 & 496.99 & 179 & 1326.56 & 510.45 \\
\hline 42 & 988.22 & 495.81 & 88 & 1080.22 & 496.56 & 134 & 1172.22 & 496.87 & 180 & 1334.13 & 511.29 \\
\hline 43 & 990.22 & 495.35 & 89 & 1082.22 & 496.66 & 135 & 1174.22 & 496.75 & 181 & 1342.29 & 512.07 \\
\hline 44 & 992.22 & 495.35 & 90 & 1084.22 & 496.77 & 136 & 1176.22 & 496.63 & 182 & 1357.78 & 513.88 \\
\hline 45 & 994.22 & 495.35 & 91 & 1086.22 & 496.74 & 137 & 1178.22 & 496.51 & - & - & - \\
\hline 46 & 996.22 & 495.35 & 92 & 1088.22 & 496.71 & 138 & 1180.22 & 496.39 & - & - & - \\
\hline
\end{tabular}


Tabela 66 - Características Geométricas da Seção SF109400 do Rio São Francisco

\begin{tabular}{|c|c|c|c|c|c|c|c|c|c|c|c|}
\hline$\overline{\mathrm{n}^{\mathrm{o}}}$ & $\mathrm{h}(\mathrm{m})$ & $\mathrm{z}(\mathrm{m})$ & $\overline{\mathrm{n}^{\mathrm{o}}}$ & $\mathrm{h}(\mathrm{m})$ & $z(m)$ & $\overline{\mathrm{n}^{\mathrm{o}}}$ & $\mathrm{h}(\mathrm{m})$ & $\mathrm{z}(\mathrm{m})$ & $\overline{\mathrm{n}^{\mathrm{o}}}$ & $\mathrm{h}(\mathrm{m})$ & $\mathrm{z}(\mathrm{m})$ \\
\hline 1 & 0 & 514 & 47 & 1246 & 496.1 & 93 & 1338 & 494.81 & 139 & 1430 & 494.23 \\
\hline 2 & 234.83 & 506.38 & 48 & 1248 & 496.08 & 94 & 1340 & 494.82 & 140 & 1432 & 494.19 \\
\hline 3 & 260.91 & 506.35 & 49 & 1250 & 496.07 & 95 & 1342 & 494.86 & 141 & 1434 & 494.1 \\
\hline 4 & 285.19 & 506.33 & 50 & 1252 & 496.07 & 96 & 1344 & 494.88 & 142 & 1436 & 493.88 \\
\hline 5 & 307.67 & 506.39 & 51 & 1254 & 496 & 97 & 1346 & 494.9 & 143 & 1438 & 493.83 \\
\hline 6 & 335.3 & 506.41 & 52 & 1256 & 496.06 & 98 & 1348 & 494.91 & 144 & 1440 & 493.97 \\
\hline 7 & 350.4 & 506.34 & 53 & 1258 & 496.06 & 99 & 1350 & 494.93 & 145 & 1442 & 494.01 \\
\hline 8 & 376.63 & 506.35 & 54 & 1260 & 496.05 & 100 & 1352 & 494.96 & 146 & 1444 & 494.03 \\
\hline 9 & 406.08 & 506.39 & 55 & 1262 & 496.04 & 101 & 1354 & 494.98 & 147 & 1446 & 493.97 \\
\hline 10 & 431.54 & 506.4 & 56 & 1264 & 496.03 & 102 & 1356 & 494.99 & 148 & 1448 & 493.72 \\
\hline 11 & 444.26 & 506.4 & 57 & 1266 & 496.01 & 103 & 1358 & 495 & 149 & 1450 & 493.52 \\
\hline 12 & 457.24 & 506.48 & 58 & 1268 & 496 & 104 & 1360 & 495 & 150 & 1452 & 493.42 \\
\hline 13 & 470.04 & 506.44 & 59 & 1270 & 495.99 & 105 & 1362 & 495 & 151 & 1454 & 493.46 \\
\hline 14 & 482.68 & 506.54 & 60 & 1272 & 495.96 & 106 & 1364 & 494.81 & 152 & 1456 & 493.51 \\
\hline 15 & 493.81 & 506.89 & 61 & 1274 & 495.93 & 107 & 1366 & 494.62 & 153 & 1458 & 493.53 \\
\hline 16 & 515.36 & 506.97 & 62 & 1276 & 495.9 & 108 & 1368 & 493.99 & 154 & 1460 & 494.12 \\
\hline 17 & 518.39 & 507.26 & 63 & 1278 & 495.81 & 109 & 1370 & 493.61 & 155 & 1462 & 494.32 \\
\hline 18 & 529.71 & 507.36 & 64 & 1280 & 495.81 & 110 & 1372 & 494.72 & 156 & 1464 & 494.03 \\
\hline 19 & 551.22 & 507.53 & 65 & 1282 & 495.88 & 111 & 1374 & 494.96 & 157 & 1466 & 494.31 \\
\hline 20 & 576.89 & 507.56 & 66 & 1284 & 495.89 & 112 & 1376 & 495.12 & 158 & 1468 & 494.25 \\
\hline 21 & 589.56 & 507.42 & 67 & 1286 & 495.79 & 113 & 1378 & 495.1 & 159 & 1470 & 494.22 \\
\hline 22 & 613.89 & 507.08 & 68 & 1288 & 495.67 & 114 & 1380 & 494.99 & 160 & 1472 & 494.21 \\
\hline 23 & 627.39 & 506.85 & 69 & 1290 & 495.66 & 115 & 1382 & 494.91 & 161 & 1474 & 494.2 \\
\hline 24 & 655.44 & 506.27 & 70 & 1292 & 495.64 & 116 & 1384 & 494.72 & 162 & 1476 & 494.12 \\
\hline 25 & 665.83 & 505.6 & 71 & 1294 & 495.6 & 117 & 1386 & 494.59 & 163 & 1478 & 494.32 \\
\hline 26 & 690.63 & 505.37 & 72 & 1296 & 495.39 & 118 & 1388 & 494.24 & 164 & 1480 & 494.67 \\
\hline 27 & 702.1 & 505.37 & 73 & 1298 & 495.26 & 119 & 1390 & 493.93 & 165 & 1482 & 494.76 \\
\hline 28 & 716.72 & 505.19 & 74 & 1300 & 495.36 & 120 & 1392 & 493.83 & 166 & 1484 & 494.99 \\
\hline 29 & 734.5 & 504.96 & 75 & 1302 & 495.21 & 121 & 1394 & 494.54 & 167 & 1486 & 494.99 \\
\hline 30 & 748.83 & 505.05 & 76 & 1304 & 495.08 & 122 & 1396 & 494.63 & 168 & 1488 & 495.33 \\
\hline 31 & 761.3 & 504.97 & 77 & 1306 & 494.99 & 123 & 1398 & 494.56 & 169 & 1490 & 495.74 \\
\hline 32 & 774.35 & 504.82 & 78 & 1308 & 494.71 & 124 & 1400 & 494.52 & 170 & 1492 & 495.81 \\
\hline 33 & 799.58 & 504.95 & 79 & 1310 & 494.58 & 125 & 1402 & 494.51 & 171 & 1494 & 495.91 \\
\hline 34 & 828.31 & 504.99 & 80 & 1312 & 494.69 & 126 & 1404 & 494.41 & 172 & 1496 & 496.33 \\
\hline 35 & 865.11 & 505.31 & 81 & 1314 & 494.7 & 127 & 1406 & 494.4 & 173 & 1498 & 497 \\
\hline 36 & 903.5 & 505.43 & 82 & 1316 & 494.72 & 128 & 1408 & 494.35 & 174 & 1500 & 497.02 \\
\hline 37 & 931.37 & 505.42 & 83 & 1318 & 494.8 & 129 & 1410 & 494.32 & 175 & 1512.57 & 501.6 \\
\hline 38 & 964.98 & 505.57 & 84 & 1320 & 494.82 & 130 & 1412 & 494.3 & 176 & 1557.78 & 504.59 \\
\hline 39 & 1002.23 & 505.72 & 85 & 1322 & 494.81 & 131 & 1414 & 494.23 & 177 & 1609.53 & 504.49 \\
\hline 40 & 1046.53 & 505.89 & 86 & 1324 & 494.74 & 132 & 1416 & 494.27 & 178 & 1678.59 & 503.69 \\
\hline 41 & 1120.12 & 504.75 & 87 & 1326 & 494.71 & 133 & 1418 & 494.3 & 179 & 1741.67 & 503.85 \\
\hline 42 & 1168.08 & 504.78 & 88 & 1328 & 494.69 & 134 & 1420 & 494.3 & 180 & 1858.92 & 502.92 \\
\hline 43 & 1214.06 & 502.11 & 89 & 1330 & 494.72 & 135 & 1422 & 494.32 & 181 & 2067.63 & 513.81 \\
\hline 44 & 1241.37 & 497.02 & 90 & 1332 & 494.74 & 136 & 1424 & 494.31 & - & - & - \\
\hline 45 & 1242 & 496.97 & 91 & 1334 & 494.79 & 137 & 1426 & 494.29 & - & - & - \\
\hline 46 & 1244 & 497.24 & 92 & 1336 & 494.8 & 138 & 1428 & 494.25 & - & - & - \\
\hline
\end{tabular}


Tabela 67 - Características Geométricas da Seção SF102500 do Rio São Francisco

\begin{tabular}{|c|c|c|c|c|c|c|c|c|c|c|c|}
\hline $\mathrm{n}^{\mathrm{o}}$ & $\mathrm{h}(\mathrm{m})$ & $\mathrm{z}(\mathrm{m})$ & $\mathrm{n}^{\mathrm{o}}$ & $\overline{h(m)}$ & $\mathrm{z}(\mathrm{m})$ & $\mathrm{n}^{\mathrm{o}}$ & $\mathrm{h}(\mathrm{m})$ & $\mathrm{z}(\mathrm{m})$ & $\mathrm{n}^{\mathrm{o}}$ & $\overline{h(m)}$ & $\bar{z}(\mathrm{~m})$ \\
\hline 1 & 0 & 512.86 & 41 & 700 & 493.95 & 81 & 780 & 493.26 & 121 & 860 & 495.18 \\
\hline 2 & 40 & 511.64 & 42 & 702 & 493.88 & 82 & 782 & 493.52 & 122 & 862 & 495.25 \\
\hline 3 & 60 & 511.1 & 43 & 704 & 493.8 & 83 & 784 & 493.77 & 123 & 864 & 495.25 \\
\hline 4 & 95 & 509.7 & 44 & 706 & 493.73 & 84 & 786 & 494.03 & 124 & 866 & 495.25 \\
\hline 5 & 120 & 508.74 & 45 & 708 & 493.65 & 85 & 788 & 494.04 & 125 & 868 & 495.25 \\
\hline 6 & 155 & 507.28 & 46 & 710 & 493.58 & 86 & 790 & 493.96 & 126 & 870 & 495.33 \\
\hline 7 & 175 & 506.44 & 47 & 712 & 493.51 & 87 & 792 & 493.89 & 127 & 872 & 495.42 \\
\hline 8 & 210 & 505.67 & 48 & 714 & 493.43 & 88 & 794 & 493.82 & 128 & 874 & 495.52 \\
\hline 9 & 245 & 504.51 & 49 & 716 & 493.36 & 89 & 796 & 493.74 & 129 & 876 & 495.61 \\
\hline 10 & 275 & 503.68 & 50 & 718 & 493.32 & 90 & 798 & 493.67 & 130 & 878 & 495.62 \\
\hline 11 & 315 & 502.66 & 51 & 720 & 493.3 & 91 & 800 & 493.59 & 131 & 880 & 495.54 \\
\hline 12 & 340 & 502.29 & 52 & 722 & 493.28 & 92 & 802 & 493.65 & 132 & 882 & 495.46 \\
\hline 13 & 375 & 501.94 & 53 & 724 & 493.27 & 93 & 804 & 493.84 & 133 & 884 & 495.39 \\
\hline 14 & 400 & 501.63 & 54 & 726 & 493.25 & 94 & 806 & 494.03 & 134 & 886 & 495.42 \\
\hline 15 & 435 & 501.59 & 55 & 728 & 493.23 & 95 & 808 & 494.22 & 135 & 888 & 495.49 \\
\hline 16 & 460 & 501.65 & 56 & 730 & 493.22 & 96 & 810 & 494.26 & 136 & 890 & 495.56 \\
\hline 17 & 485 & 501.97 & 57 & 732 & 493.2 & 97 & 812 & 494.29 & 137 & 892 & 495.59 \\
\hline 18 & 515 & 501.84 & 58 & 734 & 493.19 & 98 & 814 & 494.31 & 138 & 894 & 495.62 \\
\hline 19 & 555 & 501.87 & 59 & 736 & 493.17 & 99 & 816 & 494.34 & 139 & 896 & 495.64 \\
\hline 20 & 580 & 502.5 & 60 & 738 & 493.15 & 100 & 818 & 494.27 & 140 & 898 & 495.63 \\
\hline 21 & 615 & 503.59 & 61 & 740 & 493.14 & 101 & 820 & 494.2 & 141 & 900 & 495.61 \\
\hline 22 & 645 & 500.64 & 62 & 742 & 493.07 & 102 & 822 & 494.12 & 142 & 902 & 495.59 \\
\hline 23 & 665 & 496.76 & 63 & 744 & 492.99 & 103 & 824 & 494.08 & 143 & 904 & 495.8 \\
\hline 24 & 666 & 496.5 & 64 & 746 & 492.9 & 104 & 826 & 494.15 & 144 & 906 & 496.22 \\
\hline 25 & 668 & 495.67 & 65 & 748 & 492.82 & 105 & 828 & 494.22 & 145 & 908 & 496.76 \\
\hline 26 & 670 & 494.85 & 66 & 750 & 492.73 & 106 & 830 & 494.28 & 146 & 918 & 498.9 \\
\hline 27 & 672 & 494.33 & 67 & 752 & 492.65 & 107 & 832 & 494.35 & 147 & 938 & 502.99 \\
\hline 28 & 674 & 494.3 & 68 & 754 & 492.65 & 108 & 834 & 494.42 & 148 & 957.87 & 503.04 \\
\hline 29 & 676 & 494.27 & 69 & 756 & 492.7 & 109 & 836 & 494.48 & 149 & 976.31 & 502.35 \\
\hline 30 & 678 & 494.24 & 70 & 758 & 492.74 & 110 & 838 & 494.57 & 150 & 997.3 & 502.04 \\
\hline 31 & 680 & 494.21 & 71 & 760 & 492.79 & 111 & 840 & 494.78 & 151 & 1042.12 & 502.16 \\
\hline 32 & 682 & 494.18 & 72 & 762 & 492.84 & 112 & 842 & 495 & 152 & 1106.56 & 502.29 \\
\hline 33 & 684 & 494.15 & 73 & 764 & 492.83 & 113 & 844 & 495.22 & 153 & 1143.13 & 502.34 \\
\hline 34 & 686 & 494.13 & 74 & 766 & 492.82 & 114 & 846 & 495.44 & 154 & 1196.13 & 502.88 \\
\hline 35 & 688 & 494.1 & 75 & 768 & 492.81 & 115 & 848 & 495.49 & 155 & 1223.11 & 502.9 \\
\hline 36 & 690 & 494.08 & 76 & 770 & 492.79 & 116 & 850 & 495.39 & 156 & 1306.21 & 502.21 \\
\hline 37 & 692 & 494.06 & 77 & 772 & 492.78 & 117 & 852 & 495.3 & 157 & 1358.12 & 501.27 \\
\hline 38 & 694 & 494.03 & 78 & 774 & 492.77 & 118 & 854 & 495.21 & 158 & 1418.35 & 503.76 \\
\hline 39 & 696 & 494.01 & 79 & 776 & 492.76 & 119 & 856 & 495.12 & 159 & 1494.4 & 511.43 \\
\hline 40 & 698 & 493.99 & 80 & 778 & 493.01 & 120 & 858 & 495.11 & - & - & - \\
\hline
\end{tabular}


Tabela 68 - Características Geométricas da Seção SF95600 do Rio São Francisco

\begin{tabular}{|c|c|c|c|c|c|c|c|c|c|c|c|}
\hline$\overline{n^{\circ}}$ & $\overline{\mathrm{h}(\mathrm{m})}$ & $\overline{\mathrm{z}(\mathrm{m})}$ & $\overline{n^{\circ}}$ & $\overline{\mathrm{h}(\mathrm{m})}$ & $\overline{\mathrm{z}(\mathrm{m})}$ & $\overline{n^{\circ}}$ & $\overline{\mathrm{h}(\mathrm{m})}$ & $\overline{z z(m)}$ & $\overline{\mathrm{n}^{\circ}}$ & $\overline{\mathrm{h}(\mathrm{m})}$ & $\overline{z z(m)}$ \\
\hline 1 & 0 & 510 & 43 & 968 & 493.73 & 85 & 1052 & 490.71 & 127 & 1136 & 492.18 \\
\hline 2 & 185 & 504.08 & 44 & 970 & 492.84 & 86 & 1054 & 490.95 & 128 & 1138 & 492.11 \\
\hline 3 & 221 & 503.51 & 45 & 972 & 491.96 & 87 & 1056 & 490.97 & 129 & 1140 & 492.13 \\
\hline 4 & 246 & 503.11 & 46 & 974 & 491.07 & 88 & 1058 & 490.99 & 130 & 1142 & 492.17 \\
\hline 5 & 266 & 503 & 47 & 976 & 490.77 & 89 & 1060 & 491.01 & 131 & 1144 & 492.19 \\
\hline 6 & 299 & 502.54 & 48 & 978 & 490.43 & 90 & 1062 & 491.04 & 132 & 1146 & 492.21 \\
\hline 7 & 324 & 502.18 & 49 & 980 & 490.16 & 91 & 1064 & 491.06 & 133 & 1148 & 492.23 \\
\hline 8 & 357 & 502.24 & 50 & 982 & 490.15 & 92 & 1066 & 491.08 & 134 & 1150 & 492.23 \\
\hline 9 & 381.53 & 502.02 & 51 & 984 & 490.15 & 93 & 1068 & 491.21 & 135 & 1152 & 492.25 \\
\hline 10 & 403.39 & 503.19 & 52 & 986 & 490.14 & 94 & 1070 & 491.34 & 136 & 1154 & 492.26 \\
\hline 11 & 423.91 & 503.23 & 53 & 988 & 490.14 & 95 & 1072 & 491.48 & 137 & 1156 & 492.28 \\
\hline 12 & 445.33 & 503.2 & 54 & 990 & 490.14 & 96 & 1074 & 491.61 & 138 & 1158 & 492.3 \\
\hline 13 & 457.69 & 503.28 & 55 & 992 & 490.2 & 97 & 1076 & 491.74 & 139 & 1160 & 492.33 \\
\hline 14 & 475.14 & 503.34 & 56 & 994 & 490.23 & 98 & 1078 & 491.87 & 140 & 1162 & 492.33 \\
\hline 15 & 485.49 & 503.23 & 57 & 996 & 490.27 & 99 & 1080 & 491.9 & 141 & 1164 & 492.26 \\
\hline 16 & 499.16 & 503.04 & 58 & 998 & 490.3 & 100 & 1082 & 491.92 & 142 & 1166 & 492.2 \\
\hline 17 & 520.65 & 502.16 & 59 & 1000 & 490.3 & 101 & 1084 & 491.95 & 143 & 1168 & 492.13 \\
\hline 18 & 531.07 & 502.16 & 60 & 1002 & 490.37 & 102 & 1086 & 491.98 & 144 & 1170 & 492.06 \\
\hline 19 & 541.06 & 501.72 & 61 & 1004 & 490.37 & 103 & 1088 & 492.01 & 145 & 1172 & 492.06 \\
\hline 20 & 559.55 & 500.66 & 62 & 1006 & 490.46 & 104 & 1090 & 492.05 & 146 & 1174 & 491.96 \\
\hline 21 & 588.93 & 500.36 & 63 & 1008 & 490.51 & 105 & 1092 & 492.06 & 147 & 1176 & 491.94 \\
\hline 22 & 611.79 & 500.03 & 64 & 1010 & 490.55 & 106 & 1094 & 492.07 & 148 & 1178 & 491.88 \\
\hline 23 & 642.23 & 499.31 & 65 & 1012 & 490.6 & 107 & 1096 & 492.09 & 149 & 1180 & 492.01 \\
\hline 24 & 667.86 & 499.96 & 66 & 1014 & 490.64 & 108 & 1098 & 492.1 & 150 & 1182 & 492.14 \\
\hline 25 & 674.46 & 500.15 & 67 & 1016 & & 109 & 1100 & 492.12 & 151 & 1184 & 492.14 \\
\hline 26 & 688.35 & 500.46 & 68 & 1018 & 490.7 & 110 & 1102 & 492.14 & 152 & 1186 & 492.27 \\
\hline 27 & 714.75 & 500.96 & 69 & 1020 & 490.74 & 111 & 1104 & 492.14 & 153 & 1188 & 492.66 \\
\hline 28 & 738.4 & 501.39 & 70 & 1022 & 490.77 & 112 & 1106 & 492.14 & 154 & 1190 & 492.47 \\
\hline 29 & 750.28 & 500.47 & 71 & 1024 & 490.8 & 113 & 1108 & 492.18 & 155 & 1192 & 492.28 \\
\hline 30 & 762.8 & 500.19 & 72 & 1026 & 490.83 & 114 & 1110 & 492.22 & 156 & 1194 & 492.09 \\
\hline 31 & 776.76 & 499.86 & 73 & 1028 & 490.86 & 115 & 1112 & 492.25 & 157 & 1196 & 492.89 \\
\hline 32 & 805.53 & 499.65 & 74 & 1030 & 490.86 & 116 & 1114 & 492.29 & 158 & 1198 & 493.96 \\
\hline 33 & 816.68 & 499.82 & 75 & 1032 & 490.85 & 117 & 1116 & 492.33 & 159 & 1200 & 494.55 \\
\hline 34 & 829.82 & 500.25 & 76 & 1034 & 490.85 & 118 & 1118 & 492.33 & 160 & 1203.58 & 496.87 \\
\hline 35 & 858.1 & 501.12 & 77 & 1036 & 490.84 & 119 & 1120 & 492.33 & 161 & 1218.5 & 499.28 \\
\hline 36 & 871.71 & 501.62 & 78 & 1038 & 490.84 & 120 & 1122 & 492.42 & 162 & 1229.89 & 500.09 \\
\hline 37 & 896.32 & 501.85 & 79 & 1040 & 490.84 & 121 & 1124 & 492.45 & 163 & 1246.49 & 502.76 \\
\hline 38 & 926.1 & 503.03 & 80 & 1042 & 490.83 & 122 & 1126 & 492.48 & 164 & 1268.11 & 501.73 \\
\hline 39 & 944.5 & 500.85 & 81 & 1044 & 490.85 & 123 & 1128 & 492.48 & 165 & 1294.57 & 501.86 \\
\hline 40 & 956.76 & 497.44 & 82 & 1046 & 490.87 & 124 & 1130 & 492.41 & 166 & 1328.55 & 510.64 \\
\hline 41 & 965 & 494.55 & 83 & 1048 & 490.69 & 125 & 1132 & 492.33 & - & - & - \\
\hline 42 & 966 & 494.61 & 84 & 1050 & 490.69 & 126 & 1134 & 492.26 & - & - & - \\
\hline
\end{tabular}


Tabela 69 - Características Geométricas da Seção SF92600 do Rio São Francisco

\begin{tabular}{|c|c|c|c|c|c|c|c|c|c|c|c|}
\hline $\mathrm{n}^{\mathrm{o}}$ & $\mathrm{h}(\mathrm{m})$ & $\mathrm{z}(\mathrm{m})$ & $\mathrm{n}^{\mathrm{o}}$ & $\mathrm{h}(\mathrm{m})$ & $\mathrm{z}(\mathrm{m})$ & $\mathrm{n}^{\mathrm{o}}$ & $\mathrm{h}(\mathrm{m})$ & $\mathrm{z}(\mathrm{m})$ & $\mathrm{n}^{\circ}$ & $\mathrm{h}(\mathrm{m})$ & $\mathrm{z}(\mathrm{m})$ \\
\hline 1 & 0 & 510 & 43 & 1766 & 490.42 & 85 & 1850 & 491.13 & 127 & 1934 & 491.05 \\
\hline 2 & 715.67 & 498.45 & 44 & 1768 & 490.34 & 86 & 1852 & 491.13 & 128 & 1936 & 490.19 \\
\hline 3 & 758.15 & 498.43 & 45 & 1770 & 490.31 & 87 & 1854 & 490.99 & 129 & 1938 & 491.02 \\
\hline 4 & 808.02 & 498.43 & 46 & 1772 & 490.3 & 88 & 1856 & 490.81 & 130 & 1940 & 490.99 \\
\hline 5 & 862.83 & 498.31 & 47 & 1774 & 490.22 & 89 & 1858 & 490.56 & 131 & 1942 & 490.99 \\
\hline 6 & 906.19 & 498.14 & 48 & 1776 & 490.32 & 90 & 1860 & 490.34 & 132 & 1944 & 490.94 \\
\hline 7 & 966.53 & 498.09 & 49 & 1778 & 490.24 & 91 & 1862 & 490.42 & 133 & 1946 & 490.92 \\
\hline 8 & 1009.08 & 498.02 & 50 & 1780 & 490.2 & 92 & 1864 & 490.5 & 134 & 1948 & 490.91 \\
\hline 9 & 1058.26 & 498.05 & 51 & 1782 & 490.15 & 93 & 1866 & 490.72 & 135 & 1950 & 490.89 \\
\hline 10 & 1084.5 & 498.25 & 52 & 1784 & 490.16 & 94 & 1868 & 490.94 & 136 & 1952 & 490.88 \\
\hline 11 & 1111.53 & 498.78 & 53 & 1786 & 490.16 & 95 & 1870 & 490.99 & 137 & 1954 & 490.84 \\
\hline 12 & 1141.73 & 498.47 & 54 & 1788 & 490.17 & 96 & 1872 & 491.06 & 138 & 1956 & 490.84 \\
\hline 13 & 1190 & 497.96 & 55 & 1790 & 490.24 & 97 & 1874 & 491 & 139 & 1958 & 491.32 \\
\hline 14 & 1246.34 & 498.05 & 56 & 1792 & 490.22 & 98 & 1876 & 490.94 & 140 & 1960 & 491.51 \\
\hline 15 & 1290.91 & 498.14 & 57 & 1794 & 490.21 & 99 & 1878 & 490.71 & 141 & 1962 & 491.71 \\
\hline 16 & 1345.59 & 498.93 & 58 & 1796 & 490.2 & 100 & 1880 & 490.52 & 142 & 1964 & 491.95 \\
\hline 17 & 1404.97 & 500.21 & 59 & 1798 & 490.15 & 101 & 1882 & 490.42 & 143 & 1966 & 490.82 \\
\hline 18 & 1457.72 & 500.27 & 60 & 1800 & 490.32 & 102 & 1884 & 490.31 & 144 & 1968 & 490.79 \\
\hline 19 & 1488.04 & 499.13 & 61 & 1802 & 490.45 & 103 & 1886 & 490.4 & 145 & 1970 & 490.65 \\
\hline 20 & 1509.56 & 498.81 & 62 & 1804 & 490.58 & 104 & 1888 & 490.41 & 146 & 1972 & 490.56 \\
\hline 21 & 1549.66 & 498.73 & 63 & 1806 & 490.66 & 105 & 1890 & 490.7 & 147 & 1974 & 490.5 \\
\hline 22 & 1586.14 & 499.5 & 64 & 1808 & 490.52 & 106 & 1892 & 490.98 & 148 & 1976 & 490.32 \\
\hline 23 & 1625.1 & 500.66 & 65 & 1810 & 490.35 & 107 & 1894 & 491.11 & 149 & 1978 & 490.21 \\
\hline 24 & 1661.09 & 501.35 & 66 & 1812 & 490.41 & 108 & 1896 & 490.98 & 150 & 1980 & 490.14 \\
\hline 25 & 1693.85 & 499.49 & 67 & 1814 & 490.5 & 109 & 1898 & 490.97 & 151 & 1982 & 490.38 \\
\hline 26 & 1707.17 & 499.53 & 68 & 1816 & 490.68 & 110 & 1900 & 490.95 & 152 & 1984 & 490.42 \\
\hline 27 & 1721.11 & 498.02 & 69 & 1818 & 490.88 & 111 & 1902 & 490.94 & 153 & 1986 & 490.52 \\
\hline 28 & 1737.03 & 493.96 & 70 & 1820 & 490.88 & 112 & 1904 & 490.94 & 154 & 1988 & 490.98 \\
\hline 29 & 1738 & 493.32 & 71 & 1822 & 490.92 & 113 & 1906 & 490.96 & 155 & 1990 & 491.12 \\
\hline 30 & 1740 & 492.96 & 72 & 1824 & 490.93 & 114 & 1908 & 490.98 & 156 & 1992 & 491.9 \\
\hline 31 & 1742 & 492.85 & 73 & 1826 & 490.93 & 115 & 1910 & 490.99 & 157 & 1994 & 492.49 \\
\hline 32 & 1744 & 492.42 & 74 & 1828 & 490.94 & 116 & 1912 & 491.09 & 158 & 1996 & 493.39 \\
\hline 33 & 1746 & 492.22 & 75 & 1830 & 491 & 117 & 1914 & 491.1 & 159 & 1998 & 493.92 \\
\hline 34 & 1748 & 491.95 & 76 & 1832 & 491.1 & 118 & 1916 & 491.1 & 160 & 2000 & 493.96 \\
\hline 35 & 1750 & 491.71 & 77 & 1834 & 491.19 & 119 & 1918 & 491.12 & 161 & 2004.6 & 495.27 \\
\hline 36 & 1752 & 491.56 & 78 & 1836 & 491.21 & 120 & 1920 & 491.13 & 162 & 2016.29 & 499.03 \\
\hline 37 & 1754 & 491.49 & 79 & 1838 & 491.2 & 121 & 1922 & 491.13 & 163 & 2036.9 & 499.97 \\
\hline 38 & 1756 & 490.92 & 80 & 1840 & 491.14 & 122 & 1924 & 491.14 & 164 & 2054.78 & 499.56 \\
\hline 39 & 1758 & 490.62 & 81 & 1842 & 491.14 & 123 & 1926 & 491.14 & 165 & 2093.65 & 501.59 \\
\hline 40 & 1760 & 490.6 & 82 & 1844 & 491.14 & 124 & 1928 & 491.13 & 166 & 2132.18 & 505.32 \\
\hline 41 & 1762 & 490.53 & 83 & 1846 & 491.14 & 125 & 1930 & 491.11 & 167 & 2188.79 & 509.76 \\
\hline 42 & 1764 & 490.49 & 84 & 1848 & 491.14 & 126 & 1932 & 491.1 & - & - & - \\
\hline
\end{tabular}


Tabela 70 - Características Geométricas da Seção SF86600 do Rio São Francisco

\begin{tabular}{|c|c|c|c|c|c|c|c|c|c|c|c|}
\hline$\overline{n^{\circ}}$ & $\overline{\mathrm{h}(\mathrm{m})}$ & $\overline{\mathrm{z}(\mathrm{m})}$ & $\overline{n^{\circ}}$ & $\overline{\mathrm{h}(\mathrm{m})}$ & $\overline{z z(m)}$ & $\overline{\mathrm{n}^{\circ}}$ & $\overline{\mathrm{h}(\mathrm{m})}$ & $\overline{\mathrm{z}(\mathrm{m})}$ & $\overline{\mathrm{n}^{\mathrm{o}}}$ & $\overline{h(m)}$ & $\overline{\mathrm{z}(\mathrm{m})}$ \\
\hline 1 & 0 & 508.75 & 44 & 240 & 491.03 & 87 & 326 & 490.13 & 130 & 412 & 489.38 \\
\hline 2 & 21 & 506.5 & 45 & 242 & 491.03 & 88 & 328 & 490.02 & 131 & 414 & 489.37 \\
\hline 3 & 41 & 503.9 & 46 & 244 & 491.03 & 89 & 330 & 490.02 & 132 & 416 & 489.37 \\
\hline 4 & 66 & 502.04 & 47 & 246 & 491.02 & 90 & 332 & 490.02 & 133 & 418 & 489.36 \\
\hline 5 & 101 & 499.42 & 48 & 248 & 491 & 91 & 334 & 490.02 & 134 & 420 & 489.36 \\
\hline 6 & 136 & 499.41 & 49 & 250 & 490.99 & 92 & 336 & 490.02 & 135 & 422 & 489.33 \\
\hline 7 & 169 & 493.41 & 50 & 252 & 490.97 & 93 & 338 & 490.02 & 136 & 424 & 489.32 \\
\hline 8 & 170 & 493.31 & 51 & 254 & 490.96 & 94 & 340 & 490.01 & 137 & 426 & 489.32 \\
\hline 9 & 171 & 492.99 & 52 & 256 & 490.94 & 95 & 342 & 490.01 & 138 & 428 & 489.3 \\
\hline 10 & 172 & 492.88 & 53 & 258 & 490.93 & 96 & 344 & 490.01 & 139 & 430 & 489.29 \\
\hline 11 & 174 & 492.67 & 54 & 260 & 490.91 & 97 & 346 & 490 & 140 & 432 & 489.28 \\
\hline 12 & 176 & 492.43 & 55 & 262 & 490.89 & 98 & 348 & 489.91 & 141 & 434 & 489.27 \\
\hline 13 & 178 & 492.26 & 56 & 264 & 490.88 & 99 & 350 & 489.89 & 142 & 436 & 489.26 \\
\hline 14 & 180 & 492.09 & 57 & 266 & 490.88 & 100 & 352 & 489.88 & 143 & 438 & 489.24 \\
\hline 15 & 182 & 491.97 & 58 & 268 & 490.88 & 101 & 354 & 489.88 & 144 & 440 & 489.22 \\
\hline 16 & 184 & 491.83 & 59 & 270 & 490.87 & 102 & 356 & 489.81 & 145 & 442 & 493.41 \\
\hline 17 & 186 & 491.71 & 60 & 272 & 490.86 & 103 & 358 & 489.79 & 146 & 472.15 & 495.35 \\
\hline 18 & 188 & 491.66 & 61 & 274 & 490.86 & 104 & 360 & 489.75 & 147 & 504.31 & 497.65 \\
\hline 19 & 190 & 491.62 & 62 & 276 & 490.85 & 105 & 362 & 489.71 & 148 & 534.24 & 495.97 \\
\hline 20 & 192 & 491.57 & 63 & 278 & 490.85 & 106 & 364 & 489.69 & 149 & 569.13 & 498.63 \\
\hline 21 & 194 & 491.52 & 64 & 280 & 490.84 & 107 & 366 & 489.67 & 150 & 599.32 & 500.42 \\
\hline 22 & 196 & 491.49 & 65 & 282 & 490.83 & 108 & 368 & 489.66 & 151 & 622.11 & 498.8 \\
\hline 23 & 198 & 491.49 & 66 & 284 & 490.83 & 109 & 370 & 489.63 & 152 & 664.01 & 499.54 \\
\hline 24 & 200 & 491.45 & 67 & 286 & 490.83 & 110 & 372 & 489.57 & 153 & 694.31 & 500.2 \\
\hline 25 & 202 & 491.38 & 68 & 288 & 490.83 & 111 & 374 & 489.55 & 154 & 746.15 & 498.71 \\
\hline 26 & 204 & 491.31 & 69 & 290 & 490.82 & 112 & 376 & 489.55 & 155 & 803.3 & 498.65 \\
\hline 27 & 206 & 491.24 & 70 & 292 & 490.82 & 113 & 378 & 489.54 & 156 & 853.22 & 499.22 \\
\hline 28 & 208 & 491.24 & 71 & 294 & 490.81 & 114 & 380 & 489.53 & 157 & 898.25 & 498.32 \\
\hline 29 & 210 & 491.2 & 72 & 296 & 490.81 & 115 & 382 & 489.51 & 158 & 943.12 & 497.63 \\
\hline 30 & 212 & 491.18 & 73 & 298 & 490.73 & 116 & 384 & 489.5 & 159 & 988.12 & 497.58 \\
\hline 31 & 214 & 491.17 & 74 & 300 & 490.72 & 117 & 386 & 489.5 & 160 & 1038.25 & 497.72 \\
\hline 32 & 216 & 491.17 & 75 & 302 & 490.72 & 118 & 388 & 489.49 & 161 & 1093.42 & 497.96 \\
\hline 33 & 218 & 491.15 & 76 & 304 & 490.64 & 119 & 390 & 489.49 & 162 & 1133.57 & 498.3 \\
\hline 34 & 220 & 491.13 & 77 & 306 & 490.6 & 120 & 392 & 489.49 & 163 & 1188.12 & 498.42 \\
\hline 35 & 222 & 491.13 & 78 & 308 & 490.58 & 121 & 394 & 489.48 & 164 & 1243.24 & 498.7 \\
\hline 36 & 224 & 491.11 & 79 & 310 & 490.55 & 122 & 396 & 489.48 & 165 & 1288.34 & 499.09 \\
\hline 37 & 226 & 491.1 & 80 & 312 & 490.52 & 123 & 398 & 489.46 & 166 & 1333.12 & 499.28 \\
\hline 38 & 228 & 491.1 & 81 & 314 & 490.51 & 124 & 400 & 489.44 & 167 & 1386.31 & 499.76 \\
\hline 39 & 230 & 491.08 & 82 & 316 & 490.46 & 125 & 402 & 489.44 & 168 & 1443.13 & 500.17 \\
\hline 40 & 232 & 491.06 & 83 & 318 & 490.38 & 126 & 404 & 489.43 & 169 & 1483.29 & 500.73 \\
\hline 41 & 234 & 491.05 & 84 & 320 & 490.3 & 127 & 406 & 489.43 & 170 & 1503.33 & 500.88 \\
\hline 42 & 236 & 491.04 & 85 & 322 & 490.26 & 128 & 408 & 489.4 & 171 & 1542 & 505 \\
\hline 43 & 238 & 491.03 & 86 & 324 & 490.14 & 129 & 410 & 489.4 & - & - & - \\
\hline
\end{tabular}


Tabela 71 - Características Geométricas da Seção SF83200 do Rio São Francisco

\begin{tabular}{|c|c|c|c|c|c|c|c|c|c|c|c|}
\hline$\overline{n^{\circ}}$ & $\overline{\mathrm{h}(\mathrm{m})}$ & $\overline{z z(m)}$ & $\overline{\mathrm{n}^{\circ}}$ & $\overline{\mathrm{h}(\mathrm{m})}$ & $\overline{\mathrm{z}(\mathrm{m})}$ & $\overline{\mathrm{n}^{\circ}}$ & $\overline{\mathrm{h}(\mathrm{m})}$ & $\bar{z} \mathrm{z}(\mathrm{m})$ & $\overline{\mathrm{n}^{\mathrm{o}}}$ & $\overline{\mathrm{h}(\mathrm{m})}$ & $\overline{\mathrm{z}(\mathrm{m})}$ \\
\hline 1 & 0 & 504.04 & 36 & 1017 & 488.52 & 71 & 1087 & 487.45 & 106 & 1157 & 489.37 \\
\hline 2 & 36 & 503.48 & 37 & 1019 & 488.47 & 72 & 1089 & 487.41 & 107 & 1159 & 489.49 \\
\hline 3 & 94 & 502.75 & 38 & 1021 & 488.43 & 73 & 1091 & 487.36 & 108 & 1161 & 489.61 \\
\hline 4 & 147 & 501.82 & 39 & 1023 & 488.41 & 74 & 1093 & 487.31 & 109 & 1163 & 489.73 \\
\hline 5 & 202 & 500.71 & 40 & 1025 & 488.4 & 75 & 1095 & 487.26 & 110 & 1165 & 489.62 \\
\hline 6 & 247 & 498.05 & 41 & 1027 & 488.38 & 76 & 1097 & 487.25 & 111 & 1167 & 489.48 \\
\hline 7 & 453 & 497.98 & 42 & 1029 & 488.37 & 77 & 1099 & 487.32 & 112 & 1169 & 489.34 \\
\hline 8 & 493 & 496.44 & 43 & 1031 & 488.34 & 78 & 1101 & 487.4 & 113 & 1171 & 489.25 \\
\hline 9 & 532 & 496.46 & 44 & 1033 & 488.31 & 79 & 1103 & 487.47 & 114 & 1173 & 489.31 \\
\hline 10 & 626 & 495.59 & 45 & 1035 & 488.2 & 80 & 1105 & 487.54 & 115 & 1175 & 489.37 \\
\hline 11 & 681 & 496.68 & 46 & 1037 & 488.01 & 81 & 1107 & 487.6 & 116 & 1177 & 489.44 \\
\hline 12 & 729 & 496.65 & 47 & 1039 & 487.82 & 82 & 1109 & 487.59 & 117 & 1179 & 489.5 \\
\hline 13 & 774 & 497.19 & 48 & 1041 & 487.8 & 83 & 1111 & 487.58 & 118 & 1181 & 489.55 \\
\hline 14 & 826 & 497.76 & 49 & 1043 & 487.91 & 84 & 1113 & 487.64 & 119 & 1183 & 489.6 \\
\hline 15 & 878 & 498.3 & 50 & 1045 & 488.02 & 85 & 1115 & 487.72 & 120 & 1185 & 489.65 \\
\hline 16 & 903 & 499.64 & 51 & 1047 & 488.02 & 86 & 1117 & 487.71 & 121 & 1187 & 489.7 \\
\hline 17 & 928 & 499.5 & 52 & 1049 & 487.94 & 87 & 1119 & 487.52 & 122 & 1189 & 489.78 \\
\hline 18 & 953 & 497.76 & 53 & 1051 & 487.86 & 88 & 1121 & 487.32 & 123 & 1191 & 490.07 \\
\hline 19 & 983 & 492.37 & 54 & 1053 & 487.79 & 89 & 1123 & 487.13 & 124 & 1193 & 490.36 \\
\hline 20 & 985 & 491.68 & 55 & 1055 & 487.71 & 90 & 1125 & 486.94 & 125 & 1195 & 490.65 \\
\hline 21 & 987 & 490.9 & 56 & 1057 & 487.8 & 91 & 1127 & 486.9 & 126 & 1197 & 491.04 \\
\hline 22 & 989 & 490.12 & 57 & 1059 & 487.94 & 92 & 1129 & 487.22 & 127 & 1199 & 491.47 \\
\hline 23 & 991 & 489.55 & 58 & 1061 & 487.91 & 93 & 1131 & 487.54 & 128 & 1201 & 491.89 \\
\hline 24 & 993 & 489.51 & 59 & 1063 & 487.87 & 94 & 1133 & 487.86 & 129 & 1203 & 492.37 \\
\hline 25 & 995 & 489.47 & 60 & 1065 & 487.83 & 95 & 1135 & 488.19 & 130 & 1210.78 & 493.89 \\
\hline 26 & 997 & 489.24 & 61 & 1067 & 487.79 & 96 & 1137 & 488.39 & 131 & 1215.52 & 495.26 \\
\hline 27 & 999 & 488.62 & 62 & 1069 & 487.74 & 97 & 1139 & 488.54 & 132 & 1220.55 & 497.05 \\
\hline 28 & 1001 & 488.27 & 63 & 1071 & 487.68 & 98 & 1141 & 488.69 & 133 & 1225.49 & 500.54 \\
\hline 29 & 1003 & 488.39 & 64 & 1073 & 487.62 & 99 & 1143 & 488.83 & 134 & 1231.06 & 502.71 \\
\hline 30 & 1005 & 488.51 & 65 & 1075 & 487.57 & 100 & 1145 & 488.98 & 135 & 1234.86 & 503.92 \\
\hline 31 & 1007 & 488.63 & 66 & 1077 & 487.55 & 101 & 1147 & 489.03 & 136 & 1240.13 & 505.13 \\
\hline 32 & 1009 & 488.74 & 67 & 1079 & 487.53 & 102 & 1149 & 489.09 & 137 & 1245.13 & 506.03 \\
\hline 33 & 1011 & 488.69 & 68 & 1081 & 487.51 & 103 & 1151 & 489.15 & 138 & 1249.24 & 506.88 \\
\hline 34 & 1013 & 488.63 & 69 & 1083 & 487.49 & 104 & 1153 & 489.21 & 139 & 1255.33 & 507.49 \\
\hline 35 & 1015 & 488.58 & 70 & 1085 & 487.47 & 105 & 1155 & 489.27 & - & - & - \\
\hline
\end{tabular}


Tabela 72 - Características Geométricas da Seção SF77200 do Rio São Francisco

\begin{tabular}{|c|c|c|c|c|c|c|c|c|c|c|c|}
\hline $\mathrm{n}^{\mathrm{o}}$ & $\overline{h(m)}$ & $\mathrm{z}(\mathrm{m})$ & $\mathrm{n}^{\mathrm{o}}$ & $\overline{h(m)}$ & $\mathrm{z}(\mathrm{m})$ & $\mathrm{n}^{\mathrm{o}}$ & $\overline{h(m)}$ & $\bar{z}(\mathrm{~m})$ & $\mathrm{n}^{\circ}$ & $\mathrm{h}(\mathrm{m})$ & $\bar{z}(\mathrm{~m})$ \\
\hline 1 & 0 & 508.25 & 43 & 657 & 489.65 & 85 & 741 & 487.72 & 127 & 825 & 487.68 \\
\hline 2 & 32 & 505.72 & 44 & 659 & 489.66 & 86 & 743 & 487.63 & 128 & 827 & 487.66 \\
\hline 3 & 67 & 503.67 & 45 & 661 & 489.68 & 87 & 745 & 487.61 & 129 & 829 & 487.64 \\
\hline 4 & 105 & 500.85 & 46 & 663 & 489.69 & 88 & 747 & 487.45 & 130 & 831 & 487.62 \\
\hline 5 & 159 & 499.58 & 47 & 665 & 489.7 & 89 & 749 & 487.5 & 131 & 833 & 487.66 \\
\hline 6 & 209 & 499.52 & 48 & 667 & 489.71 & 90 & 751 & 487.55 & 132 & 835 & 487.73 \\
\hline 7 & 259 & 498.99 & 49 & 669 & 489.73 & 91 & 753 & 487.6 & 133 & 837 & 487.8 \\
\hline 8 & 306 & 499.36 & 50 & 671 & 489.74 & 92 & 755 & 487.65 & 134 & 839 & 487.85 \\
\hline 9 & 359 & 498.28 & 51 & 673 & 489.75 & 93 & 757 & 487.44 & 135 & 841 & 487.88 \\
\hline 10 & 410 & 497.65 & 52 & 675 & 489.76 & 94 & 759 & 487.23 & 136 & 843 & 487.77 \\
\hline 11 & 455 & 497.54 & 53 & 677 & 489.76 & 95 & 761 & 487.62 & 137 & 845 & 487.66 \\
\hline 12 & 498 & 497.55 & 54 & 679 & 489.76 & 96 & 763 & 487.5 & 138 & 847 & 487.6 \\
\hline 13 & 531 & 497.55 & 55 & 681 & 489.76 & 97 & 765 & 487.38 & 139 & 849 & 487.61 \\
\hline 14 & 569 & 498.63 & 56 & 683 & 489.76 & 98 & 767 & 487.26 & 140 & 851 & 487.63 \\
\hline 15 & 603 & 491.26 & 57 & 685 & 489.76 & 99 & 769 & 487.14 & 141 & 853 & 487.73 \\
\hline 16 & 604 & 491.18 & 58 & 687 & 489.75 & 100 & 771 & 487.17 & 142 & 855 & 487.84 \\
\hline 17 & 605 & 491.04 & 59 & 689 & 489.74 & 101 & 773 & 487.23 & 143 & 857 & 487.94 \\
\hline 18 & 607 & 490.75 & 60 & 691 & 489.72 & 102 & 775 & 487.29 & 144 & 859 & 488 \\
\hline 19 & 609 & 490.46 & 61 & 693 & 489.69 & 103 & 777 & 487.35 & 145 & 861 & 488.06 \\
\hline 20 & 611 & 490.17 & 62 & 695 & 489.66 & 104 & 779 & 487.36 & 146 & 863 & 488.22 \\
\hline 21 & 613 & 490.08 & 63 & 697 & 489.63 & 105 & 781 & 487.34 & 147 & 865 & 488.86 \\
\hline 22 & 615 & 490.08 & 64 & 699 & 489.6 & 106 & 783 & 487.32 & 148 & 867 & 489.49 \\
\hline 23 & 617 & 490.09 & 65 & 701 & 489.55 & 107 & 785 & 487.3 & 149 & 869 & 490.08 \\
\hline 24 & 619 & 490.1 & 66 & 703 & 489.42 & 108 & 787 & 487.28 & 150 & 871 & 490.65 \\
\hline 25 & 621 & 490.09 & 67 & 705 & 489.3 & 109 & 789 & 487.27 & 151 & 873 & 491.26 \\
\hline 26 & 623 & 490.05 & 68 & 707 & 489.18 & 110 & 791 & 487.25 & 152 & 878.11 & 492.24 \\
\hline 27 & 625 & 490.01 & 69 & 709 & 489.08 & 111 & 793 & 487.23 & 153 & 888.24 & 493.41 \\
\hline 28 & 627 & 489.96 & 70 & 711 & 489 & 112 & 795 & 487.21 & 154 & 908.33 & 493.41 \\
\hline 29 & 629 & 489.92 & 71 & 713 & 488.93 & 113 & 797 & 487.19 & 155 & 943.36 & 496.54 \\
\hline 30 & 631 & 489.88 & 72 & 715 & 488.86 & 114 & 799 & 487.17 & 156 & 989.38 & 495.65 \\
\hline 31 & 633 & 489.86 & 73 & 717 & 488.85 & 115 & 801 & 487.15 & 157 & 1018.86 & 495.01 \\
\hline 32 & 635 & 489.83 & 74 & 719 & 488.89 & 116 & 803 & 487.12 & 158 & 1166.91 & 498.33 \\
\hline 33 & 637 & 489.81 & 75 & 721 & 488.93 & 117 & 805 & 487.17 & 159 & 1232.9 & 497.7 \\
\hline 34 & 639 & 489.78 & 76 & 723 & 488.88 & 118 & 807 & 487.23 & 160 & 1366.51 & 496.95 \\
\hline 35 & 641 & 489.76 & 77 & 725 & 488.8 & 119 & 809 & 487.29 & 161 & 1445.12 & 497.29 \\
\hline 36 & 643 & 489.73 & 78 & 727 & 488.72 & 120 & 811 & 487.34 & 162 & 1540.78 & 497.65 \\
\hline 37 & 645 & 489.7 & 79 & 729 & 488.64 & 121 & 813 & 487.4 & 163 & 1633.36 & 497.2 \\
\hline 38 & 647 & 489.68 & 80 & 731 & 488.52 & 122 & 815 & 487.41 & 164 & 1715.94 & 496.6 \\
\hline 39 & 649 & 489.65 & 81 & 733 & 488.36 & 123 & 817 & 487.4 & 165 & 1792.62 & 496.5 \\
\hline 40 & 651 & 489.62 & 82 & 735 & 488.2 & 124 & 819 & 487.39 & 166 & 1852.6 & 496.95 \\
\hline 41 & 653 & 489.63 & 83 & 737 & 488.04 & 125 & 821 & 487.44 & 167 & 1901.59 & 497.24 \\
\hline 42 & 655 & 489.64 & 84 & 739 & 487.88 & 126 & 823 & 487.57 & 168 & 2373 & 508 \\
\hline
\end{tabular}


Tabela 73 - Características Geométricas da Seção SF71100 do Rio São Francisco

\begin{tabular}{|c|c|c|c|c|c|c|c|c|c|c|c|}
\hline $\mathrm{n}^{\mathrm{o}}$ & $\mathrm{h}(\mathrm{m})$ & $\mathrm{z}(\mathrm{m})$ & $\mathrm{n}^{\mathrm{o}}$ & $\mathrm{h}(\mathrm{m})$ & $\mathrm{z}(\mathrm{m})$ & $n^{\circ}$ & $\mathrm{h}(\mathrm{m})$ & $\mathrm{z}(\mathrm{m})$ & $\mathrm{n}^{\mathrm{o}}$ & $\mathrm{h}(\mathrm{m})$ & $\mathrm{z}(\mathrm{m})$ \\
\hline 1 & 0 & 505.28 & 38 & 673 & 485.92 & 75 & 747 & 485.68 & 112 & 821 & 486.56 \\
\hline 2 & 24 & 505.15 & 39 & 675 & 485.9 & 76 & 749 & 485.59 & 113 & 823 & 486.76 \\
\hline 3 & 56 & 504.34 & 40 & 677 & 485.87 & 77 & 751 & 485.51 & 114 & 825 & 486.96 \\
\hline 4 & 93 & 503.51 & 41 & 679 & 485.92 & 78 & 753 & 485.46 & 115 & 827 & 486.85 \\
\hline 5 & 129 & 502.67 & 42 & 681 & 485.98 & 79 & 755 & 485.44 & 116 & 829 & 486.72 \\
\hline 6 & 161 & 501.94 & 43 & 683 & 486.04 & 80 & 757 & 485.42 & 117 & 831 & 486.58 \\
\hline 7 & 193 & 501.31 & 44 & 685 & 486.1 & 81 & 759 & 485.4 & 118 & 833 & 486.45 \\
\hline 8 & 223 & 500.89 & 45 & 687 & 486.16 & 82 & 761 & 485.38 & 119 & 835 & 486.32 \\
\hline 9 & 255 & 500.61 & 46 & 689 & 486.23 & 83 & 763 & 485.36 & 120 & 837 & 486.47 \\
\hline 10 & 281 & 500.34 & 47 & 691 & 486.29 & 84 & 765 & 485.38 & 121 & 839 & 486.76 \\
\hline 11 & 312 & 500.07 & 48 & 693 & 486.36 & 85 & 767 & 485.39 & 122 & 841 & 487.3 \\
\hline 12 & 344 & 499.65 & 49 & 695 & 486.28 & 86 & 769 & 485.41 & 123 & 843 & 488.41 \\
\hline 13 & 378 & 499.27 & 50 & 697 & 486.19 & 87 & 771 & 485.42 & 124 & 845 & 489.48 \\
\hline 14 & 401 & 498.82 & 51 & 699 & 486.11 & 88 & 773 & 485.4 & 125 & 849.97 & 491.41 \\
\hline 15 & 432 & 497.77 & 52 & 701 & 486.02 & 89 & 775 & 485.35 & 126 & 859.45 & 492.27 \\
\hline 16 & 467 & 496.13 & 53 & 703 & 485.94 & 90 & 777 & 485.29 & 127 & 867.06 & 494.22 \\
\hline 17 & 489 & 496.02 & 54 & 705 & 485.88 & 91 & 779 & 485.24 & 128 & 873.53 & 494.93 \\
\hline 18 & 522 & 497.43 & 55 & 707 & 485.83 & 92 & 781 & 485.18 & 129 & 881.03 & 495.1 \\
\hline 19 & 548 & 498.28 & 56 & 709 & 485.77 & 93 & 783 & 485.16 & 130 & 894.09 & 494.91 \\
\hline 20 & 581 & 498.34 & 57 & 711 & 485.72 & 94 & 785 & 485.16 & 131 & 901.04 & 495.08 \\
\hline 21 & 613 & 497.12 & 58 & 713 & 485.66 & 95 & 787 & 485.16 & 132 & 911.88 & 495.74 \\
\hline 22 & 643.5 & 489.48 & 59 & 715 & 485.67 & 96 & 789 & 485.16 & 133 & 917.38 & 495.71 \\
\hline 23 & 644 & 489.05 & 60 & 717 & 485.69 & 97 & 791 & 485.15 & 134 & 926.17 & 495.51 \\
\hline 24 & 645 & 488.51 & 61 & 719 & 485.71 & 98 & 793 & 485.15 & 135 & 935.98 & 495.55 \\
\hline 25 & 647 & 487.42 & 62 & 721 & 485.73 & 99 & 795 & 485.18 & 136 & 946.43 & 495.62 \\
\hline 26 & 649 & 486.34 & 63 & 723 & 485.74 & 100 & 797 & 485.31 & 137 & 984.59 & 495.04 \\
\hline 27 & 651 & 486.03 & 64 & 725 & 485.75 & 101 & 799 & 485.45 & 138 & 1069.4 & 494 \\
\hline 28 & 653 & 486.17 & 65 & 727 & 485.76 & 102 & 801 & 485.59 & 139 & 1117.43 & 494.31 \\
\hline 29 & 655 & 486.32 & 66 & 729 & 485.84 & 103 & 803 & 485.67 & 140 & 1154.55 & 493.88 \\
\hline 30 & 657 & 486.45 & 67 & 731 & 486.19 & 104 & 805 & 485.67 & 141 & 1211.62 & 494.24 \\
\hline 31 & 659 & 486.4 & 68 & 733 & 486.55 & 105 & 807 & 485.66 & 142 & 1286.11 & 493.04 \\
\hline 32 & 661 & 486.36 & 69 & 735 & 486.9 & 106 & 809 & 485.66 & 143 & 1332.07 & 492.8 \\
\hline 33 & 663 & 486.31 & 70 & 737 & 486.69 & 107 & 811 & 485.75 & 144 & 1381.65 & 493.4 \\
\hline 34 & 665 & 486.2 & 71 & 739 & 486.38 & 108 & 813 & 485.89 & 145 & 1432.52 & 494.12 \\
\hline 35 & 667 & 486.1 & 72 & 741 & 486.07 & 109 & 815 & 486.03 & 146 & 1472.69 & 500.73 \\
\hline 36 & 669 & 486 & 73 & 743 & 485.84 & 110 & 817 & 486.17 & 147 & 1511.17 & 503.42 \\
\hline 37 & 671 & 485.94 & 74 & 745 & 485.76 & 111 & 819 & 486.37 & - & - & - \\
\hline
\end{tabular}


Tabela 74 - Características Geométricas da Seção SF68200 do Rio São Francisco

\begin{tabular}{|c|c|c|c|c|c|c|c|c|c|c|c|}
\hline$\overline{n^{\circ}}$ & $\overline{\mathrm{h}(\mathrm{m})}$ & $\overline{\mathrm{z}(\mathrm{m})}$ & $\overline{\mathrm{n}^{\mathrm{o}}}$ & $\overline{\mathrm{h}(\mathrm{m})}$ & $\overline{z z(m)}$ & $\overline{n^{\circ}}$ & $\overline{\mathrm{h}(\mathrm{m})}$ & $\overline{\mathrm{z}(\mathrm{m})}$ & $\overline{\mathrm{n}^{\mathrm{o}}}$ & $\overline{\mathrm{h}(\mathrm{m})}$ & $\mathrm{z}(\mathrm{m})$ \\
\hline 1 & 0 & 505 & 44 & 1302 & 484.97 & 87 & 1388 & 485.19 & 130 & 1474 & 487.07 \\
\hline 2 & 291 & 494.24 & 45 & 1304 & 485.04 & 88 & 1390 & 485.18 & 131 & 1476 & 487 \\
\hline 3 & 323 & 494.47 & 46 & 1306 & 485.11 & 89 & 1392 & 485.27 & 132 & 1478 & 486.94 \\
\hline 4 & 368 & 494.37 & 47 & 1308 & 485.19 & 90 & 1394 & 485.35 & 133 & 1480 & 486.87 \\
\hline 5 & 415 & 495.36 & 48 & 1310 & 485.26 & 91 & 1396 & 485.4 & 134 & 1482 & 486.78 \\
\hline 6 & 463 & 494.97 & 49 & 1312 & 485.28 & 92 & 1398 & 485.45 & 135 & 1484 & 486.68 \\
\hline 7 & 515 & 496.28 & 50 & 1314 & 485.3 & 93 & 1400 & 485.5 & 136 & 1486 & 486.58 \\
\hline 8 & 571 & 496.65 & 51 & 1316 & 485.32 & 94 & 1402 & 485.55 & 137 & 1488 & 486.49 \\
\hline 9 & 616 & 496.78 & 52 & 1318 & 485.32 & 95 & 1404 & 485.6 & 138 & 1490 & 486.39 \\
\hline 10 & 669 & 496.99 & 53 & 1320 & 485.28 & 96 & 1406 & 485.66 & 139 & 1492 & 486.73 \\
\hline 11 & 717 & 496.99 & 54 & 1322 & 485.23 & 97 & 1408 & 485.59 & 140 & 1494 & 487.23 \\
\hline 12 & 770 & 496.96 & 55 & 1324 & 485.19 & 98 & 1410 & 485.53 & 141 & 1496 & 487.74 \\
\hline 13 & 825 & 496.77 & 56 & 1326 & 485.14 & 99 & 1412 & 485.46 & 142 & 1498 & 488.24 \\
\hline 14 & 857 & 496.66 & 57 & 1328 & 485.14 & 100 & 1414 & 485.4 & 143 & 1500 & 488.75 \\
\hline 15 & 890 & 496.29 & 58 & 1330 & 485.14 & 101 & 1416 & 485.38 & 144 & 1506.55 & 491.48 \\
\hline 16 & 923 & 495.69 & 59 & 1332 & 485.13 & 102 & 1418 & 485.4 & 145 & 1518.53 & 491.92 \\
\hline 17 & 954 & 493.99 & 60 & 1334 & 485.13 & 103 & 1420 & 485.41 & 146 & 1527.44 & 494 \\
\hline 18 & 990 & 493.17 & 61 & 1336 & 485.13 & 104 & 1422 & 485.42 & 147 & 1541 & 496.16 \\
\hline 19 & 1023 & 492.76 & 62 & 1338 & 485.13 & 105 & 1424 & 485.43 & 148 & 1547.77 & 496.41 \\
\hline 20 & 1055 & 492.62 & 63 & 1340 & 485.13 & 106 & 1426 & 485.45 & 149 & 1557.62 & 496.46 \\
\hline 21 & 1078 & 492.91 & 64 & 1342 & 485.13 & 107 & 1428 & 485.46 & 150 & 1569.03 & 496.36 \\
\hline 22 & 1109 & 494.02 & 65 & 1344 & 485.14 & 108 & 1430 & 485.47 & 151 & 1579.79 & 495.93 \\
\hline 23 & 1140 & 494.71 & 66 & 1346 & 485.15 & 109 & 1432 & 485.48 & 152 & 1593.21 & 495.47 \\
\hline 24 & 1172 & 493.87 & 67 & 1348 & 485.16 & 110 & 1434 & 485.47 & 153 & 1602.6 & 495.22 \\
\hline 25 & 1202 & 494.98 & 68 & 1350 & 485.23 & 111 & 1436 & 485.46 & 154 & 1615.28 & 495.19 \\
\hline 26 & 1241 & 494.68 & 69 & 1352 & 485.32 & 112 & 1438 & 485.46 & 155 & 1628.78 & 495.26 \\
\hline 27 & 1270.98 & 488.75 & 70 & 1354 & 485.4 & 113 & 1440 & 485.49 & 156 & 1646.35 & 495.68 \\
\hline 28 & 1271 & 488.74 & 71 & 1356 & 485.45 & 114 & 1442 & 485.53 & 157 & 1658.95 & 495.49 \\
\hline 29 & 1272 & 488.08 & 72 & 1358 & 485.49 & 115 & 1444 & 485.56 & 158 & 1670.4 & 495.49 \\
\hline 30 & 1274 & 486.77 & 73 & 1360 & 485.53 & 116 & 1446 & 485.59 & 159 & 1681.89 & 495.43 \\
\hline 31 & 1276 & 485.45 & 74 & 1362 & 485.52 & 117 & 1448 & 485.63 & 160 & 1745.38 & 495.18 \\
\hline 32 & 1278 & 484.89 & 75 & 1364 & 485.4 & 118 & 1450 & 485.66 & 161 & 1799.23 & 495.52 \\
\hline 33 & 1280 & 484.77 & 76 & 1366 & 485.3 & 119 & 1452 & 485.76 & 162 & 1843.62 & 496.34 \\
\hline 34 & 1282 & 484.65 & 77 & 1368 & 485.21 & 120 & 1454 & 485.87 & 163 & 1881.86 & 496.91 \\
\hline 35 & 1284 & 484.72 & 78 & 1370 & 485.13 & 121 & 1456 & 485.98 & 164 & 1948.91 & 497.57 \\
\hline 36 & 1286 & 484.81 & 79 & 1372 & 485.2 & 122 & 1458 & 486.08 & 165 & 2007.05 & 497.92 \\
\hline 37 & 1288 & 484.79 & 80 & 1374 & 485.29 & 123 & 1460 & 486.19 & 166 & 2066.67 & 498.51 \\
\hline 38 & 1290 & 484.7 & 81 & 1376 & 485.38 & 124 & 1462 & 486.3 & 167 & 2125.45 & 499.26 \\
\hline 39 & 1292 & 484.72 & 82 & 1378 & 485.44 & 125 & 1464 & 486.48 & 168 & 2184 & 500.41 \\
\hline 40 & 1294 & 484.83 & 83 & 1380 & 485.41 & 126 & 1466 & 486.68 & 169 & 2226.74 & 501.41 \\
\hline 41 & 1296 & 484.88 & 84 & 1382 & 485.39 & 127 & 1468 & 486.87 & 170 & 2269.29 & 502.83 \\
\hline 42 & 1298 & 484.91 & 85 & 1384 & 485.36 & 128 & 1470 & 487.06 & 171 & 2342.35 & 505.02 \\
\hline 43 & 1300 & 484.94 & 86 & 1386 & 485.27 & 129 & 1472 & 487.14 & . & - & - \\
\hline
\end{tabular}


Tabela 75 - Características Geométricas da Seção SF63800 do Rio São Francisco

\begin{tabular}{|c|c|c|c|c|c|c|c|c|c|c|c|}
\hline $\mathrm{n}^{\mathrm{o}}$ & $\overline{\mathrm{h}(\mathrm{m})}$ & $\overline{z(m)}$ & $\mathrm{n}^{\mathrm{o}}$ & $\overline{\mathrm{h}(\mathrm{m})}$ & $\mathrm{z}(\mathrm{m})$ & $\mathrm{n}^{\mathrm{o}}$ & $\mathrm{h}(\mathrm{m})$ & $\bar{z}(\mathrm{~m})$ & $\mathrm{n}^{\mathrm{o}}$ & $\mathrm{h}(\mathrm{m})$ & $\mathrm{z}(\mathrm{m})$ \\
\hline 1 & 0 & 505 & 39 & 1812 & 485.97 & 77 & 1888 & 485.89 & 115 & 1964 & 487.87 \\
\hline 2 & 763 & 492.85 & 40 & 1814 & 486 & 78 & 1890 & 485.91 & 116 & 1966 & 487.89 \\
\hline 3 & 785 & 493.03 & 41 & 1816 & 486.04 & 79 & 1892 & 485.93 & 117 & 1968 & 487.77 \\
\hline 4 & 802 & 493.3 & 42 & 1818 & 486.07 & 80 & 1894 & 485.95 & 118 & 1970 & 487.63 \\
\hline 5 & 834 & 493.6 & 43 & 1820 & 486.1 & 81 & 1896 & 485.97 & 119 & 1972 & 487.49 \\
\hline 6 & 857 & 494.15 & 44 & 1822 & 486.14 & 82 & 1898 & 485.99 & 120 & 1974 & 487.46 \\
\hline 7 & 1121 & 492.66 & 45 & 1824 & 486.17 & 83 & 1900 & 486.02 & 121 & 1976 & 487.45 \\
\hline 8 & 1143 & 494.07 & 46 & 1826 & 486.06 & 84 & 1902 & 486.05 & 122 & 1978 & 487.43 \\
\hline 9 & 1167 & 494.14 & 47 & 1828 & 485.91 & 85 & 1904 & 486.08 & 123 & 1980 & 487.42 \\
\hline 10 & 1193 & 493.79 & 48 & 1830 & 485.77 & 86 & 1906 & 486.11 & 124 & 1982 & 487.4 \\
\hline 11 & 1222 & 492.87 & 49 & 1832 & 485.63 & 87 & 1908 & 486.2 & 125 & 1984 & 487.38 \\
\hline 12 & 1416 & 492.25 & 50 & 1834 & 485.49 & 88 & 1910 & 486.43 & 126 & 1986 & 487.37 \\
\hline 13 & 1435 & 492.62 & 51 & 1836 & 485.35 & 89 & 1912 & 486.66 & 127 & 1988 & 487.43 \\
\hline 14 & 1463 & 493.04 & 52 & 1838 & 485.21 & 90 & 1914 & 486.9 & 128 & 1990 & 487.67 \\
\hline 15 & 1495 & 493.99 & 53 & 1840 & 485.2 & 91 & 1916 & 487.13 & 129 & 1992 & 487.9 \\
\hline 16 & 1527 & 493 & 54 & 1842 & 485.2 & 92 & 1918 & 487.21 & 130 & 1994 & 488.13 \\
\hline 17 & 1551 & 492.76 & 55 & 1844 & 485.19 & 93 & 1920 & 487.23 & 131 & 1996 & 488.37 \\
\hline 18 & 1582 & 493.16 & 56 & 1846 & 485.18 & 94 & 1922 & 487.25 & 132 & 1998 & 488.6 \\
\hline 19 & 1605 & 493.57 & 57 & 1848 & 485.17 & 95 & 1924 & 487.27 & 133 & 2000 & 488.83 \\
\hline 20 & 1639 & 494.47 & 58 & 1850 & 485.19 & 96 & 1926 & 487.28 & 134 & 2020.31 & 492.04 \\
\hline 21 & 1663 & 495.6 & 59 & 1852 & 485.27 & 97 & 1928 & 487.3 & 135 & 2040 & 494.92 \\
\hline 22 & 1694 & 491.87 & 60 & 1854 & 485.34 & 98 & 1930 & 487.32 & 136 & 2060.09 & 495.3 \\
\hline 23 & 1705.05 & 488.83 & 61 & 1856 & 485.42 & 99 & 1932 & 487.36 & 137 & 2080.97 & 494.81 \\
\hline 24 & 1782 & 486.97 & 62 & 1858 & 485.49 & 100 & 1934 & 487.42 & 138 & 2101.82 & 494.84 \\
\hline 25 & 1784 & 486.96 & 63 & 1860 & 485.57 & 101 & 1936 & 487.49 & 139 & 2122.72 & 494.42 \\
\hline 26 & 1786 & 486.94 & 64 & 1862 & 485.66 & 102 & 1938 & 487.56 & 140 & 2142.86 & 494 \\
\hline 27 & 1788 & 486.93 & 65 & 1864 & 485.76 & 103 & 1940 & 487.63 & 141 & 2177 & 494.07 \\
\hline 28 & 1790 & 486.84 & 66 & 1866 & 485.86 & 104 & 1942 & 487.69 & 142 & 2221.41 & 493.98 \\
\hline 29 & 1792 & 486.65 & 67 & 1868 & 485.96 & 105 & 1944 & 487.72 & 143 & 2266.49 & 496 \\
\hline 30 & 1794 & 486.54 & 68 & 1870 & 486.06 & 106 & 1946 & 487.69 & 144 & 2322.4 & 498.31 \\
\hline 31 & 1796 & 486.44 & 69 & 1872 & 486.16 & 107 & 1948 & 487.67 & 145 & 2384.53 & 500.24 \\
\hline 32 & 1798 & 486.34 & 70 & 1874 & 486.09 & 108 & 1950 & 487.68 & 146 & 2430.73 & 501.48 \\
\hline 33 & 1800 & 486.25 & 71 & 1876 & 485.98 & 109 & 1952 & 487.81 & 147 & 2459.15 & 502.37 \\
\hline 34 & 1802 & 486.17 & 72 & 1878 & 485.86 & 110 & 1954 & 487.94 & 148 & 2495.42 & 503.49 \\
\hline 35 & 1804 & 486.12 & 73 & 1880 & 485.75 & 111 & 1956 & 487.91 & 149 & 2530.17 & 504.61 \\
\hline 36 & 1806 & 486.06 & 74 & 1882 & 485.74 & 112 & 1958 & 487.87 & - & - & - \\
\hline 37 & 1808 & 486.01 & 75 & 1884 & 485.82 & 113 & 1960 & 487.84 & - & - & - \\
\hline 38 & 1810 & 485.95 & 76 & 1886 & 485.88 & 114 & 1962 & 487.86 & - & - & - \\
\hline
\end{tabular}


Tabela 76 - Características Geométricas da Seção SF57000 do Rio São Francisco

\begin{tabular}{|c|c|c|c|c|c|c|c|c|c|c|c|}
\hline$\overline{n^{\circ}}$ & $\overline{\mathrm{h}(\mathrm{m})}$ & $\overline{\mathrm{z}(\mathrm{m})}$ & $\overline{n^{\circ}}$ & $\overline{\mathrm{h}(\mathrm{m})}$ & $\overline{z z(m)}$ & $\overline{\mathrm{n}^{\circ}}$ & $\overline{\mathrm{h}(\mathrm{m})}$ & $\overline{\mathrm{z}(\mathrm{m})}$ & $\overline{\mathrm{n}^{\mathrm{o}}}$ & $\overline{h(m)}$ & $\overline{\mathrm{z}(\mathrm{m})}$ \\
\hline 1 & 0 & 504.59 & 44 & 463 & 484.59 & 87 & 549 & 483.9 & 130 & 635 & 483.36 \\
\hline 2 & 31 & 503.28 & 45 & 465 & 484.6 & 88 & 551 & 483.89 & 131 & 637 & 483.51 \\
\hline 3 & 44 & 502.4 & 46 & 467 & 484.6 & 89 & 553 & 483.87 & 132 & 639 & 483.66 \\
\hline 4 & 71 & 501.13 & 47 & 469 & 484.61 & 90 & 555 & 483.86 & 133 & 641 & 483.69 \\
\hline 5 & 99 & 499.51 & 48 & 471 & 484.62 & 91 & 557 & 483.83 & 134 & 643 & 483.72 \\
\hline 6 & 135 & 497.59 & 49 & 473 & 484.64 & 92 & 559 & 483.79 & 135 & 645 & 483.74 \\
\hline 7 & 171 & 496.04 & 50 & 475 & 484.65 & 93 & 561 & 483.75 & 136 & 647 & 483.98 \\
\hline 8 & 208 & 494.03 & 51 & 477 & 484.66 & 94 & 563 & 483.71 & 137 & 649 & 484.61 \\
\hline 9 & 239 & 492.6 & 52 & 479 & 484.68 & 95 & 565 & 483.67 & 138 & 651 & 485.25 \\
\hline 10 & 269 & 491.93 & 53 & 481 & 484.7 & 96 & 567 & 483.64 & 139 & 653 & 486.21 \\
\hline 11 & 300 & 492.24 & 54 & 483 & 484.74 & 97 & 569 & 483.62 & 140 & 655 & 487.18 \\
\hline 12 & 331 & 493.55 & 55 & 485 & 484.78 & 98 & 571 & 483.6 & 141 & 657 & 488.15 \\
\hline 13 & 360 & 493.84 & 56 & 487 & 484.82 & 99 & 573 & 483.58 & 142 & 660.32 & 490.66 \\
\hline 14 & 384 & 492.96 & 57 & 489 & 484.86 & 100 & 575 & 483.56 & 143 & 668.03 & 492.43 \\
\hline 15 & 403 & 491.17 & 58 & 491 & 484.89 & 101 & 577 & 483.54 & 144 & 676.63 & 493.07 \\
\hline 16 & 410 & 488.15 & 59 & 493 & 484.77 & 102 & 579 & 483.47 & 145 & 681.58 & 493.77 \\
\hline 17 & 413 & 487.33 & 60 & 495 & 484.64 & 103 & 581 & 483.41 & 146 & 689.34 & 494.77 \\
\hline 18 & 413.97 & 487.35 & 61 & 497 & 484.52 & 104 & 583 & 483.35 & 147 & 698.49 & 495.05 \\
\hline 19 & 414 & 487.33 & 62 & 499 & 484.39 & 105 & 585 & 483.28 & 148 & 708.54 & 495.14 \\
\hline 20 & 415 & 486.71 & 63 & 501 & 484.24 & 106 & 587 & 483.22 & 149 & 731.86 & 495 \\
\hline 21 & 417 & 485.46 & 64 & 503 & 484.09 & 107 & 589 & 483.18 & 150 & 751.5 & 494.67 \\
\hline 22 & 419 & 484.9 & 65 & 505 & 484.08 & 108 & 591 & 483.15 & 151 & 781.17 & 493.6 \\
\hline 23 & 421 & 484.89 & 66 & 507 & 484.1 & 109 & 593 & 483.12 & 152 & 805.88 & 493.28 \\
\hline 24 & 423 & 484.88 & 67 & 509 & 484.13 & 110 & 595 & 483.09 & 153 & 853.84 & 492.99 \\
\hline 25 & 425 & 484.96 & 68 & 511 & 484.15 & 111 & 597 & 483.13 & 154 & 901.47 & 492.45 \\
\hline 26 & 427 & 485.14 & 69 & 513 & 484.19 & 112 & 599 & 483.19 & 155 & 934.5 & 492.13 \\
\hline 27 & 429 & 485.31 & 70 & 515 & 484.23 & 113 & 601 & 483.24 & 156 & 969.18 & 491.77 \\
\hline 28 & 431 & 485.32 & 71 & 517 & 484.28 & 114 & 603 & 483.29 & 157 & 1032.99 & 491.9 \\
\hline 29 & 433 & 485.23 & 72 & 519 & 484.33 & 115 & 605 & 483.33 & 158 & 1106.81 & 490.59 \\
\hline 30 & 435 & 485.14 & 73 & 521 & 484.37 & 116 & 607 & 483.36 & 159 & 1174.9 & 492.02 \\
\hline 31 & 437 & 485.06 & 74 & 523 & 484.35 & 117 & 609 & 483.39 & 160 & 1241.11 & 494.23 \\
\hline 32 & 439 & 485.02 & 75 & 525 & 484.33 & 118 & 611 & 483.4 & 161 & 1310.57 & 495.97 \\
\hline 33 & 441 & 484.97 & 76 & 527 & 484.31 & 119 & 613 & 483.27 & 162 & 1372.14 & 496.53 \\
\hline 34 & 443 & 484.93 & 77 & 529 & 484.28 & 120 & 615 & 483.14 & 163 & 1442.54 & 496.19 \\
\hline 35 & 445 & 484.88 & 78 & 531 & 484.38 & 121 & 617 & 483.21 & 164 & 1510.99 & 495.68 \\
\hline 36 & 447 & 484.84 & 79 & 533 & 484.48 & 122 & 619 & 483.31 & 165 & 1577.44 & 495.31 \\
\hline 37 & 449 & 484.8 & 80 & 535 & 484.49 & 123 & 621 & 483.33 & 166 & 1618.12 & 495.31 \\
\hline 38 & 451 & 484.75 & 81 & 537 & 484.17 & 124 & 623 & 483.25 & 167 & 1654.28 & 495.33 \\
\hline 39 & 453 & 484.71 & 82 & 539 & 483.85 & 125 & 625 & 483.21 & 168 & 1690.54 & 495.3 \\
\hline 40 & 455 & 484.67 & 83 & 541 & 483.87 & 126 & 627 & 483.18 & 169 & 1702.08 & 495.37 \\
\hline 41 & 457 & 484.63 & 84 & 543 & 483.89 & 127 & 629 & 483.17 & 170 & 2157 & 505 \\
\hline 42 & 459 & 484.59 & 85 & 545 & 483.92 & 128 & 631 & 483.23 & - & - & - \\
\hline 43 & 461 & 484.58 & 86 & 547 & 483.92 & 129 & 633 & 483.29 & - & - & - \\
\hline
\end{tabular}


Tabela 77 - Características Geométricas da Seção SF53400 do Rio São Francisco

\begin{tabular}{|c|c|c|c|c|c|c|c|c|c|c|c|}
\hline$\overline{n^{\circ}}$ & $\overline{\mathrm{h}(\mathrm{m})}$ & $\mathrm{z}(\mathrm{m})$ & $\mathrm{n}^{\mathrm{o}}$ & $\overline{\mathrm{h}(\mathrm{m})}$ & $\overline{z z(m)}$ & $\overline{n^{\circ}}$ & $\overline{\mathrm{h}(\mathrm{m})}$ & $\overline{z z(m)}$ & $\overline{n^{\circ}}$ & $\overline{\mathrm{h}(\mathrm{m})}$ & $\overline{\mathrm{z}(\mathrm{m})}$ \\
\hline 1 & 0 & 497.24 & 45 & 1170 & 484.21 & 89 & 1258 & 483.88 & 133 & 1346 & 483.29 \\
\hline 2 & 25 & 496.61 & 46 & 1172 & 484.23 & 90 & 1260 & 483.85 & 134 & 1348 & 483.25 \\
\hline 3 & 68 & 496.22 & 47 & 1174 & 484.26 & 91 & 1262 & 483.81 & 135 & 1350 & 483.31 \\
\hline 4 & 119 & 494.8 & 48 & 1176 & 484.28 & 92 & 1264 & 483.77 & 136 & 1352 & 483.37 \\
\hline 5 & 170 & 494.13 & 49 & 1178 & 484.31 & 93 & 1266 & 483.73 & 137 & 1354 & 483.29 \\
\hline 6 & 226 & 493.74 & 50 & 1180 & 484.33 & 94 & 1268 & 483.73 & 138 & 1356 & 483.21 \\
\hline 7 & 275 & 493.64 & 51 & 1182 & 484.36 & 95 & 1270 & 483.8 & 139 & 1358 & 483.3 \\
\hline 8 & 324 & 493.68 & 52 & 1184 & 484.31 & 96 & 1272 & 483.87 & 140 & 1360 & 483.54 \\
\hline 9 & 378 & 493.39 & 53 & 1186 & 484.25 & 97 & 1274 & 483.9 & 141 & 1362 & 483.66 \\
\hline 10 & 429 & 492.69 & 54 & 1188 & 484.19 & 98 & 1276 & 483.93 & 142 & 1364 & 483.66 \\
\hline 11 & 482 & 491.21 & 55 & 1190 & 484.16 & 99 & 1278 & 483.96 & 143 & 1366 & 483.73 \\
\hline 12 & 538 & 490.75 & 56 & 1192 & 484.13 & 100 & 1280 & 483.94 & 144 & 1368 & 483.83 \\
\hline 13 & 594 & 490.95 & 57 & 1194 & 484.09 & 101 & 1282 & 483.86 & 145 & 1370 & 484.71 \\
\hline 14 & 640 & 490.79 & 58 & 1196 & 484 & 102 & 1284 & 483.77 & 146 & 1372 & 486.27 \\
\hline 15 & 687 & 490.37 & 59 & 1198 & 483.91 & 103 & 1286 & 483.68 & 147 & 1378.91 & 488.67 \\
\hline 16 & 731 & 490.96 & 60 & 1200 & 483.87 & 104 & 1288 & 483.63 & 148 & 1387.9 & 489.86 \\
\hline 17 & 763 & 490.58 & 61 & 1202 & 483.87 & 105 & 1290 & 483.57 & 149 & 1396.95 & 492.45 \\
\hline 18 & 796 & 490.37 & 62 & 1204 & 483.86 & 106 & 1292 & 483.51 & 150 & 1406 & 492.66 \\
\hline 19 & 861 & 490.32 & 63 & 1206 & 483.89 & 107 & 1294 & 483.46 & 151 & 1414.73 & 492.08 \\
\hline 20 & 894 & 490.83 & 64 & 1208 & 483.92 & 108 & 1296 & 483.43 & 152 & 1426.24 & 491.54 \\
\hline 21 & 929 & 491.56 & 65 & 1210 & 483.95 & 109 & 1298 & 483.4 & 153 & 1443.2 & 491.16 \\
\hline 22 & 969 & 492.08 & 66 & 1212 & 483.98 & 110 & 1300 & 483.4 & 154 & 1463.27 & 490.84 \\
\hline 23 & 995 & 492.59 & 67 & 1214 & 483.92 & 111 & 1302 & 483.42 & 155 & 1489.2 & 490.75 \\
\hline 24 & 1030 & 491.19 & 68 & 1216 & 483.85 & 112 & 1304 & 483.45 & 156 & 1526.44 & 490.57 \\
\hline 25 & 1054 & 486.27 & 69 & 1218 & 483.8 & 113 & 1306 & 483.47 & 157 & 1562.67 & 490.63 \\
\hline 26 & 1056 & 486.27 & 70 & 1220 & 483.79 & 114 & 1308 & 483.58 & 158 & 1596.72 & 490.84 \\
\hline 27 & 1058 & 485.62 & 71 & 1222 & 483.78 & 115 & 1310 & 483.72 & 159 & 1632.8 & 490.89 \\
\hline 28 & 1060 & 484.96 & 72 & 1224 & 483.8 & 116 & 1312 & 483.87 & 160 & 1670.66 & 491.07 \\
\hline 29 & 1062 & 484.31 & 73 & 1226 & 483.82 & 117 & 1314 & 483.96 & 161 & 1742.04 & 491.37 \\
\hline 30 & 1064 & 483.66 & 74 & 1228 & 483.84 & 118 & 1316 & 484.05 & 162 & 1788.04 & 491.8 \\
\hline 31 & 1066 & 483.41 & 75 & 1230 & 483.87 & 119 & 1318 & 484.06 & 163 & 1850.28 & 492.16 \\
\hline 32 & 1068 & 483.43 & 76 & 1232 & 483.91 & 120 & 1320 & 484.06 & 164 & 1918.02 & 492.73 \\
\hline 33 & 1070 & 483.45 & 77 & 1234 & 484 & 121 & 1322 & 484.06 & 165 & 2006.01 & 493.3 \\
\hline 34 & 1072 & 483.51 & 78 & 1236 & 484.09 & 122 & 1324 & 483.95 & 166 & 2049.6 & 493.78 \\
\hline 35 & 1074 & 483.58 & 79 & 1238 & 484.14 & 123 & 1326 & 483.84 & 167 & 2107.01 & 494.38 \\
\hline 36 & 1076 & 483.64 & 80 & 1240 & 484.1 & 124 & 1328 & 483.77 & 168 & 2136.55 & 494.74 \\
\hline 37 & 1154 & 483.63 & 81 & 1242 & 484.05 & 125 & 1330 & 483.69 & 169 & 2215.15 & 495.59 \\
\hline 38 & 1156 & 483.68 & 82 & 1244 & 484 & 126 & 1332 & 483.64 & 170 & 2275.78 & 495.71 \\
\hline 39 & 1158 & 483.75 & 83 & 1246 & 483.96 & 127 & 1334 & 483.61 & 171 & 2320.84 & 496.82 \\
\hline 40 & 1160 & 483.82 & 84 & 1248 & 483.91 & 128 & 1336 & 483.57 & 172 & 2372.53 & 496.47 \\
\hline 41 & 1162 & 483.91 & 85 & 1250 & 483.87 & 129 & 1338 & 483.51 & 173 & 2420.61 & 497.39 \\
\hline 42 & 1164 & 484 & 86 & 1252 & 483.84 & 130 & 1340 & 483.45 & 174 & 2457.76 & 497.77 \\
\hline 43 & 1166 & 484.09 & 87 & 1254 & 483.85 & 131 & 1342 & 483.39 & - & - & - \\
\hline 44 & 1168 & 484.18 & 88 & 1256 & 483.87 & 132 & 1344 & 483.33 & - & - & - \\
\hline
\end{tabular}


Tabela 78 - Características Geométricas da Seção SF44700 do Rio São Francisco

\begin{tabular}{|c|c|c|c|c|c|c|c|c|c|c|c|}
\hline $\mathrm{n}^{\mathrm{o}}$ & $\mathrm{h}(\mathrm{m})$ & $\mathrm{z}(\mathrm{m})$ & $\mathrm{n}^{\mathrm{o}}$ & $\overline{h(m)}$ & $\mathrm{z}(\mathrm{m})$ & $\mathrm{n}^{\mathrm{o}}$ & $\mathrm{h}(\mathrm{m})$ & $\mathrm{z}(\mathrm{m})$ & $\mathrm{n}^{\mathrm{o}}$ & $\mathrm{h}(\mathrm{m})$ & $\bar{z}(\mathrm{~m})$ \\
\hline 1 & 0 & 493.44 & 41 & 947 & 484.08 & 81 & 1105 & 483.56 & 121 & 1185 & 482.95 \\
\hline 2 & 51 & 490.84 & 42 & 949 & 484.04 & 82 & 1107 & 483.62 & 122 & 1187 & 482.96 \\
\hline 3 & 101 & 491.39 & 43 & 1029 & 484.83 & 83 & 1109 & 483.67 & 123 & 1189 & 482.97 \\
\hline 4 & 151 & 491.95 & 44 & 1031 & 484.86 & 84 & 1111 & 483.72 & 124 & 1191 & 482.98 \\
\hline 5 & 201 & 492.59 & 45 & 1033 & 484.89 & 85 & 1113 & 483.78 & 125 & 1193 & 482.99 \\
\hline 6 & 251 & 493 & 46 & 1035 & 484.93 & 86 & 1115 & 483.83 & 126 & 1195 & 483 \\
\hline 7 & 305 & 491.96 & 47 & 1037 & 484.98 & 87 & 1117 & 483.88 & 127 & 1197 & 483.01 \\
\hline 8 & 352 & 490.91 & 48 & 1039 & 485.04 & 88 & 1119 & 483.9 & 128 & 1199 & 482.99 \\
\hline 9 & 404 & 490.65 & 49 & 1041 & 485.05 & 89 & 1121 & 483.89 & 129 & 1201 & 482.94 \\
\hline 10 & 453 & 490.7 & 50 & 1043 & 485.06 & 90 & 1123 & 483.88 & 130 & 1203 & 482.89 \\
\hline 11 & 504 & 490.76 & 51 & 1045 & 485.07 & 91 & 1125 & 483.87 & 131 & 1205 & 482.84 \\
\hline 12 & 552 & 490.91 & 52 & 1047 & 485.08 & 92 & 1127 & 483.86 & 132 & 1207 & 482.79 \\
\hline 13 & 603 & 491.02 & 53 & 1049 & 485.08 & 93 & 1129 & 483.85 & 133 & 1209 & 482.7 \\
\hline 14 & 653 & 491.23 & 54 & 1051 & 485.05 & 94 & 1131 & 483.84 & 134 & 1211 & 482.61 \\
\hline 15 & 703 & 491.56 & 55 & 1053 & 485.03 & 95 & 1133 & 483.83 & 135 & 1213 & 482.52 \\
\hline 16 & 754 & 491.61 & 56 & 1055 & 485.08 & 96 & 1135 & 483.82 & 136 & 1215 & 482.43 \\
\hline 17 & 804 & 492.34 & 57 & 1057 & 485.2 & 97 & 1137 & 483.81 & 137 & 1217 & 482.34 \\
\hline 18 & 854 & 492.61 & 58 & 1059 & 484.61 & 98 & 1139 & 483.7 & 138 & 1219 & 482.28 \\
\hline 19 & 904 & 485.75 & 59 & 1061 & 483.7 & 99 & 1141 & 483.53 & 139 & 1221 & 482.23 \\
\hline 20 & 905 & 485.52 & 60 & 1063 & 483.98 & 100 & 1143 & 483.36 & 140 & 1223 & 482.4 \\
\hline 21 & 907 & 485.06 & 61 & 1065 & 484.02 & 101 & 1145 & 483.18 & 141 & 1225 & 482.77 \\
\hline 22 & 909 & 484.6 & 62 & 1067 & 484.02 & 102 & 1147 & 483.01 & 142 & 1227 & 483.14 \\
\hline 23 & 911 & 484.15 & 63 & 1069 & 484.02 & 103 & 1149 & 482.84 & 143 & 1229 & 483.51 \\
\hline 24 & 913 & 484.07 & 64 & 1071 & 483.94 & 104 & 1151 & 482.7 & 144 & 1231 & 483.44 \\
\hline 25 & 915 & 484.1 & 65 & 1073 & 483.88 & 105 & 1153 & 482.67 & 145 & 1233 & 483.36 \\
\hline 26 & 917 & 484.14 & 66 & 1075 & 484.04 & 106 & 1155 & 482.64 & 146 & 1235 & 483.29 \\
\hline 27 & 919 & 484.21 & 67 & 1077 & 484.14 & 107 & 1157 & 482.61 & 147 & 1237 & 483.45 \\
\hline 28 & 921 & 484.31 & 68 & 1079 & 484.1 & 108 & 1159 & 482.58 & 148 & 1239 & 483.95 \\
\hline 29 & 923 & 484.41 & 69 & 1081 & 484.05 & 109 & 1161 & 482.55 & 149 & 1241 & 484.46 \\
\hline 30 & 925 & 484.51 & 70 & 1083 & 484.04 & 110 & 1163 & 482.55 & 150 & 1243 & 484.96 \\
\hline 31 & 927 & 484.52 & 71 & 1085 & 484.04 & 111 & 1165 & 482.65 & 151 & 1245 & 485.65 \\
\hline 32 & 929 & 484.5 & 72 & 1087 & 484.03 & 112 & 1167 & 482.74 & 152 & 1248.02 & 487.49 \\
\hline 33 & 931 & 484.45 & 73 & 1089 & 484.02 & 113 & 1169 & 482.84 & 153 & 1252.2 & 489.08 \\
\hline 34 & 933 & 484.38 & 74 & 1091 & 483.91 & 114 & 1171 & 482.93 & 154 & 1257.59 & 489.74 \\
\hline 35 & 935 & 484.31 & 75 & 1093 & 483.77 & 115 & 1173 & 483.03 & 155 & 1261.97 & 489.35 \\
\hline 36 & 937 & 484.27 & 76 & 1095 & 483.63 & 116 & 1175 & 483.05 & 156 & 1266 & 491.53 \\
\hline 37 & 939 & 484.23 & 77 & 1097 & 483.56 & 117 & 1177 & 483.03 & 157 & 1286.6 & 491.05 \\
\hline 38 & 941 & 484.19 & 78 & 1099 & 483.56 & 118 & 1179 & 483.01 & 158 & 1297.58 & 493.62 \\
\hline 39 & 943 & 484.16 & 79 & 1101 & 483.55 & 119 & 1181 & 482.99 & - & - & - \\
\hline 40 & 945 & 484.13 & 80 & 1103 & 483.55 & 120 & 1183 & 482.96 & - & - & - \\
\hline
\end{tabular}


Tabela 79 - Características Geométricas da Seção SF38800 do Rio São Francisco - Parte I

\begin{tabular}{ccc|ccc|ccc}
\hline \hline $\mathrm{n}^{\mathrm{o}}$ & $\mathrm{h}(\mathrm{m})$ & $\mathrm{z}(\mathrm{m})$ & $\mathrm{n}^{\mathrm{o}}$ & $\mathrm{h}(\mathrm{m})$ & $\mathrm{z}(\mathrm{m})$ & $\mathrm{n}^{\mathrm{o}}$ & $\mathrm{h}(\mathrm{m})$ & $\mathrm{z}(\mathrm{m})$ \\
\hline 1 & 0 & 495 & 37 & 1662 & 481.65 & 73 & 1734 & 482.35 \\
2 & 500 & 490 & 38 & 1664 & 481.85 & 74 & 1736 & 482.38 \\
3 & 801.76 & 486.2 & 39 & 1666 & 481.98 & 75 & 1738 & 482.51 \\
4 & 898.28 & 486.48 & 40 & 1668 & 482.03 & 76 & 1740 & 482.68 \\
5 & 978.28 & 486.91 & 41 & 1670 & 482.08 & 77 & 1742 & 482.56 \\
6 & 1129.16 & 487.63 & 42 & 1672 & 482.11 & 78 & 1744 & 482.39 \\
7 & 1249.72 & 488.81 & 43 & 1674 & 482.14 & 79 & 1746 & 482.27 \\
8 & 1350.08 & 489.14 & 44 & 1676 & 482.11 & 80 & 1748 & 482.18 \\
9 & 1430.63 & 489.1 & 45 & 1678 & 481.97 & 81 & 1750 & 482.12 \\
10 & 1500.87 & 489.4 & 46 & 1680 & 481.88 & 82 & 1752 & 482.23 \\
11 & 1563 & 490.38 & 47 & 1682 & 481.8 & 83 & 1754 & 482.36 \\
12 & 1613 & 485.26 & 48 & 1684 & 481.77 & 84 & 1756 & 482.46 \\
13 & 1614 & 484.98 & 49 & 1686 & 481.87 & 85 & 1758 & 482.59 \\
14 & 1616 & 484.42 & 50 & 1688 & 481.95 & 86 & 1760 & 482.73 \\
15 & 1618 & 483.86 & 51 & 1690 & 481.95 & 87 & 1762 & 482.73 \\
16 & 1620 & 483.3 & 52 & 1692 & 481.96 & 88 & 1764 & 482.74 \\
17 & 1622 & 482.73 & 53 & 1694 & 481.96 & 89 & 1766 & 482.72 \\
18 & 1624 & 482.17 & 54 & 1696 & 481.92 & 90 & 1768 & 482.7 \\
19 & 1626 & 481.71 & 55 & 1698 & 481.86 & 91 & 1770 & 482.66 \\
20 & 1628 & 481.51 & 56 & 1700 & 481.8 & 92 & 1772 & 482.64 \\
21 & 1630 & 481.3 & 57 & 1702 & 481.74 & 93 & 1774 & 482.64 \\
22 & 1632 & 481.1 & 58 & 1704 & 481.86 & 94 & 1776 & 482.58 \\
23 & 1634 & 481.03 & 59 & 1706 & 481.98 & 95 & 1778 & 482.53 \\
24 & 1636 & 481.14 & 60 & 1708 & 482.1 & 96 & 1780 & 482.55 \\
25 & 1638 & 481.25 & 61 & 1710 & 482.22 & 97 & 1782 & 482.62 \\
26 & 1640 & 481.39 & 62 & 1712 & 482.17 & 98 & 1784 & 482.68 \\
27 & 1642 & 481.54 & 63 & 1714 & 482.12 & 99 & 1786 & 482.75 \\
28 & 1644 & 481.69 & 64 & 1716 & 482.07 & 100 & 1788 & 482.83 \\
29 & 1646 & 481.72 & 65 & 1718 & 482.01 & 101 & 1790 & 482.89 \\
30 & 1648 & 481.75 & 66 & 1720 & 481.95 & 102 & 1792 & 482.94 \\
31 & 1650 & 481.79 & 67 & 1722 & 481.88 & 103 & 1794 & 483.1 \\
32 & 1652 & 481.75 & 68 & 1724 & 481.82 & 104 & 1796 & 483.27 \\
33 & 1654 & 481.67 & 69 & 1726 & 481.76 & 105 & 1798 & 483.42 \\
34 & 1656 & 481.59 & 70 & 1728 & 482.09 & 106 & 1800 & 483.55 \\
35 & 1658 & 481.54 & 71 & 1730 & 482.26 & 107 & 1802 & 483.68 \\
36 & 1660 & 481.5 & 72 & 1732 & 482.32 & 108 & 1804 & 483.71 \\
\hline \hline & & & & & & & &
\end{tabular}


Tabela 80 - Características Geométricas da Seção SF38800 do Rio São Francisco - Parte II

\begin{tabular}{|c|c|c|c|c|c|c|c|c|}
\hline 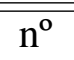 & $\overline{\mathrm{h}(\mathrm{m})}$ & $\overline{\mathrm{z}(\mathrm{m})}$ & $\overline{\overline{n^{\circ}}}$ & $\overline{\mathrm{h}(\mathrm{m})}$ & $\overline{\mathrm{z}(\mathrm{m})}$ & $\overline{n^{\circ}}$ & $\overline{\mathrm{h}(\mathrm{m})}$ & $\overline{\mathrm{z}(\mathrm{m})}$ \\
\hline 109 & 1806 & 483.6 & 144 & 1876 & 483.89 & 179 & 1946 & 482.94 \\
\hline 110 & 1808 & 483.39 & 145 & 1878 & 483.88 & 180 & 1948 & 482.99 \\
\hline 111 & 1810 & 483.36 & 146 & 1880 & 483.84 & 181 & 1950 & 483.06 \\
\hline 112 & 1812 & 483.47 & 147 & 1882 & 483.8 & 182 & 1952 & 483.14 \\
\hline 113 & 1814 & 483.61 & 148 & 1884 & 483.78 & 183 & 1954 & 483.18 \\
\hline 114 & 1816 & 483.5 & 149 & 1886 & 483.76 & 184 & 1956 & 483.16 \\
\hline 115 & 1818 & 483.41 & 150 & 1888 & 483.71 & 185 & 1958 & 483.14 \\
\hline 116 & 1820 & 483.49 & 151 & 1890 & 483.61 & 186 & 1960 & 483.19 \\
\hline 117 & 1822 & 483.42 & 152 & 1892 & 483.58 & 187 & 1962 & 483.24 \\
\hline 118 & 1824 & 483.25 & 153 & 1894 & 483.6 & 188 & 1964 & 483.3 \\
\hline 119 & 1826 & 483.22 & 154 & 1896 & 483.62 & 189 & 1966 & 483.3 \\
\hline 120 & 1828 & 483.36 & 155 & 1898 & 483.62 & 190 & 1968 & 483.3 \\
\hline 121 & 1830 & 483.52 & 156 & 1900 & 483.58 & 191 & 1970 & 483.3 \\
\hline 122 & 1832 & 483.46 & 157 & 1902 & 483.53 & 192 & 1972 & 483.31 \\
\hline 123 & 1834 & 483.39 & 158 & 1904 & 483.49 & 193 & 1974 & 483.36 \\
\hline 124 & 1836 & 483.28 & 159 & 1906 & 483.46 & 194 & 1976 & 483.43 \\
\hline 125 & 1838 & 483.22 & 160 & 1908 & 483.49 & 195 & 1978 & 483.49 \\
\hline 126 & 1840 & 483.21 & 161 & 1910 & 483.48 & 196 & 1980 & 483.55 \\
\hline 127 & 1842 & 483.36 & 162 & 1912 & 483.45 & 197 & 1982 & 483.59 \\
\hline 128 & 1844 & 483.55 & 163 & 1914 & 483.42 & 198 & 1984 & 483.63 \\
\hline 129 & 1846 & 483.59 & 164 & 1916 & 483.45 & 199 & 1986 & 483.67 \\
\hline 130 & 1848 & 483.64 & 165 & 1918 & 483.49 & 200 & 1988 & 483.74 \\
\hline 131 & 1850 & 483.68 & 166 & 1920 & 483.5 & 201 & 1990 & 483.81 \\
\hline 132 & 1852 & 483.71 & 167 & 1922 & 483.42 & 202 & 1992 & 483.88 \\
\hline 133 & 1854 & 483.68 & 168 & 1924 & 483.34 & 203 & 1994 & 484.11 \\
\hline 134 & 1856 & 483.62 & 169 & 1926 & 483.31 & 204 & 1996 & 484.48 \\
\hline 135 & 1858 & 483.56 & 170 & 1928 & 483.31 & 205 & 1998 & 484.85 \\
\hline 136 & 1860 & 483.55 & 171 & 1930 & 483.31 & 206 & 2000 & 485.26 \\
\hline 137 & 1862 & 483.64 & 172 & 1932 & 483.28 & 207 & 2050 & 487.41 \\
\hline 138 & 1864 & 483.71 & 173 & 1934 & 483.26 & 208 & 2211.18 & 489.79 \\
\hline 139 & 1866 & 483.7 & 174 & 1936 & 483.23 & 209 & 2391.76 & 496.89 \\
\hline 140 & 1868 & 483.84 & 175 & 1938 & 483.17 & 210 & 2522.35 & 498.14 \\
\hline 141 & 1870 & 483.81 & 176 & 1940 & 483.11 & 211 & 2652.94 & 499.09 \\
\hline 142 & 1872 & 483.7 & 177 & 1942 & 483.05 & 212 & 2783.53 & 500.67 \\
\hline 143 & 1874 & 483.81 & 178 & 1944 & 482.99 & 213 & 2914.12 & 502.04 \\
\hline
\end{tabular}


Tabela 81 - Características Geométricas da Seção SF35400 do Rio São Francisco - Parte I

\begin{tabular}{|c|c|c|c|c|c|c|c|c|}
\hline $\mathrm{n}^{\mathrm{o}}$ & $\mathrm{h}(\mathrm{m})$ & $\mathrm{z}(\mathrm{m})$ & $\mathrm{n}^{\mathrm{o}}$ & $\mathrm{h}(\mathrm{m})$ & $\mathrm{z}(\mathrm{m})$ & $\mathrm{n}^{\mathrm{o}}$ & $\mathrm{h}(\mathrm{m})$ & $\mathrm{z}(\mathrm{m})$ \\
\hline 1 & 0 & 490 & 41 & 1636 & 482.23 & 81 & 1716 & 482.36 \\
\hline 2 & 541 & 486.23 & 42 & 1638 & 482.15 & 82 & 1718 & 482.32 \\
\hline 3 & 573 & 486.16 & 43 & 1640 & 482.06 & 83 & 1720 & 482.29 \\
\hline 4 & 615 & 486.03 & 44 & 1642 & 482.05 & 84 & 1722 & 482.27 \\
\hline 5 & 672 & 486.11 & 45 & 1644 & 482.07 & 85 & 1724 & 482.25 \\
\hline 6 & 729 & 486.03 & 46 & 1646 & 482.09 & 86 & 1726 & 482.24 \\
\hline 7 & 778 & 485.79 & 47 & 1648 & 482.11 & 87 & 1728 & 482.23 \\
\hline 8 & 822 & 485.87 & 48 & 1650 & 482.17 & 88 & 1730 & 482.23 \\
\hline 9 & 878 & 485.91 & 49 & 1652 & 482.23 & 89 & 1732 & 482.22 \\
\hline 10 & 924 & 485.22 & 50 & 1654 & 482.25 & 90 & 1734 & 482.23 \\
\hline 11 & 973 & 485.38 & 51 & 1656 & 482.26 & 91 & 1736 & 482.26 \\
\hline 12 & 1007 & 486.25 & 52 & 1658 & 482.28 & 92 & 1738 & 482.29 \\
\hline 13 & 1045 & 486.15 & 53 & 1660 & 482.29 & 93 & 1740 & 482.32 \\
\hline 14 & 1083 & 485.87 & 54 & 1662 & 482.29 & 94 & 1742 & 482.35 \\
\hline 15 & 1121 & 486.5 & 55 & 1664 & 482.3 & 95 & 1744 & 482.31 \\
\hline 16 & 1191 & 486.61 & 56 & 1666 & 482.3 & 96 & 1746 & 482.24 \\
\hline 17 & 1223 & 486.75 & 57 & 1668 & 482.37 & 97 & 1748 & 482.17 \\
\hline 18 & 1256 & 486.96 & 58 & 1670 & 482.44 & 98 & 1750 & 482.16 \\
\hline 19 & 1288 & 486.74 & 59 & 1672 & 482.45 & 99 & 1752 & 482.19 \\
\hline 20 & 1325 & 486.82 & 60 & 1674 & 482.44 & 100 & 1754 & 482.23 \\
\hline 21 & 1364 & 486.83 & 61 & 1676 & 482.44 & 101 & 1756 & 482.2 \\
\hline 22 & 1401 & 486.78 & 62 & 1678 & 482.43 & 102 & 1758 & 482.17 \\
\hline 23 & 1433 & 486.72 & 63 & 1680 & 482.43 & 103 & 1760 & 482.18 \\
\hline 24 & 1465 & 486.52 & 64 & 1682 & 482.42 & 104 & 1762 & 482.3 \\
\hline 25 & 1501 & 486.62 & 65 & 1684 & 482.44 & 105 & 1764 & 482.24 \\
\hline 26 & 1534 & 486.61 & 66 & 1686 & 482.45 & 106 & 1766 & 482.15 \\
\hline 27 & 1565 & 486.83 & 67 & 1688 & 482.46 & 107 & 1768 & 482.2 \\
\hline 28 & 1592 & 487.83 & 68 & 1690 & 482.47 & 108 & 1770 & 482.23 \\
\hline 29 & 1613 & 483.87 & 69 & 1692 & 482.48 & 109 & 1772 & 482.23 \\
\hline 30 & 1614 & 482.9 & 70 & 1694 & 482.49 & 110 & 1774 & 482.23 \\
\hline 31 & 1616 & 482.25 & 71 & 1696 & 482.51 & 111 & 1776 & 482.24 \\
\hline 32 & 1618 & 482.06 & 72 & 1698 & 482.54 & 112 & 1778 & 482.27 \\
\hline 33 & 1620 & 482.12 & 73 & 1700 & 482.57 & 113 & 1780 & 482.3 \\
\hline 34 & 1622 & 482.12 & 74 & 1702 & 482.59 & 114 & 1782 & 482.32 \\
\hline 35 & 1624 & 482.09 & 75 & 1704 & 482.58 & 115 & 1784 & 482.33 \\
\hline 36 & 1626 & 482.05 & 76 & 1706 & 482.56 & 116 & 1786 & 482.33 \\
\hline 37 & 1628 & 482.05 & 77 & 1708 & 482.53 & 117 & 1788 & 482.34 \\
\hline 38 & 1630 & 482.05 & 78 & 1710 & 482.49 & 118 & 1790 & 482.4 \\
\hline 39 & 1632 & 482.12 & 79 & 1712 & 482.44 & 119 & 1792 & 482.5 \\
\hline 40 & 1634 & 482.22 & 80 & 1714 & 482.4 & 120 & 1794 & 482.59 \\
\hline
\end{tabular}


Tabela 82 - Características Geométricas da Seção SF35400 do Rio São Francisco - Parte II

\begin{tabular}{|c|c|c|c|c|c|c|c|c|}
\hline $\mathrm{n}^{\mathrm{o}}$ & $\mathrm{h}(\mathrm{m})$ & $\mathrm{z}(\mathrm{m})$ & $\mathrm{n}^{\mathbf{o}}$ & $\mathrm{h}(\mathrm{m})$ & $\mathrm{z}(\mathrm{m})$ & $\mathrm{n}^{\mathrm{o}}$ & $\mathrm{h}(\mathrm{m})$ & $\mathrm{z}(\mathrm{m})$ \\
\hline 121 & 1796 & 482.59 & 161 & 1876 & 481.43 & 201 & 1956 & 480.46 \\
\hline 122 & 1798 & 482.51 & 162 & 1878 & 481.47 & 202 & 1958 & 480.27 \\
\hline 123 & 1800 & 482.33 & 163 & 1880 & 481.51 & 203 & 1960 & 480.14 \\
\hline 124 & 1802 & 482.34 & 164 & 1882 & 481.54 & 204 & 1962 & 480.1 \\
\hline 125 & 1804 & 482.35 & 165 & 1884 & 481.17 & 205 & 1964 & 480.05 \\
\hline 126 & 1806 & 482.4 & 166 & 1886 & 480.61 & 206 & 1966 & 480.01 \\
\hline 127 & 1808 & 482.46 & 167 & 1888 & 480.65 & 207 & 1968 & 479.98 \\
\hline 128 & 1810 & 482.52 & 168 & 1890 & 480.97 & 208 & 1970 & 480.01 \\
\hline 129 & 1812 & 482.49 & 169 & 1892 & 481.3 & 209 & 1972 & 480.04 \\
\hline 130 & 1814 & 482.36 & 170 & 1894 & 481.3 & 210 & 1974 & 480.07 \\
\hline 131 & 1816 & 482.33 & 171 & 1896 & 481.24 & 211 & 1976 & 480.11 \\
\hline 132 & 1818 & 482.3 & 172 & 1898 & 481.18 & 212 & 1978 & 480.14 \\
\hline 133 & 1820 & 482.28 & 173 & 1900 & 481.14 & 213 & 1980 & 480.14 \\
\hline 134 & 1822 & 482.27 & 174 & 1902 & 481.14 & 214 & 1982 & 480.14 \\
\hline 135 & 1824 & 482.29 & 175 & 1904 & 481.15 & 215 & 1984 & 480.24 \\
\hline 136 & 1826 & 482.31 & 176 & 1906 & 481.15 & 216 & 1986 & 480.46 \\
\hline 137 & 1828 & 482.33 & 177 & 1908 & 481.05 & 217 & 1988 & 480.67 \\
\hline 138 & 1830 & 482.33 & 178 & 1910 & 480.93 & 218 & 1990 & 480.88 \\
\hline 139 & 1832 & 482.34 & 179 & 1912 & 480.85 & 219 & 1992 & 481.1 \\
\hline 140 & 1834 & 482.33 & 180 & 1914 & 480.85 & 220 & 1994 & 481.31 \\
\hline 141 & 1836 & 482.29 & 181 & 1916 & 480.86 & 221 & 1996 & 481.84 \\
\hline 142 & 1838 & 482.16 & 182 & 1918 & 480.86 & 222 & 1998 & 482.46 \\
\hline 143 & 1840 & 481.98 & 183 & 1920 & 480.84 & 223 & 2000 & 483.87 \\
\hline 144 & 1842 & 481.87 & 184 & 1922 & 480.77 & 224 & 2013.64 & 487.26 \\
\hline 145 & 1844 & 481.98 & 185 & 1924 & 480.7 & 225 & 2037.74 & 488.83 \\
\hline 146 & 1846 & 482.02 & 186 & 1926 & 480.63 & 226 & 2075.6 & 487.59 \\
\hline 147 & 1848 & 481.97 & 187 & 1928 & 480.55 & 227 & 2110.08 & 487.52 \\
\hline 148 & 1850 & 481.93 & 188 & 1930 & 480.52 & 228 & 2142.85 & 487.55 \\
\hline 149 & 1852 & 481.89 & 189 & 1932 & 480.49 & 229 & 2177.02 & 487.47 \\
\hline 150 & 1854 & 481.85 & 190 & 1934 & 480.47 & 230 & 2233.23 & 487.55 \\
\hline 151 & 1856 & 481.82 & 191 & 1936 & 480.42 & 231 & 2281.77 & 487.38 \\
\hline 152 & 1858 & 481.79 & 192 & 1938 & 480.38 & 232 & 2339.5 & 487.15 \\
\hline 153 & 1860 & 481.77 & 193 & 1940 & 480.36 & 233 & 2409.72 & 487.37 \\
\hline 154 & 1862 & 481.72 & 194 & 1942 & 480.35 & 234 & 2475.82 & 487.42 \\
\hline 155 & 1864 & 481.65 & 195 & 1944 & 480.34 & 235 & 2571.02 & 487.33 \\
\hline 156 & 1866 & 481.59 & 196 & 1946 & 480.38 & 236 & 2644.4 & 487.73 \\
\hline 157 & 1868 & 481.49 & 197 & 1948 & 480.42 & 237 & 2688.44 & 487.78 \\
\hline 158 & 1870 & 481.39 & 198 & 1950 & 480.46 & 238 & 2722.55 & 488.34 \\
\hline 159 & 1872 & 481.37 & 199 & 1952 & 480.49 & 239 & 2817.08 & 489.7 \\
\hline 160 & 1874 & 481.4 & 200 & 1954 & 480.53 & 240 & 2867.42 & 492.15 \\
\hline
\end{tabular}


Tabela 83 - Características Geométricas da Seção SF32000 do Rio São Francisco - Parte I

\begin{tabular}{|c|c|c|c|c|c|c|c|c|}
\hline $\mathrm{n}^{\mathrm{o}}$ & $\mathrm{h}(\mathrm{m})$ & $\mathrm{z}(\mathrm{m})$ & $\mathrm{n}^{\mathrm{o}}$ & $h(m)$ & $\mathrm{z}(\mathrm{m})$ & $\mathrm{n}^{\mathrm{o}}$ & $\mathrm{h}(\mathrm{m})$ & $\mathrm{z}(\mathrm{m})$ \\
\hline 1 & 0 & 488.15 & 44 & 136.15 & 81.36 & 87 & 222.15 & 180.96 \\
\hline 2 & 188.3 & & 5 & & & & & \\
\hline 3 & 243.33 & 487. & 6 & 5 & & م & 5 & 3101 \\
\hline 4 & 3 & 4 & r & & & 90 & 12 & 04 \\
\hline 5 & 407.22 & 485 & 48 & 114 & & 91 & 5 & \\
\hline 6 & 49247 & 48 & 9 & 5 & & & 5 & 48109 \\
\hline 7 & 592.49 & 486.59 & 50 & 1148 & 481.31 & 93 & 123 & 481.12 \\
\hline 8 & 695.08 & 486.73 & 51 & 1150 & $4 \varepsilon$ & 94 & 23 & 481.16 \\
\hline 9 & 3.44 & 487.1 & 52 & & & 95 & 123 & \\
\hline 10 & 3.65 & 486.7 & 3 & 1154 & 481 & 96 & 124 & 481.09 \\
\hline 11 & & & 54 & & & 97 & & \\
\hline 12 & 1024.31 & 485 & 55 & 11 & & 98 & 124 & 481.07 \\
\hline 13 & & & 6 & & & 9 & & \\
\hline 14 & 6.15 & 483 & 57 & 1162 & & 100 & 124 & 481.1 \\
\hline 15 & 1 & & 5 & 11 & & 101 & 5 & \\
\hline 16 & 15 & 482 & 59 & & & & & 18 \\
\hline 17 & 15 & 481 & 60 & 11 & 48 & & 12 & 2 \\
\hline 18 & & 48 & 61 & & & & & \\
\hline 19 & 6.1 & 481.1 & 62 & 1172 & & 10 & 125 & 481.22 \\
\hline 20 & & & & & & & & \\
\hline 21 & 0.15 & 480. & 64 & 117 & & 10 & 126 & 481.23 \\
\hline 22 & & & & & & & & \\
\hline 23 & 15 & D & 66 & & & & 126 & 48 \\
\hline 24 & & & 67 & & & & & 481.24 \\
\hline 25 & 98.15 & 480 & 00 & & & & 127 & 481.28 \\
\hline 26 & $11+3$ & & 69 & & & & 1272 & 481.39 \\
\hline 27 & & 48 & 7 & & & & 127 & \\
\hline 28 & 11 & 48 & 71 & & & 11 & 127 & 481.53 \\
\hline 29 & 1 & 480 & 7 & & & & 127 & 48 \\
\hline 30 & 1 & & 73 & 11 & & 6 & 128 & 481.54 \\
\hline 31 & & A & & & & & 1282 & 481.67 \\
\hline 32 & 1 & 1 & & 119 & 481 & 1 & 128 & 481.86 \\
\hline 33 & 1114.15 & 481.06 & 76 & 1200 & & 119 & 1286 & 482.01 \\
\hline 34 & 1 & 4 & & 120 & 48 & 12 & 128 & 482.04 \\
\hline 35 & 11181 & 481. & 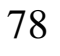 & 120 & & 121 & 1290 & 482.1 \\
\hline 36 & 1 & 481. & $7.52>$ & 120 & & 12 & 1292 & 482.19 \\
\hline 37 & & 481.31 & 80 & 1208.15 & & 123 & 1294.15 & 482.27 \\
\hline 38 & $11+3$ & & 0 & & 480 & 12 & 1296 & 482.42 \\
\hline 39 & 1126.15 & 481.47 & 82 & 1212.15 & 480.92 & 125 & 1298.15 & 482.59 \\
\hline 40 & 112815 & 481. & 83 & 1214 & 480.92 & 126 & 1300.15 & 482.76 \\
\hline 41 & & & 8 & & & 12 & 1302.15 & 482.84 \\
\hline 42 & 1132.15 & 481.29 & 85 & 1218.15 & 480.92 & 128 & 1304.15 & 482.83 \\
\hline 43 & 1134.15 & 481.3 & 86 & 1220.15 & 480.93 & 129 & 1306.15 & 482.82 \\
\hline
\end{tabular}


Tabela 84 - Características Geométricas da Seção SF32000 do Rio São Francisco - Parte II

\begin{tabular}{|c|c|c|c|c|c|c|c|c|}
\hline$\overline{\mathrm{n}^{\mathrm{o}}}$ & $\mathrm{h}(\mathrm{m})$ & $\overline{\mathrm{z}(\mathrm{m})}$ & $\overline{n^{\circ}}$ & $h(m)$ & $\overline{\mathrm{z}(\mathrm{m})}$ & $\overline{\mathrm{n}^{\circ}}$ & $h(m)$ & $\mathrm{z}(\mathrm{m})$ \\
\hline 130 & 1308.15 & 82.81 & 172 & 392.15 & 483.34 & 214 & 1476.15 & 82.48 \\
\hline 131 & 1 & 6 & 173 & 5 & 4 & 5 & & 43 \\
\hline 132 & 312.15 & 482.92 & 174 & & 483.33 & 216 & & 482.37 \\
\hline 133 & 1314 & 482.97 & 175 & 139 & 483.32 & 217 & & 482.32 \\
\hline 134 & 1316.15 & 482.96 & 176 & 1400.15 & 483.29 & 218 & & 482.26 \\
\hline 135 & 1318.15 & 482.95 & 177 & 1402.15 & 483.26 & 219 & $14 \varepsilon$ & 482.21 \\
\hline 136 & 132 & 482.93 & 178 & 14 & 483.24 & 220 & & 482.16 \\
\hline 137 & 1322 & 482.97 & 179 & 140 & 483.2 & 221 & & 482.1 \\
\hline 138 & 1 & 02 & 180 & 5 & 4 & 222 & & 482.05 \\
\hline 139 & 1326.15 & 483.03 & 181 & 141 & 483.12 & 223 & 149 & 482.01 \\
\hline 140 & 1328 & 483.04 & 182 & 1412 & 483.08 & 224 & 145 & 482.03 \\
\hline 141 & 1330 & 3.04 & 183 & 14 & 483.05 & 225 & & 482.04 \\
\hline 142 & 1332.15 & 483.03 & 184 & 141 & 483.03 & 226 & 1500 & 482.05 \\
\hline 143 & 13 & & 5 & & & 227 & & 482.07 \\
\hline 144 & 1336 & 483.02 & 186 & 142 & 483.02 & 228 & 150 & 482.07 \\
\hline 145 & & & 7 & & & 229 & & .02 \\
\hline 146 & 1340 & 483.02 & 188 & 142 & 483.02 & 230 & 15 & 481.96 \\
\hline 147 & 1 & & 189 & 14 & 02 & 231 & & .91 \\
\hline 148 & 1344 & .06 & 190 & 142 & 483.02 & 232 & & 1.9 \\
\hline 149 & 13 & 483 & 191 & 143 & 483 & 233 & & 481.94 \\
\hline 150 & 134 & 07 & 192 & 143 & $48 ?$ & 234 & & 481.99 \\
\hline 151 & 13 & 483.06 & 193 & 143 & 483 & 235 & 15 & 482.03 \\
\hline 152 & 13 & 05 & 194 & & 05 & 236 & & .05 \\
\hline 153 & 1354 & 483.05 & 195 & 143 & 483.06 & 237 & 152 & 482.05 \\
\hline 154 & 1 & 04 & 196 & 14 & 48 & 238 & & 482.06 \\
\hline 155 & 13 & 06 & 197 & 144 & 483.06 & 239 & 15 & 482.13 \\
\hline 156 & 1360 & 483.08 & 198 & 144 & 483.06 & 240 & 15 & 482.34 \\
\hline 157 & 136 & 483.11 & 199 & 144 & 483.06 & 241 & 15 & 482.56 \\
\hline 158 & 1364 & 483.13 & 200 & 144 & 483.06 & 242 & 1532 & 482.78 \\
\hline 159 & 1366 & 15 & 201 & 145 & 483.06 & 243 & 15 & 482.99 \\
\hline 160 & 1368 & 483.16 & 202 & 145 & 483.02 & 244 & 153 & 483.21 \\
\hline 161 & 1370 & 17 & 203 & 145 & 482.97 & 245 & 153 & 483.42 \\
\hline 162 & 1372.15 & 483.19 & 204 & 145 & 482.92 & 246 & 1540.15 & 483.65 \\
\hline 163 & & 483.21 & 205 & 145 & 482.88 & 247 & & 484 \\
\hline 164 & 1376.15 & 483.24 & 206 & 1460 & 482.83 & 248 & 1853.64 & 487.24 \\
\hline 165 & 1378.15 & 483.26 & 207 & 1462 & 482.79 & 249 & 2010.37 & 487.04 \\
\hline 166 & 1380.15 & 483.25 & 208 & 1464 & 482.74 & 250 & 216 & 486.48 \\
\hline 167 & 1382.15 & 483.25 & 209 & 1466 & 482.7 & 251 & 2323.83 & 487.77 \\
\hline 168 & & 483.25 & 210 & 1468 & 482.66 & 252 & 248 & 487.53 \\
\hline 169 & 1386.15 & 483.28 & 211 & 1470.15 & 482.62 & 253 & 2637.29 & 487.31 \\
\hline 170 & & & 21 & 147 & 482.58 & - & - & - \\
\hline 171 & 1390.15 & 483.35 & 213 & 1474.15 & 482.54 & & - & 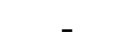 \\
\hline
\end{tabular}


Tabela 85 - Características Geométricas da Seção SF30700 do Rio São Francisco

\begin{tabular}{|c|c|c|c|c|c|c|c|c|c|c|c|}
\hline $\mathrm{n}^{\mathrm{o}}$ & $\mathrm{h}(\mathrm{m})$ & $\mathrm{z}(\mathrm{m})$ & $\mathrm{n}^{\mathrm{o}}$ & $\mathrm{h}(\mathrm{m})$ & $\mathrm{z}(\mathrm{m})$ & $\mathrm{n}^{\circ}$ & $\overline{h(m)}$ & $\mathrm{z}(\mathrm{m})$ & $\mathrm{n}^{\circ}$ & $\overline{h(m)}$ & $\overline{z(m)}$ \\
\hline 1 & 0 & 490.09 & 43 & 1028.7 & 480.94 & 85 & 1112. & 479.84 & 127 & 1196. & 480.27 \\
\hline 2 & 69.58 & 490.03 & 44 & 1030.78 & 480.92 & 86 & 1114.78 & 479.85 & 128 & 1198.78 & 480.28 \\
\hline 3 & 139.58 & 489.98 & 45 & 1032.78 & 480.89 & 87 & 1116.7 & 479.86 & 129 & 1200.7 & 480.29 \\
\hline 4 & 207.79 & 489.94 & 46 & 1034.78 & 480.86 & 88 & 1118.78 & 479.87 & 130 & 1202.78 & 480.3 \\
\hline 5 & 265.91 & 490 & 47 & 1036.78 & 480.83 & 89 & 1120.78 & 479.88 & 131 & 1204.78 & 480.31 \\
\hline 6 & 306.24 & 489.96 & 48 & 1038.78 & 480.81 & 90 & 1122.78 & 479.89 & 132 & 1206.78 & 480.32 \\
\hline 7 & 331.9 & 490 & 49 & 1040.78 & 480.78 & 91 & 1124.78 & 479.9 & 133 & 1208.78 & 480.33 \\
\hline 8 & 390.9 & 489.98 & 50 & 1042.78 & 480.75 & 92 & 1126.78 & 479.91 & 134 & 1210.7 & 480.34 \\
\hline 9 & 479.9 & 490.08 & 51 & 1044.78 & 480.72 & 93 & 1128.78 & 479.92 & 135 & 1212.78 & 480.35 \\
\hline 10 & 503.9 & 490.02 & 52 & 1046.78 & 480.7 & 94 & 1130.78 & 479.93 & 136 & 121 & 480.36 \\
\hline 11 & 539.54 & 490.04 & 53 & 1048.78 & 480.67 & 95 & 1132.78 & 479.94 & 137 & & 480.44 \\
\hline 12 & 584.75 & 490.07 & 54 & 1050.78 & 480.64 & 96 & 1134.78 & 479.95 & 138 & 1218.78 & 480.52 \\
\hline 13 & 664.75 & 490.01 & 55 & 1052.78 & 480.61 & 97 & 1136. & 479.96 & 139 & 122 & 480.6 \\
\hline 14 & 701.74 & 489.97 & 56 & 1054.78 & 480.59 & 98 & 1138.78 & 479.97 & 140 & 122 & 480.68 \\
\hline 15 & 758.32 & 489.94 & 57 & 1056.78 & 480.56 & 99 & 1140.78 & 479.98 & 141 & 12 & 480.76 \\
\hline 16 & 793.32 & 490.37 & 58 & 1058.78 & 480.53 & 100 & 1142.78 & 479.99 & 142 & & 480.84 \\
\hline 17 & 862.55 & 483.99 & 59 & 1060.78 & 480.5 & 101 & 1144.78 & 480 & 143 & 1228.78 & 480.92 \\
\hline 18 & 931.78 & 485.49 & 60 & 1062.78 & 480.47 & 102 & 1146.78 & 480.01 & 144 & 12 & 99 \\
\hline 19 & 981.78 & 483.97 & 61 & 1064.78 & 480.45 & 103 & 1148.78 & 480.02 & 145 & 1232.78 & 481.07 \\
\hline 20 & 982.78 & 483.79 & 62 & 106 & 480 & 104 & 1150 & 480.03 & 146 & 12 & 481.15 \\
\hline 21 & 984.78 & 483.4 & 63 & 1068.78 & 480.39 & 105 & 1152.78 & 480.04 & 147 & 1236.78 & 481.23 \\
\hline 22 & 986.78 & 483.31 & 64 & 1070.78 & 480.32 & 106 & 1154.78 & 480.05 & 148 & 123 & 481.36 \\
\hline 23 & 988.78 & 482.35 & 65 & 1072.78 & 480.26 & 107 & 1156.78 & 480.06 & 149 & 124 & 481.46 \\
\hline 24 & 990.78 & 481.92 & 66 & 1074.78 & 480.19 & 108 & 1158.78 & 480.07 & 150 & 1242.78 & 481.55 \\
\hline 25 & 992.78 & 481.49 & 67 & 1076.78 & 480.12 & 109 & 1160.78 & 480.08 & 151 & 12 & 481.58 \\
\hline 26 & 994.78 & 481.3 & 68 & 1078.78 & 480.05 & 110 & 1162.78 & 480.09 & 152 & 1246.78 & 481.61 \\
\hline 27 & 996.78 & 481.33 & 69 & 1080.78 & 479.98 & 111 & 1164.78 & 480.1 & 153 & 1248.78 & 481.64 \\
\hline 28 & 998.78 & 481.36 & 70 & 1082.78 & 479.92 & 112 & 1166.78 & 480.11 & 154 & 1250.78 & 481.82 \\
\hline 29 & 1000.78 & 481.33 & 71 & 1084.78 & 479.85 & 113 & 1168.78 & 480.12 & 155 & 1252.78 & 482.1 \\
\hline 30 & 1002.78 & 481.3 & 72 & 1086.78 & 479.78 & 114 & 1170.78 & 480.13 & 156 & 1254.78 & 482.35 \\
\hline 31 & 1004.78 & 481.28 & 73 & 1088.78 & 479.71 & 115 & 1172.78 & 480.15 & 157 & 1256.78 & 482.58 \\
\hline 32 & 1006.78 & 481.25 & 74 & 1090.78 & 479.72 & 116 & 1174.78 & 480.16 & 158 & 1258.78 & 482.81 \\
\hline 33 & 1008.78 & 481.22 & 75 & 1092.78 & 479.73 & 117 & 1176.78 & 480.17 & 159 & 1260.78 & 483.36 \\
\hline 34 & 1010.78 & 481.19 & 76 & 1094.78 & 479.74 & 118 & 1178.78 & 480.18 & 160 & 1262.78 & 483.97 \\
\hline 35 & 1012.78 & 481.17 & 77 & 1096.78 & 479.75 & 119 & 1180.78 & 480.19 & 161 & 1373.41 & 490.37 \\
\hline 36 & 1014.78 & 481.14 & 78 & 1098.78 & 479.76 & 120 & 1182.78 & 480.2 & 162 & 1484.41 & 490.23 \\
\hline 37 & 1016.78 & 481.11 & 79 & 1100.78 & 479.77 & 121 & 1184.78 & 480.21 & 163 & 1595.21 & 490.08 \\
\hline 38 & 1018.78 & 481.08 & 80 & 1102.78 & 479.79 & 122 & 1186.78 & 480.22 & 164 & 1706.01 & 490.5 \\
\hline 39 & 1020.78 & 481.06 & 81 & 1104.78 & 479.8 & 123 & 1188.78 & 480.23 & 165 & 1816.81 & 487.62 \\
\hline 40 & 1022.78 & 481.03 & 82 & 1106.78 & 479.81 & 124 & 1190.78 & 480.24 & 166 & 1927.61 & 488.19 \\
\hline 41 & 1024.78 & 481 & 83 & 1108.78 & 479.82 & 125 & 1192.78 & 480.25 & 167 & 2038. & 488.06 \\
\hline 42 & 1026.78 & 480.97 & 84 & 1110.78 & 479.83 & 126 & 1194.78 & 480.26 & - & - & - \\
\hline
\end{tabular}


Tabela 86 - Características Geométricas da Seção SF29000 do Rio São Francisco - Parte I

\begin{tabular}{|c|c|c|c|c|c|c|c|c|c|c|c|}
\hline $\mathrm{n}^{\mathrm{o}}$ & $\mathrm{h}(\mathrm{m})$ & $\mathrm{z}(\mathrm{m})$ & II & $\mathrm{h}(\mathrm{m})$ & $\mathrm{z}(\mathrm{m})$ & 11 & $\mathrm{~h}(\mathrm{~m})$ & $\mathrm{z}(\mathrm{m})$ & II & $\mathrm{h}(\mathrm{m})$ & $\mathrm{z}(\mathrm{m})$ \\
\hline 1 & 0 & & 28 & & & 60 & & & 107 & & \\
\hline 2 & & & & & & & & & & & \\
\hline 3 & & & & & & & & & 5 & & \\
\hline 4 & 67. & & & 2 & & 2 & 2 & & 6 & & \\
\hline 5 & & & & & & & & & Ji & & \\
\hline 0 & & & & & & & & & 8 & & \\
\hline 7 & & & & & & & & & & & \\
\hline 8 & & & 4 & & & & & & 0 & & \\
\hline 9 & & & & & & & & & & & \\
\hline 10 & 22 & & 4 & & & & & & 2 & & .56 \\
\hline 11 & & & & & & & & & 3 & & \\
\hline 12 & & & 4 & & & & & & 4 & & \\
\hline 13 & & & 47 & & & & & & 5 & & .39 \\
\hline 14 & & & 4 & & & & & & & & \\
\hline 15 & & & 49 & & & & & & 7 & & 49 \\
\hline 16 & & & 5 & & & & & & & & \\
\hline 17 & & & 51 & & & & & & 9 & & \\
\hline 18 & & & & & & & & & & & \\
\hline 19 & & & 53 & & & & & & 21 & & \\
\hline 20 & & & & & & & & & & & \\
\hline 21 & & & & & & & & & 3 & & \\
\hline 22 & & & 56 & & & & & & & & \\
\hline 23 & & & 5 & & & & & & 25 & & \\
\hline 24 & & & & & & & & & & & \\
\hline 25 & & & & & & & & & 21 & & \\
\hline 26 & & & 60 & & & & & & 28 & & .88 \\
\hline 27 & & & 61 & & & & & & & & \\
\hline 28 & 407 & & 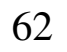 & 47 & & 9 & 2 & & 0 & & 83 \\
\hline 29 & & & 63 & & & & & & 131 & & 481.8 \\
\hline 30 & & & 6 & & & & & & 32 & & \\
\hline 31 & & & 65 & & & 9 & & & 133 & & 481.87 \\
\hline 32 & & & 66 & & & & & & 13 & & \\
\hline 33 & & & 67 & & & & & & & & 481.99 \\
\hline 34 & 419.92 & 48 & 68 & 487.92 & 481.83 & 102 & 555.92 & 481.72 & 136 & 623.92 & 482.05 \\
\hline
\end{tabular}


Tabela 87 - Características Geométricas da Seção SF29000 do Rio São Francisco - Parte II

\begin{tabular}{|c|c|c|c|c|c|c|c|c|c|c|c|}
\hline 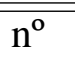 & $\mathrm{h}(\mathrm{m})$ & $\overline{z z(m)}$ & $\overline{\mathrm{n}^{\mathrm{o}}}$ & $\mathrm{h}(\mathrm{m})$ & $\mathrm{z}(\mathrm{m})$ & $\overline{n^{\circ}}$ & $\mathrm{h}(\mathrm{m})$ & $\mathrm{z}(\mathrm{m})$ & 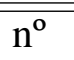 & $\mathrm{h}(\mathrm{m})$ & $\mathrm{z}(\mathrm{m})$ \\
\hline 137 & 625.92 & 482.1 & 171 & 693.92 & 482.24 & 205 & 761.92 & 482.57 & 239 & 829.92 & 482.65 \\
\hline 138 & 627.92 & 481.95 & 172 & 695.92 & 482.11 & 206 & 763.92 & 482.59 & 240 & 831.92 & 482.69 \\
\hline 139 & 629.92 & 481.94 & 173 & 697.92 & 482.11 & 207 & 765.92 & 482.62 & 241 & 833.92 & 482.72 \\
\hline 140 & 631.92 & 481.89 & 174 & 699.92 & 482.13 & 208 & 767.92 & 482.61 & 242 & 835.92 & 482.76 \\
\hline 141 & 633.92 & 481.87 & 175 & 701.92 & 482.17 & 209 & 769.92 & 482.57 & 243 & 837.92 & 482.8 \\
\hline 142 & 635.92 & 481.74 & 176 & 703.92 & 482.22 & 210 & 771.92 & 482.53 & 244 & 839.92 & 482.84 \\
\hline 143 & 637.92 & 481.4 & 177 & 705.92 & 482.27 & 211 & 773.92 & 482.5 & 245 & .92 & 482.87 \\
\hline 144 & 639.92 & 481.47 & 178 & 707.92 & 482.33 & 212 & 775.92 & 482.46 & 246 & 843.92 & 482.91 \\
\hline 145 & 641.92 & 481.54 & 179 & 709.92 & 48 & 213 & 777.92 & .42 & 247 & 92 & 482.96 \\
\hline 146 & 643.92 & 481.62 & 180 & 711.92 & 482.34 & 214 & 779.92 & 482.39 & 248 & 847.92 & 483.02 \\
\hline 147 & 645.92 & 481.69 & 181 & 713.92 & 482.24 & 215 & 781.92 & 482.35 & 249 & 849.92 & 483.08 \\
\hline 148 & 647.92 & 481.72 & 182 & 715.92 & 482.21 & 216 & 783.92 & 482.31 & 250 & 851.92 & 483.14 \\
\hline 149 & 649.92 & 481.75 & 183 & 717.92 & 482.35 & 217 & 785.92 & 482.28 & 251 & 853.92 & 483.2 \\
\hline 150 & 651.92 & 481.77 & 184 & 719.92 & 482 & 218 & 787.92 & 482.24 & 252 & 92 & 483.26 \\
\hline 151 & 653.92 & 481.8 & 185 & 721.92 & 482.34 & 219 & 789.92 & 482.26 & 253 & 857.92 & 483.32 \\
\hline 152 & 655.92 & 481.83 & 186 & 723.92 & 482 & 220 & 791.92 & 482.28 & 254 & & .38 \\
\hline 153 & 657.92 & 481.84 & 187 & 725.92 & 482.28 & 221 & 793.92 & 482.31 & 255 & 861.92 & 483.42 \\
\hline 154 & 659.92 & 481.8 & 188 & 727.92 & 48 & 222 & 795.92 & 33 & 256 & 92 & 483.47 \\
\hline 155 & 661.92 & 481.75 & 189 & 729.92 & 482.22 & 223 & 797.92 & 482.36 & 257 & 865.92 & 483.52 \\
\hline 156 & 663.92 & 481.7 & 190 & 731.92 & 482.27 & 224 & 799.92 & 482.38 & 258 & 867.92 & 483.57 \\
\hline 157 & 665.92 & 481.66 & 191 & 733.92 & 482.38 & 225 & 801.92 & 482.4 & 259 & 869.92 & 483.62 \\
\hline 158 & 667.92 & 481.61 & 192 & 735.92 & 482.41 & 226 & 803.92 & 482.43 & 260 & 871.92 & 483.67 \\
\hline 159 & 669.92 & 481.55 & 193 & 737.92 & 482.41 & 227 & 805.92 & 482.46 & 261 & 873.92 & 483.72 \\
\hline 160 & 671.92 & 481.49 & 194 & 739.92 & 482.41 & 228 & 807.92 & 482.5 & 262 & 875.92 & 483.77 \\
\hline 161 & 673.92 & 481.42 & 195 & 741.92 & 482.42 & 229 & 809.92 & 482.54 & 263 & 877.92 & 483.82 \\
\hline 162 & 675.92 & 481.38 & 196 & 743.92 & 482.42 & 230 & 811.92 & 482.58 & 264 & 879.92 & 483.87 \\
\hline 163 & 677.92 & 481.38 & 197 & 745.92 & 482.42 & 231 & 813.92 & 482.62 & 265 & 897.89 & 484.81 \\
\hline 164 & 679.92 & 481.52 & 198 & 747.92 & 482.43 & 232 & 815.92 & 482.62 & 266 & 915.84 & 484 \\
\hline 165 & 681.92 & 481.75 & 199 & 749.92 & 482.43 & 233 & 817.92 & 482.62 & 267 & 933.79 & 487.25 \\
\hline 166 & 683.92 & 481.47 & 200 & 751.92 & 482.44 & 234 & 819.92 & 482.62 & 268 & 951.74 & 486.89 \\
\hline 167 & 685.92 & 481.61 & 201 & 753.92 & 482.46 & 235 & 821.92 & 482.62 & 269 & 969.69 & 486.85 \\
\hline 168 & 687.92 & 481.91 & 202 & 755.92 & 482.49 & 236 & 823.92 & 482.62 & 270 & 987.64 & 486.73 \\
\hline 169 & 689.92 & 482.2 & 203 & 757.92 & 482.51 & 237 & 825.92 & 482.62 & 271 & 1005.59 & 486.27 \\
\hline 170 & 691.92 & 482.38 & 204 & 759.92 & 482.54 & 238 & 827.92 & 482.62 & 272 & 1279.92 & 490 \\
\hline
\end{tabular}




\section{APÊNDICE B - Parâmetros Calibrados para o MGB-IPH}

Tabela 88 - Parâmetros Fixos de Albedo para o MGB-IPH

\begin{tabular}{|c|c|c|c|c|c|c|c|c|c|c|c|c|}
\hline $\begin{array}{l}\text { Unidade de Resposta } \\
\text { Hidrológica }\end{array}$ & n & V & mar & br & mai & an & jul & ago & set & out & $\mathrm{V}$ & dez \\
\hline Ira em Solos & 0.15 & 0.15 & 0.15 & 0.15 & 0.15 & 0.15 & 0.15 & 0.15 & 0.15 & 0.15 & 0.15 & 0.15 \\
\hline $\begin{array}{l}\text { Campos, Cerrado e } \\
\text { Estepes em solos pro- } \\
\text { fundos }\end{array}$ & 3 & 0.13 & 0.13 & 0.13 & 0.13 & 0.13 & 0.13 & 0.13 & 0.13 & 0.13 & 0.13 & 0.1 \\
\hline $\begin{array}{l}\text { Floresta em solos } \\
\text { profundos }\end{array}$ & .11 & 0.11 & 0.11 & 0.11 & 0.11 & 0.11 & 0.11 & 0.11 & 0.11 & 0.11 & 0.1 & 0.11 \\
\hline ltura em Solo & 15 & 0.15 & 0.15 & 0.15 & 0.15 & 0.15 & 0.15 & 0.15 & 0.15 & 0.15 & 0.15 & 0.15 \\
\hline $\begin{array}{l}\text { Campos, Cerrado e } \\
\text { Estepes em solo mé- } \\
\text { dio }\end{array}$ & 0.13 & 0.13 & 0.13 & 0.13 & 0.13 & 0.13 & 0.13 & 0.13 & 0.13 & 0.13 & 0.13 & 0.1 \\
\hline $\begin{array}{l}\text { Floresta em solo mé- } \\
\text { dio }\end{array}$ & 0.11 & 0.11 & 0.11 & 0.11 & 0.11 & 0.11 & 0.11 & 0.11 & 0.11 & 0.11 & 0.11 & 0.11 \\
\hline $\begin{array}{l}\text { Áreas Semi- } \\
\text { Impermeáveis }\end{array}$ & 15 & 0.15 & 0.15 & 0.15 & 0.15 & 0.15 & 0.15 & 0.15 & 0.15 & 0.15 & 0.15 & 0.15 \\
\hline gua & 0.08 & 0.08 & 0.08 & 0.08 & 0.08 & 0.08 & 0.08 & 0.08 & 0.08 & 0.08 & 0.08 & 0.08 \\
\hline
\end{tabular}


Tabela 89 - Parâmetros Fixos de Índice de Área Foliar (IAF) para o MGB-IPH

\begin{tabular}{|c|c|c|c|c|c|c|c|c|c|c|c|c|}
\hline $\begin{array}{l}\text { Unidade de Resposta } \\
\text { Hidrológica }\end{array}$ & jan & fev & $\overline{\mathrm{ma}}$ & $\overline{a b r}$ & $\overline{\mathrm{ma}}$ & $\overline{\text { jun }}$ & $\overline{\text { jul }}$ & $\overline{\mathrm{ago}}$ & $\overline{\text { set }}$ & out & $\overline{\text { nov }}$ & $\overline{\mathrm{dez}}$ \\
\hline $\begin{array}{l}\text { Agricultura em Solos } \\
\text { profundos }\end{array}$ & 4 & 4 & 4 & 4 & 4 & 4 & 4 & 4 & 4 & 4 & 4 & 4 \\
\hline $\begin{array}{l}\text { Campos, Cerrado e } \\
\text { Estepes em solos pro- } \\
\text { fundos }\end{array}$ & 4 & 4 & 4 & 4 & 4 & 4 & 4 & 4 & 4 & 4 & 4 & 4 \\
\hline $\begin{array}{l}\text { Floresta em solos } \\
\text { profundos }\end{array}$ & 6 & 6 & 6 & 6 & 6 & 6 & 6 & 6 & 6 & 6 & 6 & 6 \\
\hline $\begin{array}{l}\text { Agricultura em Solo } \\
\text { Médio }\end{array}$ & 4 & 4 & 4 & 4 & 4 & 4 & 4 & 4 & 4 & 4 & 4 & 4 \\
\hline $\begin{array}{l}\text { Campos, Cerrado e } \\
\text { Estepes em solo mé- } \\
\text { dio }\end{array}$ & 4 & 4 & 4 & 4 & 4 & 4 & 4 & 4 & 4 & 4 & 4 & 4 \\
\hline $\begin{array}{l}\text { Floresta em solo mé- } \\
\text { dio }\end{array}$ & 6 & 6 & 6 & 6 & 6 & 6 & 6 & 6 & 6 & 6 & 6 & 6 \\
\hline $\begin{array}{l}\text { Áreas Semi- } \\
\text { Impermeáveis }\end{array}$ & 4 & 4 & 4 & 4 & 4 & 4 & 4 & 4 & 4 & 4 & 4 & 4 \\
\hline Água & 0 & 0 & 0 & 0 & 0 & 0 & 0 & 0 & 0 & 0 & 0 & 0 \\
\hline
\end{tabular}

Tabela 90 - Parâmetros Fixos de Altura do Dossel (Z) para o MGB-IPH

\begin{tabular}{|c|c|c|c|c|c|c|c|c|c|c|c|c|}
\hline $\begin{array}{l}\text { Unidade de Resposta } \\
\text { Hidrológica }\end{array}$ & jan & fev & mar & $a b r$ & mai & jun & jul & ago & set & out & nov & $\overline{\mathrm{dez}}$ \\
\hline $\begin{array}{l}\text { Agricultura em Solos } \\
\text { profundos }\end{array}$ & 4 & 4 & 4 & 4 & 4 & 4 & 4 & 4 & 4 & 4 & 4 & 4 \\
\hline $\begin{array}{l}\text { Campos, Cerrado e } \\
\text { Estepes em solos pro- } \\
\text { fundos }\end{array}$ & 8 & 8 & 8 & 8 & 8 & 8 & 8 & 8 & 8 & 8 & 8 & 8 \\
\hline $\begin{array}{l}\text { Floresta em solos } \\
\text { profundos }\end{array}$ & 9 & 9 & 9 & 9 & 9 & 9 & 9 & 9 & 9 & 9 & 9 & 9 \\
\hline $\begin{array}{l}\text { Agricultura em Solo } \\
\text { Médio }\end{array}$ & 4 & 4 & 4 & 4 & 4 & 4 & 4 & 4 & 4 & 4 & 4 & 4 \\
\hline $\begin{array}{l}\text { Campos, Cerrado e } \\
\text { Estepes em solo mé- } \\
\text { dio }\end{array}$ & 8 & 8 & 8 & 8 & 8 & 8 & 8 & 8 & 8 & 8 & 8 & 8 \\
\hline $\begin{array}{l}\text { Floresta em solo mé- } \\
\text { dio }\end{array}$ & 9 & 9 & 9 & 9 & 9 & 9 & 9 & 9 & 9 & 9 & 9 & 9 \\
\hline $\begin{array}{l}\text { Áreas Semi- } \\
\text { Impermeáveis }\end{array}$ & 6 & 6 & 6 & 6 & 6 & 6 & 6 & 6 & 6 & 6 & 6 & 6 \\
\hline Água & 0.1 & 0.1 & 0.1 & 0.1 & 0.1 & 0.1 & 0.1 & 0.1 & 0.1 & 0.1 & 0.1 & 0.1 \\
\hline
\end{tabular}


Tabela 91 - Parâmetros Fixos de Resistência Superficial (RS) para o MGB-IPH

Unidade de Resposta jan fev mar abr mai jun jul ago set out nov dez Hidrológica

\begin{tabular}{|c|c|c|c|c|c|c|c|c|c|c|c|c|}
\hline $\begin{array}{l}\text { Agricultura em Solos } \\
\text { profundos }\end{array}$ & 60 & 60 & 60 & 60 & 60 & 60 & 60 & 60 & 60 & 60 & 60 & 60 \\
\hline $\begin{array}{l}\text { Campos, Cerrado e } \\
\text { Estepes em solos pro- } \\
\text { fundos }\end{array}$ & 60 & 60 & 60 & 60 & 60 & 60 & 60 & 60 & 60 & 60 & 60 & 60 \\
\hline $\begin{array}{l}\text { Floresta em solos } \\
\text { profundos }\end{array}$ & 60 & 60 & 60 & 60 & 60 & 60 & 60 & 60 & 60 & 60 & 60 & 60 \\
\hline $\begin{array}{l}\text { Agricultura em Solo } \\
\text { Médio }\end{array}$ & 60 & 60 & 60 & 60 & 60 & 60 & 60 & 60 & 60 & 60 & 60 & 60 \\
\hline $\begin{array}{l}\text { Campos, Cerrado e } \\
\text { Estepes em solo mé- } \\
\text { dio }\end{array}$ & 60 & 60 & 60 & 60 & 60 & 60 & 60 & 60 & 60 & 60 & 60 & 60 \\
\hline $\begin{array}{l}\text { Floresta em solo mé- } \\
\text { dio }\end{array}$ & 60 & 60 & 60 & 60 & 60 & 60 & 60 & 60 & 60 & 60 & 60 & 60 \\
\hline $\begin{array}{l}\text { Áreas Semi- } \\
\text { Impermeáveis }\end{array}$ & 60 & 60 & 60 & 60 & 60 & 60 & 60 & 60 & 60 & 60 & 60 & 60 \\
\hline Água & 0 & 0 & 0 & 0 & 0 & 0 & 0 & 0 & 0 & 0 & 0 & 0 \\
\hline
\end{tabular}

Tabela 92 - Parâmetros Calibráveis para o MGB: CI, CS, CB e QB

\begin{tabular}{ccccc}
\hline \hline Parâmetro & Bacia 1 & Bacia 2 & Bacia 3 & Bacia 4 \\
\hline CI & 12 & 4.41 & 9.94 & 8 \\
CS & 120 & 172 & 95.44 & 100 \\
CB & 4000 & 2426 & 648 & 2000 \\
QB & 0.01 & 0.01 & 0.01 & 0.01 \\
\hline Parâmetro & Bacia 5 & Bacia 6 & Bacia 7 & Bacia 8 \\
\hline CI & 15.2 & 29.07 & 5 & 6.01 \\
CS & 134.4 & 104.6 & 50 & 108.2 \\
CB & 1498 & 2078 & 2000 & 4141.2 \\
QB & 0.01 & 0.01 & 0.01 & 0.01 \\
\hline Parâmetro & Bacia 9 & Bacia 10 & Bacia 11 & Bacia 12 \\
\hline CI & 17.82 & 3.61 & 3.61 & 2.3 \\
CS & 198.4 & 183.9 & 183.9 & 128 \\
CB & 9817.2 & 1248 & 1248 & 2640 \\
QB & 0.01 & 0.01 & 0.01 & 0.01 \\
\hline Parâmetro & Bacia 13 & - & - & - \\
\hline CI & 1.81 & - & - & - \\
CS & 99.2 & - & - & - \\
CB & 1190.4 & - & - & - \\
QB & 0.01 & - & - & - \\
\hline \hline
\end{tabular}


Tabela 93 - Parâmetros Calibráveis Wm, b, Kbas, Kint, XL, CAP e Wc para as Bacia 1, 2, 3 e 4

\begin{tabular}{|c|c|c|c|c|c|c|c|}
\hline \multicolumn{8}{|c|}{ Bacia 1} \\
\hline Unidade de resposta Hidrológica & $\mathrm{Wm}$ & $\mathrm{b}$ & Kbas & Kint & XL & CAP & Wc \\
\hline Agricultura em Solos profundos & 313 & 0.2 & 0.78 & 4.72 & 0.6 & 0 & 0 \\
\hline Campos, Cerrado e Estepes em solos profundos & 313 & 0.2 & 0.78 & 4.72 & 0.6 & 0 & 0 \\
\hline Floresta em solos profundos & 313 & 0.2 & 0.78 & 4.72 & 0.6 & 0 & 0 \\
\hline Agricultura em Solo Médio & 250 & 0.26 & 1.99 & 4.72 & 0.6 & 0 & 0 \\
\hline Campos, Cerrado e Estepes em solo médio & 250 & 0.26 & 1.99 & 4.72 & 0.6 & 0 & 0 \\
\hline Floresta em solo médio & 250 & 0.26 & 1.99 & 4.72 & 0.6 & 0 & 0 \\
\hline Áreas Semi-Impermeáveis & 20 & 0.26 & 1.99 & 4.72 & 0.6 & 0 & 0 \\
\hline Água & 0 & 0 & 0 & 0 & 0 & 0 & 0 \\
\hline \multicolumn{8}{|c|}{ Bacia 2} \\
\hline Unidade de resposta Hidrológica & $\mathrm{Wm}$ & $\mathrm{b}$ & Kbas & Kint & XL & CAP & Wc \\
\hline Agricultura em Solos profundos & 710 & 0.18 & 0.93 & 1.91 & 0.6 & 0 & 0 \\
\hline Campos, Cerrado e Estepes em solos profundos & 710 & 0.18 & 0.93 & 1.91 & 0.6 & 0 & 0 \\
\hline Floresta em solos profundos & 710 & 0.18 & 0.93 & 1.91 & 0.6 & 0 & 0 \\
\hline Agricultura em Solo Médio & 164 & 0.45 & 2.02 & 1.91 & 0.6 & 0 & 0 \\
\hline Campos, Cerrado e Estepes em solo médio & 164 & 0.45 & 2.02 & 1.91 & 0.6 & 0 & 0 \\
\hline Floresta em solo médio & 164 & 0.45 & 2.02 & 1.91 & 0.6 & 0 & 0 \\
\hline Áreas Semi-Impermeáveis & 20 & 0.45 & 2.02 & 1.91 & 0.6 & 0 & 0 \\
\hline Água & 0 & 0 & 0 & 0 & 0 & 0 & 0 \\
\hline \multicolumn{8}{|c|}{ Bacia 3} \\
\hline Unidade de resposta Hidrológica & Wm & $\mathrm{b}$ & Kbas & Kint & XL & CAP & Wc \\
\hline Agricultura em Solos profundos & 948 & 0.44 & 1.77 & 3.73 & 0.6 & 0 & 0 \\
\hline Campos, Cerrado e Estepes em solos profundos & 948 & 0.44 & 1.77 & 3.73 & 0.6 & 0 & 0 \\
\hline Floresta em solos profundos & 948 & 0.44 & 1.77 & 3.73 & 0.6 & 0 & 0 \\
\hline Agricultura em Solo Médio & 158.5 & 0.53 & 0.6 & 3.73 & 0.6 & 0 & 0 \\
\hline Campos, Cerrado e Estepes em solo médio & 158.5 & 0.53 & 0.6 & 3.73 & 0.6 & 0 & 0 \\
\hline Floresta em solo médio & 158.5 & 0.53 & 0.6 & 3.73 & 0.6 & 0 & 0 \\
\hline Áreas Semi-Impermeáveis & 13.8 & 0.32 & 0.6 & 3.73 & 0.6 & 0 & 0 \\
\hline Água & 0 & 0 & 0 & 0 & 0 & 0 & 0 \\
\hline \multicolumn{8}{|c|}{ Bacia 4} \\
\hline Unidade de resposta Hidrológica & $\mathrm{Wm}$ & $\mathrm{b}$ & Kbas & Kint & $\mathrm{XL}$ & CAP & $\mathrm{Wc}$ \\
\hline Agricultura em Solos profundos & 600 & 0.13 & 0.57 & 3.72 & 0.6 & 0 & 0 \\
\hline Campos, Cerrado e Estepes em solos profundos & 600 & 0.13 & 0.57 & 3.72 & 0.6 & 0 & 0 \\
\hline Floresta em solos profundos & 600 & 0.13 & 0.57 & 3.72 & 0.6 & 0 & 0 \\
\hline Agricultura em Solo Médio & 360 & 0.18 & 1.24 & 3.72 & 0.6 & 0 & 0 \\
\hline Campos, Cerrado e Estepes em solo médio & 360 & 0.18 & 1.24 & 3.72 & 0.6 & 0 & 0 \\
\hline Floresta em solo médio & 360 & 0.18 & 1.24 & 3.72 & 0.6 & 0 & 0 \\
\hline Áreas Semi-Impermeáveis & 20 & 0.18 & 1.24 & 3.72 & 0.6 & 0 & 0 \\
\hline Água & 0 & 0 & 0 & 0 & 0 & 0 & 0 \\
\hline
\end{tabular}


Tabela 94 - Parâmetros Calibráveis Wm, b, Kbas, Kint, XL, CAP e Wc para a Bacia 5, 6, 7 e 8

\begin{tabular}{|c|c|c|c|c|c|c|c|}
\hline \multicolumn{8}{|c|}{ Bacia 5} \\
\hline Unidade de resposta Hidrológica & $\mathrm{Wm}$ & $\mathrm{b}$ & Kbas & Kint & $\mathrm{XL}$ & CAP & Wc \\
\hline Agricultura em Solos profundos & 282.5 & 0.5 & 2 & 30 & 0.6 & 0 & 0 \\
\hline Campos, Cerrado e Estepes em solos profundos & 282.5 & 0.5 & 2 & 30 & 0.6 & 0 & 0 \\
\hline Floresta em solos profundos & 282.5 & 0.5 & 2 & 30 & 0.6 & 0 & 0 \\
\hline Agricultura em Solo Médio & 246.6 & 0.35 & 4.52 & 30 & 0.6 & 0 & 0 \\
\hline Campos, Cerrado e Estepes em solo médio & 246.6 & 0.35 & 4.52 & 30 & 0.6 & 0 & 0 \\
\hline Floresta em solo médio & 246.6 & 0.35 & 4.52 & 30 & 0.6 & 0 & 0 \\
\hline Áreas Semi-Impermeáveis & 8 & 0.38 & 4.52 & 4.87 & 0.6 & 0 & 0 \\
\hline Água & 0 & 0 & 0 & 0 & 0 & 0 & 0 \\
\hline \multicolumn{8}{|c|}{ Bacia 6} \\
\hline Unidade de resposta Hidrológica & $\mathrm{Wm}$ & $\mathrm{b}$ & Kbas & Kint & $\mathrm{XL}$ & CAP & $\mathrm{Wc}$ \\
\hline Agricultura em Solos profundos & 415.3 & 0.25 & 0.56 & 13.13 & 0.6 & 0 & 0 \\
\hline Campos, Cerrado e Estepes em solos profundos & 415.3 & 0.25 & 0.56 & 13.13 & 0.6 & 0 & 0 \\
\hline Floresta em solos profundos & 415.3 & 0.25 & 0.56 & 13.13 & 0.6 & 0 & 0 \\
\hline Agricultura em Solo Médio & 245.6 & 0.23 & 2.68 & 13.13 & 0.6 & 0 & 0 \\
\hline Campos, Cerrado e Estepes em solo médio & 245.6 & 0.23 & 2.68 & 13.13 & 0.6 & 0 & 0 \\
\hline Floresta em solo médio & 245.6 & 0.23 & 2.68 & 13.13 & 0.6 & 0 & 0 \\
\hline Áreas Semi-Impermeáveis & 45.4 & 0.23 & 2.68 & 13.13 & 0.6 & 0 & 0 \\
\hline Água & 0 & 0 & 0 & 0 & 0 & 0 & 0 \\
\hline \multicolumn{8}{|c|}{ Bacia 7} \\
\hline Unidade de resposta Hidrológica & $\mathrm{Wm}$ & $\mathrm{b}$ & Kbas & Kint & XL & CAP & Wc \\
\hline Agricultura em Solos profundos & 300 & 0.35 & 2.34 & 9.87 & 0.6 & 0 & 0 \\
\hline Campos, Cerrado e Estepes em solos profundos & 300 & 0.35 & 2.34 & 9.87 & 0.6 & 0 & 0 \\
\hline Floresta em solos profundos & 300 & 0.35 & 2.34 & 9.87 & 0.6 & 0 & 0 \\
\hline Agricultura em Solo Médio & 100 & 0.35 & 2.86 & 9.87 & 0.6 & 0 & 0 \\
\hline Campos, Cerrado e Estepes em solo médio & 100 & 0.35 & 2.86 & 9.87 & 0.6 & 0 & 0 \\
\hline Floresta em solo médio & 100 & 0.35 & 2.86 & 9.87 & 0.6 & 0 & 0 \\
\hline Áreas Semi-Impermeáveis & 40 & 0.35 & 0.86 & 1.87 & 0.6 & 0 & 0 \\
\hline Água & 0 & 0 & 0 & 0 & 0 & 0 & 0 \\
\hline \multicolumn{8}{|c|}{ Bacia 8} \\
\hline Unidade de resposta Hidrológica & $\mathrm{Wm}$ & $\mathrm{b}$ & Kbas & Kint & $\mathrm{XL}$ & CAP & $\mathrm{Wc}$ \\
\hline Agricultura em Solos profundos & 762.6 & 0.15 & 1.34 & 4.87 & 0.6 & 0 & 0 \\
\hline Campos, Cerrado e Estepes em solos profundos & 762.6 & 0.15 & 1.34 & 4.87 & 0.6 & 0 & 0 \\
\hline Floresta em solos profundos & 762.6 & 0.15 & 1.34 & 4.87 & 0.6 & 0 & 0 \\
\hline Agricultura em Solo Médio & 263.1 & 0.18 & 0.86 & 4.87 & 0.6 & 0 & 0 \\
\hline Campos, Cerrado e Estepes em solo médio & 263.1 & 0.18 & 0.86 & 4.87 & 0.6 & 0 & 0 \\
\hline Floresta em solo médio & 263.1 & 0.18 & 0.86 & 4.87 & 0.6 & 0 & 0 \\
\hline Áreas Semi-Impermeáveis & 72.5 & 0.18 & 0.86 & 4.87 & 0.6 & 0 & 0 \\
\hline Água & 0 & 0 & 0 & 0 & 0 & 0 & 0 \\
\hline
\end{tabular}


Tabela 95 - Parâmetros Calibráveis Wm, b, Kbas, Kint, XL, CAP e Wc para a Bacia 9, 10, 11, 12

\begin{tabular}{|c|c|c|c|c|c|c|c|}
\hline \multicolumn{8}{|c|}{ Bacia 9} \\
\hline Unidade de resposta Hidrológica & $\mathrm{Wm}$ & $\mathrm{b}$ & Kbas & Kint & $\mathrm{XL}$ & CAP & Wc \\
\hline Agricultura em Solos profundos & 1065.6 & 0.13 & 0.57 & 3.72 & 0.6 & 0 & 0 \\
\hline Campos, Cerrado e Estepes em solos profundos & 1065.6 & 0.13 & 0.57 & 3.72 & 0.6 & 0 & 0 \\
\hline Floresta em solos profundos & 1065.6 & 0.13 & 0.57 & 3.72 & 0.6 & 0 & 0 \\
\hline Agricultura em Solo Médio & 535.2 & 0.18 & 1.24 & 3.72 & 0.6 & 0 & 0 \\
\hline Campos, Cerrado e Estepes em solo médio & 535.2 & 0.18 & 1.24 & 3.72 & 0.6 & 0 & 0 \\
\hline Floresta em solo médio & 535.2 & 0.18 & 1.24 & 3.72 & 0.6 & 0 & 0 \\
\hline Áreas Semi-Impermeáveis & 37.9 & 0.18 & 1.24 & 3.72 & 0.6 & 0 & 0 \\
\hline Água & 0 & 0 & 0 & 0 & 0 & 0 & 0 \\
\hline \multicolumn{8}{|c|}{ Bacia 10} \\
\hline Unidade de resposta Hidrológica & $\mathrm{Wm}$ & $\mathrm{b}$ & Kbas & Kint & XL & CAP & Wc \\
\hline Agricultura em Solos profundos & 355.8 & 0.16 & 1.84 & 6.9 & 0.6 & 0 & 0 \\
\hline Campos, Cerrado e Estepes em solos profundos & 355.8 & 0.16 & 1.84 & 6.9 & 0.6 & 0 & 0 \\
\hline Floresta em solos profundos & 355.8 & 0.16 & 1.84 & 6.9 & 0.6 & 0 & 0 \\
\hline Agricultura em Solo Médio & 356.4 & 0.44 & 1.22 & 6.9 & 0.6 & 0 & 0 \\
\hline Campos, Cerrado e Estepes em solo médio & 356.4 & 0.44 & 1.22 & 6.9 & 0.6 & 0 & 0 \\
\hline Floresta em solo médio & 356.4 & 0.44 & 1.22 & 6.9 & 0.6 & 0 & 0 \\
\hline Áreas Semi-Impermeáveis & 66.4 & 0.44 & 1.22 & 6.9 & 0.6 & 0 & 0 \\
\hline Água & 0 & 0 & 0 & 0 & 0 & 0 & 0 \\
\hline \multicolumn{8}{|c|}{ Bacia 11} \\
\hline Unidade de resposta Hidrológica & $\mathrm{Wm}$ & $\mathrm{b}$ & Kbas & Kint & $\mathrm{XL}$ & CAP & $\mathrm{Wc}$ \\
\hline Agricultura em Solos profundos & 355.8 & 0.16 & 1.84 & 6.9 & 0.6 & 0 & 0 \\
\hline Campos, Cerrado e Estepes em solos profundos & 355.8 & 0.16 & 1.84 & 6.9 & 0.6 & 0 & 0 \\
\hline Floresta em solos profundos & 355.8 & 0.16 & 1.84 & 6.9 & 0.6 & 0 & 0 \\
\hline Agricultura em Solo Médio & 356.4 & 0.44 & 1.22 & 6.9 & 0.6 & 0 & 0 \\
\hline Campos, Cerrado e Estepes em solo médio & 356.4 & 0.44 & 1.22 & 6.9 & 0.6 & 0 & 0 \\
\hline Floresta em solo médio & 356.4 & 0.44 & 1.22 & 6.9 & 0.6 & 0 & 0 \\
\hline Áreas Semi-Impermeáveis & 66.4 & 0.44 & 1.22 & 6.9 & 0.6 & 0 & 0 \\
\hline Água & 0 & 0 & 0 & 0 & 0 & 0 & 0 \\
\hline \multicolumn{8}{|c|}{ Bacia 12} \\
\hline Unidade de resposta Hidrológica & $\mathrm{Wm}$ & $\mathrm{b}$ & Kbas & Kint & $\mathrm{XL}$ & CAP & $\mathrm{Wc}$ \\
\hline Agricultura em Solos profundos & 562.7 & 0.21 & 1.82 & 2.4 & 0.6 & 0 & 0 \\
\hline Campos, Cerrado e Estepes em solos profundos & 562.7 & 0.21 & 1.82 & 2.4 & 0.6 & 0 & 0 \\
\hline Floresta em solos profundos & 488.3 & 0.21 & 1.82 & 2.4 & 0.6 & 0 & 0 \\
\hline Agricultura em Solo Médio & 196.1 & 0.24 & 0.58 & 2.4 & 0.6 & 0 & 0 \\
\hline Campos, Cerrado e Estepes em solo médio & 196.1 & 0.24 & 0.58 & 2.4 & 0.6 & 0 & 0 \\
\hline Floresta em solo médio & 196.1 & 0.24 & 0.58 & 2.4 & 0.6 & 0 & 0 \\
\hline Áreas Semi-Impermeáveis & 12.7 & 0.24 & 0.58 & 2.4 & 0.6 & 0 & 0 \\
\hline Água & 0 & 0 & 0 & 0 & 0 & 0 & 0 \\
\hline
\end{tabular}


Tabela 96 - Parâmetros Calibráveis Wm, b, Kbas, Kint, XL, CAP e Wc para a Bacia 13

\begin{tabular}{cccccccc}
\hline \hline Unidade de resposta Hidrológica & $\mathrm{Wm}$ & $\mathrm{b}$ & $\mathrm{Kbas}$ & $\mathrm{Kint}$ & $\mathrm{XL}$ & $\mathrm{CAP}$ & $\mathrm{Wc}$ \\
\hline Agricultura em Solos profundos & 684.6 & 0.14 & 1.8 & 1.61 & 0.6 & 0 & 0 \\
Campos, Cerrado e Estepes em solos profundos & 469.8 & 0.14 & 1.8 & 1.61 & 0.6 & 0 & 0 \\
Floresta em solos profundos & 594 & 0.14 & 1.8 & 1.61 & 0.6 & 0 & 0 \\
Agricultura em Solo Médio & 314.7 & 0.14 & 1.8 & 1.61 & 0.6 & 0 & 0 \\
Campos, Cerrado e Estepes em solo médio & 313.2 & 0.14 & 1.8 & 1.61 & 0.6 & 0 & 0 \\
Floresta em solo médio & 217.8 & 0.14 & 1.8 & 1.61 & 0.6 & 0 & 0 \\
Áreas Semi-Impermeáveis & 30.1 & 0.14 & 1.8 & 1.61 & 0.6 & 0 & 0 \\
Água & 0 & 0 & 0 & 0 & 0 & 0 & 0 \\
\hline \hline
\end{tabular}





\section{APÊNDICE C - Geometria dos canais da configuração do SOBEK}

Tabela 97 - Configuração Geométrica de nós para o SOBEK - Rio Abaetés

\begin{tabular}{lllll}
\hline \hline $\begin{array}{l}\text { Localização } \\
(\mathrm{m})\end{array}$ & $\begin{array}{l}\text { Identificação } \\
\text { do Nó }\end{array}$ & $\begin{array}{l}\text { Transecto Equiva- } \\
\text { lente }\end{array}$ & $\begin{array}{l}\text { Largura Máxima } \\
\text { da Seção }(\mathrm{m})\end{array}$ & $\begin{array}{l}\text { Manning } \\
\left(\mathrm{s} / \mathrm{m}^{-1 / 3}\right)\end{array}$ \\
\hline 0.000 & PBR040 & - & - & - \\
1.000 & P_35200_1 & RA35200 & 89.610 & 0.003 \\
1189.600 & P_34000_1 & RA34000 & 140.020 & 0.003 \\
5048.120 & P_30100_1 & RA30100 & 105.000 & 0.03 \\
10984.300 & P_24200_1 & RA24200 & 136.000 & 0.03 \\
14725.520 & P_20400_1 & RA20400 & 131.000 & 0.025 \\
15808.070 & P_19300_1 & RA19300 & 110.000 & 0.025 \\
18655.860 & P_16500_1 & RA16500 & 102.000 & 0.025 \\
22761.770 & P_12400_1 & RA12400 & 124.200 & 0.025 \\
35120.560 & P_0_1 & RA0 & 601.490 & 0.025 \\
\hline \hline
\end{tabular}

Tabela 98 - Configuração Geométrica de nós para o SOBEK - Rio São Francisco 1

\begin{tabular}{lllll}
\hline \hline $\begin{array}{l}\text { Localização } \\
(\mathrm{m})\end{array}$ & $\begin{array}{l}\text { Identificação } \\
\text { do Nó }\end{array}$ & $\begin{array}{l}\text { Transecto Equiva- } \\
\text { lente }\end{array}$ & $\begin{array}{l}\text { Largura Máxima } \\
\text { da Seção }(\mathrm{m})\end{array}$ & $\begin{array}{l}\text { Manning } \\
\left(\mathrm{s} / \mathrm{m}^{-1 / 3}\right)\end{array}$ \\
\hline 0.000 & TresMarias & - & - & - \\
1.000 & P_159600_2 & SF159600 & 348.110 & 0.02 \\
625.600 & P_156000_2 & SF156000 & 331.970 & 0.02 \\
4284.450 & P_153200_2 & SF153200 & 374.690 & 0.02 \\
7040.200 & P_148800_2 & SF148800 & 357.660 & 0.025 \\
11456.280 & P_144800_2 & SF144800 & 366.910 & 0.025 \\
15487.580 & P_142200_2 & SF142200 & 345.460 & 0.02 \\
18047.300 & P_137600_2 & SF137600 & 349.820 & 0.025 \\
22687.350 & P_134000_2 & SF134000 & 315.750 & 0.02 \\
26260.140 & P_130300_2 & SF130300 & 318.560 & 0.025 \\
29914.630 & P_127210_2 & SF127210 & 592.590 & 0.025 \\
\hline \hline
\end{tabular}


Tabela 99 - Configuração Geométrica de nós para o SOBEK - Rio São Francisco 2

\begin{tabular}{lllll}
\hline \hline $\begin{array}{l}\text { Localização } \\
(\mathrm{m})\end{array}$ & $\begin{array}{l}\text { Identificação } \\
\text { do Nó }\end{array}$ & $\begin{array}{l}\text { Transecto Equiva- } \\
\text { lente }\end{array}$ & $\begin{array}{l}\text { Largura Máxima } \\
\text { da Seção }(\mathrm{m})\end{array}$ & $\begin{array}{l}\text { Manning } \\
\left(\mathrm{s} / \mathrm{m}^{-1 / 3}\right)\end{array}$ \\
\hline 0.000 & P_127210_2 & SF127210 & 592.590 & 0.025 \\
1.000 & P_127190_3 & SF127190 & 592.590 & 0.025 \\
3141.930 & P_122100_3 & SF122100 & 340.590 & 0.025 \\
8233.590 & P_118800_3 & SF118800 & 335.120 & 0.025 \\
11533.170 & P_116400_3 & SF116400 & 296.090 & 0.015 \\
13895.210 & P_111700_3 & SF111700 & 391.640 & 0.015 \\
18678.440 & P_109400_3 & SF109400 & 389.700 & 0.025 \\
20972.120 & P_102500_3 & SF102500 & 323.000 & 0.025 \\
27853.150 & P_95600_3 & SF95600 & 320.390 & 0.023 \\
34707.440 & P_92600_3 & SF92600 & 375.810 & 0.015 \\
37722.300 & P_86600_3 & SF86600 & 463.320 & 0.02 \\
43730.310 & P_83200_3 & SF83200 & 297.490 & 0.02 \\
47128.040 & P_77200_3 & SF77200 & 597.910 & 0.023 \\
53136.050 & P_71100_3 & SF71100 & 330.880 & 0.023 \\
59215.690 & P_68200_3 & SF68200 & 306.770 & 0.015 \\
62175.190 & P_63800_3 & SF63800 & 397.090 & 0.015 \\
66548.170 & P_57000_3 & SF57000 & 338.490 & 0.023 \\
73377.580 & P_53400_3 & SF53400 & 1645.000 & 0.023 \\
76933.500 & P_44700_3 & SF44700 & 1337.260 & 0.023 \\
85664.660 & P_38800_3 & SF38800 & 1501.540 & 0.023 \\
91495.370 & P_35400_3 & SF35400 & 1276.760 & 0.023 \\
94941.360 & P_32000_3 & SF32000 & 1700.330 & 0.015 \\
98320.540 & P_30700_3 & SF30700 & 2105.770 & 0.015 \\
99665.450 & P_29000_3 & SF29000 & 1250.000 & 0.03 \\
99666.450 & PiraporaPonte & - & - & - \\
\hline \hline & & & & \\
\hline
\end{tabular}




\section{APÊNDICE D - Geometria dos canais da configuração do SPRNT}

Tabela 100 - SPRNT: Configuração completa do rio Abaetés

\begin{tabular}{lllllll}
\hline \hline Seção Transversal & Comprimento $(\mathrm{m})$ & Manning $(\mathrm{n})$ & $\mathrm{z0}(\mathrm{m})$ & $\mathrm{sR}(\mathrm{m} / \mathrm{m})$ & $\mathrm{zR}$ & $\mathrm{hR}(\mathrm{m})$ \\
\hline RA35200 & 1189.6 & 0.035 & 543.95 & 0.001255639 & 542.4562919 & 1.49 \\
RA34000 & 3858.52 & 0.030 & 543.21 & 0.001255639 & 538.3650919 & 4.84 \\
RA30100 & 5936.18 & 0.040 & 533.26 & 0.001255639 & 525.806301 & 7.45 \\
RA24200 & 3741.22 & 0.045 & 520.06 & 0.001255639 & 515.3623783 & 4.70 \\
RA20400 & 1082.55 & 0.040 & 518.99 & 0.001255639 & 517.630708 & 1.36 \\
RA19300 & 2847.79 & 0.030 & 514.71 & 0.001255639 & 511.1342039 & 3.58 \\
RA16500 & 4105.91 & 0.035 & 510.51 & 0.001255639 & 505.3544593 & 5.16 \\
RA12400 & 12359.79 & 0.040 & 509.25 & 0.001255639 & 493.7305658 & 15.52 \\
RA0 & 0 & 0.040 & 499.85 & 0.001255639 & 499.85 & 0.00 \\
\hline \hline
\end{tabular}

Tabela 101 - SPRNT: Configuração completa do rio São Francisco 1

\begin{tabular}{lllllll}
\hline \hline Seção Transversal & Comprimento $(\mathrm{m})$ & Manning $(\mathrm{n})$ & $\mathrm{z} 0(\mathrm{~m})$ & $\mathrm{sR}(\mathrm{m} / \mathrm{m})$ & $\mathrm{zR}$ & $\mathrm{hR}(\mathrm{m})$ \\
\hline SF159600 & 625.6 & 0.040 & 509.07 & 0.0003082 & 508.87719 & 0.19 \\
SF156000 & 3658.85 & 0.040 & 509.59 & 0.0003082 & 508.4623421 & 1.13 \\
SF153200 & 2755.75 & 0.040 & 508.67 & 0.0003082 & 507.8206776 & 0.85 \\
SF148800 & 4416.08 & 0.025 & 504.82 & 0.0003082 & 503.4589637 & 1.36 \\
SF144800 & 4031.3 & 0.025 & 504.10 & 0.0003082 & 502.857553 & 1.24 \\
SF142200 & 2559.72 & 0.020 & 502.53 & 0.0003082 & 501.7410941 & 0.79 \\
SF137600 & 4640.05 & 0.025 & 502.00 & 0.0003082 & 500.5699362 & 1.43 \\
SF134000 & 3572.79 & 0.020 & 499.83 & 0.0003082 & 498.7288658 & 1.10 \\
SF130300 & 3655.49 & 0.025 & 500.28 & 0.0003082 & 499.1533776 & 1.13 \\
SF127210 & 0 & 0.030 & 499.85 & 0.0003082 & 499.85 & 0.00 \\
\hline \hline
\end{tabular}


Tabela 102 - SPRNT: Configuração completa do rio São Francisco 2

\begin{tabular}{lllllll}
\hline \hline Seção Transversal & Comprimento $(\mathrm{m})$ & Manning $(\mathrm{n})$ & $\mathrm{z} 0(\mathrm{~m})$ & $\mathrm{sR}(\mathrm{m} / \mathrm{m})$ & $\mathrm{zR}$ & $\mathrm{hR}(\mathrm{m})$ \\
\hline SF127190 & 3141.93 & 0.030 & 499.85 & 0.000244826 & 499.0807744 & 0.77 \\
SF122100 & 5091.66 & 0.030 & 497.92 & 0.000244826 & 496.6734302 & 1.25 \\
SF118800 & 3299.58 & 0.035 & 495.86 & 0.000244826 & 495.0521776 & 0.81 \\
SF116400 & 2362.04 & 0.030 & 493.89 & 0.000244826 & 493.3117116 & 0.58 \\
SF111700 & 4783.23 & 0.030 & 494.83 & 0.000244826 & 493.6589418 & 1.17 \\
SF109400 & 2293.68 & 0.025 & 493.42 & 0.000244826 & 492.8584479 & 0.56 \\
SF102500 & 6881.03 & 0.025 & 492.65 & 0.000244826 & 490.9653462 & 1.68 \\
SF95600 & 6854.29 & 0.023 & 490.14 & 0.000244826 & 488.4618928 & 1.68 \\
SF92600 & 3014.86 & 0.015 & 490.14 & 0.000244826 & 489.4018844 & 0.74 \\
SF86600 & 6008.01 & 0.020 & 489.22 & 0.000244826 & 487.749084 & 1.47 \\
SF83200 & 3397.73 & 0.020 & 486.90 & 0.000244826 & 486.068148 & 0.83 \\
SF77200 & 6008.01 & 0.023 & 487.12 & 0.000244826 & 485.649084 & 1.47 \\
SF71100 & 6079.64 & 0.030 & 485.15 & 0.000244826 & 483.6615472 & 1.49 \\
SF68200 & 2959.5 & 0.015 & 484.65 & 0.000244826 & 483.925438 & 0.72 \\
SF63800 & 4372.98 & 0.020 & 485.17 & 0.000244826 & 484.0993816 & 1.07 \\
SF57000 & 6829.41 & 0.025 & 483.09 & 0.000244826 & 481.4179841 & 1.67 \\
SF53400 & 3555.92 & 0.030 & 483.21 & 0.000244826 & 482.339419 & 0.87 \\
SF44700 & 8731.16 & 0.030 & 482.23 & 0.000244826 & 480.0923866 & 2.14 \\
SF38800 & 5830.71 & 0.035 & 481.03 & 0.000244826 & 479.6024916 & 1.43 \\
SF35400 & 3445.99 & 0.035 & 479.98 & 0.000244826 & 479.1363327 & 0.84 \\
SF32000 & 3379.18 & 0.040 & 480.79 & 0.000244826 & 479.9626895 & 0.83 \\
SF30700 & 1344.91 & 0.030 & 479.71 & 0.000244826 & 479.3807313 & 0.33 \\
SF29000 & 1662.02 & 0.030 & 481.38 & 0.000244826 & 480.9730946 & 0.41 \\
\hline \hline
\end{tabular}

Tabela 103 - SPRNT: Configuração reduzida do rio Abaetés

\begin{tabular}{lllllll}
\hline \hline Seção Transversal & Comprimento $(\mathrm{m})$ & Manning $(\mathrm{n})$ & $\mathrm{z} 0(\mathrm{~m})$ & $\mathrm{sR}(\mathrm{m} / \mathrm{m})$ & $\mathrm{zR}$ & $\mathrm{hR}(\mathrm{m})$ \\
\hline PBR040 & 10984.3 & 0.001255639 & 0.035945741 & 530.1576847 & 13.79 & \\
RA24200 & 11777.47 & 0.001255639 & 0.037427177 & 505.2717495 & 14.79 & \\
RA12400 & 12359.79 & 0.001255639 & 0.040 & 493.7305658 & 15.52 & \\
RA0 & 1.0 & 0.001255639 & 0.040 & 499.85 & 0.00 & \\
\hline \hline
\end{tabular}

Tabela 104 - SPRNT: Configuração completa do rio São Francisco 1

\begin{tabular}{lllllll}
\hline \hline Seção Transversal & Comprimento $(\mathrm{m})$ & Manning $(\mathrm{n})$ & $\mathrm{z} 0(\mathrm{~m})$ & $\mathrm{sR}(\mathrm{m} / \mathrm{m})$ & $\mathrm{zR}$ & $\mathrm{hR}(\mathrm{m})$ \\
\hline TMARIAS & 11456.28 & 0.0003082 & 0.034217914 & 505.5391734 & 3.53 & \\
SF144800 & 11231.07 & 0.0003082 & 0.023860429 & 500.6385832 & 3.46 & \\
SF134000 & 7228.28 & 0.0003082 & 0.023 & 497.6022434 & 2.23 & \\
SF127210 & 1.0 & 0.0003082 & 0.030 & 499.85 & 0.00 & \\
\hline \hline
\end{tabular}


Tabela 105 - SPRNT: Configuração completa do rio São Francisco 2

\begin{tabular}{lllllll}
\hline \hline Seção Transversal & Comprimento $(\mathrm{m})$ & Manning $(\mathrm{n})$ & $\mathrm{z0}(\mathrm{m})$ & $\mathrm{sR}(\mathrm{m} / \mathrm{m})$ & $\mathrm{zR}$ & $\mathrm{hR}(\mathrm{m})$ \\
\hline SF127190 & 11533.17 & 0.000244826 & 0.031430474 & 497.0263822 & 2.82 & \\
SF116400 & 9438.95 & 0.000244826 & 0.028784992 & 491.5791013 & 2.31 & \\
SF102500 & 13735.32 & 0.000244826 & 0.024 & 489.287239 & 3.36 & \\
SF92600 & 12420.6 & 0.000244826 & 0.018786347 & 487.0991164 & 3.04 & \\
SF77200 & 12087.65 & 0.000244826 & 0.027 & 484.1606312 & 2.96 & \\
SF68200 & 7332.48 & 0.000244826 & 0.018 & 482.8548196 & 1.80 & \\
SF57000 & 10385.33 & 0.000244826 & 0.027 & 480.5474031 & 2.54 & \\
SF44700 & 8731.16 & 0.000244826 & 0.030 & 480.0923866 & 2.14 & \\
SF38800 & 9276.7 & 0.000244826 & 0.035 & 478.7588243 & 2.27 & \\
SF32000 & 6386.11 & 0.000244826 & 0.035291453 & 479.2265154 & 1.56 & \\
PIRAPORAPTE & 1.0 & 0.000244826 & 0.03 & 480.97 & 0.41 & \\
\hline \hline
\end{tabular}





\section{APÊNDICE E - RTC-Tools - Geometria para Onda Difusiva de Malha Grosseira do RTC-Tools}

Tabela 106 - Valores de Cota, Largura da Seção e Armazenamento para a Seção PBR040 - Onda Difusiva Grosseira (DW30km)

\begin{tabular}{llllll}
\hline \hline Cota $(\mathrm{m})$ & Largura $(\mathrm{m})$ & Armazenamento $\left(\mathrm{m}^{3}\right)$ & Cota $(\mathrm{m})$ & Largura $(\mathrm{m})$ & Armazenamento $\left(\mathrm{m}^{3}\right)$ \\
\hline 544.67 & 59.76 & 335913.0581 & 548.15 & 93.06 & 5426567.85 \\
544.79 & 61.74 & 456511.0936 & 548.54 & 96.63 & 6056756.05 \\
544.9 & 66.76 & 569695.6594 & 548.91 & 100.13 & 6643692.81 \\
544.99 & 67.14 & 679979.1339 & 549.25 & 103.56 & 7256671.779 \\
545.21 & 67.5 & 933153.2761 & 549.58 & 107.26 & 7836828.698 \\
545.4 & 67.83 & 1162822.147 & 549.91 & 110.81 & 8415406.16 \\
545.56 & 68.14 & 1485035.696 & 550.2 & 114.11 & 8995414.518 \\
545.7 & 68.44 & 1748678.125 & 550.51 & 124.13 & 9592512.134 \\
545.84 & 68.72 & 1976141.699 & 550.8 & 165.03 & 10290276.53 \\
545.97 & 69 & 2170507.9 & 551.07 & 180.78 & 11043076.54 \\
546.1 & 69.28 & 2354585.076 & 551.36 & 207.75 & 11677788.72 \\
546.21 & 69.54 & 2532500.971 & 551.73 & 242.41 & 12343105.61 \\
546.33 & 69.79 & 2709415.308 & 552.06 & 428.96 & 13002754.84 \\
546.45 & 70.13 & 2877326.411 & 552.25 & 434.2 & 13661821.1 \\
546.56 & 70.64 & 3043021.111 & 552.35 & 439.41 & 14237795.34 \\
546.66 & 71.18 & 3200342.679 & 553.64 & 445.51 & 15145160.31 \\
546.77 & 71.68 & 3357343.246 & 553.79 & 449.67 & 15757700.15 \\
546.87 & 72.14 & 3508610.956 & 553.94 & 454.28 & 16354201.84 \\
546.98 & 72.68 & 3658630.017 & 554.11 & 459.53 & 16937137.79 \\
547.08 & 75.54 & 3799975.905 & 554.23 & 464.31 & 17533424.63 \\
547.17 & 75.87 & 3943415.284 & 554.36 & 468.54 & 18134336.24 \\
547.28 & 76.52 & 4087582.337 & 554.51 & 472.58 & 18688817.2 \\
547.48 & 80.82 & 4366390.456 & 554.64 & 507.65 & 19283493.56 \\
547.57 & 85.56 & 4504766.163 & 554.76 & 508.66 & 19813158.57 \\
547.74 & 89.43 & 4779093.965 & 554.87 & 509.68 & 20401123 \\
\hline \hline
\end{tabular}


Tabela 107 - Valores de Cota, Largura da Seção e Armazenamento para a Seção TMarias - Onda Difusiva Grosseira (DW30km)

\begin{tabular}{llllll}
\hline \hline Cota $(\mathrm{m})$ & Largura $(\mathrm{m})$ & Armazenamento $\left(\mathrm{m}^{3}\right)$ & Cota $(\mathrm{m})$ & Largura $(\mathrm{m})$ & Armazenamento $\left(\mathrm{m}^{3}\right)$ \\
\hline 509.57 & 117.58 & 498233.5486 & 511.68 & 243.52 & 8573270.681 \\
509.64 & 119.11 & 687617.3537 & 511.86 & 247.54 & 9566670.044 \\
509.7 & 120.59 & 869309.1256 & 512.02 & 250.39 & 10494601.94 \\
509.76 & 121.81 & 1042764.022 & 512.18 & 253.13 & 11512656.03 \\
509.89 & 126.48 & 1459870.476 & 512.33 & 255.54 & 12449388.6 \\
510.01 & 127.68 & 1805441.019 & 512.47 & 256.18 & 13317990.25 \\
510.11 & 130.1 & 2136237.187 & 512.61 & 256.57 & 14173979.96 \\
510.21 & 133.74 & 2443259.169 & 512.75 & 259.28 & 14988216.55 \\
510.31 & 137.21 & 2751456.914 & 512.88 & 261.8 & 15822516.81 \\
510.4 & 143.73 & 3039536.23 & 513.01 & 264.2 & 16608762.99 \\
510.48 & 149.76 & 3320787.158 & 513.14 & 265.53 & 17373920.42 \\
510.57 & 156.91 & 3610911.386 & 513.27 & 266.8 & 18104781.16 \\
510.64 & 160.04 & 3892966.168 & 513.4 & 271.62 & 18839263.75 \\
510.71 & 162.42 & 4162271.622 & 513.52 & 275.24 & 19554027.96 \\
510.78 & 164.66 & 4451658.091 & 513.64 & 277.94 & 20257044.26 \\
510.85 & 169.65 & 4726404.61 & 513.75 & 280.12 & 20982784.97 \\
510.92 & 177.33 & 4991298.935 & 513.86 & 281.82 & 21643518.57 \\
510.99 & 184.45 & 5325087.223 & 513.98 & 283.47 & 22341430.54 \\
511.06 & 191.47 & 5589295.468 & 514.08 & 284.89 & 23025335.47 \\
511.12 & 198.5 & 5858290.117 & 514.18 & 286.36 & 23723387.01 \\
511.18 & 202.61 & 6111677.19 & 514.28 & 287.8 & 24388683.4 \\
511.25 & 205.72 & 6365021.593 & 514.37 & 289.16 & 25040193.72 \\
511.37 & 234.82 & 6826925.465 & 514.48 & 290.71 & 25719803.15 \\
511.41 & 236.23 & 7054583.92 & 514.57 & 292 & 26399782.57 \\
511.49 & 238.66 & 7473708.948 & 514.67 & 293.46 & 27039689.7 \\
\hline \hline
\end{tabular}


Tabela 108 - Valores de Cota, Largura da Seção e Armazenamento para a Seção N01 - Onda Difusiva Grosseira (DW30km)

\begin{tabular}{llllll}
\hline \hline Cota $(\mathrm{m})$ & Largura $(\mathrm{m})$ & Armazenamento $\left(\mathrm{m}^{3}\right)$ & Cota $(\mathrm{m})$ & Largura $(\mathrm{m})$ & Armazenamento $\left(\mathrm{m}^{3}\right)$ \\
\hline 500.6 & 35.59 & 1248721.722 & 503.03 & 287.37 & 20714925.17 \\
500.81 & 70.62 & 1696714.599 & 503.21 & 303.32 & 23119875.37 \\
500.9 & 73.67 & 2122905.957 & 503.42 & 358.21 & 25443997.07 \\
500.98 & 75.17 & 2527170.116 & 503.56 & 366.87 & 27611518.66 \\
501.16 & 79.14 & 3448982.466 & 503.66 & 368.51 & 29706839.91 \\
501.33 & 84.29 & 4292897.661 & 503.8 & 379.01 & 31793847.47 \\
501.47 & 89.58 & 5187421.759 & 503.93 & 394.81 & 33814355.94 \\
501.65 & 106.89 & 6041831.186 & 504.05 & 410.4 & 35772226.39 \\
501.85 & 163.51 & 6863381.911 & 504.18 & 436.21 & 37766649.45 \\
501.93 & 173.11 & 7623962.06 & 504.31 & 463.6 & 39688578.77 \\
502.01 & 180.51 & 8369965.793 & 504.41 & 493.98 & 41590662.45 \\
502.1 & 198.91 & 9191128.902 & 504.5 & 495.41 & 43450125.28 \\
502.18 & 210.9 & 9894146.199 & 504.58 & 496.59 & 45236375.59 \\
502.24 & 218.37 & 10553575.41 & 504.66 & 497.88 & 46984943.94 \\
502.29 & 224.52 & 11182950.67 & 504.73 & 498.94 & 48709253.76 \\
502.35 & 229.6 & 11816468.19 & 504.8 & 500.07 & 50443463.59 \\
502.4 & 233.72 & 12417833.7 & 504.87 & 501.23 & 52157944.86 \\
502.46 & 242.47 & 12992705.4 & 504.94 & 502.35 & 53790671.01 \\
502.5 & 246.01 & 13600191.28 & 505.01 & 503.45 & 55476754.52 \\
502.55 & 249.56 & 14134974.52 & 505.08 & 504.52 & 57059075.9 \\
502.59 & 253.11 & 14705499.44 & 505.15 & 505.56 & 58745783.94 \\
502.64 & 256.83 & 15256613.68 & 505.22 & 506.6 & 60485926.22 \\
502.73 & 263.12 & 16349914.55 & 505.28 & 507.6 & 62216528.52 \\
502.76 & 264.52 & 16876331.44 & 505.35 & 508.7 & 63770294.48 \\
502.84 & 268.42 & 17951478.17 & 505.42 & 509.74 & 67305408.87 \\
\hline \hline
\end{tabular}


Tabela 109 - Valores de Cota, Largura da Seção e Armazenamento para a Seção N02 - Onda Difusiva Grosseira (DW30km)

\begin{tabular}{llllll}
\hline \hline Cota $(\mathrm{m})$ & Largura $(\mathrm{m})$ & Armazenamento $\left(\mathrm{m}^{3}\right)$ & Cota $(\mathrm{m})$ & Largura $(\mathrm{m})$ & Armazenamento $\left(\mathrm{m}^{3}\right)$ \\
\hline 490.64 & 93.54 & 1005410.153 & 492.37 & 249.04 & 15994086.47 \\
490.72 & 101.02 & 1392904.394 & 492.54 & 250.64 & 17830917.76 \\
490.8 & 106.79 & 1744219.718 & 492.69 & 251.69 & 19541343.84 \\
490.87 & 116.47 & 2087736.921 & 492.85 & 252.79 & 21194293.65 \\
491.04 & 175.2 & 2842668.151 & 493 & 255.37 & 22785104.58 \\
491.15 & 220.19 & 3522177.677 & 493.15 & 256.5 & 24304343.39 \\
491.23 & 227.67 & 4167304.127 & 493.28 & 257.55 & 25765687.28 \\
491.29 & 228.5 & 4761541.529 & 493.42 & 258.24 & 27215908.2 \\
491.36 & 229.47 & 5305511.471 & 493.55 & 258.93 & 28620331.13 \\
491.41 & 230.45 & 5884651.824 & 493.67 & 259.59 & 30005498.41 \\
491.47 & 231.58 & 6440143.681 & 493.8 & 260.25 & 31375349.39 \\
491.53 & 233.46 & 7007220.11 & 493.92 & 261.05 & 32720833.89 \\
491.58 & 235.44 & 7549761.673 & 494.04 & 263.59 & 34055224.9 \\
491.63 & 236.82 & 8098254.499 & 494.16 & 264.46 & 35360493.43 \\
491.68 & 238.21 & 8627781.003 & 494.28 & 265.31 & 36631964.93 \\
491.73 & 239.44 & 9144231.96 & 494.39 & 266.15 & 37927941.53 \\
491.77 & 240.42 & 9613618.115 & 494.5 & 266.97 & 39159927.27 \\
491.82 & 241.36 & 10070581.59 & 494.61 & 267.78 & 40409416.49 \\
491.86 & 242.29 & 10520229.02 & 494.72 & 268.58 & 41620567.37 \\
491.91 & 243.2 & 10980119.44 & 494.82 & 269.37 & 42832330.06 \\
491.95 & 244.12 & 11417528.19 & 494.92 & 270.14 & 44054372.69 \\
491.99 & 244.59 & 11850311.19 & 495.03 & 270.9 & 45202904.3 \\
492.07 & 245.45 & 12697806.9 & 495.13 & 271.66 & 46383101.24 \\
492.11 & 245.87 & 13101841.85 & 495.23 & 272.4 & 47508050.8 \\
492.18 & 246.69 & 14077244.1 & 495.33 & 273.11 & 48676178.79 \\
\hline \hline
\end{tabular}


Tabela 110 - Valores de Cota, Largura da Seção e Armazenamento para a Seção N03 - Onda Difusiva Grosseira (DW30km)

\begin{tabular}{llllll}
\hline \hline Cota $(\mathrm{m})$ & Largura $(\mathrm{m})$ & Armazenamento $\left(\mathrm{m}^{3}\right)$ & Cota $(\mathrm{m})$ & Largura $(\mathrm{m})$ & Armazenamento $\left(\mathrm{m}^{3}\right)$ \\
\hline 483.07 & 80.27 & 592464.2766 & 485.13 & 335.41 & 10469364.14 \\
483.16 & 81.9 & 807431.7326 & 485.28 & 337.89 & 11807952.04 \\
483.24 & 83.25 & 1006126.841 & 485.41 & 338.82 & 12960270.66 \\
483.32 & 85.8 & 1186617.383 & 485.54 & 339.73 & 14047508.07 \\
483.49 & 95.05 & 1602750.177 & 485.66 & 340.6 & 15092302.62 \\
483.66 & 112.13 & 2012320.739 & 485.77 & 341.32 & 16073705.46 \\
483.78 & 121.95 & 2391599.527 & 485.89 & 342.37 & 17063069.87 \\
483.93 & 152.7 & 2805499.803 & 486 & 343.35 & 18018726.27 \\
484.03 & 167.64 & 3162367.863 & 486.1 & 344.25 & 18935361.54 \\
484.14 & 200.55 & 3543733.856 & 486.2 & 345.15 & 19843154.52 \\
484.22 & 215.85 & 3895603.484 & 486.29 & 346 & 20718999.44 \\
484.28 & 227.34 & 4225305.112 & 486.39 & 346.91 & 21628550.22 \\
484.35 & 238.83 & 4594357.299 & 486.49 & 347.81 & 22502462.04 \\
484.4 & 247.84 & 4951600.154 & 486.59 & 348.7 & 23353196.63 \\
484.46 & 257.7 & 5412766.875 & 486.7 & 349.62 & 24246080.84 \\
484.52 & 268.59 & 5791447.304 & 486.78 & 350.38 & 25057385.01 \\
484.56 & 275.21 & 6139732.102 & 486.88 & 351.24 & 25878192.73 \\
484.61 & 280.19 & 6500219.531 & 486.97 & 352.05 & 26704534.85 \\
484.65 & 284.74 & 6809577.256 & 487.06 & 352.85 & 27526277.05 \\
484.7 & 290.1 & 7160948.809 & 487.14 & 353.55 & 28317235.42 \\
484.74 & 294.93 & 7478390.888 & 487.23 & 354.4 & 29173594.37 \\
484.78 & 299.45 & 7782944.256 & 487.32 & 355.16 & 30016158.15 \\
484.85 & 306.76 & 8330839.071 & 487.4 & 355.91 & 30828767.57 \\
484.89 & 309.58 & 8609507.898 & 487.48 & 356.65 & 31598180.6 \\
484.96 & 313.95 & 9159551.8 & 487.57 & 357.46 & 32412265.2 \\
\hline \hline
\end{tabular}


Tabela 111 - Valores de Cota e Largura da Seção para a Seção Pirapora - Onda Difusiva Grosseira (DW30km)

\begin{tabular}{llll}
\hline \hline Cota $(\mathrm{m})$ & Largura $(\mathrm{m})$ & Cota $(\mathrm{m})$ & Largura $(\mathrm{m})$ \\
\hline 481.79 & 173.43 & 483.02 & 455.41 \\
481.86 & 213.95 & 483.14 & 459.6 \\
481.91 & 245.25 & 483.25 & 463.59 \\
481.95 & 275.31 & 483.35 & 467.43 \\
482.02 & 289.04 & 483.45 & 472.02 \\
482.09 & 292.98 & 483.55 & 476.25 \\
482.15 & 300.07 & 483.64 & 480.31 \\
482.21 & 303.87 & 483.73 & 484.28 \\
482.26 & 318.55 & 483.82 & 488.75 \\
482.32 & 336.16 & 483.91 & 492.95 \\
482.37 & 354.35 & 483.99 & 494.94 \\
482.42 & 372.46 & 484.07 & 498.82 \\
482.46 & 390.3 & 484.15 & 502.92 \\
482.5 & 396.53 & 484.23 & 506.94 \\
482.54 & 404.08 & 484.3 & 510.89 \\
482.58 & 410.5 & 484.37 & 514.59 \\
482.61 & 417.84 & 484.45 & 518.58 \\
482.65 & 436.11 & 484.52 & 522.11 \\
482.68 & 437.77 & 484.59 & 525.76 \\
482.71 & 439.65 & 484.66 & 529.51 \\
482.74 & 441.34 & 484.73 & 537.23 \\
482.77 & 442.83 & 484.8 & 548.76 \\
482.82 & 445.73 & 484.88 & 557.45 \\
482.85 & 447.26 & 484.94 & 565.37 \\
482.9 & 450.42 & 485.02 & 582.83 \\
\hline \hline
\end{tabular}




\section{APÊNDICE F - RTC-Tools - Geometria para Onda Difusiva Malha Refinada do RTC-Tools}

Tabela 112 - Valores de Cota, Largura da Seção e Armazenamento para a Seção PBR040 - Onda Difusiva Refinada (DW10km)

\begin{tabular}{llllll}
\hline \hline Cota $(\mathrm{m})$ & Largura $(\mathrm{m})$ & Armazenamento $\left(\mathrm{m}^{3}\right)$ & Cota $(\mathrm{m})$ & Largura $(\mathrm{m})$ & Armazenamento $\left(\mathrm{m}^{3}\right)$ \\
\hline 544.67 & 59.76 & 335913.0581 & 548.15 & 93.06 & 5426567.85 \\
544.79 & 61.74 & 456511.0936 & 548.54 & 96.63 & 6056756.05 \\
544.9 & 66.76 & 569695.6594 & 548.91 & 100.13 & 6643692.81 \\
544.99 & 67.14 & 679979.1339 & 549.25 & 103.56 & 7256671.779 \\
545.21 & 67.5 & 933153.2761 & 549.58 & 107.26 & 7836828.698 \\
545.4 & 67.83 & 1162822.147 & 549.91 & 110.81 & 8415406.16 \\
545.56 & 68.14 & 1485035.696 & 550.2 & 114.11 & 8995414.518 \\
545.7 & 68.44 & 1748678.125 & 550.51 & 124.13 & 9592512.134 \\
545.84 & 68.72 & 1976141.699 & 550.8 & 165.03 & 10290276.53 \\
545.97 & 69 & 2170507.9 & 551.07 & 180.78 & 11043076.54 \\
546.1 & 69.28 & 2354585.076 & 551.36 & 207.75 & 11677788.72 \\
546.21 & 69.54 & 2532500.971 & 551.73 & 242.41 & 12343105.61 \\
546.33 & 69.79 & 2709415.308 & 552.06 & 428.96 & 13002754.84 \\
546.45 & 70.13 & 2877326.411 & 552.25 & 434.2 & 13661821.1 \\
546.56 & 70.64 & 3043021.111 & 552.35 & 439.41 & 14237795.34 \\
546.66 & 71.18 & 3200342.679 & 553.64 & 445.51 & 15145160.31 \\
546.77 & 71.68 & 3357343.246 & 553.79 & 449.67 & 15757700.15 \\
546.87 & 72.14 & 3508610.956 & 553.94 & 454.28 & 16354201.84 \\
546.98 & 72.68 & 3658630.017 & 554.11 & 459.53 & 16937137.79 \\
547.08 & 75.54 & 3799975.905 & 554.23 & 464.31 & 17533424.63 \\
547.17 & 75.87 & 3943415.284 & 554.36 & 468.54 & 18134336.24 \\
547.28 & 76.52 & 4087582.337 & 554.51 & 472.58 & 18688817.2 \\
547.48 & 80.82 & 4366390.456 & 554.64 & 507.65 & 19283493.56 \\
547.57 & 85.56 & 4504766.163 & 554.76 & 508.66 & 19813158.57 \\
547.74 & 89.43 & 4779093.965 & 554.87 & 509.68 & 20401123 \\
\hline \hline
\end{tabular}


Tabela 113 - Valores de Cota, Largura da Seção e Armazenamento para a Seção Três Marias Onda Difusiva Refinada (DW10km)

\begin{tabular}{llllll}
\hline \hline Cota $(\mathrm{m})$ & Largura $(\mathrm{m})$ & Armazenamento $\left(\mathrm{m}^{3}\right)$ & Cota $(\mathrm{m})$ & Largura $(\mathrm{m})$ & Armazenamento $\left(\mathrm{m}^{3}\right)$ \\
\hline 509.57 & 117.58 & 155580.783 & 511.68 & 243.52 & 2823818.848 \\
509.64 & 119.11 & 210903.7875 & 511.86 & 247.54 & 3149277.046 \\
509.7 & 120.59 & 269342.9745 & 512.02 & 250.39 & 3446851.653 \\
509.76 & 121.81 & 323499.006 & 512.18 & 253.13 & 3734777.555 \\
509.89 & 126.48 & 471445.786 & 512.33 & 255.54 & 4009546.807 \\
510.01 & 127.68 & 582432.0515 & 512.47 & 256.18 & 4272279.479 \\
510.11 & 130.1 & 699615.634 & 512.61 & 256.57 & 4534341.025 \\
510.21 & 133.74 & 801097.5175 & 512.75 & 259.28 & 4785965.938 \\
510.31 & 137.21 & 904334.178 & 512.88 & 261.8 & 5039628.95 \\
510.4 & 143.73 & 998874.6325 & 513.01 & 264.2 & 5284645.926 \\
510.48 & 149.76 & 1091827.969 & 513.14 & 265.53 & 5539203.266 \\
510.57 & 156.91 & 1190010.188 & 513.27 & 266.8 & 5764641.952 \\
510.64 & 160.04 & 1282447.333 & 513.4 & 271.62 & 6003882.426 \\
510.71 & 162.42 & 1371292.497 & 513.52 & 275.24 & 6235520.117 \\
510.78 & 164.66 & 1455697.97 & 513.64 & 277.94 & 6463367.957 \\
510.85 & 169.65 & 1536732.874 & 513.75 & 280.12 & 6685798.815 \\
510.92 & 177.33 & 1618653.618 & 513.86 & 281.82 & 6894419.571 \\
510.99 & 184.45 & 1697418.969 & 513.98 & 283.47 & 7122239.033 \\
511.06 & 191.47 & 1790426.778 & 514.08 & 284.89 & 7334323.237 \\
511.12 & 198.5 & 1894538.173 & 514.18 & 286.36 & 7544406.053 \\
511.18 & 202.61 & 1980715.712 & 514.28 & 287.8 & 7751919.878 \\
511.25 & 205.72 & 2062957.969 & 514.37 & 289.16 & 7946133.512 \\
511.37 & 234.82 & 2204827.822 & 514.48 & 290.71 & 8161822.062 \\
511.41 & 236.23 & 2282566.867 & 514.57 & 292 & 8361832.231 \\
511.49 & 238.66 & 2418180.837 & 514.67 & 293.46 & 8561845.709 \\
\hline \hline
\end{tabular}


Tabela 114 - Valores de Cota, Largura da Seção e Armazenamento para a Seção N01a - Onda Difusiva Refinada (DW10km)

\begin{tabular}{llllll}
\hline \hline Cota $(\mathrm{m})$ & Largura $(\mathrm{m})$ & Armazenamento $\left(\mathrm{m}^{3}\right)$ & Cota $(\mathrm{m})$ & Largura $(\mathrm{m})$ & Armazenamento $\left(\mathrm{m}^{3}\right)$ \\
\hline 505.64 & 36.94 & 231291.5656 & 509.28 & 178.24 & 3944147.579 \\
505.81 & 38.81 & 323591.9162 & 509.52 & 187.2 & 4413773.007 \\
505.95 & 42.16 & 406615.2676 & 509.73 & 195.07 & 4855141.058 \\
506.07 & 43.8 & 480905.647 & 510.04 & 230.23 & 5399481.645 \\
506.34 & 47.16 & 642833.7664 & 510.25 & 252.38 & 5877002.981 \\
506.57 & 50.05 & 786890.6676 & 510.41 & 263.14 & 6301910 \\
506.79 & 54.37 & 926216.0534 & 510.56 & 272.74 & 6720351.478 \\
506.99 & 59.94 & 1060948.989 & 510.71 & 280.79 & 7120654.205 \\
507.19 & 66.48 & 1200206.965 & 510.86 & 285.72 & 7530444.809 \\
507.35 & 72.55 & 1330594.746 & 510.98 & 286.56 & 7896048.128 \\
507.5 & 78.28 & 1458386.086 & 511.09 & 287.33 & 8253851.363 \\
507.65 & 84.61 & 1592466.671 & 511.2 & 288.14 & 8607590.184 \\
507.78 & 89.25 & 1719072.43 & 511.32 & 288.95 & 8944792.202 \\
507.89 & 93.56 & 1838840.865 & 511.43 & 289.75 & 9276977.89 \\
507.99 & 95.39 & 1985867.636 & 511.53 & 290.52 & 9612063.243 \\
508.09 & 96.96 & 2119908.208 & 511.64 & 291.25 & 9957936.195 \\
508.18 & 99.39 & 2243581.951 & 511.75 & 292.02 & 10295950.22 \\
508.43 & 132.59 & 2439583.452 & 511.84 & 292.63 & 10610601.05 \\
508.52 & 142.68 & 2569487.443 & 511.94 & 293.32 & 10923128.86 \\
508.59 & 146.7 & 2685882.174 & 512.04 & 294.61 & 11249995.04 \\
508.67 & 150.5 & 2805438.395 & 512.14 & 296.12 & 11564910.47 \\
508.75 & 158.16 & 2929583.235 & 512.24 & 297.03 & 11863424.65 \\
508.88 & 166.34 & 3158161.868 & 512.33 & 297.93 & 12180487.94 \\
508.93 & 168.5 & 3263397.597 & 512.44 & 298.91 & 12496570.62 \\
509.03 & 171.41 & 3459443.712 & 512.52 & 299.71 & 12784873.84 \\
\hline \hline
\end{tabular}


Tabela 115 - Valores de Cota, Largura da Seção e Armazenamento para a Seção N01b - Onda Difusiva Refinada (DW10km)

\begin{tabular}{llllll}
\hline \hline Cota $(\mathrm{m})$ & Largura $(\mathrm{m})$ & Armazenamento $\left(\mathrm{m}^{3}\right)$ & Cota $(\mathrm{m})$ & Largura $(\mathrm{m})$ & Armazenamento $\left(\mathrm{m}^{3}\right)$ \\
\hline 502.99 & 89.08 & 257422.7511 & 504.72 & 259.89 & 4534897.445 \\
503.09 & 97.15 & 348901.6963 & 504.88 & 260.71 & 5045491.912 \\
503.18 & 110.93 & 433996.3865 & 505.04 & 261.48 & 5538167.647 \\
503.25 & 135.81 & 523940.13 & 505.19 & 268.76 & 5999554.513 \\
503.4 & 182.44 & 749088.5815 & 505.34 & 273.04 & 6456333.607 \\
503.5 & 210.46 & 941968.4018 & 505.48 & 276.75 & 6899454.188 \\
503.57 & 214.8 & 1157230.051 & 505.61 & 278.59 & 7328740.509 \\
503.64 & 218.84 & 1355516.274 & 505.74 & 280.27 & 7738043.753 \\
503.71 & 222.56 & 1533966.651 & 505.87 & 281.67 & 8150356.296 \\
503.77 & 225.06 & 1699660.386 & 506 & 283.09 & 8558333.182 \\
503.83 & 227.44 & 1873335.692 & 506.12 & 284.22 & 8953949.615 \\
503.88 & 229.66 & 2034158.581 & 506.23 & 285.33 & 9331796.467 \\
503.94 & 232.06 & 2184375.603 & 506.35 & 286.49 & 9715302.503 \\
504 & 238.63 & 2334211.663 & 506.47 & 287.59 & 10078278.55 \\
504.05 & 242.02 & 2481643.39 & 506.57 & 288.6 & 10434307.6 \\
504.1 & 246.37 & 2644661.303 & 506.69 & 289.74 & 10808288.88 \\
504.15 & 252.6 & 2796243.296 & 506.77 & 291.44 & 11128915.05 \\
504.2 & 257.12 & 2940343.743 & 506.89 & 295.97 & 11490710.23 \\
504.24 & 257.32 & 3081370.596 & 507 & 300.53 & 11855880.1 \\
504.28 & 257.55 & 3196007.645 & 507.12 & 305.08 & 12223700.36 \\
504.32 & 257.78 & 3326124.549 & 507.22 & 309.06 & 12561188.85 \\
504.36 & 258 & 3432241.939 & 507.33 & 313.42 & 12918865.35 \\
504.43 & 258.44 & 3667533.981 & 507.43 & 317.4 & 13279709.79 \\
504.47 & 258.65 & 3785960.011 & 507.54 & 321.79 & 13643546.13 \\
504.54 & 259.03 & 4009842.445 & 507.64 & 325.79 & 13997492.17 \\
\hline \hline
\end{tabular}


Tabela 116 - Valores de Cota, Largura da Seção e Armazenamento para a Seção N01 - Onda Difusiva Refinada (DW10km)

\begin{tabular}{llllll}
\hline \hline Cota $(\mathrm{m})$ & Largura $(\mathrm{m})$ & Armazenamento $\left(\mathrm{m}^{3}\right)$ & Cota $(\mathrm{m})$ & Largura $(\mathrm{m})$ & Armazenamento $\left(\mathrm{m}^{3}\right)$ \\
\hline 500.6 & 35.59 & 235504.9692 & 503.03 & 287.37 & 4360702.059 \\
500.81 & 70.62 & 341593.6869 & 503.21 & 303.32 & 4905607.05 \\
500.9 & 73.67 & 428736.6312 & 503.42 & 358.21 & 5447472.861 \\
500.98 & 75.17 & 506252.8605 & 503.56 & 366.87 & 5921598.63 \\
501.16 & 79.14 & 681049.8519 & 503.66 & 368.51 & 6338841.181 \\
501.33 & 84.29 & 849421.5819 & 503.8 & 379.01 & 6802580.576 \\
501.47 & 89.58 & 1008613.294 & 503.93 & 394.81 & 7243388.831 \\
501.65 & 106.89 & 1176472.8 & 504.05 & 410.4 & 7676488.685 \\
501.85 & 163.51 & 1382298.255 & 504.18 & 436.21 & 8124480.057 \\
501.93 & 173.11 & 1540949.944 & 504.31 & 463.6 & 8582698.457 \\
502.01 & 180.51 & 1686974.975 & 504.41 & 493.98 & 8989439.467 \\
502.1 & 198.91 & 1840407.074 & 504.5 & 495.41 & 9397719.056 \\
502.18 & 210.9 & 1977028.9 & 504.58 & 496.59 & 9759303.338 \\
502.24 & 218.37 & 2111188.186 & 504.66 & 497.88 & 10142881.09 \\
502.29 & 224.52 & 2238621.812 & 504.73 & 498.94 & 10479743.41 \\
502.35 & 229.6 & 2366542.9 & 504.8 & 500.07 & 10834339.39 \\
502.4 & 233.72 & 2492253.924 & 504.87 & 501.23 & 11199337.89 \\
502.46 & 242.47 & 2613983.481 & 504.94 & 502.35 & 11555605.39 \\
502.5 & 246.01 & 2731554.167 & 505.01 & 503.45 & 11917739.56 \\
502.55 & 249.56 & 2846304.781 & 505.08 & 504.52 & 12270579.12 \\
502.59 & 253.11 & 2958871.899 & 505.15 & 505.56 & 12610314.64 \\
502.64 & 256.83 & 3070077.305 & 505.22 & 506.6 & 12951461.7 \\
502.73 & 263.12 & 3291486.416 & 505.28 & 507.6 & 13293404.99 \\
502.76 & 264.52 & 3386109.629 & 505.35 & 508.7 & 13637840.61 \\
502.84 & 268.42 & 3600253.145 & 505.42 & 509.74 & 13970945.95 \\
\hline \hline
\end{tabular}


Tabela 117 - Valores de Cota, Largura da Seção e Armazenamento para a Seção N02a - Onda Difusiva Refinada (DW10km)

\begin{tabular}{llllll}
\hline \hline Cota $(\mathrm{m})$ & Largura $(\mathrm{m})$ & Armazenamento $\left(\mathrm{m}^{3}\right)$ & Cota $(\mathrm{m})$ & Largura $(\mathrm{m})$ & Armazenamento $\left(\mathrm{m}^{3}\right)$ \\
\hline 494.92 & 33.33 & 188375.9622 & 497.37 & 192.7 & 3598194.345 \\
495.1 & 35.59 & 254464.1646 & 497.58 & 194.51 & 4004840.489 \\
495.38 & 84.16 & 338848.5342 & 497.77 & 195.87 & 4386065.288 \\
495.47 & 102.58 & 417453.0455 & 497.95 & 196.99 & 4753317.73 \\
495.63 & 124.42 & 584106.971 & 498.12 & 198.11 & 5105598.628 \\
495.75 & 129.68 & 753857.8665 & 498.29 & 199.18 & 5457997.895 \\
495.86 & 136.43 & 935612.4636 & 498.45 & 200.17 & 5792185.209 \\
495.96 & 145.22 & 1087715.065 & 498.61 & 200.96 & 6115502.735 \\
496.05 & 149.12 & 1223709.355 & 498.76 & 201.74 & 6433200.375 \\
496.13 & 152.34 & 1361866.677 & 498.92 & 202.51 & 6743973.891 \\
496.22 & 161.3 & 1490781.506 & 499.06 & 203.05 & 7049563.15 \\
496.29 & 163.15 & 1627869.086 & 499.21 & 203.52 & 7349005.877 \\
496.36 & 164.85 & 1748691.776 & 499.35 & 203.97 & 7642487.148 \\
496.42 & 166.69 & 1858534.927 & 499.5 & 204.44 & 7921904.729 \\
496.49 & 168.52 & 1966515.193 & 499.63 & 204.88 & 8203835.367 \\
496.55 & 170.28 & 2064988.611 & 499.76 & 205.29 & 8490744.625 \\
496.61 & 171.94 & 2172015.454 & 499.89 & 205.72 & 8766772.687 \\
496.67 & 173.54 & 2269462.891 & 500.03 & 206.5 & 9055306.925 \\
496.73 & 175.12 & 2377770.851 & 500.16 & 207.95 & 9326660.139 \\
496.78 & 176.66 & 2473209.411 & 500.29 & 213.14 & 9593443.654 \\
496.84 & 178.16 & 2579457.982 & 500.42 & 218.29 & 9861606.581 \\
496.89 & 179.65 & 2685493.794 & 500.55 & 223.38 & 10134200.29 \\
496.99 & 182.57 & 2892136.437 & 500.67 & 228 & 10392870.19 \\
497.04 & 183.96 & 2986501.361 & 500.79 & 232.95 & 10652719.97 \\
497.14 & 186.64 & 3169056.216 & 500.93 & 238.27 & 10926029.33 \\
\hline \hline
\end{tabular}


Tabela 118 - Valores de Cota, Largura da Seção e Armazenamento para a Seção N02b - Onda Difusiva Refinada (DW10km)

\begin{tabular}{llllll}
\hline \hline Cota $(\mathrm{m})$ & Largura $(\mathrm{m})$ & Armazenamento $\left(\mathrm{m}^{3}\right)$ & Cota $(\mathrm{m})$ & Largura $(\mathrm{m})$ & Armazenamento $\left(\mathrm{m}^{3}\right)$ \\
\hline 493.32 & 62.25 & 305109.6777 & 495.72 & 235.41 & 5136110.779 \\
493.44 & 67.49 & 409910.9715 & 495.9 & 237.05 & 5704015.099 \\
493.53 & 70.75 & 510231.8412 & 496.07 & 238.25 & 6244101.252 \\
493.62 & 76.02 & 603695.4795 & 496.23 & 239.39 & 6763789.518 \\
493.82 & 90.66 & 817576.6061 & 496.39 & 240.35 & 7271472.081 \\
493.98 & 103.5 & 1014720.697 & 496.54 & 241.32 & 7758331.061 \\
494.14 & 126.78 & 1225427.637 & 496.68 & 242.41 & 8238518.65 \\
494.27 & 146.72 & 1431184.782 & 496.82 & 243.62 & 8701071.996 \\
494.37 & 160.67 & 1607946.496 & 496.96 & 244.97 & 9171011.664 \\
494.45 & 163.37 & 1775877.496 & 497.09 & 246.29 & 9612623.059 \\
494.52 & 165.63 & 1964416.912 & 497.22 & 247.49 & 10044635.06 \\
494.59 & 167.16 & 2229497.355 & 497.35 & 248.83 & 10475784.26 \\
494.65 & 168.04 & 2434392.051 & 497.48 & 250.07 & 10896103.5 \\
494.72 & 168.88 & 2610214.13 & 497.6 & 251.27 & 11309073.95 \\
494.78 & 169.72 & 2771163.201 & 497.71 & 252.37 & 11718339.15 \\
494.84 & 170.45 & 2919816.888 & 497.83 & 253.53 & 12116823.25 \\
494.89 & 171.15 & 3062996.769 & 497.96 & 254.76 & 12524613.05 \\
494.95 & 171.77 & 3196283.476 & 498.06 & 255.78 & 12890112.05 \\
495.01 & 172.45 & 3339263.077 & 498.18 & 256.98 & 13309812.54 \\
495.06 & 173.11 & 3463382.417 & 498.28 & 257.97 & 13651781 \\
495.12 & 174.91 & 3601801.552 & 498.4 & 259.14 & 14062146.28 \\
495.18 & 179.77 & 3749064.505 & 498.5 & 260.09 & 14396213.33 \\
495.3 & 193.14 & 4030487.486 & 498.62 & 261.23 & 14790936.66 \\
495.36 & 196.35 & 4171086.268 & 498.72 & 262.25 & 15153024.29 \\
495.48 & 210.48 & 4464298.539 & 498.81 & 263.16 & 15486038.06 \\
\hline \hline
\end{tabular}


Tabela 119 - Valores de Cota, Largura da Seção e Armazenamento para a Seção N02 - Onda Difusiva Refinada (DW10km)

\begin{tabular}{llllll}
\hline \hline Cota $(\mathrm{m})$ & Largura $(\mathrm{m})$ & Armazenamento $\left(\mathrm{m}^{3}\right)$ & Cota $(\mathrm{m})$ & Largura $(\mathrm{m})$ & Armazenamento $\left(\mathrm{m}^{3}\right)$ \\
\hline 490.64 & 93.54 & 290204.3915 & 492.37 & 249.04 & 4708295.107 \\
490.72 & 101.02 & 395460.4357 & 492.54 & 250.64 & 5234866.97 \\
490.8 & 106.79 & 489185.7116 & 492.69 & 251.69 & 5729976.647 \\
490.87 & 116.47 & 587372.3088 & 492.85 & 252.79 & 6221005.691 \\
491.04 & 175.2 & 813856.8516 & 493 & 255.37 & 6687848.799 \\
491.15 & 220.19 & 1019070.112 & 493.15 & 256.5 & 7137937.598 \\
491.23 & 227.67 & 1201144.973 & 493.28 & 257.55 & 7576271.89 \\
491.29 & 228.5 & 1380083.681 & 493.42 & 258.24 & 8003026.902 \\
491.36 & 229.47 & 1546974.634 & 493.55 & 258.93 & 8409441.005 \\
491.41 & 230.45 & 1700412.724 & 493.67 & 259.59 & 8811812.137 \\
491.47 & 231.58 & 1859659.436 & 493.8 & 260.25 & 9209235.907 \\
491.53 & 233.46 & 2067479.221 & 493.92 & 261.05 & 9604751.877 \\
491.58 & 235.44 & 2235683.307 & 494.04 & 263.59 & 10006658.31 \\
491.63 & 236.82 & 2406326.229 & 494.16 & 264.46 & 10395279.3 \\
491.68 & 238.21 & 2560818.349 & 494.28 & 265.31 & 10771719.52 \\
491.73 & 239.44 & 2718398.672 & 494.39 & 266.15 & 11167518.74 \\
491.77 & 240.42 & 2861337.422 & 494.5 & 266.97 & 11545715.01 \\
491.82 & 241.36 & 2996550.553 & 494.61 & 267.78 & 11919986.68 \\
491.86 & 242.29 & 3129773.828 & 494.72 & 268.58 & 12289907.52 \\
491.91 & 243.2 & 3270180.804 & 494.82 & 269.37 & 12649196.27 \\
491.95 & 244.12 & 3399222.235 & 494.92 & 270.14 & 13018298.69 \\
491.99 & 244.59 & 3530774.407 & 495.03 & 270.9 & 13370345.13 \\
492.07 & 245.45 & 3793730.498 & 495.13 & 271.66 & 13740384.46 \\
492.11 & 245.87 & 3920187.097 & 495.23 & 272.4 & 14076853.33 \\
492.18 & 246.69 & 4153750.453 & 495.33 & 273.11 & 14418258.25 \\
\hline \hline
\end{tabular}


Tabela 120 - Valores de Cota, Largura da Seção e Armazenamento para a Seção N03a - Onda Difusiva Refinada (DW10km)

\begin{tabular}{llllll}
\hline \hline Cota $(\mathrm{m})$ & Largura $(\mathrm{m})$ & Armazenamento $\left(\mathrm{m}^{3}\right)$ & Cota $(\mathrm{m})$ & Largura $(\mathrm{m})$ & Armazenamento $\left(\mathrm{m}^{3}\right)$ \\
\hline 487.65 & 92.22 & 290669.3023 & 490 & 243.18 & 4433549.73 \\
487.74 & 104.03 & 394422.0793 & 490.19 & 258.56 & 4975703.936 \\
487.81 & 109.66 & 493947.1331 & 490.35 & 260.22 & 5453708.086 \\
487.88 & 116.43 & 589340.1806 & 490.5 & 261.8 & 5905257.385 \\
488.02 & 122.3 & 801959.8843 & 490.65 & 263.32 & 6344862.116 \\
488.13 & 126.02 & 989659.0617 & 490.79 & 264.75 & 6774398.371 \\
488.24 & 128.58 & 1175117.368 & 490.93 & 266.14 & 7187351.625 \\
488.33 & 130 & 1336299.554 & 491.06 & 267.49 & 7590207.034 \\
488.43 & 131.49 & 1488857.158 & 491.19 & 268.9 & 7985018.068 \\
488.51 & 132.85 & 1642207.353 & 491.32 & 270.55 & 8370224.076 \\
488.59 & 134.37 & 1781234.041 & 491.44 & 271.76 & 8742656.482 \\
488.67 & 136.24 & 1920466.667 & 491.56 & 272.93 & 9127660.939 \\
488.75 & 138.42 & 2058138.643 & 491.68 & 274.08 & 9491237.932 \\
488.83 & 140.75 & 2197629.407 & 491.79 & 275.25 & 9855442.141 \\
488.92 & 151.51 & 2345266.711 & 491.91 & 276.35 & 10220856.73 \\
489 & 154.38 & 2476931.215 & 492.02 & 277.44 & 10576214.92 \\
489.06 & 156.22 & 2598531.542 & 492.12 & 278.42 & 10908355.61 \\
489.13 & 157.75 & 2717053.457 & 492.23 & 279.55 & 11266095.43 \\
489.19 & 159.15 & 2835577.521 & 492.33 & 280.85 & 11597985.77 \\
489.25 & 160.32 & 2947374.674 & 492.44 & 282.34 & 11949189.67 \\
489.3 & 161.45 & 3060040.884 & 492.55 & 283.71 & 12290162.13 \\
489.36 & 162.58 & 3171671.406 & 492.64 & 284.97 & 12599688.79 \\
489.47 & 164.7 & 3388948.706 & 492.75 & 286.38 & 12935130.84 \\
489.51 & 165.5 & 3484981.234 & 492.84 & 287.61 & 13246565.83 \\
489.78 & 229.21 & 3891158.875 & 492.95 & 289.05 & 13601622.82 \\
\hline \hline
\end{tabular}


Tabela 121 - Valores de Cota, Largura da Seção e Armazenamento para a Seção N03b - Onda Difusiva Refinada (DW10km)

\begin{tabular}{llllll}
\hline \hline Cota $(\mathrm{m})$ & Largura $(\mathrm{m})$ & Armazenamento $\left(\mathrm{m}^{3}\right)$ & Cota $(\mathrm{m})$ & Largura $(\mathrm{m})$ & Armazenamento $\left(\mathrm{m}^{3}\right)$ \\
\hline 485.36 & 97.92 & 318996.7536 & 487.21 & 220.6 & 5378206.117 \\
485.46 & 134.13 & 458615.9676 & 487.39 & 221.58 & 5985583.757 \\
485.53 & 157.42 & 579983.8677 & 487.57 & 222.53 & 6569635.855 \\
485.58 & 164.55 & 695855.7123 & 487.73 & 223.45 & 7132756.673 \\
485.69 & 174.96 & 927407.3916 & 487.9 & 224.34 & 7675309.673 \\
485.78 & 176.82 & 1146193.086 & 488.05 & 225.2 & 8177629.356 \\
485.86 & 178.5 & 1359175.302 & 488.2 & 226.03 & 8661877.251 \\
485.94 & 179.94 & 1553659.031 & 488.35 & 226.83 & 9154190.156 \\
486.01 & 181.52 & 1725766.155 & 488.49 & 227.61 & 9629197.038 \\
486.08 & 182.99 & 1937418.67 & 488.63 & 228.36 & 10101867.71 \\
486.15 & 184.29 & 2142436.221 & 488.77 & 229.14 & 10570862.41 \\
486.21 & 185.53 & 2320287.027 & 488.9 & 230.15 & 11014427.38 \\
486.27 & 186.76 & 2504289.354 & 489.03 & 231.12 & 11464211.64 \\
486.33 & 187.69 & 2696777.125 & 489.16 & 232.08 & 11899807.44 \\
486.39 & 188.42 & 2880827.541 & 489.29 & 233.03 & 12314283.46 \\
486.45 & 190.6 & 3064829.242 & 489.41 & 233.92 & 12745811.02 \\
486.5 & 192.78 & 3227823.142 & 489.53 & 234.83 & 13160284.38 \\
486.56 & 194.95 & 3390016.258 & 489.65 & 235.72 & 13567990.85 \\
486.61 & 196.89 & 3547734.45 & 489.77 & 236.6 & 13969266.15 \\
486.66 & 198.82 & 3716056.704 & 489.88 & 237.46 & 14363680.79 \\
486.71 & 200.72 & 3872962.73 & 490 & 238.32 & 14769966.6 \\
486.76 & 202.54 & 4024763.606 & 490.11 & 239.15 & 15152558.85 \\
486.85 & 206.02 & 4317884.99 & 490.22 & 239.98 & 15524223.86 \\
486.9 & 208.03 & 4463231.546 & 490.33 & 240.8 & 15899321.32 \\
486.99 & 212.53 & 4728023.315 & 490.44 & 241.61 & 16269999.28 \\
\hline \hline
\end{tabular}


Tabela 122 - Valores de Cota, Largura da Seção e Armazenamento para a Seção N03 - Onda Difusiva Refinada (DW10km)

\begin{tabular}{llllll}
\hline \hline Cota $(\mathrm{m})$ & Largura $(\mathrm{m})$ & Armazenamento $\left(\mathrm{m}^{3}\right)$ & Cota $(\mathrm{m})$ & Largura $(\mathrm{m})$ & Armazenamento $\left(\mathrm{m}^{3}\right)$ \\
\hline 483.75 & 162.35 & 308975.7336 & 485.11 & 310.95 & 5157188.052 \\
483.82 & 183.1 & 415159.1828 & 485.25 & 311.58 & 5758489.97 \\
483.87 & 209.57 & 510005.8028 & 485.39 & 312.17 & 6290944.4 \\
483.91 & 229.44 & 601609.8608 & 485.52 & 312.74 & 6812849.123 \\
484.01 & 256.83 & 820345.0288 & 485.65 & 313.29 & 7313422.577 \\
484.08 & 272.69 & 1037721.194 & 485.77 & 313.83 & 7781452.989 \\
484.15 & 282.73 & 1232077.298 & 485.88 & 314.32 & 8260524.172 \\
484.21 & 288.9 & 1466944.458 & 486 & 314.82 & 8716676.824 \\
484.26 & 294.86 & 1661938.561 & 486.11 & 315.32 & 9146529.318 \\
484.31 & 301.74 & 1896737.446 & 486.23 & 315.81 & 9575991.648 \\
484.36 & 307.37 & 2086279.498 & 486.34 & 318.55 & 9994159.594 \\
484.4 & 307.58 & 2250688.95 & 486.45 & 319.38 & 10421935.11 \\
484.45 & 307.84 & 2441129.83 & 486.55 & 320.2 & 10848307.95 \\
484.49 & 308.06 & 2606356.155 & 486.66 & 320.99 & 11268737.91 \\
484.53 & 308.27 & 2783114.944 & 486.76 & 321.77 & 11696541.44 \\
484.57 & 308.48 & 2944801.214 & 486.86 & 322.54 & 12068624.63 \\
484.61 & 308.69 & 3100857.965 & 486.95 & 323.27 & 12470738.65 \\
484.65 & 308.89 & 3249985.042 & 487.04 & 324.01 & 12860343.58 \\
484.68 & 309.08 & 3389527.539 & 487.14 & 324.73 & 13243002.97 \\
484.72 & 309.27 & 3547897.284 & 487.23 & 325.45 & 13592235.36 \\
484.75 & 309.42 & 3695831.872 & 487.32 & 326.16 & 13993816.32 \\
484.79 & 309.57 & 3837532.105 & 487.41 & 326.85 & 14361601.67 \\
484.86 & 309.86 & 4098345.238 & 487.5 & 327.54 & 14725277.36 \\
484.89 & 310.01 & 4231547.691 & 487.59 & 328.22 & 15084707.49 \\
484.95 & 310.29 & 4505154.712 & 487.67 & 328.89 & 15440732.8 \\
\hline \hline
\end{tabular}


Tabela 123 - Valores de Cota, Largura da Seção e Armazenamento para a Seção N Pa - Onda Difusiva Refinada (DW10km)

\begin{tabular}{llllll}
\hline \hline Cota $(\mathrm{m})$ & Largura $(\mathrm{m})$ & Armazenamento $\left(\mathrm{m}^{3}\right)$ & Cota $(\mathrm{m})$ & Largura $(\mathrm{m})$ & Armazenamento $\left(\mathrm{m}^{3}\right)$ \\
\hline 482 & 79.67 & 210381.694 & 484 & 375.58 & 4086691.134 \\
482.1 & 92.7 & 289386.8379 & 484.14 & 377.15 & 4537949.888 \\
482.19 & 106.83 & 367496.5264 & 484.25 & 378.19 & 4952346.199 \\
482.25 & 112.17 & 432923.7304 & 484.37 & 379.22 & 5358835.588 \\
482.4 & 123.98 & 587120.4605 & 484.48 & 380.22 & 5757928.091 \\
482.52 & 129.96 & 734842.7317 & 484.59 & 381.19 & 6133906.746 \\
482.64 & 146.47 & 880624.0083 & 484.69 & 382.12 & 6500386.963 \\
482.75 & 163.96 & 1023360.081 & 484.8 & 383.05 & 6866834.84 \\
482.83 & 166.24 & 1143328.787 & 484.9 & 383.92 & 7221178.06 \\
482.9 & 169.1 & 1259104.373 & 485 & 384.77 & 7571866.034 \\
482.98 & 174.77 & 1380562.343 & 485.09 & 385.57 & 7910446.855 \\
483.05 & 180.17 & 1494856.908 & 485.19 & 386.44 & 8265234.177 \\
483.12 & 185.52 & 1615011.272 & 485.28 & 387.76 & 8586475.811 \\
483.2 & 198.41 & 1766179.785 & 485.36 & 390.46 & 8889103.743 \\
483.29 & 216.61 & 2009118.497 & 485.46 & 393.62 & 9225438.549 \\
483.36 & 240.48 & 2187172.467 & 485.55 & 396.45 & 9537920.004 \\
483.43 & 254.61 & 2339620.11 & 485.62 & 398.86 & 9818541.434 \\
483.5 & 284.88 & 2506412.052 & 485.7 & 401.63 & 10126577.81 \\
483.55 & 294.91 & 2640324.522 & 485.79 & 404.37 & 10432090.88 \\
483.61 & 316.26 & 2799623.06 & 485.87 & 407.05 & 10733546.05 \\
483.65 & 329.9 & 2938816.137 & 485.95 & 409.9 & 11047505.4 \\
483.69 & 339.36 & 3060836.454 & 486.04 & 412.8 & 11373124.56 \\
483.77 & 354.8 & 3286923.482 & 486.12 & 415.41 & 11670792.01 \\
483.8 & 360.99 & 3398983.019 & 486.19 & 417.6 & 11932962.79 \\
483.87 & 370.26 & 3607838.367 & 486.26 & 446.64 & 12222052.47 \\
\hline \hline
\end{tabular}


Tabela 124 - Valores de Cota, Largura da Seção e Armazenamento para a Seção N Pb - Onda Difusiva Refinada (DW10km)

\begin{tabular}{llllll}
\hline \hline Cota $(\mathrm{m})$ & Largura $(\mathrm{m})$ & Armazenamento $\left(\mathrm{m}^{3}\right)$ & Cota $(\mathrm{m})$ & Largura $(\mathrm{m})$ & Armazenamento $\left(\mathrm{m}^{3}\right)$ \\
\hline 481.2 & 138.28 & 178646.5546 & 482.88 & 306.78 & 2699520.468 \\
481.27 & 157.86 & 247291.6231 & 483.13 & 412.21 & 3146275.287 \\
481.33 & 166.63 & 309727.5176 & 483.28 & 445.14 & 3505003.319 \\
481.38 & 173.73 & 367252.5109 & 483.39 & 461.1 & 3811097.26 \\
481.49 & 190.62 & 494728.7105 & 483.49 & 462.34 & 4098035.946 \\
481.58 & 197.7 & 607012.231 & 483.59 & 463.63 & 4372723.785 \\
481.65 & 199.14 & 710764.705 & 483.68 & 467.07 & 4642345.243 \\
481.73 & 200.2 & 806694.5263 & 483.77 & 471.59 & 4903698.71 \\
481.79 & 201.14 & 901014.0385 & 483.86 & 476.03 & 5164329.181 \\
481.86 & 202.01 & 992505.1143 & 483.95 & 480.32 & 5416891.328 \\
481.92 & 206.74 & 1085575.626 & 484.03 & 486.89 & 5666987.577 \\
481.99 & 212.81 & 1178746.449 & 484.11 & 497.45 & 5915374.63 \\
482.07 & 240.92 & 1289866.567 & 484.19 & 507.84 & 6160795.295 \\
482.13 & 246.37 & 1376585.953 & 484.27 & 518.05 & 6405319.521 \\
482.18 & 249.96 & 1461401.836 & 484.35 & 528.08 & 6649206.086 \\
482.22 & 253.48 & 1543546.453 & 484.43 & 537.97 & 6889237.212 \\
482.27 & 257.01 & 1625180.037 & 484.5 & 547.76 & 7134484.921 \\
482.32 & 260.11 & 1710783.762 & 484.58 & 557.33 & 7372956.981 \\
482.36 & 263.02 & 1786868.416 & 484.65 & 566.79 & 7614591.137 \\
482.41 & 265.53 & 1859935.72 & 484.72 & 576.14 & 7861717.334 \\
482.44 & 267.77 & 1929045.223 & 484.79 & 585.42 & 8108217.915 \\
482.49 & 270.74 & 2007677.47 & 484.86 & 594.54 & 8361743.441 \\
482.56 & 275.36 & 2142813.056 & 484.93 & 603.48 & 8616060.286 \\
482.6 & 278.28 & 2212419.158 & 485 & 612.12 & 8865820.624 \\
482.68 & 284.09 & 2350870.177 & 485.07 & 621.23 & 9135778.364 \\
\hline \hline
\end{tabular}


Tabela 125 - Valores de Cota, Largura da Seção e Armazenamento para a Seção Piraporaponte Onda Difusiva Refinada (DW10km)

\begin{tabular}{llllll}
\hline \hline Cota $(\mathrm{m})$ & Largura $(\mathrm{m})$ & Armazenamento $\left(\mathrm{m}^{3}\right)$ & Cota $(\mathrm{m})$ & Largura $(\mathrm{m})$ & Armazenamento $\left(\mathrm{m}^{3}\right)$ \\
\hline 544.67 & 59.76 & 335913.0581 & 548.15 & 93.06 & 5426567.85 \\
544.79 & 61.74 & 456511.0936 & 548.54 & 96.63 & 6056756.05 \\
544.9 & 66.76 & 569695.6594 & 548.91 & 100.13 & 6643692.81 \\
544.99 & 67.14 & 679979.1339 & 549.25 & 103.56 & 7256671.779 \\
545.21 & 67.5 & 933153.2761 & 549.58 & 107.26 & 7836828.698 \\
545.4 & 67.83 & 1162822.147 & 549.91 & 110.81 & 8415406.16 \\
545.56 & 68.14 & 1485035.696 & 550.2 & 114.11 & 8995414.518 \\
545.7 & 68.44 & 1748678.125 & 550.51 & 124.13 & 9592512.134 \\
545.84 & 68.72 & 1976141.699 & 550.8 & 165.03 & 10290276.53 \\
545.97 & 69 & 2170507.9 & 551.07 & 180.78 & 11043076.54 \\
546.1 & 69.28 & 2354585.076 & 551.36 & 207.75 & 11677788.72 \\
546.21 & 69.54 & 2532500.971 & 551.73 & 242.41 & 12343105.61 \\
546.33 & 69.79 & 2709415.308 & 552.06 & 428.96 & 13002754.84 \\
546.45 & 70.13 & 2877326.411 & 552.25 & 434.2 & 13661821.1 \\
546.56 & 70.64 & 3043021.111 & 552.35 & 439.41 & 14237795.34 \\
546.66 & 71.18 & 3200342.679 & 553.64 & 445.51 & 15145160.31 \\
546.77 & 71.68 & 3357343.246 & 553.79 & 449.67 & 15757700.15 \\
546.87 & 72.14 & 3508610.956 & 553.94 & 454.28 & 16354201.84 \\
546.98 & 72.68 & 3658630.017 & 554.11 & 459.53 & 16937137.79 \\
547.08 & 75.54 & 3799975.905 & 554.23 & 464.31 & 17533424.63 \\
547.17 & 75.87 & 3943415.284 & 554.36 & 468.54 & 18134336.24 \\
547.28 & 76.52 & 4087582.337 & 554.51 & 472.58 & 18688817.2 \\
547.48 & 80.82 & 4366390.456 & 554.64 & 507.65 & 19283493.56 \\
547.57 & 85.56 & 4504766.163 & 554.76 & 508.66 & 19813158.57 \\
547.74 & 89.43 & 4779093.965 & 554.87 & 509.68 & 20401123 \\
\hline \hline
\end{tabular}




\section{APÊNDICE G - RTC-Tools - Geometria para Casacada de Reservatórios do RTC-Tools}

Tabela 126 - Valores de Vazão, Largura da Seção e Armazenamento para o Rio Abaetés (PBR040) - Cascata de Reservatórios (RR)

\begin{tabular}{llllll}
\hline \hline Vazão $\left(\mathrm{m}^{3} / \mathrm{s}\right)$ & Largura $(\mathrm{m})$ & Armazenamento $\left(\mathrm{m}^{3}\right)$ & Vazão $\left(\mathrm{m}^{3} / \mathrm{s}\right)$ & Largura $(\mathrm{m})$ & Armazenamento $\left(\mathrm{m}^{3}\right)$ \\
\hline 40 & 500.6 & 709582.6202 & 1500 & 503.04 & 10316892.64 \\
60 & 500.81 & 951476.8237 & 1750 & 503.2 & 11520296.87 \\
80 & 500.9 & 1174139.107 & 2000 & 503.42 & 12664492.06 \\
100 & 500.98 & 1394167.103 & 2250 & 503.55 & 13808326.88 \\
150 & 501.16 & 1895904.656 & 2500 & 503.67 & 14934261.93 \\
200 & 501.33 & 2331869.56 & 2750 & 503.79 & 16034690.68 \\
250 & 501.48 & 2855979.509 & 3000 & 503.93 & 17126224.72 \\
300 & 501.65 & 3320833.053 & 3250 & 504.05 & 18215227.76 \\
350 & 501.85 & 3738518.624 & 3500 & 504.18 & 19430320.64 \\
400 & 501.93 & 4126182.31 & 3750 & 504.31 & 20662095.66 \\
450 & 502.02 & 4479614.888 & 4000 & 504.43 & 21811729.66 \\
500 & 502.11 & 4820132.305 & 4250 & 504.5 & 22971474.25 \\
550 & 502.18 & 5150519.583 & 4500 & 504.58 & 24116523.06 \\
600 & 502.23 & 5468891.173 & 4750 & 504.65 & 25236156.66 \\
650 & 502.3 & 5778120.67 & 5000 & 504.73 & 26292436.63 \\
700 & 502.35 & 6090564.694 & 5250 & 504.8 & 27677477.71 \\
750 & 502.41 & 6380730.874 & 5500 & 504.87 & 28749155.13 \\
800 & 502.45 & 6669327.57 & 5750 & 504.94 & 29761728.71 \\
850 & 502.5 & 6958243.853 & 6000 & 505.01 & 30771683.36 \\
900 & 502.55 & 7233915.944 & 6250 & 505.08 & 31781982.3 \\
950 & 502.6 & 7508181.829 & 6500 & 505.15 & 32856716.88 \\
1000 & 502.64 & 7779798.867 & 6750 & 505.22 & 34004638.32 \\
1100 & 502.72 & 8298596.457 & 7000 & 505.28 & 35120593.6 \\
1150 & 502.77 & 8560059.79 & 7250 & 505.35 & 36037701.77 \\
1250 & 502.83 & 9083206.19 & 7500 & 505.41 & 39018996.5 \\
\hline \hline
\end{tabular}


Tabela 127 - Valores de Vazão, Largura da Seção e Armazenamento para o Rio São Francisco (N01a) - Cascata de Reservatórios (RR)

\begin{tabular}{llllll}
\hline \hline Vazão $\left(\mathrm{m}^{3} / \mathrm{s}\right)$ & Largura $(\mathrm{m})$ & Armazenamento $\left(\mathrm{m}^{3}\right)$ & Vazão $\left(\mathrm{m}^{3} / \mathrm{s}\right)$ & Largura $(\mathrm{m})$ & Armazenamento $\left(\mathrm{m}^{3}\right)$ \\
\hline 40 & 500.6 & 644295.0997 & 1500 & 503.03 & 11302863.87 \\
60 & 500.81 & 883397.4 & 1750 & 503.21 & 12608541.96 \\
80 & 500.9 & 1109954.629 & 2000 & 503.43 & 13840160.36 \\
100 & 500.98 & 1328344.783 & 2250 & 503.56 & 15133813.71 \\
150 & 501.16 & 1863368.134 & 2500 & 503.68 & 16342883.39 \\
200 & 501.33 & 2311291.121 & 2750 & 503.79 & 17473643.67 \\
250 & 501.47 & 2783061.739 & 3000 & 503.93 & 18583433.01 \\
300 & 501.65 & 3217562.781 & 3250 & 504.05 & 19644663.9 \\
350 & 501.85 & 3638507.794 & 3500 & 504.18 & 20720430.06 \\
400 & 501.93 & 4029129.765 & 3750 & 504.31 & 21739027.24 \\
450 & 502.01 & 4423549.746 & 4000 & 504.42 & 22747004.24 \\
500 & 502.1 & 4816635.439 & 4250 & 504.5 & 23704028.6 \\
550 & 502.18 & 5185895.365 & 4500 & 504.58 & 24663977.13 \\
600 & 502.24 & 5544345.026 & 4750 & 504.66 & 25590776.56 \\
650 & 502.3 & 5923208.996 & 5000 & 504.73 & 26509738.8 \\
700 & 502.35 & 6301302.385 & 5250 & 504.8 & 27452023.89 \\
750 & 502.4 & 6658478.865 & 5500 & 504.87 & 28319284.84 \\
800 & 502.45 & 7077346.163 & 5750 & 504.94 & 29223550.31 \\
850 & 502.51 & 7441284.817 & 6000 & 505.01 & 30113332.2 \\
900 & 502.55 & 7776427.992 & 6250 & 505.08 & 31018101.46 \\
950 & 502.6 & 8112278.655 & 6500 & 505.15 & 31878019.2 \\
1000 & 502.64 & 8424783.143 & 6750 & 505.22 & 32728423.5 \\
1100 & 502.72 & 9030523.671 & 7000 & 505.29 & 33622019.79 \\
1150 & 502.77 & 9331924.474 & 7250 & 505.35 & 34501948.98 \\
1250 & 502.85 & 9887466.994 & 7500 & 505.42 & 35344211.72 \\
\hline \hline
\end{tabular}


Tabela 128 - Valores de Vazão, Largura da Seção e Armazenamento para o Rio São Francisco (N02) - Cascata de Reservatórios (RR)

\begin{tabular}{llllll}
\hline \hline Vazão $\left(\mathrm{m}^{3} / \mathrm{s}\right)$ & Largura $(\mathrm{m})$ & Armazenamento $\left(\mathrm{m}^{3}\right)$ & Vazão $\left(\mathrm{m}^{3} / \mathrm{s}\right)$ & Largura $(\mathrm{m})$ & Armazenamento $\left(\mathrm{m}^{3}\right)$ \\
\hline 40 & 490.86 & 728990.6091 & 1500 & 493.16 & 13095007.18 \\
60 & 490.96 & 1005968.823 & 1750 & 493.34 & 14614462.64 \\
80 & 491.05 & 1277817.007 & 2000 & 493.51 & 16077639.4 \\
100 & 491.13 & 1527401.386 & 2250 & 493.67 & 17438705.88 \\
150 & 491.28 & 2082733.429 & 2500 & 493.83 & 18715911.89 \\
200 & 491.41 & 2618000.146 & 2750 & 493.98 & 20018909.53 \\
250 & 491.54 & 3169653.395 & 3000 & 494.13 & 21274092.69 \\
300 & 491.66 & 3695372.647 & 3250 & 494.28 & 22493063.42 \\
350 & 491.77 & 4213954.106 & 3500 & 494.42 & 23728692.1 \\
400 & 491.88 & 4678694.116 & 3750 & 494.56 & 24939295.41 \\
450 & 492.01 & 5142173.393 & 4000 & 494.7 & 26083637.68 \\
500 & 492.2 & 5697773.515 & 4250 & 494.82 & 27222509.19 \\
550 & 492.31 & 6160112.727 & 4500 & 494.95 & 28297893.99 \\
600 & 492.38 & 6579937.243 & 4750 & 495.07 & 29373859.77 \\
650 & 492.44 & 6976300.206 & 5000 & 495.2 & 30401917.93 \\
700 & 492.5 & 7351348.399 & 5250 & 495.32 & 31441907.27 \\
750 & 492.54 & 7727266.147 & 5500 & 495.44 & 32490723.62 \\
800 & 492.59 & 8079729.849 & 5750 & 495.55 & 33501024.37 \\
850 & 492.64 & 8448588.095 & 6000 & 495.67 & 34554212.23 \\
900 & 492.67 & 8782896.608 & 6250 & 495.77 & 35515803.77 \\
950 & 492.72 & 9140131.434 & 6500 & 495.89 & 36534067.5 \\
1000 & 492.77 & 9504635.603 & 6750 & 495.99 & 37481875.32 \\
1100 & 492.85 & 10214110.34 & 7000 & 496.1 & 38477211.84 \\
1150 & 492.89 & 10543697.26 & 7250 & 496.21 & 39443584.87 \\
1250 & 492.97 & 11233607.9 & 7500 & 496.31 & 40383013.35 \\
\hline \hline
\end{tabular}


Tabela 129 - Valores de Vazão, Largura da Seção e Armazenamento para o Rio São Francisco (N03) - Cascata de Reservatórios (RR)

\begin{tabular}{llllll}
\hline \hline Vazão $\left(\mathrm{m}^{3} / \mathrm{s}\right)$ & Largura $(\mathrm{m})$ & Armazenamento $\left(\mathrm{m}^{3}\right)$ & Vazão $\left(\mathrm{m}^{3} / \mathrm{s}\right)$ & Largura $(\mathrm{m})$ & Armazenamento $\left(\mathrm{m}^{3}\right)$ \\
\hline 40 & 485.93 & 745662.3696 & 1500 & 488.25 & 11947002.44 \\
60 & 486.08 & 1036513.596 & 1750 & 488.42 & 13341188.11 \\
80 & 486.18 & 1300525.898 & 2000 & 488.59 & 14629480.16 \\
100 & 486.24 & 1548922.462 & 2250 & 488.74 & 15876959.33 \\
150 & 486.38 & 2111742.004 & 2500 & 488.89 & 17076959.88 \\
200 & 486.51 & 2612462.223 & 2750 & 489.01 & 18217758.15 \\
250 & 486.62 & 3082614.341 & 3000 & 489.13 & 19331337.77 \\
300 & 486.72 & 3516211.991 & 3250 & 489.25 & 20411704.86 \\
350 & 486.82 & 3927931.869 & 3500 & 489.37 & 21465502.99 \\
400 & 486.91 & 4322965.229 & 3750 & 489.49 & 22507892.62 \\
450 & 487.02 & 4716917.326 & 4000 & 489.61 & 23531343.92 \\
500 & 487.1 & 5147438.098 & 4250 & 489.72 & 24540302.9 \\
550 & 487.19 & 5545119.451 & 4500 & 489.83 & 25547273.58 \\
600 & 487.29 & 5949260.817 & 4750 & 489.94 & 26531563.51 \\
650 & 487.38 & 6350073.031 & 5000 & 490.03 & 27488134.09 \\
700 & 487.47 & 6743347.168 & 5250 & 490.15 & 28473175.94 \\
750 & 487.54 & 7093434.636 & 5500 & 490.25 & 29403143.19 \\
800 & 487.6 & 7434922.229 & 5750 & 490.34 & 30351432.79 \\
850 & 487.66 & 7771039.896 & 6000 & 490.44 & 31266505.61 \\
900 & 487.73 & 8117262.298 & 6250 & 490.53 & 32181145.54 \\
950 & 487.78 & 8442937.866 & 6500 & 490.64 & 33114819.51 \\
1000 & 487.84 & 8767168.75 & 6750 & 490.73 & 33979303.09 \\
1100 & 487.94 & 9413155.028 & 7000 & 490.81 & 34879362.87 \\
1150 & 487.99 & 9717272.315 & 7250 & 490.9 & 35726643.48 \\
1250 & 488.06 & 10497509.82 & 7500 & 490.99 & 36620111.45 \\
\hline \hline
\end{tabular}


Tabela 130 - Valores de Vazão, Largura da Seção e Armazenamento para até Pirapora - Cascata de Reservatórios (RR)

\begin{tabular}{llllll}
\hline \hline Vazão $\left(\mathrm{m}^{3} / \mathrm{s}\right)$ & Largura $(\mathrm{m})$ & Armazenamento $\left(\mathrm{m}^{3}\right)$ & Vazão $\left(\mathrm{m}^{3} / \mathrm{s}\right)$ & Largura $(\mathrm{m})$ & Armazenamento $\left(\mathrm{m}^{3}\right)$ \\
\hline 40 & 481.79 & 852212.06 & 1500 & 483.02 & 14516448.17 \\
60 & 481.86 & 1163822.53 & 1750 & 483.14 & 16297681.7 \\
80 & 481.91 & 1449820.661 & 2000 & 483.25 & 17872134.35 \\
100 & 481.95 & 1725431.842 & 2250 & 483.35 & 19364842.39 \\
150 & 482.02 & 2333676.324 & 2500 & 483.45 & 20800447.32 \\
200 & 482.09 & 2922036.193 & 2750 & 483.55 & 22160290.7 \\
250 & 482.15 & 3476289.313 & 3000 & 483.64 & 23497419.38 \\
300 & 482.21 & 4050829.341 & 3250 & 483.73 & 24822929.61 \\
350 & 482.26 & 4539947.465 & 3500 & 483.82 & 26090189.68 \\
400 & 482.32 & 5105420.451 & 3750 & 483.91 & 27340760.31 \\
450 & 482.37 & 5618829.839 & 4000 & 483.99 & 28563004.91 \\
500 & 482.42 & 6085087.124 & 4250 & 484.07 & 29809081.22 \\
550 & 482.46 & 6598999.522 & 4500 & 484.15 & 31010413.36 \\
600 & 482.5 & 7100593.837 & 4750 & 484.23 & 32182126.55 \\
650 & 482.54 & 7690474.847 & 5000 & 484.3 & 33389911.69 \\
700 & 482.58 & 8192332.095 & 5250 & 484.37 & 34512150.59 \\
750 & 482.61 & 8659915.582 & 5500 & 484.45 & 35634976.81 \\
800 & 482.65 & 9135878.896 & 5750 & 484.52 & 36762518.54 \\
850 & 482.68 & 9558766.38 & 6000 & 484.59 & 37880338.81 \\
900 & 482.71 & 10023805.95 & 6250 & 484.66 & 38968419.94 \\
950 & 482.74 & 10452981.21 & 6500 & 484.73 & 40113147.54 \\
1000 & 482.77 & 10866086.7 & 6750 & 484.8 & 41239759.35 \\
1100 & 482.82 & 11615490.94 & 7000 & 484.88 & 42332505.94 \\
1150 & 482.85 & 11994077.43 & 7250 & 484.94 & 43379587.91 \\
1250 & 482.9 & 12739286.08 & 7500 & 485.02 & 44468332.54 \\
\hline \hline
\end{tabular}





\section{APÊNDICE H - Sumário dos Resultados}

A tabela abaixo sumariza os resultados obtidos na comparação dos modelos selecionados: SOBEK que tem como equação governante a versão totalmente dinâmica das ESV; MGB-IPH que utiliza Muskingum-Cunge Não-Linear; e as três configurações do RTC-Tools, Cascada de Reservatórios (R.R.) e Onda Difusiva (D.W.) com diferentes resoluções espaciais. Na tabela estão apresentadas os indicadores de desempenho (Bias, RMSE, R $^{2}$ e NSE) e os tempos de processamento.

Tabela 131 - Desempenho estatístico e computacional dos modelos no Ponto Pirapora para os modelos hidrodinâmicos utilizados: SOBEK, MGB, R.R. e D.W.

\begin{tabular}{r|c|c|c|c|c}
\hline \hline & $\begin{array}{c}\text { Desempenho Computacional } \\
{[\mathrm{ms}]}\end{array}$ & $\begin{array}{c}\text { Bias } \\
{\left[\mathrm{m}^{3} / \mathrm{s}\right]}\end{array}$ & $\begin{array}{c}\text { RMSE } \\
{\left[\mathrm{m}^{3} / \mathrm{s}\right]}\end{array}$ & $\begin{array}{c}\mathrm{R}^{2} \\
{[-]}\end{array}$ & $\begin{array}{c}\text { NSE } \\
{[-]}\end{array}$ \\
\hline \hline SOBEK & 51090 & 13.87 & 78.62 & 0.974 & 0.988 \\
\hline MGB & 345 & 13.33 & 120.94 & 0.960 & 0.958 \\
\hline$\Delta t=60 \mathrm{~min}$ & 249 & 0.034 & 68.72 & 0.980 & 0.980 \\
R.R. $\Delta t=30 \mathrm{~min}$ & 374 & 0.050 & 68.61 & 0.980 & 0.980 \\
$\Delta t=20 \mathrm{~min}$ & 499 & 0.050 & 68.76 & 0.980 & 0.980 \\
$\Delta t=10 \mathrm{~min}$ & 749 & 0.055 & 69.00 & 0.980 & 0.979 \\
$\Delta t=60 \mathrm{~min}$ & 1560 & 0.060 & 69.29 & 0.979 & 0.979 \\
$\Delta t=40 \mathrm{~min}$ & 8814 & 0.096 & 70.93 & 0.978 & 0.978 \\
$\Delta t=30 \mathrm{~min}$ & 12496 & 0.113 & 70.79 & 0.979 & 0.978 \\
$\Delta t=20 \mathrm{~min}$ & 15709 & 0.113 & 70.59 & 0.979 & 0.978 \\
$\Delta t=10 \mathrm{~min}$ & 22090 & 0.119 & 70.51 & 0.979 & 0.978 \\
$\Delta t=60 \mathrm{~min}$ & 40419 & 0.125 & 70.44 & 0.979 & 0.979 \\
\hline$\Delta t=40 \mathrm{~min}$ & 2449 & 0.214 & 76.62 & 0.975 & 0.975 \\
$\Delta t=30 \mathrm{~min}$ & 3525 & 0.231 & 76.32 & 0.975 & 0.975 \\
$\Delta t=20 \mathrm{~min}$ & 4571 & 0.231 & 76.18 & 0.975 & 0.975 \\
$\Delta t=10 \mathrm{~min}$ & 6661 & 0.237 & 76.04 & 0.975 & 0.975 \\
D.W. 30km $\Delta t \mathrm{~km}$ & 12574 & 0.241 & 75.91 & 0.975 & 0.975 \\
\hline \hline
\end{tabular}

